\title{
ॠUSES
}

science for a changing world

Prepared in cooperation with the U.S. Fish and Wildlife Service, Environmental Contaminants Division

\section{Mercury in Birds of San Francisco Bay-Delta, California- Trophic Pathways, Bioaccumulation, and Ecotoxicological Risk to Avian Reproduction}

Open-File Report 2014-1251

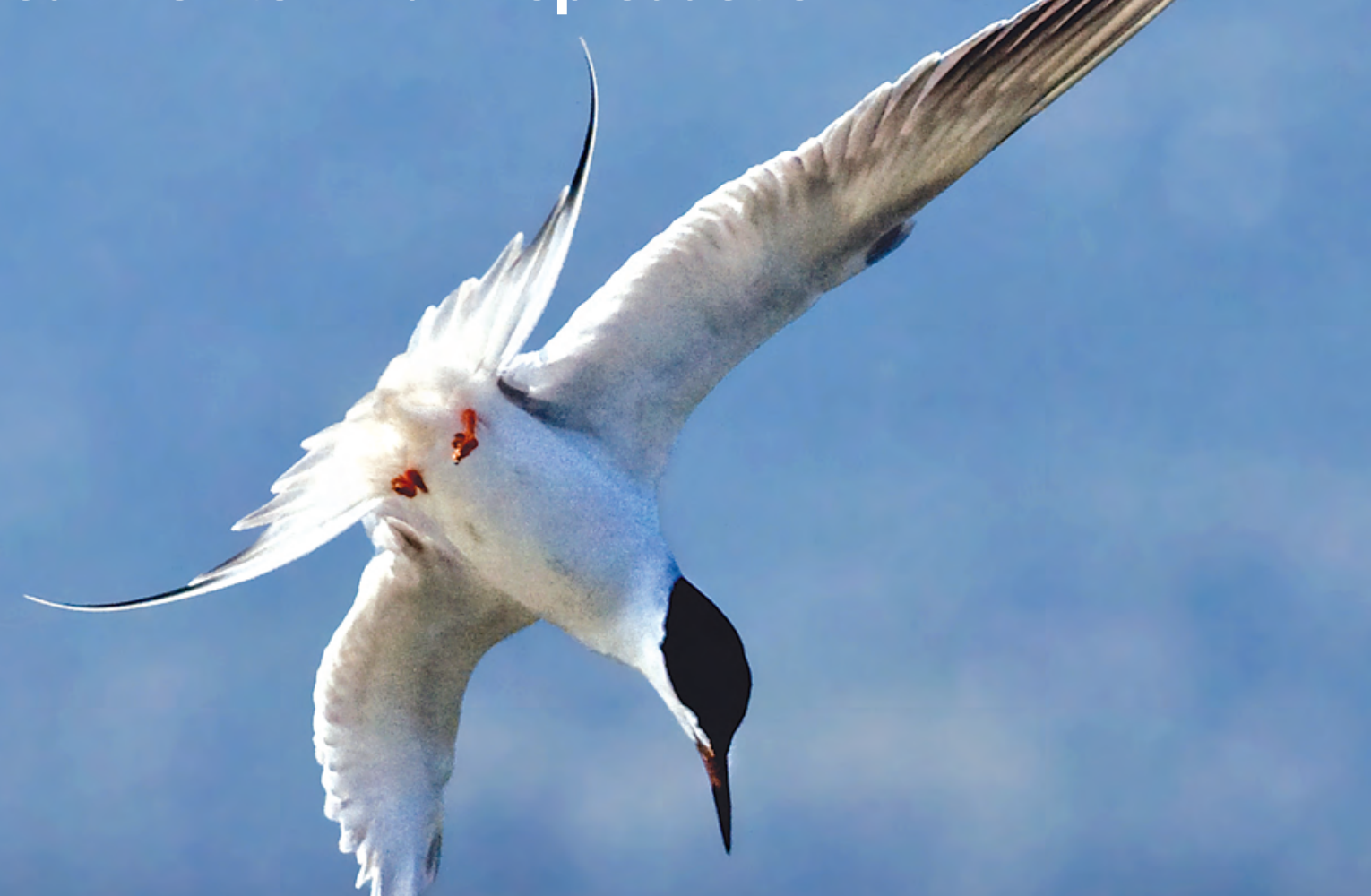


Cover: Forster's tern plunge-diving for fish in San Francisco Bay. Photograph taken by Ken Phenicie in 2008 and used with permission. 


\section{Mercury in Birds of San Francisco Bay-Delta, California- Trophic Pathways, Bioaccumulation, and Ecotoxicological Risk to Avian Reproduction}

By Joshua T. Ackerman, Collin A. Eagles-Smith, Gary Heinz, Susan E. De La Cruz, John Y. Takekawa, A. Keith Miles, Terry L. Adelsbach, Mark P. Herzog, Jill D. Bluso-Demers, Scott A. Demers, Garth Herring, David J. Hoffman, C. Alex Hartman, James J. Willacker, Thomas H. Suchanek, Steve E. Schwarzbach, and Thomas C. Maurer

Prepared in cooperation with the U.S. Fish and Wildlife Service, Environmental Contaminants Division

Open-File Report 2014-1251

U.S. Department of the Interior

U.S. Geological Survey 


\section{U.S. Department of the Interior \\ SALLY JEWELL, Secretary}

\section{U.S. Geological Survey \\ Suzette M. Kimball, Acting Director}

U.S. Geological Survey, Reston, Virginia: 2014

For more information on the USGS-the Federal source for science about the Earth, its natural and living resources, natural hazards, and the environment-visit http://www.usgs.gov or call 1-888-ASK-USGS

For an overview of USGS information products, including maps, imagery, and publications, visit $h$ ttp://www.usgs.gov/pubprod

To order this and other USGS information products, visit http://store.usgs.gov

Any use of trade, firm, or product names is for descriptive purposes only and does not imply endorsement by the U.S. Government.

Although this information product, for the most part, is in the public domain, it also may contain copyrighted materials as noted in the text. Permission to reproduce copyrighted items must be secured from the copyright owner.

Suggested citation:

Ackerman, J.T., Eagles-Smith, C.A., Heinz, G.H., De La Cruz, S.E., Takekawa, J.Y., Miles, A.K., Adelsbach, T.L., Herzog, M.P., Bluso-Demers, J.D., Demers, S.A., Herring, G., Hoffman, D.J., Hartman, C.A., Willacker, J.J., Suchanek, T.H., Schwarzbach, S.E., and Maurer, T.C., 2014, Mercury in birds of San Francisco Bay-Delta, California-Trophic pathways, bioaccumulation, and ecotoxicological risk to avian reproduction: U.S. Geological Survey Open-File Report 2014-1251, 202 p., http://dx.doi.org/10.3133/ofr20141251.

ISSN 2331-1258 (online) 


\section{Acknowledgments}

This research was funded by the CALFED Bay-Delta Program's Ecosystem Restoration Program (grant number ERP-02D-C12) with additional support from the USGS Western Ecological Research Center. We thank Donna Podger and Carol Atkins of the California Bay-Delta Authority for help and project support. We thank Robin Keister, Mark Ricca, Sarah Spring, and Liz Bowen of USGS Davis Field Station; Nicole Athearn and Matt Wilson of USGS San Francisco Bay Estuary Field Station; John Henderson, Carolyn Marn, and Cathy Johnson of USFWS Environmental Contaminants Division; Mark Melancon, Jon Klimstra, and Katie Stebbins of USGS Patuxent Wildlife Research Center; Cheryl Strong (formerly) and Janet Hanson of San Francisco Bay Bird Observatory; Nils Warnock (formerly) of Point Blue Conservation Science; and Mark Colwell of Humboldt State University for collaborations, help with project design, and field and laboratory work. We thank Clyde Morris, Joy Albertson, Mendel Stewart, Joelle Buffa, Eric Mruz, Marge Kolar, and the staff at the Don Edwards San Francisco Bay National Wildlife Refuge (U.S. Fish and Wildlife Service), John Krause and the staff of the Eden Landing Ecological Reserve (California Department of Fish and Wildlife), Larry Wyckoff, Carl Wilcox, Tom Huffman, Karen Taylor, and the staff of the Napa-Sonoma Marsh Wildlife Area (California Department of Fish and Wildlife), and Lew Allen and the Can Duck Club for logistical support. We also thank Ashley Casey, Laura Young, Trevor Watts, Rosielyn DeGuzman, Sarah Stoner-Duncan, Joe Northrup, Brooke Hill, Kristen Dybala, Stacy Moskal, Angela Rex, Ross Wilming, Lindsay Dembosz, Emily Eppinger, Mychal Truwe, Kevin Aceituno, River Gates, Lani Stinson, Eli French, Mali Nakhai, Eric Palm, Louie Terrazas, Daniel Gaube, Christina Kereki, Jennifer Chastant, Holly Goyert, Jeremy Anhalt, Erika Caceres, Jodi Despot, Meg Harper, Nicole Karres, Cody Massing, John Mason, Jessica Mellinger, Christina Murphy, Anne Neumann, Martin Stafford, Amy Story, and Whitney Thornton for field and laboratory assistance. We thank Julie Yee of USGS Dixon Field Station for statistical advice. 
This page left intentionally blank 


\section{Contents}

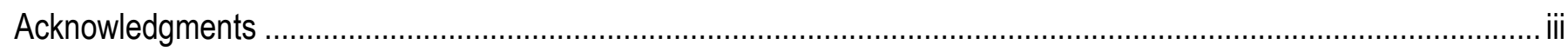

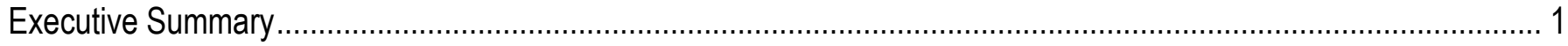

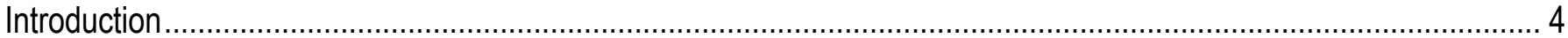

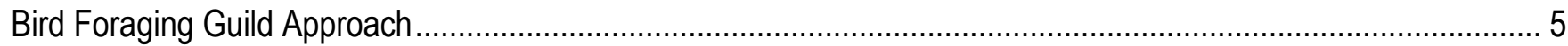

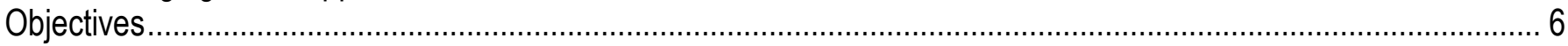

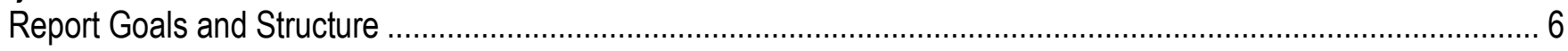

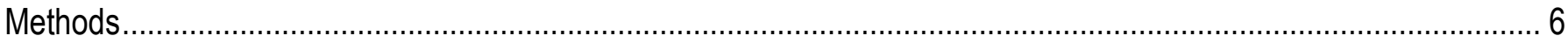

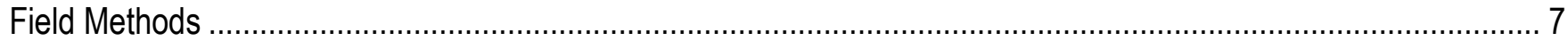

Adult Bird Capture and Sampling ............................................................................................................

Shorebird and Tern Capture and Sampling ......................................................................................

Diving Duck Capture and Sampling .................................................................................................

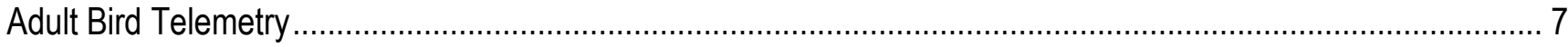

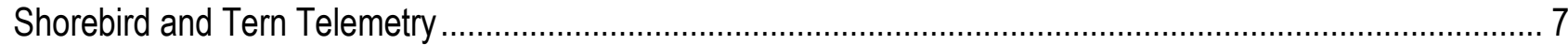

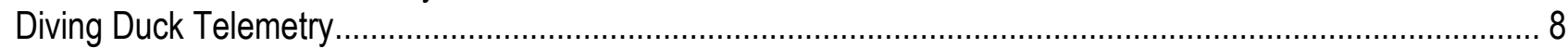

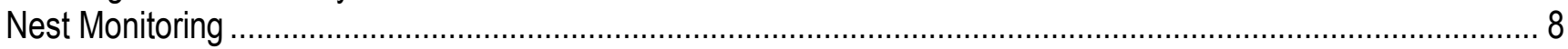

Shorebird and Tern Nest Monitoring ................................................................................................ 8

Diving Duck Nest Monitoring …………………………................................................................ 9

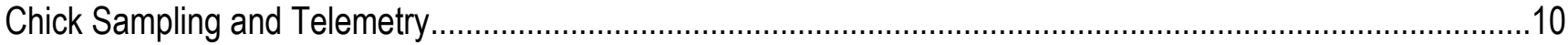

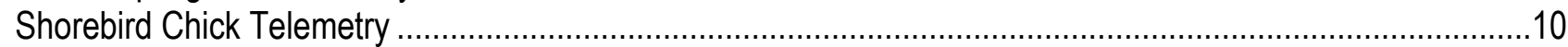

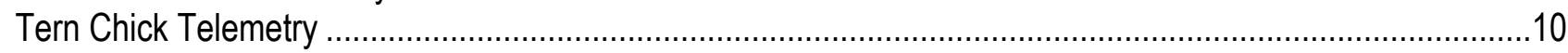

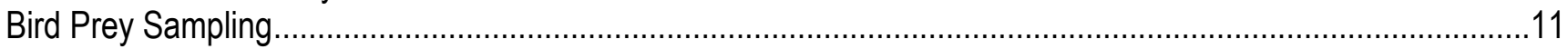

Shorebird Prey: Invertebrate Sampling ............................................................................................11

Diving Duck Prey: Benthic Invertebrate Sampling …………..........................................................12

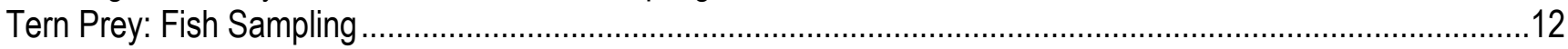

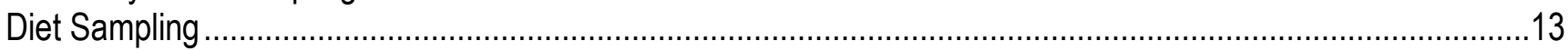

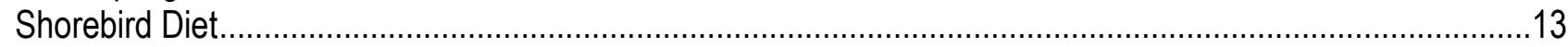

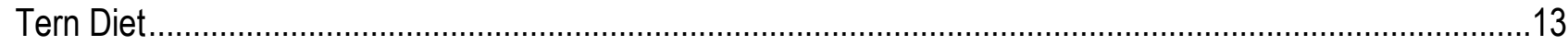

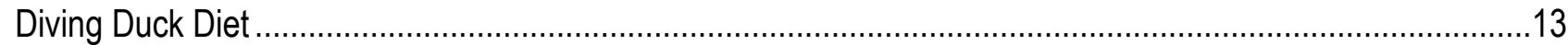

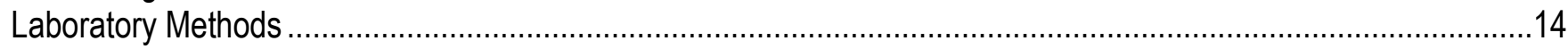

Bird Necropsy and Tissue Processing..........................................................................................14

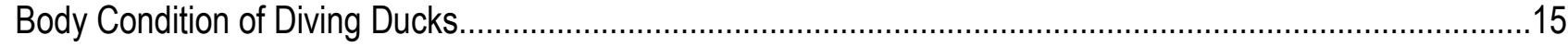

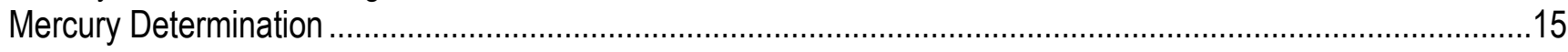

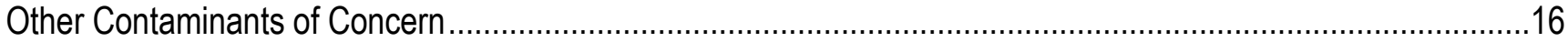

Selenium

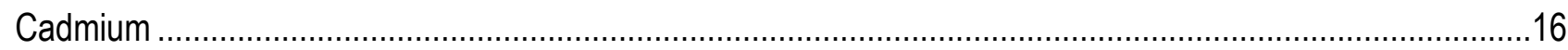

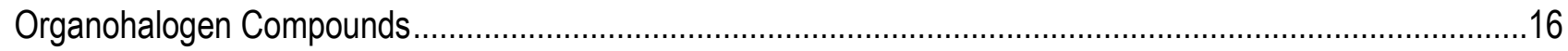

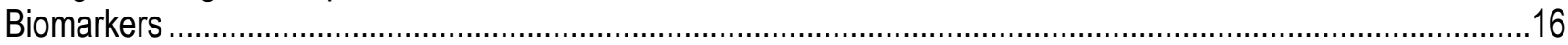

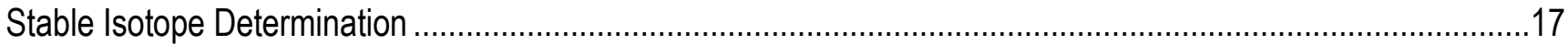

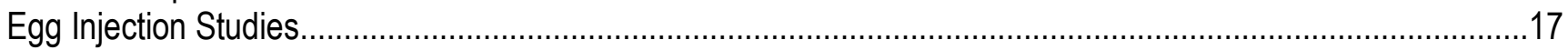

Captive Breeding and Feeding Studies.................................................................................................18

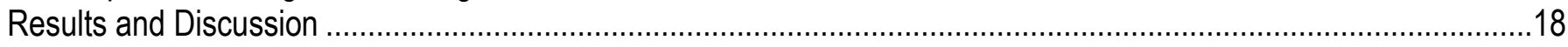

Objective 1: Examine Bird Mercury Exposure and Bioaccumulation in Three Bird Guilds ....................................18

Distribution of Mercury Among Bird Tissues and Sexes..........................................................................18

Mercury Concentrations Differ Among Species......................................................................................19

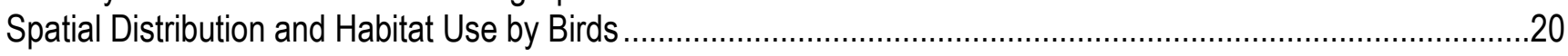




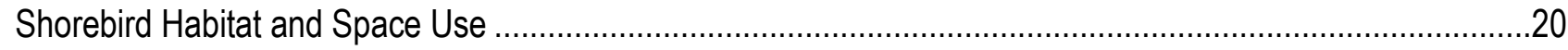

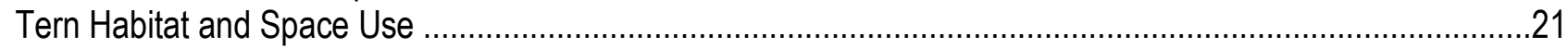

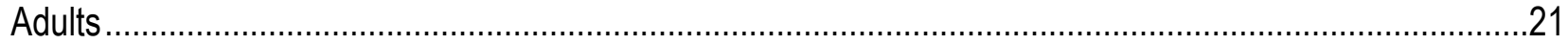

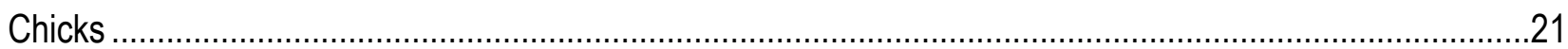

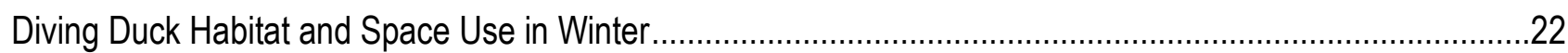

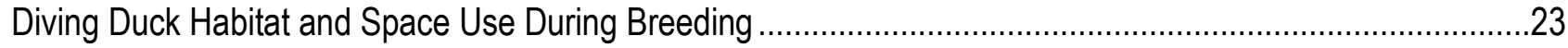

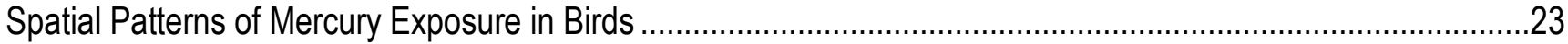

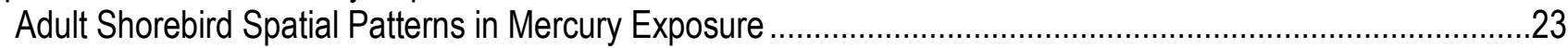

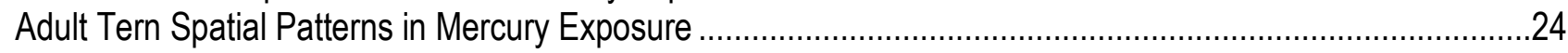

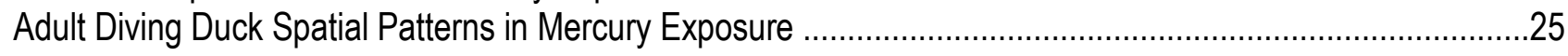

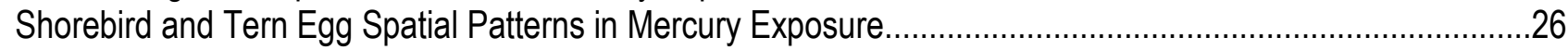

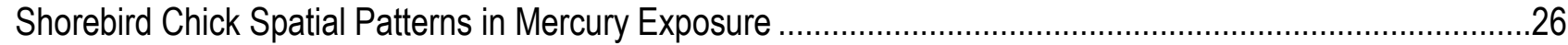

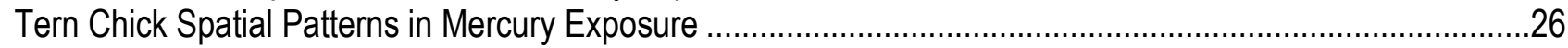

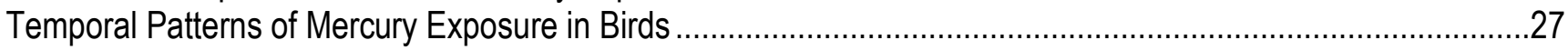

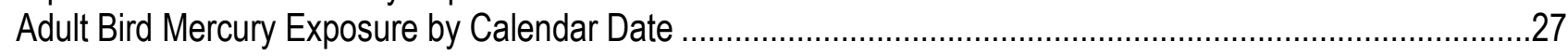

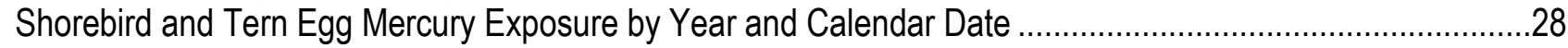

Shorebird and Tern Chick Mercury Exposure by Calendar Date ............................................................28

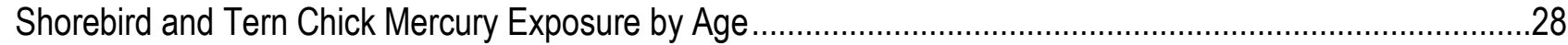

Trophic Pathways of Mercury Exposure in Birds ………………...........................................................30

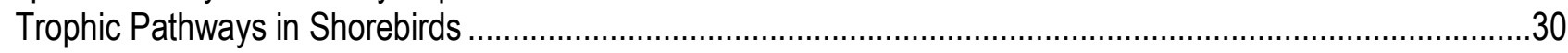

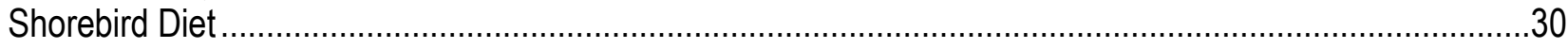

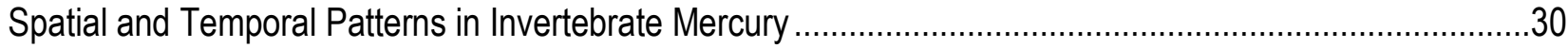

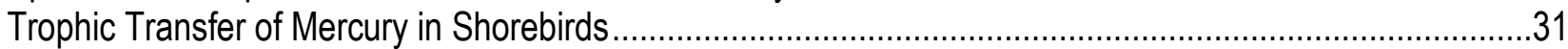

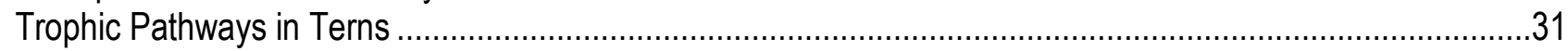

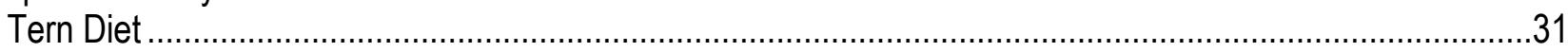

Species Patterns in Fish Mercury.................................................................................................32

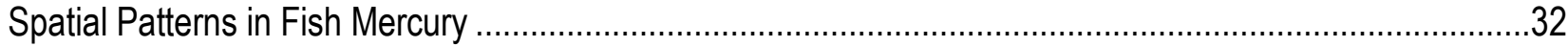

Temporal Patterns in Fish Mercury ................................................................................................

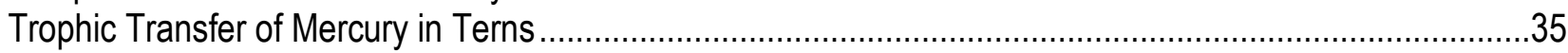

Diving Duck Trophic Pathways ……………………………….....................................................37

Spatial and Temporal Patterns in Benthic Invertebrate Mercury ........................................................37

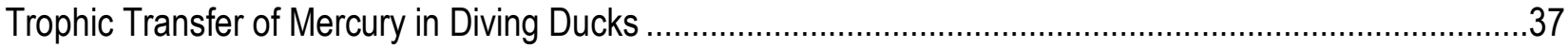

Bird Exposure to Other Contaminants of Concern .....................................................................................3

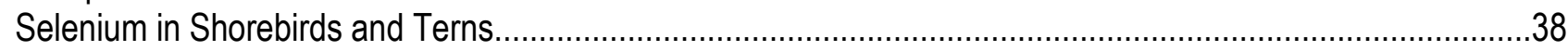

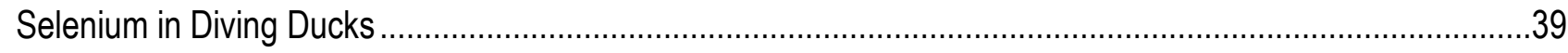

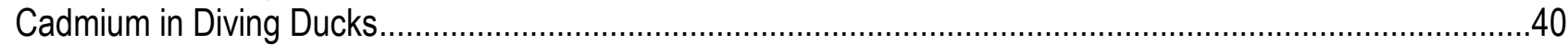

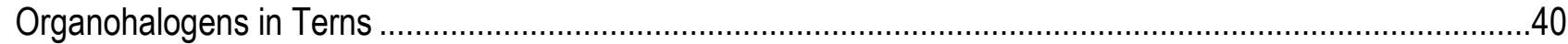

Potential Risk of Mercury to Birds .................................................................................................

Percentage of Prey Exceeding Dietary Thresholds .............................................................................41

Percentage of Invertebrate Prey Exceeding Dietary Thresholds............................................................4

Percentage of Prey Fish Exceeding Dietary Thresholds ....................................................................42

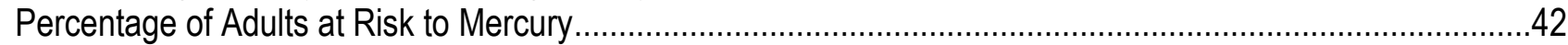

Maternal Transfer of Mercury to Eggs ...........................................................................................

Percentage of Eggs at Risk to Mercury in San Francisco Bay ..............................................................43

Percentage of Eggs at Risk to Mercury and Selenium in Migratory Ducks Breeding Outside of San Francisco

Bay . 
Objective 2: Evaluate Toxicological Effects of Mercury Exposure on Birds...........................................................44

Biochemical Effects of Mercury and Other COCs on Shorebirds and Terns ...............................................44

Demethylation of Methylmercury in Shorebird and Tern Livers ..............................................................4

Selenium Effect on Body Condition in Shorebirds and Terns ..............................................................45

Selenium Effect on Body Condition in Diving Ducks ........................................................................46

Oxidative Stress in Relation to Mercury and Selenium Concentrations in Terns ..........................................47

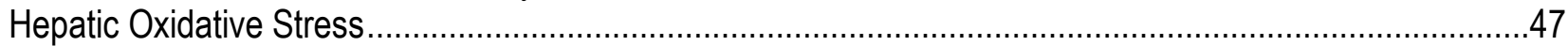

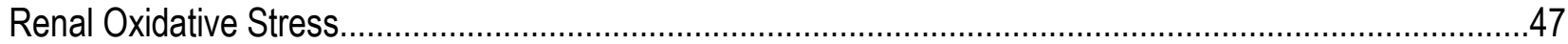

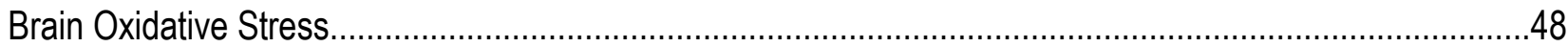

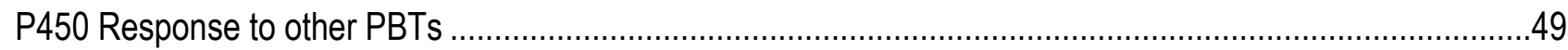

Effects of Mercury on Bird Reproduction ..........................................................................................

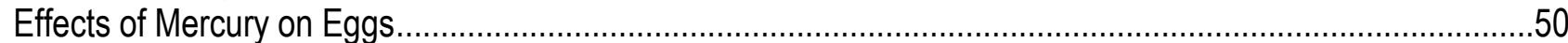

Mercury Concentrations in Random Eggs versus Failed Eggs and Abandoned Eggs ...............................50

Effects of Mercury on Embryo Deformities and Malpositions ..............................................................50

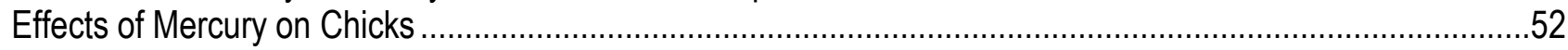

Chick Down Mercury Correlates to Whole Egg Mercury Concentrations ....................................................52

Effects of Mercury on Chick Survival (Hatch to Fledging) ……............................................................54

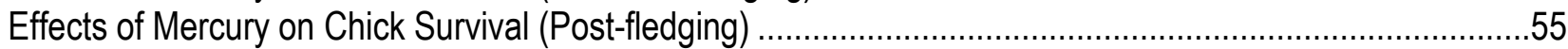

Objective 3: Examine the Differential Sensitivity of Bird Taxa to Mercury Exposure ............................................56

Egg Injection Techniques in the Laboratory to Determine the Sensitivity of Bird Embryos to Methylmercury .......56

Egg Injection Techniques to Explore Toxic Interactions of Methylmercury and Selenium ..................................58

Conduct a Controlled Feeding Study to Establish a Dose-Response Curve and No Observed Adverse Effects

Level when Methylmercury is Maternally Deposited in the Egg................................................................58

Additional Findings from Laboratory Studies ...........................................................................................59

How to Best Incubate Wild Bird Eggs ..............................................................................................59

Using Mercury Levels in Blood and Down Feathers as a Substitute for Mercury in Eggs.................................60

Mercury Increases Rapidly in Eggs of Females Eating Foods Containing Methylmercury ...............................60

Intraperitoneal Injections of Methylmercury: A Possible New Approach to Field Studies .................................60

A Simple Method for Correcting Mercury Concentrations in Eggs for Moisture Loss......................................61

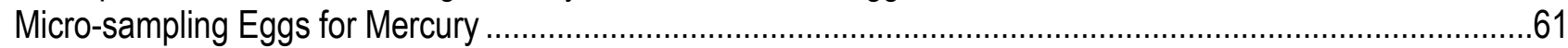

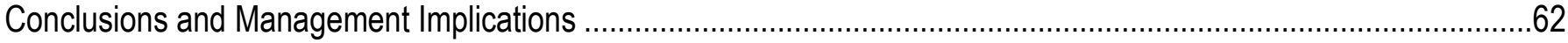

Waterbird Foraging Habitat Strongly Influences Mercury Bioaccumulation .....................................................62

Developing a Mercury Biomonitoring Program that Appropriately Incorporates Toxicological Risk to Wildlife ......62

Fish Mercury Concentrations Were Poor Predictors of Bird Mercury Concentrations and Risk to Birds ...............63

Effects of Mercury on Birds and Integrating Toxicological Risk Across Bird Life Stages ....................................64

Bird Eggs are Ideal Biomonitoring Tools for Mercury Monitoring Programs ...................................................65

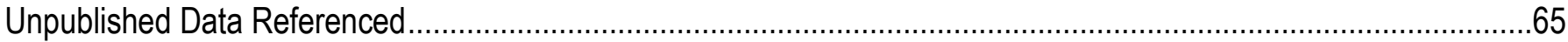

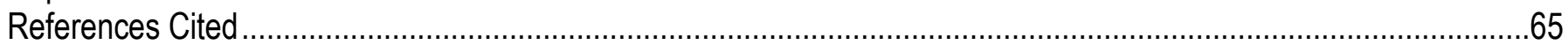

Appendix 1. Project's Product List: Citations …………………....................................................................197 


\section{Figures}

Figure 1. Study locations throughout the greater San Francisco Bay Estuary, California, used from 2003 to 2007

Figure 2. Surf scoter capture locations in San Francisco Bay, California.

Figure 3. Fish sampling locations in San Francisco Bay Estuary, California

Figure 4. Study area of surf scoter collection locations the main sub-bays of the San Francisco Bay Estuary, California

Figure 5. Total mercury (THg) concentration in liver correlated with methylmercury $(\mathrm{MeHg})$ concentrations in liver and THg concentrations in blood, kidney, muscle, breast feather, and head feather in American avocets (circles), black-necked stilts (triangles), Caspian terns (diamonds), and Forster's terns (squares)

Figure 6. Total mercury $(\mathrm{THg})$ concentrations in blood correlated with methylmercury $(\mathrm{MeHg})$ concentrations in liver and kidney and THg concentrations in kidney, muscle, breast feather and head feather in American avocets (circles), black-necked stilts (triangles), Caspian terns (diamonds), and Forster's terns (squares)................ 84

Figure 7. Total mercury (THg) concentrations (least-squares mean $\pm \mathrm{SE}$ ) in livers of five waterbird species sampled from San Francisco Bay, California, during the pre-breeding season (March 1-April 23, 2004-06)..... . .85

Figure 8. Total mercury ( $\mathrm{THg}$ ) concentrations (least-squares mean $\pm \mathrm{SE}$ ) in various tissues of pre-breeding (open bars) and breeding (solid bars) waterbirds in San Francisco Bay, California.

Figure 9. Core use areas and telemetry locations of American avocet females radio-marked in the South Bay at Pond A8 ( $N=254)$, Coyote Creek Marsh ( $N=287)$, and Eden Landing Ecological Reserve ( $N=116)$ sites in San Francisco Bay, California, during spring 2005

Figure 10. Core use areas and telemetry locations of black-necked stilts radio-marked in the South Bay at New Chicago Marsh ( $\mathrm{N}=474)$ and Eden Landing Ecological Reserve ( $\mathrm{N}=43$ ) sites in San Francisco Bay, California, during spring 2005

Figure 11. Core use areas and telemetry locations of black-necked stilts radio-marked in the North Bay ( $\mathrm{N}=230)$ site in San Francisco Bay, California during spring 2005.

Figure 12. Core use areas and telemetry locations of American avocet females radio-marked in the South Bay at Ponds A8 ( $N=651)$ and A16 ( $N=185)$, Coyote Creek Marsh ( $N=777)$, and Eden Landing Ecological Reserve ( $\mathrm{N}=134$ ) sites in San Francisco Bay, California, during spring 2006

Figure 13. Core use areas and telemetry locations of black-necked stilts radio-marked in the South Bay at New Chicago Marsh ( $\mathrm{N}=905)$, Pond $\mathrm{A} 8(\mathrm{~N}=83)$, and Eden Landing Ecological Reserve $(\mathrm{N}=195)$ sites in San Francisco Bay, California, during spring 2006.

Figure 14. Distance (mean $\pm \mathrm{SE}$ ) radio-marked avocets were located from their nests decreased as the nest initiation date approached during the pre-incubation stage in South San Francisco Bay, California, during 2005 and 2006 .....

Figure 15. Home range and core area size fluctuations of a representative American avocet during four breeding stages (A) pre-incubation, (B).. incubation, (C) brood-rearing, and (D) post-breeding in the South San Francisco Bay, California

Figure 16. Core use areas (50 percent utilization distributions, UD) and telemetry locations of Forster's terns radio-marked in West Alviso (circles, $\mathrm{N}=206$ ), East Alviso (triangles, $\mathrm{N}=141$ ), and Eden Landing Ecological Reserve (stars, $\mathrm{N}=62$ ) sites in south San Francisco Bay, California, during spring 2005 .

Figure 17. Core use areas (50 percent utilization distributions, UD) and telemetry locations of Forster's terns radio-marked in West Alviso (circles, $\mathrm{N}=360$ ) and East Alviso (triangles, $\mathrm{N}=111$ ) sites in south San Francisco Bay, California, during spring 2006

Figure 18. Radio-telemetry locations of Forster's terns in South San Francisco Bay, California, during 2005 and 2006, with the dominant habitat types depicted

Figure 19. Radio-telemetry locations of Forster's terns in North San Francisco Bay, California, during 2005 , with the dominant habitat types depicted. 
Figure 20. The mean ( \pm standard error) home-range and core-area size of Forster's terns in South San Francisco Bay, California, in relation to breeding stage during 2005 and 2006.

Figure 21. Seasonal habitat selection ratios ( $S$; mean and simultaneous Bonferroni 95 percent confidence intervals) of (A) foraging and (B) roosting Forster's terns in San Francisco Bay, California, during 2005 and 2006.

Figure 22. Habitat selection ratios ( $S$; mean and simultaneous Bonferroni 95 percent confidence intervals) " of pre-breeding and breeding Forster's terns in San Francisco Bay, California, during 2005 and 2006 100

Figure 23. Habitat selection ratios ( $S$; mean and simultaneous Bonferroni 95 percent confidence intervals) of pre-breeding and breeding Forster's terns in San Francisco Bay, California, in salt ponds during 2005 and 2006101

Figure 24. Telemetry locations of postfledging Forster's terns radio-marked at the Pond N7 colony in south San Francisco Bay, California, during 2006.

Figure 25. Habitat selection ratios ( $S$; mean and simultaneous 95 percent confidence limits calculated using the Bonferroni inequality) of postfledging Forster's terns radio-marked at the Pond N7 colony in south San Francisco Bay, California, during 2006

Figure 26. Monthly collective range estimates of all radio-marked surf scoters in San Francisco Bay, California, during four winter months in 2003-04 and 2004-05.....

Figure 27. Mean $( \pm S E)$ home range sizes (50 percent fixed kernel density) of individual male and female radio-marked surf scoters in San Francisco Bay, California, decreased over 4 months during winter 2003-04 and 2004-05

Figure 28. Mean $( \pm S E)$ monthly distance traveled between locations for radio-marked males and female surf scoters during the winters of 2003-04 and 2004-05 in San Francisco Bay, California. 105

Figure 29. Classification and regression tree (CART) for Pacific coast surf scoters breeding in the northern boreal forest of Canada 106

Figure 30. Repeated migratory routes for six individual surf scoters from two wintering sites (Puget Sound: PS, San Francisco Bay: SF) followed by satellite transmitter during the springs of 2005 and 2006.

Figure 31. Blood mercury concentrations ( $\mu \mathrm{g} / \mathrm{g}$ wet weight, ww) of American avocets and black-necked stilts among sites in San Francisco Bay, California, during spring 2005 and 2006 108

Figure 32. Total mercury (THg) concentrations (least squares mean $\pm \mathrm{SE}$ ) in various tissues of four waterbird species form North Bay (open bars), Central South Bay (hatched bars), and Lower South Bay (solid bars) in San Francisco Bay, California, during 2005 and 2006

Figure 33. Total mercury concentrations ( $\mu \mathrm{g} / \mathrm{g}$ wet weight [ww]) in blood of Forster's terns differed among sites in San Francisco Bay, California, during spring 2005 and 2006.

Figure 34. Total mercury ( $\mathrm{THg})$ concentrations (least squares mean $\pm \mathrm{SE}$ ) in eggs of American avocets among regions and wetland sites within San Francisco Bay, California, during 2005-07 ....

Figure 35. Total mercury (THg) concentrations (least squares mean \pm SE) in eggs of black-necked stilts among regions and wetland sites within San Francisco Bay, California, during 2005-07

Figure 36. Total mercury (THg) concentrations (least squares mean $\pm \mathrm{SE}$ ) in eggs of Forster's terns among regions and wetland sites within San Francisco Bay, California, during 2005-07.

Figure 37. Box plots depicting total mercury concentrations ( $\mu \mathrm{g} / \mathrm{g}$ fresh weight [fw]) in down feathers of American avocet (filled) and black-necked stilt chicks (unfilled) at hatching differed among sites in South San Francisco Bay, California, during spring 2005 and 2006

Figure 38. Box plots depicting total mercury concentrations $(\mathrm{THg})$ in $(\mathrm{A})$ blood $(\mu \mathrm{g} / \mathrm{g}$ wet weight [ww]) and (B) breast feathers ( $\mu \mathrm{g} / \mathrm{g}$ fresh weight [fw]) of Forster's tern chicks nearing fledging in South San Francisco Bay, California, during summer 2006.

Figure 39. Total mercury ( $\mathrm{THg})$ concentrations changed with sampling date in livers of surf scoters sampled in San Francisco Bay, California, during 2004 and 2005. 
Figure 40. Total mercury concentrations ( $\mu \mathrm{g} / \mathrm{g}$ wet weight [ww]) in blood of Forster's terns increased with capture date in San Francisco Bay, California, during spring 2005 and 2006.

Figure 41. Log total mercury (THg) concentrations in eggs of (top) American avocet, (middle)

black-necked stilts, and (bottom) Forster's terns by nest initiation date (day of year) in San Francisco

Bay, California, during 2005-07

Figure 42. Total mercury concentrations $(\mu \mathrm{g} / \mathrm{g}$ fresh weight [fw]) in down feathers of American

avocet (circles) and black-necked stilt chicks (triangles) increased with hatching date (day of year) at the

three main study sites in South San Francisco Bay, California, during 2005 (unfilled) and 2006 (filled).

Figure 43. Blood mercury concentrations ( $\mu \mathrm{g} / \mathrm{g}$ wet weight [ww]) in fledglings decreased with hatch date

(annual day) at the $(A)$ Pond $A 7(N=23)$ and $(B)$ Pond N7 (N=67) Forster's tern colonies in South San

Francisco Bay, California, during summer of 2006

Figure 44. (A) Total mercury (THg) concentrations in blood, (B) chick mass (g), and (C) proportion of

fully grown feathers as Forster's tern chicks age from hatching ( 0 days) to postfledging in San Francisco

Bay, California ...

Figure 45. Total mercury (THg) concentrations in (A) liver, $(B)$ kidney, $(E)$ muscle, and $(F)$ fully grown feathers, and methylmercury (MeHg) concentrations in (C) liver and (D) kidney as Forster's tern chicks age from hatching ( 0 days) to postfledging (chicks fledge at 28 days) in San Francisco Bay, California.

Figure 46. Total mercury (THg) concentrations in blood of (A) black-necked stilt and (B) American

avocet chicks as they age from hatching to postfledging in San Francisco Bay, California

Figure 47. Proportional change in an individual specimen's blood total mercury ( $\mathrm{THg})$ concentration

(final $\mathrm{THg}$ concentration divided by initial THg concentration) was negatively related to the proportional change in its body mass (final mass divided by initial mass) between sampling events for Forster's tern chicks in San Francisco Bay, California

Figure 48. Mean percent number $(\% \mathrm{~N})$ and percent frequency of occurrence (\%FO) of prey items found in the esophagus and proventriculus of adult female black-necked stilts collected in the North Bay (NB) and South Bay (SB) from 2005 and 2006 during pre-breeding (NB, N=3; SB, N=5) and breeding periods $(\mathrm{NB}, \mathrm{N}=7 ; \mathrm{SB}, \mathrm{N}=6)$.

Figure 49. Mean percent number $(\% \mathrm{~N})$ and percent frequency of occurrence $(\% \mathrm{FO})$ of prey items found in the gizzard of adult female black-necked stilts collected in the North Bay (NB) and South Bay (SB) from 2005 and 2006 during pre-breeding ( $N B, N=6 ; S B, N=11$ ) and breeding periods (NB, $N=6 ; S B, N=9$ ).

Figure 50. Mean percent number $(\% \mathrm{~N})$ and percent frequency of occurrence $(\% \mathrm{FO})$ of prey items found in the esophagus and proventriculus of adult female American avocets collected in the South Bay (SB) from 2005 and 2006 during pre-breeding $(\mathrm{N}=10)$ and breeding periods $(\mathrm{N}=10)$.....

Figure 51. Mean percent number $(\% \mathrm{~N})$ and percent frequency of occurrence $(\% \mathrm{FO})$ of prey items found in the gizzard of adult female American avocets collected in the North Bay (NB) and South Bay (SB) from 2005 and 2006 during pre-breeding (NB, $N=6 ; S B, N=37$ ) and breeding periods (NB, N=1; $S B, N=25)$.

Figure 52. Mean percent number $(\% \mathrm{~N})$ and percent frequency of occurrence $(\% \mathrm{FO})$ of prey items found in the esophagus and proventriculus $(\mathrm{N}=24)$ or gizzard $(\mathrm{N}=27)$ of black-necked stilt chicks collected in the South Bay from 2005 and 2006.

Figure 53. Mean percent number $(\% \mathrm{~N})$ and percent frequency of occurrence (\%FO) of prey items found in the esophagus and proventriculus $(\mathrm{N}=16)$ or gizzard $(\mathrm{N}=36)$ of American avocet chicks collected in the South Bay from 2005 and 2006

Figure 54. Mean $( \pm S E)$ invertebrate abundances from benthic grab samples located at stilt and avocet foraging areas in the South Bay.

Figure 55. Mean $( \pm S E)$ invertebrate abundances from aquatic sweep samples located at stilt and avocet foraging areas in the South Bay. Includes only taxa with $>10$ individuals

Figure 56. Methylmercury concentrations in Corixidae collected at avocet and stilt pre-breeding and breeding collection sites throughout San Francisco Bay, California . 
Figure 57. Corixidae methylmercury concentrations $(\mu \mathrm{g} / \mathrm{g} \mathrm{dw})$ decreased with date in New Chicago Marsh and Pond A8 in the South San Francisco Bay, California, March 1-September 20, 2006. 131

Figure 58. Stable isotope ratios of carbon $\left(\delta^{13} \mathrm{C}\right)$, nitrogen $\left(\delta^{15} \mathrm{~N}\right)$, and sulfur $\left(\delta^{34} \mathrm{~S}\right)$ in whole blood of pre-breeding (open symbols) and breeding (closed symbols) American avocets (triangles), black-necked stilts (squares), Forster's terns (circles), and Caspian terns (diamonds) sampled from San Francisco Bay, California, during 2005-06.

Figure 59. Relations between log whole blood total mercury ( $\mathrm{THg})$ concentrations $(\mu \mathrm{g} / \mathrm{g} \mathrm{ww}$ ) and whole blood stable isotope ratios of carbon $\left(\delta^{13} \mathrm{C}\right)$, nitrogen $\left(\delta^{15} \mathrm{~N}\right)$, and sulfur $\left(\delta^{34} \mathrm{~S}\right)$ in pre-breeding (green symbols) and breeding (orange symbols) American avocets and black-necked stilts .....

Figure 60. Composition of fish returns to Forster's tern colonies in San Francisco Bay, California, in 2005 and 2006

Figure 61. Comparisons of total mercury (THg) concentrations (size normalized least squares means \pm standard error) among fish species from wetlands in San Francisco Bay, California 135

Figure 62. Total mercury $(\mathrm{THg})$ concentrations (least squares means \pm standard error) in size-standardized fish from wetlands in San Francisco Bay, California.

Figure 63. Total mercury $(\mathrm{THg})$ concentrations (least squares means \pm standard error) across different habitat types in size-standardized fish from wetlands in San Francisco Bay, California 137

Figure 64. Geometric mean fish total mercury $(\mathrm{THg})$ concentrations $(\mu \mathrm{g} / \mathrm{g} \mathrm{dw})$ in relation to mean sulphur $\left(\delta^{34} \mathrm{~S}\right)$ stable isotope ratios from San Francisco Bay, California

Figure 65. Relation between fish total mercury ( $\mathrm{THg}$ ) concentrations (partial residual; $\mu \mathrm{g} / \mathrm{g} \mathrm{dw}$ ) and carbon $\left(\delta^{13} \mathrm{C}\right)$, nitrogen $\left(\delta^{15} \mathrm{~N}\right)$, and sulfur $\left(\delta^{34} \mathrm{~S}\right)$ stable isotope ratios.

Figure 66. Site-specific short-term variation in whole-body total mercury $(\mathrm{THg})$ concentrations in (A and B) longjaw mudsuckers ( $C$ and $\mathrm{D}$ ) and threespine sticklebacks.

Figure 67. Relation between the temporal trend in whole-body prey fish total mercury $(\mathrm{THg})$ concentrations and the timing of Forster's tern nest initiation and chick hatching....

Figure 68. Relations between log whole blood total mercury (THg) concentrations $(\mu \mathrm{g} / \mathrm{g} \mathrm{ww}$ ) and whole blood table isotope ratios of carbon $\left(\delta^{13} \mathrm{C}\right)$, nitrogen $\left(\delta^{15} \mathrm{~N}\right)$, and sulfur $\left(\delta^{34} \mathrm{~S}\right)$ in pre-breeding (green symbols) and breeding (orange symbols) Caspian terns and Forster's terns

Figure 69. Correlation between single-species in mean fish total mercury $(\mathrm{THg})$ concentrations $(\mu \mathrm{g} / \mathrm{g} \mathrm{dw} ; \pm \mathrm{SE})$, and corresponding Forster's tern THg concentrations in pre-breeding blood ( $\mu \mathrm{g} / \mathrm{g} \mathrm{ww} ; \pm \mathrm{SE}$ ), breeding blood ( $\mu \mathrm{g} / \mathrm{g} \mathrm{ww} ; \mathrm{SE})$, and eggs $(\mu \mathrm{g} / \mathrm{g}$ fww; $\pm \mathrm{SE}$ ) sampled from the same wetland location where fish were sampled.

Figure 70. Total mercury (geometric mean and 95 percent confidence intervals) concentrations in predominant surf scoter prey items from three subembayments of the San Francisco Bay Estuary, California ........ 144 Figure 71. Selenium (geometric mean and 95 percent confidence intervals) concentrations in predominant surf scoter prey items from three sub-embayments of the San Francisco Bay Estuary, California ........ 145 Figure 72. Cadmium (geometric mean and 95 percent confidence intervals) concentrations in predominant surf scoter prey items from three sub-embayments of the San Francisco Bay Estuary, California ....... 146 Figure 73. Mean proportion of each prey category in seasonal diets of Central Bay female surf scoters during $2003-04$ and $2004-05$, as determined using stable isotope ratios of nitrogen $\left(\delta^{15} \mathrm{~N}\right)$ and carbon $\left(\delta^{13} \mathrm{C}\right)$ signatures from scoter plasma and prey in isotopic mixing model

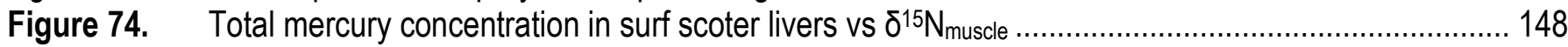

Figure 75. Selenium concentrations (least squares mean $\pm S E$ ) in adult livers for (A) pre-breeding (solid bars) and breeding (open bars); (B) female (solid bars) and male (open bars); and (C) lower South Bay (open bars), central South Bay (hatched bars), and North Bay (closed bars) waterbirds in San Francisco Bay, California 
Figure 76. Geometric means and 95 percent confidence intervals for hepatic selenium (Se) in female surf scoters collected in three San Francisco Bay sub-embayments (SU, Suisun; SP, San Pablo; CB, Central Bay) during fall, winter, spring of 2003-04 (dark bars, 2004) and 2004-05 (light grey bars, 2005)

Figure 77. Selenium concentration in liver compared with proportions of $(A)$ clams, $(B)$ herring roe, and (C) crab in surf scoter diets based on mixing models incorporating nitrogen $\left(\delta^{15} \mathrm{~N}\right)$ and carbon $\left(\delta^{13} \mathrm{C}\right)$ in surf scoter plasma and prey

Figure 78. Geometric means and 95 percent confidence intervals renal cadmium $(C d)$ in female surf scoters collected in three San Francisco Bay sub-embayments (SU, Suisun; SP, San Pablo; CB, Central Bay) during fall, winter, spring of 2003-04 (dark bars, 2004) and 2004-05 (light grey bars, 2005).....

Figure 79. Distribution of PCB congeners in livers of Forster's tern and Caspian tern from

San Francisco Bay, California

Figure 80. Correlation among PBDEs, PCBs, and DDTs in livers of Caspian tern adults and

Forster's tern adults and chicks from San Francisco Bay, California

Figure 81. Correlations of PBDEs, PCBs, and DDTs with selenium (Se) and total mercury (THg) in livers of Caspian tern adults and Forster's tern adults and chicks from San Francisco Bay, California.....

Figure 82. Proportion of $(A)$ pre-breeding and $(B)$ breeding waterbirds at risk to reproductive impairment based on blood mercury (THg) concentrations in San Francisco Bay, California ....

Figure 83. Mean total mercury $(\mathrm{THg})$ concentrations in full clutches of eggs was strongly correlated with blood THg concentrations of incubating females (American avocets, red; black-necked stilts, yellow; Forster's terns, blue) in San Francisco Bay, California, during 2005-07.

Figure 84. Geometric mean total mercury $(\mathrm{THg})$ concentrations in eggs of the most common shorebird and tern species that bred in San Francisco Bay, California, during 2005-07.

Figure 85. Percentage of eggs with total mercury concentrations $\geq 0.5 \mu \mathrm{g} / \mathrm{g}$ fww (hatched bars, moderate risk) and $\geq 1.0 \mu \mathrm{g} / \mathrm{g}$ fww (solid bars, high risk) in San Francisco Bay, California, during 2005-07 ....

Figure 86. Modeled mercury demethylation response (solid change-point line) \pm 95 percent confidence limits (dashed change-point lines) in livers of adult American avocet, black-necked stilt, Caspian tern, and Forester's terns with all species combined in San Francisco Bay, California.

Figure 87. Modeled mercury demethylation responses (solid line) \pm 95 percent confidence limits (dashed lines) in livers of American avocet, black-necked stilt, and Forster's tern chicks in San Francisco Bay, California .....

Figure 88. Comparative demethylation responses in (a) American avocet and black-necked stilts and

(b) Caspian tern and Forster's tern adults in San Francisco Bay, California.

Figure 89. Relationship between inorganic mercury and selenium of adult (a) American avocets and black-necked stilts and (b) Caspian terns and Forster's terns

Figure 90. Partial leverage plots depicting the relationship between adult body mass in grams and liver Se concentrations (dry weight) while accounting for the effects of structural body size, reproductive stage, and sex for four waterbird species during pre-breeding (open circles) and breeding (closed circles) seasons in San Francisco Bay, California 163

Figure 91. Leverage plots for the relationship between total mercury (THg) concentrations (mg/g dry weight) and a suite of biomarkers in livers of Forster's tern and Caspian tern adults (closed circles and closed triangles, respectively), and Forster's tern chicks (open circles) from San Francisco Bay, California

Figure 92. Leverage plots for the relationship between total mercury (THg) concentrations (mg/g dry weight) and a suite of biomarkers in kidneys of Forster's tern and Caspian tern adults (closed circles and closed triangles, respectively), and Forster's tern chicks (open circles) from San Francisco Bay, California 165

Figure 93. Leverage plots for the relationship between total mercury $(\mathrm{THg})$ concentrations $(\mathrm{mg} / \mathrm{g}$ dry weight) and a suite of biomarkers in brains of prebreeding Forster's tern and Caspian tern adults (closed circles and closed triangles, respectively), breeding adult Forster's terns (semi-closed circles), and Forster's tern chicks (open circles) from San Francisco Bay, California 
Figure 94. Total mercury (THg) concentrations (least squares means $\pm \mathrm{SE}$ ) in failed to hatch Forster's tern eggs were higher than randomly sampled eggs from successful nests in San Francisco Bay, California, during 2005-07......

Figure 95. The probability that Forster's tern embryos were malpositioned increased with egg total mercury (THg) concentrations in San Francisco Bay, California, during 2005-07

Figure 96. Conceptual diagrams of potential mechanisms for avian egg hatching failure due to $(A)$ parental dietary mercury exposure during reproduction and $(B)$ parental transfer of dietary mercury to the embryo.....

Figure 97. Mercury concentrations in down feathers ( $\mu \mathrm{g} / \mathrm{g}$ fresh weight [fw]) of pipping chicks were highly correlated $\left(R^{2}=0.96\right)$ with mercury concentrations in the reconstructed fresh whole-egg homogenate $(\mu \mathrm{g} / \mathrm{g}$ fresh wet weight [fww]) for Forster's terns (circles), American avocets (squares), and black-necked stilts (triangles) in South San Francisco Bay, California ..

Figure 98. Mercury concentrations in down feathers $(\mu \mathrm{g} / \mathrm{g}$ fresh weight [fw]) of newly hatched chicks found in the nest were correlated $\left(R^{2}=0.79\right)$ with albumen mercury concentrations ( $\mu \mathrm{g} / \mathrm{g}$ wet weight $[\mathrm{ww}]$ ) micro-sampled from an egg in the same nest when the eggs were $\leq 3$ days incubated in South San Francisco Bay, California.

Figure 99. Mercury concentrations in down feathers $(\mu \mathrm{g} / \mathrm{g}$ fresh weight [fw]) of recaptured Forster's tern chicks ( $\leq 10$ days of age) were correlated $\left(r^{2}=0.74\right)$ with mercury concentrations in down feathers of the same chicks sampled just after they hatched ( $\leq 3$ days of age) in South San Francisco Bay, California.....

Figure 100. Daily survival rates of American avocet (circles) and black-necked stilt (triangles) chicks increased with chick age, but were relatively unaffected by total mercury concentrations in down feathers at hatching.....

Figure 101. Box plots depicting total mercury concentrations ( $\mu \mathrm{g} / \mathrm{g}$ fresh weight, hereafter fw) in down feathers of American avocet and black-necked stilt chicks found dead (filled) were higher than concentrations in chicks that were sampled while live (unfilled) just after hatching in South San Francisco Bay, California .....

Figure 102. Cumulative survival probability (with confidence intervals $[\mathrm{Cl}]$ ) for juvenile Forster's terns during the 35-day postfledging period at the Pond N7 tern colony in South San Francisco Bay, California, during summer 2006.

Figure 103. Response of the embryos of 26 species to injected doses of methylmercury

Figure 104. Response of the embryos of 26 species to injected doses of methylmercury....... 177

Figure 105. A comparison of the toxicity of methylmercury dissolved in corn oil versus water 178

Figure 106. Hatching of mallard eggs dosed with a geometric range of mercury as methylmercury chloride ....... 179

Figure 107. Mercury concentrations in mallard eggs in relation to the concentrations of mercury in the blood of the females that laid the eggs.

Figure 108. Mercury increases in the eggs of female mallards fed diets containing different concentrations of methylmercury.....

Figure 109. Mercury concentrations in the eggs of a mallard injected with $500 \mu \mathrm{g} / \mathrm{g}$ methylmercury chloride dissolved in propylene glycol

Figure 110. Total mercury $(\mathrm{THg})$ concentrations in the thin albumen of an egg versus total mercury concentrations in the whole egg 


\section{Tables}

Table 1. Population range sizes and percentage use of habitat types within 50 and 95 percent utilization distributions (UD) of pre-breeding American avocets and black-necked stilts radio-marked at each site during spring 2005 and 2006 in San Francisco Bay, California

Table 2. Linear movements, home ranges, core areas, and average distance from nest of American avocets in South San Francisco Bay, California during 2005 and 2006 184

Table 3. Population range sizes and percentage use of habitat types within 50 and 95 percent utilization distributions (UD) of pre-breeding Forster's terns radio-marked at each site during spring of 2005 and 2006 in the San Francisco Bay, California.

Table 4. Factors affecting the mean $( \pm S E)$ distance from nest and the mean $( \pm S E)$ foraging range of Forster's terns in South San Francisco Bay, California during 2005 and 2006

Table 5. Summary of surf scoters marked and total locations in two sub-bays of San Francisco Bay during the winters of 2003-04 and 2004-05

Table 6. Number and age of foraging females collected in Central, San Pablo, and Suisun Bays during fall $(F)$, winter (W), and spring (S) of 2003-04 and 2004-05.

Table 7. Tissue samples collected from American avocets (AMAV) and black-necked stilts (BNST) in the North Bay (NB) and South Bay (SB) for isotopic analysis

Table 8. $\quad$ Mean percent number $(\% \mathrm{~N})$ and percent frequency of Occurrence $(\% \mathrm{FO})$ of prey items found in the esophagus and proventriculus of chicks and adult female black-necked stilts collected from the North Bay (NB) and South Bay (SB) in 2005 and 2006. No chicks were collected in the North Bay

Table 9. Mean percent number $(\% \mathrm{~N})$ and percent frequency of occurrence $(\% \mathrm{FO})$ of prey items found in the esophagus and proventriculus of chicks and adult female American avocets collected from the North Bay (NB) and South Bay (SB) in 2005 and 2006. No chicks were collected in the North Bay.....

Table 10. Mean percent number $(\% \mathrm{~N})$ and percent frequency of occurrence (\%FO) of prey items found in the esophagus and proventriculus of adult female black-necked stilts collected from the North Bay (NB) and South Bay (SB) in 2005 and 2006 during pre-breeding and breeding periods.

Table 11. Mean percent number $(\% \mathrm{~N})$ and percent frequency of occurrence $(\% \mathrm{FO})$ of prey items found in the esophagus and proventriculus of adult female American avocets from the North Bay (NB) and South Bay (SB) in 2005 and 2006 during pre-breeding and breeding periods.

Table 12. Mean number of individuals of all identified invertebrates in benthic grab samples located at stilt and avocet foraging areas in the South Bay....

Table 13. Mean number of individuals of all identified invertebrates in aquatic sweep samples located at stilt and avocet foraging areas in the South Bay....

Table 14. Methylmercury and total mercury dry weight concentrations found in benthic invertebrates located at American avocets foraging areas within San Francisco Bay by season.

Table 15. Methylmercury and total mercury dry weight concentrations found in benthic invertebrates located at Black-necked stilt foraging areas within San Francisco Bay.

Table 16. Esophageal contents expressed as aggregate percent dry mass for surf scoters collected during 2003-2004 (2004) and 2004-2005 (2005) in three sub-bays of the San Francisco Bay Estuary...... 193

Table 17. Sample size, geometric means $(\mu \mathrm{g} / \mathrm{g} \mathrm{dw}), \pm$ standard error and 95 percent $\mathrm{Cl}$ for hepatic selenium (Se) and total mercury ( $\mathrm{THg})$, and renal cadmium $(\mathrm{Cd})$ in female surf scoters only collected during fall (F), winter (W), spring (S) 2003-04 (2004) and 2004-05 (2005) in three sub-bays of San

Francisco Bay.

Table 18. Means \pm SE (sample size) of $P 450$ EROD activity $(\mathrm{pmol} / \mathrm{min} / \mathrm{mg})$ in liver tissue samples from Caspian tern and Forster's tern adults and chicks in San Francisco Bay 195

Table 19. Occurrence of embryo malpositions and deformities in Forster's tern, American avocet, and black-necked stilt eggs in South San Francisco Bay during 2005-07. 


\section{Conversion Factors}

\begin{tabular}{|c|c|c|}
\hline Multiply & By & To obtain \\
\hline \multicolumn{3}{|c|}{ Length } \\
\hline centimeter $(\mathrm{cm})$ & 0.3937 & inch (in.) \\
\hline millimeter (mm) & 0.03937 & inch (in.) \\
\hline meter $(\mathrm{m})$ & 3.281 & foot $(\mathrm{ft})$ \\
\hline kilometer (km) & 0.6214 & mile (mi) \\
\hline meter $(\mathrm{m})$ & 1.094 & yard (yd) \\
\hline \multicolumn{3}{|c|}{ Area } \\
\hline square meter $\left(\mathrm{m}^{2}\right)$ & 0.0002471 & acre \\
\hline square meter $\left(\mathrm{m}^{2}\right)$ & 10.76 & square foot $\left(\mathrm{ft}^{2}\right)$ \\
\hline hectare (ha) & 2.471 & acre \\
\hline hectare (ha) & 0.003861 & square mile $\left(\mathrm{mi}^{2}\right)$ \\
\hline square kilometer $\left(\mathrm{km}^{2}\right)$ & 0.3861 & square mile $\left(\mathrm{mi}^{2}\right)$ \\
\hline square kilometer $\left(\mathrm{km}^{2}\right)$ & 247.1 & acre \\
\hline hectare (ha) & 0.003861 & square mile $\left(\mathrm{mi}^{2}\right)$ \\
\hline \multicolumn{3}{|c|}{ Volume } \\
\hline liter (L) & 0.264172 & gallon (gal) \\
\hline milliliter $(\mathrm{mL})$ & 0.0333814 & ounce, fluid (fl. oz) \\
\hline \multicolumn{3}{|c|}{ Mass } \\
\hline $\operatorname{gram}(\mathrm{g})$ & 0.03527 & ounce, avoirdupois (oz) \\
\hline milligram (mg) & 0.00003527 & ounce, avoirdupois (oz) \\
\hline microgram $(\mu \mathrm{g})$ & 0.00000003527 & ounce, avoirdupois (oz) \\
\hline \multicolumn{3}{|c|}{ Density } \\
\hline gram per cubic centimeter $\left(\mathrm{g} / \mathrm{cm}^{3}\right)$ & 62.4220 & pound per cubic foot $\left(\mathrm{lb} / \mathrm{ft}^{3}\right)$ \\
\hline
\end{tabular}

Temperature in degrees Celsius $\left({ }^{\circ} \mathrm{C}\right)$ may be converted to degrees Fahrenheit $\left({ }^{\circ} \mathrm{F}\right)$ as follows:

${ }^{\circ} \mathrm{F}=\left(1.8 x^{\circ} \mathrm{C}\right)+32$ 


\section{Abbreviations and Acronyms}

\begin{tabular}{ll}
\hline $\mathrm{dw}$ & dry weight \\
$\mathrm{ww}$ & wet weight \\
$\mathrm{fww}$ & fresh wet weight \\
$\mathrm{fw}$ & fresh weight \\
$\mathrm{Hg}$ & mercury \\
$\mathrm{THg}$ & total mercury \\
$\mathrm{MeHg}$ & methylmercury \\
LC50 & lethal concentration causing mortality in 50 percent of the \\
& population \\
\hline
\end{tabular}




\section{Mercury in Birds of San Francisco Bay-Delta, California: Trophic Pathways, Bioaccumulation, and Ecotoxicological Risk to Avian Reproduction}

By Joshua T. Ackerman ${ }^{1}$, Collin A. Eagles-Smith ${ }^{1,2}$, Gary Heinz ${ }^{1}$, Susan De La Cruz¹, John Y. Takekawa1 ${ }^{1}$ A. Keith Miles $^{1}$, Terry L. Adelsbach ${ }^{2}$, Mark P. Herzog ${ }^{1}$, Jill D. Bluso-Demers ${ }^{1,3}$, Scott A. Demers ${ }^{1,3}$, Garth Herring ${ }^{1}$, David J. Hoffman ${ }^{1}$, C. Alex Hartman ${ }^{1}$, James J. Willacker ${ }^{1}$, Thomas H. Suchanek1, Steve E. Schwarzbach¹, and Thomas C. Maurer $^{2}$

\section{Executive Summary}

San Francisco Bay Estuary in northern California has a legacy of mercury contamination, which could reduce the health and reproductive success of waterbirds in the estuary. The goal of this study was to use an integrated field and laboratory approach to evaluate the risks of mercury exposure to birds in the estuary. We examined mercury bioaccumulation, and other contaminants of concern, in five waterbird species that depend heavily on San Francisco Bay Estuary for foraging and breeding habitat: American avocets (Recurvirostra americana), black-necked stilts (Himantopus mexicanus), Forster's terns (Sterna forsteri), Caspian terns (Hydroprogne caspia), and surf scoters (Melanitta perspicillata). These species have different foraging habitats and diets that represent three distinct foraging guilds within the estuary's food web. In this report, we provide an integrated synthesis of the primary findings from this study and results are synthesized from 54 peer-reviewed publications generated to date with other unpublished results.

We found that migratory waterbirds arriving in San Francisco Bay Estuary were exposed to elevated mercury concentrations, relative to other staging areas used along the Pacific Flyway. Upon arrival in the estuary, mercury concentrations in birds increased rapidly and continued to increase throughout their stay in the estuary. In particular, mercury concentrations in Forster's terns nearly tripled during the short, 2-month period from the time they arrived in the estuary to when they began breeding. Similarly, mercury concentrations in over-wintering surf scoters more than tripled prior to their departure to their northern breeding grounds. Our captive rearing studies on mallards (Anas platyrhynchos) showed that mercury obtained from exposure to a new diet source was transferred to eggs in less than a week. Thus, migratory birds arriving to breed in San Francisco Bay Estuary are exposed to elevated mercury concentrations in their environment precisely at the critical time period for breeding.

\footnotetext{
${ }^{1}$ U.S. Geological Survey.

${ }^{2}$ U. S. Fish and Wildlife Service, Environmental Contaminants Division.

${ }^{3}$ Humboldt State University, Wildlife Department.
} 
Mercury concentrations varied substantially among breeding waterbird species (Forster's terns: 2.32 micrograms per gram wet weight ( $\mu \mathrm{g} / \mathrm{g}$ ww) blood, Caspian terns: $1.45 \mu \mathrm{g} / \mathrm{g}$ ww blood, stilts: 1.26 $\mu \mathrm{g} / \mathrm{g}$ ww blood, and avocets: $0.50 \mu \mathrm{g} / \mathrm{g}$ ww blood). Species differences were dictated largely by foraging habitat, and to a lesser extent by trophic position. Radio-marked birds used relatively small, localized areas, especially during egg formation and nesting when mercury is transferred to offspring and may affect reproductive behaviors. In particular, telemetry data showed that shorebirds and Forster's terns strongly selected wetland habitats along the estuary's margin, especially salt pond habitats.

Within species, the most important factor influencing mercury concentrations in birds was location. Mercury concentrations were highest in the southern area of San Francisco Bay (including many wetlands associated with the South Bay Salt Pond Restoration Project and the Don Edwards San Francisco Bay National Wildlife Refuge), as well as some wetland sites in the North Bay (including wetlands of the Napa-Sonoma Marsh Wildlife Area). Mercury concentrations in biota often were highly wetland specific, with adjacent wetlands exhibiting mercury concentrations that differed substantially for bird eggs (as much as 340 percent difference) and prey fish (as much as 400 percent difference). Together with the bird telemetry data showing high site fidelity and small home ranges, especially during the breeding season, these results indicate that birds are useful bioindicators of localized contamination and that mercury hot-spots were prevalent in the San Francisco Bay Estuary.

Not only were wetland habitats along the estuary's margins the preferred foraging and breeding areas for birds, but these habitats also had the highest mercury concentrations in bird prey. For shorebirds, 30 percent of invertebrate (Corixidae) samples from wetlands exceeded the 0.50 microgram per gram dry weight $(\mu \mathrm{g} / \mathrm{g} \mathrm{dw})$ methylmercury dietary threshold for birds that is associated with impaired reproduction. Similarly, of the more than 3,000 prey fish sampled, 26 percent had total mercury concentrations exceeding the $0.20 \mu \mathrm{g} / \mathrm{g}$ ww threshold for sublethal effects in fish, and 12 percent exceeded the $0.30 \mu \mathrm{g} / \mathrm{g}$ ww dietary threshold for fish-eating birds that is associated with impaired reproduction. Mercury concentrations differed substantially among prey fish species (Mississippi silversides: $0.83 \pm 0.02 \mu \mathrm{g} / \mathrm{g} \mathrm{dw}$, topsmelt: $0.55 \pm 0.02 \mu \mathrm{g} / \mathrm{g} \mathrm{dw}$, northern anchovy: $0.51 \pm 0.04$ $\mu \mathrm{g} / \mathrm{g} \mathrm{dw}$, threespine stickleback: $0.45 \pm 0.01 \mu \mathrm{g} / \mathrm{g} \mathrm{dw}$, rainwater killifish: $0.44 \pm 0.02 \mu \mathrm{g} / \mathrm{g} \mathrm{dw}$, staghorn sculpin: $0.38 \pm 0.03 \mu \mathrm{g} / \mathrm{g} \mathrm{dw}$, longjaw mudsuckers: $0.36 \pm 0.01 \mu \mathrm{g} / \mathrm{g} \mathrm{dw}$, yellowfin goby: $0.36 \pm 0.02 \mu \mathrm{g} / \mathrm{g}$ $\mathrm{dw}$, prickly sculpin: $0.35 \pm 0.03 \mu \mathrm{g} / \mathrm{g} \mathrm{dw}$, and shiner surfperch: $0.29 \pm 0.04 \mu \mathrm{g} / \mathrm{g} \mathrm{dw}$ ). Fish returns to Forster's tern colonies indicated that fish with the highest mercury concentrations also made up a large proportion of Forster's tern diets (Mississippi silversides: 11 percent, topsmelt: 12 percent, threespine stickleback: 25 percent, longjaw mudsuckers: 36 percent of tern diet).

Mercury concentrations in prey varied substantially with calendar date, and this was an important contributor to avian reproductive risk from mercury contamination. In particular, mercury concentrations in prey fish increased substantially from March to a maximum mercury concentration in May, then decreased into July. This rapid increase and peak in prey fish mercury concentrations coincided with the period when 78 percent of Forster's tern eggs were developed and 31 percent of chicks hatched. Thus, mercury concentrations in prey fish were elevated precisely when piscivorous birds were breeding, which maximized risk to potential reproductive impairment during this sensitive timeframe. 
High levels of mercury contamination have resulted in several negative effects on bird health and reproduction within the San Francisco Bay Estuary. In adults, we found that birds initiated a physiological mechanism whereby they demethylate (detoxify) methylmercury in their livers. We estimated that this demethylation threshold occurs at $8.51 \mu \mathrm{g} / \mathrm{g} \mathrm{dw}$ in the liver, and that this threshold differs among bird taxa. We also determined other sublethal effects on adult terns, including increased oxidative stress at higher mercury concentrations in the liver, kidneys, and brain.

In addition to sublethal effects on adult birds, mercury can be most detrimental to avian reproduction. Using a mercury concentration in blood of $3.0 \mu \mathrm{g} / \mathrm{g}$ ww as a toxic threshold, we estimated that 5-6 percent of breeding avocets, stilts, and Caspian terns and 48 percent of breeding Forster's terns were at high-risk to potential reproductive impairment. Mercury concentrations in eggs were strongly correlated to those in the incubating female parent, confirming that females with high mercury concentrations also will lay eggs with high mercury concentrations. Overall, mercury concentrations in eggs of birds breeding in the estuary were considered high (Forster's terns: $1.47 \pm 0.05$ micrograms per gram fresh wet weight $[\mu \mathrm{g} / \mathrm{g}$ fww], Caspian terns: $0.75 \pm 0.09 \mu \mathrm{g} / \mathrm{g}$ fww, stilts: $0.66 \pm 0.04 \mu \mathrm{g} / \mathrm{g}$ fww, and avocets: $0.22 \pm 0.01 \mu \mathrm{g} / \mathrm{g}$ fww), often exceeding commonly used toxicity thresholds for bird eggs. For example, 98 percent of Forster's tern eggs, 88 percent of Caspian tern eggs, 68 percent of stilt eggs, and 17 percent of avocet eggs exceeded $0.5 \mu \mathrm{g} / \mathrm{g}$ fww (moderate risk) and 79 percent of Forster's tern eggs, 13 percent of Caspian tern eggs, 31 percent of stilt eggs, and 3 percent of avocet eggs even exceeded 1.0 $\mu \mathrm{g} / \mathrm{g}$ fww (high risk).

We found several lines of evidence from the field and the laboratory indicating that mercury contamination might be impairing reproduction of birds breeding in San Francisco Bay Estuary. First, mercury concentrations in Forster's tern eggs were 28 percent higher in failed-to-hatch eggs (mean: 1.84 $\mu \mathrm{g} / \mathrm{g}$ fww) than in randomly sampled eggs from successful nests (mean: $1.44 \mu \mathrm{g} / \mathrm{g}$ fww), which indicated that mercury might be impairing egg hatchability. Second, the probability of an embryo being malpositioned within Forster's tern eggs increased with mercury concentrations in the egg, and malpositioned embryos have difficulty hatching out of the egg. Third, our egg injection studies revealed that species sensitivity to methylmercury varied considerably among the 26 bird species studied, and several tern species that are closely related to the Forster's terns and Caspian terns that breed in the estuary are more sensitive to mercury toxicity than the traditional mallard model for which so many of the toxicity thresholds have been developed. Fourth, we found that mercury concentrations in juvenile birds changed rapidly as they aged, and varied by more than an order of magnitude over this short, 40day period. Chick mercury concentrations exhibited a robust U-shaped pattern from hatching through postfledging. This U-shaped pattern has important toxicological implications, and indicates that juvenile birds are at highest risk to mercury toxicity shortly after hatching when maternally deposited mercury concentrations are still high and again after fledging when opportunities for growth dilution and excretion of mercury into feathers are limited. Accordingly, we found that mercury concentrations in down feathers at hatching were higher among dead stilt chicks (mean: $16.43 \mu \mathrm{g} / \mathrm{g} \mathrm{fw}$ ) than in randomlysampled live chicks (mean: $9.98 \mu \mathrm{g} / \mathrm{g}$ fw).

One of the strongest aspects of our study was that we developed several mathematical equations to integrate toxicity risk for all three avian life-stages into a single tissue matrix. Our goal was to be able to convert all the observed effects of mercury on adults, eggs, and chicks into a single tissue matrixeggs. By condensing effects into equivalent concentrations in bird eggs, regulatory targets and risk 
thresholds can take into account multiple reproductive endpoints and future monitoring efforts can focus on bird egg sampling for mercury monitoring programs. Specifically, the liver demethylation threshold of $8.51 \mu \mathrm{g} / \mathrm{g} \mathrm{dw}$ translates into an equivalent egg mercury concentration of $0.65 \mu \mathrm{g} / \mathrm{g}$ fww. This egg mercury concentration is also equivalent to a blood mercury concentration of $1.3 \mu \mathrm{g} / \mathrm{g}$ ww, which happens to be near a mercury exposure level often characterized as having moderate risk to birds. Thus, an egg mercury concentration of $0.65 \mu \mathrm{g} / \mathrm{g}$ fww provides a conservative effect level for birds in San Francisco Bay Estuary where negative effects of mercury on birds begin to manifest.

Although mercury was the most important contaminant with elevated levels, other contaminants of concern (selenium, cadmium, polychlorinated biphenyls [PCBs], dichlorodiphenyltrichloroethanes (DDTs), and polybrominated diphenyl ethers [PDBEs]) also were present in birds in the San Francisco Bay Estuary. In particular, selenium levels were somewhat elevated and selenium concentrations in livers (avocets: $7.92 \pm 0.64 \mu \mathrm{g} / \mathrm{g}$ dw, stilts: $5.29 \pm 0.38 \mu \mathrm{g} / \mathrm{g} \mathrm{dw}$, Forster's terns $7.13 \pm 0.38 \mu \mathrm{g} / \mathrm{g} \mathrm{dw}$, Caspian terns: $6.73 \pm 0.78 \mu \mathrm{g} / \mathrm{g} \mathrm{dw}$, and surf scoters: $32.91 \pm 1.86 \mu \mathrm{g} / \mathrm{g} \mathrm{dw}$ ) were negatively related to body condition in Forster's terns.

\section{Introduction}

San Francisco Bay Estuary (Estuary) in California has a legacy of mercury (Hg) contamination from both mercury mining and gold extraction (Hornberger and others, 1999; Singer and others, 2013), and this pollution is thought to reduce the health and reproductive success of some waterbirds breeding in the estuary (Schwarzbach and others, 2006; Ackerman and others, 2007, 2008a, 2008d, 2012; EaglesSmith and others, 2009a, 2009b; Herring, 2010; Herring and others, 2012). Sedimentary mercury deposits might become more bio-available in the estuary because of current restoration plans to convert existing habitats, especially former salt evaporation ponds, into tidal marshes (Goals Project, 1999; Singer and others, 2013).

San Francisco Bay is the largest estuary on the west coast of North America, but it has lost nearly 80 percent of its tidal salt marshes and 40 percent of its tidal flats over the past two centuries due to urban development, agriculture, and salt production (Goals Project, 1999). In particular, more than 13,000 ha of artificial salt evaporation ponds were constructed within the former baylands (Goals Project, 1999). Recently, however, more than 10,000 ha of salt ponds have been transferred to government ownership and federal and state agencies are beginning to implement a plan to convert some of these salt ponds into tidal and managed marsh habitats (Goals Project, 1999; http://www.southbayrestoration.org/). Additional wetland habitats also are being restored throughout the estuary. The restoration of these wetlands might accelerate the production of methylmercury $(\mathrm{MeHg})$ and increase the contamination of aquatic biota in the estuary.

San Francisco Bay Estuary supports more than half a million wintering and migrating shorebirds annually and is recognized as a site of hemispheric importance to shorebirds (Page and others, 1999; Stenzel and others, 2002). Shorebird populations are largest during spring when they either breed locally or stage in San Francisco Bay during migration to acquire the necessary resources to travel to distant breeding areas and successfully reproduce (Warnock and Bishop, 1998; Stenzel and others, 2002) Additionally, more than a quarter million ducks, or 39 percent of the diving ducks that use the Pacific Flyway, over-winter in the estuary (Accurso, 1992). Several contaminants, including mercury and selenium, occur at such elevated concentrations that the estuary currently is listed as impaired under section 303(d) of the Federal Clean Water Act (San Francisco Bay Regional Water Quality Control Board, 2006). Thus, nearly 1 million waterbirds annually may be at risk to mercury contamination accumulated while foraging in the estuary. 


\section{Bird Foraging Guild Approach}

Estuarine waterbirds form distinct foraging guilds that are distinguished by their feeding method, diet preferences, and habitat use (Takekawa and others, 2001). These guilds include (1) surface feeding and littoral zone probing shorebirds, (2) benthic feeding diving ducks, and (3) plunge diving and fisheating terns. Each of these guilds represents a unique component of the food web and foraging pathway in the San Francisco Bay Estuary ecosystem for mercury bioaccumulation. By examining variation in contaminant uptake by the major foraging guilds, we were able to provide a comprehensive understanding of mercury bioaccumulation related to avian habitat use in the estuary.

We examined mercury bioaccumulation, and other contaminants of concern, in five waterbird species that depend heavily on San Francisco Bay for foraging and breeding habitat. Specifically, we studied American avocets (Recurvirostra americana, hereafter avocets), black-necked stilts (Himantopus mexicanus, hereafter stilts), Forster's terns (Sterna forsteri), Caspian terns (Hydroprogne caspia), and surf scoters (Melanitta perspicillata). These species have different foraging habitats and diets that represent three distinct foraging guilds within the San Francisco Bay (the bay) food web.

Avocets and stilts are the two most abundant breeding shorebirds in San Francisco Bay (Stenzel and others, 2002; Rintoul and others, 2003). More than 4,000 avocets and 1,000 stilts, roughly 20 percent of their wintering populations, breed locally, making San Francisco Bay the largest breeding area for these species on the Pacific Coast (Stenzel and others, 2002; Rintoul and others, 2003). Avocets and stilts forage primarily on aquatic insects and crustaceans (Robinson and others, 1999; Ackerman and others, 2013a). However, stilts use more vegetated marsh habitats than avocets, whereas avocets use more tidal flat habitats along the bay's margins (Rintoul and others, 2003; Ackerman and others, 2007). Avocets and stilts over-winter in San Francisco Bay and Central Valley, California (Robinson and others, 1999; Stenzel and others, 2002; Ackerman and others, 2013a).

Forster's terns and Caspian terns are piscivorous species; however, they exhibit distinct foraging behavior and prey selection (Cuthbert and Wires, 1999; McNicholl and others, 2001). Forster's terns mainly forage on small fish ( $<10 \mathrm{~cm}$; McNicholl and others, 2001) in wetlands along the bay's margins (Ackerman and others, 2008a), whereas Caspian terns mainly forage on larger fish (5-30 cm; Cuthbert and Wires, 1999) in open bay habitats (Lyons and others, 2005). Approximately 30 percent of the Pacific Coast breeding population of Forster's terns nests in the San Francisco Bay (McNicholl and others, 2001; Strong and others, 2004). Unlike avocets and stilts, Forster's terns and Caspian terns overwinter outside of the estuary and arrive in the spring to breed (Cuthbert and Wires, 1999; McNicholl and others, 2001).

Surf scoters are the most abundant wintering sea duck in the San Francisco Bay Estuary (Accurso, 1992). Scoters are diving sea ducks that feed on benthic invertebrates, including bivalves and crustaceans. During spring, scoters migrate north to breed in the Northwest Territories of Canada (De La Cruz and others, 2009) and could be transporting San Francisco Bay contaminants to northern breeding grounds. 


\section{Objectives}

Our goal was to use an integrated field and laboratory approach to evaluate the risks of mercury exposure to birds in the San Francisco Bay-Delta. This information is necessary to devise and prioritize mercury control strategies protective of Bay-Delta avian species. Specifically, we integrated a field assessment of contaminant exposure and effects with a laboratory assessment of the variation in sensitivity of avian embryos to methylmercury. Our field approach evaluated exposure and bioaccumulation pathways of mercury to three foraging guilds of aquatic birds. We also evaluated the potential influence of other contaminants of concern (COCs), primarily selenium (Se), polychlorinated biphenyls (PCBs) and polybrominated diphenyl ethers (PBDEs), which co-occur with mercury in some areas of the Bay-Delta. Our complementary laboratory approach provided data on the variation in methylmercury sensitivity among avian species, and established methylmercury dose-response relationships and threshold concentrations associated with avian embryo toxicity. The three main objectives were to:

- Objective 1: Examine bird mercury exposure and bioaccumulation in three bird guilds,

- Objective 2: Evaluate toxicological effects of mercury exposure on birds, and

- Objective 3: Examine the differential sensitivity of bird taxa to mercury exposure.

\section{Report Goals and Structure}

This CALFED-funded project (ERP-02D-C12) has been successful, producing more than 54 peer-reviewed journal publications and book chapters, 11 magazine articles, 3 reports, and 4 Master's Theses and Dissertations that have used data funded in whole or in part by this project. The goal of this final report is to synthesize these numerous results into a single document. We briefly describe the methods for the entire project, and then synthesize the data in the section, "Results and Discussion." Results from statistical analyses are shown in the report only when they have not been included in a specific peer-reviewed publication. Detailed methods, statistical analyses, and results are available in the citations listed in appendix 1, which lists all peer-reviewed publications and magazine articles that have been published from this project.

\section{Methods}

We conducted our study at several locations throughout the San Francisco Bay Estuary $\left(37.8^{\circ} \mathrm{N}\right.$, $122.3^{\circ} \mathrm{W}$ ) during 2003-07. Sampling was done in five major regions: Lower South Bay, Central South Bay, Central Bay, North Bay (also called San Pablo Bay), and Suisun Bay (fig. 1). All major wetland habitat types were sampled during the study (open bay, sloughs, tidal flats, tidal marsh, salt ponds, and diked wetlands), with specific emphasis on wetland habitats along the bay's margin where most waterbirds breed in the Estuary. 


\section{Field Methods}

\section{Adult Bird Capture and Sampling}

\section{Shorebird and Tern Capture and Sampling}

We captured pre-breeding birds (shorebirds: March-April; terns: April-May) with remotely detonated net-launchers (Coda Enterprises, Mesa, Arizona) or rocket nets set at known foraging and roosting sites. We captured breeding birds (April-July) on their nests using remotely triggered bow nets, except for Caspian terns, which were collected at an off-colony site due to permit restrictions. For livecaptured birds, we sampled blood and feathers and marked birds with leg bands and radio transmitters. We also collected a smaller subset of birds using a shotgun and steel shot or a high-powered air rifle while they were foraging; these birds were necropsied for internal tissues. Because terns have monomorphic plumage, it is difficult to identify males from females in the field. We therefore developed the first discriminant function to determine an individual's sex using morphological measurements for Forster's terns (Bluso and others, 2006) and Caspian terns (Ackerman and others, 2008c), which thereafter were used to identify male and female terns. We used bill shape of avocets (Ackerman and others, 2013a) and plumage coloration of stilts (Robinson and others, 1999) to determine sex of captured shorebirds.

\section{Diving Duck Capture and Sampling}

We captured wintering surf scoters with floating mist nets (Kaiser and others, 1995) or from a boat with a net gun (Coda Enterprises, Mesa, Arizona) in the San Pablo Bay and the Central Bay (fig. 2) during November and December 2003 and 2004. We banded, weighed, and measured each captured bird and then used a combination of plumage characteristics and cloacal examination to determine sex and bursal depth measurements to estimate age (Mather and Esler, 1999). A veterinarian surgically implanted coelomic radio or satellite transmitters with external whip antennas (VHF: 22 to 24-g, model A2310, Advanced Telemetry Systems, Insanti, Minnesota; Platform terminal transmitter PTT: 38g model PTT-100, Microwave Telemetry, Columbia, Maryland) in juveniles and after second year (ASY) males and females (Korschgen and others, 1996; Mulcahy and Esler, 1999). While scoters were anesthetized, we sampled blood ( 3 to $6 \mathrm{ml}, \leq 1$ percent of body mass) from the jugular vein.

\section{Adult Bird Telemetry}

\section{Shorebird and Tern Telemetry}

We radio-marked pre-breeding shorebirds (February-April) and terns (April-May) in 2005 and 2006 to examine space use of habitats when they were acquiring food resources that would be used for egg formation, and we tracked birds throughout the breeding season when additional exposure to mercury through their diet could influence breeding behavior. We radio-marked birds with a radio transmitter (Model A2470, Advanced Telemetry Systems, Isanti, Minnesota) attached to a metal leg band on the tibia (following Plissner and others, 2000; Haig and others, 2002). 
We tracked radio-marked birds from trucks and fixed-wing aircraft equipped with dual 4element Yagi antenna systems (Advanced Telemetry Systems, Isanti, Minnesota). To ensure coverage throughout San Francisco Bay, we used fixed tracking routes through all main North and South Bay former salt ponds (including North Bay, Alviso, Moffett, and Eden Landing salt ponds), marshes (NapaSonoma Marsh Wildlife Area, New Chicago Marsh, and Coyote Creek Marsh), and mud flats. For each location by truck, we obtained at least two azimuths within several minutes to minimize movement error. We used triangulation program software (LOAS, version 3.0.1, Ecological Software Solutions) to calculate Universal Transverse Mercator (UTM) coordinates for each location.

\section{Diving Duck Telemetry}

We tracked marked scoters daily with vehicle-mounted antenna systems from November through April 2003-04 and 2004-05, as described in the section "Shorebird and Tern Telemetry." We surveyed the entire San Francisco Bay each day, alternating between two different routes to obtain locations on each individual during targeted periods during each week. We obtained at least one location per individual in each period during each week. To avoid autocorrelation, locations from the same individual were collected at least 2 hours apart. Test transmitters on buoys in the centers of the San Pablo and Central Bays were detectable with our null-peak system from all observation sites used in our study.

\section{Nest Monitoring}

\section{Shorebird and Tern Nest Monitoring}

Throughout the nesting season (April through August), we entered each nesting colony weekly to monitor waterbird nesting activity. We marked each newly initiated nest uniquely and recorded UTM coordinates of each nest (Garmin GPSMAP 76, Garmin International Inc., Olathe, Kansas). At each weekly nest visit, we floated eggs to determine embryo age (Ackerman and Eagles-Smith, 2010b), recorded clutch size, determined overall nest fate (hatched, failed-to-hatch, abandoned, or depredated), and determined the fate of each individual egg (hatched, failed-to-hatch, abandoned, or depredated).

To assess whether mercury concentrations in failed-to-hatch and abandoned eggs were higher than expected, we randomly collected one egg from several nests at 6-12 days in incubation. We then followed the fate of the remaining eggs in the nest and classified the nest as successful if $\geq 1$ of the remaining eggs hatched. For our random egg sample, we used only those random eggs that were collected from successful nests. We collected failed-to-hatch and naturally abandoned eggs opportunistically during routine nest monitoring. We defined failed-to-hatch eggs as those eggs that did not successfully hatch despite the fact that other siblings within the clutch successfully hatched. Importantly, eggs from nests that were depredated, abandoned, or where all eggs were either infertile or dead were excluded from our definition of failed-to-hatch eggs. We defined abandoned eggs as those clutches that were naturally abandoned by their parents without any obvious sign of depredation, disturbance, or flooding. We excluded any eggs that contained signs of physical damage, such as cracks or dents in the shell.

After egg collection, we stored eggs in the refrigerator until egg dissection. Before dissecting the egg, we measured the length and width of each egg $( \pm 0.01 \mathrm{~mm})$ with digital calipers, and the whole mass of each egg $( \pm 0.01 \mathrm{~g})$ with a digital balance. We opened each egg with scissors, removed all egg contents into a tared polypropylene jar, and recorded egg content mass. We then immediately froze the egg until preparation for mercury analysis. 
We estimated daily nest survival rates based on weekly nest visits using logistic exposure models (Shaffer, 2004). A nest was considered to have survived an interval if the clutch was still completely or partially intact, embryo development had progressed, and there were no signs of nest abandonment (such as cold eggs). A nest was also considered successful if $\geq 1$ egg successfully hatched. A nest was considered unsuccessful if it was destroyed or abandoned. Exposure days were calculated as the number of days between nest visits, except when a final nest fate occurred between visits (hatched, depredated, or abandoned). For hatched nests, we calculated exposure days for the final interval based on the expected hatch date (Ackerman and Eagles-Smith, 2010b). For depredated nests, we calculated exposure days for the final interval as the mid-point between nest visits. For abandoned nests, we calculated exposure days for the final interval as the difference between the developmental age of the eggs when the nest was abandoned (estimated via egg flotation) and the developmental age of the eggs when the nest was last visited. We censored nests that were abandoned due to investigator disturbance (such as breeding collections).

\section{Diving Duck Nest Monitoring}

For the cross-seasonal component of our project, we leveraged three additional concurrent studies of surf scoters in the Pacific Flyway. These studies were started separately to examine migration from different wintering sites; however, the similarities in timing and methodology of each study provided us with the unique opportunity to bolster sample sizes and to compare migration timing (De La Cruz and others, 2009), breeding synchrony, and nest site characteristics (Takekawa and others, 2011), and contaminants in eggs among birds across the Pacific Flyway.

We used aerial telemetry to search for nests of VHF and PTT-marked scoters from San Francisco Bay and three other wintering areas across breeding areas in Northwest Territories, Canada. Nesting locations of surf scoters were determined primarily from birds marked with satellite transmitters. Locations were obtained from the Argos data system (CLS ${ }^{\text {TM }}$, France). In 2005 and 2006, nesting locations were supplemented from aerial searches of scoters marked with VHF transmitters. Observers used one or two receivers to listen to and locate marked individuals as they flew in fixedwing aircraft outfitted with dual four-element Yagi antennas (Advanced Telemetry Systems, Isanti, Minnesota). Telemetry flights in Canada were flown in a grid pattern over most of the Northern Boreal Forest in the Northwest Territories from Inuvik to the Alberta border and from the MacKenzie River in the west to tree line in the east.

When marked birds were found we landed in nearby lakes and used hand-held telemetry units to find nest sites. We measured nest site characteristics and collected two eggs from each nest. Eggs were refrigerated until processed. We determined volume, measured length and width $( \pm 0.01 \mathrm{~mm})$, and weighed each egg $( \pm 0.01 \mathrm{~g})$. Eggs were opened with clean scalpel and scissors, albumin and yolk were placed in separate tared chemically clean I-CHEM® glass vials (Chase Scientific Glass, Rockwood, Tennessee), and mass of each egg was recorded. If an embryo was present, we recorded developmental stage, gross abnormalities, and positioning. Samples were frozen at $-20{ }^{\circ} \mathrm{C}$ until analyses. Albumin and yolks from each egg were analyzed for total mercury (THg), Se, organochlorines, PCB, PBDE, and isotopes. 


\section{Chick Sampling and Telemetry}

\section{Shorebird Chick Telemetry}

For shorebird chicks, we studied the effects of egg mercury concentrations on subsequent avocet and stilt chick survival from hatching to fledging. To do so, it was necessary to demonstrate that down feathers of chicks were a reliable index of mercury concentrations in the whole egg (Ackerman and Eagles-Smith, 2009a) so that samples of mercury concentrations could be collected from chicks without potentially influencing their subsequent survival.

Based on nest monitoring data, we returned to nests at their estimated hatch date (Ackerman and Eagles-Smith, 2010b). We only radio-marked recently hatched chicks ( $\leq 2$ days old) that were found in or near their nest bowl. We used only one chick per brood for survival rate estimation; if more than one chick was present during a nest visit, we randomly selected one chick for radio marking. We collected 10-15 downy feathers from the rump and mantle of each radio-marked chick for subsequent mercury analysis. We also salvaged all the dead chicks found near the nesting colonies, sampled their down feathers, and measured their structural size to estimate their age. We stored feathers in individually labeled Whirl-paks ${ }^{\circledR}$ (Nasco, Modesto, California) until laboratory analysis.

We radio-marked chicks with transmitters that had a duration range of 21-50 days, depending on the transmitter model (Model BD-2T, Holohil Systems Ltd., Carp, Ontario, Canada; Model A2410 modified, Advanced Telemetry Systems Inc., Isanti, Minnesota). Transmitters weighed $1.1 \mathrm{~g}$ for avocets and $0.8 \mathrm{~g}$ for stilts, and were $\leq 19 \mathrm{~mm}$ long $\times \leq 8 \mathrm{~mm}$ wide. We attached a radio transmitter to each chick's back with sutures (Ethicon® Vicryl FS-2, 3-0, Ethicon Inc., Piscataway, New Jersey) threaded through front and rear channels on the transmitter, and knots were secured with cyanoacrylic glue (Loctite 422, Henkel Corp., Rocky Hill, Connecticut). After radio-marking, we returned chicks to their nest within $23 \pm 12$ minutes of capture (mean \pm standard deviation).

We tracked radio-marked chicks daily to determine mortality and predator type. We determined locations of radio-marked chicks using truck systems as described above. Radio-marked chicks that went missing were searched for daily until they were found or until the transmitter duration had been exceeded. We used a hand-held Yagi antenna and receiver to locate the transmitter and chick within 24 hours of suspected chick mortality.

\section{Tern Chick Telemetry}

For tern chicks, we studied the effects of mercury on survival during the postfledging period when mercury concentrations are high (Ackerman and others, 2011). We monitored Forster's tern colonies weekly from nest initiation (early May) until the last tern chick fledged (late August). At each visit, we monitored nests to determine nest fate and hand-captured every chick on the nesting colony to measure their size. We banded chicks with stainless steel U.S. Geological Survey leg bands, weighed them with a spring scale $\left( \pm 1.0\right.$ g with a 100 -g or 300 -g Pesola ${ }^{\circledR}$ spring scale, Pesola Ag, Baar, Switzerland), and we measured exposed culmen length and short tarsus (tarsometatarus bone) length with digital calipers $\left( \pm 0.01 \mathrm{~mm}\right.$ with Fowler ${ }^{\circledR}$ electronic digital calipers, Newton, Massachusetts) and flattened wing chord length with a wing board $( \pm 1.0 \mathrm{~mm})$. For this study, we were specifically interested in only those chicks that were approaching fledging at about 28 days of age. We defined postfledging tern chicks as those that had fledged and were capable of flight ( $>28$ days of age), but still might have been periodically fed by their parents. We estimated each chick's age using a multiple regression equation we developed during this project that is based on a chick's structural size (Ackerman and others, 2011). 
We estimated survival of postfledging chicks using radio telemetry at the tern colony in Pond N7, which was the largest Forster's tern colony in San Francisco Bay during 2006 (N>600 nests; J.T. Ackerman, U.S. Geological Survey, unpub. data). We radio-marked chicks on July 5 or July 12, 2006, when most chicks at Pond N7 were fledging. We selected chicks for radio-marking that were about 25days of age to ensure that chicks were marked just before they fledged at about 28-days of age. We estimated hatching dates for each radio-marked chick by back-calculation using the estimated age at the date of capture. We attached radio transmitters to the midline of a chick's mantle with sutures and tracked radio-marked postfledging terns as described above. Chicks that were not detected were searched for each day until found or until the transmitter was determined to have quit working. We also used an automated telemetry data logger system (AVM Instrument Co., Livermore, California) at the Pond N7 colony to continuously monitor whether radio-marked terns were present or absent from their natal colony. This system continuously scanned all 30 of the frequencies for the radio-marked terns, with a cycle of about 20 minutes. When we believed the chick had died, we used hand-held Yagi antenna systems and receivers to find the transmitter and chick within 24 hours.

For contaminant analyses, we collected blood and breast feathers from live chicks that were $\geq 21$ days of age between June 28 and August 17, 2006 at colonies within Ponds A7 and N7. Samples from blood and feathers were collected once from each chick. In addition to sampling breast feathers from apparently healthy, live fledglings, we also sampled breast feathers for mercury analysis from salvaged chicks that were found dead on the colonies during routine monitoring activities.

\section{Bird Prey Sampling}

\section{Shorebird Prey: Invertebrate Sampling}

We sampled the avian prey base in conjunction with avocet and stilt collections to determine prey availability and to conduct prey contaminant analysis (collected separately). Ekman Grab samples were collected from each location where a bird was collected. Additionally, pelagic sweeps of a large mesh $(0.05 \mathrm{~mm})$ planktonic tow were conducted at each location when water depth allowed. Samples collected for contaminant analysis were rinsed through a 500- $\mu \mathrm{m}$ sieve while in the field and frozen at $20^{\circ} \mathrm{C}$ within 4 hours of collection until processed for contaminants and stable isotope analyses. Benthic prey availability samples were placed in 1-gallon zip-top bags and kept on wet ice while in the field.

Within 1 week of collection, all samples were washed using the elutriation sieving method. The samples were placed in a bucket of clean water and the largest, heaviest sediments settled to the bottom, and the water with suspended invertebrates was then poured onto the $0.5 \mathrm{~mm}$ sieve. The sieve was scanned, and any invertebrates were picked from the sieve and placed into a labeled $40 \mathrm{~mL}$ vial containing 70 percent ethanol with 1 percent rose Bengal tissue dye for preservation. This process was repeated until the sample was completely broken up and rinsed into the sieve. The remaining sample matrix was placed into labeled jars containing ethanol and rose Bengal dye solution. The invertebrate samples were then sorted and counted under stereo dissection microscopes. Invertebrates were identified to the lowest possible taxonomic unit. 


\section{Diving Duck Prey: Benthic Invertebrate Sampling}

Typically on the same day, but always within 7 days of collecting each surf scoter, we sampled benthic invertebrate prey for contaminant and isotope analyses by taking five grab samples with an Ekman dredge (6-in ${ }^{3}$, Wildlife Supply Co., Yulee, Florida) in the collection location. All benthic samples were rinsed and processed as described above. We did not purge invertebrate gut contents before freezing (for example, Linville and others, 2002), but birds can assimilate contaminants from sediments that are ingested with or in prey (Hui and Beyer, 1998; Beyer and Fries, 2003).

Esophagi (including proventriculus), gizzards, and benthic grab sample items were identified, sorted, and counted to lowest possible taxon using 7-35 times dissecting scopes. Wet mass $( \pm 0.001 \mathrm{~g})$ was determined for each individual food item. For esophagi samples, dry masses $( \pm 0.001 \mathrm{~g})$ were determined for each prey type by drying at $80{ }^{\circ} \mathrm{C}$ until samples reached a constant mass. We calculated aggregate percent dry mass or relative percentage of each prey type averaged across all birds, as well as frequency of occurrence or number with the prey divided by the total in the sample (Swanson and others, 1974). For bivalves, length (longest axis) and width were measured $( \pm 0.01 \mathrm{~mm})$ using electronic calipers, and each prey taxa was separated into two size class groups based on prey size preferences determined in previous work on diets of San Francisco Bay diving duck (J.Y. Takekawa, unpub. data; Lovvorn and others, 2013): 0-12 and 12-25 mm in length.

To prepare benthic grab samples for contaminant and isotope analyses, we composited invertebrates from the same sampling location into samples consisting of between 2 and 127 individuals depending on the taxa and biomass needed for analyses. Bivalves were shucked and placed into chemically clean I-CHEM ${ }^{\circledR}$ glass vials (Chase Scientific Glass, Rockwood, Tennessee) for additional processing. All benthic invertebrates were prepared for contaminant and isotope analyses as outlined below.

\section{Tern Prey: Fish Sampling}

We sampled fish from salt pond, wetland, slough, and open bay habitats throughout the South Bay and North Bay study areas (fig. 3) to achieve two primary objectives. First, to assess the spatial mercury concentrations in prey fish across the regions, we sampled fish from randomly selected telemetry locations in the pre-breeding core use areas of individually radio-marked Forster's terns (Bluso-Demers and others, unpub. data; Ackerman and others, 2008a). Across all habitats and locations, we sampled 10 fish species, including longjaw mudsucker (Gillichthys mirabilis), Mississippi silverside (Menidia audens), northern anchovy (Engraulis mordax), prickly sculpin (Cottus asper), rainwater killifish (Lucania parva), shiner surfperch (Cymatogaster aggregata), staghorn sculpin (Laptocottus armatus), topsmelt (Atherinops affinis), threespine stickleback (Gasterosteus aculeatus), and yellowfin goby (Acanthogobius flavimanus). In 2006, we evaluated the intra-annual temporal variation in longjaw mudsucker and threespine stickleback mercury concentrations in three wetlands containing active tern colonies: New Chicago Marsh, Pond A16, and Pond A8. In order to link temporal trends in fish mercury concentrations with potential exposure to Forster's terns, we selected three fixed sampling stations for fish in each wetland that were based on tern population home ranges determined for radio-marked individuals that used each pond during the previous year (2005). At each station, we deployed three anchored minnow traps for as long as 4 days, at approximately 3 -week intervals over a period of months from March 22 to July 28, 2005. Traps were baited with canned cat food that was carefully punctured to make a tiny hole that prevented fishes from consuming the food. 


\section{Diet Sampling}

\section{Shorebird Diet}

Avocets and stilts were observed foraging for $\geq 15$ minutes to assure gut contents came from the sampling location before birds were collected. Within 10 minutes of collection, 70 percent ethanol was injected into the gastrointestinal (GI) tract to prevent further digestion of any prey items. After GI tract preservation, pectoral muscle tissues were removed from each bird for isotopic analysis. Esophagus and proventriculus also were removed from each bird and stored in 70 percent ethanol with 1 percent rose Bengal tissue dye. Prey items from esophagi (including proventriculus) and gizzards were identified, sorted, and counted to lowest possible taxon using 7-35 times dissecting scopes. These tissues were kept on wet ice in the field and stored at $-20^{\circ} \mathrm{C}$ until analyzed.

The prey number was standardized to a percentage on a per bird basis. Then mean percent number and frequency of occurrence metrics (Hyslop, 1980) were calculated as

$$
\begin{aligned}
& \text { mean percent number: } \% N_{i}=\frac{\sum_{j=1}^{n} N_{i j}}{n} \times 100 \\
& \text { percent frequency of occurrence: } \% F O_{i}=\frac{n_{i}}{n} \times 100
\end{aligned}
$$

where $N_{i j}$ is the proportion of prey $i$ in an individual sample $j, n_{i}$ is the number of samples containing prey $i$, and $n$ is the total number of samples. These metrics were calculated for avocet and stilts for each combination of season, location, and sex. The mean prey-specific number refers to the average proportion of each prey consumed $i$, but only when prey $i$ was consumed. When mean prey-specific number is multiplied by percent frequency of occurrence, or the proportion of samples containing prey $i$, the result is mean percent number. Mean percent number is a compound index that summarizes overall importance of prey $i$ in the diet (Brown and others, 2012).

\section{Tern Diet}

During weekly Forster's tern colony nest monitoring visits, we thoroughly searched each nesting island for unconsumed fish returned to the colonies by terns, that we assumed represented avian piscivorous prey availability (Fraser, 1997). After collection, we placed fish in labeled polyethylene bags for storage at $-20^{\circ} \mathrm{C}$ until processing. In the laboratory, each fish was thoroughly washed, weighed, and measured. Fish were identified to species when possible (Moyle, 2002), otherwise to family. Because fish were in various stages of desiccation when collected, we dried all fish at $50{ }^{\circ} \mathrm{C}$ for 48 hours (or until a constant mass was achieved in two successive weight recordings) then measured dry length and mass to develop comparable biomass estimates among individuals.

\section{Diving Duck Diet}

We collected surf scoters across three periods (fall (autumn), winter, spring) and in three subbays (Suisun Bay, San Pablo Bay, and Central Bay; fig. 4) during 2003-04 and 2004-05 to evaluate temporal and spatial relations among contaminant concentrations, diet, and body condition. To avoid potential bias in individual condition (Dufour and others, 1993; Pace III and Afton, 1999) we did not use decoys to attract scoters. We observed all birds foraging for a minimum of 10 minutes to help ensure that diet items would be present in the upper gastrointestinal tract, and then collected them using 
steel shot. Immediately upon collection, heart blood $(1-5 \mathrm{~mL})$ was drawn and placed in a heparinized vacutainer and 70 percent ethanol solution was injected into the gastrointestinal tract to prevent continued digestion of prey items. Afterwards birds were dissected for tissue samples and food content within digestive tract. Whole blood $(0.5 \mathrm{~mL})$ was reserved in $2 \mathrm{~mL}$ polyethylene low temperature freezer vials for later analyses. Within 4 hours of collection, the remaining blood was centrifuged and plasma was drawn off and frozen for isotope analyses. All other samples were kept on wet ice in the field and stored at $-20^{\circ} \mathrm{C}$ until analyzed.

\section{Laboratory Methods}

\section{Bird Necropsy and Tissue Processing}

Immediately upon collection, we sampled whole blood from all birds using heparinized needles and syringes, and transferred blood to labeled polypropylene cryovials. Samples were frozen in the field on dry ice prior to transport to the laboratory for storage at $-20^{\circ} \mathrm{C}$. Using nitric acid and hexane rinsed stainless steel necropsy tools, we excised the liver, kidneys, and brain for chemical and biomarker analyses. Small aliquots $(\sim 1 \mathrm{~g}$ wet weight) were subsampled from the tip of the larger lobe of each liver for oxidative stress and P450 measurements and placed in sterile, polypropylene cryovials. The remaining tissue samples were stored in chemically cleaned I-CHEM glass vials (Chase Scientific Glass, Rockwood, Tennessee). We also excised a sub-sample of breast muscle ( $\sim \mathrm{g}$ wet weight) from the top of the pectoralis, within $3 \mathrm{~cm}$ of the keel, and feathers from both the crown and breast at the base of the bird's keel. We placed muscle and feather samples in Whirl-paks ${ }^{\circledR}$ (Nasco, Modesto, California). All samples were immediately placed on dry ice, where they were stored until return to the laboratory, within 48 hours. In the laboratory, samples were stored at $-20{ }^{\circ} \mathrm{C}$ until analysis.

In order to process tissues for total mercury, methylmercury, selenium, and stable isotope analyses, we thawed liver, kidney, and muscle samples at room temperature, rinsed them in deionized water, and blotted them dry with clean Kimwipes ${ }^{\circledR}$ (Kimberly-Clark, Roswell, Georgia), then measured their wet mass to $0.0001 \mathrm{~g}$ on an analytical balance (Ohaus Adventurer Balance, model AR064, Ohaus, Pine Brook, New Jersey). We oven-dried tissue samples at 50 to $60{ }^{\circ} \mathrm{C}$ for 48 hours, or until they reached a constant mass. Once dried, we reweighed each tissue to the nearest $0.0001 \mathrm{~g}$ and then homogenized samples to a uniform consistency using a Wiley mill (Thomas Scientific, Swedesboro, New Jersey) or by hand using a porcelain mortar and pestle. We stored dry tissues in glass vials in an opaque desiccator prior to analyses.

We washed feathers in a 1 percent Alconox solution (Alconox, White Plains, New York) while mechanically scrubbing each feather to remove surface debris. We then dried feathers at $60{ }^{\circ} \mathrm{C}$ for as much as 24 hours and stored them in a desiccator prior to analysis. We thawed blood samples to room temperature, inverted the cryovials several times, and thoroughly mixed the blood by stirring with a clean pipette tip to ensure sample homogeneity. Many stilt and tern blood samples were elevated in mercury to such an extent that, in order to avoid saturating the atomic absorbance cells or bias from carry-over effects (Butala and others, 2006), we diluted the blood samples with deionized water at a ratio of four parts water to one part blood. We then pipetted a $200 \mu \mathrm{L}$ aliquot of diluted blood into a quartz sample vessel for analysis. 


\section{Body Condition of Diving Ducks}

Proximate body composition analyses were done at the Bird Studies Canada Avian Energetics Laboratory (Port Rowan, Ontario, Canada). Sex was determined by combination of plumage characteristics and cloacal examination; age was determined by estimating bursal depth (Mather and Esler, 1999; Iverson and others, 2003). Morphological features, including keel length, body length, total length, skull width and length, diagonal tarsus length, bill width and length, exposed culmen length, flat wing length, and ninth primary length, were measured to the nearest $0.1 \mathrm{~mm}$. Abdominal fat pads were removed, weighed to the nearest $0.01 \mathrm{~g}$ and then processed with the rest of the carcass. For our analyses, we defined total body mass as the entire thawed bird without the kidney, liver, and upper gastrointestinal tract. Sample homogenates were prepared by grinding entire bodies (including skin and feathers and excluding all internal organs) in a 1-horsepower Hobart meat grinder through a 1-cm diameter plate, followed by a $0.5-\mathrm{cm}$ plate. Homogenate sub-samples were dried to a constant weight at $95{ }^{\circ} \mathrm{C}$. Dried samples were weighed and ground in a Hobart grinder with a $0.5-\mathrm{cm}$ plate and then a Molinex coffee grinder (Model 505) to achieve maximum homogeneity. To determine total carcass fat (TCF), cellulose thimbles were filled with 10-g homogenate subsamples, dried to a constant weight, and lipids were extracted with petroleum ether in a modified Soxhlet extractor. Remaining homogenate was dried to a constant weight and used as a measure of total body lean mass. Lean samples were placed in Coors porcelain crucibles and ashed in a $500{ }^{\circ} \mathrm{C}$ muffle furnace overnight. Sample masses were used to calculate total carcass ash (TA), and total ash-free protein (TAFP) was calculated by subtracting TA from total lean body mass.

\section{Mercury Determination}

Elsewhere we have shown that methylmercury comprises 96 percent of mercury in bird eggs (Ackerman and others, 2013b) and 94 percent of mercury in prey fish (Ackerman and Eagles-Smith, 2010a; Ackerman and others, U.S. Geological Survey, unpub. data, 2013), and we provide a detailed assessment of the percentage of mercury in the methylmercury form in liver and kidneys in EaglesSmith and others (2009b). Therefore, we analyzed the majority of tissue samples for total mercury only because nearly all mercury in most tissues (except liver, kidney, and invertebrates) is in the methylmercury form. Mercury concentrations were calculated and reported as fresh wet weight for eggs (fww; Ackerman and others, 2013b), wet weight for blood (ww; Eagles-Smith and others, 2008a), and dry weight for all other tissues (dw; Eagles-Smith and others, 2008a).

We analyzed all samples for total mercury at the U.S. Geological Survey, Davis (California) Field Station Mercury Laboratory following EPA method 7473 (U.S. Environmental Protection Agency, 2000) on a Milestone DMA-80 Direct Mercury Analyzer (Milestone, Monroe, Connecticut). We used an integrated sequence of drying, thermal decomposition, catalytic conversion, and then amalgamation, followed by atomic absorption spectroscopy. Methylmercury determination analysis was done at Battelle Marine Sciences Laboratory (Sequim, Washington) using cold-vapor atomic fluorescence following U.S. Environmental Protection Agency method 1630 (U.S. Environmental Protection Agency, 2001). Quality assurance measures included analysis of two certified reference materials (for example, dogfish muscle tissue [DORM], dogfish liver [DOLT], or lobster hepatopancreas [TORT] by the National Research Council of Canada, Ottawa, Canada), two system and method blanks, two continuing calibration verifications, and two duplicates per batch. 


\section{Other Contaminants of Concern}

Selenium

Selenium concentrations were measured in liver and egg samples. Analyses were conducted using hydride generation, followed by atomic fluorescence spectroscopy at the Trace Elements Research Laboratory (Texas A\&M University, College Station, Texas). Certified reference materials for selenium in tissues (National Institute of Standards and Technology 2976), matrix spikes, duplicate samples, and blanks were analyzed for quality control purposes.

Cadmium

Cadmium in kidneys and invertebrates was determined at the Texas A\&M Trace Element Research Laboratory in College Station, Texas using inductively coupled plasma-mass spectroscopy (ICP-MS).

Organohalogen Compounds

Liver tissue samples were analyzed for 101 PCB congeners, 6 legacy pesticide compounds, and 38 PBDE congeners (Herring and others, 2010) by the Geochemical and Environmental Research Group, Texas A\&M University, College Station, Texas. Quantitative analyses then were done by capillary gas chromatography (CGC) with a flame ionization detector for aliphatic hydrocarbons, CGC with electron capture detector for PCBs and pesticides, and a mass spectrometer detector for PBDEs (Wade and others, 1988). Tissue samples analyzed for PCBs and pesticides were extracted following National Oceanic and Atmospheric Administration (NOAA) Status and Trends Method (MacLeod and others, 1985) with minor revisions (Wade and others, 1988).

\section{Biomarkers}

Ethoxyresorufin- $O$-dealkylase (EROD) activity was assayed in liver microsomes of all Forster's tern and Caspian tern samples collected during 2005 using the method of Burke and Mayer (1983), as adapted to a fluorescence microwell plate scanner (Melancon, 1996). Oxidative stress indicator assays of potential mercury or selenium-related effects included: liver-glutathione peroxidase (GSHpx) including total glutathione peroxidase (T-GSHpx) and selenium dependent glutathione peroxidase (SGSHpx); glutathione reductase (GSSGrd); glutathione-S-transferase (GSH-T); glucose-6-phosphate dehydrogenase (G-6-PDH); gamma-glutamyl transferase (GGT); reduced glutathione (GSH); oxidized glutathione (GSSG); total sulfhydryl concentration (TSH); protein bound sulfhydryl concentration (PBSH); thiobarbituric acid reactive substances (TBARS); kidney-blood urea nitrogen (BUN); uric acid (UA); and enzymes related to glutathione metabolism; oxidative stress; and TBARS per liver assays; brain-acetylcholinesterase (ACHE); plus all liver variables (Hoffman and others, 2011). 


\section{Stable Isotope Determination}

We measured stable isotope ratios of carbon $\left({ }^{13} \mathrm{C}\right)$, nitrogen $\left({ }^{15} \mathrm{~N}\right)$, and sulfur $\left({ }^{34} \mathrm{~S}\right)$ in avian tissues, invertebrates, and fish samples. Prior to analysis, aliquots of each sample were weighed into tin capsules to the nearest $0.01 \mathrm{mg}$. Samples were analyzed at the Colorado Plateau Stable Isotope Laboratory at Northern Arizona University in Flagstaff, Arizona by continuous-flow isotope ratio mass spectrometry using an elemental analyzer coupled to a mass spectrometer. Standard reference materials were atmospheric $\mathrm{N}_{2}$ for nitrogen and Vienna PeeDee Belemnite (VPDB) for carbon. The ratio of stable isotopes is expressed in delta $(\delta)$ notation and calculated as:

$$
\delta \mathrm{X}=\left[\left(\mathrm{R}_{\text {sample }} / \mathrm{R}_{\text {standard }}\right)-1\right] \times 100
$$

where $\mathrm{X}={ }^{15} \mathrm{~N},{ }^{13} \mathrm{C}$, or ${ }^{34} \mathrm{~S}$, and $\mathrm{R}={ }^{15} \mathrm{~N} /{ }^{14} \mathrm{~N},{ }^{13} \mathrm{C} /{ }^{12} \mathrm{C}$, or ${ }^{34} \mathrm{~S} /{ }^{32} \mathrm{~S}$ in the sample and standard as noted by the subscript.

For diving ducks, we accounted for the effect of lipids on $\delta^{13} \mathrm{C}$ using the equation $\delta^{13} \mathrm{C}_{\text {normalized }}=$ $\delta^{13} \mathrm{C}_{\text {untreated }}-3.32+0.99 \times \mathrm{C}: \mathrm{N}$ (Post and others, 2007) for both prey and bird tissue samples. We used a two-isotope, three-source mixing model without priors in Stable Isotope Analysis in the R environment (SIAR, R version 3.0.0; Parnell and Jackson, 2010) to evaluate the role of fish roe as a prey item and compare proportional source results with those from our esophageal diet analysis. The model was based on 500,000 iterations for each run and burn in was set at 50,000. We considered only prey and plasma of birds collected in the Central Bay because herring spawns occurred mainly in this region (O'Farrell and Larson, 2001; Watters and others, 2004; Bartling, 2008). We pooled prey samples into three endmember groups: bivalves (including filter feeding clam and mussel species), fish roe, and crabs (comprised of the two main crab species found in the esophageal diet). We adjusted plasma values by $+3.1 \%$ for $\delta^{15} \mathrm{~N}$ and +1.45 for $\delta^{13} \mathrm{C}$ on the basis of discrimination factors determined for whole blood of wintering canvasbacks (Aythya valisineria; Haramis and others, 2001), a benthivore with a similar body size and diet.

\section{Egg Injection Studies}

All egg injection and captive breeding studies were carried out at the U.S. Geological Survey (USGS) Patuxent Wildlife Research Center. Our egg injection procedure involved obtaining eggs from wild birds, placing the eggs in a laboratory incubator, and injecting them with methylmercury dissolved in corn oil. We injected the eggs of 26 species of birds with methylmercury.

In our egg injection studies that focused on interactions between mercury and selenium, methylmercury chloride and seleno-L-methionine were injected in many different combinations of concentrations. Mallard eggs were dosed by injecting $0,0.2,0.4,0.8$, or 1.6 microgram of mercury per gram $(\mu \mathrm{g} \mathrm{Hg} / \mathrm{g})$ of egg contents in all possible combinations with $0,0.1,0.2,0.4$, or $0.6 \mu \mathrm{g} \mathrm{Se} / \mathrm{g}$ of egg contents $(5 \times 5=25$ groups of eggs). Chickens eggs (Gallus gallus) were injected with combinations of $0,0.2,0.4,0.8$, and $1.6 \mu \mathrm{g} \mathrm{Hg} / \mathrm{g}$ and $0,0.1,0.2,0.4$, and 0.6 microgram of selenium per gram $(\mu \mathrm{g} \mathrm{Se} / \mathrm{g}$; $5 \times 5=25$ groups). Double-crested cormorant eggs (Phalacrocorax auritus) were injected with combinations of $0,0.2,0.4$, and $0.8 \mu \mathrm{g} \mathrm{Hg} / \mathrm{g}$ and $0,0.1,0.2$, and $0.4 \mu \mathrm{g} \mathrm{Se} / \mathrm{g}(4 \times 4=16$ groups). All the mercury and selenium concentrations were on a wet-weight basis. The eggs were artificially incubated, and all hatchlings and dead embryos were examined for deformities. Data on hatching success of eggs also were collected. 


\section{Captive Breeding and Feeding Studies}

We randomized 1 adult female and 1 adult male mallard to each of one hundred $1-\mathrm{m}^{2}$ breeding pens, and 1 of 5 dietary concentrations of mercury $(0,1,2,4$, or $8 \mu \mathrm{g} \mathrm{Hg} / \mathrm{g})$ was randomized to each pen. Eggs were collected each day and incubated in a laboratory incubator. Some eggs were saved for mercury analysis. Ducklings that hatched were banded, weighed, and kept in heated pens for 6 days.

In another part of this reproductive experiment we examined a toxicological response called hormesis (a phenomenon in which a chemical causes beneficial effects at a low dose, but harmful effects at higher doses). Thirty pairs of breeding mallards were fed a control diet and 20 pairs were fed $0.5 \mu \mathrm{g} \mathrm{Hg} / \mathrm{g}$ on a dry-weight basis. Eggs were collected and incubated in a laboratory incubator. The 17 th egg (which was about halfway through the egg laying sequence of most females) was saved from three randomly selected control females and from every mercury-treated female for mercury analysis. Ducklings that hatched were banded and weighed, and 6 days after hatching the ducklings were reweighed and then sacrificed.

\section{Results and Discussion}

\section{Objective 1: Examine Bird Mercury Exposure and Bioaccumulation in Three Bird Guilds}

\section{Distribution of Mercury Among Bird Tissues and Sexes}

Between 2005 and 2006, we sampled 174 Forster's terns, 50 Caspian terns, 217 black-necked stilts, and 439 American avocets. Total mercury concentrations in liver and blood were strongly related to total mercury and methylmercury concentrations of other internal tissues for all species and life stages (figs. 5 and 6; Eagles-Smith and others, 2008b). These results are not surprising because blood distributes methylmercury throughout the body tissues, and represents a dynamic equilibrium between dietary mercury assimilation and tissue mercury redistribution (Fournier and others, 2002). Although blood-to-tissue relationships were strong for all species and life stages combined $\left(R^{2} \geq 0.87\right)$, we found that relationships generally were weakest for chicks $\left(0.71<R^{2}<0.76\right)$, likely due to their rapid growth and feather production as they age (Ackerman and others, 2011). Unlike with liver or blood, total mercury in breast feathers was poorly correlated with total mercury and methylmercury in internal tissues $\left(R^{2} \leq 0.36\right)$. Feathers represent a discrete depuration and sequestration repository for mercury only during the period of feather growth (Bearhop and others, 2000), and do not represent changes in tissue concentrations once blood supply to the feathers atrophies (Furness and others, 1986). Thus, molt patterns and migration strategies can convolute the interpretation and utility of feather total mercury concentrations as indicators of mercury exposure, especially in migratory adults (Furness and others, 1986; Thompson and Furness, 1989a). For example, we found that breast feathers were much poorer indicators of mercury concentrations in internal tissues for breeding adults $\left(0.01<R^{2}<0.30\right)$ than they were for pre-breeding adults $\left(0.14<R^{2}<0.79\right)$. In fact, there were no significant relationships between total mercury in blood and breast feathers for breeding avocets, stilts, or Caspian terns (all $R^{2} \leq 0.10$ and all $\mathrm{P} \geq 0.08$ ). Head feathers were similarly poorly correlated with internal tissues. However, head feather total mercury concentrations differed from those in breast feathers for adult avocets and stilts, suggesting that there was substantial temporal separation between when feathers were grown and when internal tissues were sampled, especially for breeding adults. Molt generally occurs in late winter to early spring, just prior to our pre-breeding sampling period, and again after breeding in late summer to early fall (Ackerman and others, 2013a). Thus, mercury exposure in breeding bird internal tissues was several months removed from when breast feathers were grown. 
Typically, fully-grown feathers are relatively poor predictors of internal tissue mercury concentrations in free-living chicks (Ackerman and others, 2011) and adults (Eagles-Smith and others, 2008b), particularly in migratory birds. Therefore, feathers typically are not recommended for mercury monitoring programs. However, feathers can be useful indicators in rare circumstances where life-time bird home ranges are extremely small (such as is the case for endangered California clapper rails; Ackerman and others, 2012) and down feathers are useful to indicate embryonic mercury exposure in the egg (Ackerman and Eagles-Smith, 2009a).

\section{Mercury Concentrations Differ Among Species}

Because there is only a limited timeframe in which all five species are in the San Francisco Bay Estuary, we constrained our comparison among bird species only to samples collected between March 1 and April 23 when the species co-occur. During this timeframe we determined that liver total mercury concentrations were highest in Caspian terns, followed by Forster's terns, stilts, scoters, and avocets (fig. 7; Eagles-Smith and others, 2009b). Mercury concentrations in fish-eating birds (Forster's terns and Caspian terns) generally were the highest of all five species, a result consistent with other studies that have shown elevated mercury concentrations in upper trophic-level waterbirds (Braune, 1987; Evers and others, 2005; Borga and others, 2006). However, relatively high mercury levels also were detected in stilts, especially compared to avocets, which often co-occur and forage on similar foods (Ackerman and others, 2007, 2013a).

In our subsequent analysis that included only the four species that breed in the San Francisco Bay Estuary (Forster's tern, Caspian terns, American avocets, and black-necked stilts), we incorporated both pre-breeding and breeding data, and found large differences in mercury concentrations in Forster's tern tissues compared to those in Caspian terns. Upon arrival in the Estuary, mercury concentrations in Caspian terns exceeded all other species. Forster's terns had relatively lower pre-breeding mercury concentrations compared with Caspian terns, similar to concentrations measured in stilts, which forage on invertebrates (fig. 8; Eagles-Smith and others, 2009a). However, within 2 months, mercury concentrations in Forster's terns nearly tripled, exceeding those in breeding Caspian terns or any other species we examined (fig. 8; Eagles-Smith and others, 2009a). It is unclear why these two species had such different mercury levels upon entering the Estuary, but different mercury levels may be due to differential wintering distributions, diet, or molt cycles. Little is known about wintering locations of Forster's terns or Caspian terns, but most of the Pacific Coast population overwinter in Mexico and Guatemala and follow coastal migration routes (Cuthbert and Wires, 1999; McNicholl and others, 2001). It is also possible that some individuals overwinter in the Estuary or along the coast of California. Satellite telemetry studies would be valuable for determining wintering locations.

Caspian terns and Forster's terns are primarily fish-eaters, but Caspian terns tend to take larger prey than Forster's terns (Cuthbert and Wires, 1999; McNicholl and others, 2001), and mercury concentrations in fish often increase with fish length (Wiener and others, 2003). Thus, mercury concentrations in pre-breeding Caspian terns may have been elevated relative to Forster's terns because of differences in prey size and associated mercury levels. During the breeding period Caspian terns presumably still preyed on larger fish, yet their mercury concentrations were substantially lower than that of Forster's terns'. This is likely because Forster's terns foraged along the bay's margins in salt ponds and marshes (Ackerman and others, 2008a) where microbial methylmercury production is elevated relative to the open-bay (Marvin-Di Pasquale and Agee, 2003). Conversely, Caspian terns forage more in the open-bay than Forster's terns, and mercury concentrations in fish from the open-bay are as much as 7.4 times lower than in salt ponds and marshes along the bay's margins (Eagles-Smith and Ackerman, 2014). 
Foraging habitat also may explain the distinctive species differences in mercury concentrations we detected between invertebrate-foraging shorebirds. Mercury levels in stilt tissues were nearly 5 times higher than those in avocets. In fact, mercury concentrations in stilts approached those in fish-eating Caspian terns. These differences between stilts and avocets are particularly striking because both species co-occur in wetlands along the Estuary's margins (Rintoul and others, 2003) and they both forage on crustaceans and other small invertebrates. However, their differential microhabitat use in wetlands may explain these differences. Pre-breeding avocets used a much higher proportion of tidal mudflats and tidal marsh than stilts, whereas stilts used managed and muted-tidal pickleweed (Sarcocornia pacifica) marshes more so than avocets (Ackerman and others, 2007). This differential habitat use also has been supported by stable isotope data showing a C3 (pickleweed) carbon signature in stilt tissues and a C4 (cordgrass; Spartina spp) carbon signature in avocets tissues (see section, "Trophic Transfer of Mercury in Shorebirds"), indicating that each species obtained their prey from different microhabitats. Wetlands have been shown to be zones of enhanced methylmercury production (Hall and others, 2008), and there is evidence that marshes and areas with higher vegetation root density also show greater methylmercury production than mudflats and unvegetated sediments (Canario and others, 2007).

\section{Spatial Distribution and Habitat Use by Birds}

\section{Shorebird Habitat and Space Use}

To understand site differences in mercury concentrations, we radio-marked and tracked 115 avocets and 94 stilts and obtained 2,393 and 1,928 telemetry locations, respectively, during the prebreeding season. Pre-breeding radio-marked birds showed high site fidelity and generally remained near their capture site (figs. 9-13; Ackerman and others, 2007). For example, 60 and 48 percent of avocet core use areas for Pond A8 and Coyote Creek Marsh, respectively, were within the pond site of capture (table 1; Ackerman and others, 2007). Similarly, 75 percent and 40 percent of stilt core use areas for New Chicago Marsh and Pond A8, respectively, were within the pond site of capture (table 1; Ackerman and others, 2007).

Furthermore, pre-breeding avocet movements were influenced by the future nesting site, such that the distance between future nest sites and daily locations decreased with the number of days prior to incubation (fig. 14; Demers and others, 2008). The distance of avocet locations from the nest site averaged $1.76 \pm 0.24 \mathrm{~km}$ during pre-breeding, $0.58 \pm 0.19 \mathrm{~km}$ during incubation, and $0.44 \pm 0.25 \mathrm{~km}$ during brood-rearing (Demers and others, 2008). Similarly, post-breeding distances from nest sites increased with the number of days after nesting was completed and averaged $4.29 \pm 0.74 \mathrm{~km}$ (table 2; Demers and others, 2008). Avocet core use areas were reduced from $220 \pm 44$ ha during pre-incubation to $56 \pm 18$ ha during incubation and $38 \pm 26$ ha during brood-rearing, then increased again during the post-breeding season to $665 \pm 168$ ha (table 2; Demers and others, 2008). For example, figure 15 shows how an individual avocet's home range contracted from pre-breeding to breeding periods (Demers and others, 2008). These data demonstrate that avocets use relatively small areas, especially during egg formation and nesting when mercury could be transferred to their offspring and effect reproductive behaviors.

Avocets generally used salt pond habitats, tidal marshes, tidal flats, and managed marshes, but capture-site influenced space use due to high site fidelity (table 1; Ackerman and others, 2007). For example, avocets radio-marked at Pond A8 and Eden Landing Ecological Reserve were mainly located in salt ponds, whereas avocets radio-marked in Coyote Creek Marsh were mainly located in tidal marshes and tidal flats that were adjacent to the capture site. Stilts also often used salt pond habitats, but they tended to use managed marshes, such as New Chicago Marsh, more than avocets (table 1; 
Ackerman and others, 2007). Overall, avocets primarily used salt ponds, tidal marshes, tidal flats, and managed marshes, whereas stilts mainly used salt ponds, managed marshes, and tidal marshes.

Tern Habitat and Space Use

Adults

To understand site differences in mercury concentrations, we radio-marked and tracked 72 Forster's terns and obtained 1,012 telemetry locations during the pre-breeding season. Radio-marked terns generally remained within the area where they were captured (figs. 16-19), although there was some overlap between terns captured at East Alviso and Eden Landing in 2005 (fig. 16; Ackerman and others, 2008a) and East Alviso and West Alviso terns in 2006 (fig. 17; Ackerman and others, 2008a). For example, 37-87 percent of Forster's tern core use areas were within the pond site of capture depending on the specific site and year (table 3; Ackerman and others, 2008a).

Similar to shorebirds, home-range size and core-use areas of Forster's terns decreased as the breeding season progressed (fig. 20; Bluso-Demers and others, 2008), with terns generally located within $1.0 \pm 0.25 \mathrm{~km}$ of the nest during incubation compared to $4.0 \pm 0.92 \mathrm{~km}$ during pre-breeding and $8.1 \pm 1.86 \mathrm{~km}$ during post-breeding (table 4; Bluso-Demers and others, 2008). These data demonstrate that Forster's terns also have relatively small space use areas during egg formation and nesting when mercury could be transferred to their offspring and effect reproductive behaviors.

Adult terns mainly used salt ponds, managed and tidal marshes, and tidal flats, and were relatively absent from bays, sloughs, and lagoons (table 3; Ackerman and others, 2008a). Locations occurred most often in salt pond habitats ( 74 percent), followed by tidal marsh ( 9 percent), managed marsh ( 7 percent), slough ( 3 percent), tidal flat ( 3 percent), lagoon ( 2 percent), upland ( 2 percent), and bay (1 percent) habitats (Bluso-Demers and others, unpub. data). At the core-area scale, Forster's terns selected salt ponds and avoided bay habitats during the pre-breeding and breeding seasons (fig. 21; Bluso-Demers and others, unpublished data). Terns also selected managed marsh during the prebreeding and breeding seasons in 2005 and during the pre-breeding season in 2006, selected tidal flats in the pre-breeding season and avoided it in the breeding season in 2006, and selected tidal marsh in the breeding season in 2005 and in the pre-breeding and breeding seasons in 2006 (fig. 22; Bluso-Demers and others, unpub. data). Additionally, Forster's terns selected low salinity ( $<30 \mathrm{~g} / \mathrm{L})$ salt ponds during both the pre-breeding and breeding seasons, avoided mid (31-80 g/L), high $(81-150 \mathrm{~g} / \mathrm{L})$, or extra-high $(>150 \mathrm{~g} / \mathrm{L})$ salinity salt ponds in the pre-breeding season, and avoided mid- and extra-high salinity salt ponds in the breeding season (fig. 23; Bluso-Demers and others, unpublished data). Forster's terns used high salinity salt ponds in proportion to their availability during the breeding season (fig. 23; BlusoDemers and others, unpublished data). In sum, Forster's terns generally foraged in wetland habitats along the bay's margins, preferring to use managed salt pond and marsh habitats with salinity levels near that of seawater.

\section{Chicks}

We also radio-marked 30 Forster's tern chicks just before they fledged at $25 \pm 1.4$ (standard deviation) days of age (Ackerman and others, 2009) and tracked them for as many as 44 days after they fledged (fig. 24). Similar to adults, postfledging terns selected salt pond habitats (fig. 25) and were most often located within salt ponds ( 94 percent), followed by tidal marsh ( 2 percent), lagoon ( 1 percent), managed marsh (1 percent), tidal flat (1 percent), slough ( $<1$ percent), and bay ( $<1$ percent) habitats (Ackerman and others, 2009). In salt ponds, postfledging terns were located closer to salt pond levees (58 m) than was expected by chance (107 m; Ackerman and others, 2009). 


\section{Diving Duck Habitat and Space Use in Winter}

We radio-marked 151 surf scoters during the winters of 2003-04 and 2004-05 (table 5) to determine movements, home range, and resource selection. Of all surf scoters, 27 percent were captured in San Pablo Bay and 73 percent in the Central Bay, reflecting the typical annual relative abundance of sea ducks in these regions (Accurso, 1992). Scoter presence and density were nonrandom and were most influenced by the presence of herring roe, but seagrass and particularly the interaction of herring with seagrass also were important predictors (De La Cruz and others, 2014). Scoters also were increasingly associated with higher salinity as winter progressed, and were associated with the deepest water depths in mid-winter.

Monthly collective ranges (fig. 26; De La Cruz and others, 2014) indicated that surf scoters were distributed in a consistent overall pattern and had similar defined core use areas during 2004 and 2005. Scoters were concentrated in San Pablo Bay during December and January of both years. In January, individuals began to disperse from San Pablo Bay, and their distribution shifted to the Central Bay during February and March. In contrast, the western shoreline of the Central Bay below Oakland and the eastern shoreline north of the San Mateo Bridge were used as core areas during all study months. Surf scoters used Suisun Bay during January and February 2004 and January 2005. We also identified Richardson Bay on the west side of the Central Bay as a core use area during January 2004 and January-March 2005 (fig. 26; De La Cruz and others, 2014).

Fifty-two marked individuals had $>10$ locations in at least 1 month and were used in individual home range and movement distance analyses. Sex and the interaction of month and year were identified as the most important predictors of 95 and 50 percent fixed kernel density home range sizes (De La Cruz and others, 2014). Home range sizes of males and females were slightly smaller in December and January 2004 than in the same months in 2005 (fig. 27). December home ranges of females (2004: $51.01 \pm 19.68 \mathrm{~km}^{2}$ and 2005: $\left.98.57 \mathrm{~km}^{2}\right)$ were larger than those of males (2004: $24.70 \pm 2.3 \mathrm{~km}^{2}$ and 2005: $35.30 \pm 9.46 \mathrm{~km}^{2}$ ), but became more similar between the sexes by February. Overall in 2004 and 2005, the mean home range size (50 percent fixed kernel density) decreased over winter for both sexes (fig. 27).

The interaction between month and sex was the best fitting model explaining distance moved between consecutive locations, and no other models were supported. Surf scoters moved greater distances during December and January than in February and March (fig. 28). Males made larger movements between sequential locations than females during January when the population shifted from San Pablo Bay and Suisun Bay to the Central Bay (De La Cruz and others, 2014).

Together, collective ranges, monthly home ranges, and distances moved indicated that surf scoters traveled farther and used larger areas of San Francisco Bay early in winter, but tended to restrict their movements and areas used later in winter. Movements were consistent with seasonal patterns of availability in resources important to scoters, such as the decline of benthic invertebrates in northern regions of San Francisco Bay (Poulton and others, 2002; Lovvorn and others, 2013) concomitant with increasing availability of highly profitable herring roe localized in the Central Bay. Site fidelity and seasonal movements can play large roles in risks for wildlife in regions where contaminant distributions vary spatially, like San Francisco Bay. Similar to other taxa from this study (Ackerman and others, 2007), scoters had small kernel home ranges and strong site fidelity (De La Cruz and others, 2014) increasing the probability that contaminant concentrations were accumulated by individuals from the localized sub-bays they used. 


\section{Diving Duck Habitat and Space Use During Breeding}

We integrated data sets from four different wintering areas along the Pacific Coast to delineate the western breeding range and nest site selection for our sample of radio-marked surf scoters. Rather than finding wide temporal and spatial variation that might be expected for a species with a large breeding range in an ecosystem characterized by extreme variation (Chapin III and others, 2006), we determined that surf scoters settled in a relatively narrow arc of habitat parallel to the receding snowline. Compared with random locations, both the logistic regression and classification and regression tree (CART) analyses found consistent evidence that surf scoter nesting areas were located closer to the snowline and in areas with lower elevational gradients and more lakes in the Northwest Territories of Canada (figs. 29 and 30; 4×4 km scale; Takekawa and others, 2011).

We found remarkable breeding synchrony for most birds regardless of their wintering origin and differences in distances from the breeding grounds. Surf scoters wintering in Mexico were the only birds that arrived slightly later, although their sample size was small. Surf scoters began arriving to their northern boreal forest breeding grounds about May 24 (day of year $=144 \pm 0.7$; De La Cruz and others, 2009) and flew to nesting areas along the northeastern edge of their breeding range. They settled at nesting areas after only 5 days during the ice and snow breakup period, when availability of open water and food resources would be uncertain. Significant stored resources from wintering or migration stopover areas may be required for surf scoters to reproduce successfully in light of their short settling period, as well as unpredictable pre-breeding resources and the short Arctic summer (Klaassen and others, 2006; Jonsson, 2014).

For the eight surf scoters that were located nesting in consecutive years, we found philopatry and high nesting area fidelity (Takekawa and others, 2011). Female waterfowl show a high degree of nesting area fidelity, and the "local-knowledge" hypothesis suggests that females obtain an advantage in terms of food resources, distribution of conspecifics, and predator activity by returning to breed in the same area (Rohwer, 1992).

\section{Spatial Patterns of Mercury Exposure in Birds}

\section{Adult Shorebird Spatial Patterns in Mercury Exposure}

We captured or collected 373 avocets and 157 stilts during the pre-breeding seasons in 2005 and 2006 and assessed mercury concentrations in their blood. Capture site was the most important variable predicting mercury concentrations in shorebirds, followed by species and sex (fig. 31; Ackerman and others, 2007). In each of the six tissues that were studied, birds captured at sites in the southernmost portion of the bay had, by far, the highest mercury concentrations (fig. 32; Eagles-Smith and others, 2009a). Mercury concentrations in birds from the North Bay were similar to those in the central area of San Francisco Bay (fig. 32; Eagles-Smith and others, 2009a). Birds were especially contaminated with mercury in Pond A8 (avocets: $0.58 \pm 0.04 \mu \mathrm{g} / \mathrm{g}$ ww and stilts: $3.31 \pm 0.96 \mu \mathrm{g} / \mathrm{g} w w$ ) and New Chicago Marsh (stilts: $1.72 \pm 0.11 \mu \mathrm{g} / \mathrm{g} \mathrm{ww})$. Pond A8 and New Chicago Marsh had some of the largest breeding populations of avocets (minimum estimate in Pond A8 was 188 nests in 2005 and 208 in 2006) and stilts (minimum estimate in New Chicago Marsh was 101 nests in 2005 and 309 in 2006) within the entire San Francisco Bay (Ackerman and others, 2014b; Ackerman and Herzog, 2012). Thus, a large proportion of breeding shorebirds are nesting in areas with the highest mercury levels. Using radio telemetry, we confirmed that birds remained near their capture site during the pre-breeding season (late February to mid-April), indicating that differences in bird mercury concentrations among sites were probably due to differences in foraging areas and dietary mercury uptake (Ackerman and others, 2007; Demers and others, 2008). 
We also determined that mercury concentrations in stilts $(1.09 \pm 0.10 \mu \mathrm{g} / \mathrm{g} \mathrm{ww})$ were higher than those in avocets $(0.25 \pm 0.01 \mu \mathrm{g} / \mathrm{g} w \mathrm{w})$ captured at the same sites (fig. 31A; Ackerman and others, 2007). Although avocets and stilts (Recurvirostridae) often are associated together and forage on similar foods, their use of micro-habitats and possibly aquatic prey types can differ (Hamilton, 1975; Robinson and others, 1999; Ackerman and others, 2013a). For example, avocets tended to use salt ponds and tidal flats more often than stilts, whereas stilts tended to use managed marshes more often than avocets (Ackerman and others, 2007). Furthermore, within the same site, avocets tended to use the more open water and mudflat habitats, whereas stilts used the more vegetated areas (Rintoul and others, 2003). Such differences in micro-habitat selection may lead to different mercury exposure levels. The higher mercury concentrations in stilts also may indicate a higher trophic level feeding by stilts than avocets because stilts appear to be more likely to feed on fish (Robinson and others, 1999; Ackerman and others, 2013a), whereas avocets in San Francisco Bay appear to consume mainly aquatic invertebrates.

In both species, pre-breeding males (stilts: $1.32 \pm 0.17 \mu \mathrm{g} / \mathrm{g}$ ww; avocets: $0.32 \pm 0.03 \mu \mathrm{g} / \mathrm{g} \mathrm{ww}$ ) mercury concentrations were higher than pre-breeding females (stilts: $1.15 \pm 0.12 \mu \mathrm{g} / \mathrm{g}$ ww; avocets: $0.21 \pm 0.02 \mu \mathrm{g} / \mathrm{g} w w$; figs. 31B-C; Ackerman and others, 2007). Mean mercury concentrations were 1.8 and 1.3 times higher in males than females in avocets and stilts, respectively. It is unlikely that sex differences in mercury concentrations of avocets and stilts were due to sexual size dimorphism because sexes differed in size by $<0.5$ percent. Sex differences in mercury concentrations could be due to foraging strategies (consumption rates or prey size selection), but differences might also have been caused by females depurating methylmercury into eggs in the prior breeding season (see section, "Maternal Transfer of Mercury to Eggs"). Mercury concentrations generally do not differ between the sexes when tissues representing accumulation during the non-breeding season (for example, feathers) are analyzed (Thompson and others, 1991; Burger and Gochfeld, 1992; Burger, 1995), but males typically have higher mercury concentrations than females during the breeding season in common loons (Gavia immer; Evers and others, 1998; Scheuhammer and others, 1998; Burgess and others, 2005), gulls (Braune and Gaskin, 1987; Lewis and others, 1993), American white pelicans (Pelecanus erythrorhyncos; Donaldson and Braune, 1999), and Forster's terns (Eagles-Smith and others, 2009a). Lewis and others (1993) calculated that female herring gulls (Larus argentatus) depurated about 15-24 percent of their body burden of mercury into their clutch. These data indicate that females depurate methylmercury into eggs, but it is unclear whether such a large reduction in female mercury concentration (43 percent for avocets and 25 percent for stilts) could occur solely due to depuration into eggs and if it could still be detected nearly 10 months later, just prior to the subsequent breeding season, as we observed in our study. Most likely, sex differences in mercury concentrations in the blood of prebreeding birds were due to factors in addition to egg depuration, such as differences in foraging strategies or physiology (for example, Burgess and others, 2005; Evers and others, 2005).

\section{Adult Tern Spatial Patterns in Mercury Exposure}

We captured or collected 130 Forster's terns during the pre-breeding seasons in 2005 and 2006. Terns captured at sites in the southernmost area of the bay generally had higher mercury concentrations than terns from the North Bay or Central Bay, but results depended on the tissue type (fig. 32; EaglesSmith and others, 2009a). Factors explaining mercury concentrations in Forster's terns differed among tissue types, with smaller-scale patterns being best explained by concentrations in blood (Ackerman and others, 2008a). Capture site and capture date were by far the most important variables influencing blood mercury concentrations of pre-breeding Forster's terns, but sex and year also influenced blood concentrations to a smaller degree (Ackerman and others, 2008a). In particular, mercury concentrations in blood differed among capture sites (fig. 33; Ackerman and others, 2008a). Mercury concentrations in 
Forster's tern blood were highest in the lower South San Francisco Bay in the East Alviso salt pond complex of the Don Edwards San Francisco Bay National Wildlife Refuge (1.66 $\pm 0.22 \mu \mathrm{g} / \mathrm{g}$ wet weight), followed by North San Francisco Bay in the Napa-Sonoma Marshes Wildlife Area $(0.97 \pm 0.17 \mu \mathrm{g} / \mathrm{g}$ wet weight), South San Francisco Bay at West Alviso (0.91 $\pm 0.12 \mu \mathrm{g} / \mathrm{g}$ wet weight), and South-Central San Francisco Bay at Eden Landing Ecological Reserve $(0.77 \pm 0.14 \mu \mathrm{g} / \mathrm{g}$ wet weight; fig. 33; Ackerman and others, 2008a). We also found the highest blood mercury concentrations in stilts and avocets in the East Alviso ponds (Ackerman and others, 2007). The East Alviso pond area had at least four separate tern breeding colonies (in Ponds A7, A8, A16, and New Chicago Marsh), and, depending on the year, held many of the breeding Forster's terns in the San Francisco Bay (Ackerman and Herzog, 2012). For example, 32 percent and 22 percent of all Forster's terns breeding in the San Francisco Bay nested in East Alviso ponds in 2005 and 2006, respectively. Therefore, a large number of breeding terns are nesting in areas that have the highest potential for exposure to mercury. Using radio-telemetry, we determined that terns were mainly located near their region of capture during the pre-breeding season (figs. 16 and 17; Ackerman and others, 2008a), indicating that differences in tern mercury concentrations among capture sites may have been partly due to differences in foraging areas and locations of dietary mercury uptake.

Mercury concentrations in blood, and especially in feathers, were higher in male than in female Forster's terns (Ackerman and others, 2008a). Overall, mercury concentrations in males were 1.4, 1.6, and 1.8 times higher than females for blood, breast feathers, and head feathers, respectively. Males typically have higher mercury concentrations than females during the breeding season, indicating mercury depuration into eggs (Braune and Gaskin, 1987; Lewis and others, 1993; Evers and others, 1998; Scheuhammer and others, 1998; Burgess and others, 2005). In contrast, mercury concentrations generally do not differ between sexes when tissues representing accumulation during the non-breeding season (for example, feathers) are analyzed (Thompson and others, 1991; Burger and Gochfeld, 1992; Burger, 1995). Because we used several tissues representing different pre-breeding time frames, it is unlikely that mercury depuration into eggs by females could be the sole explanation for the sex differences observed. Several authors have suggested that males have higher mercury burdens than females because they are larger and, therefore, consume more and larger prey (Evers and others, 1998; Scheuhammer and others, 1998; Burgess and others, 2005). However, in our case, there is no sexual size dimorphism in body mass for Forster's terns (Bluso and others, 2006). Hence, it remains unclear why we detected sex differences in mercury concentrations of pre-breeding Forster's terns.

\section{Adult Diving Duck Spatial Patterns in Mercury Exposure}

We collected 139 female and 19 male surf scoters in 3 San Francisco Bay sub-regions (Suisun Bay, North Bay, and Central Bay) during fall (October-December), winter (January-March), and spring (April) of 2003-04 and 2004-05 (table 6). We found differences in total mercury concentrations among sites, with significantly higher concentrations in scoters collected from Suisun Bay $(3.53 \pm 0.44 \mu \mathrm{g} / \mathrm{g} \mathrm{dw})$ and the North Bay $(3.43 \pm 0.34 \mu \mathrm{g} / \mathrm{g} \mathrm{dw})$ than in scoters from the Central Bay $(2.73 \pm 0.27 \mu \mathrm{g} / \mathrm{g} \mathrm{dw})$, although Tukey-Kramer pairwise tests (all $\mathrm{P}>0.05)$ suggested that the effect of site was relatively small (Eagles-Smith and others, 2009a). There was no indication of differential mercury accumulation rates among the three sub-bays. Males $(3.71 \pm 0.52 \mu \mathrm{g} / \mathrm{g} \mathrm{dw})$ had higher mercury concentrations than females $(2.78 \pm 0.18 \mu \mathrm{g} / \mathrm{g} \mathrm{dw})$, and concentrations were slightly higher in $2005(3.89 \pm 0.26 \mu \mathrm{g} / \mathrm{g} \mathrm{dw})$ than in 2004 $(3.21 \pm 0.28 \mu \mathrm{g} / \mathrm{g} \mathrm{dw}$; Eagles-Smith and others, 2009a). Concentrations remained elevated in surf scoters sampled just prior to spring migration; therefore, migrating scoters may transport cross-seasonal burdens of mercury into their Boreal Forest breeding grounds, increasing the potential for reproductive effects relative to scoters over-wintering in other areas along the Pacific Flyway. 
Shorebird and Tern Egg Spatial Patterns in Mercury Exposure

Between 2005 and 2007, we sampled 567 avocet, 216 stilt, and 374 Forster's tern eggs from 8 regions and 36 wetland sites in San Francisco Bay. Mercury concentrations in eggs of all three primary bird species exhibited significant spatial variation, differing both among regions (avocets: $\mathrm{F}_{7,532}=16.35$, $\mathrm{P}<0.0001$; fig. 34 ; stilts: $\mathrm{F}_{6,199}=9.03$, $\mathrm{P}<0.0001$; fig. 35; Forster's terns: $\mathrm{F}_{5,360}=8.92, \mathrm{P}<0.0001$; fig. 36) and wetland sites nested in regions for all species except stilts (avocets: $F_{24,532}=3.92, P<0.0001$; fig. 34; stilts: $\mathrm{F}_{7,199}=1.43, \mathrm{P}=0.20$; fig. 35; Forster's terns: $\mathrm{F}_{5,360}=3.29, \mathrm{P}=0.01$; fig. 36) while statistically accounting for the effects of year and nest initiation date (as described in detail in the section, "Temporal Patterns of Bird Mercury Exposure"). Among all wetland sites, mercury concentrations in eggs differed by as much as 10.5 times for avocets, 12.7 times for stilts, and 4.7 times for Forster's terns. Even within regions, mercury concentrations in eggs differed among wetlands by as much as 3.6 times for avocets, 8.3 times for stilts, and 3.0 times for Forster's terns. In fact, wetland sites that were directly adjacent to one another, such as ponds A1 and A2W in the Moffett Region, differed in egg mercury concentrations by 3.4 times for avocets (fig. 34). Together with the telemetry data showing high site fidelity and small space use by birds during egg formation and incubation (Ackerman and others, 2007, 2008a; Bluso-Demers and others, 2008; Demers and others, 2008), these data indicate that bird eggs are good bioindicators of wetland-specific and local mercury exposure to wildlife.

\section{Shorebird Chick Spatial Patterns in Mercury Exposure}

We captured 158 avocet and 79 stilt chicks at hatching and sampled their down feathers for mercury concentrations (Ackerman and others, 2008d). Capture site was the most important variable influencing mercury concentrations in chick down feathers, but year, species, and hatching date also had important effects on concentrations. Mercury concentrations in avocet and stilt chick down feathers were highest for chicks hatching in salt pond A8 $(7.19 \pm 0.87 \mu \mathrm{g} / \mathrm{g}$ fw), followed by New Chicago Marsh $(6.88 \pm 0.58 \mu \mathrm{g} / \mathrm{g}$ fw $)$, salt pond A16 $(6.02 \pm 0.86 \mu \mathrm{g} / \mathrm{g} \mathrm{fw})$, Coyote Creek Lagoon $(3.37 \pm 1.07 \mu \mathrm{g} / \mathrm{g} \mathrm{fw})$, Newark salt ponds $(2.01 \pm 0.38 \mu \mathrm{g} / \mathrm{g} \mathrm{fw})$, and Moffett salt ponds $(1.85 \pm 0.68 \mu \mathrm{g} / \mathrm{g}$ fw; fig. 37 ; Ackerman and others, 2008d). Site differences are not surprising considering that adult avocets and stilts show strong site-fidelity to ponds during the pre-breeding season (Ackerman and others, 2007) and that down feathers represent mercury concentrations and embryonic exposure in the egg (Ackerman and EaglesSmith, 2009a). Even while controlling for site effects, stilt chicks had higher mercury concentrations in down feathers than avocet chicks (fig. 37; Ackerman and others, 2008d). We also observed higher blood mercury concentrations in adult stilts than in avocets during the pre-breeding season in San Francisco Bay; species differences are likely due to differences in use of microhabitats (Ackerman and others, 2014b, 2007, 2008d).

\section{Tern Chick Spatial Patterns in Mercury Exposure}

We monitored 893 tern chicks in 2006, of which 76 percent were hatched at the Pond N7 tern colony, 15 percent were hatched at the Pond A7 tern colony, and only 9 percent were hatched at Ponds A8, A16, or New Chicago Marsh (Ackerman and others, 2008b). Few chicks ( $<1$ percent) reached the postfledging stage at Ponds A8, A16, or New Chicago Marsh. We therefore selected chicks that were nearing fledging ( $\geq 21$ days of age) within tern colonies at Ponds $A 7$ and N7 for our postfledging tern chick studies. We collected blood and breast feathers from 90 chicks in 2006; 67 chicks were sampled at Pond N7 and 23 chicks were sampled at Pond A7. 
Mercury concentrations in blood and feathers of fledgling Forster's terns were mostly influenced by colony site (fig. 38; Ackerman and others, 2008b). Fledgling mercury concentrations in Pond A7 (Alviso salt pond complex) were about 1.7 and 2.0 times higher in blood and breast feathers, respectively, than fledglings raised in Pond N7 (Newark salt pond complex; Ackerman and others, 2008b). Roughly 15 percent of the 893 monitored chicks raised in South San Francisco Bay in 2006 hatched at this higher mercury site and 76 percent hatched at the Pond N7 colony (Ackerman and others, 2008b). We also determined that site was the most important factor explaining blood mercury concentrations of pre-breeding adult Forster's terns in San Francisco Bay and that terns exhibited fairly high site fidelity relative to their mobility (Ackerman and others, 2008b). Considering that Forster's tern parents likely foraged near their nest sites, higher mercury concentrations in fledglings raised at Pond A7 were consistent with our other results showing high mercury concentrations in birds in the southern San Francisco Bay.

\section{Temporal Patterns of Mercury Exposure in Birds}

\section{Adult Bird Mercury Exposure by Calendar Date}

We sampled mercury concentrations in 174 Forster's terns, 50 Caspian terns, 217 stilts, 439 avocets, and 158 surf scoters. Generally, we found that migratory waterbirds arriving in San Francisco Bay were exposed to prey with higher mercury concentrations than they had experienced previously at other migration sites. This finding was evidenced by comparing the temporal trends in mercury concentrations among bird species that have differing arrival dates and spend differing times of the year in San Francisco Bay. For example, mercury concentrations in surf scoters increased during their overwintering period in San Francisco Bay from their arrival in early November to their departure in late April (fig. 39; Eagles-Smith and others, 2009a). Similarly, mercury concentrations increased with capture date for pre-breeding Forster's terns (fig. 40; Ackerman and others, 2008a). In fact, tern blood mercury concentrations more than tripled during the 45-day pre-breeding period from the time of their arrival to San Francisco Bay in late March to when they begin breeding locally in mid-May (Ackerman and others, 2008a). In contrast, avocet and stilt mercury concentrations did not vary with date during the pre-breeding season (Ackerman and others, 2007) likely because they over-winter in the bay (and other local areas in the Central Valley) and are thus already exposed to the elevated levels of mercury in the San Francisco Bay-Delta watershed. Thus, Forster's terns and other migratory birds arriving in San Francisco Bay to breed are exposed to elevated mercury concentrations in their environment precisely at the critical period for breeding. We later show (Objective 3) that eggs of mallards fed mercurycontaminated diets reach their peak mercury concentrations in just 23 days, indicating that exposure to a new diet source containing mercury can be transferred to eggs in less than 1 week (Heinz and others, 2009a).

We specifically compared mercury concentrations in pre-breeding birds to breeding birds, and determined that breeding birds generally had higher mercury concentrations in each of the six tissues sampled (fig. 8; Eagles-Smith and others, 2009a). Of the four locally breeding birds studied, the largest increase in mercury concentrations was detected in Forster's terns between the pre-breeding and breeding seasons (Eagles-Smith and others, 2009a). Mercury concentrations in Forster's terns were between 2.5 and 2.9 times higher (depending on the tissue type) during the breeding season than during the pre-breeding season (fig. 8; Eagles-Smith and others, 2009a). As with Forster's terns, mercury concentrations in Caspian terns were higher during the breeding than pre-breeding season for all tissues except blood (fig. 8; Eagles-Smith and others, 2009a). Avocet mercury concentrations also were higher in breeding than pre-breeding birds for all tissues, except liver (fig. 8; Eagles-Smith and others, 2009a). 
In contrast, there were generally no differences in mercury concentrations between pre-breeding and breeding stilts, except in muscle tissue where breeders had higher concentrations than pre-breeders (fig. 8; Eagles-Smith and others, 2009a). Therefore, mercury concentrations in most bird species and tissues generally were at their highest levels during the breeding season when mercury exerts its toxic effects on reproduction.

\section{Shorebird and Tern Egg Mercury Exposure by Year and Calendar Date}

Although the most important factors influencing egg mercury concentrations were spatial variables (see above), mercury concentrations in bird eggs also differed temporally. Although statistically accounting for region and site effects, mercury concentrations in bird eggs differed among years in all species (avocets: $\mathrm{F}_{2,532}=8.43, \mathrm{P}<0.001$; stilts: $\mathrm{F}_{2,199}=8.79, \mathrm{P}=0.001$; Forster's terns: $\mathrm{F}_{2,360}=12.33, \mathrm{P}<0.0001$ ), and nest initiation dates in avocets and stilts (avocets: $\mathrm{F}_{1,532}=10.28, \mathrm{P}=0.001$; stilts: $\mathrm{F}_{1,199}=26.5, \mathrm{P}<0.0001$; Forster's terns: $\left.\mathrm{F}_{1,360}=3.05, \mathrm{P}=0.08\right)$. Mercury concentrations in bird eggs were higher in 2006 (avocets: $0.18 \pm 0.02$; stilts: $0.54 \pm 0.06$; Forster's terns: $1.71 \pm 0.13$ ), than in 2007 (avocets: $0.14 \pm 0.01$; stilts: $0.40 \pm 0.04$; Forster's terns: $1.24 \pm 0.07$ ) or 2005 (avocets: $0.13 \pm 0.01$; stilts: $0.47 \pm 0.09$; Forster's terns: $1.11 \pm 0.08$ ). Although the effect was relatively small compared to the effects of site and year, mercury concentrations in bird eggs increased with nest initiation date by 31 percent for avocets and 22 percent for terns over a typical 60-day nesting season, but decreased with nest initiation date by 49 percent for stilts (fig. 41). These data indicate that Forster's tern adults continue to increase in their body burden of mercury after arriving in San Francisco Bay to breed (Ackerman and others, 2008a; Eagles-Smith and others, 2009a), and eggs laid later in the season tend to have higher mercury concentrations than eggs laid earlier in the breeding season. The increase in egg mercury concentrations in avocets is consistent with our results for adult avocets, where we determined that mercury concentrations were higher in breeding than pre-breeding avocets (Eagles-Smith and others, 2009a). The decrease in egg mercury concentrations in stilts also is consistent with our results for adult stilts, where we determined that mercury concentrations were no different between breeding and pre-breeding stilts (Eagles-Smith and others, 2009a).

\section{Shorebird and Tern Chick Mercury Exposure by Calendar Date}

Hatching date also influenced mercury levels in chicks, although to a smaller degree than site, year, and species (Ackerman and others, 2008d; b). On average, mercury concentrations in chick down feathers of avocet and stilt increased by 81 percent during the typical 60 -day shorebird nesting season (fig. 42; Ackerman and others, 2008d). Conversely, mercury concentrations in blood of nearly-fledged Forster's tern chicks (at $25 \pm 1.5$ [SD] days of age) decreased with hatch date by 28 percent during the typical 50-day tern hatching period (fig. 43; Ackerman and others, 2008b). Fledgling blood mercury concentrations, however, are highly variable due to growth dilution and depuration into growing feathers (Ackerman and others, 2011).

\section{Shorebird and Tern Chick Mercury Exposure by Age}

Total mercury and methylmercury concentrations in juvenile birds changed rapidly as they aged, and varied by more than an order of magnitude over this short period (approximately 40 days; Ackerman and others, 2011). Chick mercury concentrations exhibited a quadratic, U-shaped pattern from hatching through postfledging at both low- and high-mercury contaminated sites, where blood mercury concentrations differed by 2.0 (terns) to 2.3 (stilts) times (figs. 44-46; Ackerman and others, 2011). We found a similar U-shaped pattern in mercury concentrations as chicks aged for all four internal tissues and in each of three waterbird species (figs. 45 and 46; Ackerman and others, 2011), 
which represented birds with both precocial young (stilts and avocets) and semi-precocial, nidicolous young (Forster's terns) that are fed by their parents at nesting colonies until they fledge at about 28 days of age (Ackerman and others, 2009). These similar results among tissues and species indicate that this U-shaped pattern may be ubiquitous among birds. Other studies have documented a general decrease and then increase in mercury concentrations as juvenile birds aged (Honda and others, 1986; Spalding and others, 2000a; Kenow and others, 2007), but none have documented such rapid changes in mercury concentrations over a short period.

The U-shaped pattern of mercury concentrations as chicks aged was likely driven by the increase in body mass and the development of feathers that are inherently correlated with age (figs. 44-46; Ackerman and others, 2011). Tern chicks gained mass rapidly until just before they fledged at approximately 28 days of age, increasing in size from hatching by nearly 10 fold (fig. 44B; Ackerman and others, 2011). Simultaneously, tern chicks were mostly covered with down feathers until 10 days of age, at which time the amount of fully grown feathers increased from $<1$ percent to $>80$ percent at the time of fledging (fig. 44C; Ackerman and others, 2011). Accordingly, mercury concentrations in chicks were highest immediately after hatching, due to in ovo exposure from maternally deposited mercury into the egg, then concentrations rapidly decreased as chicks aged and diluted their body burden of mercury through growth in size and mercury depuration into growing feathers (fig. 44C; Ackerman and others, 2011). Mercury concentrations then began to increase just before and during fledging when body mass growth and feather production slowed, while chicks presumably continued to acquire mercury through their diets (fig. 44A; Ackerman and others, 2011). Chick age at the inflection point when mercury concentrations stopped decreasing and started increasing occurred shortly before chicks became flighted (approximately 20 days after hatching for terns and at a culmen length of 37-39 $\mathrm{mm}$ for stilts). In the week prior to fledging, mass growth and feather production slowed such that mercury concentrations were no longer reduced by mass dilution and mercury depuration into feathers, because mercury acquired through diet likely exceeded dilution and excretion pathways. Overall, total mercury concentrations in tern chick blood decreased by 86 percent from hatching to 20 days of age and then increased by 42 percent from 20 to 28 days of age at the time of fledging, resulting in an 80 percent decrease in total mercury concentrations from hatching to fledging (Ackerman and others 2011).

Whereas several studies have demonstrated the importance of feather growth for reducing mercury concentrations in juvenile birds (Honda and others, 1986; Monteiro and Furness, 2001; Fournier and others, 2002; Kenow and others, 2007; Condon and Cristol, 2009), no studies have quantitatively demonstrated the importance of mass dilution. We found that the proportional change in an individual chick's blood mercury concentration was strongly related to the proportional change in its body mass, such that mercury concentrations decreased more in those chicks that gained proportionately more mass between sampling periods (fig. 47; Ackerman and others, 2011). In fact, there was more support for the influence of mass dilution than for mercury excretion into feathers as the main mechanism reducing mercury concentrations in aging chicks (Ackerman and others 2011). However, it must be noted that chick mass and feather growth are inherently correlated with age, and not finding a statistically significant effect of the feather production on chick mercury concentrations does not indicate that mercury depuration into feathers was not biologically important for reducing concentrations of mercury in chicks. On the contrary, these results indicate that the residual effect of mass was more important than the residual effect of feather production after the aggregate effect of age on mercury concentrations was taken into account. 
The general U-shaped pattern of mercury concentrations in juvenile birds from hatching to fledging has important toxicological implications. Assuming similar sensitivities among ages, juvenile birds are at highest risk to mercury toxicity shortly after hatching when maternally deposited mercury concentrations are still high and again after fledging when opportunities for mass dilution and excretion of mercury into feathers are limited. The hatching and postfledging stages (especially just before a juvenile's first feather molt) are therefore hypothesized to be an especially sensitive time for survival of juvenile birds (Ackerman and others, 2011).

\section{Trophic Pathways of Mercury Exposure in Birds}

\section{Trophic Pathways in Shorebirds}

\section{Shorebird Diet}

Stomach contents were collected and tissues were analyzed for stable isotopes to assess sitespecific diet in stilts and avocets (table 7). Contents of the esophagus and proventriculus (hereafter collectively referred to as PVC) and gizzard indicate a differing diet between pre-breeding and breeding periods for stilts and avocets in the South Bay. During the pre-breeding period, diet PVC was dominated primarily by Ephydridae (tables 8-11), both in number and in frequency (figs. 48-49). During the breeding period, the diet of both species shifted to predominately Corixidae (figs. 48-49). This shift in diet may reflect the shifting availability of prey during pre-breeding and breeding periods. Benthic grab and sweep data indicated that Corixidae were far more abundant during breeding than pre-breeding seasons (figs. 50-51; tables 12-13), which indicates stilts and avocets both forage on the seasonally abundant prey. However, benthic grabs cannot effectively sample adult Ephydridae, so it is unclear whether the reduced representation in the diet is a reflection of reduced availability or an artifact of sampling methods.

Although fewer birds were collected in the North Bay, it is clear that Corixidae (water boatman) also were an important part of the diet of both stilts and avocets in the area. They appeared in the gizzard of 100 percent of pre-breeding and 83 percent of breeding stilts in the South Bay (figs. 52-53). Unlike in stilts or avocets in the South Bay, Coleoptera adults were regularly consumed by stilts in the North Bay during both pre-breeding and breeding periods (fig. 48).

The diets of avocet and stilt chicks were far more varied than those of adults (tables 8 and 9). In both the PVC and gizzard samples, Corixidae dominated the diet of chicks of both species, with Ephydridae, Amphipods, Mysids, and Spionidae larvae also being important (figs. 54 and 55). Avocet and stilt chicks may be more opportunistic in their diet selection, foraging on whatever is available to them in the rearing area.

\section{Spatial and Temporal Patterns in Invertebrate Mercury}

We sampled invertebrates at nine sites in 2005 and 2006 during pre-breeding and post-breeding seasons. Of 13 taxa, only Corixidae were found at all 9 sites. We therefore used Corixidae to assess methylmercury differences among sites, seasons, and years. Methylmercury concentrations differed among sites $\left(\mathrm{F}_{8,136}=26.65, \mathrm{P}<0.0001\right)$ and between pre-breeding and post-breeding seasons $\left(\mathrm{F}_{1,136}=43.85, \mathrm{P}<0.0001\right)$, but not between years $\left(\mathrm{F}_{1,136}=0.99, \mathrm{P}=0.32\right)$. Geometric mean methylmercury concentrations were highest in the South Bay at Rectangle Marsh $(1.75 \mu \mathrm{g} / \mathrm{g} \mathrm{dw})$ and Pond A8 $(0.77$ $\mu \mathrm{g} / \mathrm{g} \mathrm{dw}$ ); intermediate at Pond A16 (South Bay: $0.45 \mu \mathrm{g} / \mathrm{g} \mathrm{dw}$ ), Pond 1 (North Bay: $0.42 \mu \mathrm{g} / \mathrm{g} \mathrm{dw}$ ), and New Chicago Marsh (South Bay: $0.30 \mu \mathrm{g} / \mathrm{g} \mathrm{dw}$ ); and lowest at Mare Island (North Bay: $0.20 \mu \mathrm{g} / \mathrm{g} \mathrm{dw}$ ), Coyote Creek Lagoon (South Bay: $0.19 \mu \mathrm{g} / \mathrm{g} \mathrm{dw}$ ), Eden Landing (Central Bay: $0.16 \mu \mathrm{g} / \mathrm{g} \mathrm{dw}$ ), and 
Newark (Central Bay: $0.05 \mu \mathrm{g} / \mathrm{g} \mathrm{dw}$; fig. 56). Corixidae methylmercury concentrations were near or exceeded reported dietary effects levels $(0.50 \mu \mathrm{g} / \mathrm{g} \mathrm{dw})$ for birds at 4 of 9 sites. Time series analysis at Pond A8 and New Chicago Marsh indicated that methylmercury concentrations decreased throughout the bird breeding season (fig. 57). Methylmercury concentrations generally were higher in Corixidae than in all other taxa (tables 14 and 15), possibly because they can be predatory and eat other invertebrates.

\section{Trophic Transfer of Mercury in Shorebirds}

Stable isotope ratios in whole blood of stilts and avocets suggest that these species rely on different prey resources throughout the San Francisco Bay Estuary during both pre-breeding and breeding periods. During both periods, $\delta^{13} \mathrm{C}$ in stilts was substantially depleted compared to avocets (fig. 58) whereas $\delta^{15} \mathrm{~N}$ showed little interspecific variation. There were no differences in $\delta^{34} \mathrm{~S}$ ratios between stilts and avocets during the prebreeding period (fig. 58), but during the breeding period $\delta^{34} \mathrm{~S}$ showed a trend of enrichment in stilts and depletion in avocets such that stilt whole blood $\delta^{34} \mathrm{~S}$ ratios were more than 7 per mil higher than avocets during the breeding season. Additionally, although stilt $\delta^{13} \mathrm{C}$ stable isotope ratios did not change between pre-breeding and breeding periods, $\delta^{13} \mathrm{C}$ ratios in avocet whole blood became enriched during that period.

We evaluated the relation between avocet and stilt blood total mercury concentrations and their respective $\delta^{13} \mathrm{C}, \delta^{15} \mathrm{~N}$, and $\delta^{34} \mathrm{~S}$ ratios during the prebreeding and breeding periods. After accounting for site, sex, and year effects, we determined that total mercury concentrations increased with $\delta^{13} \mathrm{C}$ ratios in breeding avocets $\left(\mathrm{F}_{1,24.87}=4.98, \mathrm{P}=0.04\right)$, but not in pre-breeding avocets $\left(\mathrm{F}_{1,326.7}=2.69, \mathrm{P}=0.10\right)$, nor stilts during either period (breeding: $\mathrm{F}_{1,31.03}=1.06, \mathrm{P}=0.31$; pre-breeding: $\mathrm{F}_{1,105}=0.07, \mathrm{P}=0.79$; fig. 59). Whole blood total mercury concentrations were not correlated with blood $\delta^{15} \mathrm{~N}$ ratios in avocets (breeding: $\mathrm{F}_{1,25.41}=0.27, \mathrm{P}=0.39$; pre-breeding: $\left.\mathrm{F}_{1,327.7}=0.07, \mathrm{P}=0.79\right)$, nor in breeding stilts $\left(\mathrm{F}_{1,32.93}=0.23\right.$, $\mathrm{P}=0.63)$, but increased with $\delta^{15} \mathrm{~N}$ in pre-breeding stilts $\left(\mathrm{F}_{1,103}=7.89, \mathrm{P}=0.01\right.$; fig. 59). In both avocets and stilts, blood total mercury concentrations were highly correlated with blood ${ }^{34} \mathrm{~S}$ ratios during both breeding (avocets: $\mathrm{F}_{1,23.07}=71.38, \mathrm{P}<0.0001$; stilts: $\mathrm{F}_{1,32.63}=5.47, \mathrm{P}=0.03$ ), and prebreeding (avocets: $\mathrm{F}_{1}$, $313.8=173.2, \mathrm{P}<0.0001$; stilts: $\mathrm{F}_{1,87.45}=24.41, \mathrm{P}<0.0001$; fig. 59).

The absence of a relationship between total mercury concentrations and $\delta^{15} \mathrm{~N}$ is not surprising because baseline $\delta^{15} \mathrm{~N}$ ratios vary widely among wetland locations and we were unable to baseline correct $\delta^{15} \mathrm{~N}$ ratios for each bird sample and every wetland. The strong relationship between $\delta^{34} \mathrm{~S}$ and blood total mercury concentrations suggests that there are dominant environmental drivers associated with total mercury bioaccumulation in shorebirds in San Francisco Bay Estuary.

Trophic Pathways in Terns

\section{Tern Diet}

We collected and identified 799 fish (14 species) that were returned to colony by Forester's terns. Diet differed among Forster's tern colonies (fig. 60). Mudsuckers and sticklebacks together accounted for 61 percent of the colony returns ( 36 and 25 percent, respectively). The remainder of colony returns consisted of 13 other species, of which only a few comprised $>5$ percent of the total sample (12 percent topsmelt; 11 percent Mississippi silversides; and 6 percent yellowfin goby). Forster's terns delivered mudsuckers ranging in size from 35 to $124 \mathrm{~mm}$ (mean \pm standard error [SE] $=$ $68.3 \pm 1.1 \mathrm{~mm})$ and sticklebacks from 21 to $55 \mathrm{~mm}($ mean $\pm \mathrm{SE}=40.2 \pm 0.3 \mathrm{~mm})$. 


\section{Species Patterns in Fish Mercury}

To evaluate trophic transfer of mercury to Forster's terns, we collected fish prey items across the foraging area. We sampled 3,098 individual fish across 10 species from 27 managed wetlands, 3 tidal sloughs and marshes, and 2 open bay regions of the San Francisco Bay. Across all sites, dates, and fish lengths, the geometric mean total mercury concentrations ( \pm standard error) in whole-body fish were $0.83 \pm 0.02 \mu \mathrm{g} / \mathrm{g} \mathrm{dw}$ in Mississippi silversides $(\mathrm{N}=486), 0.55 \pm 0.02 \mu \mathrm{g} / \mathrm{g}$ dw in topsmelt $(\mathrm{N}=365)$, $0.51 \pm 0.04 \mu \mathrm{g} / \mathrm{g} \mathrm{dw}$ in northern anchovy $(\mathrm{N}=89), 0.45 \pm 0.01 \mu \mathrm{g} / \mathrm{g} \mathrm{dw}$ in threespine stickleback $(\mathrm{N}=687)$, $0.44 \pm 0.02 \mu \mathrm{g} / \mathrm{g} \mathrm{dw}$ in rainwater killifish $(\mathrm{N}=297), 0.38 \pm 0.03 \mu \mathrm{g} / \mathrm{g}$ dw in staghorn sculpin $(\mathrm{N}=54)$, $0.36 \pm 0.01 \mu \mathrm{g} / \mathrm{g} \mathrm{dw}$ in longjaw mudsuckers $(\mathrm{N}=1,000), 0.36 \pm 0.02 \mu \mathrm{g} / \mathrm{g} \mathrm{dw}$ in yellowfin goby $(\mathrm{N}=74)$, $0.35 \pm 0.03 \mu \mathrm{g} / \mathrm{g} \mathrm{dw}$ in prickly sculpin $(\mathrm{N}=20)$, and $0.29 \pm 0.04 \mu \mathrm{g} / \mathrm{g} \mathrm{dw}$ in shiner surfperch $(\mathrm{N}=26$; Eagles-Smith and Ackerman, 2014).

After accounting for wetland site, date, and year, the least square mean total mercury concentrations in length-standardized fish differed substantially among species (fig. 61). There was a 2.4-fold difference between the species with the highest (silverside: $0.87 \pm 0.03 \mu \mathrm{g} / \mathrm{g} \mathrm{dw}$ ) and lowest (mudsucker: $0.37 \pm 0.01 \mu \mathrm{g} / \mathrm{g} \mathrm{dw}$ ) mercury concentrations. We found a general pattern where mercury concentrations were highest in the most pelagic-oriented species (Mississippi silverside and northern anchovy), lowest in the most benthic-oriented species (longjaw mudsucker and yellowfin goby), and intermediate in those species that generally exhibit less habitat specificity (threespine stickleback, rainwater killifish, topsmelt, and staghorn sculpin (Eagles-Smith and Ackerman, 2014).

\section{Spatial Patterns in Fish Mercury}

Using a multi-species evaluation of mercury bioaccumulation across 32 wetland and open water sites, we found strong spatial variation in mercury concentrations of small fishes that we sampled. Fish mercury concentrations differed among wetland complexes and wetland sites nested within complexes (fig. 62). Total mercury concentrations in fish within wetland complexes differed by more than 4-fold. Among all wetland sites, mercury concentrations varied considerably with nearly a 15 -fold range in mean mercury concentrations between the wetland sites with the highest and lowest mercury concentrations. Even in complexes, mean mercury concentrations between wetland sites with the highest and lowest mercury concentrations differed by up to 4-fold. Wetland sites directly adjacent to one another and separated only by a narrow levee, such as Ponds A5 and A8 in the Central Alviso Region, differed in fish mercury concentrations by a factor of 4 (fig. 62).

While statistically accounting for the effects of species, wetland site, date, and year, we found that habitat type substantially influenced fish mercury concentrations. Specifically, we found that fish mercury concentrations were substantially more elevated in managed wetland habitats along the bay's margins than in the open bay habitat that occupies most of the San Francisco Bay area aquatic environment. Fish mercury concentrations were highest in seasonal saline wetlands and high-salinity (60-80 parts per thousand [ppt]) salt ponds, followed by breached salt ponds and medium-salinity (40$60 \mathrm{ppt}$ ) salt ponds (fig. 63). Total mercury concentrations in fish from seasonal saline wetlands and high-salinity salt ponds were more than 7 times higher than in subtidal, open bay habitats, and at least 2 times higher than any other wetland habitat. Total mercury concentrations in fish from subtidal, open bay sites were 2.7 times lower than any of the managed wetland habitats, and 2.4 times lower than tidal sloughs and marshes. Tidal sloughs and marshes had mercury concentrations similar to low salinity salt ponds. 
Not only are fish in wetlands along the bay's margins elevated in mercury, but these habitats also are the preferred foraging and breeding areas for the Forster's terns, stilts, and avocets (BlusoDemers and others, unpublished data; Ackerman and others, 2007, 2008a). Despite representing only a small proportion of the bay's area, the combination of high fish mercury and high waterbird use makes these wetlands along the bay's margins hotspots for mercury bioaccumulation.

The mechanisms driving these patterns were unclear; therefore, we evaluated stable isotope ratios in fish species to determine the importance of food web processes relative to environmental processes in driving mercury bioaccumulation in San Francisco Bay Estuary. Across the study, mean $\delta^{13} \mathrm{C}$ and $\delta^{15} \mathrm{~N}$ ratios in fish were not correlated with geometric mean total mercury concentrations in any of the five fish species that had broad spatial distributions across wetland sites. However, $\delta^{34} \mathrm{~S}$ was positively correlated with total mercury in all species (mudsuckers: $\mathrm{F}_{1,32}=8.63, \mathrm{P}=0.01, R^{2}=0.21$; silversides: $\mathrm{F}_{1,17}=11.57, \mathrm{P}=0.003, R^{2}=0.41$; killifish: $\mathrm{F}_{1,15}=7.87, \mathrm{P}=0.01, R^{2}=0.34$; topsmelt: $\mathrm{F}_{1,16}=11.83$, $\mathrm{P}=0.003, R^{2}=0.43$; stickleback: $\mathrm{F}_{1,23}=4.24, \mathrm{P}=0.05, R^{2}=0.16$; fig. 64$)$. These data suggest that pond-level characteristics, potentially including hydrologic connectivity (Fry and Chumchal, 2011); water chemistry (Fry, 2002), and sedimentary-sulfate reduction (Peterson and others, 1986; Canfield, 2001) are important drivers of mercury accumulation in forage fishes. However, our inability to adequately characterize variation in baseline isotope values hinders the quantification of trophic processes across wetlands.

The relationships between size-adjusted total mercury concentrations in fish and $\mathrm{C}, \mathrm{N}$, and $\mathrm{S}$ isotope ratios varied by habitat type. In low salinity ponds, we found $\delta^{13} \mathrm{C}, \delta^{15} \mathrm{~N}$, and $\delta^{34} \mathrm{~S}$ were all positively correlated with total mercury concentrations across fish (fig. 65) and were of approximately equal importance (relative variable weights: $V_{\mathrm{C}}=0.98, V_{\mathrm{N}}=1.00, V_{\mathrm{S}}=1.00$ ) in determining fish mercury concentrations. Notably, the only habitat type where $\delta^{13} \mathrm{C}$ and $\delta^{15} \mathrm{~N}$ had high relative importance was low salinity ponds, suggesting that trophic processes might play a more important role in determining mercury concentrations in these systems compared to other habitat types. This difference in importance may reflect higher fish and invertebrate diversity, and thus increased trophic complexity, in lower salinity ponds of San Francisco Bay (Takekawa and others, 2006). We found that $\delta^{34} \mathrm{~S}$ was the primary determinant of mercury concentrations in moderate-salinity ponds, high-salinity ponds, and seasonal wetlands ( $V_{s}=1.00,0.98$, and 1.00 , respectively), whereas none of the three isotopes were important in tidal slough $\left(V_{\mathrm{C}}=0.13, V_{\mathrm{N}}=0.15\right.$, and $\left.V_{\mathrm{S}}=0.17\right)$ or open bay habitats $\left(V_{\mathrm{C}}=0.26, V_{\mathrm{N}}=0.24\right.$, and $\left.V_{\mathrm{S}}=0.28\right)$. Importantly, in saline ponds and wetlands, the habitats shown to have the highest mercury concentrations in fish (Eagles-Smith and Ackerman, 2014), $\delta^{34} \mathrm{~S}$ was consistently the most important determinant of mercury concentrations. In contrast, $\delta^{34} \mathrm{~S}$ was not important in tidal slough or open bay habitats where mercury concentrations in forage fish were consistently low (Eagles-Smith and Ackerman, 2014).

Among site-years, the relative importance of the three isotopes varied substantially and, in nearly all cases with the exception of seasonal wetlands, we observed as much variation among wetland sites in the same habitat type as we observed across habitat types. The high variability in the importance of all isotopes among wetland sites, regardless of habitat type, coupled with the results of our broaderscale analyses, strongly implicate site-level characteristics in driving patterns of methylmercury bioaccumulation in prey fish. In particular, consistently positive relationships between mercury concentrations in fish and $\delta^{34} \mathrm{~S}$ suggests that sulfur biogeochemistry plays a critical role in these patterns. 
Within estuarine environments, $\delta^{34} \mathrm{~S}$ reflects three primary processes: mixing of freshwater inputs that have generally low $\delta^{34} \mathrm{~S}$ values with seawater in which marine derived sulfates have a $\delta^{34} \mathrm{~S}$ value of approximately 21per mil (Fry, 2002); fine-scale salinity gradients reflecting both marine sulfates and independent fractionation (Fry and Chumchal, 2011); and activities of sulfur reducing bacteria (Peterson and others, 1986; Canfield, 2001). Variation in $\delta^{34} \mathrm{~S}$ due to salinity is minimal greater than $0.6 \mathrm{ppt}$ (Fry and Chumchal, 2011), far lower than the salinities in any of the habitats in the current study, and thus unlikely to drive the patterns observed. Likewise, $\delta^{34} \mathrm{~S}$ is unlikely to reflect differing inputs of marine sulfates to ponds because many of the ponds are hydrologically isolated and mercury concentrations were lowest in fish from tidal habitats (Eagles-Smith and Ackerman, 2014). Microbial sulfur-reduction enriches $\delta^{34} \mathrm{~S}$ in food webs (Canfield, 2001) and is also tightly linked to the production of bioaccumulative methylmercury (Benoit and others, 2003). Additionally, the pond and wetland habitats with the highest fish mercury concentrations and importance of $\delta^{34} \mathrm{~S}$ are the most hydrologically isolated from the tidal influence of the open bay and thus experience minimal flushing that would remove build-ups of sulfur substrates and methylmercury. These data suggest that targeted management activities, such as increasing tidal connectivity between ponds and wetlands, may have disproportionately large effects on mercury bioaccumulation.

\section{Temporal Patterns in Fish Mercury}

Fish mercury concentrations varied temporally, both among years and by date. Fish mercury concentrations were higher in $2005(0.55 \pm 0.02 \mu \mathrm{g} / \mathrm{g} \mathrm{dw})$ and $2007(0.57 \pm 0.03 \mu \mathrm{g} / \mathrm{g} \mathrm{dw})$ than in 2006 $(0.43 \pm 0.01 \mu \mathrm{g} / \mathrm{g} \mathrm{dw})$ or $2008(0.40 \pm 0.01 \mu \mathrm{g} / \mathrm{g} \mathrm{dw})$. Fish mercury concentrations also followed a quadratic relationship with date, where fish mercury concentrations increased from spring to a maximum value in June, then decreased again in fall.

We found that over the 18-week sampling period there was a consistent temporal trend in mercury concentrations for both stickleback and mudsuckers. In all three wetlands, mercury was significantly related to date, following a quadratic function where mercury concentrations increased substantially from March to a maximum concentration in May, then decreased toward the end of the sampling period in July (fig. 66; Eagles-Smith and Ackerman, 2009). In Pond A16, size-normalized mercury concentrations increased between mid-March and late May by 27 percent in mudsuckers and 79 percent in sticklebacks. Mercury concentrations then decreased by 42 percent in mudsuckers and 47 percent in sticklebacks by late July. Similar, though less pronounced, temporal patterns occurred in New Chicago Marsh. Mudsucker mercury concentrations in New Chicago Marsh increased 42 percent between March and mid-May, then decreased 53 percent by late July. Stickleback mercury concentrations in New Chicago Marsh were more variable, increasing 33 percent between March and May and decreasing 37 percent from May to late July. Mercury concentrations were substantially elevated in Pond A8 and increased by 18 percent between March and April, decreased by 19 percent by mid-May, which was the final sampling interval when stickleback were present in that wetland.

Based on the quadratic model parameters, we categorized the peak mercury concentration period as occurring between May 1 and June 10 (fig. 67; Eagles-Smith and Ackerman, 2009). Mercury concentrations during the peak period were significantly higher than during the non-peak period in mudsuckers from Pond A16 and New Chicago Marsh, and in stickleback from Pond A16. There was a trend toward high mercury concentrations during the peak period in stickleback from New Chicago Marsh, but the difference was not statistically significant.

During weekly colony visits, we found 715 tern nests initiated between April 22 and July 25, 2006. Overall, 68 percent of tern nests were initiated between May 1 and June 10 when mercury concentrations peaked in fish (fig. 67; Eagles-Smith and Ackerman, 2009). Because mercury in eggs is 
primarily in the albumen, which is synthesized from dietary protein approximately 7 days prior to egg laying (Astheimer, 1986; Hobson, 1995), we adjusted nest initiation dates 7 days earlier for comparison to fish mercury concentrations. Using this timeframe, 78 percent of eggs were developed when parents were exposed to peak mercury concentrations in prey fish. We also determined chick hatching dates for 444 successful nests (range: May 23 to August 16) and found that 31 percent of chicks hatched during the period of peak fish mercury concentrations (fig. 67; Eagles-Smith and Ackerman, 2009).

These results have important implications for interpreting risk to wildlife, as well as for waterquality monitoring programs. Reproduction is thought to be the most sensitive endpoint of mercury toxicity in waterbirds (Scheuhammer and Sandheinrich, 2008). Among the most critical exposure periods for waterbirds is when maternal mercury is deposited into eggs during egg formation (Evers and others, 2008). Methylmercury in eggs is known to impair hatchability (Evers and others, 2008; Heinz and others, 2009b) and may influence early chick survival (Ackerman and others, 2008b). Albumen proteins typically are derived exogenously from dietary sources acquired only a few days before egg laying (Astheimer, 1986; Hobson, 1995). Thus, there is a very narrow, critical exposure period of approximately 7 days over which dietary mercury is deposited into eggs. Tern nest initiation began in late April when mercury concentrations in fish were peaking. Thus, most nesting terns (78 percent) were exposed to peak mercury concentrations in prey during the critical period of egg formation. Consistent with these findings, we have documented high mercury concentrations in tern eggs in the Estuary (see section, "Percentage of Eggs at Risk to Mercury in San Francisco Bay") that may be impairing egg hatchability. Additionally, the 3-5 fold increase in adult tern liver and blood mercury concentrations from pre-breeding to breeding suggests that short term variation in prey mercury levels likely propagated rapidly into terns after they arrived in the estuary.

If assessing wildlife risk is a goal of monitoring programs, then fish sampling should occur during or just before critical life-history phases for wildlife, such as egg laying and chick rearing in waterbirds. In our study, risk to wildlife would have been greatly underestimated if monitoring was restricted to sampling during the early spring or late summer. Instead, the peak exposure of mercury in fish overlapped with peak egg laying, exacerbating mercury risk to waterbirds in San Francisco Bay Estuary. Finally, monitoring programs should conduct high-resolution time series studies initially, in order to understand how mercury varies seasonally, and then incorporate additional time-series studies at regular intervals in subsequent years to calibrate comparisons among years.

\section{Trophic Transfer of Mercury in Terns}

Similar to our findings in the shorebird guild, fish-eating birds showed contrasting trends in their stable isotope signatures. During the pre-breeding period, $\delta^{13} \mathrm{C}$ ratios in blood of Forster's terns and Caspian terns did not differ. However, the trends changed in opposite directions over the breeding period, with $\delta^{13} \mathrm{C}$ ratios in Forster's terns becoming more depleted, whereas Caspian tern $\delta^{13} \mathrm{C}$ became enriched (fig. 68). As a result, blood $\delta^{13} \mathrm{C}$ ratios during the breeding season were greater than 3 permil more enriched in Caspian terns than in Forster's terns. Additionally, $\delta^{15} \mathrm{~N}$ ratios increased by 3 permil between pre-breeding and breeding in Caspian terns, whereas they did not change in Forster's terns. Similar to our findings with $\delta^{13} \mathrm{C}$, ratios of $\delta^{34} \mathrm{~S}$ became more enriched in Caspian terns between prebreeding and breeding, whereas Forster's tern $\delta^{34} \mathrm{~S}$ ratios became more depleted. Thus, breeding Caspian tern $\delta^{34} \mathrm{~S}$ ratios were 4.9 permil more enriched than those in Forster's terns (fig. 68). These data suggest that foraging habitat and the trophic ecology of Forster's terns and Caspian terns differ substantially from one another when the birds arrive in the estuary. 
As a result of the partitioning between species in foraging ecology, as exhibited in the stable isotope ratios, we found strikingly different relationships between mercury concentrations and isotopic signatures in Forster's terns and Caspian terns (fig. 68). During the pre-breeding period, mercury concentrations decreased sharply with increasing $\delta^{34} \mathrm{~S}$ in Forster's terns $\left(\mathrm{F}_{1,84.62}=8.48, \mathrm{P}=0.01\right)$, whereas there was no relationship with $\delta^{34} \mathrm{~S}$ in pre-breeding Caspian terns $\left(\mathrm{F}_{1,22.86}=0.91, \mathrm{P}=0.35\right)$. However, during the breeding season, $\delta^{34} \mathrm{~S}$ ratios were not correlated with blood mercury concentrations in either Forster's terns $\left(\mathrm{F}_{1,36.04}=3.20, \mathrm{P}=0.08\right)$ or Caspian terns $\left(\mathrm{F}_{1,13}=1.70, \mathrm{P}=0.21\right)$. During the pre-breeding period, mercury decreased with more enriched $\delta^{13} \mathrm{C}$ values in Forster's terns $\left(\mathrm{F}_{1,88.23}=9.12, \mathrm{P}=0.003\right)$, but was positively correlated with $\delta^{13} \mathrm{C}$ in pre-breeding Caspian terns $\left(\mathrm{F}_{1,23.14}=4.17, \mathrm{P}=0.05\right)$. During the breeding period, mercury concentrations increased with $\delta^{13} \mathrm{C}$ in Forster's terns $\left(\mathrm{F}_{1,33.84}=4.87, \mathrm{P}=0.03\right)$ but did not vary with $\delta^{13} \mathrm{C}$ in Caspian terns $\left(\mathrm{F}_{1,12.09}=0.38, \mathrm{P}=0.55\right)$. Blood mercury concentrations were not related to blood $\delta^{15} \mathrm{~N}$ ratios during the breeding season in Caspian terns $\left(\mathrm{F}_{1,11.01}=0.51, \mathrm{P}=0.49\right)$ nor in Forster's terns $\left(\mathrm{F}_{1,36.93}=0.26, \mathrm{P}=0.61\right)$. However, mercury concentrations were positively correlated with $\delta^{15} \mathrm{~N}$ in pre-breeding Caspian terns $\left(\mathrm{F}_{1,27}=4.97, \mathrm{P}=0.03\right)$ and negatively correlated with $\delta^{15} \mathrm{~N}$ in prebreeding Forster's terns $\left(\mathrm{F}_{1,88.98}=12.39, \mathrm{P}=0.001\right)$.

We evaluated the trophic transfer of mercury to Forster's terns by assessing the relationship between pond-year-specific geometric mean mercury concentrations in individual fish species, and blood mercury concentrations from pre-breeding and breeding Forster's terns sampled from the same ponds, as well as Forster's tern egg mercury concentrations from colonies located in the ponds from which fish were sampled. Generally, mercury concentrations in individual fish species were not correlated with mercury concentrations in Forster's tern blood or eggs among wetlands (fig. 69). During the pre-breeding period, Forster's tern blood mercury concentrations were correlated only with mercury concentrations in rainwater killifish $\left(R^{2}=0.85, \mathrm{P}=0.003, \mathrm{~N}=7\right)$, but not with mercury concentrations in longjaw mudsuckers $\left(R^{2}=0.04, \mathrm{P}=0.66, \mathrm{~N}=7\right)$, Mississippi silversides $\left(R^{2}=0.26, \mathrm{P}=0.19, \mathrm{~N}=8\right)$, topsmelt $\left(R^{2}=0.07, \mathrm{P}=0.56, \mathrm{~N}=7\right)$, threespine sticklebacks $\left(R^{2}=0.04, \mathrm{P}=0.66, \mathrm{~N}=7\right)$, or yellowfin gobies $\left(R^{2}=0.12\right.$, $\mathrm{P}=0.44, \mathrm{~N}=7$ ) sampled from the same wetlands during the same year (fig. 69). During the breeding season, Forster's tern blood mercury concentrations were correlated only with mercury concentrations in rainwater killifish $\left(R^{2}=0.99, \mathrm{P}=0.01, \mathrm{~N}=3\right)$ and topsmelt $\left(R^{2}=0.93, \mathrm{P}=0.03, \mathrm{~N}=4\right)$, but not with mercury concentrations in longjaw mudsuckers $\left(R^{2}=0.39, \mathrm{P}=0.26, \mathrm{~N}=5\right)$ or Mississippi silversides $\left(R^{2}=0.32, \mathrm{P}=0.43, \mathrm{~N}=4\right)$ sampled from the same wetlands during the same year (fig. 69). The only overlap was between Forster's tern blood and fish at two sites for threespine stickleback and yellowfin goby during the breeding season, so we could not assess those relationships.

We found similar poor relationships between mercury concentrations in fish and bird eggs sampled in the same wetland (fig. 69). We only found a significant correlation between colony-specific egg mercury concentrations and threespine stickleback mercury concentrations $\left(R^{2}=0.80, \mathrm{P}=0.04, \mathrm{~N}=5\right)$. Conversely, we did not find a relationship between mercury concentrations in Forster's tern eggs and mercury concentrations in longjaw mudsuckers $\left(R^{2}=0.20, \mathrm{P}=0.32, \mathrm{~N}=7\right)$, Mississippi silversides $\left(R^{2}=0.74, \mathrm{P}=0.06, \mathrm{~N}=5\right)$, rainwater killifish $\left(R^{2}=0.05, \mathrm{P}=0.68, \mathrm{~N}=6\right)$, topsmelt $\left(R^{2}=0.27, \mathrm{P}=0.23, \mathrm{~N}=7\right)$, or yellowfin gobies $\left(R^{2}=0.81, \mathrm{P}=0.10, \mathrm{~N}=4\right)$ sampled from the same wetlands during the same year.

These results highlight the complexity of trophic transfer of mercury to fish-eating waterbirds in San Francisco Bay Estuary. The high spatial variability in fish mercury concentrations, coupled with bird habitat use and diet preferences, limits the utility of single-species fish monitoring for understanding risk of mercury to waterbirds. 


\section{Diving Duck Trophic Pathways}

\section{Spatial and Temporal Patterns in Benthic Invertebrate Mercury}

Total mercury, selenium, and cadmium concentrations were higher in bivalves than in other surf scoter prey items that we identified (figs. 70-72). Confidence intervals overlapped among seasons and between size classes (0-12 and 12-25 mm) for total mercury, selenium, and cadmium in bivalves; therefore, we combined by season and size class to compare with other prey taxa. Among surf scoter prey items, mean total mercury was highest in Central Bay Corbula amurensis $(0.25 \mu \mathrm{g} / \mathrm{g} \mathrm{dw}[-0.73-$ 1.26]) and Musculista senhousia $(0.23 \mu \mathrm{g} / \mathrm{g} \mathrm{dw}$ [0.19-0.26]). Temporally, there was little change in total mercury concentrations in bivalve prey items among seasons (fig. 70). In the North Bay, Corbula total mercury decreased an insignificant amount from $0.18 \mu \mathrm{g} / \mathrm{g} \mathrm{dw}(0.12-0.22)$ in fall to $0.10 \mu \mathrm{g} / \mathrm{g} \mathrm{dw}$ [0.09-0.13] in spring. In the Central Bay, mean total mercury concentrations in Venerupis were consistent among fall $(0.14 \mu \mathrm{g} / \mathrm{g} \mathrm{dw}$ [0.09-0.18]), winter $(0.16 \mu \mathrm{g} / \mathrm{g} \mathrm{dw}$ [0.11-0.20], and spring $(0.16$ $\mu \mathrm{g} / \mathrm{g} \mathrm{dw}[0.03-0.20])$. Total mercury concentrations in all scoter prey items were less than $0.5 \mu \mathrm{g} / \mathrm{g} \mathrm{dw}$, the dietary threshold at which reproductive effects were seen in mallards (Heinz, 1996). Interestingly, 36 percent of Macoma spp, an abundant bivalve in the estuary that was not found in scoter esophagi (De La Cruz, 2010) samples that exceeded this dietary threshold. This demonstrates the importance of having specific knowledge of local avian diets to aid in interpretation of their risk of mercury exposure.

Selenium concentrations in Corbula from San Pablo and Suisun Bays were 1.7 and 1.9 times higher than concentrations of the next most abundant clam Macoma, which is consistent with the findings of earlier studies (Linville and others, 2002). We also determined that selenium concentrations were similar among all sub-bays. Concentrations (mean and range) of selenium in Corbula from Suisun Bay $(6.40 \mu \mathrm{g} / \mathrm{g} \mathrm{dw}$ [5.19-7.73]) and San Pablo Bay $(5.73 \mu \mathrm{g} / \mathrm{g} \mathrm{dw}$ [5.35-6.23]), overlapped with those of Venerupis selenium concentrations in San Pablo Bay $(5.15 \mu \mathrm{g} / \mathrm{g}$ dw [3.95-6.45]) as well as those of Venerupis (5.41 $\mu \mathrm{g} / \mathrm{g} \mathrm{dw}$ [5.08-5.87]) and Musculista (5.40 $\mu \mathrm{g} / \mathrm{g} \mathrm{dw}$ [4.48-6.37]) in Central Bay (fig. 71).

Except for Corbula in Suisun Bay $(3.57 \mu \mathrm{g} / \mathrm{g}, \mathrm{N}=1)$, mean cadmium concentrations (fig. 72) were similar among Corbula $(1.31 \mu \mathrm{g} / \mathrm{g} \mathrm{dw}$ [0.97-1.98]) and Venerupis $1.19 \mu \mathrm{g} / \mathrm{g} \mathrm{dw}$ [0.11-2.28] in San Pablo and in Central Bay (1.13 $\mu \mathrm{g} / \mathrm{g}$ dw [0.99-1.38]; De La Cruz 2010).

\section{Trophic Transfer of Mercury in Diving Ducks}

Traditional gut or fecal analyses provide identification of specific prey items; however, they may underestimate contributions of fragile or easily digestible prey such as Pacific herring (Clupea palasi) roe. Stable isotopes provide a means of calculating the contribution of these prey types as well as determining integrated diet over different time scales by analyzing tissues with different turnover rates (Tieszen and others, 1983; Hobson and Clark, 1992; Hilderbrand and others, 1996). A combination of these methods has been used to decipher ontogenetic, seasonal and interannual shifts in diets of other species (Stapp, 2002; Meckstroth and others, 2007; Herreman and others, 2009; Grimaldo and others, 2009; Plass-Johnson and others, 2013). 
Our combined esophageal and isotope results indicated scoter diets are spatially distinct along a salinity gradient (Stewart and others, 2004) and are dominated by Corbula in San Pablo and Suisun Bays and by Venerupis in the Central Bay (table 16; De La Cruz, 2010). We found good correspondence between diet items in esophagi and stable isotope signatures during fall and winter; however, this association was not as strong in spring, highlighting the fact that combining both methods improved our ability to define diets. For example, in spring 2005, esophageal data showed that surf scoters on San Pablo Bay were foraging on clam siphons. This interpretation would not be possible with isotope ratios; however, this finding has important implications as it suggests scoters may have been responding to depletion of invasive Corbula by foraging on the siphons of species that were buried deeper in the substrate (Zwarts and Wanink, 1989; Zwarts and others, 1992).

We used isotopic mixing models to evaluate the role of herring roe compared to other prey items in surf scoter diets. Our results indicated bivalves comprised the largest proportion of diets in the Central Bay during each season in both years. Diet composition was between 45 and 69 percent bivalves in 2004 and 48 and 65 percent in 2005 (fig. 73; De La Cruz, 2010). Roe comprised the greatest proportion of prey in Central Bay diets during winter 2005 (33 percent [fig. 73]; De La Cruz, 2010). Crabs were consistently present at lower levels ranging from 8 to 26 percent across seasons and years.

We used linear regression to evaluate relationships between diet indices (isotope ratios and isotopic mixing model results) and contaminant concentrations in surf scoters. We found a weak but significant positive relationship between hepatic total mercury and consumer trophic level expressed by $\delta^{15} \mathrm{~N}_{\text {muscle }}\left(R^{2}=0.1014\right.$ [fig. 74]; De La Cruz, 2010). However, $\delta^{13} \mathrm{C}_{\text {muscle }}$ did not explain variations in total mercury $\left(R^{2}=0.02\right)$, suggesting that foraging location is not a good predictor of hepatic mercury in surf scoters. Diet proportions obtained from mixing models were not related to hepatic total mercury

(percent clam: $R^{2}=0.02$; percent herring roe: $R^{2}=0.02$; percent crab: $R^{2}=0.03$; De La Cruz, 2010).

\section{Bird Exposure to Other Contaminants of Concern}

\section{Selenium in Shorebirds and Terns}

Selenium is thought to have important interactive effects with mercury and can influence its toxicity (Berry and Ralston, 2008). Therefore, we evaluated selenium concentrations in livers of 156 adult and 50 chick American avocets, black-necked stilts, Forster's terns, and Caspian terns. We found that selenium concentrations were variable and influenced by several factors including species, region, reproductive stage, age, and sex (fig. 75; Ackerman and Eagles-Smith, 2009b). Adult selenium concentrations in livers ranged from 3.07 to $48.70 \mu \mathrm{g} / \mathrm{g} \mathrm{dw}$ in avocets (geometric mean $\pm \mathrm{SE}: 7.92 \pm 0.64$ $\mu \mathrm{g} / \mathrm{g} \mathrm{dw}), 2.28$ to $41.10 \mu \mathrm{g} / \mathrm{g} \mathrm{dw}$ in stilts $(5.29 \pm 0.38 \mu \mathrm{g} / \mathrm{g} \mathrm{dw}), 3.73$ to $14.50 \mu \mathrm{g} / \mathrm{g} \mathrm{dw}$ in Forster's terns $(7.13 \pm 0.38 \mu \mathrm{g} / \mathrm{g} \mathrm{dw})$, and 4.77 to $14.40 \mu \mathrm{g} / \mathrm{g} \mathrm{dw}$ in Caspian terns $(6.73 \pm 0.78 \mu \mathrm{g} / \mathrm{g} \mathrm{dw})$. For chicks, liver selenium concentrations (geometric mean $\pm \mathrm{SE}$ ) across all regions and sexes were $4.31 \pm 0.34 \mu \mathrm{g} / \mathrm{g} \mathrm{dw}$ in avocets $(\mathrm{N}=17$; range: 2.42 to $8.05 \mu \mathrm{g} / \mathrm{g} \mathrm{dw}), 4.35 \pm 0.39 \mu \mathrm{g} / \mathrm{g} \mathrm{dw}$ in stilts $(\mathrm{N}=16$; range: 2.11 to 7.98 $\mu \mathrm{g} / \mathrm{g} \mathrm{dw}$ ), and $3.19 \pm 0.10 \mu \mathrm{g} / \mathrm{g} \mathrm{dw}$ in Forster's terns ( $\mathrm{N}=17$; range: 2.55 to $4.39 \mu \mathrm{g} / \mathrm{g} \mathrm{dw})$. Avocets had higher selenium concentrations in the North Bay compared to the South Bay, whereas stilt selenium concentrations were similar between these regions, and Forster's terns had lower selenium concentrations in the North Bay compared to the South Bay. Female avocets had higher selenium concentrations than male avocets, but there were no sex differences among stilts or Forster's terns. Of the factors assessed, reproductive stage had the most consistent effect among species. Pre-breeding birds tended to have higher liver selenium concentrations than breeding birds, but this trend was only statistically significant for Forster's terns. Forster's tern chicks had lower selenium concentrations than adults, whereas avocet and stilt adults and chicks were similar. 
Generally, geometric mean selenium concentrations in the breeding waterbirds we studied were lower than wintering shorebirds and diving ducks previously sampled in the San Francisco Bay Estuary (Ohlendorf and others, 1986; Hothem and others, 1998; Hui and others, 2001; Takekawa and others, 2002). For example, selenium concentrations in livers of greater scaup (19.3 $\mu \mathrm{g} / \mathrm{g} \mathrm{dw})$ and surf scoters $(34.4 \mu \mathrm{g} / \mathrm{g} \mathrm{dw})$ from San Francisco Bay in 1982 (Ohlendorf and others, 1986), greater scaup and canvasbacks from San Pablo Bay (scaup: $20.7 \mu \mathrm{g} / \mathrm{g} \mathrm{dw}$, canvasbacks: 9.02-11.9 $\mu \mathrm{g} / \mathrm{g} \mathrm{dw}$ ), Central Bay (scaup: $32.7 \mu \mathrm{g} / \mathrm{g} \mathrm{dw}$ ), Grizzly Bay (canvasbacks: $5.66 \mu \mathrm{g} / \mathrm{g} \mathrm{dw}$ ), Alviso Slough (canvasbacks: 10.4 $\mu \mathrm{g} / \mathrm{g} \mathrm{dw}$ ), and Alameda Flood Control Channel (scaup: $27.4 \mu \mathrm{g} / \mathrm{g} \mathrm{dw}$, canvasbacks: $14.2 \mu \mathrm{g} / \mathrm{g} \mathrm{dw}$ ) in 1986 (Hothem and others, 1998), and greater scaup and surf scoters from Tomales Bay (scaup: $13 \mu \mathrm{g} / \mathrm{g}$ dw, scoter: $20 \mu \mathrm{g} / \mathrm{g} \mathrm{dw}$ ) and Suisun Bay (scaup: $67 \mu \mathrm{g} / \mathrm{g} \mathrm{dw}$, scoter: $119 \mu \mathrm{g} / \mathrm{g} \mathrm{dw}$; Hui and others, 2001) in 1989 were higher than the species we studied. Lower selenium concentrations in breeding shorebirds and terns in 2005 compared to the diving ducks studied in the 1980s and shorebirds in the early 1990s, likely were not due to a decrease in selenium availability over time. For example, selenium concentrations in surf scoter livers sampled during the same years were still at elevated levels $(32.9 \mu \mathrm{g} / \mathrm{g}$ dw). Instead, higher selenium concentrations in diving ducks compared to shorebirds and terns in San Francisco Bay likely is due to diet and how selenium cycles in the estuary. Diving ducks forage mainly on benthic bivalves which bioaccumulate selenium to a higher degree than aquatic invertebrates typically consumed by shorebirds; this difference in selenium concentrations has been shown to propagate up the food webs in San Francisco Bay (Stewart and others, 2004).

\section{Selenium in Diving Ducks}

Surf scoter mean hepatic selenium concentrations were higher in Suisun and San Pablo Bays than in the Central Bay across all seasons and between years, although in 2005, confidence intervals of scoters from all three regions overlapped (fig. 76, table 17). Liver selenium concentrations in $>96$ percent of scoters from all three regions exceeded the reproductive impairment effect threshold $(11 \mu \mathrm{g} / \mathrm{g}$ $\mathrm{dw}$ ) for captive mallards (Heinz, 1996). The predicted physiological effect threshold (33 $\mu \mathrm{g} / \mathrm{g} \mathrm{dw}$; Heinz, 1996) was exceeded by 19 percent (Central Bay), 81 percent (San Pablo Bay), and 96 percent (Suisun Bay) of scoters (De La Cruz, 2010). Liver selenium concentration was inversely related to

$\delta^{15} \mathrm{~N}_{\text {muscle }}\left(R^{2}=0.30\right)$ and $\delta^{13} \mathrm{C}_{\text {muscle }}\left(R^{2}=0.14\right.$; De La Cruz, 2010). Scoter diets, as determined using isotopic mixing models incorporating $\delta^{15} \mathrm{~N}$ and $\delta^{13} \mathrm{C}$ signatures from scoter plasma and prey, showed even stronger relationships with selenium concentrations. Proportion of clams was positively related to selenium concentrations in scoter livers $\left(R^{2}=0.41\right.$; fig. $\left.77 \mathrm{~A}\right)$, whereas, proportions of herring roe or crab in diet were inversely related to selenium concentrations (herring roe: $R^{2}=0.36$, fig. $77 \mathrm{~B}$; crabs: $R^{2}=0.36$; fig. 77C; De La Cruz, 2010). The mixing models indicated that scoters from Suisun and San Pablo Bays consumed proportionally more clams whereas scoters from Central Bay consumed proportionally more herring roe and crabs (fig. 77A-C). The majority of marked scoters left Suisun Bay and San Pablo Bay by February (De La Cruz and others, 2014), likely in response to prey depletion (Poulton and others, 2002; Lovvorn and others, 2013), and moved to the Central Bay where it appeared their exposure to selenium decreased due to a diversified diet (De La Cruz, 2010). 


\section{Cadmium in Diving Ducks}

Renal cadmium concentrations in scoters ranged from $0.56-65.6 \mu \mathrm{g} / \mathrm{g}$ dw across locations and

collection periods. Mean concentrations were spatially and temporally variable as demonstrated by the considerable overlap among all 95 percent CIs; however, the highest mean concentration occurring in the Central Bay during spring 2005 (32.26 $\mu \mathrm{g} / \mathrm{g} \mathrm{dw}$ [26.72-39.68]; fig. 78, table 17). Renal cadmium concentrations were highly variable in female scoters, and were similar to those in males collected from the North Bay and South Bay during 1985 (geometric means ranged from 20.0 to $39.6 \mu \mathrm{g} / \mathrm{g} \mathrm{dw}$; Ohlendorf and Fleming, 1988). Tissue effect thresholds for cadmium concentrations are not well defined in birds (Furness, 1996); however, renal cadmium in San Francisco Bay scoters was within the broad range of those that caused metabolism effects under food-stress conditions in juvenile mallards (arithmetic mean range 3.8 to $136.2 \mu \mathrm{g} / \mathrm{g} \mathrm{dw}$; DiGiulio and Scanlon, 1985), and were slightly lower than those that appeared to interfere with vitamin A metabolism in male surf scoters from British Columbia (geometric means from 34.2 to $40.6 \mu \mathrm{g} / \mathrm{g} \mathrm{dw}$; Harris and others, 2007). Only 2 of the 42 bivalve samples we measured for cadmium exceeded the $2 \mu \mathrm{g} / \mathrm{g} \mathrm{dw}$ dietary threshold at which effects on elemental metabolism in birds have been shown to occur (Furness, 1996). In a laboratory study, Corbula accumulated 22 times more cadmium from seawater than Macoma (Wallace and others, 2003), but we found that mean cadmium was only 3.7 times higher in Corbula than in Macoma collected in San Pablo Bay. Cadmium has been shown to be more bioavailable in Corbula than in Macoma (Wallace and Luoma, 2003), providing an additional mechanism by which Corbula consumption could increase cadmium exposure for predators in the estuary.

\section{Organohalogens in Terns}

Although mercury is a priority pollutant in the San Francisco Bay, the estuary also is subjected to contamination from a suite of other persistent bioaccumulative and toxic pollutants (PBTs), such as PCBs, DDTs, and PDBEs. We evaluated $\sum$ PBDEs, $\sum$ PCBs (fig. 79), and $\sum D D T$ in a subset of Forster's terns and Caspian tern livers to assess the potential implications of multi-contaminant exposure in the bay (Herring and others, 2010). Concentrations of these contaminants were similar between species, regions, sexes, and breeding stage for adult birds, although there was a nonsignificant trend of higher $\sum$ PCBs and $\sum$ PBDEs in adults from Central South Bay and Lower South Bay than North Bay. Concentrations of $\sum$ PBDE, $\sum$ PCB, and $\sum$ DDT were higher in Forster's tern adults than in chicks. None of the PCB or PBDE homologues in adults differed by species, sexes, nesting stage, or among regions, nor did PCB or PBDE homologs differ between ages for Forster's terns. In the San Francisco Bay, the Central South Bay and the Lower South Bay differed from the northern areas of the bay in several aspects that might influence PBT availability. The Central South Bay and Lower South Bay areas have a human population base twice as large as the North Bay area, is a seasonally negative estuary (evaporation exceeds the fresh water supply from rivers and from local rain), receives less than 10 percent of the freshwater river runoff from San Francisco Bay area rivers, but receives as much as 76 percent of the total San Francisco Bay wastewater, and has limited flushing capacity (Squire and others, 2002). Additionally, seasonal winds transport sediment from the North Bay to the Central South Bay and Lower South Bay. Sediments in the San Francisco Bay act as contaminant reservoirs and processes that result in potential accumulation of sediment in areas of the San Francisco Bay may result in increased localized contaminant availability (Schoellhamer and others, 2007). 
Forster's tern $\sum$ DDT was positively correlated with $\sum$ PBDE and $\sum$ PCB, and $\sum$ PCB was positively correlated with $\sum$ PBDE (fig. 80; Herring and others, 2010). Similarly, Caspian tern $\sum$ PCBs were positively correlated with $\sum$ DDTs, but $\sum$ PBDEs were not correlated with $\sum$ DDTs or $\sum$ PCBs (fig. 80; Herring and others, 2010). Liver tissue and selenium concentrations and $\sum$ DDTs were positively correlated for Forster's terns and Caspian terns combined; there was a non-significant positive trend between $\sum$ PBDEs and selenium, and there was no correlation between $\sum$ PCBs and selenium (fig. 81; Herring and others, 2010). Conversely, Forster's tern and Caspian tern $\sum$ PBDEs, $\sum$ PCBs, and $\sum D D T s$ were not correlated with liver tissue THg (fig. 81; Herring and others, 2010).

Concentrations of PCBs and DDT in San Francisco Bay Forster's terns and Caspian terns were all lower than concentrations significantly harmful to adult birds (Custer and Heinz, 1980). The highest individual PCB concentration we observed in a San Francisco Bay bird was $9.4 \mu \mathrm{g} / \mathrm{g} w w$, with the highest mean concentration of $3.2 \pm 1.3 \mu \mathrm{g} / \mathrm{g}$ ww. American black ducks (A. rubripes) fed $10(\mu \mathrm{g} / \mathrm{g}) / \mathrm{d} \mathrm{dw}$ DDE resulting in mean carcass DDE concentrations of $151.5 \mu \mathrm{g} / \mathrm{g} \mathrm{dw}$ (male) and $159.6 \mu \mathrm{g} / \mathrm{g} \mathrm{dw}$ (female) impaired reproduction, but no mortality occurred (Longcore and Stendell, 1977). The highest DDT concentration we observed was $1.3 \mu \mathrm{g} / \mathrm{g}$ ww, with a mean concentration of $0.5 \pm 0.1 \mu \mathrm{g} / \mathrm{g}$ ww. Concentrations of DDTs do not appear to be high enough to result in impaired reproduction. Fernie and others (2005) dosed American kestrel (Falco sparverius) chicks with $15.6(\mu \mathrm{g} / \mathrm{g}) / \mathrm{d}$ ww of PBDE, resulting in carcass homogenate concentrations of $86.1 \mu \mathrm{g} / \mathrm{g}$ ww and observed increased measures of oxidative stress. The highest PBDE concentration we observed was $1.1 \mu \mathrm{g} / \mathrm{g}$ ww, with a mean concentration of $0.3 \pm 0.1 \mu \mathrm{g} / \mathrm{g}$ ww.

\section{Potential Risk of Mercury to Birds}

\section{Percentage of Prey Exceeding Dietary Thresholds}

\section{Percentage of Invertebrate Prey Exceeding Dietary Thresholds}

Total mercury in invertebrate prey of shorebirds exceeded the $0.50 \mu \mathrm{g} / \mathrm{g} \mathrm{dw}$ dietary threshold associated with impaired bird reproduction (Heinz, 1979) in 21 percent of samples analyzed in San Francisco Bay. The geometric mean total mercury concentration for all invertebrate species was $0.42 \pm 0.04 \mu \mathrm{g} / \mathrm{g} \mathrm{dw}$. Prey taxa exceeding the toxicity threshold were Artemia (20 percent; $\mathrm{N}=20$ ), Corixidae (22 percent; $\mathrm{N}=77$ ), and Mysids (50 percent; $\mathrm{N}=4$ ). In the South Bay, 26 percent of Corixidae $(\mathrm{N}=61), 36$ percent of Artemia $(\mathrm{N}=11)$, and 100 percent of Mysid $(\mathrm{N}=2)$ samples exceeded the toxicity threshold. In the Central Bay, all invertebrate taxa analyzed were less than the toxicity threshold. In the North Bay, 25 percent of Corixidae samples exceeded the toxicity threshold $(\mathrm{N}=4)$, and no other invertebrate species were above this level. During the shorebird-breeding period, the diet of avocets and stilts consisted of predominately seasonally abundant Corixidae (see above); thus, Corixidae might be an invertebrate taxa of particular concern regarding trophic transfer of total mercury. 


\section{Percentage of Prey Fish Exceeding Dietary Thresholds}

Prey fish mercury concentrations were elevated in comparison to forage fish from other locations around the world, and relative to toxicological risk thresholds. The mean total mercury concentration for all fishes in San Francisco Bay Estuary was $0.16 \mu \mathrm{g} / \mathrm{g}$ ww (Eagles-Smith and Ackerman, 2014), which is 3-6 times higher than ecologically similar prey fish species from Narraganset Bay Estuary, Rhode Island (Szczebak and Taylor, 2011), 4 times higher than the Gulf of Maine (Chen and others, 2009), and 4-20 times higher than Barataria Bay Louisiana (Fry and Chumchal, 2012). Of the nearly 3,100 fish that we sampled, 26 percent $(\mathrm{N}=796)$ had total mercury concentrations exceeding $0.20 \mu \mathrm{g} / \mathrm{g}$ ww (Eagles-Smith and Ackerman, 2014), a whole-body tissue benchmark associated with potential sublethal effects in fish (Beckvar and others, 2005). Additionally, 12 percent $(\mathrm{N}=386)$ of all fish sampled exceeded $0.30 \mu \mathrm{g} / \mathrm{g}$ ww (Eagles-Smith and Ackerman, 2014), which is a dietary benchmark developed for some fish-eating bird species that is associated with impaired reproduction (Albers and others, 2007; Burgess and Meyer, 2008; Shore and others, 2011).

Most of the fish that exceeded the wildlife toxicity benchmarks were from the managed wetlands and wetlands along the margins of the Bay, as opposed to the open bay habitats. No fish sampled from the open bay habitats exceeded the $0.30 \mu \mathrm{g} / \mathrm{g}$ ww wildlife criterion and only 9 percent exceeded the fish health threshold in the open bay habitat (Eagles-Smith and Ackerman, 2014). In particular, 36 percent of silversides exceeded the wildlife risk benchmark in managed wetlands, whereas no silversides sampled from the open bay habitat exceeded the benchmark in this study (Eagles-Smith and Ackerman, 2014), nor was the benchmark exceeded in open bay habitats in prior studies in San Francisco Bay (Greenfield and Jahn, 2010). Thus, the wetland habitats along the bay's margins not only had the prey fish with the highest mercury concentrations (Eagles-Smith and Ackerman, 2014), but these wetland habitats also are the preferred foraging and breeding areas for piscivorous birds in the estuary (Ackerman and others, 2008a; Bluso-Demers and others, unpublished data). Despite representing only a small proportion of the bay's area, the combination of high fish mercury and high waterbird use may make these wetlands along the bay's margin hotspots for mercury bioaccumulation.

\section{Percentage of Adults at Risk to Mercury}

Data across multiple taxa are still lacking, but a threshold for high risk of deleterious effects has been developed for common loon blood at $3 \mu \mathrm{g} / \mathrm{g}$ ww, above which 41 percent fewer young were produced than loons with $<1.0 \mu \mathrm{g} / \mathrm{g}$ mercury in blood (Evers and others, 2008). We compared blood mercury concentrations in Forster's terns, Caspian terns, black-necked stilts, and American avocets to these loon benchmarks in order to provide a relative estimate of risk to mercury exposure. During the pre-breeding period, blood mercury concentrations in 0 percent of avocets, 16 percent of stilts, 10 percent of Caspian terns, and 13 percent of Forster's terns exceeded this threshold value (fig. 82; Eagles-Smith and others, 2009a). By the onset of breeding, 5-6 percent of avocets, stilts, and Caspian terns exceeded this value. Importantly, 48 percent of breeding Forster's terns had blood mercury concentrations exceeding this high-risk threshold (fig. 82; Eagles-Smith and others, 2009a). 
Maternal Transfer of Mercury to Eggs

We captured 77 adult females (avocet, stilt, and Forster's tern) during the incubating period and compared their mercury concentrations to their clutch's mean egg mercury concentrations. Mean total mercury concentrations in eggs were strongly correlated with mercury concentrations in the incubating adult females' blood $\left(R^{2}=0.79, \mathrm{~F}_{1,75}=282.85, \mathrm{P}<0.0001\right.$; fig. 83) and liver $\left(R^{2}=0.80, \mathrm{~F}_{1,81}=319.27\right.$, $\mathrm{P}<0.0001)$. These results indicate that mercury in adults is transferred to offspring in a predictable way, and that parents with high mercury concentrations will lay eggs with high mercury concentrations. The specific equations for mercury concentrations in eggs related to adults were:

$$
\begin{gathered}
\ln (\text { Mean Egg THg })=0.8677803 \times \ln (\text { Blood THg })-0.658504 \\
\ln (\text { Mean Egg THg })=0.9911862 \times \ln (\text { Liver THg })-2.55224
\end{gathered}
$$

Percentage of Eggs at Risk to Mercury in San Francisco Bay

Mercury concentrations in eggs of birds breeding in San Francisco Bay were considered high. Geometric mean egg total mercury concentrations were $1.47 \pm 0.05 \mu \mathrm{g} / \mathrm{g}$ fww for Forster's terns, $0.75 \pm 0.09 \mu \mathrm{g} / \mathrm{g}$ fww for Caspian terns, $0.66 \pm 0.04 \mu \mathrm{g} / \mathrm{g}$ fww for stilts, and $0.22 \pm 0.01 \mu \mathrm{g} / \mathrm{g}$ fww for avocets (fig. 84). In particular, mercury concentrations in Forster's tern and Caspian tern eggs were above mercury toxicity levels developed in the laboratory for two closely relate tern species: common terns LC50 was $0.87 \mu \mathrm{g} / \mathrm{g}$ ww and royal terns LC50 was $0.40 \mu \mathrm{g} / \mathrm{g}$ ww. Although injected mercury likely is more toxic than maternally derived mercury (Heinz and others, 2009b), current mercury concentrations in Forster's tern eggs in the San Francisco Bay are considered high. For example, 99 percent of Forster's tern eggs we sampled were above the toxic threshold concentration calculated for royal terns, 88 percent were above the toxic threshold concentration calculated for common terns, 79 percent were above $1.0 \mu \mathrm{g} / \mathrm{g}$ fww (fig. 85), which is a commonly used toxicity threshold (review by Scheuhammer and others, 2007), and 34 percent were above the mean mercury concentrations in failedto-hatch eggs $(1.84 \mu \mathrm{g} / \mathrm{g}$ fww) that we observed in San Francisco Bay (see below). Similarly, 94 percent of Caspian tern eggs were above the toxic threshold for royal terns, 25 percent were above the toxic threshold for common terns, and 13 percent were above $1.0 \mu \mathrm{g} / \mathrm{g}$ fww (fig. 85). Although they had lower mercury concentrations than terns, 68 percent of stilt eggs and 17 percent of avocet eggs still exceeded $0.5 \mu \mathrm{g} / \mathrm{g}$ fww and 31 percent of stilt eggs and 3 percent of avocet eggs even exceeded the higher toxicity threshold of $1.0 \mu \mathrm{g} / \mathrm{g}$ fww (fig. 85). Although sensitivity to mercury can differ widely among species (Heinz and others, 2009b), the large percentage of eggs sampled that had mercury concentrations above common toxicity thresholds suggest that mercury might be impairing avian reproduction in San Francisco Bay and is an area of conservation concern that should be closely monitored.

\section{Percentage of Eggs at Risk to Mercury and Selenium in Migratory Ducks Breeding Outside of San Francisco Bay}

We collected 11 eggs from 3 scoters that wintered in San Francisco Bay and nested in the Northwest Territories of Canada. Additionally, we obtained four oviduct eggs from surf scoters of unknown wintering origin collected during a concomitant study of breeding propensity (Wilson, 2014). The geometric means were similar and 95 percent confidence intervals overlapped for total mercury in eggs of scoters that wintered in San Francisco Bay $(0.20 \pm 0.08 \mu \mathrm{g} / \mathrm{g}$ fww $)$ compared to those from unknown wintering areas $(0.14 \pm 0.07 \mu \mathrm{g} / \mathrm{g}$ fww $)$. We estimated that 9 percent of scoter eggs were greater than $0.5 \mu \mathrm{g} / \mathrm{g}$ fww, and none were greater than $1.0 \mu \mathrm{g} / \mathrm{g}$ fww toxicity thresholds (fig. 85). This suggests that scoter reproduction may not be influenced by cross-seasonal exposure to mercury on their wintering area; however, our results should be interpreted with caution given the small sample sizes available. 
Surf scoters foraging in San Francisco Bay accumulate selenium concentrations above reproductive threshold concentrations and many depart for spring migration with high selenium burdens. Selenium is depurated quickly in the livers of laboratory mallards (half life = 3.3 days; Heinz and others, 1990) and in the blood of lesser scaup (half life = 16-22 days, depending on dose; DeVink and others, 2008a) after they are removed from a selenium diet and satellite telemetry indicates that spring migration takes an average of 47 days for San Francisco Bay female surf scoters (De La Cruz and others, 2009) However, we found hepatic selenium concentrations of migrating female scoters collected along the Pacific Coast for a related study were elevated above physiological ( $\geq 33 \mu \mathrm{g} / \mathrm{g} \mathrm{dw})$ and reproductive ( $\geq 11 \mu \mathrm{g} / \mathrm{g} \mathrm{dw}$ ) effect concentrations, suggesting continued exposure in the marine environment. Concentrations in livers of females collected on the breeding grounds within a week of the mean arrival date (May $25 \pm 1.7$ days; De La Cruz and others, 2009) were only slightly elevated $(13.67 \pm 7.66 \mu \mathrm{g} / \mathrm{g} \mathrm{dw})$, suggesting rapid depuration upon exposure to freshwater breeding habitat. Further, mean selenium concentrations in livers $(6.72 \pm 7.20 \mu \mathrm{g} / \mathrm{g} \mathrm{dw})$ from four nesting females of unknown wintering origin were less than reproductive effect concentrations. Mean selenium in oviduct egg samples from the same females $(0.46 \pm 0.08 \mu \mathrm{g} / \mathrm{g}$ fww; $1.26 \pm 0.27 \mu \mathrm{g} / \mathrm{g} \mathrm{dw})$ were 5.3 times lower than matched livers and similar to concentrations in known San Francisco Bay eggs $(0.58 \pm 0.08 \mu \mathrm{g} / \mathrm{g}$ fww; $1.71 \pm 0.38 \mu \mathrm{g} / \mathrm{g} \mathrm{dw}$ ). No scoter eggs sampled were greater than $1.0 \mu \mathrm{g} / \mathrm{g} \mathrm{ww}$ selenium toxicity threshold suggested to impair reproduction in wild birds (Heinz and others, 1989).

\section{Objective 2: Evaluate Toxicological Effects of Mercury Exposure on Birds}

\section{Biochemical Effects of Mercury and Other COCs on Shorebirds and Terns}

\section{Demethylation of Methylmercury in Shorebird and Tern Livers}

Several studies have suggested that methylmercury may be detoxified in the liver of waterbirds (Thompson and Furness, 1989b; Kim and others, 1996; Scheuhammer and others, 1998; Henny and others, 2002). It is thought that this detoxification is driven by a demethylation process by which methylmercury is converted to inorganic mercury in the liver. We assessed methylmercury demethylation in the livers of adults and chicks of all four waterbird species studied. In adults (all species combined), we found strong evidence for a threshold model where at low concentrations of total mercury in livers the proportion of mercury composed of methylmercury was high (about 88 percent) and remained constant, whereas there was a steep, linear decrease in percentage of methylmercury with increasing total mercury concentrations in excess of $8.51 \pm 0.93 \mu \mathrm{g} / \mathrm{g} \mathrm{dw}$ (fig. 86; Eagles-Smith and others, 2009b). Conversely, there was no evidence for a demethylation threshold in chicks, and we found that percentage methylmercury values decreased linearly with increasing total mercury concentrations (fig. 87; Eagles-Smith and others, 2009b). This lack of a threshold may have been due, at least in part, to a lack of mercury concentrations greater than the threshold that were more common in adults. For example, less than 7 percent of all chicks sampled had liver total mercury concentrations over $8.20 \mu \mathrm{g} / \mathrm{g} \mathrm{dw}$.

For adults, we also found taxonomic differences in the demethylation responses by avian guild, with shorebirds showing a higher demethylation rate than terns when concentrations exceeded the threshold, whereas terns had a lower demethylation threshold $(7.48 \pm 1.48 \mu \mathrm{g} / \mathrm{g} \mathrm{dw})$ than avocets and stilts $(9.91 \pm 1.29 \mu \mathrm{g} / \mathrm{g} \mathrm{dw}$ [fig. 88]; Eagles-Smith and others, 2009b). The taxonomic differences in the demethylation response in adults suggests that methylmercury demethylation may occur more rapidly in avocets and stilts than in terns, but that avocets and stilts may not initiate demethylation until they reach relatively higher total mercury concentrations. Alternatively, avocets and stilts likely are exposed to 
methylmercury at a lower rate than terns because they primarily forage at a lower trophic level on invertebrates (Ackerman and others, 2013a), as opposed to fish, which are the main prey of terns (Cuthbert and Wires, 1999; McNicholl and others, 2001). Additionally, avocets and stilts likely are exposed to a relatively greater amount of dietary inorganic mercury than terns due to their foraging ecology. As a result, the methylmercury pool in tern livers may be continually replenished at a relatively higher rate compared to avocets and stilts, which likely would result in a dampened response in decreasing percentage methylmercury values even if demethylation was occurring at the same rate.

Finally, we assessed the role of selenium in the demethylation process. Selenium concentrations were positively correlated with inorganic mercury in livers of birds greater than the demethylation threshold (avocets and stilts: $R^{2}=0.54, \mathrm{~N}=23$; Forster's and Caspian terns: $R^{2}=0.15, \mathrm{~N}=39$; fig. 89 ; Eagles-Smith and others, 2009b), but not less than the threshold (avocets and stilts: $R^{2}=0.04, \mathrm{~N}=77$; Forster's and Caspian terns: $R^{2}=0.06, \mathrm{~N}=19$; fig. 89; Eagles-Smith and others, 2009b). This suggests that selenium may act as a binding site for demethylated mercury, and may reduce the potential for secondary toxicity. Our findings indicate that waterbirds demethylate mercury in their livers if exposure exceeds a threshold value, and suggest that taxonomic differences in demethylation ability may be an important factor in evaluating species-specific risk to methylmercury exposure. Further, we provide strong evidence for a threshold of approximately $8.5 \mu \mathrm{g} / \mathrm{g} \mathrm{dw}$ of total mercury in the liver where demethylation is initiated.

Although little is known regarding the physiological mechanisms of methylmercury demethylation in the avian liver (Ikemoto and others, 2004; Scheuhammer and Sandheinrich, 2008), it is suspected to be an active, energy-dependent process. This hypothesis is consistent with the biphasic response in percentage methylmercury relative to liver total mercury concentrations in adults. At concentrations less than toxicity thresholds, there is little benefit to expending energy in demethylation processes, whereas at mercury concentrations approaching or exceeding toxicity thresholds it becomes increasingly advantageous to direct energy to protective mechanisms. However, it is currently unclear whether differences in demethylation thresholds among species are due to differing species sensitivities to the toxic effects of methylmercury, or instead that species differ in their physiological ability to expend energy in the demethylation process.

\section{Selenium Effect on Body Condition in Shorebirds and Terns}

Resolving the effects of mercury on wildlife in San Francisco Bay is somewhat confounded by simultaneous, cumulative exposure to other contaminants. We examined the relationship between liver selenium concentrations and body condition in a subset of birds in this study and found that when controlling for other physical factors that could influence body condition, adult body condition was negatively related to liver selenium concentrations in Forster's terns, but not avocets, stilts, or Caspian terns (fig. 90; Ackerman and Eagles-Smith, 2009b). Chick body condition was not influenced by liver selenium concentrations in avocets (Ackerman and Eagles-Smith, 2009b). 
Reproductive impairment in mallards has been associated with liver selenium concentrations exceeding $11 \mu \mathrm{g} / \mathrm{g} \mathrm{dw}$, and physiological impairment has been associated with levels exceeding $33 \mu \mathrm{g} / \mathrm{g}$ dw. Average liver selenium concentrations for San Francisco Bay waterbirds were well below these toxicity levels, but selenium concentrations varied by as much as 16 -fold in avocets. We found that 27 percent of avocets, 20 percent of Caspian terns, 15 percent of Forster's terns, and 5 percent of stilts had liver selenium concentrations $\geq 11 \mu \mathrm{g} / \mathrm{g} \mathrm{dw}$, but only 2 percent of shorebirds and no terns had concentrations $\geq 33 \mu \mathrm{g} / \mathrm{g}$ dw. Nonetheless, we did find that body condition was negatively related to liver selenium concentrations in adult Forster's terns, while explicitly accounting for other factors that could influence body condition, such as reproductive stage and sex. However, the relationship was weak and it is unclear whether this pattern actually represents cause and effect, especially because we did not find the same negative relationship in the other three species. Additionally, the positive correlation between selenium and DDT in terns (fig. 81; Herring and others, 2010) suggests the possibility that the body condition relationships could be a response to exposure to other contaminants that covary with selenium.

\section{Selenium Effect on Body Condition in Diving Ducks}

Despite elevated concentrations of selenium in most surf scoters collected in San Francisco Bay, we found only weak relationships between selenium and body condition indices (De La Cruz, 2010). For selenium, $>50$ percent of all scoters exceeded the $33 \mu \mathrm{g} / \mathrm{g}$ dw physiological effects threshold (Heinz, 1996), yet we found a slight positive relationship between selenium and total protein (partial correlation: $\mathrm{r}=0.19, \mathrm{P}=0.04$, slope=9.36). Takekawa and others (2002) found a negative relationship between total protein and hepatic selenium concentration in wintering canvasbacks (Aythya valisineria) and laboratory studies have shown similar results with captive birds (Yamamoto and Santolo, 2000; Franson and others, 2007). However, our findings are more similar to recent field studies showing no effect of selenium on protein and lipids in greater scaup (Aythya marila; Badzinski and others, 2009), lesser scaup (Aythya affinis), or white-winged scoters (Melanitta fusca; DeVink and others, 2008b), albeit selenium concentrations measured in these studies were 2-8 times lower than those for scoters in San Francisco Bay. Results from laboratory dosing studies designed to simulate lesser scaup selenium exposure during spring migration showed no effects of selenium treatment (DeVink and others, 2008b). In a laboratory study designed to examine over-winter exposure to selenium, lesser scaup lipids decreased in the highest selenium treatment groups in relation to cold weather; however, similar to the results of Heinz and Fitzgerald (1993) with mallards, these birds were able to regain mass as the weather warmed (Brady, 2009). Selenium concentrations in affected scaup from Brady's (2009) study were similar to those we found in San Francisco Bay scoter females. San Francisco Bay winters typically are mild and cold induced stress in diving ducks may be less common than on other major sea and bay duck wintering areas. 


\section{Oxidative Stress in Relation to Mercury and Selenium Concentrations in Terns}

We assessed the biochemical effects of mercury and selenium exposure on Forster's terns by examining liver, kidney, and brain mercury concentrations in relation to organ-specific indices of oxidative stress and glutathione metabolism. We examined these relationships separately in liver, kidney, and brain tissues. Glutathione is considered to be the primary soluble intracellular low molecular weight compound involved in maintaining the integrity of living cells. Its actions are catalyzed by a system of enzymes that use the properties of glutathione to react with potentially harmful endogenous compounds and xenobiotics including mercury and excess selenium (Hoffman, 2002). Changes in glutathione status and, in particular, depletion of the reduced form of glutathione (GSH) and increase in the oxidized form (GSSG) are thought to increase the likelihood of injury to liver and other tissues. Therefore, the replenishment of GSH is an important strategy for meeting the challenge of sustained or acute oxidative stress (Hoffman, 2002)

\section{Hepatic Oxidative Stress}

After controlling for the effects of species, life stage, and sex, a significant relationship was determined between liver total mercury concentrations and both GSH and GGT (fig. 91; Hoffman and others, 2011), as well as a marginally significant relationship between liver total mercury concentrations and GSSG:GSH ratios. Both GSH and GGT decreased with increasing total mercury concentrations in livers, whereas GSSG:GSH activity increased with total mercury concentrations (fig. 91; Hoffman and others, 2011). Selenium concentrations were not related to any of the biomarker responses.

Hepatic depletion of GSH and the concomitant increase in GSSG:GSH ratio is consistent with the findings of many other studies. Hepatic GSH concentrations were negatively correlated to mercury levels in double-crested cormorant nestlings, snowy egret nestlings, great blue heron (Ardea herodias) embryos, adult surf scoters, ruddy ducks (Oxyura jamaicensis), and greater scaup (Custer and others, 1997; Hoffman and others, 1998, 2009; Henny and others, 2002). Increased hepatic GSSG:GSH ratio was related to mercury in mallards, greater scaup, and double-crested cormorants. However, in two studies where birds were dosed with methylmercury at various concentrations, hepatic GSH was not affected in common loons and increased only slightly in great egrets (Ardea alba; Kenow and others, 2008). The decrease in hepatic GGT activity in terns in the present study is somewhat unusual because GGT activity generally is quite low in avian liver tissue including terns, but considerably higher in kidneys of birds. Few effects if any of mercury on hepatic GGT activity of other avian species have been reported, whereas there have been reported effects on kidney GGT (Henny and others, 2002; Hoffman and others, 2009). GGT is produced primarily by the liver in mammals and catalyzes GSH, so it plays a key role in the synthesis and degradation of GSH. Therefore, decreased GGT activity as seen in the present study would be expected to contribute to oxidative stress.

\section{Renal Oxidative Stress}

After controlling for species, life stage, and sex effects, renal total mercury concentrations were only related with GSSG activity, which was positively correlated with total mercury concentrations (fig. 92; Hoffman and others, 2011). Increases in both renal GSSG and GSSG:GSH ratio were reported in young snowy egrets and in young black-crowned night herons (Nycticorax nycticorax) that were associated with renal mercury (Hoffman and others, 2009). In contrast, GSSG decreased in young cormorants (Henny and others, 2002). Other evidence of renal toxicity linked to mercury in birds includes alterations (Henny and others, 2002; Hoffman and others, 2009) in renal G-6-PDH activity 
which was depressed in adult and young snowy egrets but elevated in loon chicks and great egret nestlings which may account for lack of renal glutathione oxidative shifts in those two species (Kenow and others, 2008).

\section{Brain Oxidative Stress}

In brain tissue, there were significant life stage $\times$ total mercury interactions for TSH, TBARS, PBSH, GSSGred, and G-6-PDH, indicating that oxidative stress response to brain total mercury concentrations differed among life stages. Therefore, separate analyses were done for pre-breeding adults (models included total mercury, species, and sex), breeding adults, (models included total mercury and sex), and chicks (models included only total mercury). In pre-breeding adults, brain total mercury concentrations only influenced G-6-PDH activity (fig. 93; Hoffman and others, 2011), where there was a slight increase in G-6-PDH activity with increasing total mercury concentrations. An increase in G-6-PDH activity is considered a compensatory mechanism that would increase the supply of NADPH as a cofactor for the enzyme GSSGrd, which in turn converts GSSG to the reduced form GSH in order to maintain the status of reduced to oxidized glutathione and other thiols. Conversely, total mercury concentrations in breeding adult brains were correlated with TBARS, PBSH, GSSGred, and G-6-PDH (fig. 93; Hoffman and others, 2011). TBARS increased with increasing total mercury concentrations, whereas PBSH, GSSGred, and G-6-PDH activities decreased with increasing total mercury concentrations.

These findings indicate the most severe oxidative stress was apparent in breeding adult terns that also had the highest levels of brain mercury. This was manifested by the combination of increased TBARS (lipid peroxidation), decreased thiols as PBSH, and decreased protective antioxidant enzyme activities, GSSGred and G-6-PDH. Both these enzymes are linked to maintaining the status of NADPH, GSH, and other reduced thiols such as PBSH. In chicks, both TSH and PBSH decreased significantly with increasing total mercury concentrations, but no other biomarkers were correlated with brain total mercury concentrations. Similar negative correlations between brain total mercury and brain TSH and PBSH concentrations also were found, similar to reduced thiol depletion in young snowy egrets (Hoffman and others, 2009). Other studies have reported depletion of brain GSH linked to mercury in young double-crested cormorants and adult and young snowy egrets (Henny and others, 2002). Increase in the ratio of brain GSSG:GSH associated with increased brain mercury also has been reported in loon chicks (Kenow and others, 2008), whereas a decrease was reported in young snowy egrets (Henny and others, 2002; Hoffman and others, 2009). Effects on neural tissue associated with oxidative stress have included vacuolar change and inflammation of peripheral nerves in young snowy egrets that were correlated with blood and tissue mercury (Hoffman and others, 2009). More severe vacuolar degeneration and inflammation of peripheral nerves occurred in young double-crested cormorants that had higher blood mercury concentrations than snowy egrets (Henny and others, 2002).

The evidence of neurological cellular oxidative stress (increased lipid peroxidation, decreased protective thiols, and decreased protective antioxidant enzyme activities) with increasing brain total mercury concentrations in breeding Forster's terns suggests the potential for impaired breeding behavior as a result of mercury exposure. Other studies have reported behavioral effects of methylmercury in birds. Heinz (1979) reported that mallard hens with brain mercury of approximately $0.5 \mu \mathrm{g} / \mathrm{g}$ ww laid a greater percentage of eggs outside their nest boxes and fewer eggs than controls, and ducklings were less responsive to maternal calls but exhibited hypersensitivity to fright stimulus. In great egret chicks, low-dosed birds with brain mercury of $3.4 \mu \mathrm{g} / \mathrm{g} \mathrm{ww}$ exhibited decreased activity, greater tendency to seek shade, and less motivation to hunt prey (Bouton and others, 1999). Significant oxidative stress was not apparent at this level, but was apparent at a higher dose, which resulted in ataxia (Hoffman and 
others, 2005). In loon chicks with blood mercury of about $3 \mu \mathrm{g} / \mathrm{g} w \mathrm{w}$, oxidative stress in brain tissue was apparent and included increased GSSG and ratio of GSSG to GSH (Kenow and others, 2008). These same loon chicks were less likely or able to right themselves when placed in a supine position on their backs (Kenow and others, 2010). Young loon chicks in the field demonstrated increased time spent preening and decreased time riding on the backs of their parents with increasing blood mercury concentrations in chicks (Nocera and Taylor, 1998), and adults showed altered breeding behaviors with blood mercury $>3 \mu \mathrm{g} / \mathrm{g}$ ww (Evers and others, 2008). Although oxidative stress indices were not part of these field studies, collectively they suggest that when oxidative stress is apparent in brain tissue the likelihood of behavioral effects increases substantially.

P450 Response to other PBTs

Induction of P450 EROD is a common bio-indicator of organochlorine exposure. We found that P450 EROD activity was higher in adult Forster's terns than adult Caspian terns, and higher in prebreeding birds than breeding birds (table 18; Herring and others, 2010). It was also higher in adult Forster's terns than in chicks (table 18; Herring and others, 2010). Additionally, there were spatial differences in P450 induction where birds from the Central Bay had higher activity than either the North Bay or the Lower South Bay (table 18). Despite these differences in P450 activity we found no correlation with PBTs in either species or age classes even though at a broad scale EROD activity responses occurred in a predictable manner based on regional contaminant levels and foraging habitat exposure for Caspian terns and Forster's terns. For example, we found higher PBT concentrations in Central South Bay than in North Bay and higher concentrations in Forster's terns than in Caspian terns. Increased EROD activity in Forster's terns collected in the Central South Bay may be related to the general trend of higher PBTs ( $\sum$ PCBs and $\sum$ PBDEs) observed in tern tissue for this region. Consistent with this finding, She and others (2008) reported higher PCBs and PBDEs in Caspian tern and Forster's tern eggs in this area and Oros and others (2005) reported higher PBDEs in both water and sediment in this area. Additionally, She and others (2008) also found that PCBs were higher in Forster's terns than in Caspian terns, similar to our results for the liver tissue samples in Forster's terns and Caspian terns.

\section{Effects of Mercury on Bird Reproduction}

We monitored 1,274 shorebird nests, including 816 avocet nests $(2005: \mathrm{N}=337 ; 2006: \mathrm{N}=479)$ and 458 stilt nests (2005: $\mathrm{N}=123 ; 2006$ : $\mathrm{N}=335)$. Total chick production was 1,248 avocet and 561 stilt chicks, or 1.53 avocet and 1.22 stilt chicks per nesting attempt (Ackerman and others, 2014b). Total number of fledged chicks was 72 avocets and 239 stilts, or 0.09 avocet and 0.52 stilt chicks fledged per nesting attempt (Ackerman and others, 2014b). Therefore, even though there were 1.8 times more avocet nests than stilt nests, stilts still fledged 3.3 times more chicks (Ackerman and others, 2014b). Greater production by stilts than avocets was the result of greater chick survival from hatching to fledging (avocet: 6 percent; stilt: 40 percent), and not because of differences in clutch size (avocet: 3.84; stilt: 3.77), nest survival (avocet: 44 percent; stilt: 35 percent), or egg hatching success (avocet: 90 percent; stilt: 92 percent; Ackerman and others, 2014b).

We also monitored 1,309 Forster's tern nests (2005: N=592; 2006: N=717). Total chick production from monitored nests was 1,750 Forster's tern chicks, or 1.34 Forster's tern chicks per nesting attempt. Using an estimated chick survival rate from hatch through fledging of 22 percent (Ackerman and others, 2014a), we estimated that the total number of fledged chicks was 385 Forster's terns, or 0.29 Forster's tern chicks fledged per nesting attempt. Overall, Forster's tern clutch size was 2.59 , nest survival was 58 percent, egg hatching success was 89 percent, and cumulative chick survival during the 35-day post-fledging period was 81 percent (Ackerman and others, 2008b). 
The nest monitoring and chick survival data were used to evaluate the effects of mercury on bird reproduction.

Effects of Mercury on Eggs

Effects of mercury on bird reproduction can manifest itself in several ways, including altered parental behavior, embryo mortality, and hatching failure. We focused on the potential influence of mercury on egg hatchability by (1) comparing mercury concentrations in randomly sampled eggs to mercury concentrations in failed to hatch eggs and abandoned eggs, and (2) examining the influence of mercury concentrations on embryo deformities and malpositions.

\section{Mercury Concentrations in Random Eggs versus Failed Eggs and Abandoned Eggs}

During our nest monitoring activities, we identified and salvaged eggs that failed to hatch in otherwise successful nests (that is, $\geq 1$ egg hatched) and eggs that were abandoned by parents for natural reasons. We also collected viable eggs randomly from active nests. Including salvaged eggs, we sampled mercury concentrations in 382 avocet, 95 stilt, and 298 Forster's tern eggs during 2005-07.

Mercury concentrations in Forster's tern eggs differed among random eggs from successful nests, naturally abandoned eggs, and failed-to-hatch eggs, after statistically accounting for the effects of colony site and year (fig. 94; Analysis of Covariance: egg type: $F_{2,282}=4.92, P=0.01$; site: $F_{11,282}=7.33$, $\mathrm{P}<0.0001$; year: $\left.\mathrm{F}_{2,282}=13.85, \mathrm{P}<0.0001\right)$. On average, mercury concentrations were 28 percent higher in failed-to-hatch eggs $(1.84 \pm 0.16 \mu \mathrm{g} / \mathrm{g}$ fww) than in randomly sampled eggs from successful nests $(1.44 \pm 0.09 \mu \mathrm{g} / \mathrm{g}$ fww; Tukey's multiple comparisons test: $\mathrm{P}<0.05)$, but abandoned eggs $(1.57 \pm 0.13 \mu \mathrm{g} / \mathrm{g}$ fww) did not differ significantly from either failed-to-hatch or random eggs (fig. 94; Tukey's multiple comparisons test: both $\mathrm{P}>0.05)$.

Mercury concentrations in avocet eggs did not differ among random eggs from successful nests $(0.15 \pm 0.01 \mu \mathrm{g} / \mathrm{g}$ fww $)$, naturally abandoned eggs $(0.18 \pm 0.02 \mu \mathrm{g} / \mathrm{g}$ fww $)$, and failed-to-hatch eggs $(0.15 \pm 0.02 \mu \mathrm{g} / \mathrm{g}$ fww $)$ were not statistically significant after accounting for the effects of colony site and year (fig. 94; ANCOVA: egg type: $\mathrm{F}_{2,351}=1.18, \mathrm{P}=0.31$; site: $\mathrm{F}_{26,351}=11.30, \mathrm{P}<0.0001$; year: $\mathrm{F}_{2,351}=3.26$, $\mathrm{P}=0.04)$. Mercury concentrations in stilt eggs did not differ among random eggs from successful nests $(0.50 \pm 0.06 \mu \mathrm{g} / \mathrm{g}$ fww $)$, naturally abandoned eggs $(0.50 \pm 0.20 \mu \mathrm{g} / \mathrm{g}$ fww $)$, and failed-to-hatch eggs $(0.43 \pm 0.07 \mu \mathrm{g} / \mathrm{g}$ fww) after accounting for the effects of colony site and year (fig. 94; ANCOVA: egg type: $\mathrm{F}_{1,78}=0.52, \mathrm{P}=0.60$; site: $\mathrm{F}_{12,78}=5.54, \mathrm{P}<0.0001$; year: $\mathrm{F}_{2,78}=0.21, \mathrm{P}=0.81$ ).

Generally, mercury concentrations in eggs differed among species (Tukey's multiple comparisons test: all $\mathrm{P}<0.05)$, and were substantially higher in Forster's terns $(1.39 \pm 0.06 \mu \mathrm{g} / \mathrm{g}$ fww) than in stilts $(0.66 \pm 0.04 \mu \mathrm{g} / \mathrm{g}$ fww $)$ and avocets $\left(0.22 \pm 0.01 \mu \mathrm{g} / \mathrm{g}\right.$ fww; $\left.F_{2,724}=575.86, \mathrm{P}<0.0001\right)$. Thus, we found reproductive effects of mercury on Forster's terns whose egg mercury concentrations were well above common toxicity thresholds (for example, $1.0 \mu \mathrm{g} / \mathrm{g}$ fww; Scheuhammer and others, 2007), but not in avocets whose eggs are generally below these toxic levels. Stilt egg mercury concentrations were moderately high and, although we did not find effects of mercury on eggs, we did find that mercury concentrations in down feathers of dead chicks were higher than those in live chicks, which indicated that egg mercury concentrations had subsequent effects on chick survival (see below; Ackerman and others, 2008d).

\section{Effects of Mercury on Embryo Deformities and Malpositions}

We examined 282 eggs for embryo malpositions (138 avocets, 41 stilts, and 103 Forster's terns) and 470 eggs for deformities (219 avocets, 78 stilts, and 173 Forster's terns; table 19; Herring, 2010). Malpositioned embryos were observed in 11 percent of all eggs $\geq 18$ days of age and embryo deformities 
were observed in 2 percent of all eggs $\geq 13$ days of age (table 19; Herring, 2010). By species, malpositioned embryos occurred in 10 percent of all avocet eggs, 10 percent of all stilt eggs, and 12 percent of all tern eggs (table 19; Herring, 2010). The most common malpositions were head between thighs (47 percent), bill under right wing, but embryo rotated so bill pointed away from air cell (24 percent), bill lying over right wing (10 percent), and head under left wing (10 percent). Head in narrow end of shell, and one or both feet positioned above the head accounted for 7 percent and 3 percent of the remaining malpositions, respectively. One of the embryos with its head in the narrow end of shell also had one foot positioned above the head.

Deformed embryos occurred in 3 percent of avocet eggs, no stilt eggs, and 1 percent of tern eggs (table 19; Herring, 2010). The eight deformities consisted of embryos with: gastroschisis (exposed organs); two upper mandibles, lower mandible fused, and three eyes; upper mandible twisted to the left and undeveloped eyes; crossbill; lower mandible irregularly shaped; no feet; curved mandible, legs twisted, and short forelimbs; and lower mandible curved up.

The probability of an embryo being malpositioned within tern eggs increased with mercury concentrations in the egg (fig. 95; Herring, 2010). Conversely, the probability of an embryo being malpositioned in avocet and stilt eggs was not related to egg mercury concentrations (Herring, 2010). Embryo deformities in avocet and tern eggs were not related to mercury concentrations (Herring, 2010). A tern embryo with the mean egg mercury concentration of $1.36 \mu \mathrm{g} / \mathrm{g}$ fww in $2005-07$, had an 8 percent probability of being malpositioned (fig. 95; Herring, 2010). Likewise, a tern embryo with an egg mercury concentration of $2.41 \mu \mathrm{g} / \mathrm{g}$ fww (10 percent of eggs had concentrations this high or higher) had a 24 percent probability of being malpositioned (fig. 95; Herring, 2010).

This is the first field study to find a relationship between malpositioned embryos and mercury concentrations in eggs. Not only did we find that failed to hatch eggs ( 27 percent) had a higher occurrence of malpositioned embryos than random eggs ( 2 percent), but that eggs abandoned by tern parents also had a higher frequency of malpositioned embryos (19 percent; table 19; Herring, 2010). These data suggest that parental behavior may play an important role in the effect of mercury on egg hatchability.

Parental behavior during incubation is important for maintaining constant egg temperature and humidity for successful embryo development and egg hatching. In addition to parental coordination of incubation activities for species with biparental care (as is the case for the three species we studied), manual turning of eggs by parents is necessary for successful embryo development (Wilson and others, 2003). Failure to properly turn eggs during incubation can result in a higher incidence of embryo malposition (Wilson and others, 2003; Elibol and Brake, 2004) and improper egg temperatures can lead to embryo deformities (Krausova and Peterka, 2007) and malpositions (Suarez and others, 1996). Failure of embryos to move into the correct pipping position also can result in hatching failure (Wilson and others, 2003). Additionally, improper parental care of eggs during embryogenesis can result in the chorioallantois adhering to the inner shell membrane, which interferes with albumen uptake and obstructs the embryo's ability to attain the correct hatching position (Wilson and others, 2003). Therefore, we hypothesize that the mechanism of egg failure may be mercury-induced impairment of parental nest attendance behaviors (fig. 96A; Herring, 2010).

Alternatively, malpositioned avian embryos may be caused by mercury-induced impairment of embryo neurological function (fig. 96B; Herring, 2010). Carvalho and others (2008) experimentally demonstrated that in ovo exposure to methylmercury resulted in increased cerebellar glutathione levels and the enzymes glutathione reductase and glutathione peroxidase in chick cerebellums. Collectively, cellular damage and increased antioxidants were correlated with decreased exploratory and increased irregular movements in 1-day old chicks (Carvalho and others, 2008). We hypothesize that an 
alternative mechanism causing failure of eggs with elevated mercury concentrations may be the direct neurological impairment of embryos, resulting in an increased likelihood of an embryo being malpositioned and decreased chances of successfully hatching from an egg (fig. 96B; Herring, 2010).

\section{Effects of Mercury on Chicks}

The strong U-shaped pattern of mercury concentrations in juvenile birds indicates that chicks are at highest risk to mercury toxicity shortly after hatching (when maternally deposited mercury concentrations are still high) and again after fledging (when opportunities for mass dilution and excretion of mercury into feathers are limited; Ackerman and others, 2011). Therefore, we studied the potential effects of mercury on chick survival by specifically asking whether (1) egg-derived mercury concentrations influence subsequent chick survival after hatching in shorebirds and (2) mercury concentrations in tern chicks influence survival after fledging. To study the influence of mercury on postfledging survival (number 2), we measured mercury concentrations in tern blood. However, because recently hatched chicks are so small, there was insufficient blood volume to sample hatchling chicks (number 1) and sampling their blood potentially could have influenced their subsequent survival, thus defeating the purpose of the study. It was therefore necessary to create a new methodology in the field of ecotoxicology to study effects of maternally-derived mercury on subsequent chick survival. Thus, we begin by describing our new methodology, and follow with the effects of mercury on chicks.

\section{Chick Down Mercury Correlates to Whole Egg Mercury Concentrations}

Down feathers develop in ovo during the embryonic phase, so they represent mercury exposure in the egg (Becker and others, 1994) during a critical developmental period. We therefore developed equations to predict mercury concentrations in eggs using down feathers that can be non-lethally sampled from recently hatched chicks.

During 2005-07, we collected 94 pipping eggs (stilts: $\mathrm{N}=16$, avocets: $\mathrm{N}=35$, terns: $\mathrm{N}=43$ ) at $22 \pm 1.5$ (SD) days in incubation. We assessed the relationship between mercury concentrations in chick down feathers and eggs over a wide range of concentrations from 0.5 to $32.4 \mu \mathrm{g} / \mathrm{g}$ fw in feathers and 0.04 to $2.79 \mu \mathrm{g} / \mathrm{g}$ fww in eggs. We found a strong correlation $\left(R^{2}=0.96\right)$ between mercury concentrations in down feathers and mercury concentrations in the reconstructed fresh whole-egg homogenate (fig. 97; Ackerman and Eagles-Smith, 2009a).

If down feathers are continuously produced in young chicks, then mercury concentrations in down sampled from pipping chicks that are still inside the egg could differ from chicks sampled after hatching. We therefore assessed the potential for this difference in down feathers by using another of our newly developed methodologies, called egg micro-sampling (Stebbins and others, 2009), to extract albumen during early egg development ( $\leq 3$ days incubated) and compared albumen mercury concentrations to down feather mercury concentrations from newly-hatched chicks in the same nest. We also showed that mercury concentrations in albumen were highly correlated with concentrations in the whole-egg (Stebbins and others, 2009). Using this micro-sampling technique, we found a strong correlation $\left(\mathrm{N}=28, R^{2}=0.79\right)$ between mercury concentrations in albumen and mercury concentrations in down feathers sampled from chicks in the same nest (fig. 98; Ackerman and Eagles-Smith, 2009a). The slope of the relationship between mercury concentrations in chick down feathers and albumen (eggs) was close to 1.0, indicating the utility of using one tissue matrix as an index of the other (fig. 98; Ackerman and Eagles-Smith, 2009a).

Another potential problem with using chick down feathers to predict mercury concentrations in

eggs is that down feather mercury concentrations after hatching might change as chicks age. This could occur if chicks continued to produce down feathers as they grew and mercury concentrations varied 
with chick age. There is substantial support demonstrating that blood mercury concentrations decrease rapidly as chicks age and dilute their body burden of mercury through growth and depuration of mercury into growing feathers (Ackerman and others, 2011). However, there is less known about the timing of down feather growth and its effect on down mercury concentrations. Initially, down feathers are developed in ovo during the embryonic phase, but young chicks also may continue to produce down feathers after hatching. We therefore verified that mercury concentrations in down feathers sampled when chicks $\leq 3$-days old were correlated $\left(R^{2}=0.74\right)$ with concentrations in down feather samples taken from the same individual recaptured 7 days later (fig. 99; Ackerman and Eagles-Smith, 2009a).

In contrast to the albumen and chick down feather relationship, the slope of the regression $(0.80)$ between mercury concentrations in down feathers of recaptured and newly hatched chicks was less than 1.0 (fig. 99; Ackerman and Eagles-Smith, 2009a). This suggests that down feathers sampled at 0-3 days of age might have been different than down feathers sampled at 7-10 days of age. If this were true, then chicks exposed to high in ovo mercury concentrations likely were exposed to lower mercury concentrations in their diet after hatching. This is illustrated by the fact that mercury concentrations in down feathers of recaptured chicks were nearly the same as newly hatched chicks at low mercury concentrations, but that at higher mercury concentrations recaptured chicks had relatively lower levels of mercury than newly hatched chicks (fig. 99; Ackerman and Eagles-Smith, 2009a). Similarly, Becker and others (1994) determined that mercury concentrations in down feathers of highly contaminated chicks were much higher than concentrations in subsequently grown feathers, whereas there was no difference in mercury concentrations among feather types in the less contaminated chicks. Both these results indicate that the difference in mercury concentrations between sequentially grown feathers will be larger in the more highly contaminated chicks. Nonetheless, the strong correlation we found between mercury concentrations in recaptured chicks and newly hatched chicks indicates that down feathers were still a reliable index of egg mercury concentrations, at least for chicks to the age of 10 days posthatch (fig. 99; Ackerman and Eagles-Smith, 2009a).

Together, our results demonstrate the utility of using chick down feather mercury concentrations to predict mercury concentrations in eggs, and the reverse. Our results have several applications for mercury monitoring programs as well as in research for assessing toxicity thresholds. In addition to the value of this technique for monitoring mercury non-lethally, the ability to predict mercury concentrations in eggs from chick down feathers, or the reverse, can improve our assessment of egg toxicity thresholds. Because avian embryos are especially sensitive to methylmercury (reviews by Thompson, 1996; Wiener and others, 2003; Scheuhammer and others, 2007), egg toxicity thresholds traditionally have been developed by examining effects of in ovo mercury concentrations on egg survival (Heinz and Hoffman, 2003; Albers and others, 2007; Heinz and others, 2009b). However, chick growth (Spalding and others, 2000a; Longcore and others, 2007), behavior (Bouton and others, 1999), and survival (Albers and others, 2007; Burgess and Meyer, 2008; Evers and others, 2008) also can be affected by methylmercury. The ability to combine both these sensitive reproductive endpoints into a single tissue matrix, could improve our understanding of mercury toxicity levels that cause reproductive impairment (Ackerman and Eagles-Smith, 2009a). For instance, in ovo mercury concentrations that impair egg hatchability are likely to be higher than those concentrations that could impair subsequent chick growth and survival, because the chick must first hatch before it has the opportunity for its growth and survival to be affected by residual mercury exposure.

We used the mercury concentration in eggs commonly associated with impaired hatchability to estimate the corresponding mercury concentration that would occur in down feathers of a newly hatched chick. Egg mercury concentrations $>1.0 \mu \mathrm{g} / \mathrm{g}$ ww often cause impaired hatchability and embryonic mortality in birds (Scheuhammer and others, 2007). Using our equation (Ackerman and Eagles-Smith, 
2009a), a concentration of $1.0 \mu \mathrm{g} / \mathrm{g}$ ww in the whole fresh egg is equivalent to $13.3 \mu \mathrm{g} / \mathrm{g}$ fw (13.0-13.7 $\mu \mathrm{g} / \mathrm{g} \mathrm{fw})$ in down feathers of recently hatched chicks. There are limited data on chick toxicity to compare this value to, but Ackerman and others (2008d) found that mercury concentrations (geometric mean $\pm \mathrm{SE})$ in down feathers of dead stilt chicks at hatching $(16.43 \pm 2.19 \mu \mathrm{g} / \mathrm{g} \mathrm{fw})$ were higher than levels in randomly-sampled live chicks of similar age $(9.98 \pm 0.77 \mu \mathrm{g} / \mathrm{g}$ fw $)$. Down feather mercury concentrations in live stilt chicks correspond to a predicted fresh egg concentration of $0.74 \mu \mathrm{g} / \mathrm{g}$ fww, whereas down feathers from dead stilt chicks correspond to a predicted fresh egg concentration of 1.19 $\mu \mathrm{g} / \mathrm{g}$ fww. These data suggest that although eggs with mercury concentrations $>1.0 \mu \mathrm{g} / \mathrm{g}$ ww can still hatch, the residual effects of maternally derived mercury on early chick mortality may continue to impair overall reproduction. This is particularly important because it means that commonly used endpoints, such as egg hatchability, likely underestimate the risk of mercury contamination to avian reproduction. However, by using the equation we derived between mercury concentrations in down feathers and eggs, inclusion of early chick mortality into the egg exposure criterion allows us to integrate toxicity risk for two avian life-stages into a single tissue matrix.

\section{Effects of Mercury on Chick Survival (Hatch to Fledging)}

For shorebird chicks, we studied the effects of in ovo egg mercury concentrations on subsequent avocet and stilt chick survival from hatching to fledging. We captured and radio-marked 158 avocet and 79 stilt chicks at hatching and sampled their down feathers for mercury concentrations during 2005 and 2006 (Ackerman and others, 2008d). Of these, 140 avocets and 75 stilts had sufficient encounter histories (that is, $>1$ post-release detection) for inclusion in survival analyses. We also collected 16 avocet and 14 stilt chicks that were found dead soon after hatching during routine nest monitoring activities at the colony.

Despite observing a wide range of mercury concentrations in chick down feathers from 0.40 $\mu \mathrm{g} / \mathrm{g}$ fw to $44.31 \mu \mathrm{g} / \mathrm{g}$ fw, we did not find strong evidence for an influence of mercury on chick survival (Ackerman and others, 2008d). The best model explaining chick survival incorporated effects of capture site, species, hatching date, and the body mass condition index. Several other candidate models provided a reasonably good fit to the data, including a model that incorporated mercury concentration as an explanatory variable. Chick survival rates tended to decrease with increasing mercury concentrations at hatching, but this pattern was not statistically robust (fig. 100; Ackerman and others, 2008d). During the first week after hatching when survival was the lowest, we observed less than a 2 percent difference in modeled chick survival rates between the minimum and maximum observed mercury concentrations (fig. 100; Ackerman and others, 2008d). This difference diminished as chicks aged so that by the fourth week there was no difference in chick survival rates in the range of observed mercury concentrations. Furthermore, variable weights indicated that mercury concentration was by far the least important variable predicting chick survival rates. Instead, species, chick age, site, year, and chick body mass at radio-marking had much more important effects on avocet and stilt chick survival rates (Ackerman and others, 2014b).

In contrast to our survival data from telemetry, we found evidence that mercury concentrations in down feathers of dead stilt chicks were higher than those in live stilt chicks sampled at similar ages (that is, newly hatched [fig. 101]; Ackerman and others, 2008d). The addition of the fate variable (alive or dead) to the most parsimonious model explaining factors influencing mercury concentrations in chicks improved the model fit by more than 4 times (Ackerman and others, 2008d). Because chicks that we radio-marked had already survived for several hours ( $\leq 2$ days) before transmitter attachment, it is possible that methylmercury had an important effect on survival during the very short period immediately after hatching, and if so, we may have missed sampling this subset of the population using 
telemetry methods, but not by sampling dead chicks found at colony sites. Indeed, chicks may be most vulnerable to methylmercury shortly after hatching when their mercury concentrations are still relatively high due to high in ovo mercury exposure (Ackerman and others, 2011).

We focused our avocet and stilt study on newly-hatched chicks because the effects of mercury are most likely to be expressed during the 28-day flightless period from hatching to fledging when chicks must learn to forage independently and escape predation (Robinson and others, 1999; Ackerman and others, 2013a). However, the post-fledgling stage also could be a sensitive period for chick survival because mercury concentrations begin increasing as feather and mass growth slows at the time of fledging (Ackerman and others, 2011). We therefore addressed the influence of mercury on post fledging survival using tern chicks in the next section below.

\section{Effects of Mercury on Chick Survival (Post-fledging)}

To study postfledging tern survival, we radio-marked 30 tern chicks just before they fledged at $25 \pm 1.4$ (SD) days (range: $23-29$ days) at the Pond N7 tern colony in 2006. The cumulative survival during the 35-day postfledging period was $0.81 \pm 0.09$ (fig. 102; Ackerman and others, 2008b). We did not find support for an influence of mercury concentrations on postfledging survival, despite observing a 2.6- and 2.8-fold range in mercury concentrations observed in radio-marked tern blood and feathers, respectively (Ackerman and others, 2008b). It is possible that mercury does affect postfledging survival at higher concentrations than we observed in our sample of radio-marked terns. For example, 9 and 16 percent of all the fledglings we sampled had blood or breast feather mercury concentrations, respectively, that were higher than those of the most contaminated chick that we happened to radiomark during this study (Ackerman and others, 2008b). If mercury effects survival only at these highest concentrations, then a much larger sample of radio-marked terns would be necessary to detect such an effect, but we were limited to only 30 radio-marked birds in this study.

\{tc $\backslash 13$ "Statistical Analyses\} We also used mercury concentrations in breast feathers from salvaged chicks that were found dead on the colonies during routine monitoring activities, and compared them to breast feathers from apparently healthy, live fledglings. We included only fledglings that were between 21 and 29 days of age when they died. Mercury concentrations in breast feathers of terns found dead $(7.46 \pm 0.48 \mu \mathrm{g} / \mathrm{g}$ fw $)$ near the age of fledging were no different than levels in randomly-sampled live terns of similar age $(7.60 \pm 0.24 \mu \mathrm{g} / \mathrm{g} \mathrm{fw}$; Ackerman and others, 2008b). This lack of a result is likely because breast feathers (unlike down feathers) are very poor indices of mercury concentrations in the internal tissues of birds (Eagles-Smith and others, 2008b), especially chicks (Ackerman and others, 2011). Thus, this last result should not be interpreted that mercury does not have an effect on fledgling survival. 
Few studies have been able to detect an effect of mercury on juvenile bird survival in the wild, despite extensive demonstrations in the laboratory. For example, we did not find an effect of mercury on survival of radio-marked avocet and stilt chicks from hatching to fledging, although we did find that newly hatched chicks found dead near nesting sites had higher mercury concentrations than similar-aged live chicks sampled randomly (Ackerman and others, 2008d). Sepúlveda and others (1999) also used radio-telemetry and did not detect an effect of natural or manipulated levels of mercury on postfledging survival of great egrets in Southern Florida. Using mark-resight methodology for common loons breeding in Wisconsin, Meyer and others (1998) found that chick production was lower at lakes where chick blood mercury concentrations were higher, but Merrill and others (2005) did not find an effect of mercury exposure on chick survival. In contrast, laboratory studies have more consistently demonstrated that methylmercury exposure can reduce chick survival (Heinz and Hoffman, 1998; but see Kenow and others, 2003) as well as chick growth (Spalding and others, 2000a) and health (Spalding and others, 2000b; Kenow and others, 2007). These results demonstrate the complexity of understanding mercury exposure on chick health and survival, and suggests that much larger sample sizes are required when studying wild bird populations to account for other factors, such as predation, that influence survival in the natural environment.

\section{Objective 3: Examine the Differential Sensitivity of Bird Taxa to Mercury Exposure}

\section{Egg Injection Techniques in the Laboratory to Determine the Sensitivity of Bird Embryos to Methylmercury}

Among wildlife, birds seem to be particularly sensitive to methylmercury, and the embryonic stage seems to be the most sensitive stage in birds. Although field studies would seem to represent the ideal way to determine whether mercury is causing reproductive impairment in a given species of bird, such studies are costly, time consuming, and sometimes are complicated by the complex assemblage of environmental factors that accompany the mercury contamination. To supplement field studies, researchers sometimes turn to captive breeding studies. The obvious advantage of these controlled breeding studies is that all the potentially complicating environmental factors that can confound field studies are set equal in a controlled study. However, most controlled breeding studies with mercury have been done with readily available game farm species, particularly the mallard. One has to pose the question, how representative are the findings on embryo toxicity from game farm mallards to a wild bird such as the common loon? Some captive breeding studies have been carried out with wild birds, such as American black ducks (Anas rubripes), American white ibises (Eudocimus albus), and American kestrels (Falco sparverius), but it is generally difficult to bring wild birds into captivity and build up the number of breeding pairs to a point where a statistically valid study can be done. Additionally, when captive breeding studies have used wild birds, these studies have proven, like their field study counterparts, to be long term and expensive. 
Egg injections represent a third approach to determine the harmful effects of methylmercury on avian reproduction. The biggest advantages of the egg injection approach are that many wild bird species can be tested that might otherwise never be studied by either field studies or controlled feeding studies and the studies are relatively fast and inexpensive. We injected methylmercury dissolved in corn oil into eggs of 26 species of wild birds, then placed the eggs in a laboratory incubator and monitored their development (Heinz and others, 2009b). The most important finding was that there were large differences in the sensitivity of the embryos of these species to methylmercury (figs. 103 and 104; Heinz and others, 2009b). Some species, such as the American kestrel, osprey (Pandion haliaetus), white ibis, snowy egret (Egretta thula), and tri-colored heron (Egretta tricolor) were very sensitive to methylmercury exposure, whereas other species, such as the mallard, hooded merganser (Lophodytes cucullatus), lesser scaup, Canada goose (Branta canadensis), double-crested cormorant (Phalacrocorax auritus), and laughing gull (Larus atricilla), were comparatively insensitive to methylmercury exposure (Heinz and others, 2009b).

The concentration of mercury in avian eggs commonly accepted to represent a threshold at which embryo toxicity begins is approximately $0.5-1.0 \mu \mathrm{g} / \mathrm{g}$ mercury on a wet-weight basis. This threshold was derived from controlled breeding studies with mallards. An important conclusion we drew from our egg injection studies was that this threshold value may not provide complete protection for many species of wild birds (Heinz and others, 2009b). In particular, mallard eggs do not seem to be sensitive to methylmercury, and toxicity thresholds derived for mallards likely underestimates true toxicity risk for most waterbird species (Heinz and others, 2009b). Among the 25 other species tested, only double-crested cormorants, with an LC50 of 2.42 (lethal concentration where 50 percent of the eggs failed to hatch), were more tolerant to mercury exposure than were mallards (LC50 = 1.79; Heinz and others, 2009b).

Another conclusion was that methylmercury has widespread teratogenic potential across many species of birds (Heinz and others, 2011b). We examined all hatched chicks and dead embryos for external deformities. When data for control eggs were summed across all 26 species and across all types of deformities, only 24 individuals out of a total of 1,533 (a rate of 1.6 percent) exhibited one or more deformities (Heinz and others, 2011b). In contrast, when data for all 26 species were summed across all the various mercury treatments there were 188 deformed individuals out of a total of 2,292 (8.20 percent; Heinz and others, 2011b). Thus, 6.6 percent more mercury-treated eggs than control eggs contained embryos with deformities (Heinz and others, 2011b).

Like field studies and captive breeding studies, egg injection studies have their own shortcomings. One shortcoming was the observation that injected methylmercury was more toxic than maternally deposited methylmercury (Heinz and others, 2009b). Therefore, although the injection procedure seems to give a good picture of the relative rankings among wild bird embryos in their sensitivity to methylmercury exposure, it is not clear what absolute levels of mercury, if they were maternally deposited in wild bird eggs, would be a threshold for harm in each species.

Because some of the 26 species were relatively insensitive to injected methylmercury (Heinz and others, 2009b), we had to use a wide range of doses, some higher than might be ecologically relevant, to inject into eggs. Corn oil was better able to dissolve these high doses than was water (which might otherwise have been the ideal solvent; Heinz and others, 2011a). However, corn oil can have some toxicity in itself, so in a separate study, with lower doses of methylmercury, we compared the toxicity of injected methylmercury when the solvent was water compared with corn oil (Heinz and others, 2011a). The toxicity was essentially the same with both solvents, suggesting that our results were not compromised by the use of corn oil in the larger study with 26 species (fig. 105; Heinz and others, 2011a). 


\section{Egg Injection Techniques to Explore Toxic Interactions of Methylmercury and Selenium}

Mercury and selenium sometimes occur together in abiotic and biotic parts of ecosystems, and the co-occurrence of elevated concentrations of mercury and selenium has been reported in birds. Although the interactions between mercury and selenium are among the best known of all environmental contaminants, these interactions can be complex. Mercury and selenium interactions are normally antagonistic, but additivity and synergism also can occur. There have been few studies that have combined the two most toxic and environmentally realistic chemical forms of these elements, methylmercury and selenomethionine.

In our interaction egg injection studies, methylmercury chloride and seleno-L-methionine were injected in many combinations (Heinz and others, 2012a). The eggs were then artificially incubated and hatchlings and dead embryos were examined for deformities. For all three species, selenomethionine alone caused more deformities than did methylmercury alone (Heinz and others, 2012a). When mallard eggs were injected with the lowest dose of selenium alone $(0.1 \mu \mathrm{g} / \mathrm{g}), 28$ of 44 embryos and hatchlings were deformed, whereas when eggs were injected with the lowest dose of mercury alone $(0.2 \mu \mathrm{g} / \mathrm{g})$, only 1 of 56 embryos or hatchlings was deformed (Heinz and others, 2012a). Two types of deformities (spina bifida and craniorachischisis), where the spine is partially open, were observed only when mercury and selenium were injected in combination (Heinz and others, 2012a). One paradoxical finding was that some doses of methylmercury seemed to counteract the harmful effect selenomethionine had on hatching of eggs, while at the same time worsening the deformities caused by selenomethionine (Klimstra and others, 2012; Heinz and others, 2012a)

\section{Conduct a Controlled Feeding Study to Establish a Dose-Response Curve and No Observed Adverse Effects Level when Methylmercury is Maternally Deposited in the Egg}

Avian reproduction has been shown to be a sensitive indicator of mercury contamination. When elevated concentrations of mercury are found in the eggs of wild birds, these concentrations are compared to what are considered to be threshold concentrations of harm. These thresholds have been determined through controlled feeding studies, generally with game farm birds such as ring-necked pheasants (Phasianus colchicus), chickens, and mallards, but also with captive colonies of wild species such as black ducks and American kestrels. Despite the findings of these earlier controlled studies, there remains much uncertainty about the degree of reproductive harm caused by various concentrations of mercury in eggs. Our goal was to measure the effects of a wide range of dietary methylmercury concentrations on the reproductive success of breeding mallards and relate the concentrations of mercury in eggs to the degree of reproductive harm.

We fed one of five dietary concentrations of mercury to 100 breeding pairs of mallards in pens (Heinz and others, 2010d). We found that fertility and hatching success of eggs was not affected by any of the dietary concentrations of mercury (Heinz and others, 2010d). However, survival of ducklings and the number of ducklings produced per female were reduced by the 4 and $8 \mu \mathrm{g} \mathrm{Hg} / \mathrm{g}$ dietary mercury treatments; these diets resulted in $5.9 \mu \mathrm{g} \mathrm{Hg} / \mathrm{g}$ and $14 \mu \mathrm{g} \mathrm{Hg} / \mathrm{g}$ mercury in eggs, respectively (Heinz and others, 2010d). Ducklings from parents fed the various mercury diets were just as heavy as controls at the time of hatching, but by 6 days of age ducklings whose parents had been fed $4 \mu \mathrm{g} \mathrm{Hg} / \mathrm{g}$ or $8 \mu \mathrm{g} \mathrm{Hg} / \mathrm{g}$ weighed less than controls (Heinz and others, 2010d). We concluded that mallard reproduction does not appear to be particularly sensitive to methylmercury (Heinz and others, 2010d), as it might be for other species as indicated in our comparison of egg hatching success after mercury injections for 26 species of birds (Heinz and others, 2009b). 
In another part of this reproduction experiment, we examined a toxicological response called hormesis - a phenomenon in which a chemical causes beneficial effects at low doses, but harmful effects at higher doses. We had 30 pairs of breeding mallards fed a control diet and 20 pairs fed $0.5 \mu \mathrm{g}$ $\mathrm{Hg} / \mathrm{g}$ on a dry-weight basis (Heinz and others, 2010b). The mercury-containing diet had no effect on fertility of eggs, but hatching success of eggs was significantly higher for females fed $0.5 \mu \mathrm{g} \mathrm{Hg} / \mathrm{g}$ mercury (72 percent) than for controls (58 percent; Heinz and others, 2010b). The mean number of ducklings produced per female was significantly higher for the pairs fed $0.5 \mu \mathrm{g} \mathrm{Hg} / \mathrm{g}$ mercury (21.4) than for controls (16.8) (Heinz and others, 2010b). Survival of ducklings through 6 days of age was the same ( 98 percent) for controls and mallards fed $0.5 \mu \mathrm{g} / \mathrm{g}$ mercury (Heinz and others, 2010b). Although mercury in the parents' diet had no effect on mean duckling weights at hatching, ducklings from parents fed $0.5 \mu \mathrm{g} / \mathrm{g}$ mercury weighed significantly more (mean $=87.2 \mathrm{~g})$ at 6 days of age than did control ducklings $(81.0 \mathrm{~g})$ (Heinz and others, 2010b). The mean concentration of mercury in eggs laid by parents fed $0.5 \mu \mathrm{g} \mathrm{Hg} / \mathrm{g}$ mercury was $0.81 \mu \mathrm{g} \mathrm{Hg} / \mathrm{g}$ on a wet-weight basis (Heinz and others, 2010b).

The finding of hormesis in the above study was supported by the findings in an egg injection study where mallard eggs were artificially incubated in the laboratory (Heinz and others, 2012b). Eggs were randomized either to a control group receiving untreated corn oil or to groups dosed with $0.05,0.1$, $0.2,0.4,0.8,1.6,3.2$, or $6.4 \mu \mathrm{g} \mathrm{Hg} / \mathrm{g}$ on a wet-weight basis in the egg. The fate of the eggs was monitored and hatching success of eggs was calculated for each group. Hormesis seemed to occur because hatching success of eggs injected with $0.05 \mu \mathrm{g} \mathrm{Hg} / \mathrm{g}$ (the lowest dose) was significantly greater (93 percent) than that of controls (73 percent), whereas hatching success decreased at progressively higher doses of mercury (fig. 106; Heinz and others, 2012b). As with our other egg injection experiments, one has to keep in mind that injected mercury is more toxic (and apparently has a more powerful hormetic effect) than maternally deposited mercury. If methylmercury has a hormetic effect at low concentrations in avian eggs, these low concentrations may be important in a regulatory sense in that they may represent a No Observed Adverse Effect Level (NOAEL).

\section{Additional Findings from Laboratory Studies}

In the course of carrying out experiments to specifically address the laboratory objective, other data were collected that supplemented the findings from the main experiments.

\section{How to Best Incubate Wild Bird Eggs}

In spite of advancements in incubator technology, artificial incubation of wild bird eggs still remains a problematic venture. Factors such as humidity, temperature, and the way the eggs are turned are all important. Because the egg injection procedure holds promise for examining the toxicity of methylmercury to many wild birds that might not otherwise be studied, we thought it was important to study how incubation conditions can be controlled to enhance embryo survival (Klimstra and others, 2009). Based on published literature, we used a temperature of $99.5^{\circ} \mathrm{F}$ for all species except those in the order Galliformes, for which $99.7^{\circ} \mathrm{F}$ is recommended. Although we did not experiment with other temperature settings, these two settings seemed satisfactory. Ensuring that eggs achieve the appropriate weight loss is also critical to successful hatching. Again, the published literature suggested a weight loss of 15 or 16 percent as being optimal for most species. We weighed eggs twice a week and made adjustments to the relative humidity for each species, and were successful in steering the eggs of most species toward this recommended weight loss. We also found that rolling the eggs through 180 degrees helped embryo survival. However, even when we paid close attention to temperature, humidity, and egg rolling, artificial incubation still cannot duplicate the success of incubation by the parent. 
Using Mercury Levels in Blood and Down Feathers as a Substitute for Mercury in Eggs

In field studies, analyzing a sample egg from each nest is a customary step in determining whether egg residues of mercury are harming hatching, but it is not always possible to collect eggs for mercury analysis. Some species are rare and taking an egg is not feasible. Other species may only lay one or two eggs, and sacrificing one for mercury analysis may be impractical. When an egg has not been collected from a nest, one has to rely of other tissues to establish exposure to mercury. When we fed female mallards diets containing methylmercury chloride, the concentration of mercury in a sample of their blood was closely correlated with the concentration of mercury in the egg they laid the day they were bled (fig. 107; Heinz and others, 2010a). Additionally, when the concentrations of mercury in the down feathers of newly hatched ducklings were plotted against mercury in whole ducklings (which would equate closely to mercury in the egg from which that duckling hatched), the $R^{2}$ value was 0.99 (P $<0.0003$; Heinz and others, 2010a). Therefore, although measuring mercury in eggs may be the most direct way of predicting possible embryo toxicity, our findings demonstrate that measuring mercury in the blood of egg laying females or in down feathers of hatchlings can be used to estimate what concentration of mercury may have been in the egg.

Mercury Increases Rapidly in Eggs of Females Eating Foods Containing Methylmercury

Once females start feeding on mercury-contaminated foods, it is important to know how fast mercury can build up to harmful levels in their eggs. We fed female mallards a control diet or diets containing $0.5,1,2,4$, or $8 \mu \mathrm{g} \mathrm{Hg} / \mathrm{g}$ (on what was similar to a dry-weight basis) as methylmercury chloride for 23 days (Heinz and others, 2009a). After 18 days on their respective mercury diets the eggs of mallards fed $0.5,1,2,4$, or $8 \mu \mathrm{g} \mathrm{Hg} / \mathrm{g}$ contained 97.8 percent, 86 percent, 90 percent, 89 percent, and 86 percent, respectively, of the peak concentrations reached after 23 days (Heinz and others, 2009a). No more than about a week may be required for a female to begin to excrete what are considered to be harmful concentrations of mercury (approximately $1 \mu \mathrm{g} \mathrm{Hg} / \mathrm{g} \mathrm{ww}$ ) into her eggs (fig. 108; Heinz and others, 2009a).

Intraperitoneal Injections of Methylmercury: A Possible New Approach to Field Studies

The ideal study of the effects of methylmercury on the reproductive success of a species of bird would be one in which a researcher could go to the same field location (for example, a colony of birds on the same nesting island) and find eggs containing mercury concentrations ranging from controls to heavily contaminated, but this type of study cannot be accomplished at any site where the food supply is contaminated with methylmercury; all eggs will contain elevated levels of mercury to some degree. Using presently available methods, one has to try to compare the reproductive performance of birds at a mercury-contaminated site with the performance of the same species at what is called an uncontaminated reference site. However, many times the reference site is far removed from the contaminated site, and many environmental factors can be different. The ideal study, with uncontaminated and mercury-contaminated eggs at the exact same site could be achieved by introducing methylmercury into breeding females at a clean site (one with very low mercury contamination) and allowing them to deposit mercury in their eggs. There could be a number of ways to introduce various concentrations of methylmercury into breeding female birds, but we elected to experiment with intraperitoneal injections. We injected female mallards with solutions of methylmercury chloride dissolved in various solvents into the intraperitoneal (Heinz and others, 2010c). Mercury in their eggs ranged from a control level $(<0.1 \mu \mathrm{g} \mathrm{Hg} / \mathrm{g})$ to several $\mu \mathrm{g} \mathrm{Hg} / \mathrm{g}$ ww (fig. 109; Heinz and others, 2010c), which more than covers the range of concentrations that has been reported in wild bird eggs. 
Intraperitoneal injections hold promise in field studies where reproductive effects are studied in a wide range of methylmercury levels in the eggs of a wild bird and under the natural conditions in the field.

A Simple Method for Correcting Mercury Concentrations in Eggs for Moisture Loss

When eggs are collected from the field for mercury or other contaminant analysis, the mercury concentrations must be corrected for any drying out of the eggs that has taken place during incubation or for evaporation of water from unhatched eggs left to sit in the nest. Otherwise, the mercury concentrations will be biased high. Traditionally, this correction involved taking measurements that could be related to egg volume and generating a correction factor. We developed a new method that is much faster (Heinz and Stebbins, 2009). A syringe is filled with deionized water, and, using the needle on the syringe, a small hole is poked through the cap (blunt) end of the eggshell, which is where the air cell rests. With the needle of the syringe in the air cell, water is injected until excess water is forced out the hole. Any overflowing water is wiped off the shell, and a small piece of tape is placed over the hole to prevent the escape of water. Then proceed, as is always done, to cut open the egg and deposit the contents into a chemically clean jar. The only additional step is to use a clean instrument to tear the underside of the inner shell membrane, releasing the injected water from the air cell into the sample jar. The entire injection procedure takes less than 1 minute per egg, and the egg contents have been restored to their original moisture content.

\section{Micro-sampling Eggs for Mercury}

The most commonly used field method for assessing the effects of mercury on the reproductive success of birds is the "sample egg" technique in which a viable egg is taken from a nest, analyzed for mercury, and then the fate of the remaining eggs in the nest are monitored and related to the mercury concentration in the sampled egg. However, implicit in this method is the assumption that mercury concentrations in the sampled eggs are appropriate proxies for those in the sibling eggs. Unfortunately this is not always the case, as mercury concentrations can vary substantially within a clutch. Ideally, mercury concentration should be measured in an egg and then be able to report the fate of that same egg, but this is impossible if whole egg is used for mercury analysis. To circumvent the problem of taking the whole egg, we developed a new technique that involves extracting a small sample of albumen from a live egg, sealing the egg, returning the egg to its nest to be naturally incubated by the parents, and then relating the hatching success of this micro-sampled egg to its mercury concentration (Stebbins and others, 2009). We found that the concentration of mercury in the micro-sample accurately predicts the concentration of mercury in the whole egg (fig. 110; Stebbins and others, 2009). Micro-sampled blacknecked stilt eggs exhibited 100 percent hatching success compared to 93 percent for the paired control eggs, demonstrating that micro-sampling is an effective tool for non-lethally sampling mercury concentrations in eggs (Stebbins and others, 2009). The micro-sampling approach can be used for monitoring rare species, where sacrificing an egg is not advisable. Additionally, micro-sampling represents an advancement in the experimental design of any field study, because the mercury level in an egg can be related to the effects of methylmercury on that same egg. 


\title{
Conclusions and Management Implications
}

\author{
Waterbird Foraging Habitat Strongly Influences Mercury Bioaccumulation
}

Among the most important findings from this study is the recognition that relatively fine scale foraging habitat is a critical driver of mercury exposure and risk in estuarine waterbird communities. Trophic position is commonly credited with being the primary causal mechanism behind mercury risk in avian communities because of the propensity for methylmercury to biomagnify with each successive step in a food chain. However, mercury methylation is largely dependent on biogeochemical processes that can vary widely among habitats, even those within close proximity to one another. The work presented here illustrates a clear linkage between habitat use and mercury bioaccumulation, even in birds that co-occur in the same locations. Additionally, we showed that waterbirds in the San Francisco Bay Estuary preferentially select some habitats in greater proportion than those habitats' relative abundance in the environment - and those habitats tended to have some of the highest mercury concentrations in prey items. This is an important observation because it highlights the need to quantitatively understand avian space use in heterogeneous environments to adequately characterize risk. Simply sampling habitats in proportion to their availability, randomly sampling from dominant habitats, or making broad assumptions about avian habitat use without quantitative support can be misleading and result in inadequately characterized mercury exposure profiles. In this study, we determined that the differences in mercury exposure profiles within bird guilds was largely a function of small-scale habitat use. Specifically, in the shorebird guild, stilts and avocets showed similar space use for most habitat types, but stilts were more commonly associated with managed seasonal marshes and avocets were more commonly associated with tidal flats and salt ponds. Similarly, Forster's terns actively selected salt ponds over the open bay, whereas Caspian terns were rarely documented foraging in salt ponds. Prey concentrations in the habitats that stilts and Forster's terns used most were generally higher than prey concentrations in the habitats that were more commonly associated with avocets and Caspian terns. These results were corroborated using multiple tools, including telemetry, stable isotope ratios, and diet sampling. This comprehensive integration of ecological vectors for mercury exposure in waterbirds in San Francisco Bay Estuary serves as a strong foundation for developing robust and informative monitoring strategies.

\section{Developing a Mercury Biomonitoring Program that Appropriately Incorporates Toxicological Risk to Wildlife}

The results of this study illustrate that there is substantial risk of mercury exposure to waterbirds in the San Francisco Bay Estuary, and this risk varies spatially and temporally. Additionally, our results indicate that current established mercury monitoring programs in the region are not yet adequate to appropriately characterize changes in mercury risk to wildlife, especially in light of ongoing restoration actions throughout the region. A robust mercury monitoring program that is designed to detect changes in mercury availability in the environment and determine risk to wildlife should include multiple biotic matrices across different habitat types. 
Small fish often are used in mercury monitoring programs because they offer greater temporal resolution than large prey fish, integrating mercury over shorter periods of time. They also serve as a prey base for many bird species, as well as sport fish, so there is a nexus to both human and wildlife health. However, several important caveats in the utility of small fish must be understood in order to minimize the potential for spurious results. Sampling designs should conform to a narrow time window (a few weeks), and should be repeated during the same time window each year due to rapid changes in fish mercury concentrations with date. Additionally, if assessing wildlife risk is a goal of monitoring programs, then fish sampling should occur during or just before critical life stages for wildlife, such as egg-laying and chick rearing in waterbirds (preferably during April-July). Finally, monitoring programs should conduct high-resolution time series studies initially to understand how mercury varies seasonally and then incorporate additional time-series studies at regular intervals in subsequent years to calibrate comparisons among years.

Importantly, the interpretation of environmental mercury risk is strongly influenced by the fish species used in monitoring programs. We found substantial differences in mercury concentrations among low trophic-level fish species. For example, mercury concentrations in the two species with the highest mercury concentrations (Mississippi silversides and northern anchovy) were 1.6 and 1.5 times higher, respectively, than those with the next highest concentrations (topsmelt), and 2.4 and 2.2 times higher, than in the species with lowest mercury concentrations (longjaw mudsucker). This has important implications for evaluating ecological risk of mercury bioaccumulation. It suggests that single-species monitoring could misinform mercury exposure risk unless the same fish species is sampled at all sites and time periods. Thus, our findings underscore the importance of using the same fish species at all sites and time periods for studies evaluating spatial and temporal comparisons of mercury exposure. Alternatively, a multi-species design using model-estimated fish mercury concentrations, as we have done for this study, is a robust approach. However, a successful multi-species design requires substantially greater funding resources to achieve spatial overlap among species across numerous sites to reach the added sample size requirements needed across species to adequately generate model estimated (for example, least-squared mean) fish mercury concentrations. This multi-species design is a powerful approach that statistically accounts for the variance associated with different fish species and provides a more integrated assessment of overall exposure through the entire fish community and risk to wildlife.

\section{Fish Mercury Concentrations Were Poor Predictors of Bird Mercury Concentrations and Risk to Birds}

Even a multi-species, temporally integrated prey fish monitoring program has limitations in terms of accurately predicting avian risk to mercury exposure. In general, we found that fish mercury concentrations were poorly correlated with bird blood or egg mercury concentrations among wetlands. This likely is the result of bird behavior and physiology, including foraging locations and diet preferences. For example, tern diets differed substantially among nesting colonies, suggesting that no single fish species adequately characterizes mercury exposure in terns across colonies in the San Francisco Bay Estuary. Therefore, bird egg monitoring is a valuable component to any mercury monitoring program because not only can it provide an index of mercury exposure at specific locations, but mercury concentrations in bird eggs can be used to directly estimate risk of mercury contamination to reductions in bird health and reproduction. 


\section{Effects of Mercury on Birds and Integrating Toxicological Risk Across Bird Life Stages}

One of the most difficult issues in ecotoxicology is to develop impairment thresholds for use by managers to regulate contaminant levels in the environment. Most impairment thresholds have been developed in the laboratory in unnatural settings, often for only a single reproductive endpoint (such as egg hatching success), and on different species. Our study made significant progress in threshold development by refining levels of mercury concentrations that are thought to influence bird reproduction. Generic egg mercury concentrations of $0.5 \mu \mathrm{g} / \mathrm{g}$ fww to $1.0 \mu \mathrm{g} / \mathrm{g}$ fww have been the most commonly used toxicity thresholds (review by Scheuhammer and others, 2007). In San Francisco Bay, we found that 79 percent of Forster's tern eggs, 31 percent of stilt eggs, 13 percent of Caspian tern eggs, and 3 percent of avocet eggs exceeded mercury concentrations of $1.0 \mu \mathrm{g} / \mathrm{g}$ fww. However, toxicity thresholds should be taxa-specific when possible because we found that species sensitivity to mercury can differ (Heinz and others, 2009b).

For birds that breed in San Francisco Bay Estuary, we found several lines of evidence indicating that mercury contamination might be impairing bird health and reproduction. First, we found that mercury concentrations in Forster's tern eggs were 28 percent higher in failed-to-hatch eggs (mean: 1.84 $\mu \mathrm{g} / \mathrm{g}$ fww) than in randomly sampled eggs from successful nests (mean: $1.44 \mu \mathrm{g} / \mathrm{g}$ fww), indicating that mercury might be impairing egg hatchability. Second, the probability of an embryo being malpositioned within Forster's tern eggs increased with mercury concentrations in the egg, such that embryos had an 8 percent probability of being malpositioned at $1.36 \mu \mathrm{g} / \mathrm{g}$ fww (Herring, 2010). Third, although we did not conduct egg injection studies directly on Forster's terns, we found that the LC50s were $0.87 \mu \mathrm{g} / \mathrm{g} \mathrm{ww}$ and $0.40 \mu \mathrm{g} / \mathrm{g}$ ww for related common terns and royal terns, respectively (Heinz and others, 2009b). Fourth, mercury concentrations in down feathers of dead stilt chicks at hatching (mean: $16.43 \mu \mathrm{g} / \mathrm{g} \mathrm{fw}$ ) were higher than levels in randomly-sampled live chicks of similar age (mean: $9.98 \mu \mathrm{g} / \mathrm{g}$ fw; Ackerman and others, 2008d). Fifth, we found that all avocets, stilts, Forster's terns, and Caspian terns demethylate methylmercury in their livers once mercury concentrations pass a threshold of $8.51 \mu \mathrm{g} / \mathrm{g} \mathrm{dw}$, which indicates that bird health could be impaired at high mercury levels (Eagles-Smith and others, 2009b). Elsewhere, we also showed that body condition was negatively correlated with mercury concentrations in endangered California clapper rails in San Francisco Bay (Rallus longirostris obsoletus; Ackerman and others, 2012).

One of the strongest aspects of our study was that we developed equations to integrate toxicity risk for all three avian life-stages into a single tissue matrix. These equations were developed with the goal of being able to convert all the observed effects in adults, eggs, and chicks into a single tissue matrix - eggs. By condensing effects into equivalent concentrations in bird eggs, regulatory targets and risk thresholds can take into account multiple reproductive endpoints, using the most cost effective sampling and monitoring protocol. To illustrate the utility of these tissue conversion equations, the liver demethylation threshold of $8.51 \mu \mathrm{g} / \mathrm{g} \mathrm{dw}$ converts into an egg mercury concentration of $0.65 \mu \mathrm{g} / \mathrm{g}$ fww. Similarly, the mercury concentration of $16.43 \mu \mathrm{g} / \mathrm{g}$ fw in down feathers of dead stilt chicks at hatching corresponds to an egg concentration of $1.19 \mu \mathrm{g} / \mathrm{g}$ fww. These equations will continue to be useful for future studies as efforts to document the effects of mercury on various avian life-stages are conducted. 


\section{Bird Eggs are Ideal Biomonitoring Tools for Mercury Monitoring Programs}

Bird eggs are an ideal sampling tissue for mercury monitoring programs for several reasons. First, mercury concentrations in eggs can be directly related to the potential for reproductive impairment, and can be indirectly related to the risk for health effects to other bird life stages using the equations we developed for this study. Second, eggs represent mercury concentrations in adult birds near the time of breeding, which is the critical time period for population growth. Third, as we demonstrated here, many birds show high site fidelity and have small home ranges during egg production and incubation. Thus, mercury concentrations in eggs represent local exposure to environmental mercury levels. Fourth, other bioindicators that often are sampled to represent mercury exposure to birds often do not correlate well and have their own inherent sampling problems. For example, we found very poor relationships between mercury concentrations in individual fish species and Forster's tern blood or eggs sampled at the same sites (fig. 69), indicating that monitoring individual fish species is not sufficient to determine risk to fish-eating birds. Additionally, mercury concentrations in prey fish changed dramatically over short periods of time in San Francisco Bay (Eagles-Smith and Ackerman, 2009), thus highlighting the importance of controlling for additional sampling biases when fish are used as indicators of mercury exposure to piscivorous birds. However, these deficiencies in prey fish sampling can be simply avoided by sampling bird eggs directly, as they often are readily available and easy to sample. Lastly, individual eggs, rather than composite egg samples, should be used in mercury monitoring programs because there are significant biases imposed by compositing eggs when estimating an egg's fresh wet weight mercury concentration, which is a critical step in calculating mercury concentrations in eggs. Therefore, bird eggs are an important and useful tool for mercury monitoring programs.

\section{Unpublished Data Referenced}

Ackerman, J.T., Marvin-DiPasquale, M., Slotton, D., Eagles-Smith, C.A., Herzog, M.P., Hartman, C.A., Agee, J.L., and Ayers, S., 2013c, The South Bay Mercury Project: using biosentinels to monitor effects of wetland restoration for the South Bay Salt Pond Restoration Project: U.S. Geological Survey, Western Ecological Research Center, Davis, CA, p. 227.

Bluso-Demers, J.D., Ackerman, J.T., and Takekawa, J.Y., unpublished data manuscript, Habitat selection by Forster's terns at multiple spatial scales in San Francisco Bay: the importance of salt ponds.

\section{References Cited}

Accurso, L.M., 1992, Distribution and abundance of wintering waterfowl in San Francisco Bay, 19881990: Arcata, Calif., Humboldt State University, Master's Thesis, p. 268.

Ackerman, J.T., Bluso-Demers, J.D., and Takekawa, J.Y., 2009, Postfledging Forster's tern movements, habitat selection, and colony attendance in San Francisco Bay: Condor, v. 111, no. 1, p. 100-110.

Ackerman, J.T., and Eagles-Smith, C.A., 2009a, Integrating toxicity risk in bird eggs and chicksUsing chick down feathers to estimate mercury concentrations in eggs: Environmental Science and Technology, v. 43, no. 6, p. 2,166-2,172.

Ackerman, J.T., and Eagles-Smith, C.A., 2009b, Selenium bioaccumulation and body condition in shorebirds and terns breeding in San Francisco Bay, California, USA: Environmental Toxicology and Chemistry, v. 28, no. 10, p. 2,134-2,141. 
Ackerman, J.T., and Eagles-Smith, C.A., 2010a, Agricultural wetlands as potential hotspots for mercury bioaccumulation-Experimental evidence using caged fish: Environmental Science and Technology, v. 44, no. 4, p. 1,451-1,457.

Ackerman, J.T., and Eagles-Smith, C.A., 2010b, Accuracy of egg flotation throughout incubation to determine embryo age and incubation day in waterbird nests: Condor, v. 112, no. 3, p. 438-446.

Ackerman, J.T., Eagles-Smith, C.A., and Herzog, M.P., 2011, Bird mercury concentrations change rapidly as chicks age-Toxicological risk is highest at hatching and fledging: Environmental Science and Technology, v. 45 , no. 12 , p. 5,418-5,425.

Ackerman, J.T., Eagles-Smith, C.A., Takekawa, J.Y., Bluso, J.D., and Adelsbach, T.L., 2008a, Mercury concentrations in blood and feathers of prebreeding Forster's terns in relation to space use of San Francisco Bay, California, USA, habitats: Environmental Toxicology and Chemistry, no. 4, p. 897908.

Ackerman, J.T., Eagles-Smith, C.A., Takekawa, J.Y., Demers, S.A., Adelsbach, T.L., Bluso, J.D., Miles, A.K., Warnock, N., Suchanek, T.H., and Schwarzbach, S.E., 2007, Mercury concentrations and space use of pre-breeding American avocets and black-necked stilts in San Francisco Bay: Science of the Total Environment, v. 384, no. 1-3, p. 452-466.

Ackerman, J.T., Eagles-Smith, C.A., Takekawa, J.Y., and Iverson, S.A., 2008b, Survival of postfledging Forster's terns in relation to mercury exposure in San Francisco Bay: Ecotoxicology, v. 17, no. 8, p. 789-801.

Ackerman, J.T., Hartman, C.A., Herzog, M.P., Takekawa, J.Y., Robinson, J.A., Oring, L.W., Skorupa, J.P., and Boettcher, R., 2013a, American avocet (Recurvirostra americana), in Poole, A., ed., The Birds of North America Online: Ithaca, New York, Cornell Lab of Ornithology.

Ackerman, J.T., and Herzog, M.P., 2012, Waterbird nest monitoring program in San Francisco Bay (2005-2010): U.S. Geological Survey Open-File Report 2012-1145, p. 16.

Ackerman, J.T., Herzog, M.P., Hartman, C.A., and Herring, G., 2014a, Forster's tern chick survival in response to a managed relocation of predatory California gulls: Journal of Wildlife Management, $\mathrm{v}$. 78 , no. 5, p. 818-829.

Ackerman, J.T., Herzog, M.P., Hartman, C.A., and Takekawa, J.Y., 2014b, Comparative reproductive biology of sympatric species-Nest and chick survival of American avocets and black-necked stilts: Journal of Avian Biology, v. 45, p. 609-623.

Ackerman, J.T., Herzog, M.P., and Schwarzbach, S.E., 2013b, Methylmercury is the predominant form of mercury in bird eggs-A synthesis: Environmental Science and Technology, v. 47, p. 2,052-2,060.

Ackerman, J.T., Overton, C.T., Casazza, M.L., Takekawa, J.Y., Eagles-Smith, C.A., Keister, R.A., and Herzog, M.P., 2012, Does mercury contamination reduce body condition of endangered California clapper rails?: Environmental Pollution, v. 162, p. 439-448.

Ackerman, J.T., Takekawa, J.Y., Bluso, J.D., Yee, J.L., and Eagles-Smith, C.A., 2008c, Gender identification of Caspian terns using external morphology and discriminant function analysis: Wilson Journal of Ornithology, v. 120, no. 2, p. 378-383.

Ackerman, J.T., Takekawa, J.Y., Eagles-Smith, C.A., and Iverson, S.A., 2008d, Mercury contamination and effects on survival of American avocet and black-necked stilt chicks in San Francisco Bay:

Ecotoxicology, v. 17, no. 2, p. 103-116.

Albers, P.H., Koterba, M.T., Rossmann, R., Link, W.A., French, J.B., Bennett, R.S., and Bauer, W.C., 2007, Effects of methylmercury on reproduction in American kestrels: Environmental Toxicology and Chemistry, v. 26, no. 9, p. 1,856-1,866.

Astheimer, L.B., 1986, Egg Formation in Cassins Auklet: Auk, v. 103, no. 4, p. 682-693. 
Badzinski, S.S., Flint, P.L., Gorman, K.B., and Petrie, S.A., 2009, Relationships between hepatic trace element concentrations, reproductive status, and body condition of female greater scaup:

Environmental Pollution, v. 157, no. 6, p. 1,886-1,893.

Bartling, R., 2008, Pacific Herring, in Status of the Fishery Report: California Department of Fish and Game, Marine Region, chap. 11.

Bearhop, S., Ruxton, G.D., and Furness, R.W., 2000, Dynamics of mercury in blood and feathers of greet skuas: Environmental Toxicology and Chemistry, v. 19, no. 6, p. 1,638-1,643.

Becker, P.H., Henning, D., and Furness, R.W., 1994, Differences in mercury contamination and elimination during feather development in gull and tern broods: Archives of Environmental Contamination and Toxicology, v. 27, no. 2, p. 162-7.

Beckvar, N., Dillon, T.M., and Read, L.B., 2005, Approaches for linking whole-body fish tissue residues of mercury or DDT to biological effects thresholds: Environmental Toxicology and Chemistry, v. 24, no. 8, p. 2,094-2,105.

Benoit, J.M., Gilmour, C.C., Heyes, A., Mason, R.P., and Miller, C.L., 2003, Geochemical and biological controls over methylmercury production and degradation in aquatic ecosystems, in Cai. Y., and Braids O.C., eds., Biogeochemistry of environmentally important trace elements: American Chemical Society Symposium Series 835, p. 262-297.

Berry, M.J., and Ralston, N.V.C., 2008, Mercury toxicity and the mitigating role of selenium: EcoHealth, v. 5, no. 4, p. 456-459.

Beyer, W.N., and Fries, G.F., 2003, Toxicological significance of soil ingestion by wild and domestic animals, in Hoffman, D.J., Rattner, B.A., Allen Burton, J.G., and Cairns, J. John, eds., Handbook of ecotoxicology (2d ed.): Boca Raton, Fla., Lewis Publishers, p. 151-166.

Bluso, J.D., Ackerman, J.T., Takekawa, J.Y., and Yee, J.L., 2006, Sexing Forster's terns using morphometric measurements: Waterbirds, v. 29, no. 4, p. 512-517.

Bluso-Demers, J.D., Colwell, M.A., Takekawa, J.Y., Ackerman, J.T., and Demers, S.A., 2008, Space use by Forster's terns breeding in South San Francisco Bay: Waterbirds, v. 31, no. 3, p. 357-364.

Borga, K., Campbell, L., Gabrielsen, G.W., Norstrom, R.J., Muir, D.C.G., and Fisk, A.T., 2006, Regional and species specific bioaccumulation of major and trace elements in Arctic seabirds: Environmental Toxicology and Chemistry, v. 25, no. 11, p. 2,927-2,936.

Bouton, S.N., Frederick, P.C., Spalding, M.G., and McGill, H., 1999, Effects of chronic, low concentrations of dietary methylmercury on the behavior of juvenile great egrets: Environmental Toxicology and Chemistry, v. 18, no. 9, p. 1,934-1,939.

Brady, C.M., 2009, Effects of dietary selenium on the health and survival of wintering Lesser Scaup: London, Ontario, Canada, University of Western Ontario, London, Master's Thesis, p. 65.

Braune, B., and Gaskin, D., 1987, Mercury levels in Bonaparte's gulls (Larus philadelphia) during autumn molt in the Quoddy region, New Brunswick, Canada: Archives of Environmental Contamination and Toxicology, v. 549, p. 539-549.

Braune, B.M., 1987, Comparison of total mercury levels in relation to diet and molt for 9 species of marine birds: Archives of Environmental Contamination and Toxicology, v. 16, no. 2, p. 217-224.

Brown, S.C., Bizzarro, J.J., Cailliet, G.M., and Ebert, D.A., 2012, Breaking with tradition-Redefining measures for diet description with a case study of the Aleutian skate Bathyraja aleutica (Gilbert 1896): Environmental Biology of Fishes, v. 95, no. 1, p. 3-20.

Burger, J., 1995, Heavy metal and selenium levels in feathers of herring gulls (Larus argentatus) Differences due to year, gender, and age at Captree, Long Island: Environmental Monitoring and Assessment, v. 38, p. 37-50. 
Burger, J., and Gochfeld, M., 1992, Heavy metal and selenium concentrations in black skimmers (Rynchops niger) — Gender differences: Archives of Environmental Contamination and Toxicology, v. 434, p. 431-434.

Burgess, N.M., Evers, D.C., and Kaplan, J.D., 2005, Mercury and other contaminants in common loons breeding in Atlantic Canada: Ecotoxicology, v. 14, no. 1-2, p. 241-52.

Burgess, N.M., and Meyer, M.W., 2008, Methylmercury exposure associated with reduced productivity in common loons: Ecotoxicology, v. 17, no. 2, p. 83-91.

Burke, M.D., and Mayer, R.T., 1983, Differential effects of phenobarbitone and 3- methylcholanthrene induction on the hepatic microsomal metabolism and cytochrome P-450-binding of phenoxazone and a homologous series of its n-alkyl ethers (alkoxyresorufins): Chemico-Biological Interactions, v. 45, p. 243-258.

Butala, S.J.M., Scanlan, L.P., and Chaudhuri, S.N., 2006, A detailed study of thermal decomposition, amalgamation/atomic absorption spectrophotometry methodology for the quantitative analysis of mercury in fish and hair: Journal of Food Protection, v. 69, p. 2,720-2,728.

Canario, J., Caetano, M., Vale, C., and Cesario, R., 2007, Evidence for elevated production of methylmercury in salt marshes: Environmental Science \& Technology, v. 41, no. 21, p. 7,376-7,382.

Canfield, D., 2001, Biogeochemistry of sulfur isotopes, in Valley, J.W., Cole, D.R., eds., Stable isotope geochemistry: Reviews in Mineralogy and Geochemistry.

Carvalho, M.C., Nazari, E.M., Farina, M., and Muller, Y.M.R., 2008, Behavioral, morphological, and biochemical changes after in ovo exposure to methylmercury in chicks: Toxicological Sciences, $\mathrm{v}$. 106, no. 1, p. 180-5.

Chapin, III, F.S., Robards, M.D., Huntington, H.P., Johnstone, J.F., Trainor, S.F., Kofinas, G.P., Ruess, R.W., Fresco, N., Natcher, D.C., and Naylor, R.L., 2006, Directional changes in ecological communities and social-ecological systems-A framework for prediction based on Alaskan examples: The American Naturalist, v. 168, p. S36-S49.

Chen, C.Y., Dionne, M., Mayes, B.M., Ward, D.M., Sturup, S., and Jackson, B.P., 2009, Mercury bioavailability and bioaccumulation in estuarine food webs in the Gulf of Maine: Environmental Science \& Technology, v. 43, no. 6, p. 1,804-1,810.

Condon, A., and Cristol, D., 2009, Feather growth influences blood mercury level of young songbirds: Environmental Toxicology and Chemistry, v. 28, no. 2, p. 395-401.

Custer, T.W., and Heinz, G.H., 1980, Reproductive success and nest attentiveness of mallard ducks fed Aroclor 1254: Environmental Pollution, v. 21, p. 313-318.

Custer, T.W., Hines, R.K., Melancon, M.J., Hoffman, D.J., Wickliffe, J.K., Bickham, J.W., Martin, J.W., and Henshel, D.S., 1997, Contaminant concentrations and biomarker response in great blue heron eggs from 10 colonies on the upper Mississippi River, USA: Environmental Toxicology and Chemistry, v. 16, no. 2, p. 260-271.

Cuthbert, F.J., and Wires, L.R., 1999, Caspian Tern (Hydroprogne caspia), in Poole, A., ed., The Birds of North America Online: Ithaca, New York, Cornell Lab of Ornithology.

De La Cruz, S.E.W., 2010, Habitat, diet, and contaminant relationships of surf scoters wintering in San Francisco Bay-Implications for conservation in urban estuaries: University of California, Davis, Ph.D. Dissertation, 215 p.

De La Cruz, S.E.W., Eadie, J.M., Miles, A.K., Yee, J., Spragens, K.A., Palm, E.C., and Takekawa, J.Y., 2014, Resource selection and space use by sea ducks during the non-breeding season-Implications for habitat conservation planning in urbanized estuaries: Biological Conservation, v. 169, p. 68-78.

De La Cruz, S.E.W., Miles, A.K., Eadie, J.M., and Takekawa, J.Y., in press, Effects of a bivalve invasion on diet and nutrient reserves of wintering sea ducks: Oecologia. 
De La Cruz, S.E.W., Takekawa, J.Y., Wilson, M.T., Nysewander, D.R., Evenson, J.R., Esler, D., Boyd, W.S., and Ward, D.H., 2009, Spring migration routes and chronology of surf scoters (Melanitta perspicillata) —A synthesis of Pacific coast studies: Canadian Journal of Zoology, v. 87, no. 11, p. 1,069-1,086.

Demers, S.A., Colwell, M.A., Takekawa, J.Y., and Ackerman, J.T., 2008, Breeding stage influences space use of female American Avocets in San Francisco Bay, California: Waterbirds, v. 31, no. 3, p. 365-371.

DeVink, J.-M., Clark, R.G., Slattery, S.M., and Wayland, M., 2008a, Is selenium affecting body condition and reproduction in boreal breeding scaup, scoters, and ring-necked ducks?: Environmental Pollution, v. 152, no. 1, p. 116-22.

DeVink, J.-M., Clark, R.G., Slattery, S.M., and Trauger, D.L., 2008b, Are late-spring boreal lesser scaup (Aythya Affinis) in poor body condition?: Auk, v. 125, no. 2, p. 291-298.

DiGiulio, R.T., and Scanlon, P.F., 1985, Effects of cadmium ingestion and food restriction on energy metabolism and tissue metal concentrations in mallard ducks (Anas platyrhynchos): Environmental Research, v. 37, no. 2, p. 433-44.

Donaldson, G., and Braune, B., 1999, Sex-related levels of selenium, heavy metals, and organochlorine compounds in American white pelicans (Pelecanus erythrorhyncos): Archives of Environmental Contamination and Toxicology, v. 114, p. 110-114.

Dufour, K.W., Ankney, C.D., Weatherhead, P.J., and Press, A., 1993, Condition and vulnerability to hunting among mallards staging at Lake St. Clair, Ontario: Journal of Wildlife Management, v. 57, no. 2, p. 209-215.

Eagles-Smith, C.A, Ackerman, J.T., Adelsbach, T.L., Takekawa, J.Y., Miles, a K., and Keister, R.A., 2008a, Mercury correlations among six tissues for four waterbird species breeding in San Francisco Bay, California, USA: Environmental Toxicology and Chemistry, v. 27, no. 10, p. 2,136-2,153.

Eagles-Smith, C.A., and Ackerman, J.T., 2009, Rapid changes in small fish mercury concentrations in estuarine wetlands-Implications for wildlife risk and monitoring programs: Environmental Science and Technology, v. 43, no. 22, p. 8,658-8,664.

Eagles-Smith, C.A., and Ackerman, J.T., 2014, Mercury bioaccumulation in estuarine wetland fishesEvaluating habitats and risk to coastal wildlife: Environmental Pollution, v. 193, p. 147-155.

Eagles-Smith, C.A., Ackerman, J.T., Adelsbach, T.L., Takekawa, J.Y., Miles, A.K., and Keister, R., 2008b, Mercury correlations among six tissues for four waterbird species breeding in San Francisco Bay, California, USA: Environmental Toxicology and Chemistry, v. 27, no. 10, p. 2,136-2,153.

Eagles-Smith, C.A., Ackerman, J.T., Cruz, S.E.W.D. La, De La Cruz, S.E.W., and Takekawa, J.Y., 2009a, Mercury bioaccumulation and risk to three waterbird foraging guilds is influenced by foraging ecology and breeding stage: Environmental Pollution, v. 157, no. 7, p. 1,993-2,002.

Eagles-Smith, C.A., Ackerman, J.T., Yee, J., and Adelsbach, T.L., 2009b, Mercury demethylation in waterbird livers-Dose-response thresholds and differences among species: Environmental Toxicology and Chemistry, v. 28, no. 3, p. 568-577.

Elibol, O., and Brake, J., 2004, Identification of critical periods for turning broiler hatching eggs during incubation: British Poultry Science, v. 45, no. 5, p. 631-637.

Evers, D., Kaplan, J., Meyer, M., Reaman, P., Braselton, W., Major, A., Burgess, N., and Scheuhammer, A.M., 1998, Geographic trend in mercury measured in common loon feathers and blood: Environmental Toxicology and Chemistry, v. 17, no. 2, p. 173-183.

Evers, D.C., Burgess, N.M., Champoux, L., Hoskins, B., Major, A., Goodale, W.M., Taylor, R.J., Poppenga, R., and Daigle, T., 2005, Patterns and interpretation of mercury exposure in freshwater avian communities in northeastern North America: Ecotoxicology, v. 14, no. 1-2, p. 193-221. 
Evers, D.C., Savoy, L.J., DeSorbo, C.R., Yates, D.E., Hanson, W., Taylor, K.M., Siegel, L.S., Cooley, J.H., Bank, M.S., Major, A., and others, 2008, Adverse effects from environmental mercury loads on breeding common loons: Ecotoxicology, v. 17, no. 2, p. 69-81.

Fernie, K.J., Shutt, J.L., Mayne, G., Hoffman, D., Letcher, R.J., Drouillard, K.G., and Ritchie, I.J., 2005, Exposure to polybrominated diphenyl ethers (PBDEs) - Changes in thyroid, vitamin A, glutathione homeostasis, and oxidative stress in American kestrels (Falco sparverius): Toxicological Sciences, v. 88, no. 2, p. 375-383.

Fournier, F., Karasov, W.H., Kenow, K.P., Meyer, M.W., and Hines, R.K., 2002, The oral bioavailability and toxicokinetics of methylmercury in common loon (Gavia immer) chicks: Comparative Biochemistry and Physiology Part A, v. 133, no. 3, p. 703-14.

Franson, J.C., Hoffman, D.J., Wells-Berlin, A., Perry, M.C., Shearn-Bochsler, V., Finley, D.L., Flint, P.L., and Hollmén, T., 2007, Effects of dietary selenium on tissue concentrations, pathology, oxidative stress, and immune function in common eiders (Somateria mollissima): Journal of toxicology and environmental health, v. 70, no. 10, p. 861-874.

Fraser, G., 1997, Feeding Ecology of Forster's Terns on Lake Osakis, Minnesota: Colonial Waterbirds, v. 20, p. 87-94.

Fry, B., 2002, Conservative mixing of stable isotopes across estuarine salinity gradients-A conceptual framework for monitoring watershed influences on downstream fisheries: Estuaries, v. 25, no. 2, p. 264-271.

Fry, B., and Chumchal, M., 2011, Sulfur stable isotope indicators of residency in estuarine fish: Limnology and Oceanography, v. 56, no. 5, p. 1,563-1,576.

Fry, B., and Chumchal, M.M., 2012, Mercury bioaccumulation in estuarine food webs: Ecological Applications, v. 22, no. 2, p. 606-623.

Furness, R.W., 1996, Cadmium in birds, in Beyer, W.N., Heinz, G.H., Redmon-Norwood, A.W., eds., Environmental Contaminants in Wildlife - Interpreting Tissue Concentrations: Boca Raton, Fla., Lewis Publishers, p. 389-404.

Furness, R.W., Muirhead, S.J., and Woodburn, M., 1986, Using bird feathers to measure mercury in the environment-Relationships between mercury content and molt: Marine Pollution Bulletin, v. 17, no. 1, p. $27-30$.

Goals Project, 1999, Baylands ecosystem habitat goals - A report of habitat recommendations prepared by the San Francisco Bay Area Wetlands Ecosystem Goals Project: San Francisco, U.S.

Environmental Protection Agency, California/San Francisco Bay Regional Water Quality Control, p. 328.

Greenfield, B.K., and Jahn, A., 2010, Mercury in San Francisco Bay forage fish: Environmental Pollution, v. 158, p. 2,716-2,724.

Grimaldo, L.F., Sommer, T., Van Ark, N., Jones, G., Holland, E., Moyle, P.B., Herbold, B., and Smith, P., 2009, Factors affecting fish entrainment into massive water diversions in a tidal freshwater estuary_Can fish losses be managed?: North American Journal of Fisheries Management, v. 29, no. 5 , p. 1,253-1,270.

Haig, S., Oring, L., Sanzenbacher, P., and Taft, O., 2002, Space use, migratory connectivity, and population segregation among willets breeding in the western Great Basin: Condor, v. 104, no. 3, p. 620-630.

Hall, B.D., Aiken, G.R., Krabbenhoft, D.P., Marvin-DiPasquale, M., and Swarzenski, C.M., 2008, Wetlands as principal zones of methylmercury production in southern Louisiana and the Gulf of Mexico region: Environmental Pollution, v. 154, no. 1, p. 124-134. 
Hamilton, R., 1975, Comparative behavior of the American avocet and the black-necked stilt (Recurvirostridae): Ornithological Monographs, no. 17, p. 1-98.

Haramis, G.M., Jorde, D.G., Macko, S.A., and Walker, J.L., 2001, Stable-isotope analysis of canvasback winter diet in Upper Chesapeake Bay: Auk, v. 118, no. 4, p. 1,008-1,017.

Harris, M.L., Wilson, L.K., Trudeau, S.F., and Elliott, J.E., 2007, Vitamin A and contaminant concentrations in surf scoters (Melanitta perspicillata) wintering on the Pacific coast of British Columbia, Canada: Science of the Total Environment, v. 378, no. 3, p. 366-75.

Heinz, G., 1979, Methylmercury-Reproductive and behavioral effects on three generations of mallard ducks: Journal of Wildlife Management, v. 43, no. 2, p. 394-401.

Heinz, G., Hoffman, D., and Gold, L., 1989, Impaired reproduction of mallards fed an organic form of selenium: Journal of Wildlife Management, v. 53, p. 418-428.

Heinz, G., Pendleton, G., Krynitsky, A.J., and Gold, L.G., 1990, Selenium accumulation and elimination in mallards: Archives of Environmental Contamination and Toxicology, v. 19, no. 3, p. 374-379.

Heinz, G., and Stebbins, K.R., 2009, A simplified method for correcting contaminant concentrations in eggs for moisture loss: Environmental Toxicology and Chemistry, v. 28, no. 7, p. 1,425-1,428.

Heinz, G.H., 1996, Selenium in birds, in Beyer, W.N., Heinz, G.H., Redmon-Norwood, A.W., eds., Environmental contaminants in wildlife-Interpreting tissue concentrations: Lewis, Boca Raton, $\mathrm{p}$. $447-458$.

Heinz, G.H., and Fitzgerald, M.A., 1993, Environmental contamination and toxicology overwinter survival of mallards fed selenium: Archives of Environmental Contamination and Toxicology, v. 25, p. $90-94$.

Heinz, G.H., and Hoffman, D.J., 1998, Methylmercury chloride and selenomethionine interactions on health and reproduction in mallards: Environmental Toxicology and Chemistry, v. 17, no. 2, p. 139145.

Heinz, G.H., and Hoffman, D.J., 2003, Embryotoxic thresholds of mercury-Estimates from individual mallard eggs: Archives of Environmental Contamination and Toxicology, v. 44, no. 2, p. 257-264.

Heinz, G.H., Hoffman, D.J., Klimstra, J.D., and Stebbins, K.R., 2009a, Rapid increases in mercury concentrations in the eggs of mallards fed methylmercury: Environmental Toxicology and Chemistry, v. 28 , no. 9, p. 1,979-1,981.

Heinz, G.H., Hoffman, D.J., Klimstra, J.D., and Stebbins, K.R., 2010a, Predicting mercury concentrations in mallard eggs from mercury in the diet or blood of adult females and from duckling down feathers: Environmental Toxicology and Chemistry, v. 29, no. 2, p. 389-392.

Heinz, G.H., Hoffman, D.J., Klimstra, J.D., and Stebbins, K.R., 2010b, Enhanced reproduction in mallards fed a low level of methylmercury-An apparent case of hormesis: Environmental Toxicology and Chemistry, v. 29, no. 3, p. 650-653.

Heinz, G.H., Hoffman, D.J., Klimstra, J.D., and Stebbins, K.R., 2010c, Intraperitoneal injections as a possible means of generating varied levels of methylmercury in the eggs of birds in field studies: Environmental Toxicology and Chemistry, v. 29, no. 5, p. 1,079-1,083.

Heinz, G.H., Hoffman, D.J., Klimstra, J.D., and Stebbins, K.R., 2010d, Reproduction in mallards exposed to dietary concentrations of methylmercury: Ecotoxicology, v. 19, no. 5, p. 977-982.

Heinz, G.H., Hoffman, D.J., Klimstra, J.D., and Stebbins, K.R., 2012a, A comparison of the teratogenicity of methylmercury and selenomethionine injected into bird eggs: Archives of Environmental Contamination and Toxicology, v. 62, no. 3, p. 519-528. 
Heinz, G.H., Hoffman, D.J., Klimstra, J.D., Stebbins, K.R., and Kondrad, S.L., 2011a, Toxicity of methylmercury injected into eggs when dissolved in water versus corn oil: Environmental Toxicology and Chemistry, v. 30, no. 9, p. 2,103-2,106.

Heinz, G.H., Hoffman, D.J., Klimstra, J.D., Stebbins, K.R., Kondrad, S.L., and Erwin, C.A., 2009b, Species differences in the sensitivity of avian embryos to methylmercury: Archives of Environmental Contamination and Toxicology, v. 56, no. 1, p. 129-138.

Heinz, G.H., Hoffman, D.J., Klimstra, J.D., Stebbins, K.R., Kondrad, S.L., and Erwin, C.A., 2011b, Teratogenic effects of injected methylmercury on avian embryos: Environmental Toxicology and Chemistry, v. 30, no. 7, p. 1,593-1,598.

Heinz, G.H., Hoffman, D.J., Klimstra, J.D., Stebbins, K.R., Kondrad, S.L., and Erwin, C.A., 2012b, Hormesis associated with a low dose of methylmercury injected into mallard eggs: Archives of Environmental Contamination and Toxicology, v. 62, no. 1, p. 141-144.

Henny, C.J., Hill, E.F., Hoffman, D.J., Spalding, M.G., and Grove, R.A., 2002, Nineteenth century mercury-Hazard to wading birds and cormorants of the Carson River, Nevada: Ecotoxicology, v. 11, no. 4 , p. 213-231.

Herreman, J.K., Blundell, G.M., and Ben-David, M., 2009, Evidence of bottom-up control of diet driven by top-down processes in a declining harbor seal Phoca vitulina richardsi population: Marine Ecology Progress Series, v. 374, p. 287-300.

Herring, G., Ackerman, J.T., Eagles-Smith, C.A., 2010, Embryo malposition as a potential mechanism for mercury-induced hatching failure in bird eggs: Environmental Toxicology and Chemistry, v. 29, no. 8, p. 1,788-1,794.

Herring, G., Ackerman, J.T., Eagles-Smith, C.A., Adelsbach, T.L., Melancon, M.J., Stebbins, K.R., and Hoffman, D.J., 2010, Organochlorine and PBDE concentrations in relation to cytochrome P450 activity in livers of Forster's terns (Sterna forsteri) and Caspian terns (Hydroprogne caspia), in San Francisco Bay, California: Archives of Environmental Contamination and Toxicology, v. 58, no. 3, p. 863-873.

Herring, G., Ackerman, J.T., and Herzog, M.P., 2012, Mercury exposure may suppress baseline corticosterone levels in juvenile birds: Environmental Science and Technology, v. 46, no. 11, p. 6,339-6,346.

Hilderbrand, G.V, Farley, S.D., Robbins, C.T., Hanley, T.A., Titus, K., and Servheen, C., 1996, Use of stable isotopes to determine diets of living and extinct bears: Canadian Journal of Zoology, v. 74, p. 2,080-2,088.

Hobson, K., 1995, Reconstructing avian diets using stable-carbon and nitrogen isotope analysis of egg components-Patterns of isotopic fractionation and turnover: Condor, v. 97, no. 3, p. 752-762.

Hobson, K.A., and Clark, R.G., 1992, Assessing avian diets using stable isotopes I-Turnover of $13 \mathrm{C}$ in tissues: Condor, v. 94, no. 1, p. 181-188.

Hoffman, D.J., 2002, Role of selenium toxicity and oxidative stress in aquatic birds: Aquatic Toxicology, v. 57, p. 11-26.

Hoffman, D.J., Eagles-Smith, C.A., Ackerman, J.T., Adelsbach, T.L., and Stebbins, K.R., 2011, Oxidative stress response of Forster's terns (Sterna forsteri) and Caspian terns (Hydroprogne caspia) to mercury and selenium bioaccumulation in liver, kidney, and brain: Environmental Toxicology and Chemistry, v. 30, no. 4, p. 920-929.

Hoffman, D.J., Henny, C.J., Hill, E.F., Grove, R.A., Kaiser, J.L., and Stebbins, K.R., 2009, Mercury and drought along the Lower Carson River, Nevada, III, Effects on blood and organ biochemistry and histopathology of snowy egrets and black-crowned night-herons on Lahontan Reservoir, 2002-2006: Journal of Toxicology and Environmental Health Part A, v. 72, no. 20, p. 1,223-1,241. 
Hoffman, D.J., Ohlendorf, H.M., Marn, C.M., and Pendleton, G.W., 1998, Association of mercury and selenium with altered glutathione metabolism and oxidative stress in diving ducks from the San Francisco Bay region, USA: Environmental Toxicology and Chemistry, v. 17, no. 2, p. 167-172. Hoffman, D.J., Spalding, M.G., and Frederick, P.C., 2005, Subchronic effects of methylmercury on plasma and organ biochemistries in great egret nestlings: Environmental Toxicology and Chemistry, v. 24 , no. 12 , p. 3,078-3,084.

Honda, K., Nasu, T., and Tatsukawa, R., 1986, Seasonal changes in mercury accumulation in the blackeared kite, Milvus migrans lineatus: Environmental Pollution, v. 42, no. 4, p. 325-334.

Hornberger, M., Luoma, S., and Geen, A. Van, 1999, Historical trends of metals in the sediments of San Francisco Bay, California: Marine Chemistry, v. 64, p. 39-55.

Hothem, R.L., Lonzarich, D.G., Takekawa, J.E., and Ohlendorf, H.M., 1998, Contaminants in wintering canvasbacks and scaups from San Francisco Bay, California: Environmental Monitoring and Assessment, v. 50, no. 1, p. 67-84.

Hui, C.A., and Beyer, W.N., 1998, Sediment ingestion of two sympatric shorebird species: Science of the Total Environment, v. 224, no. 1-3, p. 227-233.

Hui, C.A., Takekawa, J.Y., and Warnock, S.E., 2001, Contaminant profiles of two species of shorebirds foraging together at two neighboring sites in south San Francisco Bay, California: Environmental Monitoring and Assessment, v. 71, no. 2, p. 107-121.

Hyslop, E.J., 1980, Stomach contents analysis-a review of methods and their application: Journal of Fish Biology, v. 17, p. 411-429.

Ikemoto, T., Kunito, T., Tanaka, H., Baba, N., Miyazaki, N., and Tanabe, S., 2004, Detoxification mechanism of heavy metals in marine mammals and seabirds - Interaction of selenium with mercury, silver, copper, zinc, and cadmium in liver: Archives of Environmental Contamination and Toxicology, v. 47, no. 3, p. 402-413.

Iverson, S.A., Esler, D., and Boyd, W.S., 2003, Plumage characteristics as an indicator of age class in the surf scoter: Waterbirds, v. 26, no. 1, p. 56-61.

Jonsson, K.I., 2014, Capital and income breeding as alternative tactics of resource use in reproduction: Oikos, v. 78, p. 57-66.

Kaiser, G.W., Derocher, A.E., Crawford, S., Gill, M.J., and Manley, I.A., 1995, A capture technique for marbled murrelets in coastal inlets: Journal of Field Ornithology, v. 66, no. 3, p. 321-333.

Kenow, K.P., Grasman, K.A., Hines, R.K., Meyer, M.W., Gendron-Fitzpatrick, A., Spalding, M.G., and Gray, B.R., 2007, Effects of methylmercury exposure on the immune function of juvenile common loons (Gavia immer): Environmental Toxicology and Chemistry, v. 26, no. 7, p. 1,460-1,469.

Kenow, K.P., Gutreuter, S., Hines, R.K., Meyer, M.W., Fournier, F., and Karasov, W.H., 2003, Effects of methyl mercury exposure on the growth of juvenile common loons: Ecotoxicology, v. 12, no. 1-4, p. 171-82.

Kenow, K.P., Hines, R.K., Meyer, M.W., Suarez, S. a, and Gray, B.R., 2010, Effects of methylmercury exposure on the behavior of captive-reared common loon (Gavia immer) chicks: Ecotoxicology, v. 19, no. 5, p. 933-44.

Kenow, K.P., Hoffman, D.J., Hines, R.K., Meyer, M.W., Bickham, J.W., Matson, C.W., Stebbins, K.R., Montagna, P., and Elfessi, A., 2008, Effects of methylmercury exposure on glutathione metabolism, oxidative stress, and chromosomal damage in captive-reared common loon (Gavia immer) chicks: Environmental Pollution, v. 156, no. 3, p. 732-738.

Kim, E.Y., Murakami, T., Saeki, K., and Tatsukawa, R., 1996, Mercury levels and its chemical form in tissues and organs of seabirds: Archives of Environmental Contamination and Toxicology, v. 30, no. 2, p. 259-266. 
Klaassen, M., Abraham, K.F., Jefferies, R.., and Vrtiska, M., 2006, Factors affecting the site of investment, and the reliance on savings for arctic breeders-The capital-income dichotomy revisited: ARDEA, v. 94, no. 3, p. 371-384.

Klimstra, J.D., Stebbins, K.R., Heinz, G.H., Hoffman, D.J., and Kondrad, S.R., 2009, Factors related to the artificial incubation of wild bird eggs: Avian Biology Research, v. 2, no. 3, p. 121-131.

Klimstra, J.D., Yee, J.L., Heinz, G.H., Hoffman, D.J., and Stebbins, K.R., 2012, Interactions between methylmercury and selenomethionine injected into mallard eggs: Environmental Toxicology and Chemistry, v. 31, no. 3, p. 579-584.

Korschgen, C.E., Kenow, K.P., Gendron-Fitzpatrick, A. Green, W.L., and Dein, F.J., 1996, Implanting intra-abdominal radiotransmitters with external whip antennas in ducks: Journal of Wildlife Management, v. 60, no. 1, p. 132-137.

Krausova, T., and Peterka, M., 2007, Teratogenic and lethal effects of 2-24h hyperthermia episodes on chick embryos: Journal of Thermal Biology, v. 32, no. 4, p. 193-203.

Lewis, S.A., Becker, P.H., and Furness, R.W., 1993, Mercury levels in eggs, tissues, and feathers of herring gulls Larus argentatus from the German Wadden Sea Coast: Environmental Pollution, v. 80, no. 3, p. 293-9.

Linville, R.G., Luoma, S.N., Cutter, L., and Cutter, G.A., 2002, Increased selenium threat as a result of invasion of the exotic bivalve Potamocorbula amurensis into the San Francisco Bay-Delta: Aquatic Toxicology, v. 57, no. 1-2, p. 51-64.

Longcore, J.R., Haines, T.A., and Halteman, W.A., 2007, Mercury in tree swallow food, eggs, bodies, and feathers at Acadia National Park, Maine, and an EPA Superfund Site, Ayer, Massachusetts:

Environmental Monitoring and Assessment, p. 129-143.

Longcore, J.R., and Stendell, R.C., 1977, Shell thinning and reproductive impairment in black ducks after cessation of DDE dosage: Archives of Environmental Contamination and Toxicology, v. 6, p. 293-304.

Lovvorn, J., De La Cruz, S., Takekawa, J., Shaskey, L., and Richman, S., 2013, Niche overlap, threshold food densities, and limits to prey depletion for a diving duck assemblage in an estuarine bay: Marine Ecology Progress Series, v. 476, p. 251-268.

Lyons, D., Roby, D., and Collis, K., 2005, Foraging ecology of Caspian terns in the Columbia River estuary, USA: Waterbirds, v. 28, no. 3, p. 280-291.

MacLeod, W.D., Brown, D.W., Friedman, A.J., Burrow, D.G., Mayes, O., Pearce, R.W., Wigren, C.A., and Bogar, R.G., 1985, Standard analytical procedures of the NOAA national analytical facility 19851986-Extractable toxic organic compounds: Washington, D.C.., National Oceanic and Atmospheric Administration, $121 \mathrm{p}$.

Marvin-Di Pasquale, M., and Agee, J.L., 2003, Microbial mercury cycling in sediments of the San Francisco Bay-Delta: Estuaries, v. 26, no. 6, p. 1,517-1,528.

Mather, D.D., and Esler, D., 1999, Evaluation of bursal depth as an indicator of age class of Harlequin Ducks: Journal of Field Ornithology, v. 70, no. 2, p. 200-205.

McNicholl, M.K., Lowther, P.E., and Hall, J.A., 2001, Forster's Tern (Sterna forsteri), in Poole, A., ed., The Birds of North America Online: Ithaca, New York, Cornell Lab of Ornithology.

Meckstroth, A.M., Miles, A.K., and Chandra, S., 2007, Diets of introduced predators using stable isotopes and stomach contents: Journal of Wildlife Management, v. 71, no. 7, p. 2,387.

Melancon, M.J., 1996, Development of cytochromes P450 in avian species as a biomarker for environmental contaminant exposure and effect, in Bengston, D.A., Henshel, D.S., eds., Environmental toxicology and risk assessment-Biomarkers and risk assessment: Philadelphia, Pa., American Society for Testing and Materials, p. 98-108. 
Merrill, E., Hartigan, J., and Meyer, M., 2005, Does prey biomass or mercury exposure affect loon chick survival in Wisconsin?: Journal of Wildlife Management, v. 69, no. 1, p. 57-67.

Meyer, M., Evers, D., Hatigan, J.J., and Rasmussen, P.S., 1998, Patterns of common loon (Gavia immer) mercury exposure, reproduction, and survival in Wisconsin, USA: Environmental Toxicology and Chemistry, v. 17, no. 2, p. 184-190.

Monteiro, L.R., and Furness, R.W., 2001, Kinetics, dose-response, and excretion of methylmercury in free-living adult Cory's shearwaters: Environmental Science \& Technology, v. 35, no. 4, p. 739-746. Moyle, P.B., 2002, Inland fishes of California: Berkeley, University of California Press, p. 517.

Mulcahy, D.M., and Esler, D., 1999, Surgical and immediate postrelease mortality of Harlequin Ducks (Histrionicus histrionicus) implanted with abdominal radio transmitters with percutaneous antennae: Journal of Zoo and Wildlife Medicine, v. 30, no. 3, p. 397-401.

Nocera, J., and Taylor, P., 1998, In situ behavioral response of common loons associated with elevated mercury ( $\mathrm{Hg})$ exposure: Conservation Ecology, v. 2, no. 2, 10.

O'Farrell, M.R., and Larson, R.J., 2001, Year-class formation in Pacific herring (Clupea pallasi) estimated from spawning-date distributions of juveniles in San Francisco Bay, California: Fishery Bulletin, v. 103, no. 1, p. 130-141.

Ohlendorf, H.M., and Fleming, W.J., 1988, Birds and Environmental Contaminants in San Francisco and Chesapeake Bays: Marine Pollution Bulletin, v. 19, no. 9, p. 487-495.

Ohlendorf, H.M., Lowe, R.W., Kelly, P.R., and Harvey, T.E., 1986, Selenium and heavy-metals in SanFrancisco Bay diving ducks: Journal of Wildlife Management, v. 50, no. 1, p. 64-70.

Oros, D.R., Hoover, D., Rodigari, F., Crane, D., and Sericano, J., 2005, Levels and distribution of polybrominated diphenyl ethers in water, surface sediments, and bivalves from the San Francisco Estuary: Environmental Science and Technology, v. 39, no. 1, p. 33-41.

Pace III, R.M., and Afton, A.D., 1999, Direct recovery rates of lesser scaup banded in Northwest Minnesota: sources of heterogeneity: Journal of Wildlife Management, v. 63, no. 1, p. 389-395.

Page, G., Stenzel, L., and Kjelmyr, J., 1999, Overview of shorebird abundance and distribution in wetlands of the Pacific Coast of the contiguous United States: Condor, v. 101, no. 3, p. 461-471. Parnell, A., and Jackson, A., 2010, Package "siar": Stable Isotope Analysis in R, p. 25.

Peterson, B., Howarth, R., and Garritt, R., 1986, Sulfur and carbon isotopes as tracers of salt-marsh organic matter flow: Ecology, v. 67, no. 4, p. 865-874.

Plass-Johnson, J.G., McQuaid, C.D., and Hill, J.M., 2013, Stable isotope analysis indicates a lack of inter- and intra-specific dietary redundancy among ecologically important coral reef fishes: Coral Reefs, v. 32, no. 2, p. 429-440.

Plissner, J.H., Haig, S.M., and Oring, L.W., 2000, Postbreeding movements of American avocets and implications for wetland connectivity in the western Great Basin: Auk, v. 117, no. 2, p. 290-298.

Post, D., Layman, C., and Arrington, D., 2007, Getting to the fat of the matter-Models, methods and assumptions for dealing with lipids in stable isotope analyses: Oecologia, v. 152, p. 179-189.

Poulton, V.K., Lovvorn, J.R., and Takekawa, J.Y., 2002, Clam density and scaup feeding behavior in San Pablo Bay, California: Condor, v. 104, no. 3, p. 518-527.

Rintoul, C., Warnock, N., Page, G., and Hanson, J., 2003, Breeding status and habitat use of blacknecked stilts and American avocets in South San Francisco Bay: Western Birds, v. 34, no. 1, p. 2-14.

Robinson, J., Reed, J., Skorupa, J., and Oring, L., 1999, Black-necked stilt (Himantopus mexicanus), in Poole, A., and Gill, F., eds., The Birds of North America Online: Ithaca, New York, Cornell Lab of Ornithology.

Rohwer, F.C., 1992, The evolution of reproductive patterns in waterfowl, in Batt, D.J., Afton, A.D., Anderson, M.G., Ankney, C.D., Johnson, D.H., Johnson, D.H., Kadlec, J.A., and Krapu, G.L., 
Ecology and management of breeding waterfowl: Minneapolis, University of Minnesota Press, p. 486-539.

San Francisco Bay Regional Water Quality Control Board, 2006, Proposed 2006 CWA section 303(d) list of water quality limited segments: San Francisco Bay Regional Board spreacsheet, accessed February 3, 2009, at http://www.waterboards.ca.gov/water_issues/programs/tmdl/docs/303dlists2006/swrcb/r2_final303dli st.pdf

Scheuhammer, A.M., Atchison, C.M., Wong, A.H.K., and Evers, D.C., 1998, Mercury exposure in breeding common loons (Gavis immer) in Central Ontario, Canada: Environmental Toxicology and Chemistry, v. 17, no. 2, p. 191-196.

Scheuhammer, A.M., Meyer, M.W., Sandheinrich, M.B., and Murray, M.W., 2007, Effects of environmental methylmercury on the health of wild birds, mammals, and fish: Ambio, v. 36, no. 1, p. $12-8$.

Scheuhammer, A.M., and Sandheinrich, Æ.M.B., 2008, Recent advances in the toxicology of methylmercury in wildlife: Ecotoxicology, v. 17, p. 67-68.

Schoellhamer, D.H., Mumley, T.E., and Leatherbarrow, J.E., 2007, Suspended sediment and sedimentassociated contaminants in San Francisco Bay: Environmental Research, v. 105, no. 1, p. 119-131.

Schwarzbach, S.E., Albertson, J.D., Thomas, C.M., and Lank, D., 2006, Effects of predation, flooding, and contamination on reproductive success of California clapper rails (Rallus longirostris obsoletus) in San Francisco Bay: Auk, v. 123, no. 1, p. 45-60.

Sepúlveda, M., Williams, G.J., Frederick, P., and Spalding, M., 1999, Effects of mercury on health and first-year survival of free-ranging great egrets (Ardea albus) from southern Florida: Archives of Environmental Contamination and Toxicology, v. 37, p. 369-376.

Shaffer, T.L., 2004, A unified approach to analyzing nest success: Auk, v. 121, no. 2, p. 526-540. She, J., Holden, A., Adelsbach, T.L., Tanner, M., Schwarzbach, S.E., Yee, J.L., and Hooper, K., 2008, Concentrations and time trends of polybrominated diphenyl ethers (PBDEs) and polychlorinated biphenyls (PCBs) in aquatic bird eggs from San Francisco Bay, CA 2000-2003: Chemosphere, v. 73.

Shore, R.F., Pereira, E., Walker, L.A., and Thompson, D.R., 2011, Mercury in Nonmarine Birds and Mammals, in Environmental Contaminants in Biota, Beyer, W.N., and Meador, J.P., eds., Interpreting Tissue Concentrations (2nd ed.): Boca Raton, Fla., CRC Press, p. 609-626.

Singer, M.B., Aalto, R., James, L.A., Kilham, N.E., Higson, J.L., and Ghoshal, S., 2013, Enduring legacy of a toxic fan via episodic redistribution of California gold mining debris: Proceedings of the National Academy of Sciences, p. 1-6.

Spalding, M.G., Frederick, P.C., McGill, H.C., Bouton, S.N., and McDowell, L.R., 2000a, Methylmercury accumulation in tissues and its effects on growth and appetite in captive great egrets: Journal of Wildlife Diseases, v. 36, no. 3, p. 411-22.

Spalding, M.G., Frederick, P.C., McGill, H.C., Bouton, S.N., Richey, L.J., Schumacher, I.M., Blackmore, C.G., and Harrison, J., 2000b, Histologic, neurologic, and immunologic effects of methylmercury in captive great egrets: Journal of WIidlife Diseases, v. 36, no. 3, p. 423-35.

Squire, S., Scelfo, G.M., Revenaugh, J., and Flegal, A.R., 2002, Decadal trends of silver and lead contamination in San Francisco Bay surface waters: Environmental Science \& Technology, v. 36, no. 11, p. 2,379-2,386.

Stapp, P., 2002, Stable isotopes reveal evidence of predation by ship rats on seabirds on the Shiant Islands, Scotland: Journal of Applied Ecology, v. 39, no. 5, p. 831-840. 
Stebbins, K.R., Klimstra, J.D., Eagles-Smith, C.A., Ackerman, J.T., and Heinz, G.H., 2009, A nonlethal microsampling technique to monitor the effects of mercury on wild bird eggs: Environmental Toxicology and Chemistry, v. 28, no. 3, p. 465-470.

Stenzel, L.E., Hickey, C.M., Kjelmyr, J.E., and Page, G.W., 2002, Abundance and distribution of shorebirds in the San Francisco Bay area: Western Birds, v. 33, no. 2, p. 69-98.

Stewart, R.A., Luoma, S.N., Schlekat, C.E., Doblin, M.A., and Hieb, K.A., 2004, Food web pathway determines how selenium affects aquatic ecosystems-A San Francisco Bay case study:

Environmental Science and Technology, v. 38, no. 17, p. 4,519-4,526.

Strong, C.M., Spear, L.B., Ryan, T.P., and Dakin, R.E., 2004, Forster's tern, Caspian tern, and California gull colonies in San Francisco Bay-Habitat use, numbers, and trends, 1982-2003: Waterbirds, v. 27, no. 4, p. 411-423.

Suarez, M.E., Wilson, H.R., McPherson, B.N., Mather, F.B., and Wilcox, C.J., 1996, Low temperature effects on embryonic development and hatch time: Poultry Science, v. 75, no. 7, p. 924-32.

Swanson, G.A., Krapu, G.L., Bartonek, J.C., Serie, J.R., and Johnson, D.H., 1974, Advantages in mathematically weighting waterfowl food habits data: Journal of Wildlife Management, v. 38, no. 2, p. 302-307.

Szczebak, J.T., and Taylor, D.L., 2011, Ontogenetic patterns in bluefish (Pomatomus saltatrix) feeding ecology and the effect on mercury biomagnification: Environmental Toxicology and Chemistry, v. 30, no. 6 , p. 1,447-1,458.

Takekawa, J., Lu, C., and Pratt, R., 2001, Avian communities in baylands and artificial salt evaporation ponds of the San Francisco Bay Estuary: Saline Lakes, p. 317-328.

Takekawa, J.Y., De La Cruz, S.E.W., Wilson, M.T., Palm, E.C., Yee, J., Nysewander, D.R., Evenson, J.R., Eadie, J.M., Esler, D., Boyd, W.S., and others, 2011, Breeding distribution and ecology of Pacific coast Surf Scoters, in Wells, J.V., Boreal birds of North America-A hemispheric view of their conservation links and significance: Berkeley, University of California Press, p. 41-64.

Takekawa, J.Y., Miles, A.K., Schoellhamer, D.H., Athern, N.D., Saiki, M.K., Duffy, W.D., Kleinschmidt, S., Shellenbarger, G.G., and Jannusch, C.A., 2006, Trophic structure and avian communities across a salinity gradient in evaporation ponds of the San Francisco Bay estuary: Limnology and Aquatic Birds, p. 307-327.

Takekawa, J.Y., Wainwright-De La Cruz, S.E., Hothem, R.L., and Yee, J., 2002, Relating body condition to inorganic contaminant concentrations of diving ducks wintering in coastal California: Archives of Environmental Contamination and Toxicology, v. 42, no. 1, p. 60-70.

Thompson, A.D.R., Hamer, K.C., and Furness, R.W., 1991, Mercury accumulation in great skuas Catharacta skua of known age and sex, and its effects upon breeding and survival: Journal of Applied Ecology, v. 28, no. 2, p. 672-684.

Thompson, D., and Furness, R., 1989a, Comparison of the levels of total and orgnaic mercury in Seabird Feathers: Marine Pollution Bulletin, v. 20, no. 11, p. 577-579.

Thompson, D.R., 1996, Mercury in birds and terrestrial mammals, in Beyer, W.N., Heinz, G.H., Redmon-Norwood, A.W., eds., Environmental contaminants in wildlife, interpreting tissue concentrations: Boca Raton, Fla., CRC Press LCC.

Thompson, D.R., and Furness, R.W., 1989b, The chemical form of mercury stored in South Atlantic seabirds: Environmental Pollution, v. 60, no. 3-4, p. 305-17.

Tieszen, L.L., Boutton, T.W., Tesdahl, K.G., and Slade, N.A., 1983, Fractionation and turnover of stable carbon isotopes in animal tissues-Implications for $613 \mathrm{C}$ analysis of diet: Oecologia, v. 57, p. 32-37. 
U.S. Environmental Protection Agency, 2000, Method 7473, Mercury in solids and solutions by thermal decomposition, amalgamation, and atomic absorption spectrophotometry, in Test methods for evaluating solid waste, physical/chemical methods; SW 846, Update IVA: U.S. Government Printing Office (GPO): Washington, D.C.

U.S. Environmental Protection Agency, 2001, Method 1630, Methyl mercury in water by distillation, aqueous ethylation, purge and trap, and cold-vapor atomic fluorescence spectrometry, EPA-821-R-01020, Office of Water and Office of Science and Technology: Washington, D.C., U.S. Environmental Protection Agency, 49 p.

Wade, T.L., Atlas, E.L., Brooks, J.M., Kennicutt, M., Fox, R.G., Sericano, J., Garcia, B., and DeFreitas, D., 1988, NOAA Gulf of Mexico status and trends program-Trace organic contaminant distribution in sediments and oysters: Estuaries, v. 11, p. 171-179.

Wallace, W., and Luoma, S., 2003, Subcellular compartmentalization of Cd and $\mathrm{Zn}$ in two bivalves, II, Significance of trophically available metal (TAM): Marine Ecology Progress Series, v. 257, p. 125137.

Wallace, W.G., Lee, B.G., and Luoma, S.N., 2003, Subcellular compartmentalization of Cd and Zn in two bivalves, I, Significance of metal-sensitive fractions (MSF) and biologically detoxified metal (BDM): Marine Ecology Progress Series, v. 249, p. 183-197.

Warnock, N., and Bishop, M., 1998, Spring stopover ecology of migrant Western Sandpipers: Condor, v. 100 , no. 3, p. 456-467.

Watters, D.L., Brown, H.M., Griffin, F.J., Larson, E.J., and Cherr, G.N., 2004, Pacific herring spawning groungs in San Francisco Bay-1973-2000, in Feyrer, F., Brown, LR., Brown, R.L., and Orsi, J.J., eds., Early life history of fishes in the San Francisco Estuary and Watershed: Bethesda, Md., American Fisheries Society, p. 3-36.

Wiener, J.G., Krabbenhoft, D.P., Heinz, G.H., and Scheuhammer, A.M., 2003, Ecotoxicology of mercury, in Hoffman, D.J., Rattner, B., Burton, G.A.J., and Cairns, J.J., Handbook of Ecotoxicology (2d ed.): Boca Raton, Fla., CRC Press LCC.

Wilson, H.R., Neuman, S.L., Eldred, A.R., and Mather, F.B., 2003, Embryonic malpositions in broiler chickens and bobwhite quail: Journal of Applied Poultry Research, v. 12, p. 14-23.

Wilson, M.T., 2014, Overwinter survival and breeding propensity of Pacific surf scoters from San Francisco Bay, California: Davis, University of California, Masters Thesis, p. 55.

Yamamoto, J.T., and Santolo, G.M., 2000, Body condition effects in American Kestrels: Journal of Wildlife Diseases, v. 36, no. 4, p. 646-652.

Zwarts, L., Blomert, A.-M., and Wanink, J.H., 1992, Annual and seasonal variation in the food supply harvestable by knot Calidris canutus staging in the Wadden Sea in late summer: Marine Ecology Progress Series, v. 83, p. 129-139.

Zwarts, L., and Wanink, J., 1989, Siphon size and burying depth in deposit- and suspension-feeding benthic bivalves: Marine Biology, v. 100, p. 227-240. 


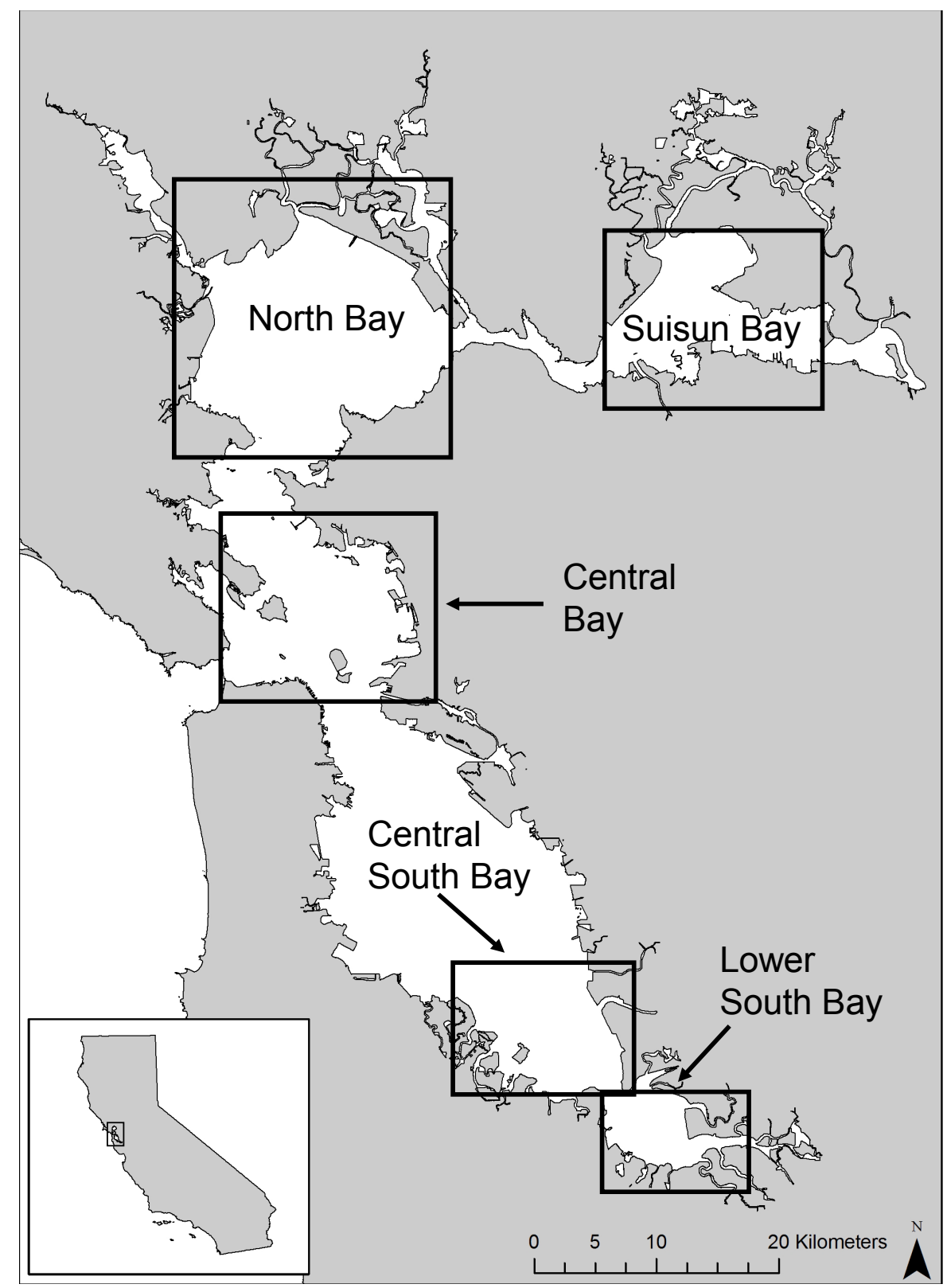

Figure 1. Study locations throughout the greater San Francisco Bay Estuary, California, used from 2003 to 2007. Sampling occurred in five major regions: Lower South Bay, Central South Bay, Central Bay, North Bay (also called San Pablo Bay), and Suisun Bay. 


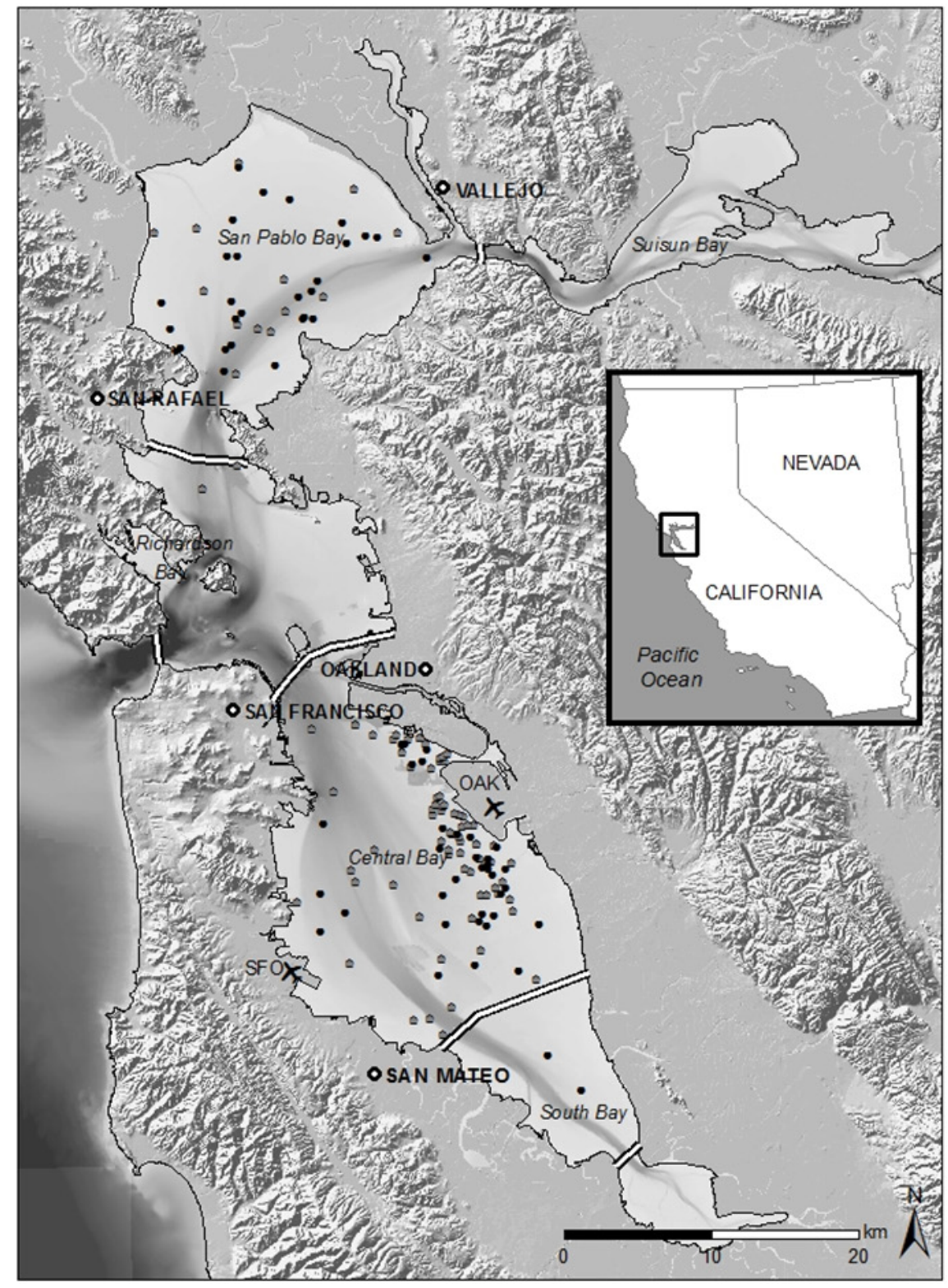

Figure 2. Surf scoter capture locations in San Francisco Bay, California. Map includes major cities, airports, bridges, and sub-bays. Surf scoters were captured throughout the Central Bay and San Pablo Bay (see section, Methods). Figure from De La Cruz and others (2014) and used with permission. 


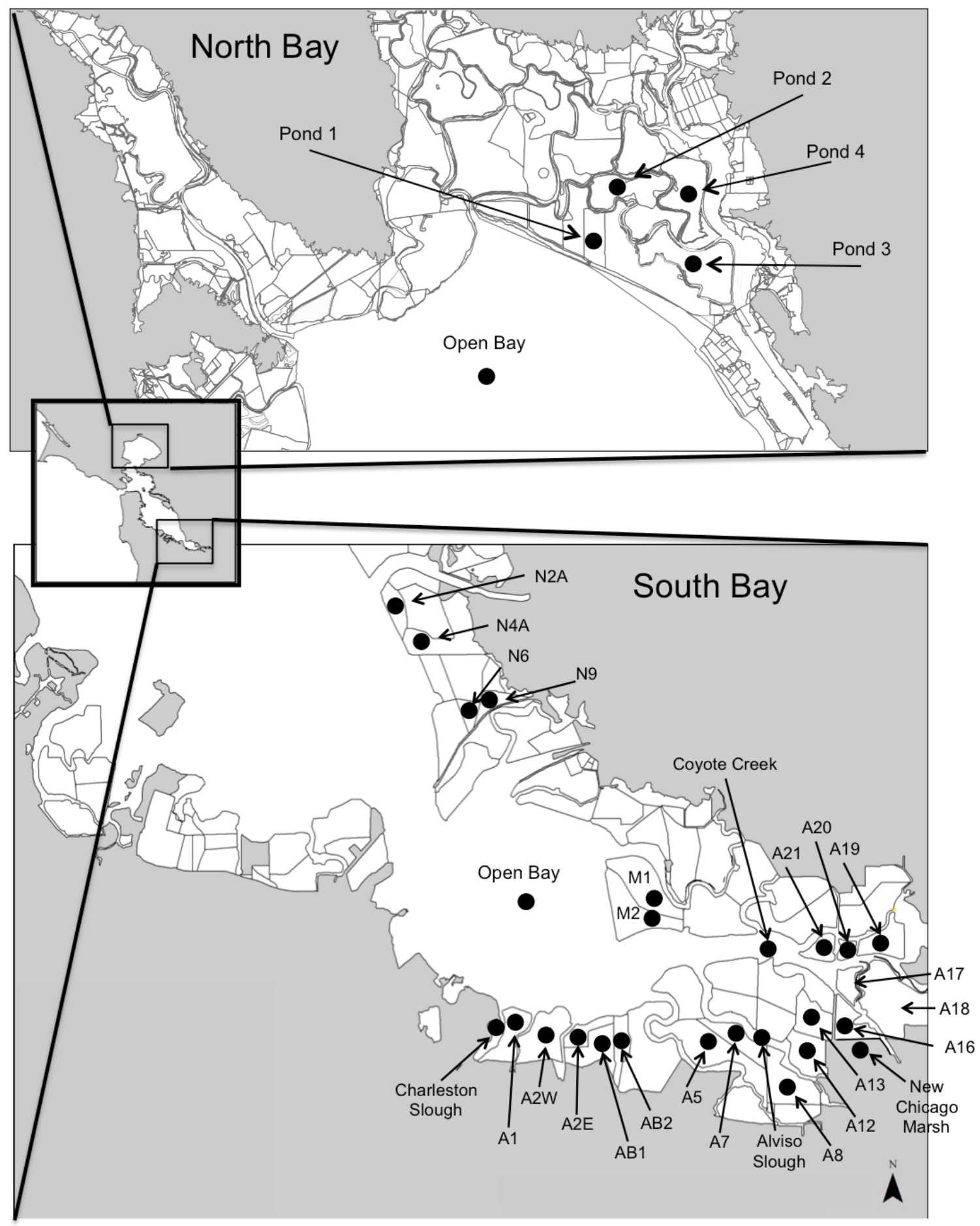

Figure 3. Fish sampling locations in San Francisco Bay Estuary, California. Most wetlands are managed ponds that were formerly salt evaporation ponds. Coyote Creek, New Chicago Marsh, and Charleston Slough are more vegetated marshes with varying degrees of muted tidal flow. Alviso Slough is a tidal slough. Figure from Eagles-Smith and Ackerman (2014) and used with permission. 


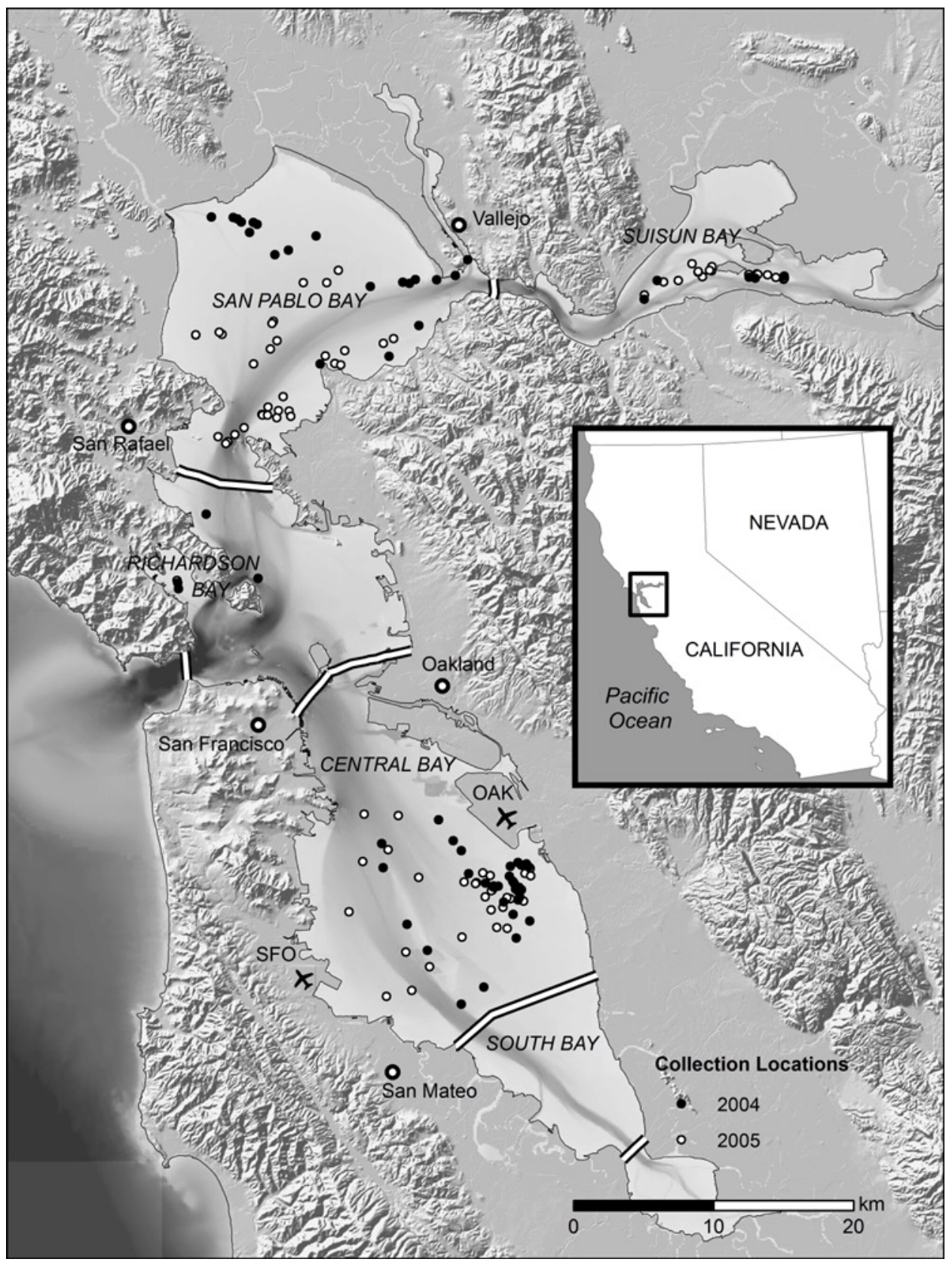

Figure 4. Study area of surf scoter collection locations the main sub-bays of the San Francisco Bay Estuary, California. Surf scoters were collected in Suisun, North (San Pablo), and Central Bays during winter and spring of 2003-04 and 2004-05. Figure from De La Cruz (2010) and used with permission. 

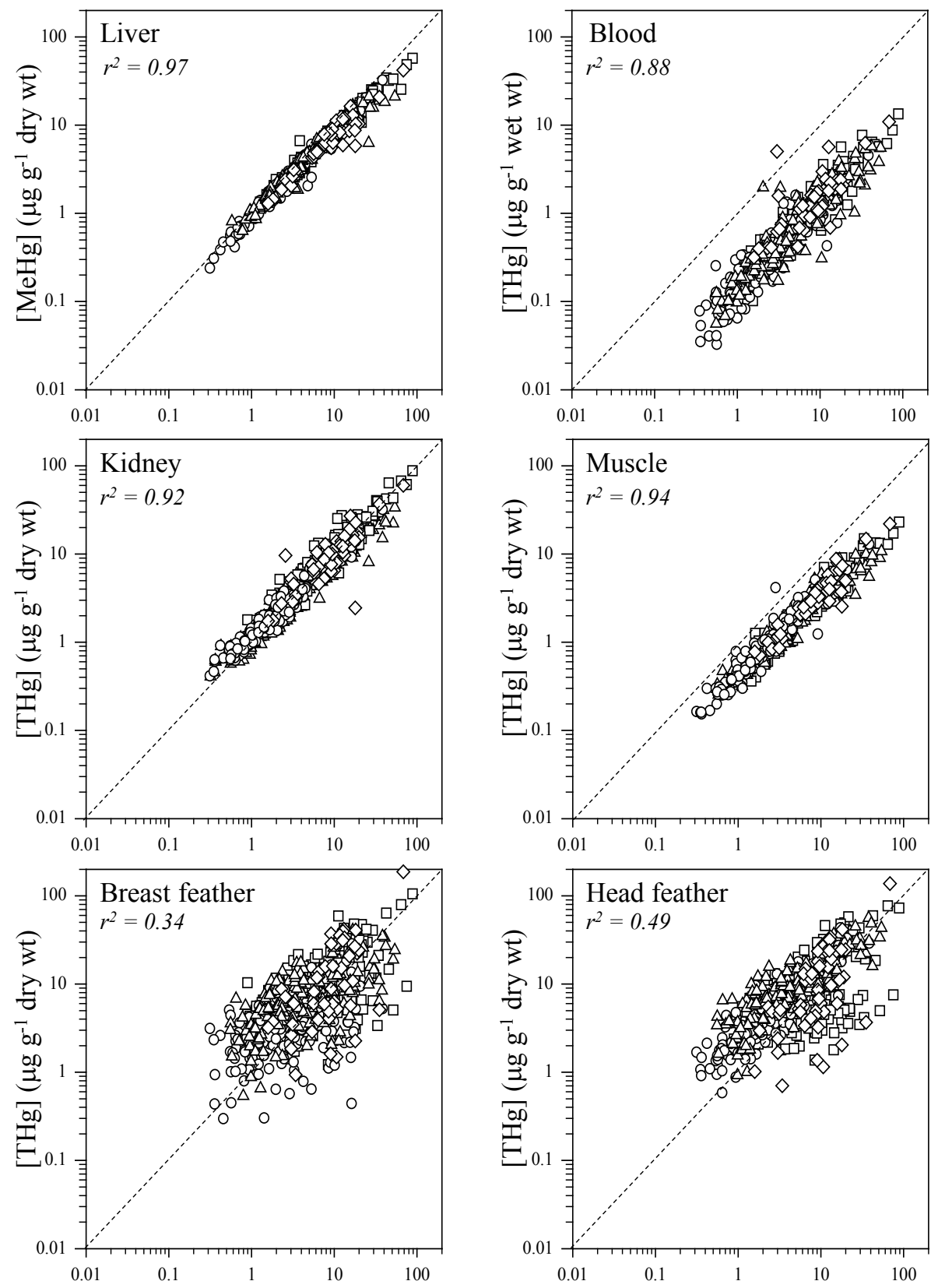

Liver $[\mathrm{THg}]\left(\mu \mathrm{g} \mathrm{g}^{-1}\right.$ dry wt)

Figure 5. Total mercury ( $\mathrm{THg})$ concentration in liver correlated with methylmercury (MeHg) concentrations in liver and $\mathrm{THg}$ concentrations in blood, kidney, muscle, breast feather, and head feather in American avocets (circles), black-necked stilts (triangles), Caspian terns (diamonds), and Forster's terns (squares). Figure from Eagles-Smith and others (2008b) and used with permission. 

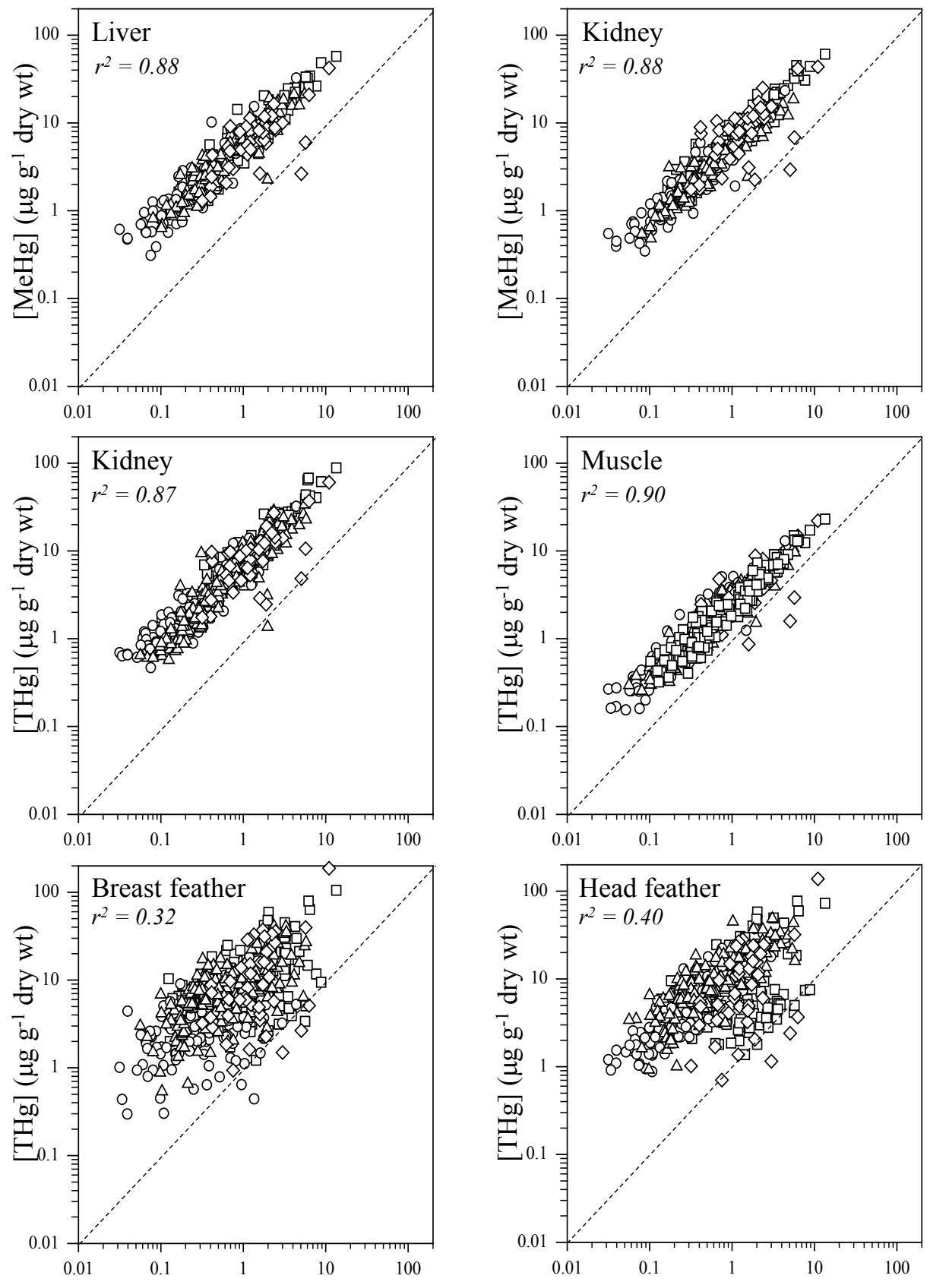

Blood $[\mathrm{THg}]\left(\mu \mathrm{g} \mathrm{g}^{-1}\right.$ wet wt)

Figure 6. Total mercury $(\mathrm{THg})$ concentrations in blood correlated with methylmercury $(\mathrm{MeHg})$ concentrations in liver and kidney and THg concentrations in kidney, muscle, breast feather and head feather in American avocets (circles), black-necked stilts (triangles), Caspian terns (diamonds), and Forster's terns (squares). Figure from Eagles-Smith and others (2008b) and used with permission. 


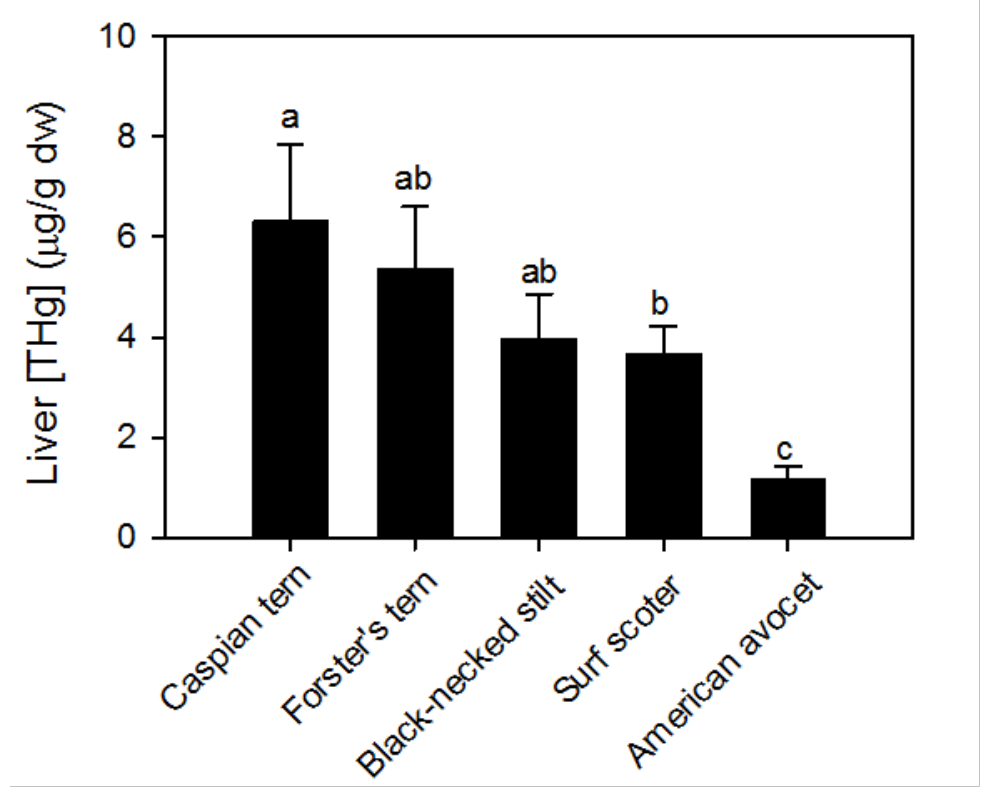

Figure 7. Total mercury ( $\mathrm{THg}$ ) concentrations (least-squares mean $\pm \mathrm{SE}$ ) in livers of five waterbird species sampled from San Francisco Bay, California, during the pre-breeding season (March 1-April 23, 2004-06). Letters above bars indicate statistical difference (Tukey-Kramer, $P<0.05$ ) when correcting for the influence of region, sex, and sampling date. Figure from Eagles-Smith and others (2009a) and used with permission. 

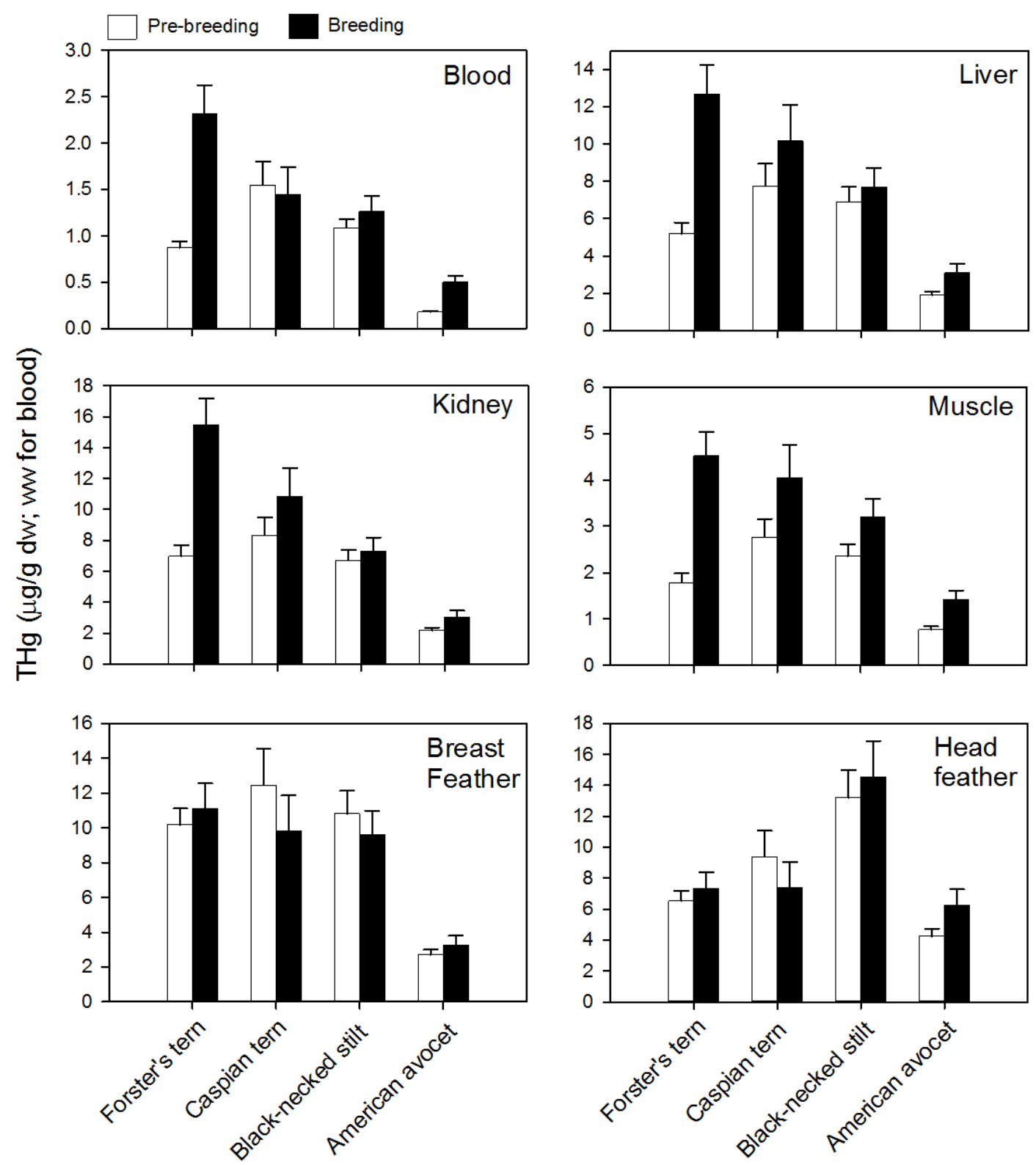

Figure 8. Total mercury (THg) concentrations (least-squares mean $\pm \mathrm{SE}$ ) in various tissues of pre-breeding (open bars) and breeding (solid bars) waterbirds in San Francisco Bay, California. Figure from Eagles-Smith and others (2009a) and used with permission. 


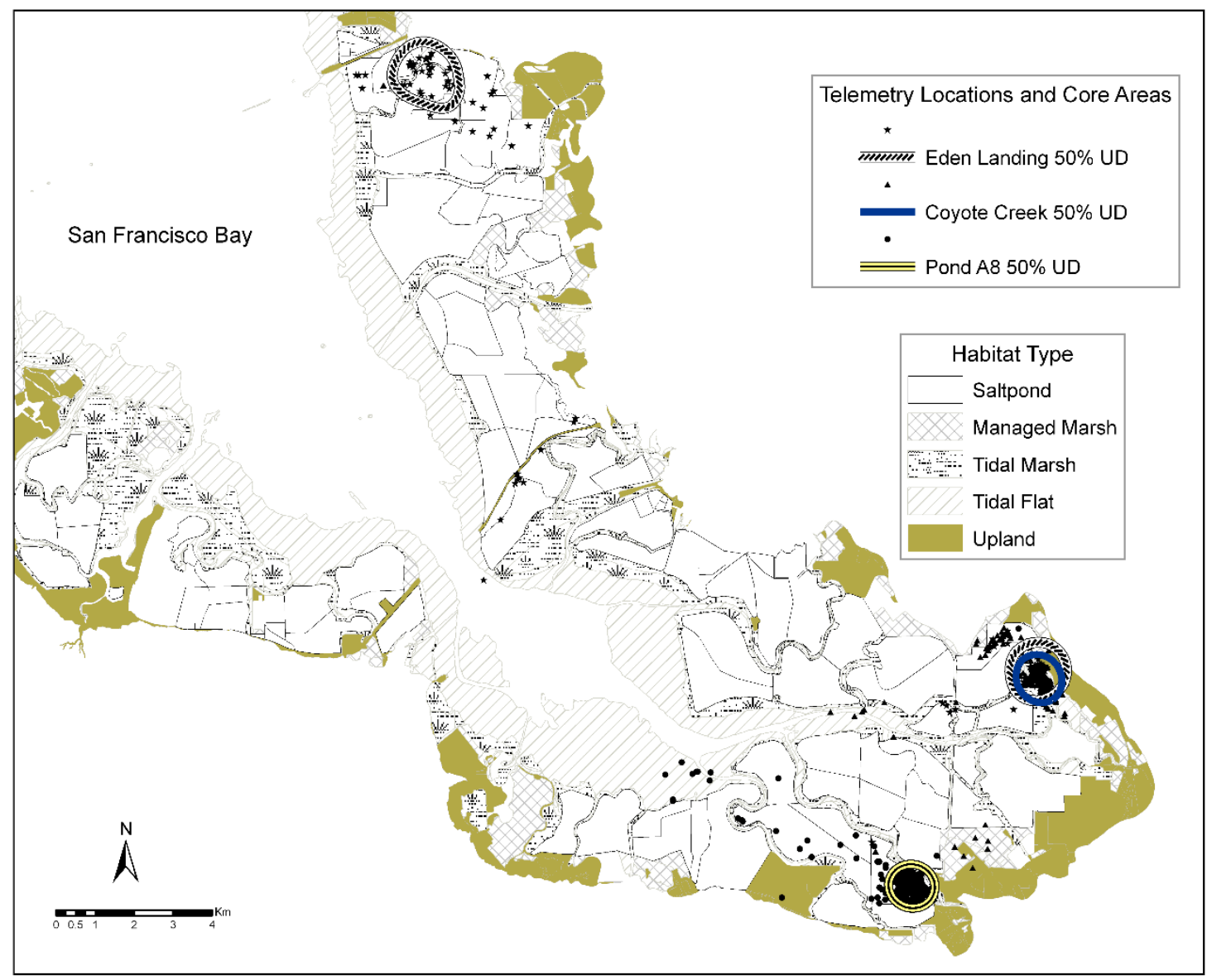

Figure 9. Core use areas and telemetry locations of American avocet females radio-marked in the South Bay at Pond A8 ( $N=254)$, Coyote Creek Marsh ( $N=287)$, and Eden Landing Ecological Reserve ( $N=116)$ sites in San Francisco Bay, California, during spring 2005. UD=utilization distribution. Figure from Ackerman and others (2007) and used with permission. 


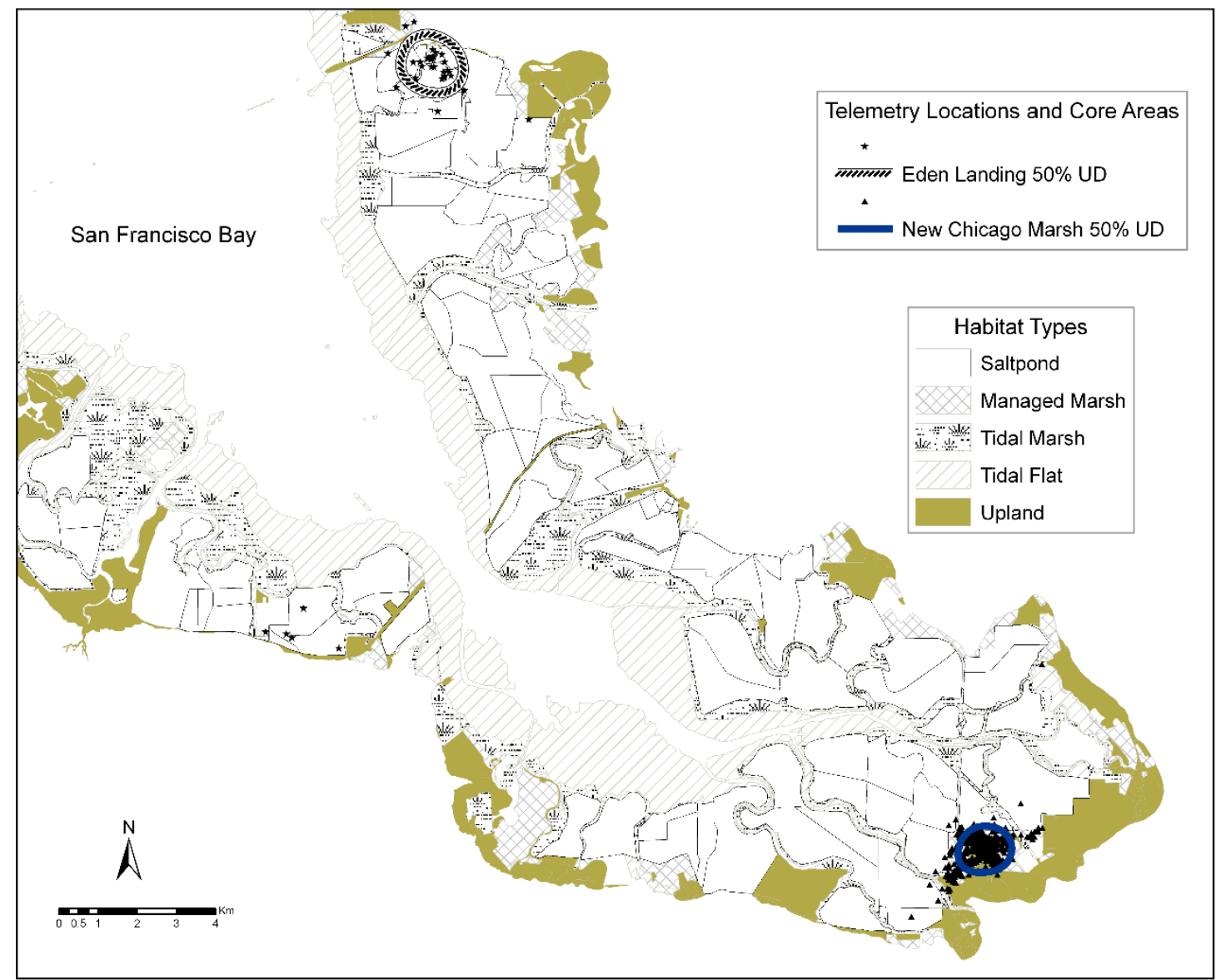

Figure 10. Core use areas and telemetry locations of black-necked stilts radio-marked in the South Bay at New Chicago Marsh ( $\mathrm{N}=474)$ and Eden Landing Ecological Reserve ( $\mathrm{N}=43$ ) sites in San Francisco Bay, California, during spring 2005. UD=utilization distribution. Figure from Ackerman and others (2007) and used with permission. 


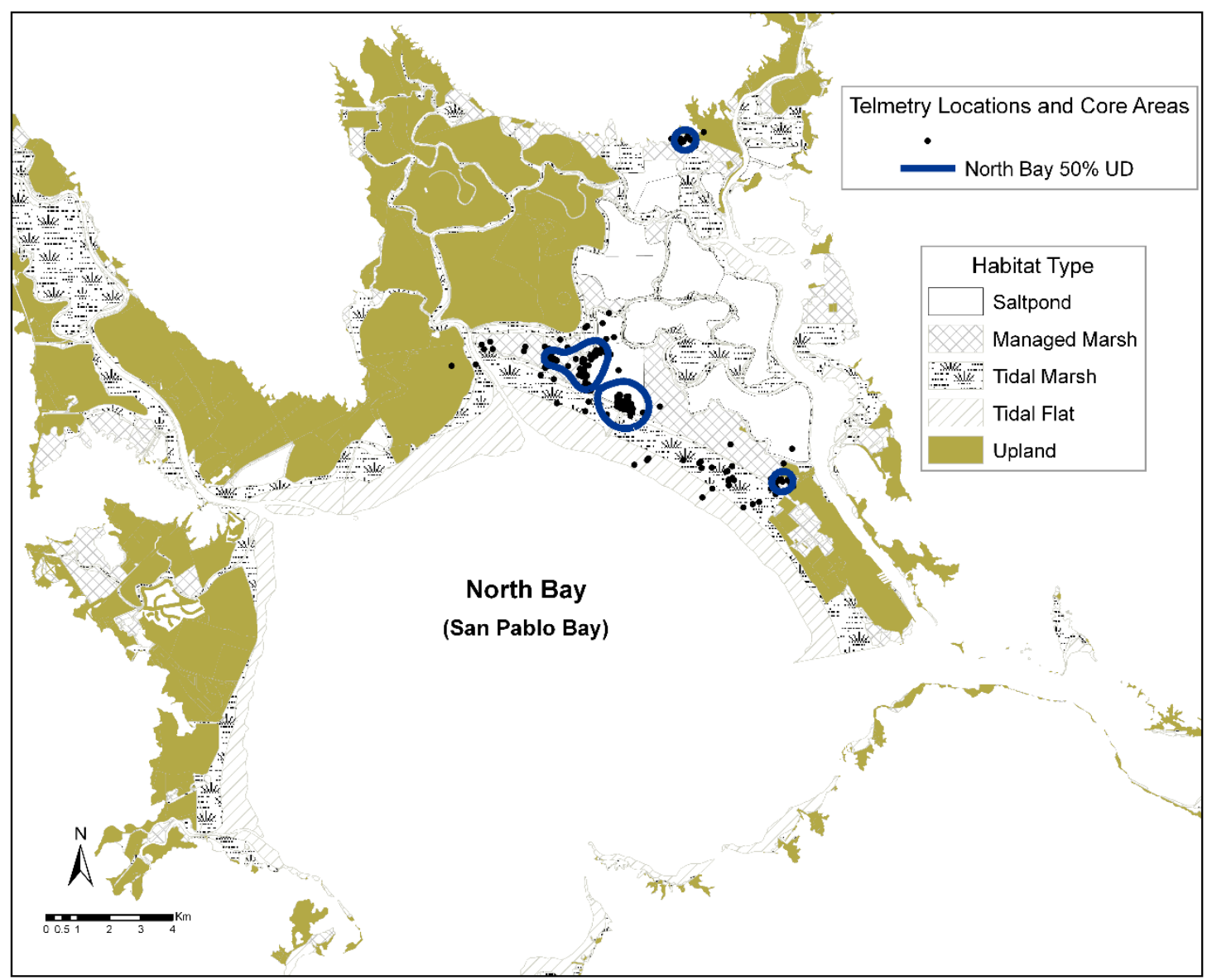

Figure 11. Core use areas and telemetry locations of black-necked stilts radio-marked in the North Bay $(\mathrm{N}=230)$ site in San Francisco Bay, California during spring 2005. UD=utilization distribution. Figure from Ackerman and others (2007) and used with permission. 


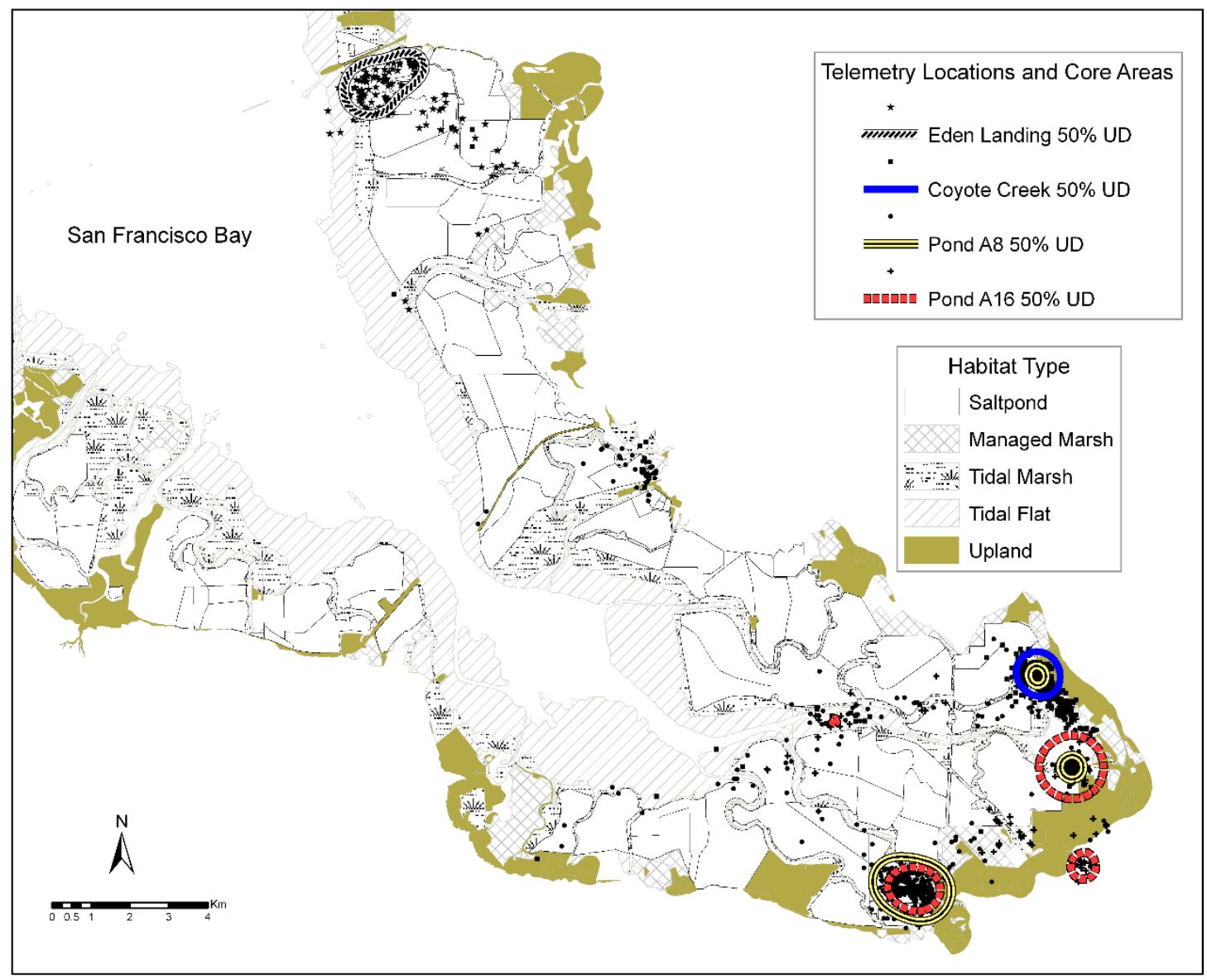

Figure 12. Core use areas and telemetry locations of American avocet females radio-marked in the South Bay at Ponds A8 ( $\mathrm{N}=651)$ and $\mathrm{A} 16(\mathrm{~N}=185)$, Coyote Creek Marsh ( $\mathrm{N}=777)$, and Eden Landing Ecological Reserve $(N=134)$ sites in San Francisco Bay, California, during spring 2006. UD=utilization distribution. Figure from Ackerman and others (2007) and used with permission. 


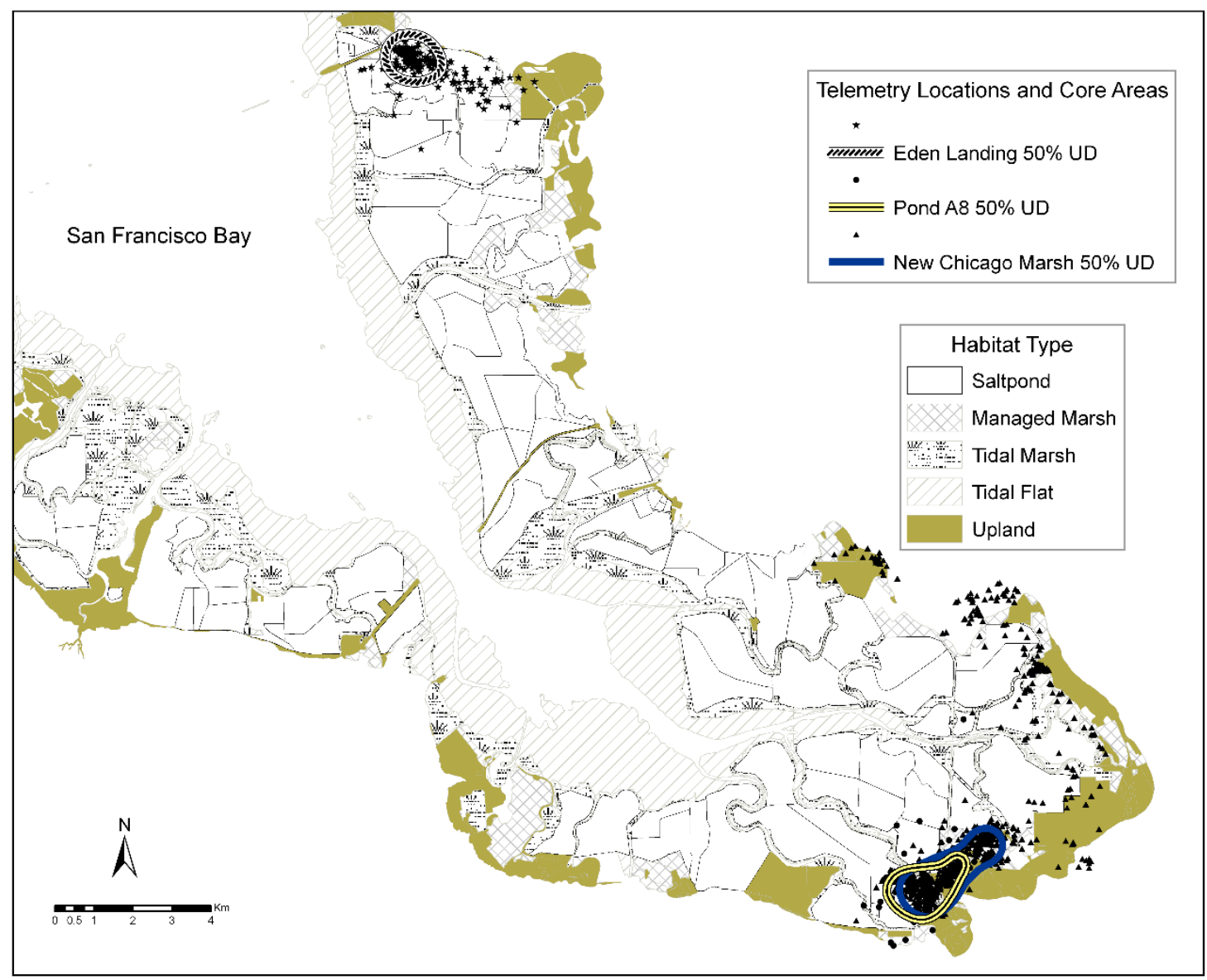

Figure 13. Core use areas and telemetry locations of black-necked stilts radio-marked in the South Bay at New Chicago Marsh ( $\mathrm{N}=905)$, Pond A8 ( $\mathrm{N}=83)$, and Eden Landing Ecological Reserve $(\mathrm{N}=195)$ sites in San Francisco Bay, California, during spring 2006. UD=utilization distribution. Figure from Ackerman and others (2007) and used with permission. 


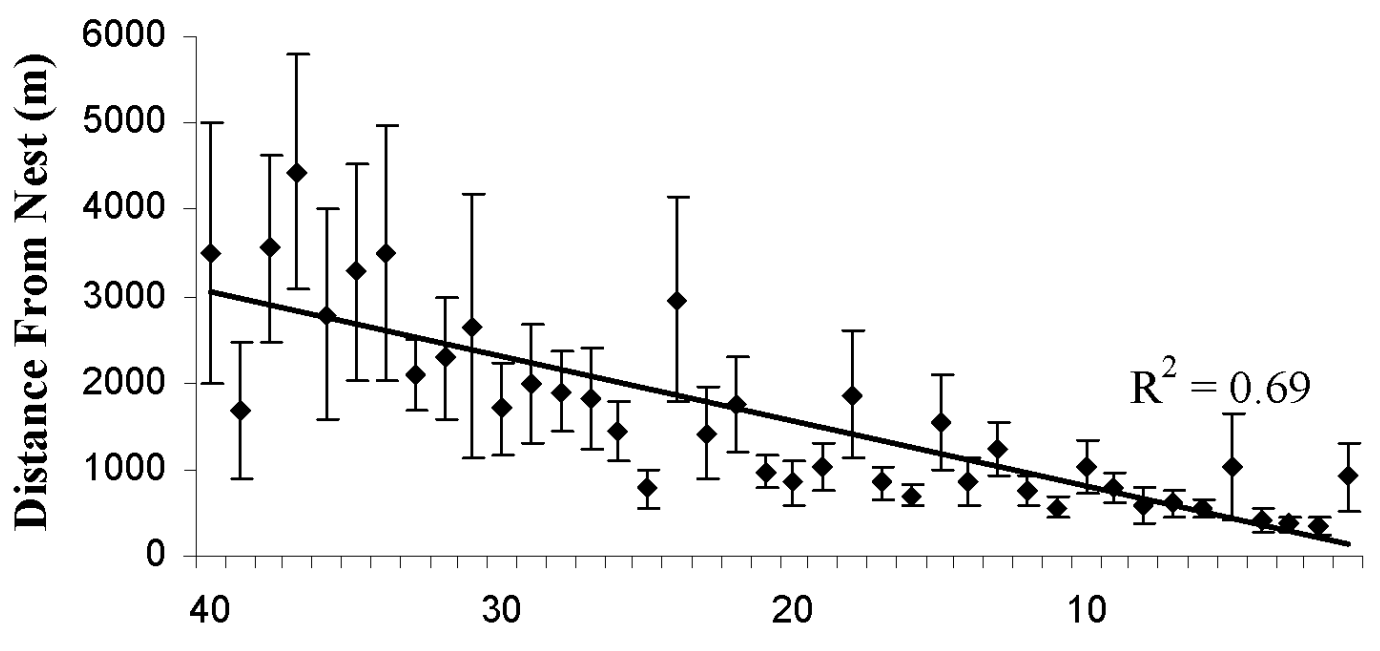

Days Prior To Incubation

Figure 14. Distance (mean $\pm \mathrm{SE}$ ) radio-marked avocets were located from their nests decreased as the nest initiation date approached during the pre-incubation stage in South San Francisco Bay, California, during 2005 and 2006. Figure from Demers and others (2008) and used with permission. 
A.

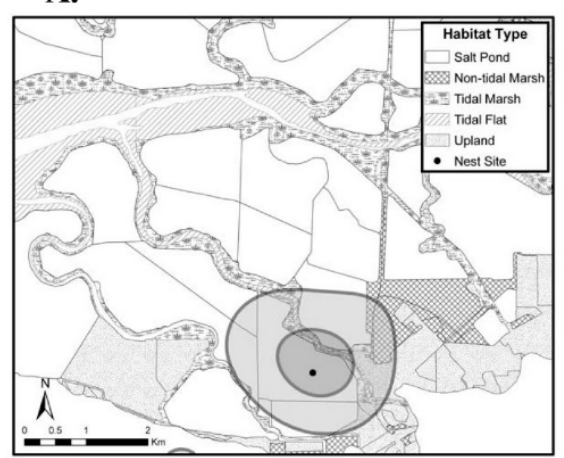

C.

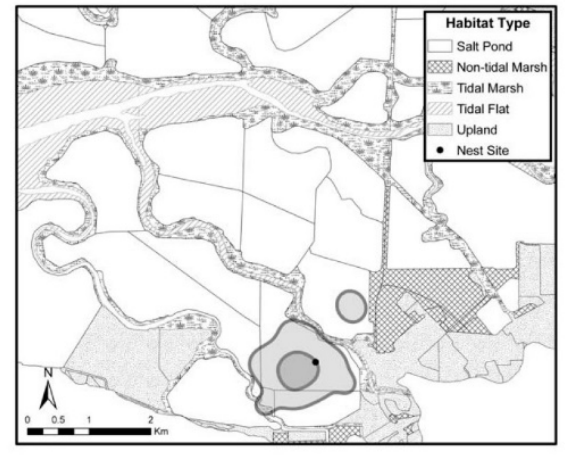

B.

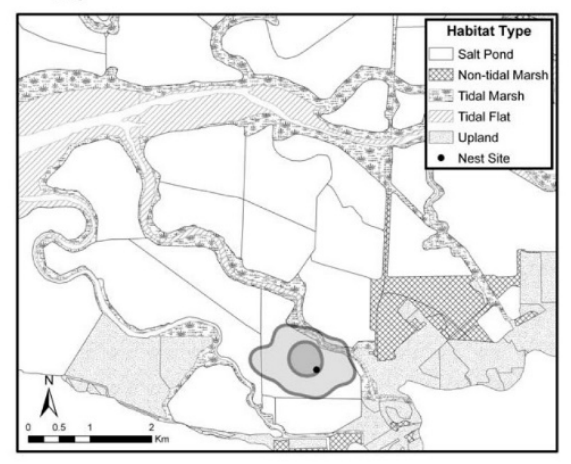

D.

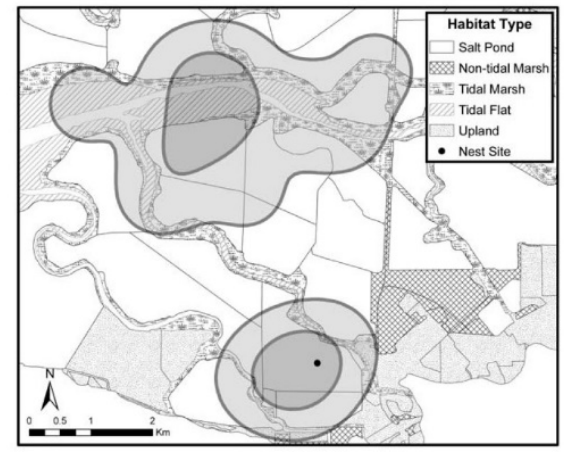

Figure 15. Home range and core area size fluctuations of a representative American avocet during four breeding stages (A) pre-incubation, (B).. incubation, (C) brood-rearing, and (D) post-breeding in the South San Francisco Bay, California. The nest site, represented by the dark point, was located in Pond A8. Home range (95 percent fixed kernel) is represented by the light outer contour and core area (50 percent fixed kernel) is represented by the dark interior contour area. Figure from Demers and others (2008) and used with permission. 


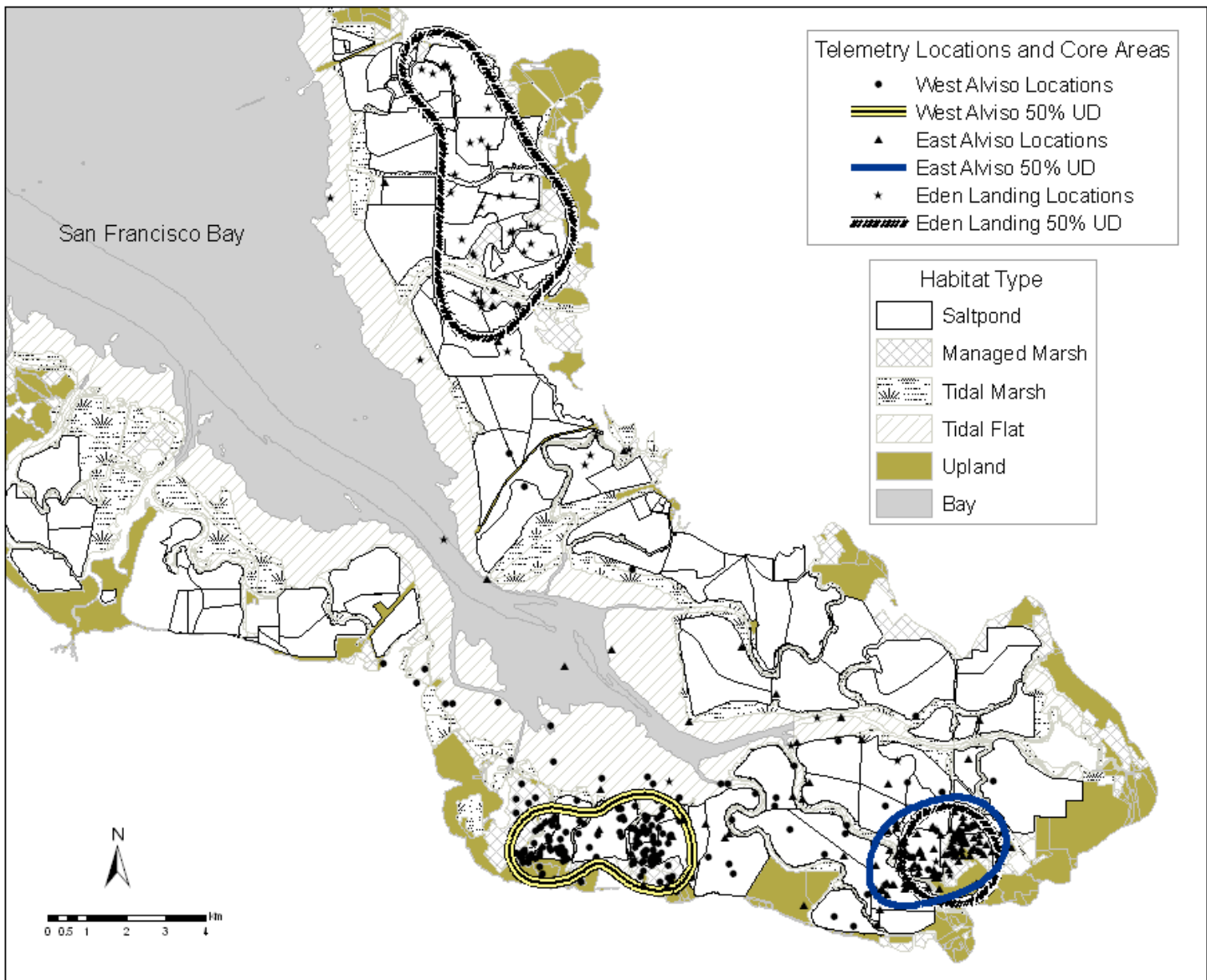

Figure 16. Core use areas ( 50 percent utilization distributions, UD) and telemetry locations of Forster's terns radiomarked in West Alviso (circles, $\mathrm{N}=206$ ), East Alviso (triangles, $\mathrm{N}=141$ ), and Eden Landing Ecological Reserve (stars, $\mathrm{N}=62$ ) sites in south San Francisco Bay, California, during spring 2005. UD=utilization distribution. Figure from Ackerman and others (2008a) and used with permission. 


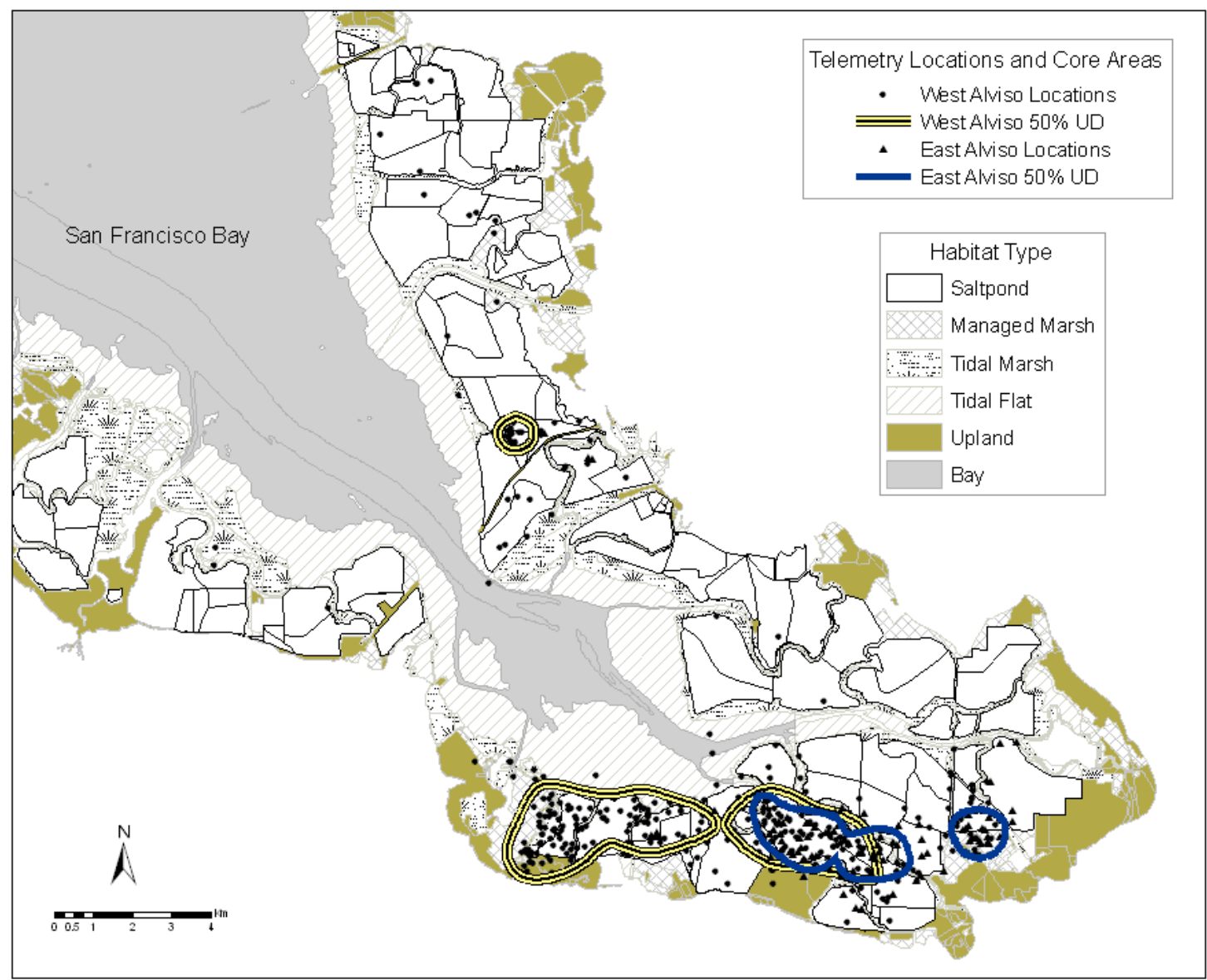

Figure 17. Core use areas (50 percent utilization distributions, UD) and telemetry locations of Forster's terns radiomarked in West Alviso (circles, $\mathrm{N}=360$ ) and East Alviso (triangles, $\mathrm{N}=111$ ) sites in south San Francisco Bay, California, during spring 2006. UD=utilization distribution. Figure from Ackerman and others (2008a) and used with permission. 


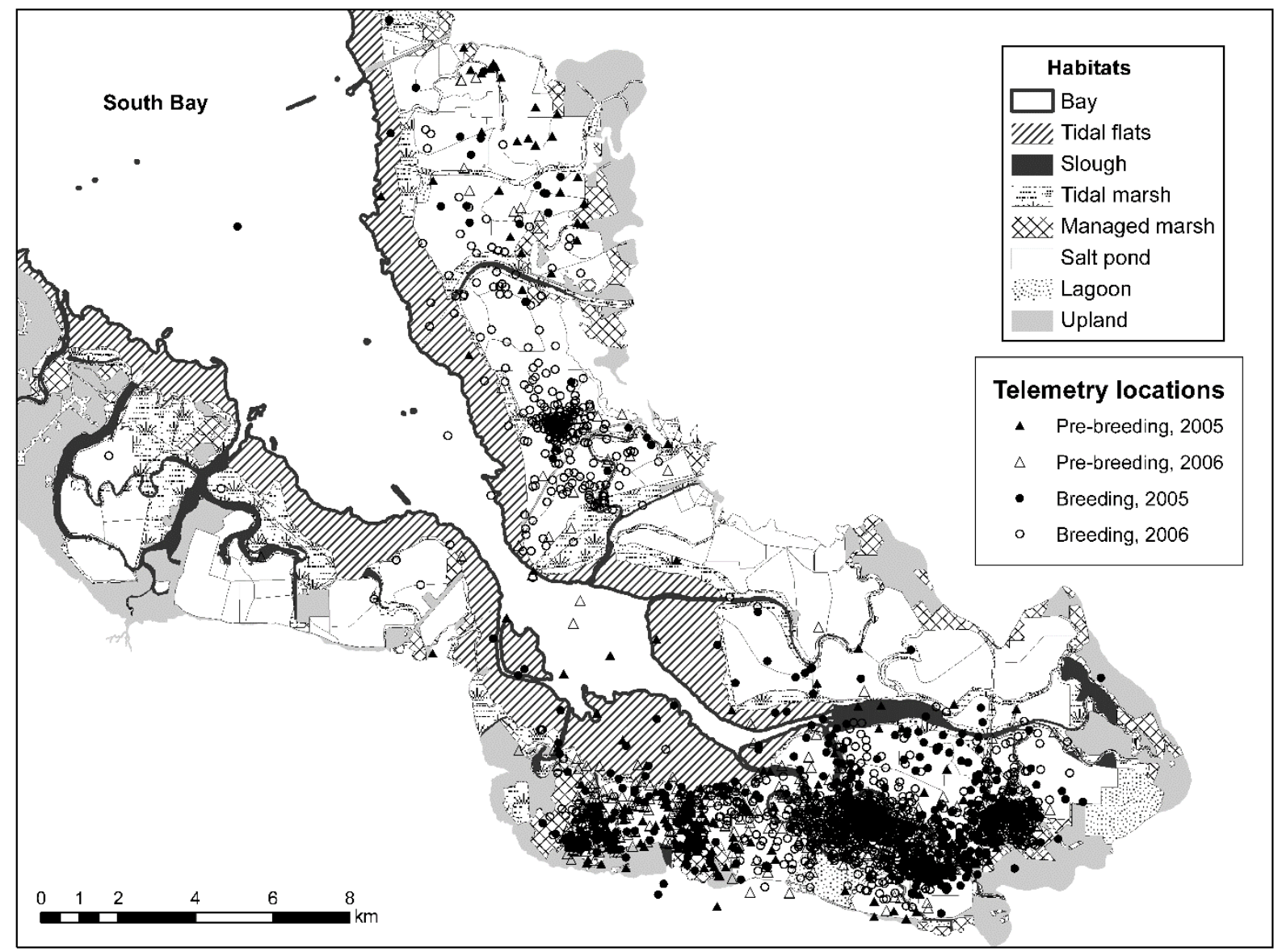

Figure 18. Radio-telemetry locations of Forster's terns in South San Francisco Bay, California, during 2005 and 2006, with the dominant habitat types depicted. Figure from Bluso-Demers and others (unpublished data). 


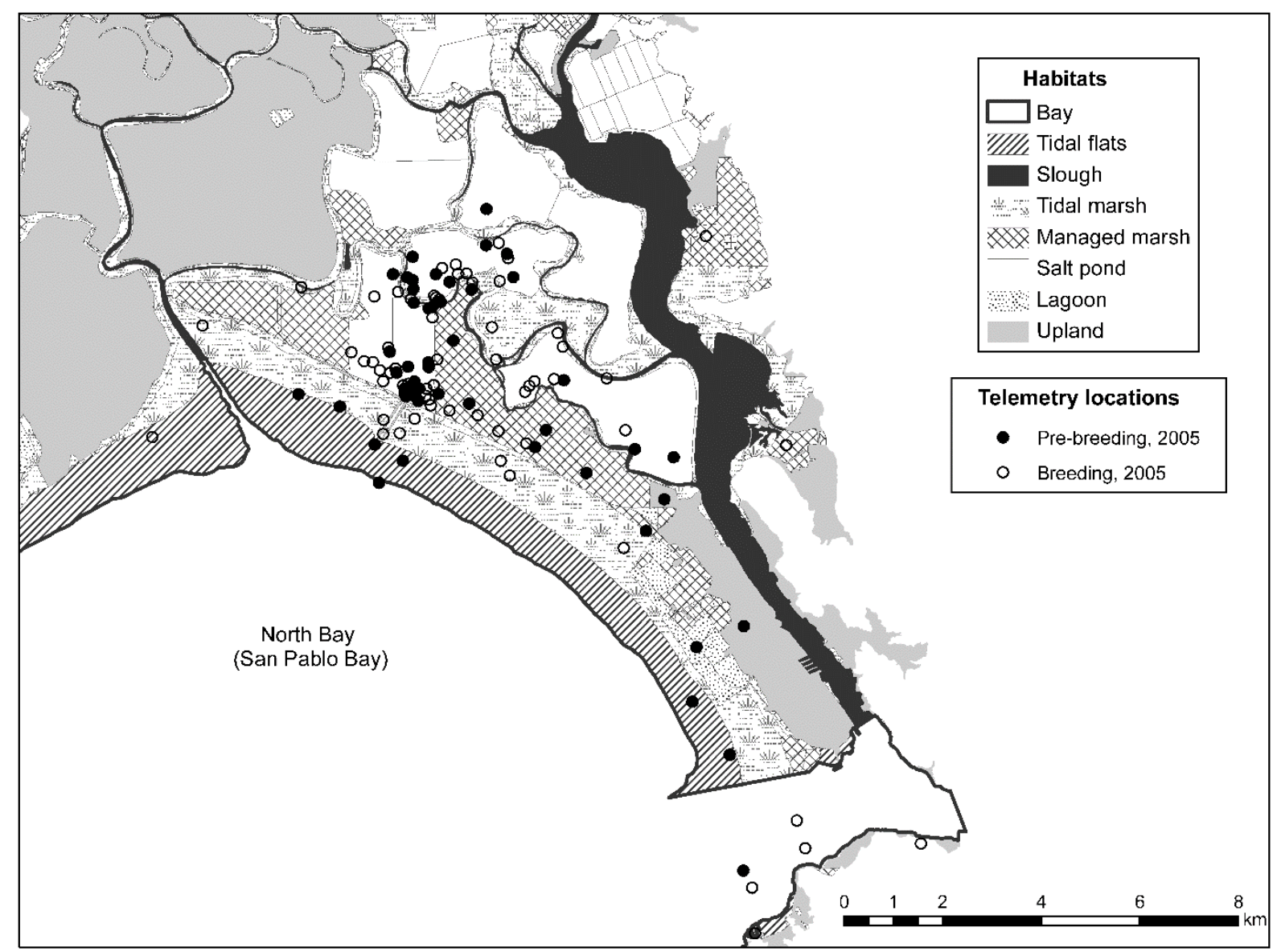

Figure 19. Radio-telemetry locations of Forster's terns in North San Francisco Bay, California, during 2005, with the dominant habitat types depicted. Figure from Bluso-Demers and others (unpublished data). 


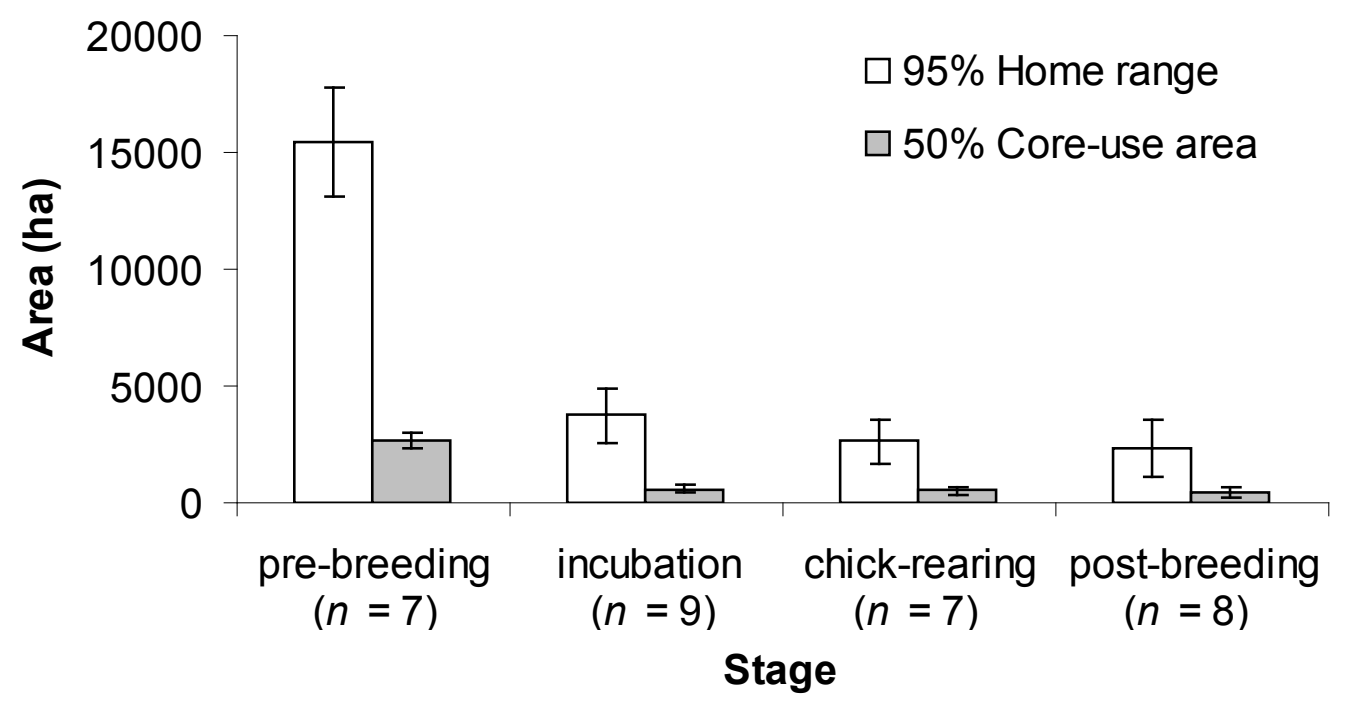

Figure 20. The mean ( \pm standard error) home-range and core-area size of Forster's terns in South San Francisco Bay, California, in relation to breeding stage during 2005 and 2006. Figure from Bluso-Demers and others (unpublished data). 

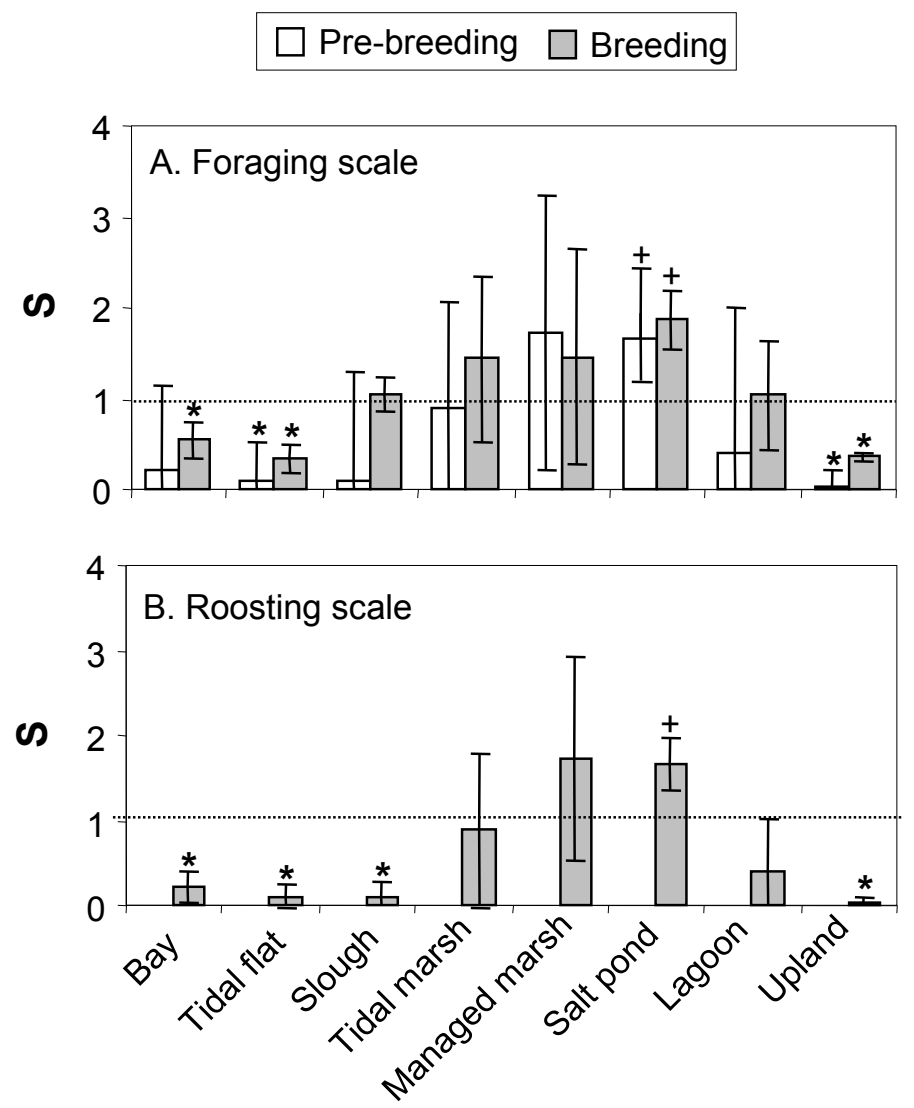

Habitats

Figure 21. Seasonal habitat selection ratios ( $S$; mean and simultaneous Bonferroni 95 percent confidence intervals) of (A) foraging and (B) roosting Forster's terns in San Francisco Bay, California, during 2005 and 2006. Symbols indicate selection of a habitat $(+)$ and avoidance of a habitat $\left({ }^{*}\right)$. Figure from Bluso-Demers and others (unpublished data). 


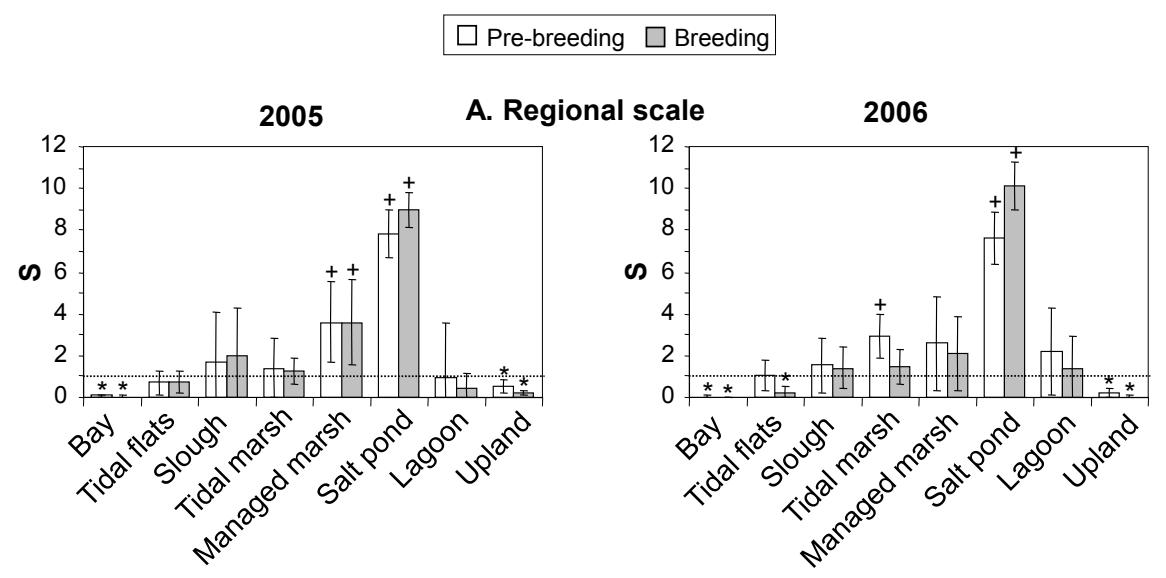

B. Core-area scale
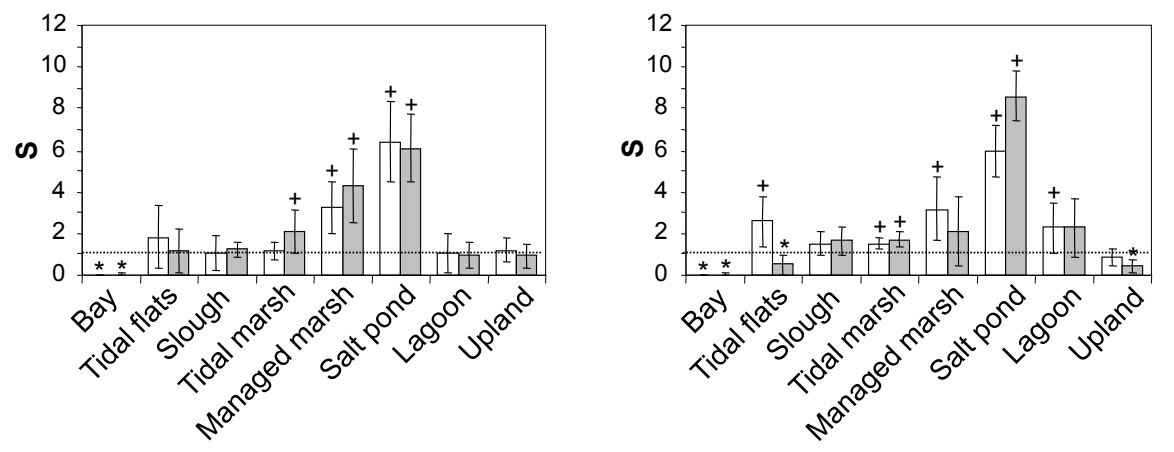

C. Location scale
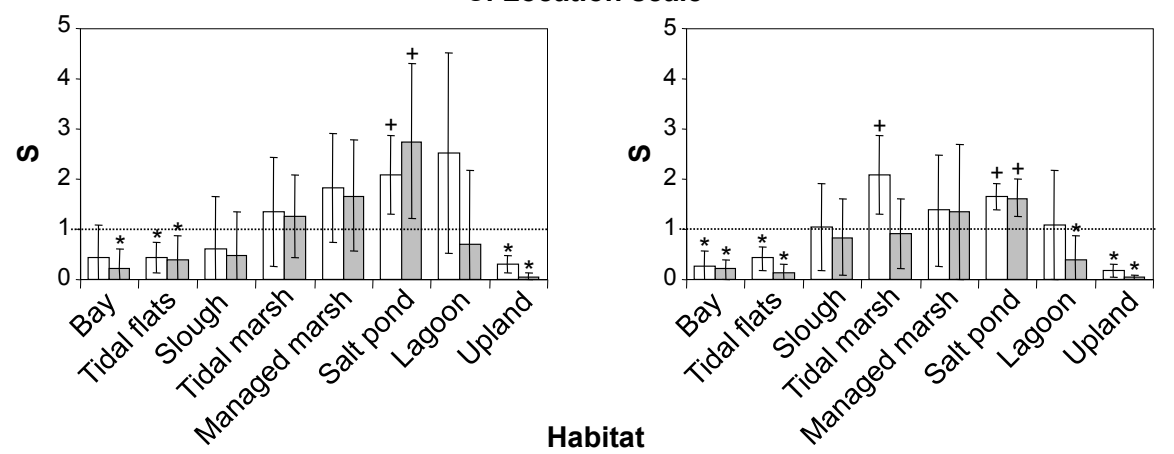

Figure 22. Habitat selection ratios ( $S$; mean and simultaneous Bonferroni 95 percent confidence intervals) of prebreeding and breeding Forster's terns in San Francisco Bay, California, during 2005 and 2006. Habitat selection was assessed hierarchically at four spatial scales: $(A)$ regional, $(B)$ core-area, and $(C)$ location. Symbols indicate selection of a habitat $(+)$ and avoidance of a habitat $\left(^{*}\right)$. Figure from Bluso-Demers and others (unpublished data). 


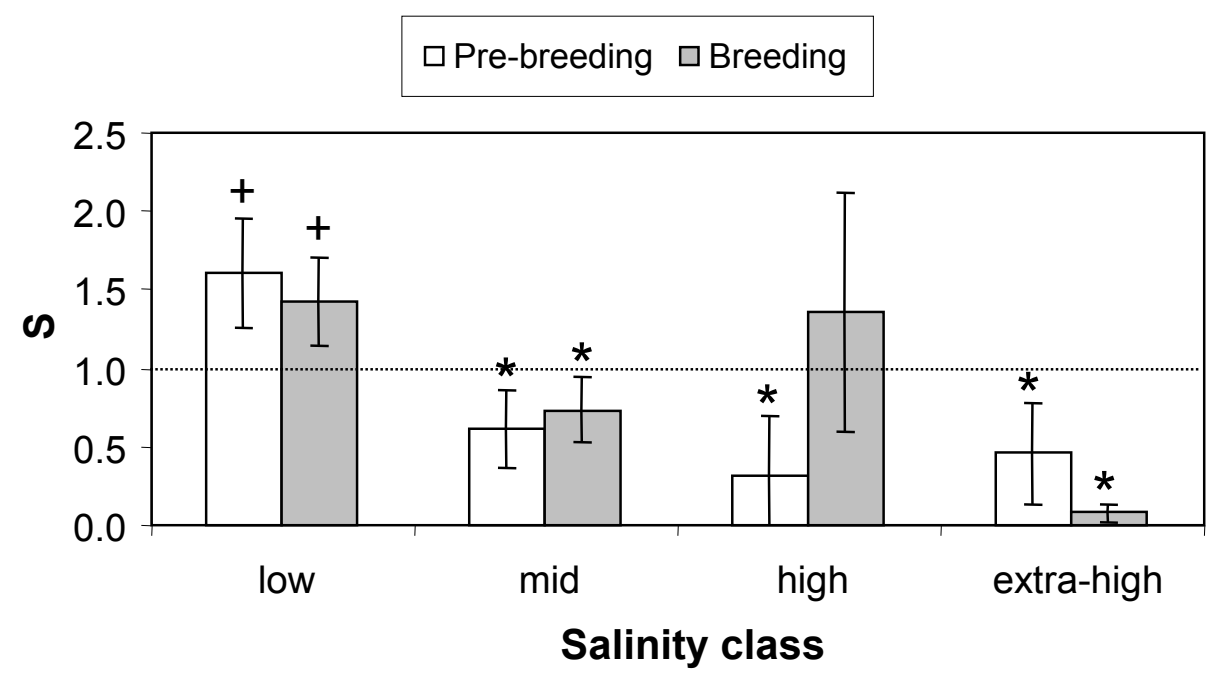

Figure 23. Habitat selection ratios ( $S$; mean and simultaneous Bonferroni 95 percent confidence intervals) of prebreeding and breeding Forster's terns in San Francisco Bay, California, in salt ponds during 2005 and 2006. Symbols indicate selection of a habitat $(+)$ and avoidance of a habitat $\left({ }^{*}\right)$. Figure from Bluso-Demers and others (unpublished data). 


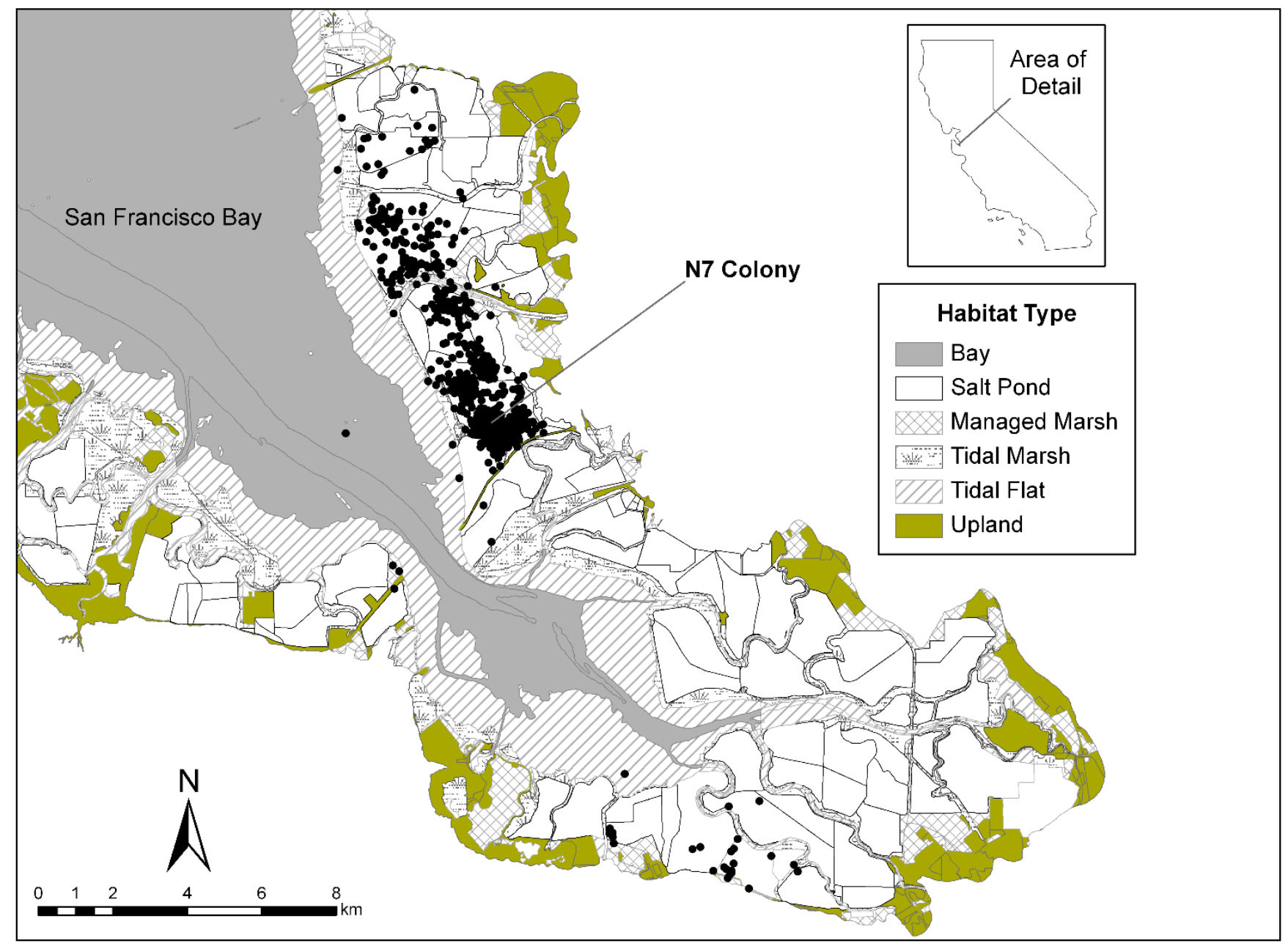

Figure 24. Telemetry locations of postfledging Forster's terns radio-marked at the Pond N7 colony in south San Francisco Bay, California, during 2006. Figure from Ackerman and others (2009) and used with permission. 


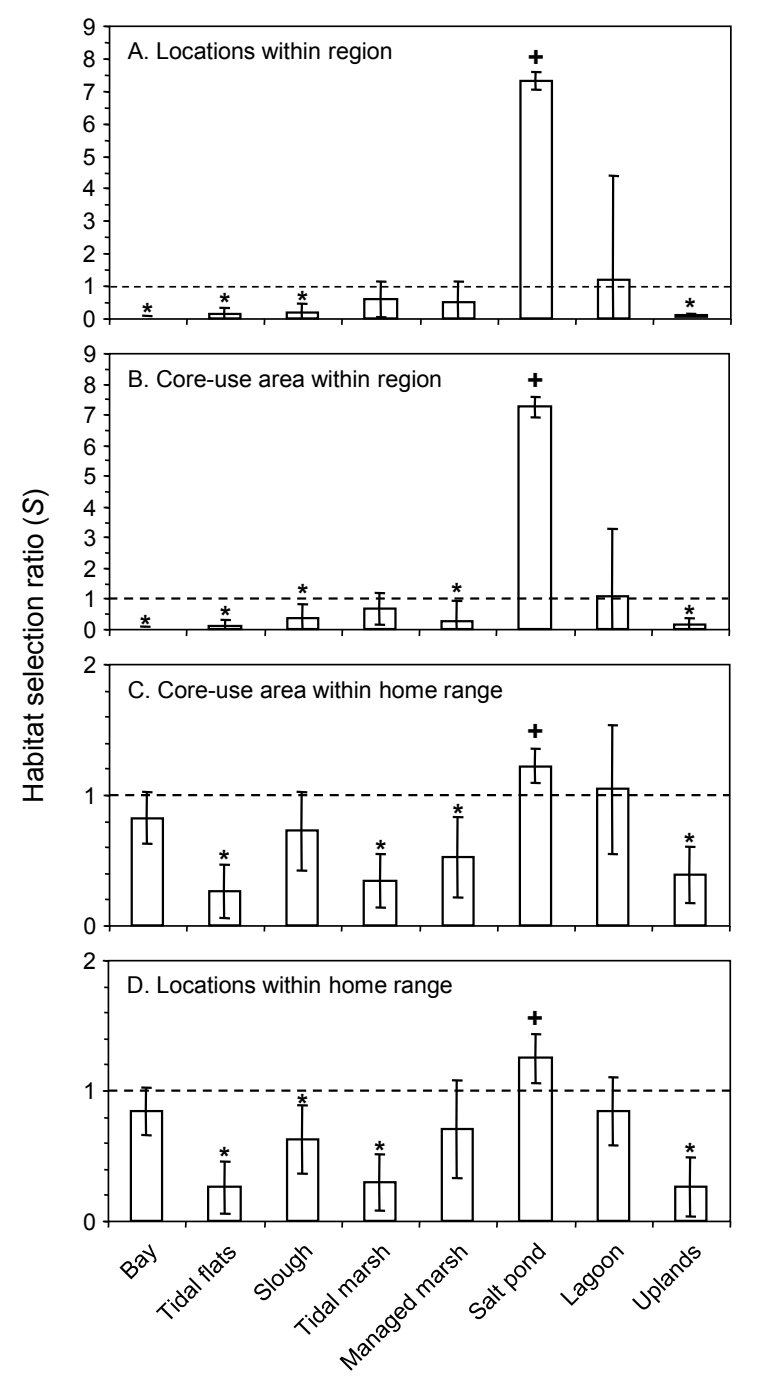

Figure 25. Habitat selection ratios ( $S$; mean and simultaneous 95 percent confidence limits calculated using the Bonferroni inequality) of postfledging Forster's terns radio-marked at the Pond N7 colony in south San Francisco Bay, California, during 2006. Habitat selection was assessed hierarchically at four spatial scales: (A) locations within region, (B) core-use area within region, (C) core-use area within home range, and (D) locations within home range. Dashed line at $S=1$ indicates the selection ratio where habitat was used in proportion to its availability; values $>1$ indicate habitat selection and $<1$ indicate habitat avoidance. Symbols indicate significant selection of a habitat (+) and significant avoidance of a habitat (*). Figure from Ackerman and others (2009) and used with permission. 

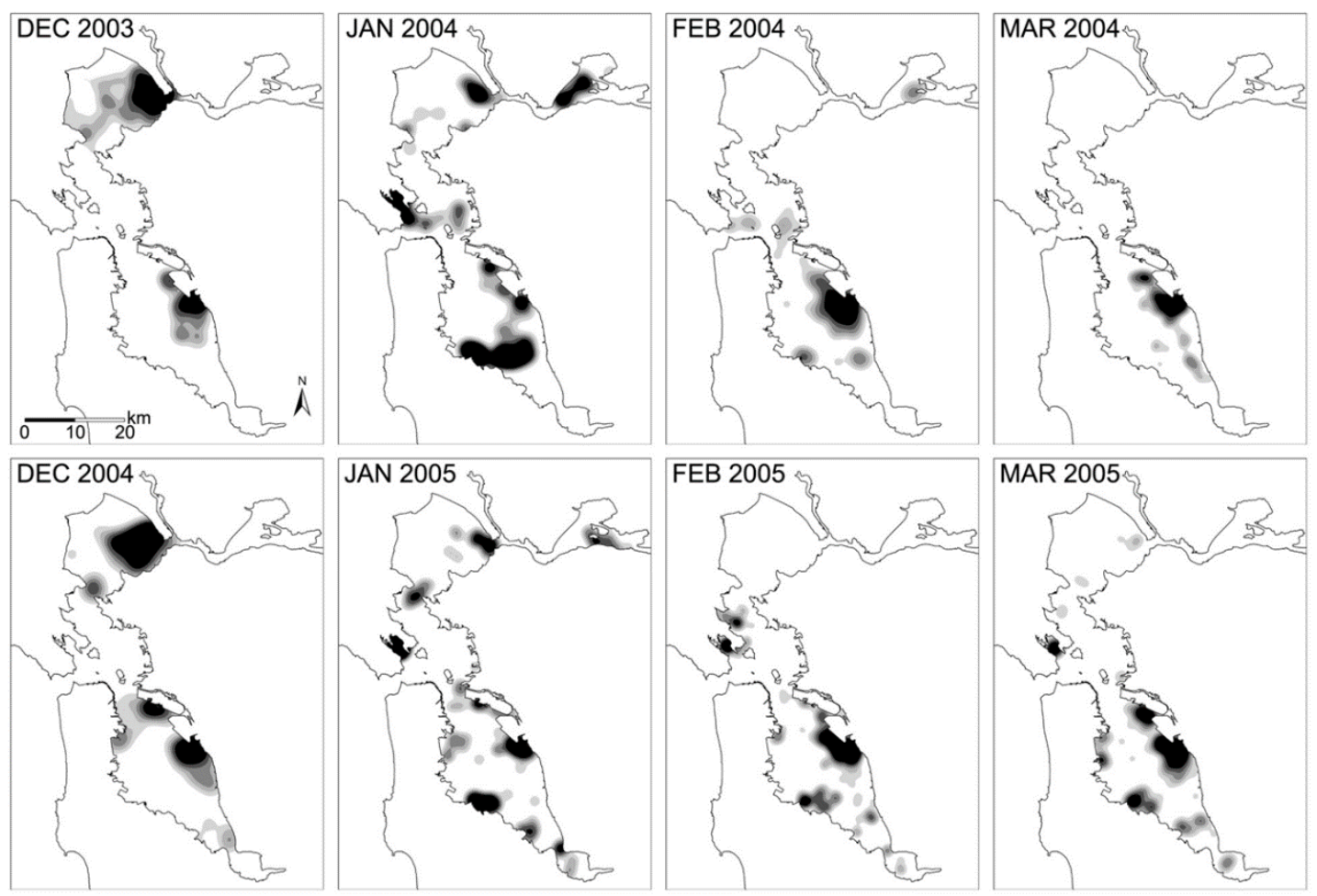

Figure 26. Monthly collective range estimates of all radio-marked surf scoters in San Francisco Bay, California, during four winter months in 2003-04 and 2004-05. Fixed-kernel densities were determined from birds with five or more locations during a month to reduce bias towards individuals with more locations. Figure from De La Cruz and others (2014) and used with permission.

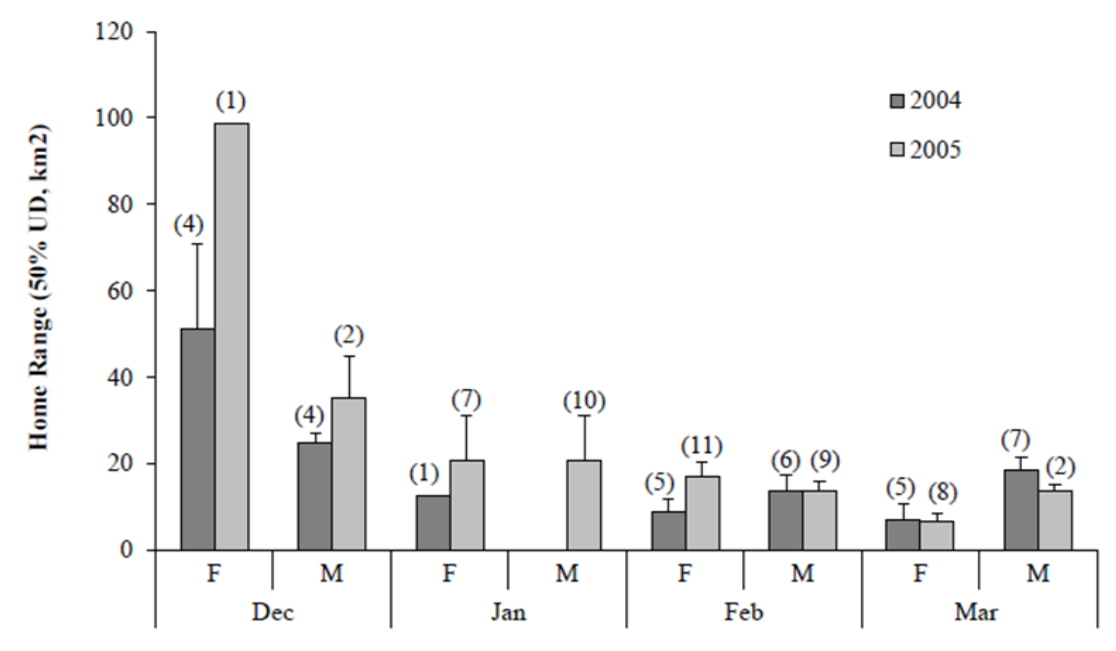

Figure 27. Mean $( \pm S E)$ home range sizes (50 percent fixed kernel density) of individual male and female radiomarked surf scoters in San Francisco Bay, California, decreased over 4 months during winter 2003-04 and 2004-05. Sample sizes are indicated in parentheses. Figure from De La Cruz and others (2014) and used with permission. 


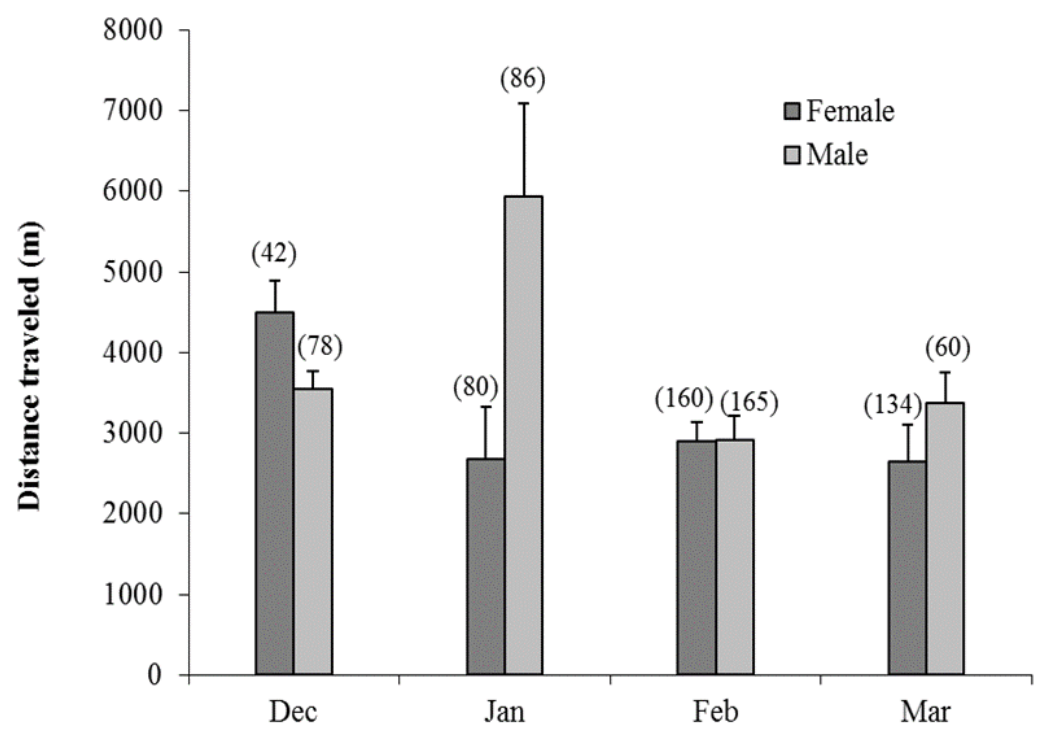

Figure 28. Mean $( \pm S E)$ monthly distance traveled between locations for radio-marked males and female surf scoters during the winters of 2003-04 and 2004-05 in San Francisco Bay, California. Sample sizes are indicated in parentheses. Figure from De La Cruz and others (2014) and used with permission. 


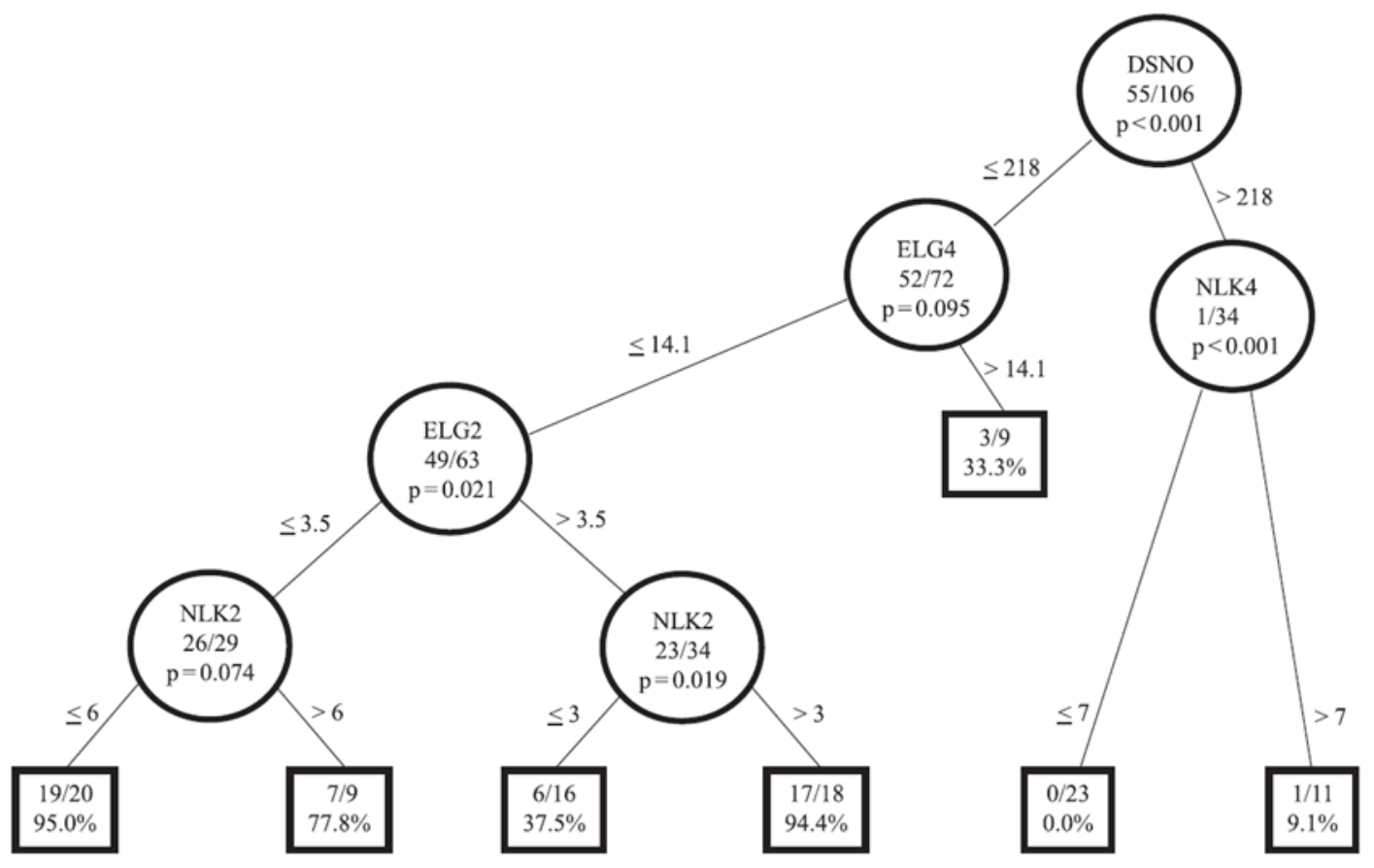

Figure 29. Classification and regression tree (CART) for Pacific coast surf scoters breeding in the northern boreal forest of Canada. The explanatory variable being split, the number of surf scoter breeding locations in the numerator and number of total locations (nesting areas and random locations) in the denominator, and the pvalue associated with the split are included in each circle. Splitting values are indicated along the branches, and boxes indicate terminal node percentages of total locations comprised of surf scoter breeding locations. Splitting variables include distance to snowline (DSNO), elevation gradient $(\mathrm{m} / \mathrm{km})$ at $4 \times 4 \mathrm{~km}$ (ELG4), and number of lakes at $4 \times 4 \mathrm{~km}$ (NLK4) and $2 \times 2 \mathrm{~km}$ (NLK2). Figure from Takekawa and others (2011) and used with permission. 


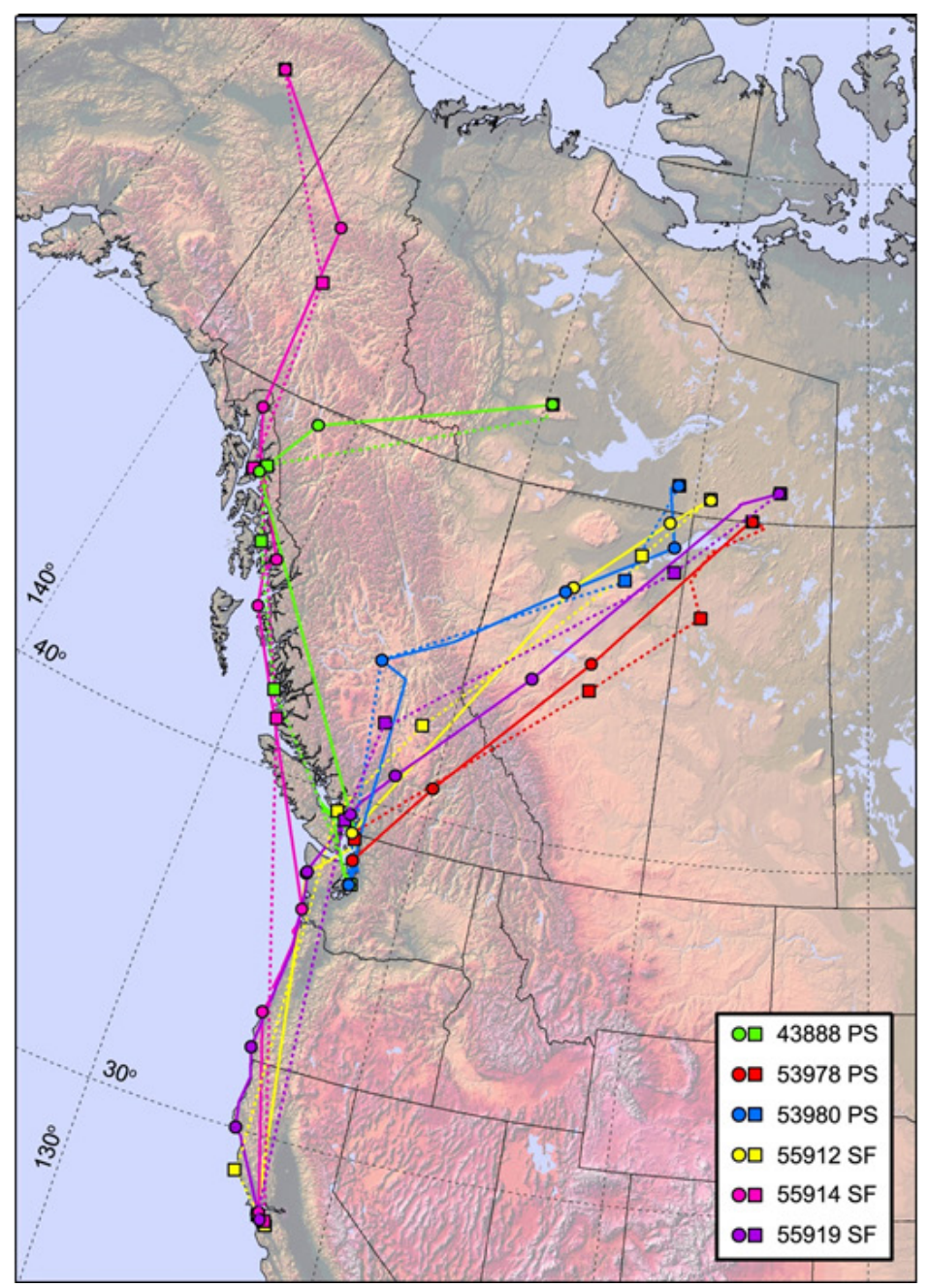

Figure 30. Repeated migratory routes for six individual surf scoters from two wintering sites (Puget Sound: PS, San Francisco Bay: SF) followed by satellite transmitter during the springs of 2005 and 2006. Solid lines represent first journeys (2005) and dashed lines indicate second journeys (2006). Solid circles represent stopover sites in 2005, and solid squares represent stopovers in 2006. Figure from De La Cruz and others (2009) and used with permission. 


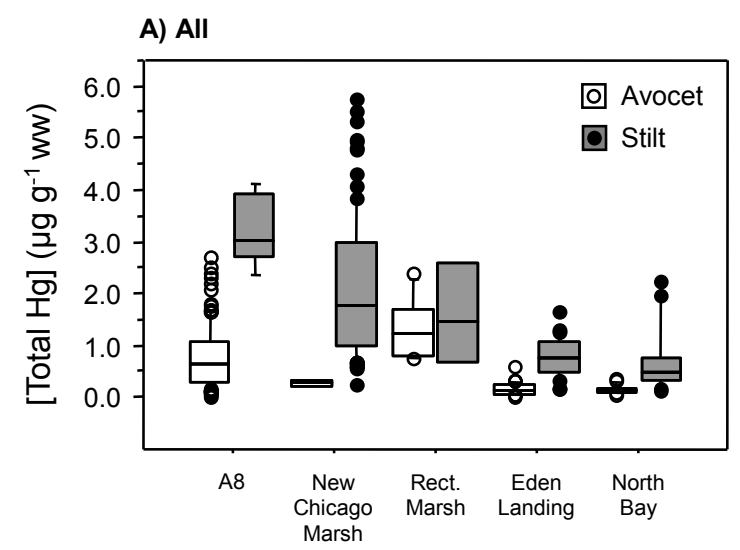

B) Stilts
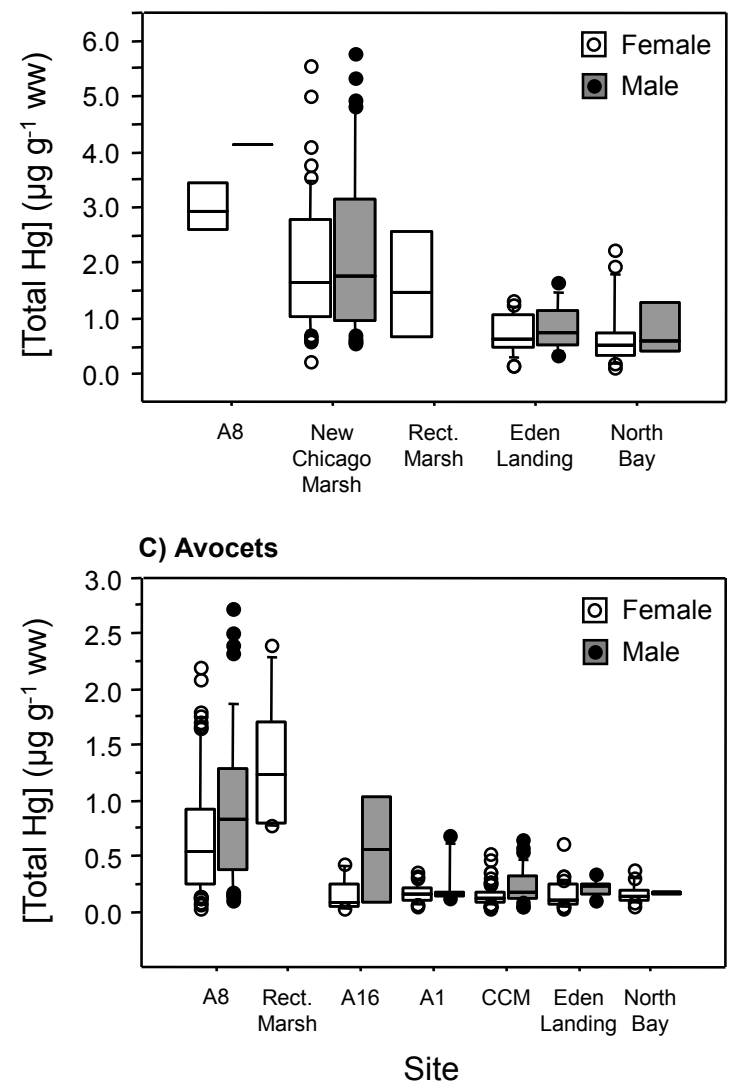

Figure 31. Blood mercury concentrations ( $\mu \mathrm{g} / \mathrm{g}$ wet weight, ww) of American avocets and black-necked stilts among sites in San Francisco Bay, California, during spring 2005 and 2006. (A) Black-necked stilts and American avocets at several sites. (B) Black-necked stilt females and males. (C) American avocet females and males. Figure from Ackerman and others (2007) and used with permission. 

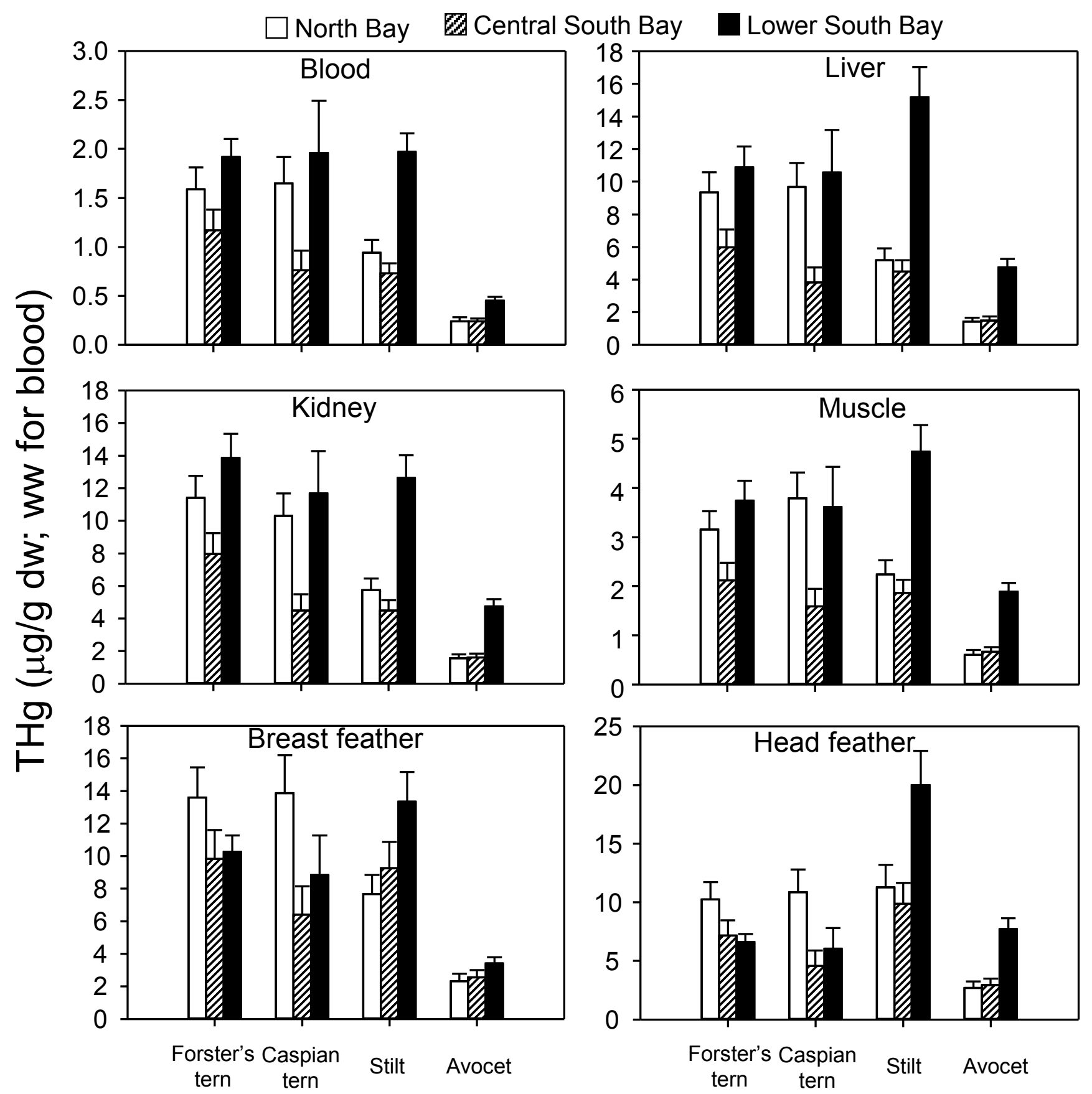

Figure 32. Total mercury (THg) concentrations (least squares mean $\pm \mathrm{SE}$ ) in various tissues of four waterbird species form North Bay (open bars), Central South Bay (hatched bars), and Lower South Bay (solid bars) in San Francisco Bay, California, during 2005 and 2006. Figure from Eagles-Smith and others (2009a) and used with permission. 


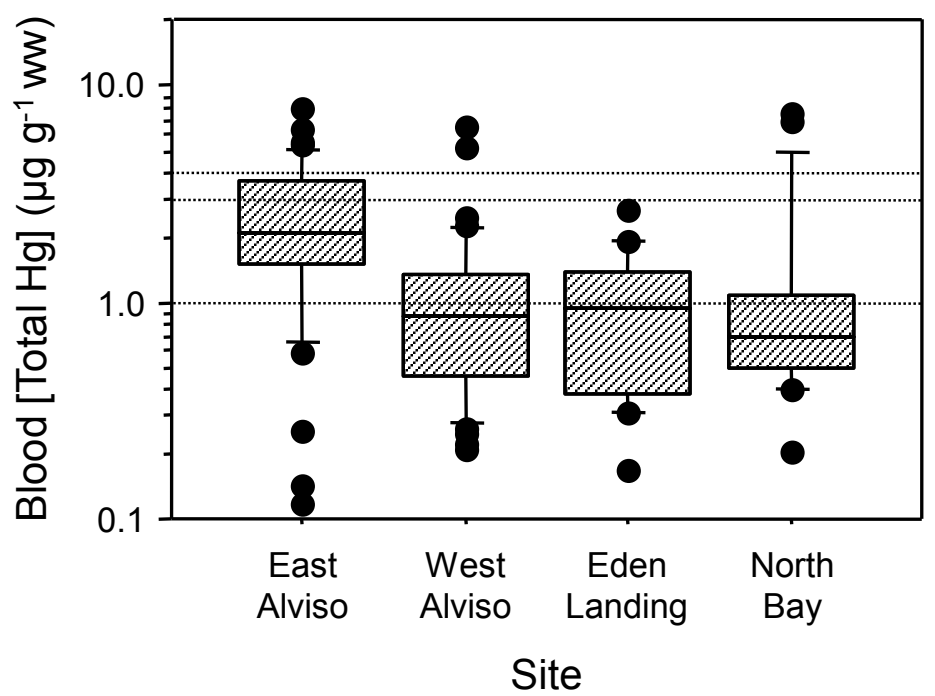

Figure 33. Total mercury concentrations ( $\mu \mathrm{g} / \mathrm{g}$ wet weight [ww]) in blood of Forster's terns differed among sites in San Francisco Bay, California, during spring 2005 and 2006. Sample sizes were 40 in East Alviso, 40 in West Alviso, 20 in Eden Landing Ecological Reserve, and 22 in North Bay. Dashed lines represent levels of risk to birds, including moderate risk (>1.0 $\mathrm{\mu g} / \mathrm{g}$ wet weight), high risk (>3.0 $\mathrm{\mu g} / \mathrm{g}$ wet weight), and extra-high risk (>4.0 $\mu \mathrm{g} / \mathrm{g}$ wet weight), that have been associated with deleterious effects in other species. Figure from Ackerman and others (2008a) and used with permission. 


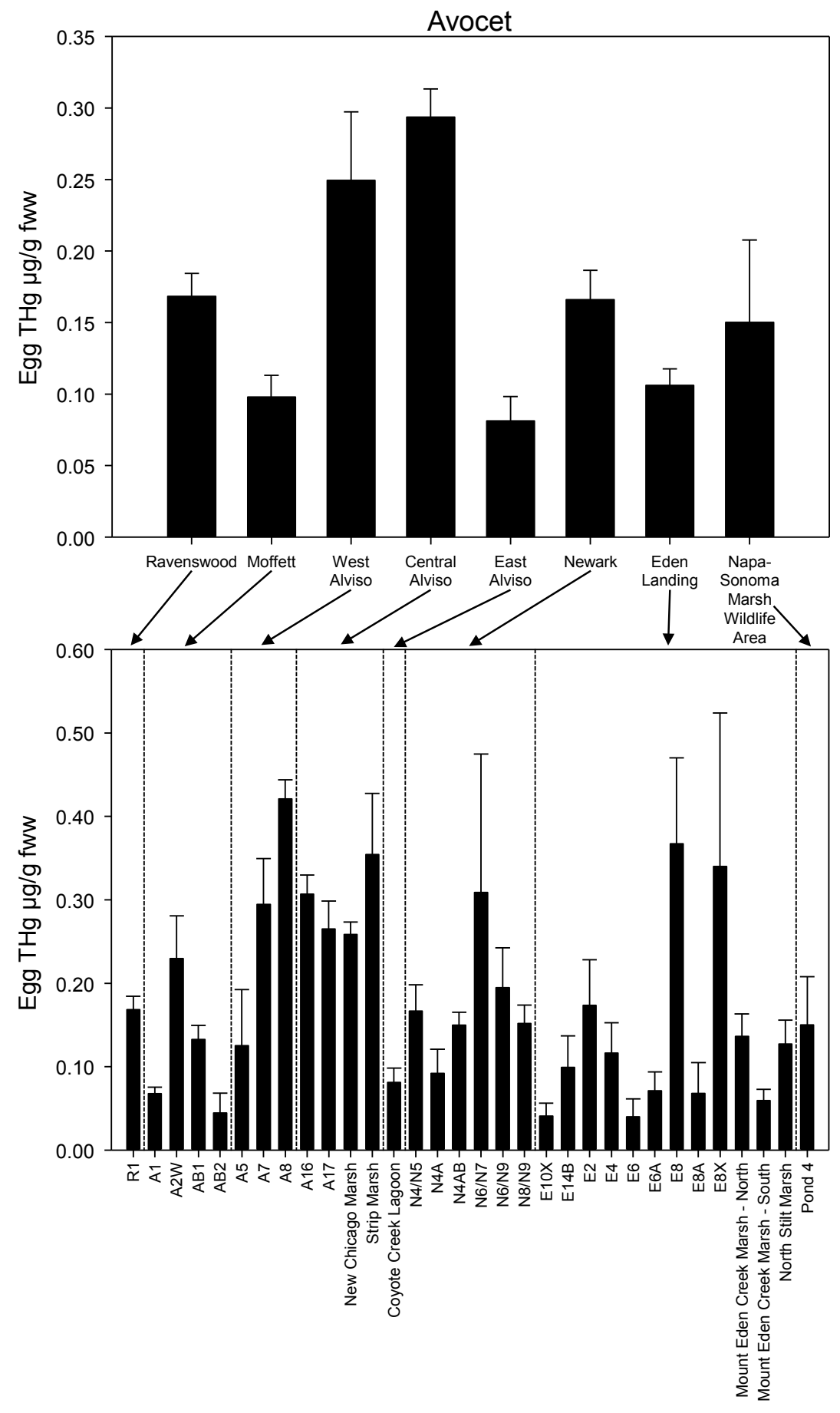

Figure 34. Total mercury (THg) concentrations (least squares mean $\pm \mathrm{SE}$ ) in eggs of American avocets among regions and wetland sites within San Francisco Bay, California, during 2005-07. Least squares means account for the global model effects of region, wetland site nested in region, year, and nest initiation date. 


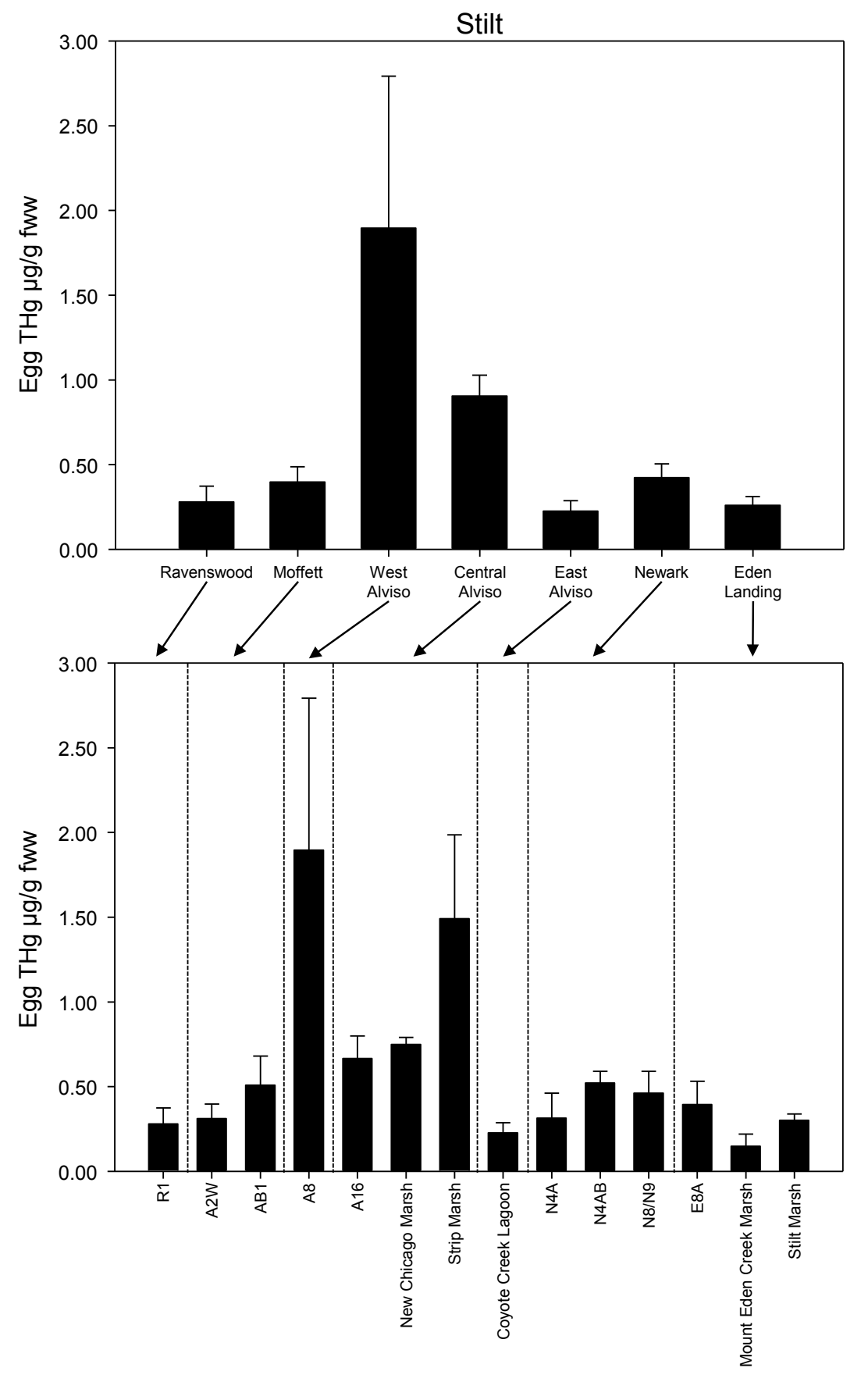

Figure 35. Total mercury (THg) concentrations (least squares mean $\pm \mathrm{SE}$ ) in eggs of black-necked stilts among regions and wetland sites within San Francisco Bay, California, during 2005-07. Least squares means account for the global model effects of region, wetland site nested within region, year, and nest initiation date. 


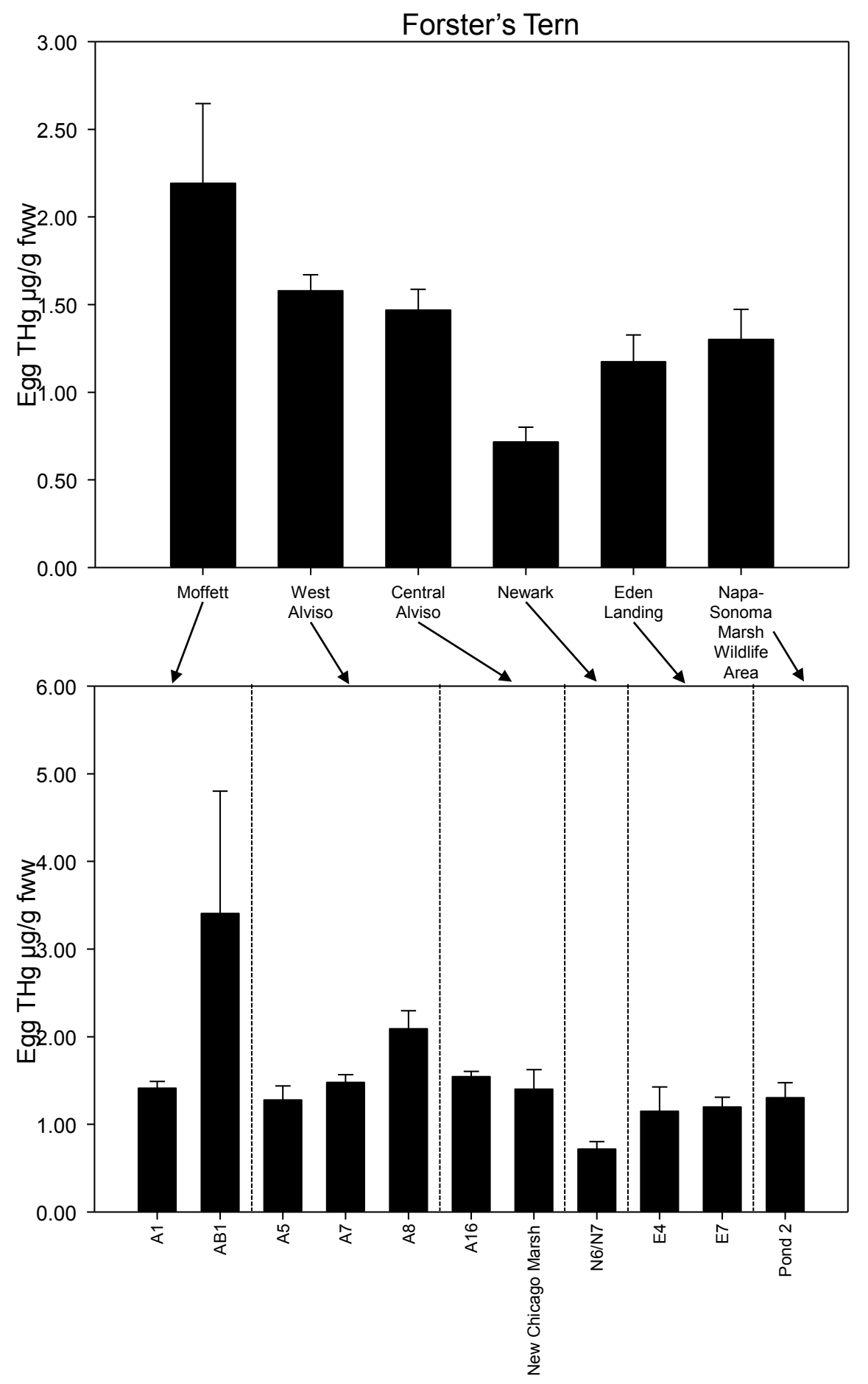

Figure 36. Total mercury ( $\mathrm{THg}$ ) concentrations (least squares mean $\pm \mathrm{SE}$ ) in eggs of Forster's terns among regions and wetland sites within San Francisco Bay, California, during 2005-07. Least squares means account for the global model effects of region, wetland site nested within region, year, and nest initiation date. 


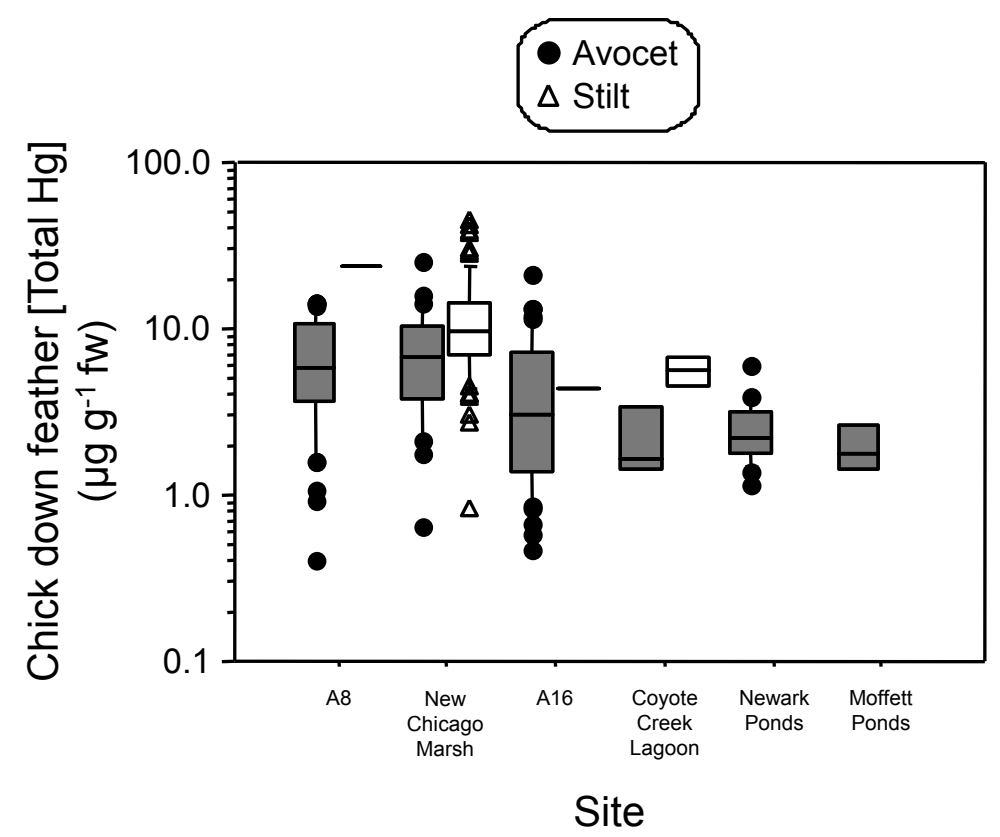

Figure 37. Box plots depicting total mercury concentrations ( $\mu \mathrm{g} / \mathrm{g}$ fresh weight [fw]) in down feathers of American avocet (filled) and black-necked stilt chicks (unfilled) at hatching differed among sites in South San Francisco Bay, California, during spring 2005 and 2006. Sample sizes for avocet and stilt chicks, respectively, were 53 and 1 in Pond A8, 27 and 75 in New Chicago Marsh, 50 and 1 in A16, 3 and 2 in Coyote Creek Lagoon, 21 and 0 in Newark Ponds, and 4 and 0 in Moffett Ponds. Figure from Ackerman and others (2008d) and used with permission. 

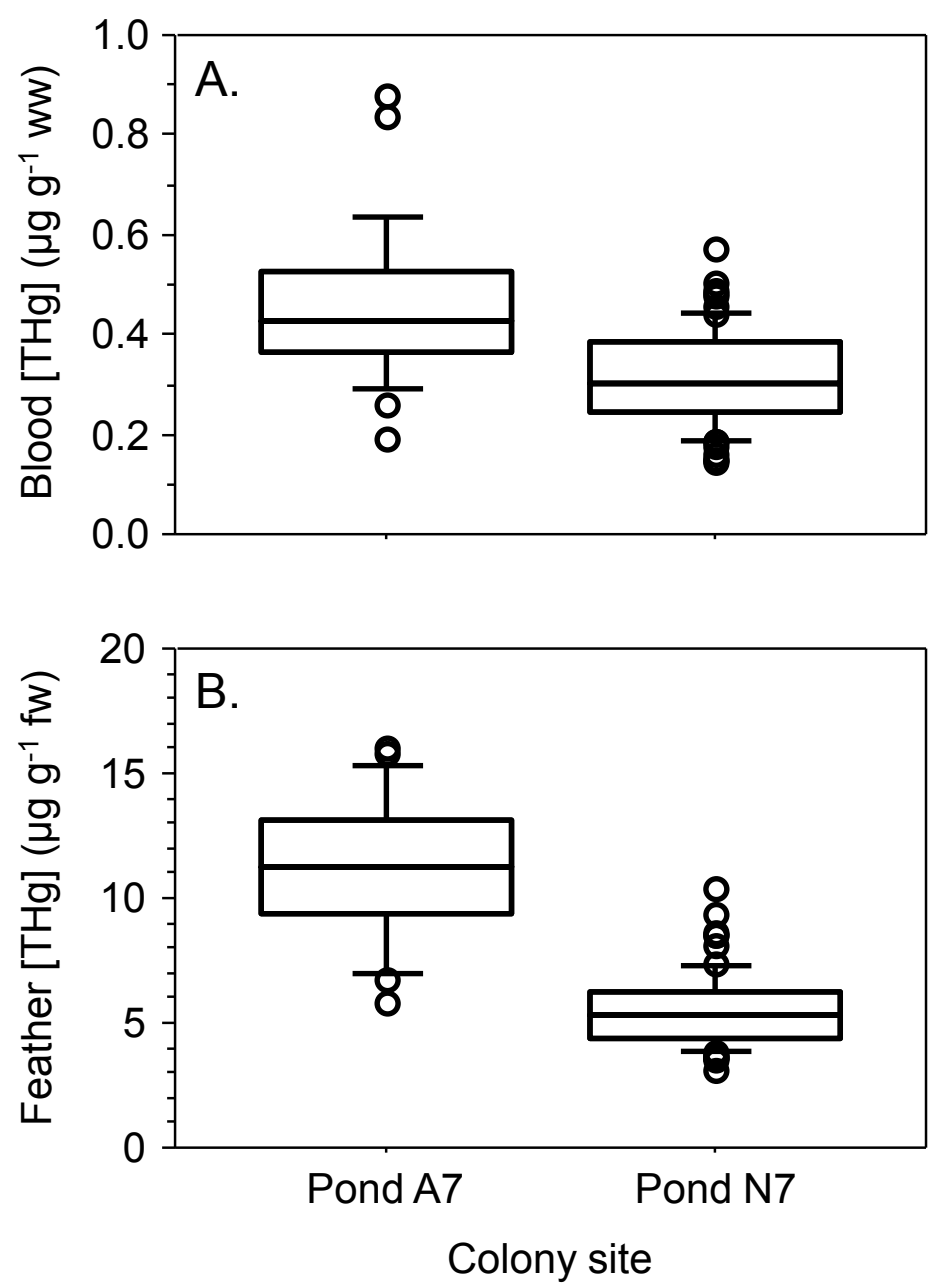

Figure 38. Box plots depicting total mercury concentrations (THg) in (A) blood ( $\mu \mathrm{g} / \mathrm{g}$ wet weight [ww]) and (B) breast feathers ( $\mu \mathrm{g} / \mathrm{g}$ fresh weight [fw]) of Forster's tern chicks nearing fledging in South San Francisco Bay, California, during summer 2006. Sample sizes were $(A) N=23$ and $(B) N=23$ for fledglings in Pond $A 7$ and $(A)$ $N=67$ and $(B) N=66$ for fledglings in Pond N7. Figure from Ackerman and others (2008b) and used with permission. 


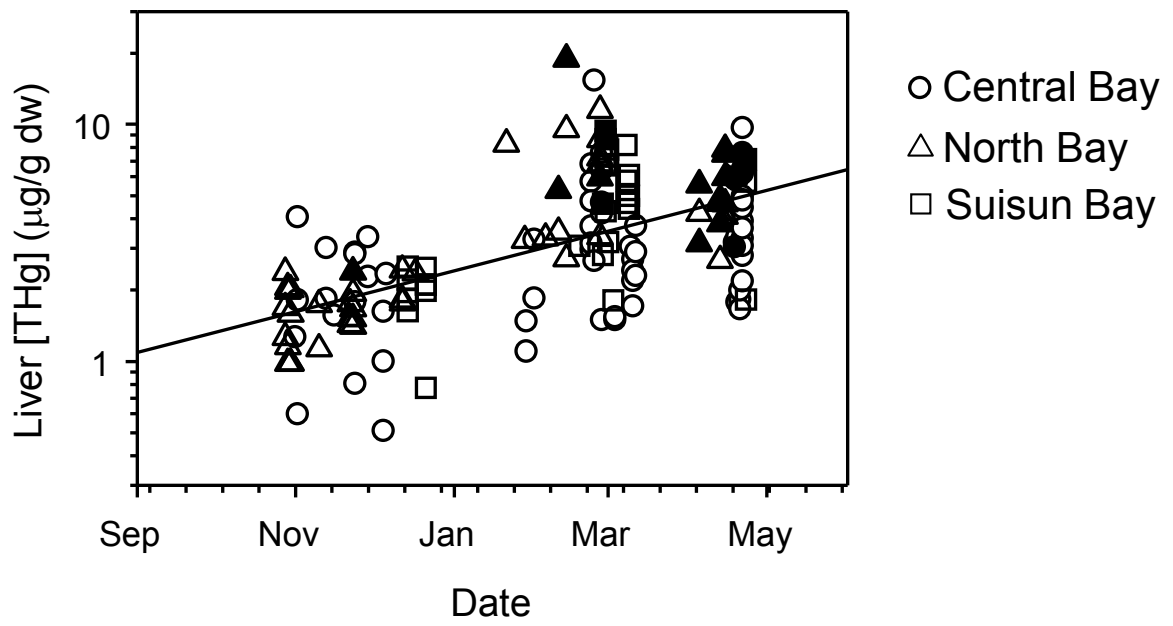

Figure 39. Total mercury ( $\mathrm{THg}$ ) concentrations changed with sampling date in livers of surf scoters sampled in San Francisco Bay, California, during 2004 and 2005. Birds were sampled from Central Bay (circles), North Bay (triangles), and Suisun Bay (squares). Open symbols represent females and solid symbols represent males. Figure from Eagles-Smith and others (2009a) and used with permission.

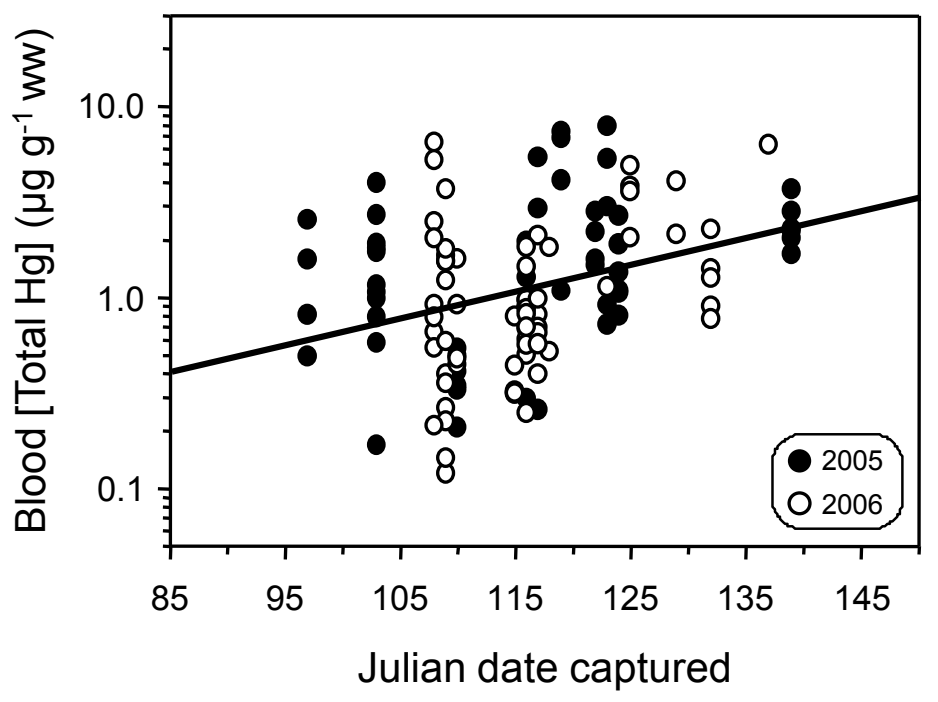

Figure 40. Total mercury concentrations ( $\mu \mathrm{g} / \mathrm{g}$ wet weight [ww]) in blood of Forster's terns increased with capture date in San Francisco Bay, California, during spring 2005 and 2006. Sample sizes were 40 in East Alviso, 40 in West Alviso, 20 in Eden Landing Ecological Reserve, and 22 in North Bay, and 58 in 2005 (filled circles) and 65 in 2006 (open circles). Figure from Ackerman and others (2008a) and used with permission. 

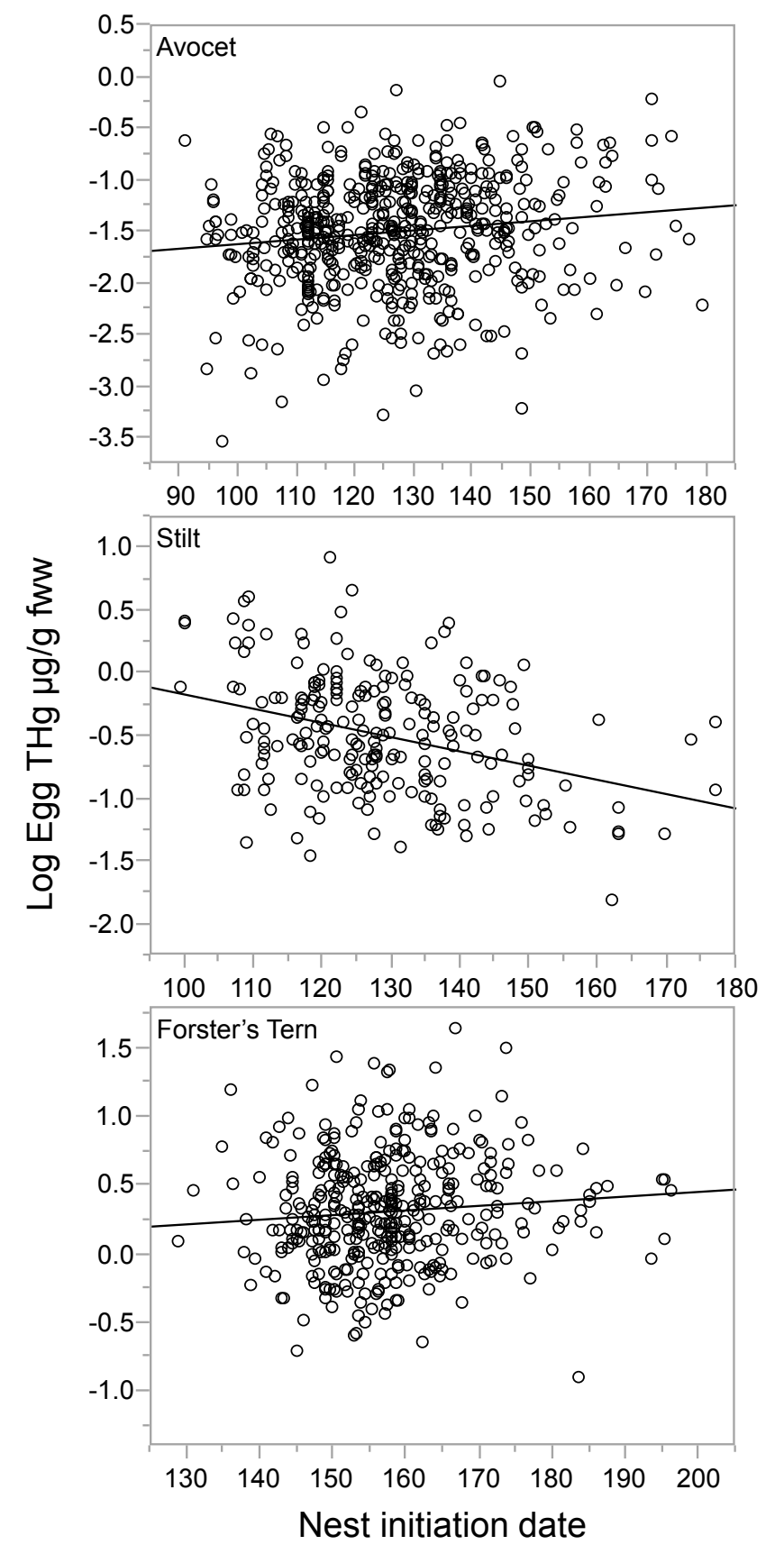

Figure 41. Log total mercury (THg) concentrations in eggs of (top) American avocet, (middle) black-necked stilts, and (bottom) Forster's terns by nest initiation date (day of year) in San Francisco Bay, California, during 200507. Leverage plot accounting for the global model effects of region, wetland site nested in region, year, and nest initiation date. 


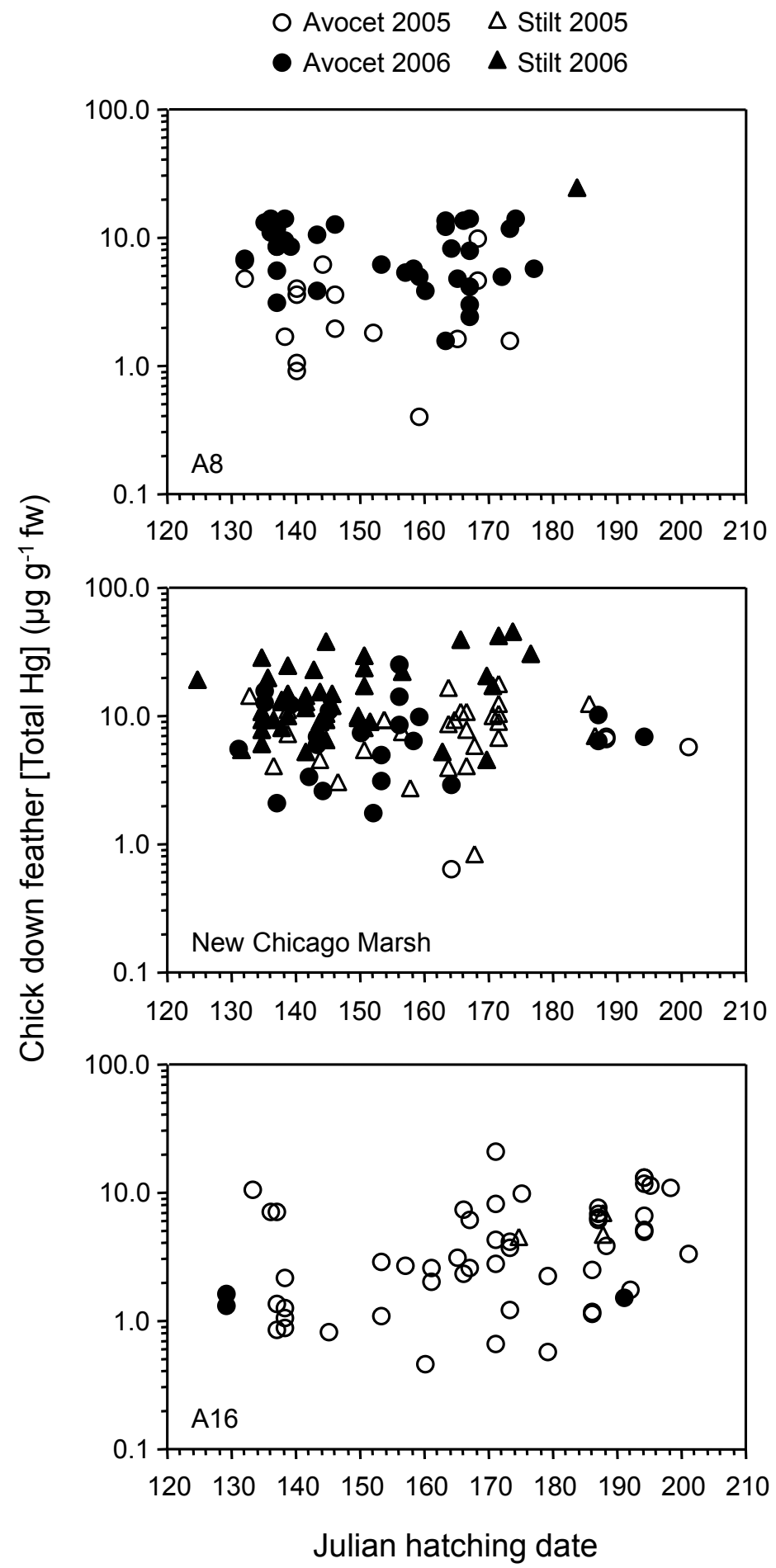

Figure 42. Total mercury concentrations ( $\mu \mathrm{g} / \mathrm{g}$ fresh weight $[\mathrm{fw}])$ in down feathers of American avocet (circles) and black-necked stilt chicks (triangles) increased with hatching date (day of year) at the three main study sites in South San Francisco Bay, California, during 2005 (unfilled) and 2006 (filled). Figure from Ackerman and others (2008d) and used with permission. 

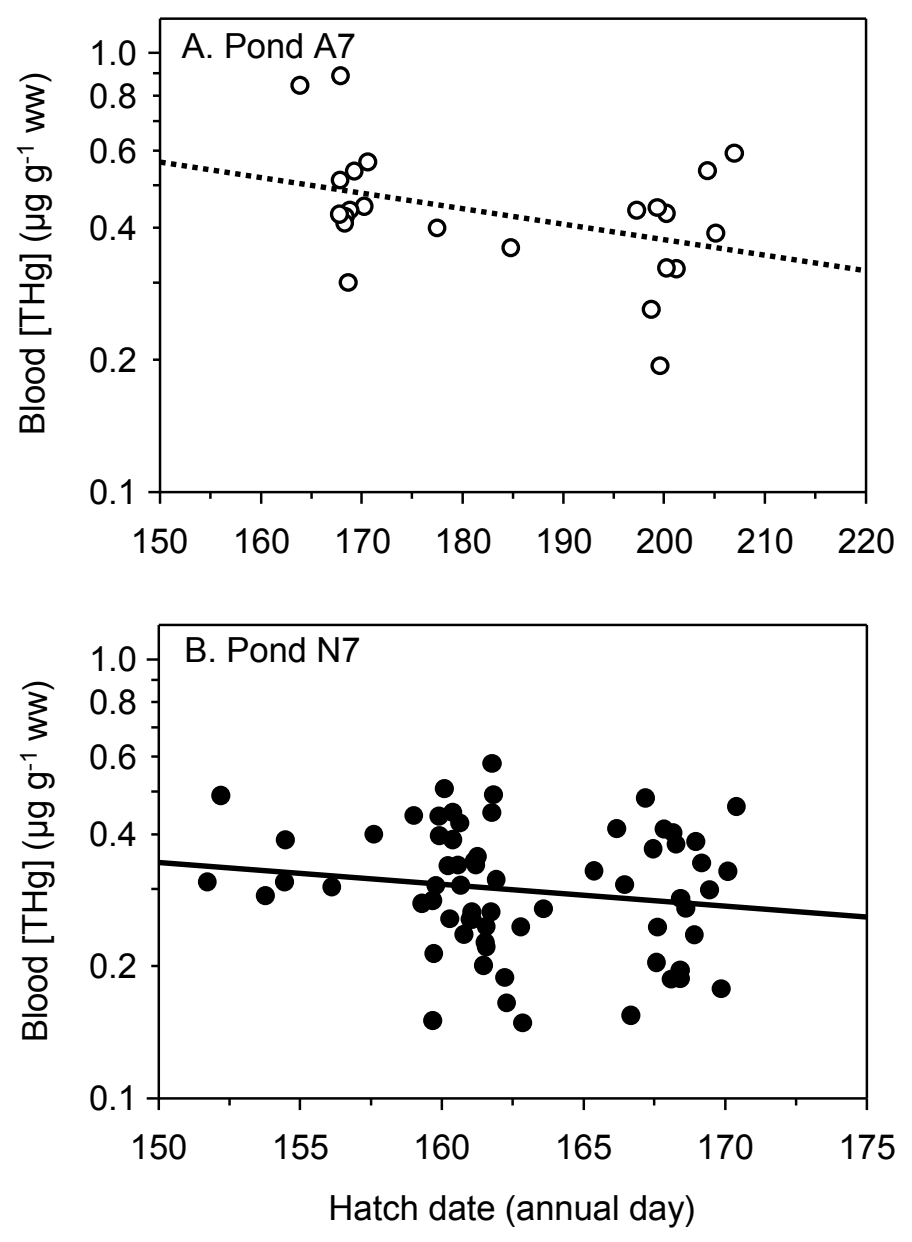

Figure 43. Blood mercury concentrations ( $\mu \mathrm{g} / \mathrm{g}$ wet weight [ww]) in fledglings decreased with hatch date (annual day) at the (A) Pond A7 (N=23) and (B) Pond N7 (N=67) Forster's tern colonies in South San Francisco Bay, California, during summer of 2006. Figure from Ackerman and others (2008b) and used with permission. 

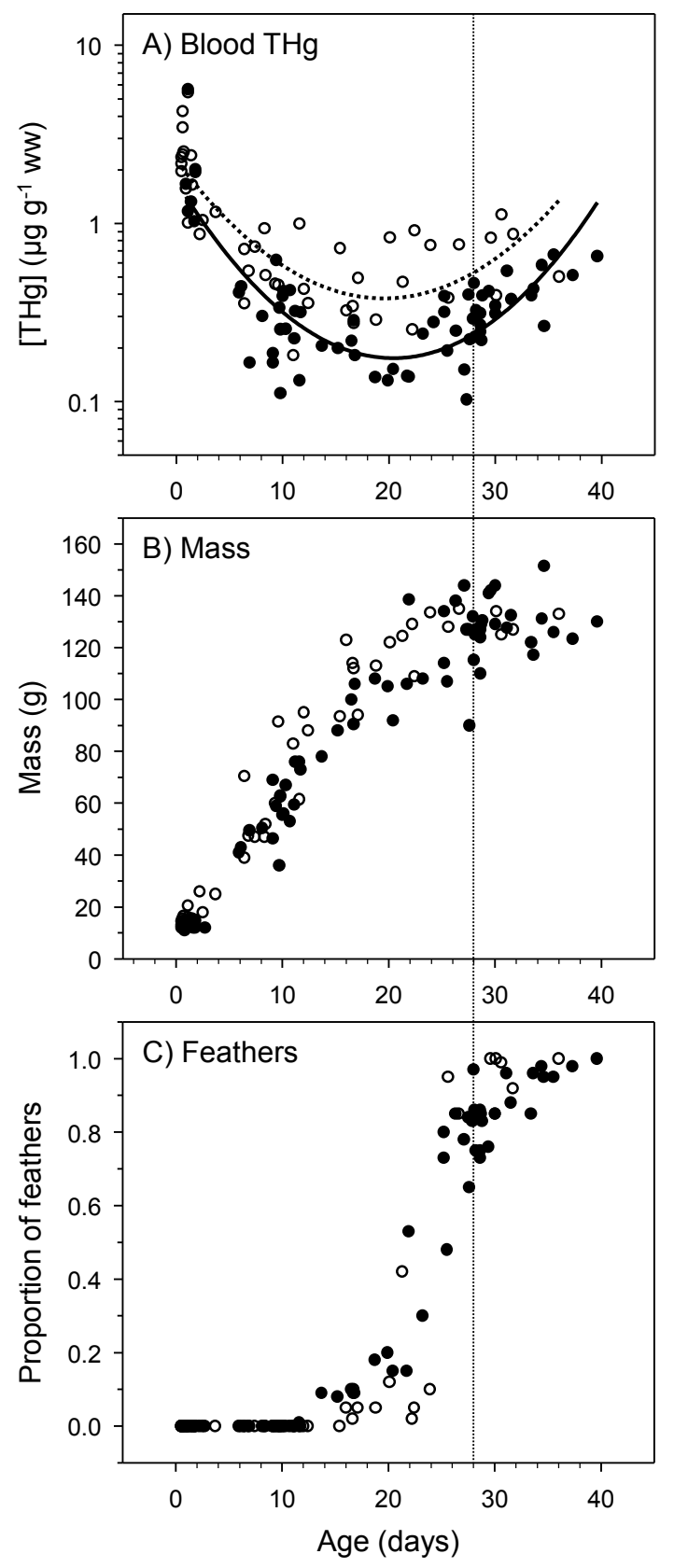

Figure 44. (A) Total mercury ( $\mathrm{THg}$ ) concentrations in blood, (B) chick mass $(\mathrm{g})$, and $(\mathrm{C})$ proportion of fully grown feathers as Forster's tern chicks age from hatching (0 days) to postfledging in San Francisco Bay, California. Open symbols indicate the higher mercury contaminated wetland (Pond A16) and closed symbols indicate the lower mercury contaminated wetland (Pond N7). The stippled vertical line indicates the approximate age when Forster's tern chicks become flighted (28 days). Figure from Ackerman and others (2011) and used with permission. 

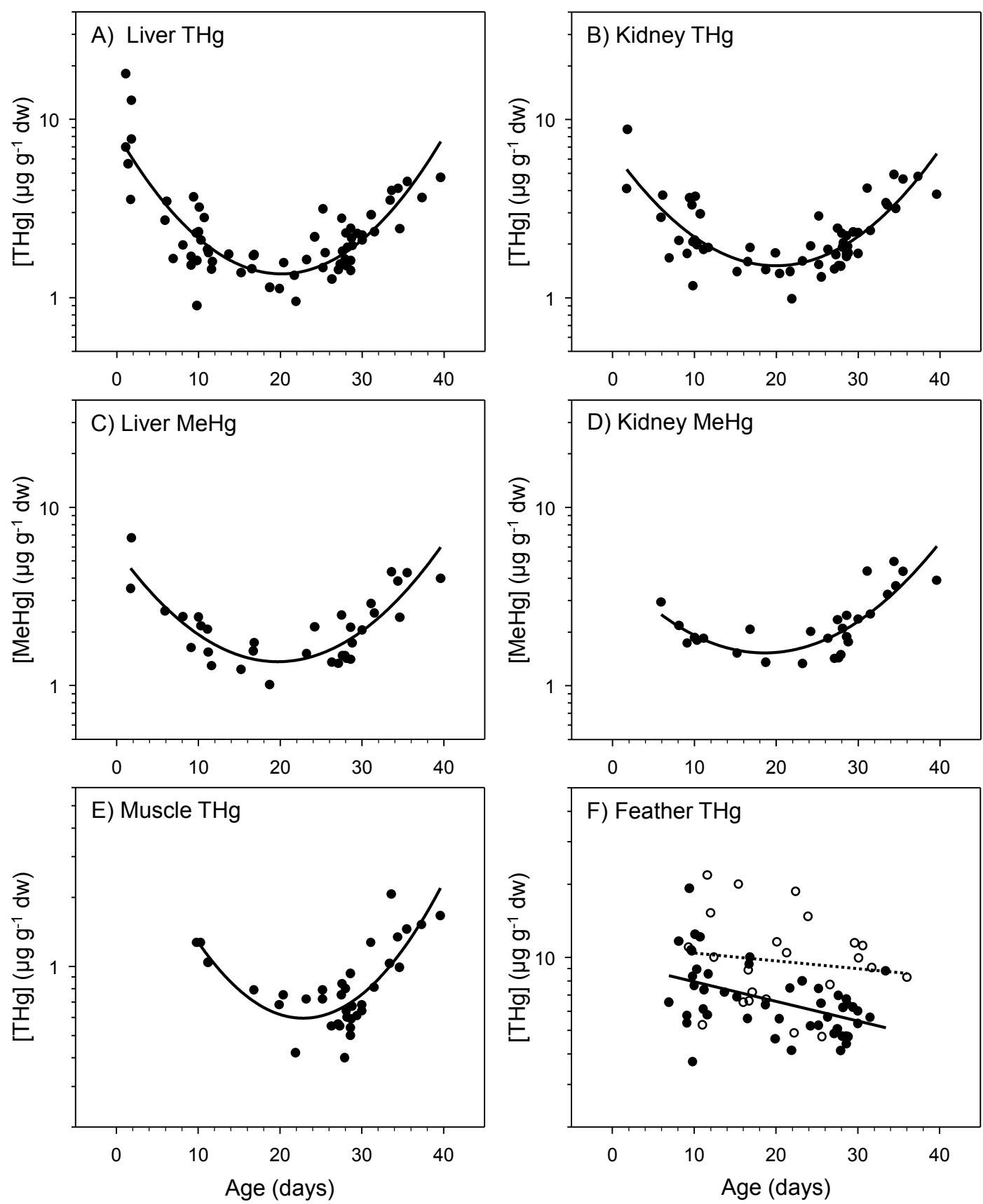

Figure 45. Total mercury (THg) concentrations in (A) liver, (B) kidney, (E) muscle, and (F) fully grown feathers, and methylmercury (MeHg) concentrations in (C) liver and (D) kidney as Forster's tern chicks age from hatching $(0$ days) to postfledging (chicks fledge at 28 days) in San Francisco Bay, California. Open symbols indicate the higher mercury $(\mathrm{Hg})$ contaminated wetland (Pond A16) and closed symbols indicate the lower $\mathrm{Hg}$ contaminated wetland (Pond N7). Figure from Ackerman and others (2011) and used with permission. 

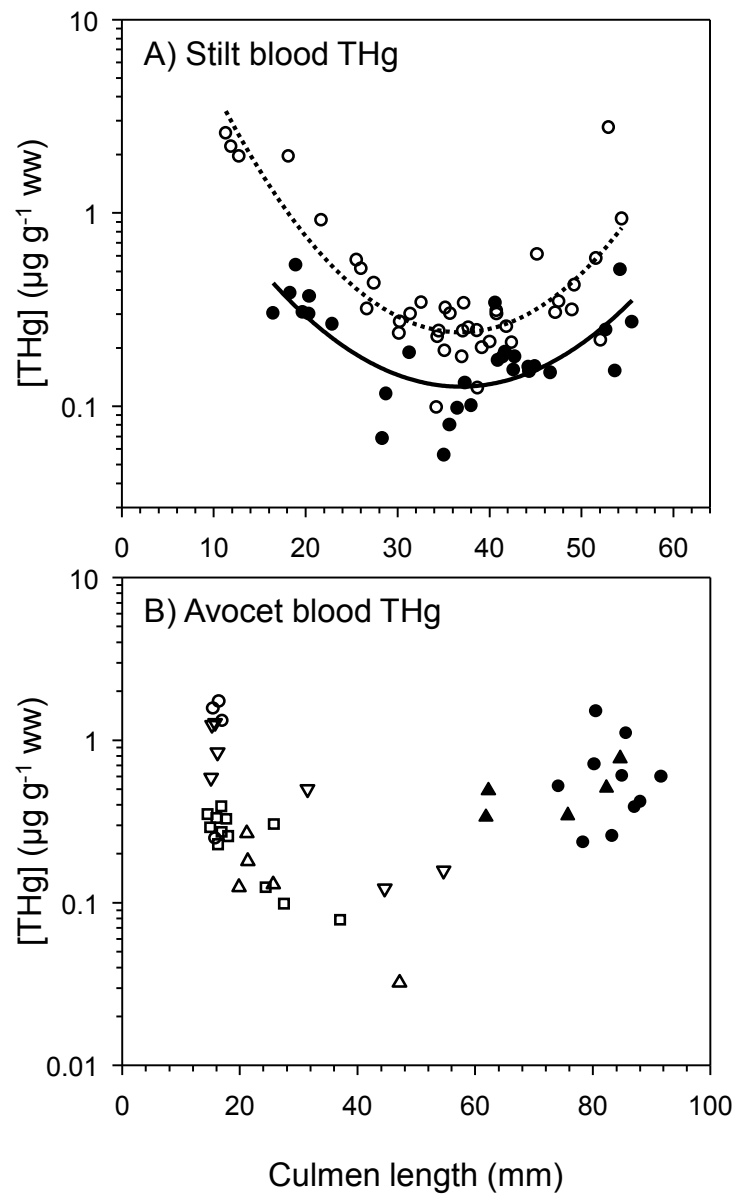

Figure 46. Total mercury (THg) concentrations in blood of (A) black-necked stilt and (B) American avocet chicks as they age from hatching to postfledging in San Francisco Bay, California. Exposed culmen length $(\mathrm{mm})$ was used as an index of age. Culmen length is approximately (A) $12 \mathrm{~mm}$ at hatching and $41 \mathrm{~mm}$ at fledging for stilts and (B) $16 \mathrm{~mm}$ at hatching and $55 \mathrm{~mm}$ at fledging for avocets. For stilts (A), open symbols indicate the higher mercury contaminated wetland (New Chicago Marsh) and closed symbols indicate the lower mercury contaminated wetland (Eden Landing Ecological Reserve). For stilts (A), data from years 2005 and 2007 were standardized to 2006. For avocets (B), different symbol shapes indicate different wetlands (circles are Alviso, triangles are Eden Landing Ecological Reserve, upside-down triangles are New Chicago Marsh, and squares are Newark wetlands) and open symbols indicate 2006 and closed symbols indicate 2005. Figure from Ackerman and others (2011) and used with permission. 


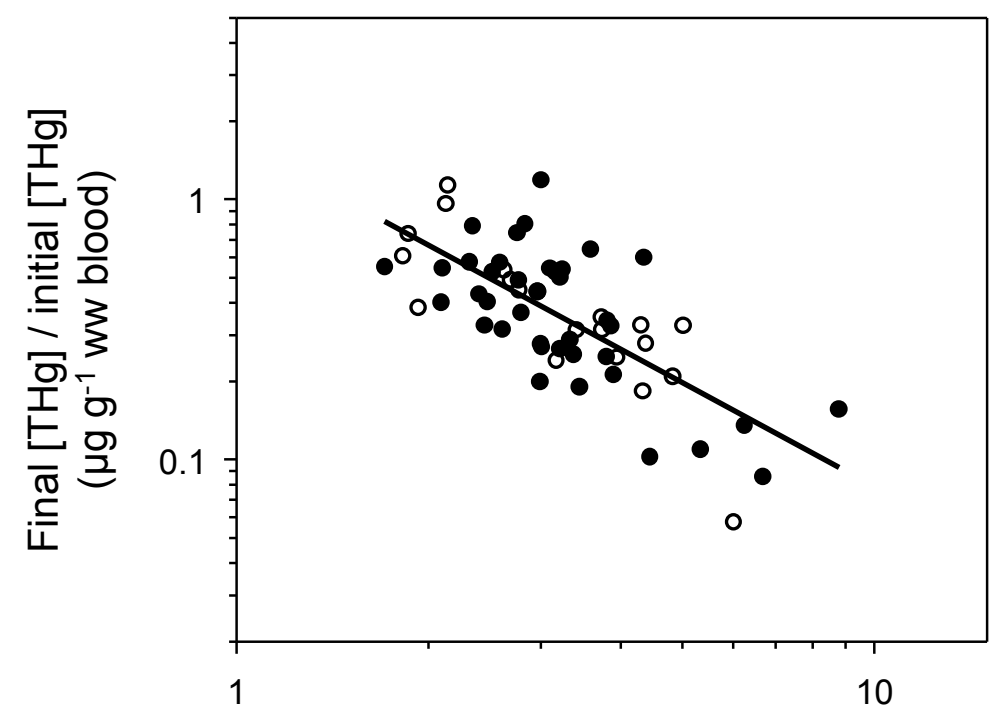

Final mass / initial mass $(g)$

Figure 47. Proportional change in an individual specimen's blood total mercury $(\mathrm{THg})$ concentration (final $\mathrm{THg}$ concentration divided by initial THg concentration) was negatively related to the proportional change in its body mass (final mass divided by initial mass) between sampling events for Forster's tern chicks in San Francisco Bay, California. Leverage plot accounting for the potential influence of age $^{2}$, age, site, date, and proportion of fully grown feathers, illustrates that mercury concentrations decreased more in chicks that gained more mass between sampling events. Initial blood mercury concentrations were estimated using mercury concentrations in down feathers. Open symbols indicate the higher mercury $(\mathrm{Hg})$ contaminated wetland (Pond A16) and closed symbols indicate the lower Hg contaminated wetland (Pond N7). Figure from Ackerman and others (2011) and used with permission. 

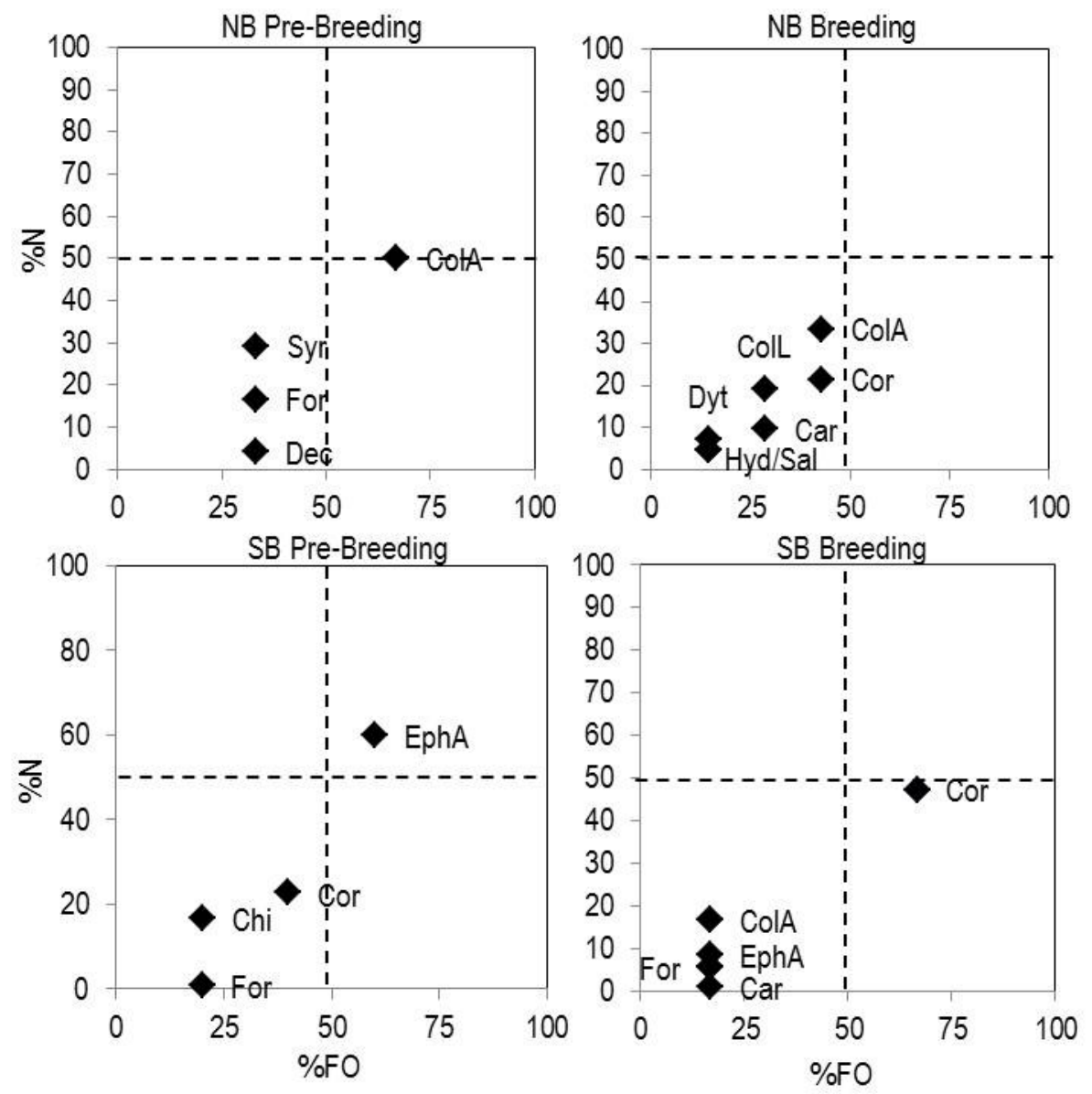

$\begin{array}{ll}\text { Carabidae } & \text { Car } \\ \text { Chironomidae } & \text { Chi } \\ \text { ColeopteraAdult } & \text { ColA } \\ \text { Coleoptera Larva } & \text { Coll } \\ \text { Corixidae } & \text { Cor } \\ \text { Decapod } & \text { Dec } \\ \text { Diptera } & \text { Dip } \\ \text { Dytiscidae } & \text { Dyt } \\ \text { EphydridaeAdult } & \text { EphA } \\ \text { EphydridaeLarva } & \text { EphL } \\ \text { Formicidae } & \text { For } \\ \text { Hydrophilidae } & \text { Hyd } \\ \text { Saldidae } & \text { Sal } \\ \text { Syrphidae } & \text { Syr }\end{array}$

Figure 48. Mean percent number $(\% \mathrm{~N})$ and percent frequency of occurrence $(\% \mathrm{FO})$ of prey items found in the esophagus and proventriculus of adult female black-necked stilts collected in the North Bay (NB) and South Bay (SB) from 2005 and 2006 during pre-breeding (NB, N=3; SB, N=5) and breeding periods (NB, N=7; SB, $\mathrm{N}=6$ ). 

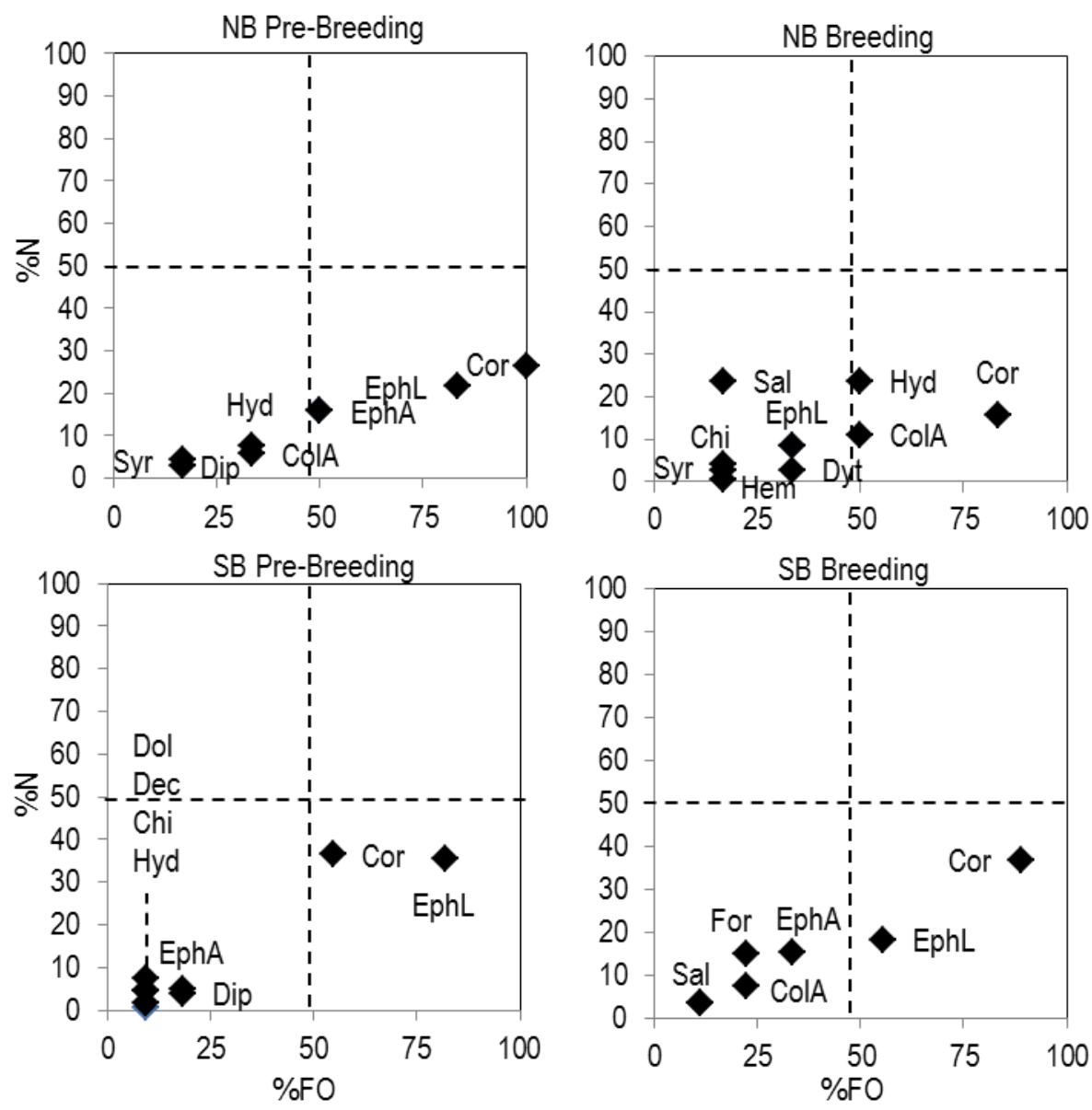

\begin{tabular}{l|l}
\hline Arachnid & Ara \\
\hline Carabidae & Car \\
\hline Coleoptera Adult & ColA \\
\hline Chironomidae & Chi \\
Corixidae & Cor \\
Decapod & Dec \\
Diptera & Dip \\
\hline Dolichopodidae & Dol \\
\hline Dytiscidae & Dyt \\
\hline EphydridaeAdult & EphA \\
\hline EphydridaeLarva & EphL \\
\hline Formicidae & For \\
\hline Hemiptera & Hem \\
\hline Hydrophilidae & Hyd \\
Saldidae & Sal \\
Syrphidae & Syr \\
& \\
&
\end{tabular}

Figure 49. Mean percent number $(\% \mathrm{~N})$ and percent frequency of occurrence $(\% \mathrm{FO})$ of prey items found in the gizzard of adult female black-necked stilts collected in the North Bay (NB) and South Bay (SB) from 2005 and 2006 during pre-breeding (NB, N=6; SB, N=11) and breeding periods (NB, N=6; SB, N=9). 

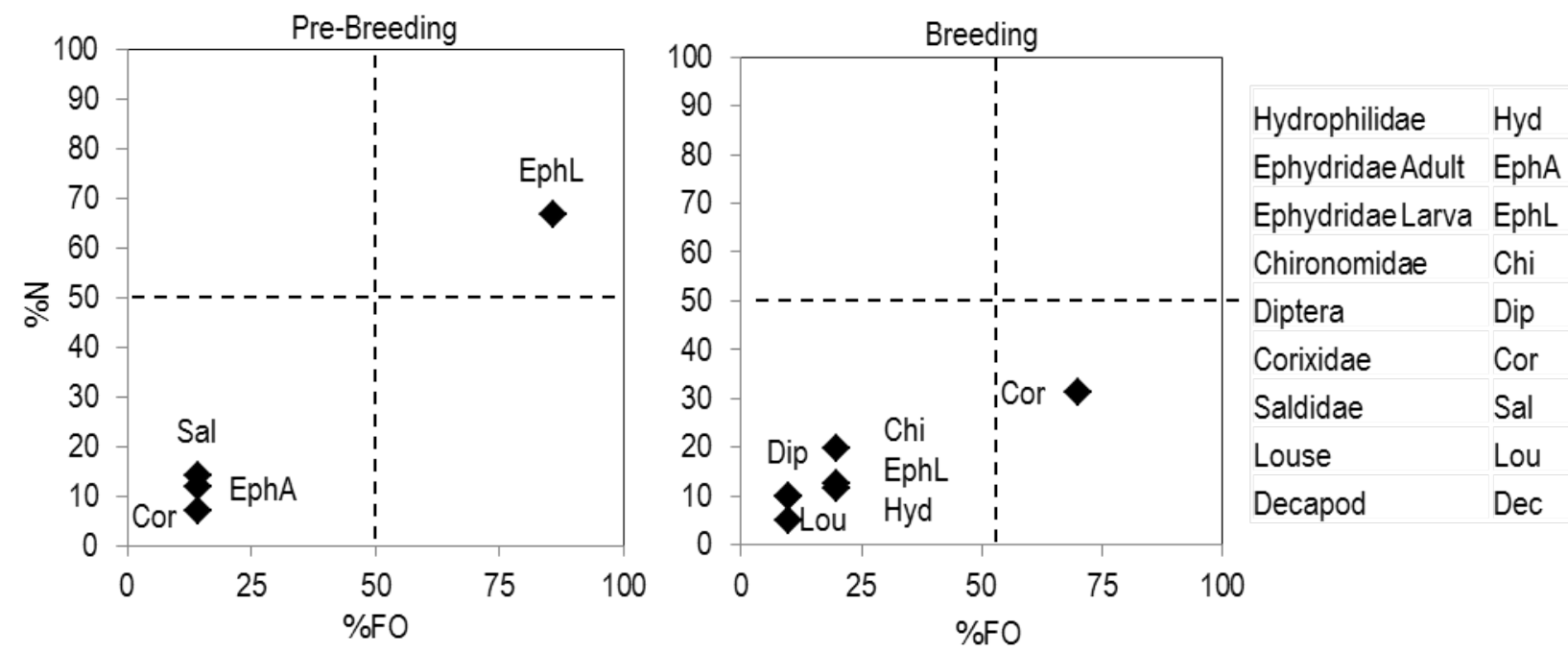

Figure 50. Mean percent number $(\% \mathrm{~N})$ and percent frequency of occurrence (\%FO) of prey items found in the esophagus and proventriculus of adult female American avocets collected in the South Bay (SB) from 2005 and 2006 during pre-breeding $(\mathrm{N}=10)$ and breeding periods $(\mathrm{N}=10)$. 

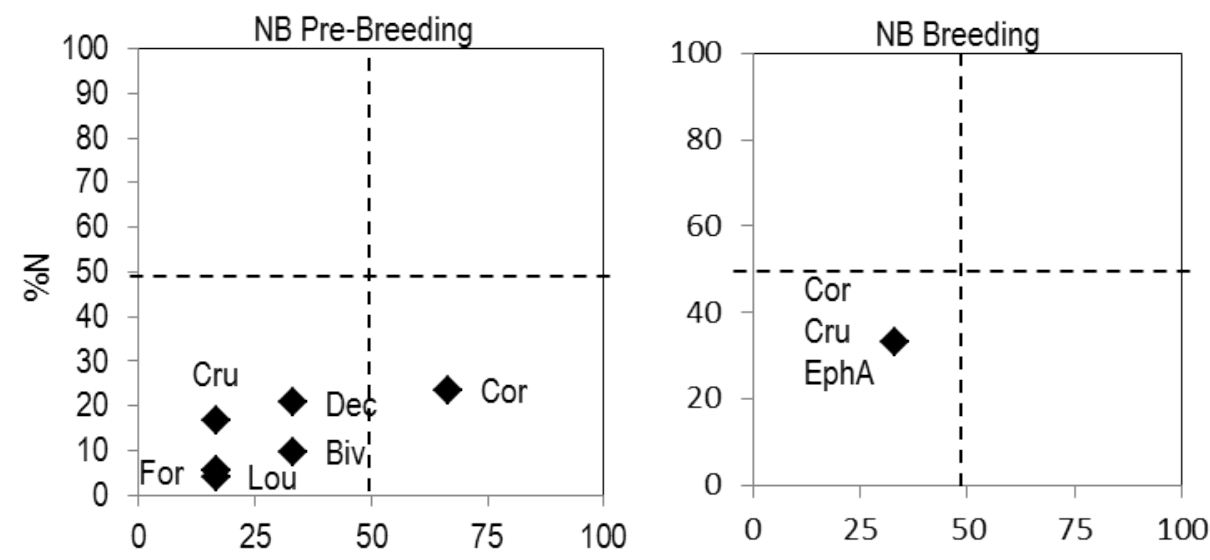

$\begin{array}{ll}\text { Bivalvia } & \text { Biv } \\ \text { Chironomidae } & \text { Chi } \\ \text { Coleoptera } & \text { Col } \\ \text { Corixidae } & \text { Cor } \\ \text { Crustacean } & \text { Cru } \\ \text { Decapod } & \text { Dec } \\ \text { Diptera } & \text { Dip }\end{array}$
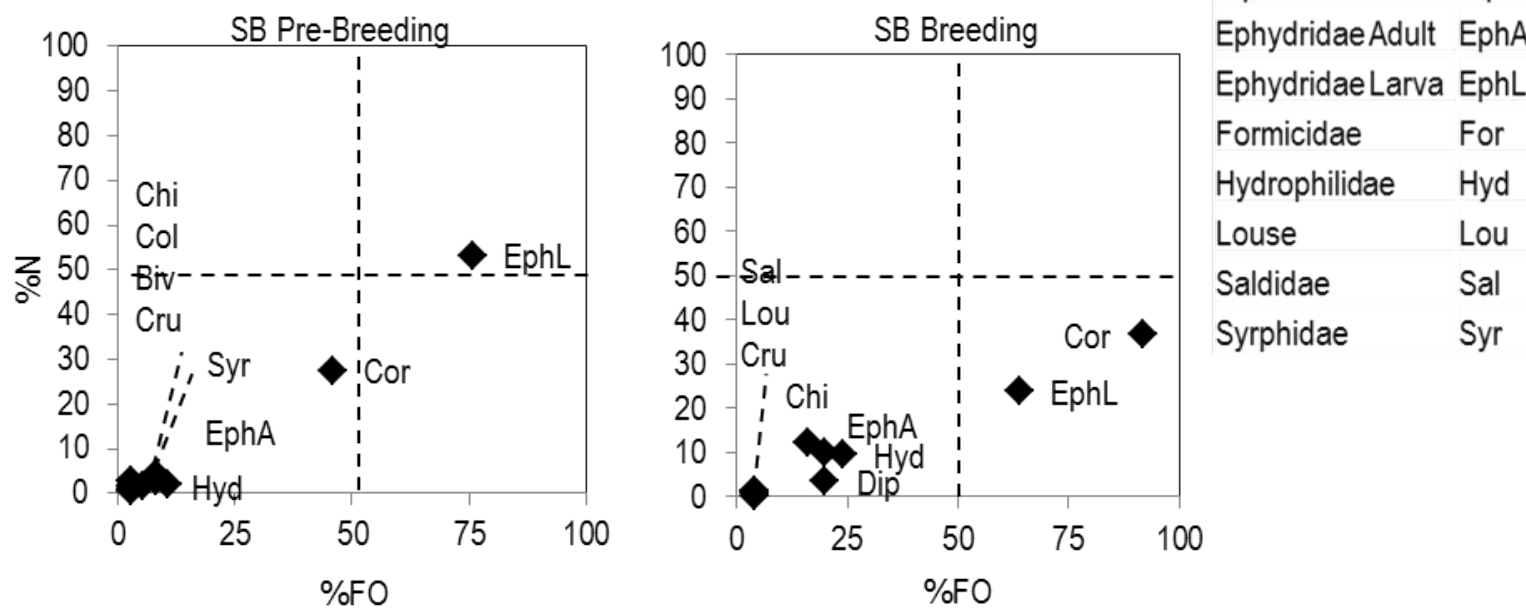

Figure 51. Mean percent number $(\% \mathrm{~N})$ and percent frequency of occurrence (\%FO) of prey items found in the gizzard of adult female American avocets collected in the North Bay (NB) and South Bay (SB) from 2005 and 2006 during pre-breeding (NB, N=6; SB, N=37) and breeding periods ( $N B, N=1 ; S B, N=25)$. 

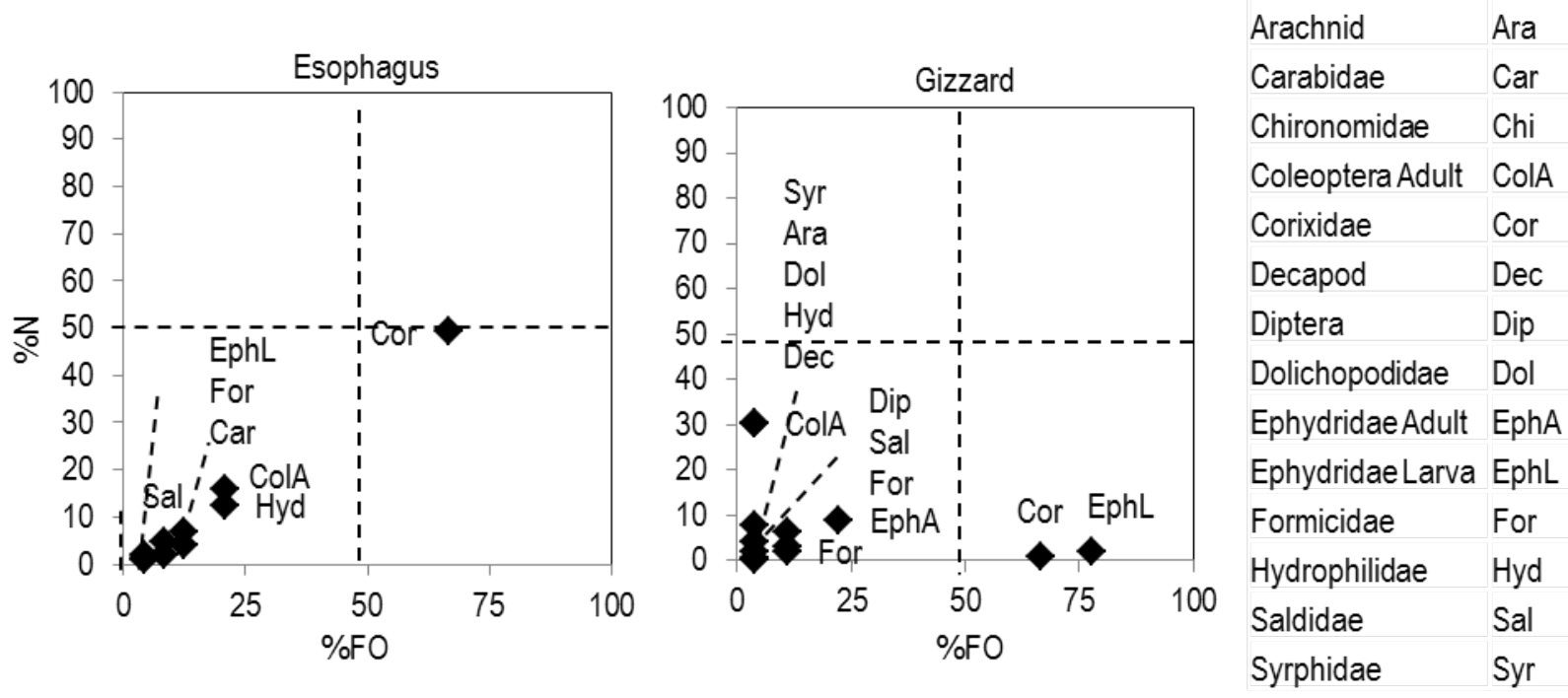

Figure 52. Mean percent number $(\% \mathrm{~N})$ and percent frequency of occurrence $(\% \mathrm{FO})$ of prey items found in the esophagus and proventriculus $(\mathrm{N}=24)$ or gizzard $(\mathrm{N}=27)$ of black-necked stilt chicks collected in the South Bay from 2005 and 2006.
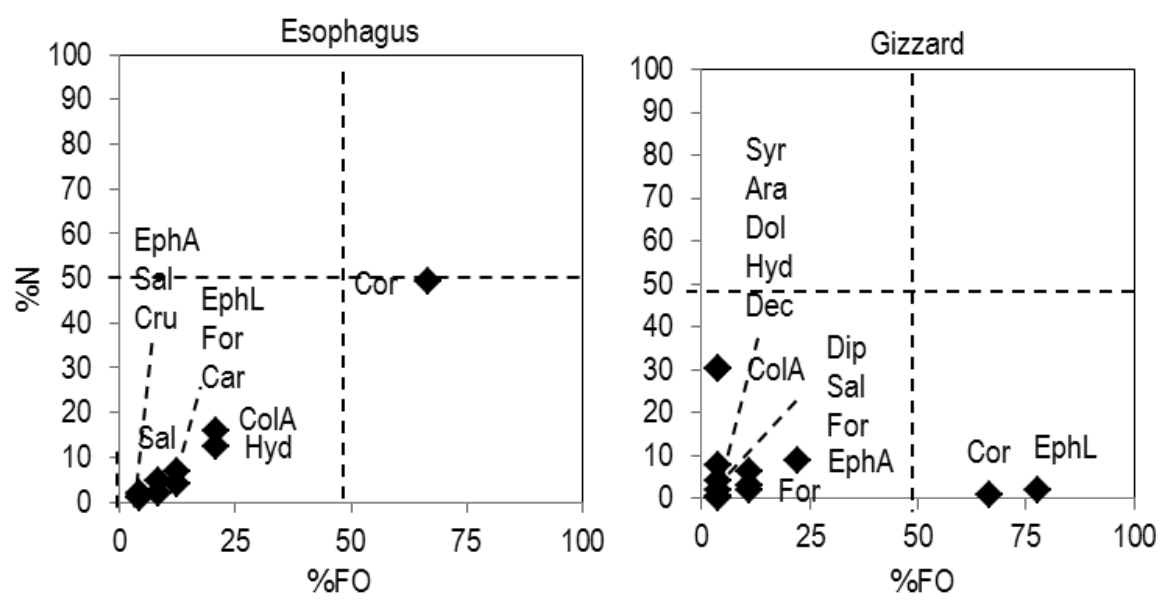

\begin{tabular}{l|l|}
\hline Arachnid & Ara \\
\hline Carabidae & Car \\
\hline Chironomidae & Chi \\
\hline Coleoptera Adult & ColA \\
\hline Corixidae & Cor \\
\hline Decapod & Dec \\
\hline Diptera & Dip \\
\hline Dolichopodidae & Dol \\
\hline EphydridaeAdult & EphA \\
\hline EphydridaeLarva & EphL \\
\hline Formicidae & For \\
\hline Hydrophilidae & Hyd \\
\hline Saldidae & Sal \\
\hline Syrphidae & Syr \\
\hline
\end{tabular}

Figure 53. Mean percent number $(\% \mathrm{~N})$ and percent frequency of occurrence $(\% \mathrm{FO})$ of prey items found in the esophagus and proventriculus $(\mathrm{N}=16)$ or gizzard $(\mathrm{N}=36)$ of American avocet chicks collected in the South Bay from 2005 and 2006. 


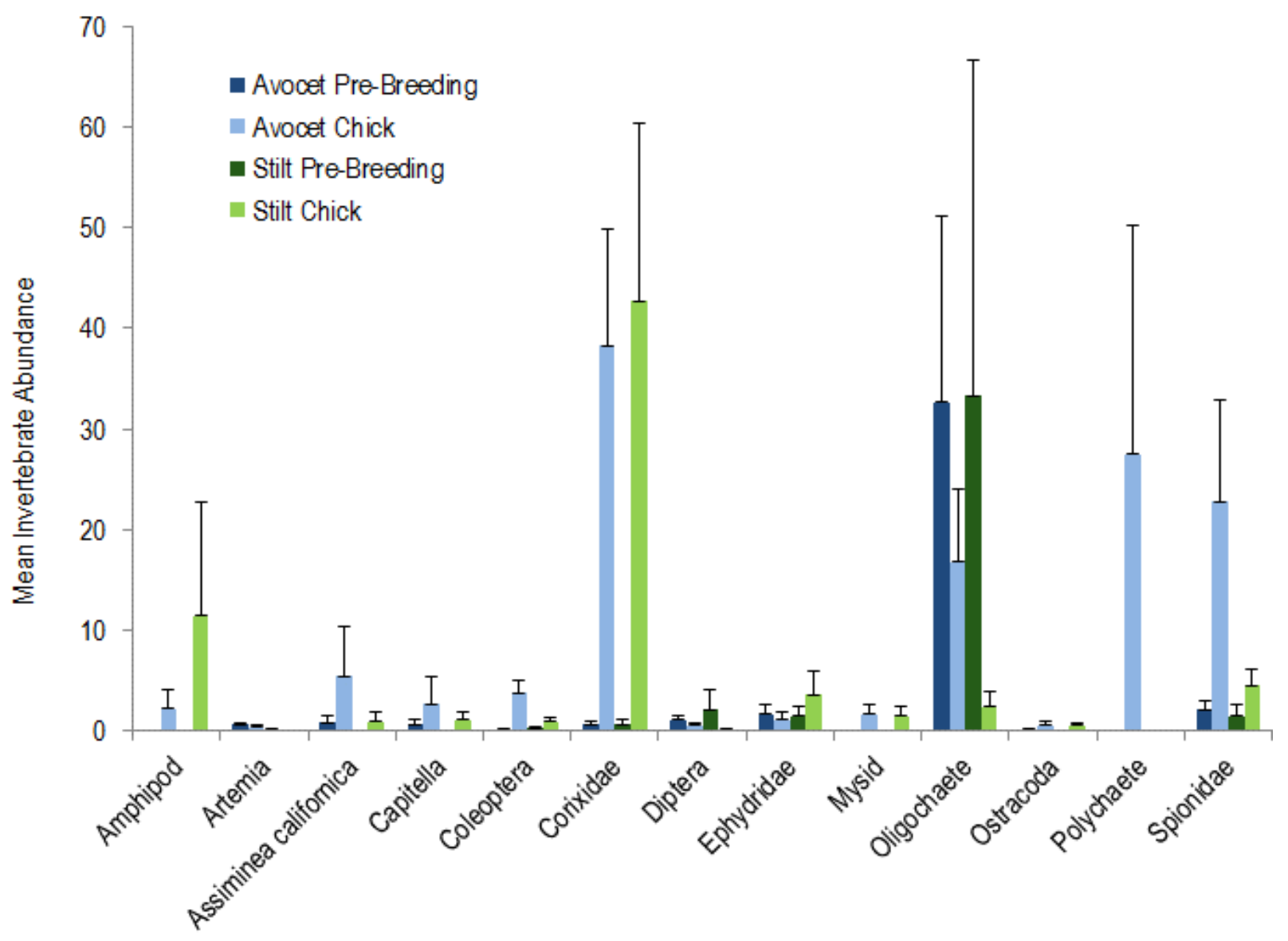

Figure 54. Mean $( \pm S E)$ invertebrate abundances from benthic grab samples located at stilt and avocet foraging areas in the South Bay. 


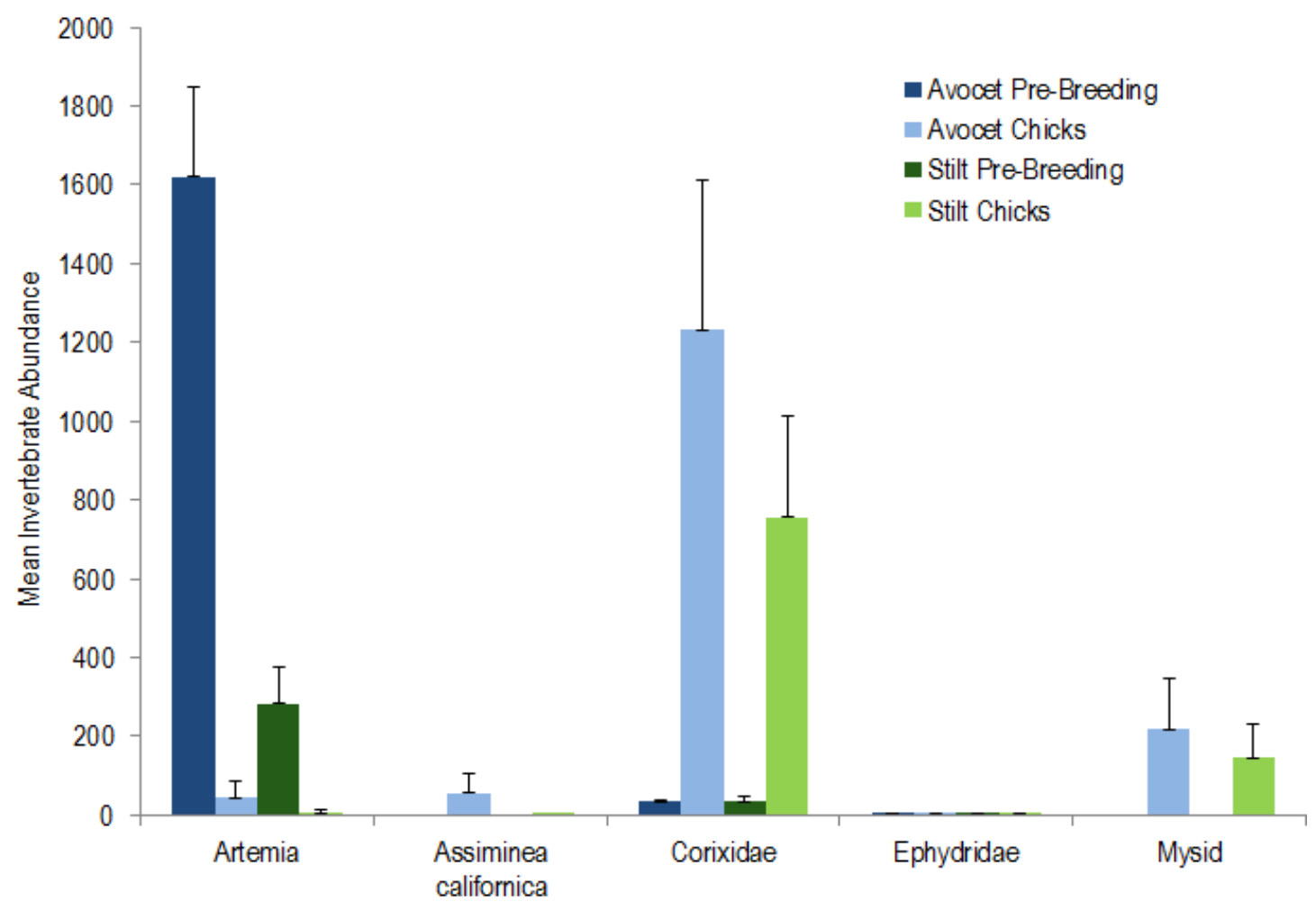

Figure 55. Mean $( \pm S E)$ invertebrate abundances from aquatic sweep samples located at stilt and avocet foraging areas in the South Bay. Includes only taxa with $>10$ individuals. 


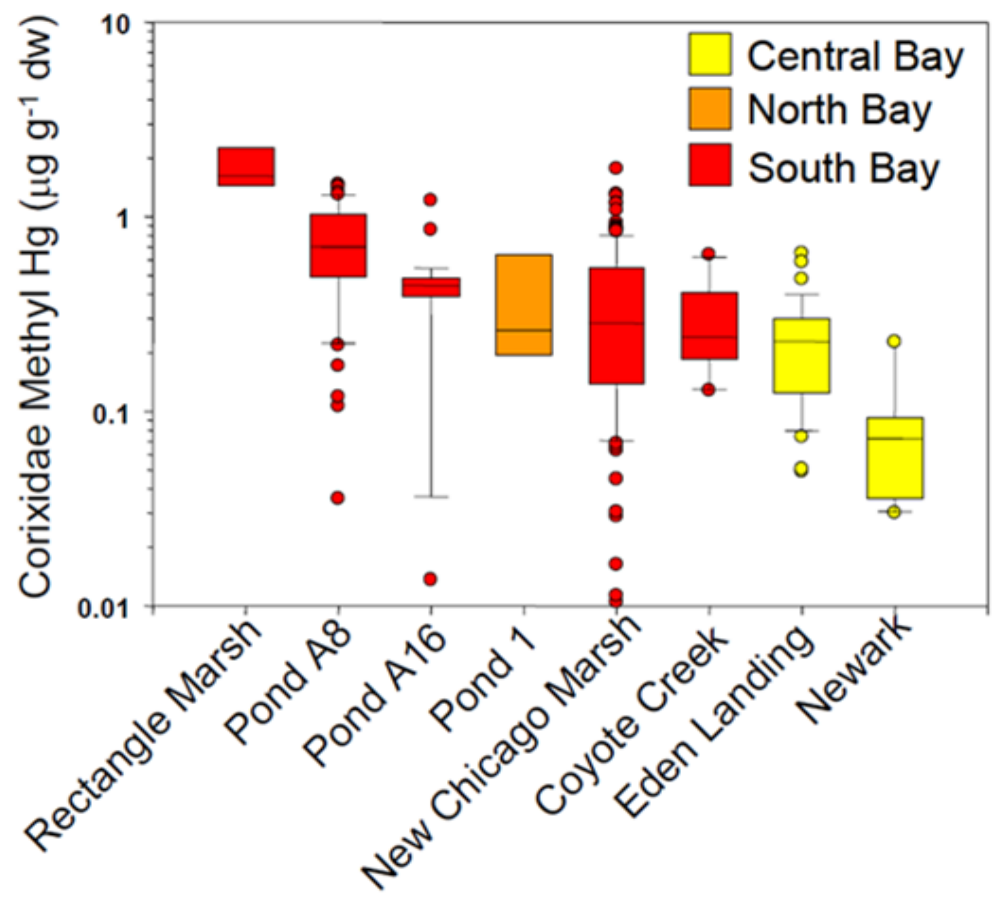

Figure 56. Methylmercury concentrations in Corixidae collected at avocet and stilt pre-breeding and breeding collection sites throughout San Francisco Bay, California. Rectangle Marsh is also known as Strip Marsh.

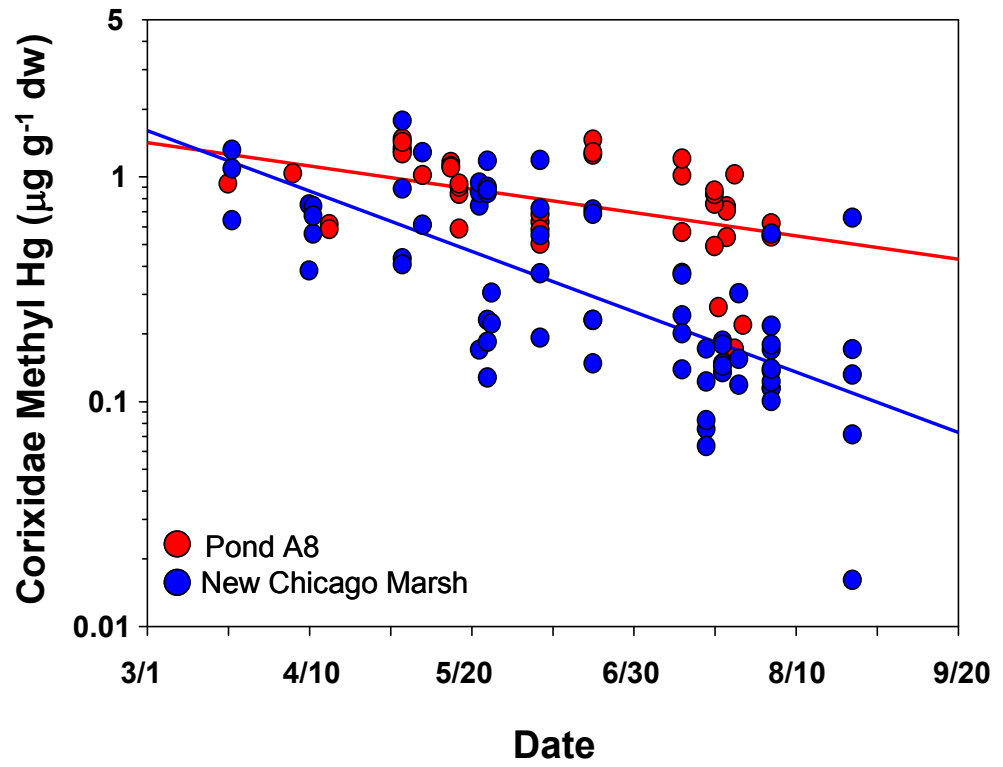

Figure 57. Corixidae methylmercury concentrations $(\mu \mathrm{g} / \mathrm{g} \mathrm{dw})$ decreased with date in New Chicago Marsh and Pond A8 in the South San Francisco Bay, California, March 1-September 20, 2006. 

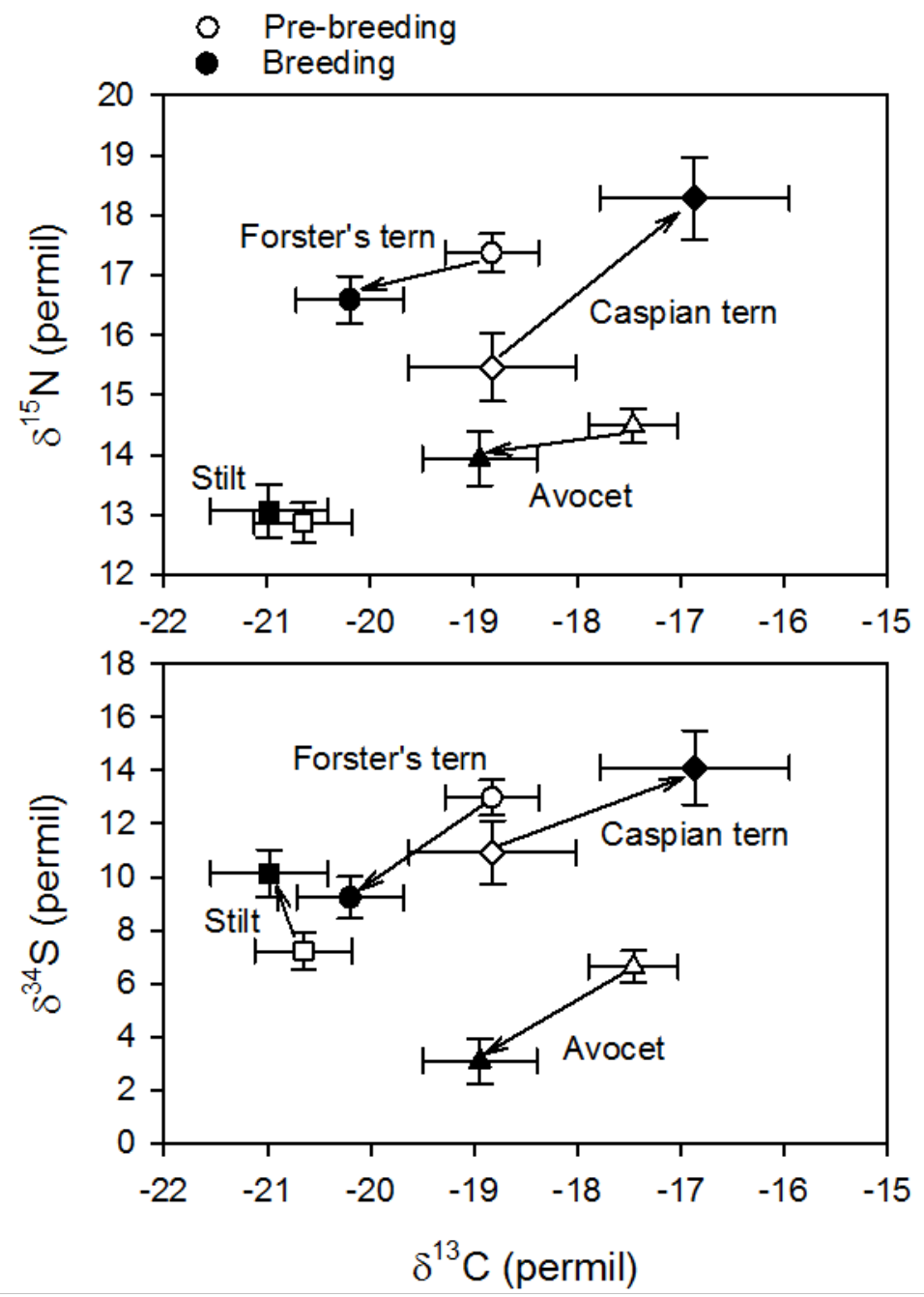

Figure 58. Stable isotope ratios of carbon $\left(\delta^{13} \mathrm{C}\right)$, nitrogen $\left(\delta^{15} \mathrm{~N}\right)$, and sulfur $\left(\delta^{34} S\right)$ in whole blood of pre-breeding (open symbols) and breeding (closed symbols) American avocets (triangles), black-necked stilts (squares), Forster's terns (circles), and Caspian terns (diamonds) sampled from San Francisco Bay, California, during 2005-06. Symbols represent least square mean ( \pm SE) isotope ratios (permil) controlling for site, date and sex. 

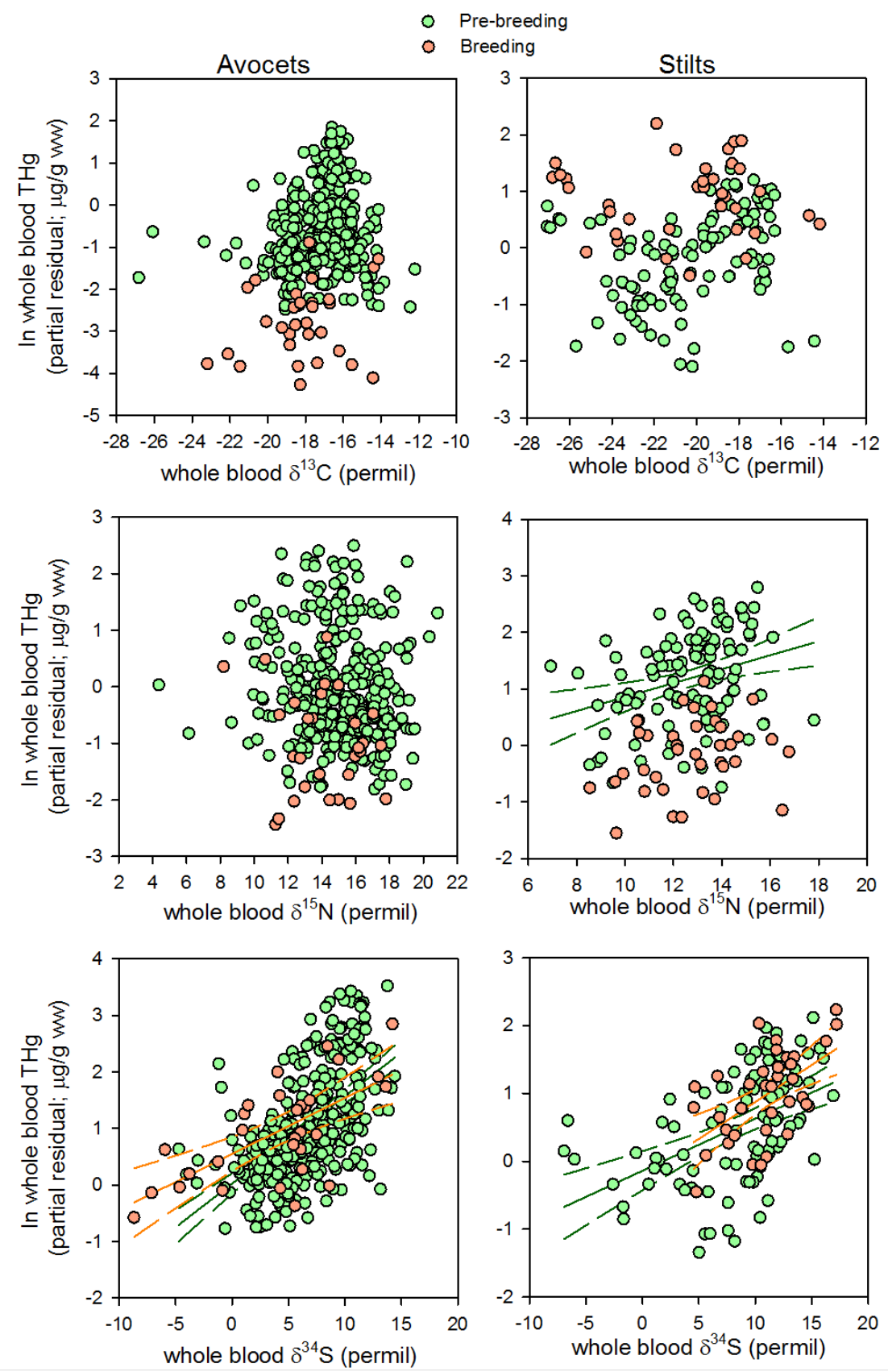

Figure 59. Relations between log whole blood total mercury (THg) concentrations $(\mu \mathrm{g} / \mathrm{g} w \mathrm{w})$ and whole blood stable isotope ratios of carbon $\left(\delta^{13} \mathrm{C}\right)$, nitrogen $\left(\delta^{15} \mathrm{~N}\right)$, and sulfur $\left(\delta^{34} \mathrm{~S}\right)$ in pre-breeding (green symbols) and breeding (orange symbols) American avocets and black-necked stilts. Linear regressions are plotted for relations where $\mathrm{P}<0.05$. Partial residual $\mathrm{THg}$ concentrations account for the influence of year, sex, and site effects. 


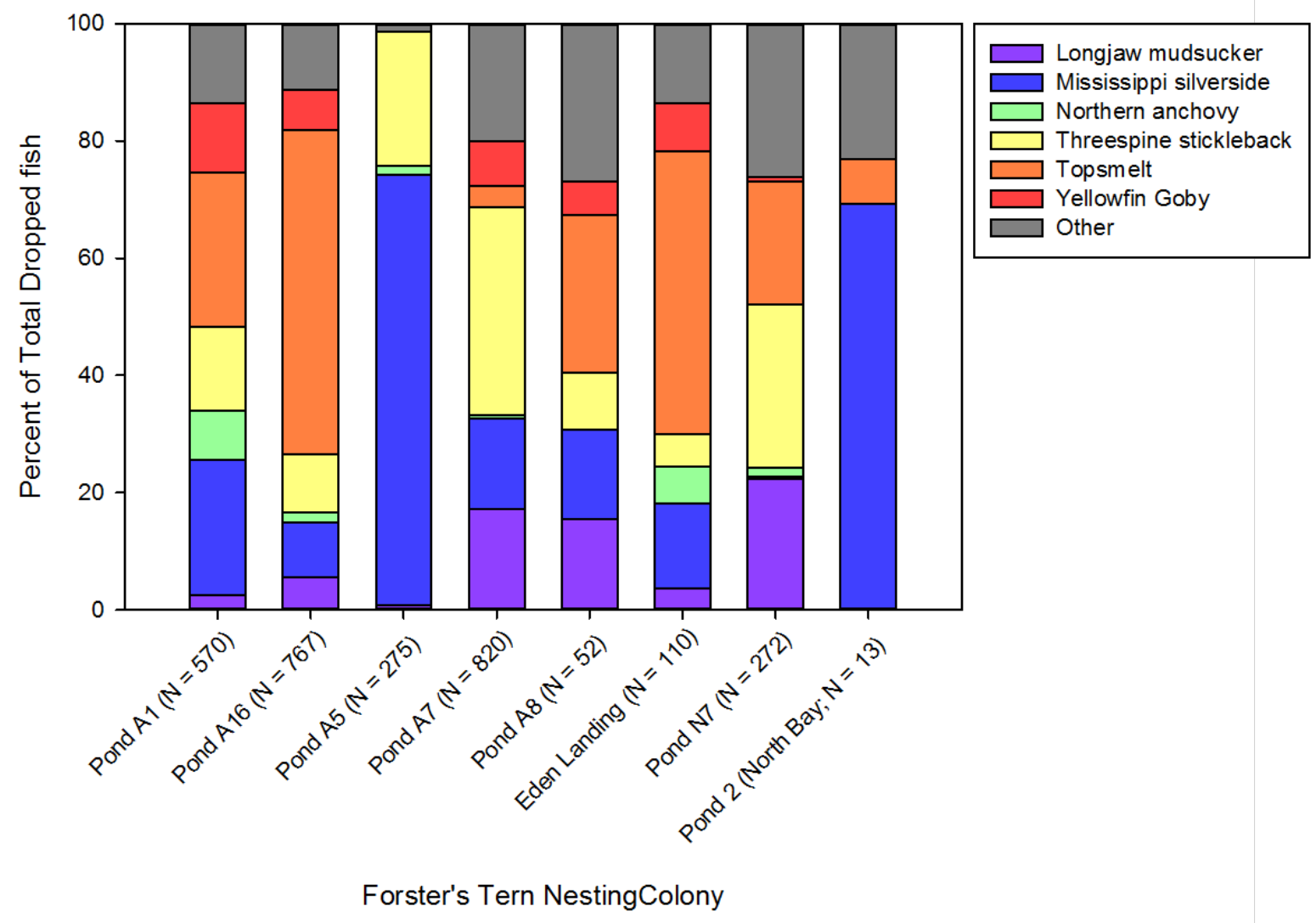

Figure 60. Composition of fish returns to Forster's tern colonies in San Francisco Bay, California, in 2005 and 2006. Data are summarized for the top six fish species found at colonies. The category "Other" is comprised of 13 other species, each of which made up less than 10 percent of returns at all colony sites. Species in the "Other" category include: arrow goby, bay pipefish, bluegill, common carp, largemouth bass, unidentified salmonids, pacific herring, rainwater killifish, shrimp, staghorn sculpin, starry flounder, surfperch, and unknown taxa. 


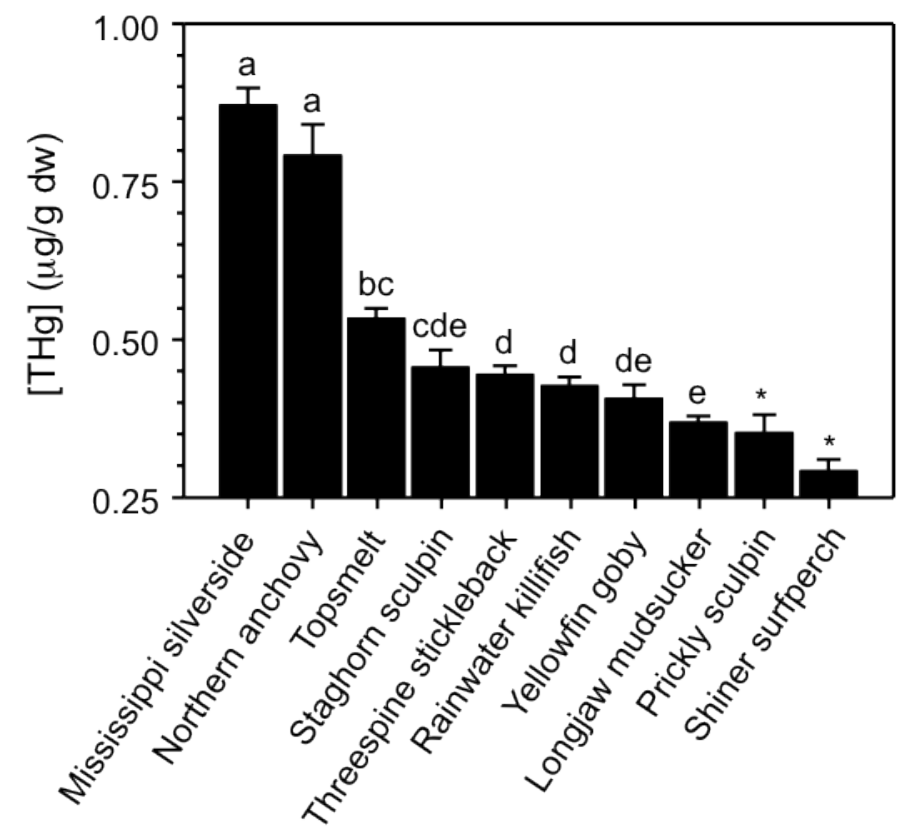

Figure 61. Comparisons of total mercury ( $\mathrm{THg}$ ) concentrations (size normalized least squares means \pm standard error) among fish species from wetlands in San Francisco Bay, California. Least squares means control for global model effects of: region, wetland [region], day of year ${ }^{2}$, and year. Concentrations are normalized to the species-specific mean length (silverside $=50 \mathrm{~mm}$, anchovy $=90 \mathrm{~mm}$, prickly sculpin $=48 \mathrm{~mm}$, surfperch $=85$ $\mathrm{mm}$, topsmelt $=85 \mathrm{~mm}$, staghorn sculpin $=85 \mathrm{~mm}$, stickleback $=39 \mathrm{~mm}$, killifish $=28 \mathrm{~mm}$, yellowfin goby $=66$ $\mathrm{mm}$, mudsucker $=50 \mathrm{~mm}$ ]Tukey's Post-Hoc Pairwise Comparisons, $\alpha<0.05]$ ). Letters above bars indicate significant differences among groups. Asterisks indicate that geometric means are presented for prickly sculpin and shiner surfperch, which did not occur at enough locations to adequately estimate representative least squared means. Figure from Eagles-Smith and Ackerman (2014) and used with permission. 


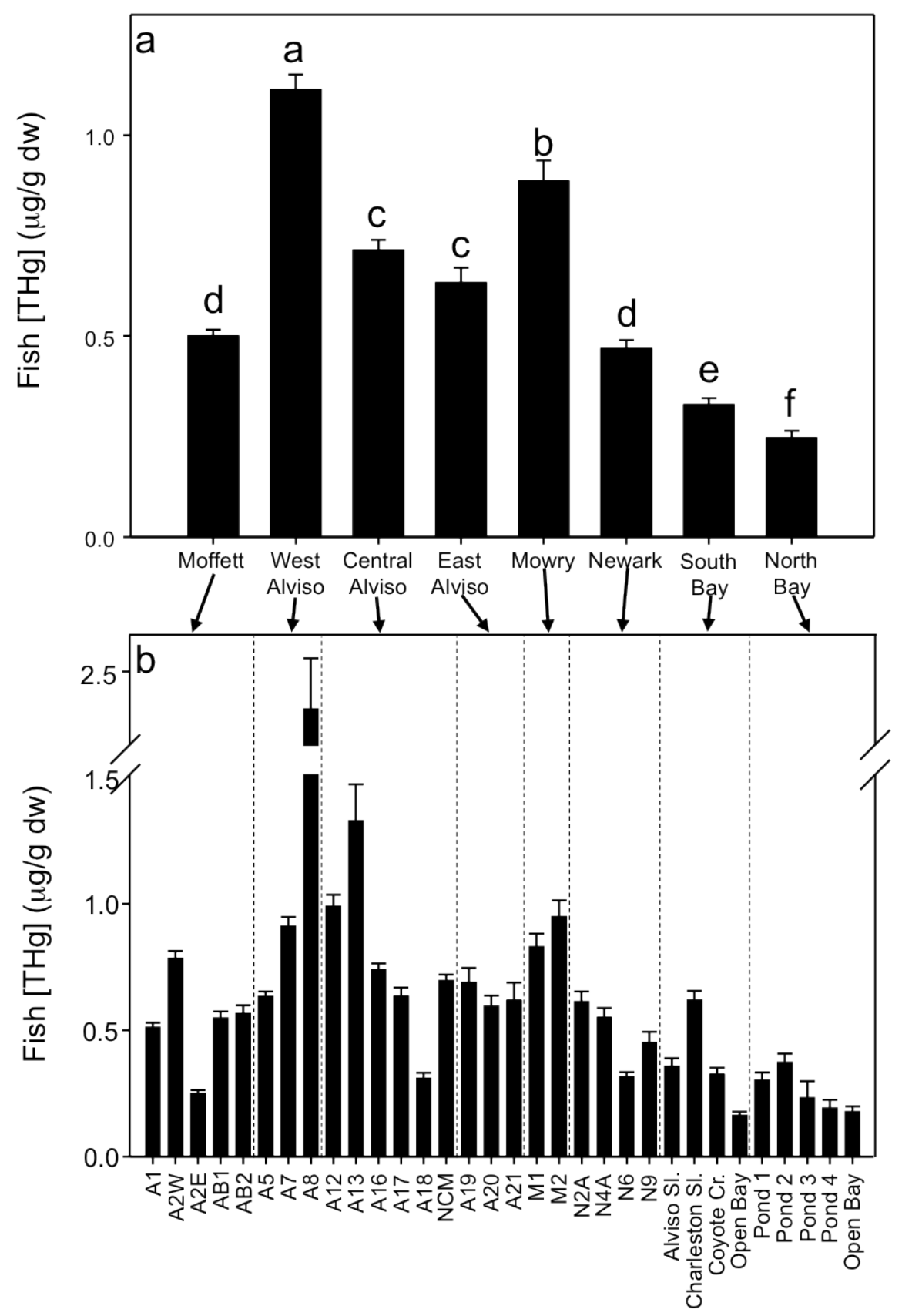

Figure 62. Total mercury $(\mathrm{THg})$ concentrations (least squares means \pm standard error) in size-standardized fish from wetlands in San Francisco Bay, California. Least squares means control for global model effects of species, region, wetland complex [region], Julian date ${ }^{2}$ and year. (a) Concentrations differed among regions; letters above bars indicate significant differences ( $a<0.05$, Tukey's Post-Hoc Pairwise Comparisons). (b) Concentrations differed among wetlands nested within regions. Figure from Eagles-Smith and Ackerman (2014) and used with permission. 


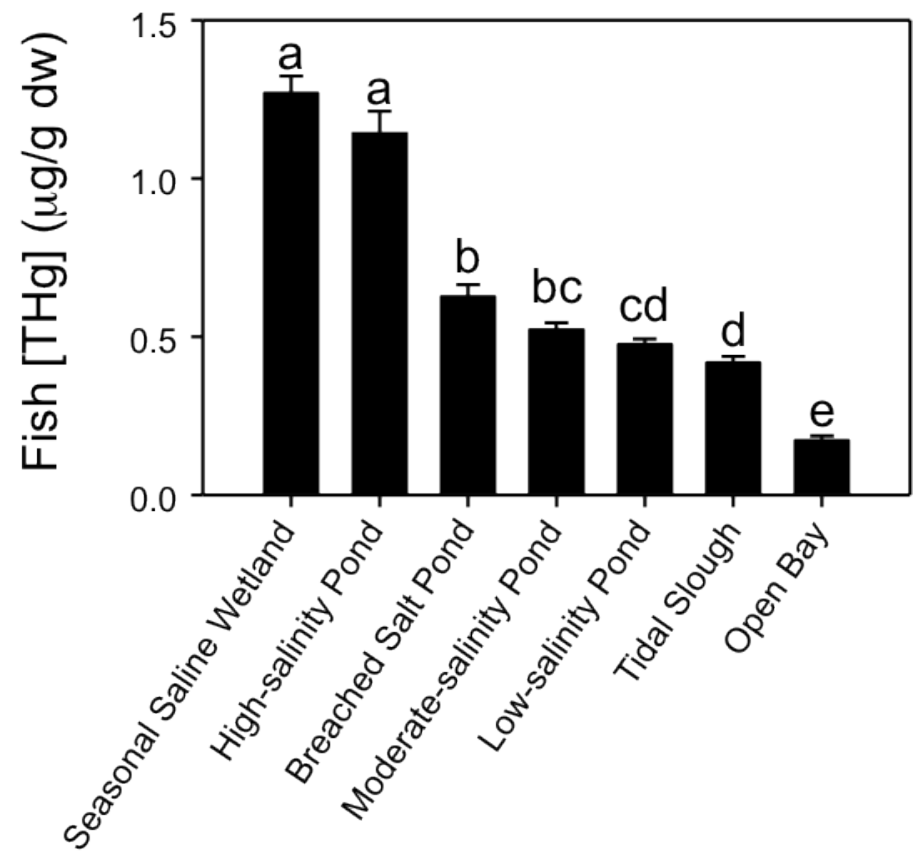

Figure 63. Total mercury $(\mathrm{THg})$ concentrations (least squares means \pm standard error) across different habitat types in size-standardized fish from wetlands in San Francisco Bay, California. Least squares means control for global model effects of species, region, wetland [region], Julian date ${ }^{2}$ and year. Letters above bars indicate significant differences ( $\alpha<0.05$, Tukey's Post-Hoc Pairwise Comparisons). Salinity levels were $20-40$ parts per thousand (ppt) for low-salinity salt ponds, 40-60 ppt for medium-salinity salt ponds, and 60-80 ppt for highsalinity salt ponds. Figure from Eagles-Smith and Ackerman (2014) and used with permission. 


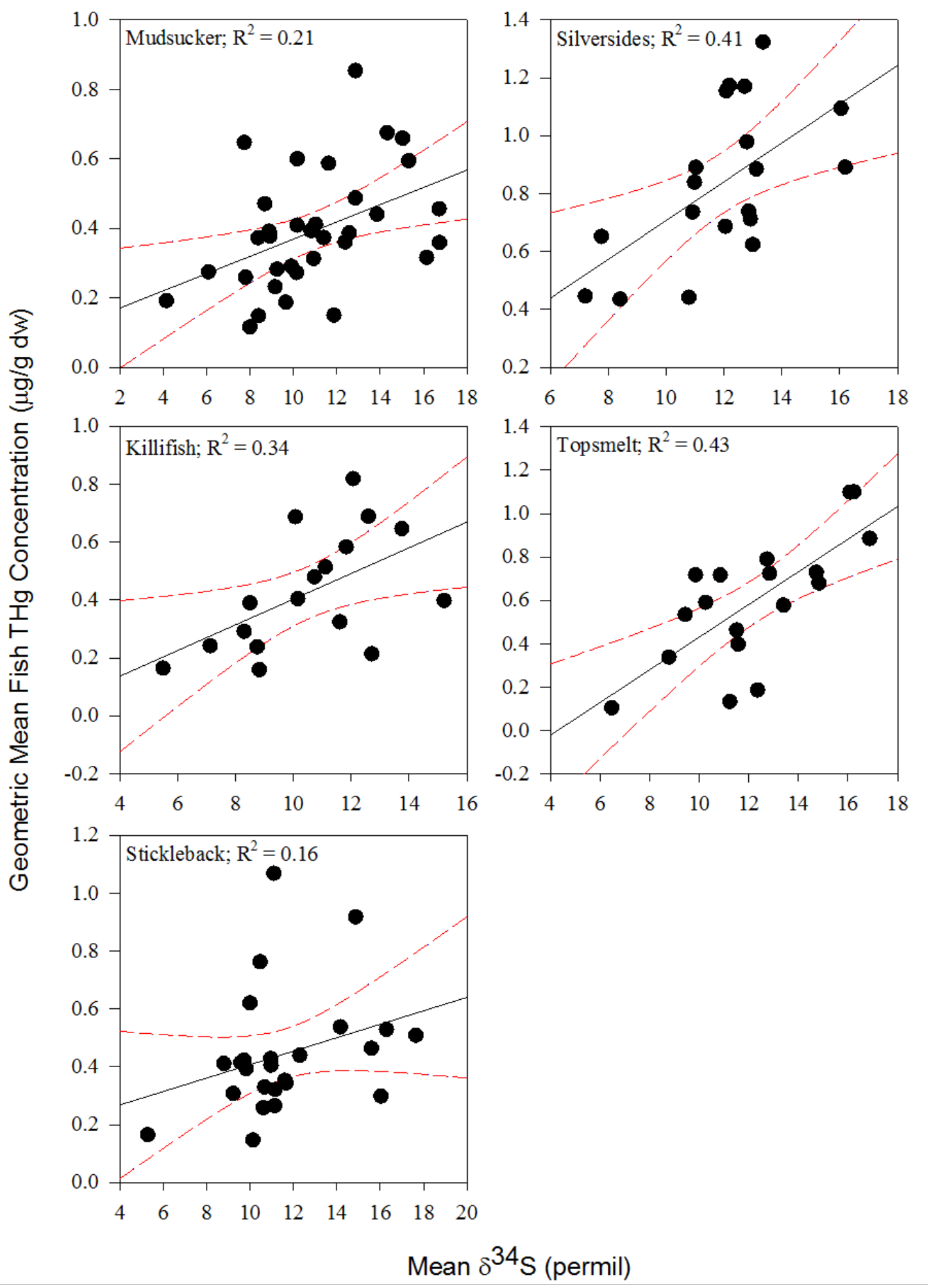

Figure 64. Geometric mean fish total mercury $(\mathrm{THg})$ concentrations $(\mu \mathrm{g} / \mathrm{g} \mathrm{dw})$ in relation to mean sulphur $\left(\delta^{34} \mathrm{~S}\right)$ stable isotope ratios from San Francisco Bay, California. Each data point represent a mean value within a site for a given year. 

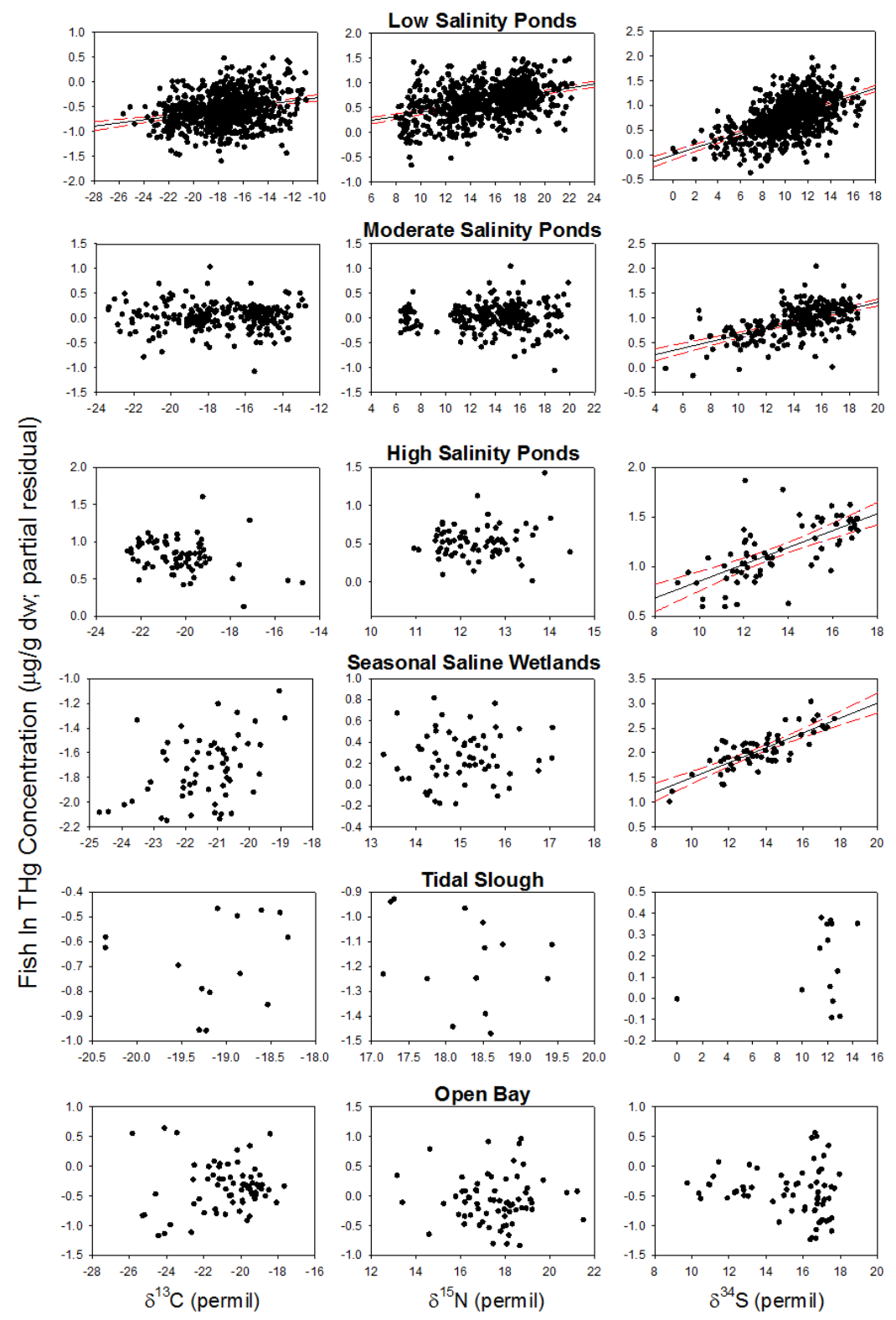

Figure 65. Relation between fish total mercury (THg) concentrations (partial residual; $\mu \mathrm{g} / \mathrm{g} \mathrm{dw}$ ) and carbon $\left(\delta^{13} \mathrm{C}\right)$, nitrogen $\left(\delta^{15} \mathrm{~N}\right)$, and sulfur $\left(\delta^{34} \mathrm{~S}\right)$ stable isotope ratios. Partial residuals represent the relation between these variables after statistically accounting for species, length, site, and date effects. Regression lines signify correlations with $\mathrm{P}<0.05$. 

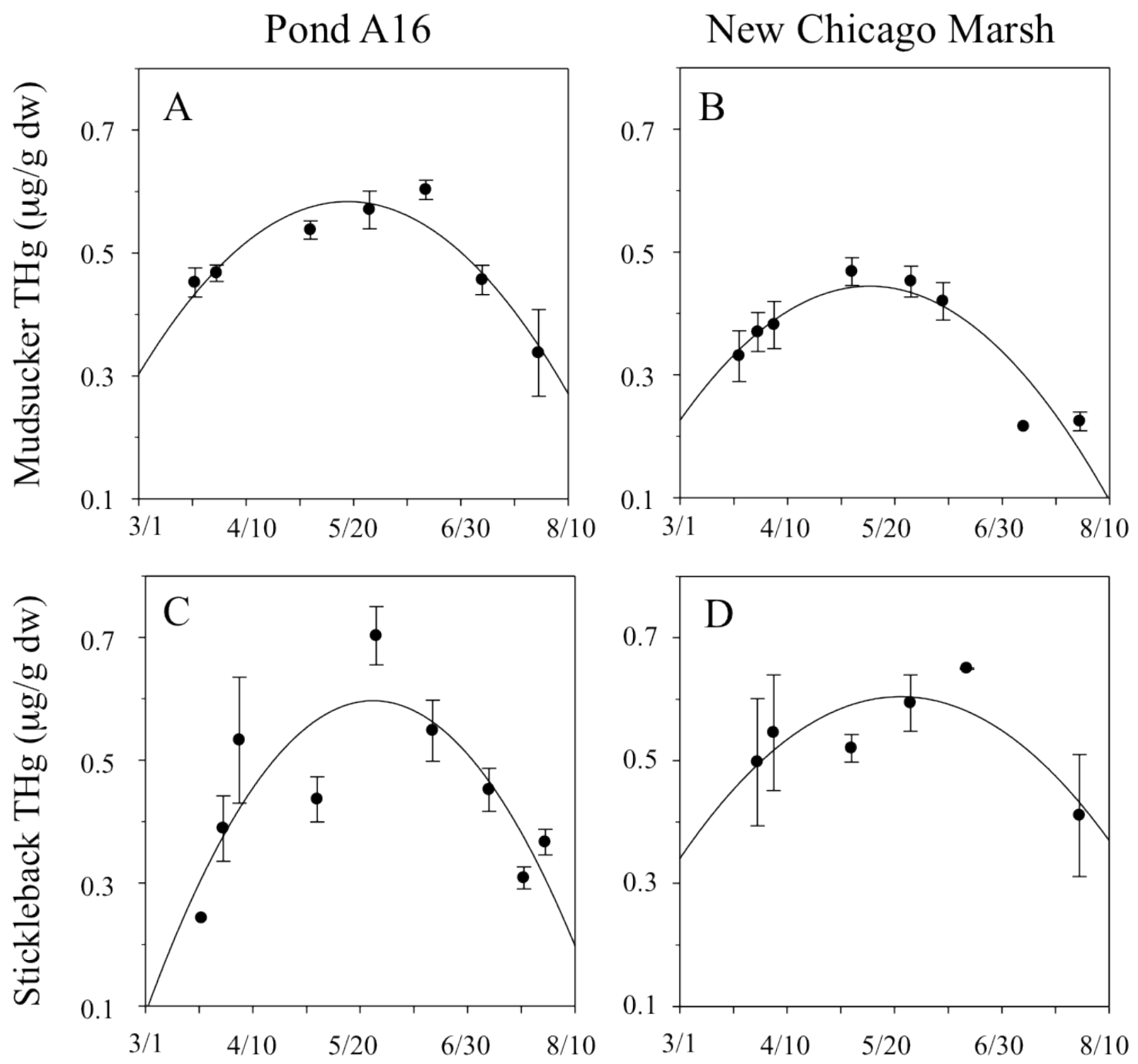

\section{Collection Date}

Figure 66. Site-specific short-term variation in whole-body total mercury ( $\mathrm{THg}$ ) concentrations in ( $\mathrm{A}$ and $\mathrm{B}$ ) longjaw mudsuckers ( $C$ and $D)$ and threespine sticklebacks. THg concentrations are length-corrected for the average size of fish returned to colonies by Forster's terns (mudsuckers, $68 \mathrm{~mm}$; stickleback, $40 \mathrm{~mm}$ ). Figure from Eagles-Smith and Ackerman (2009) and used with permission. 


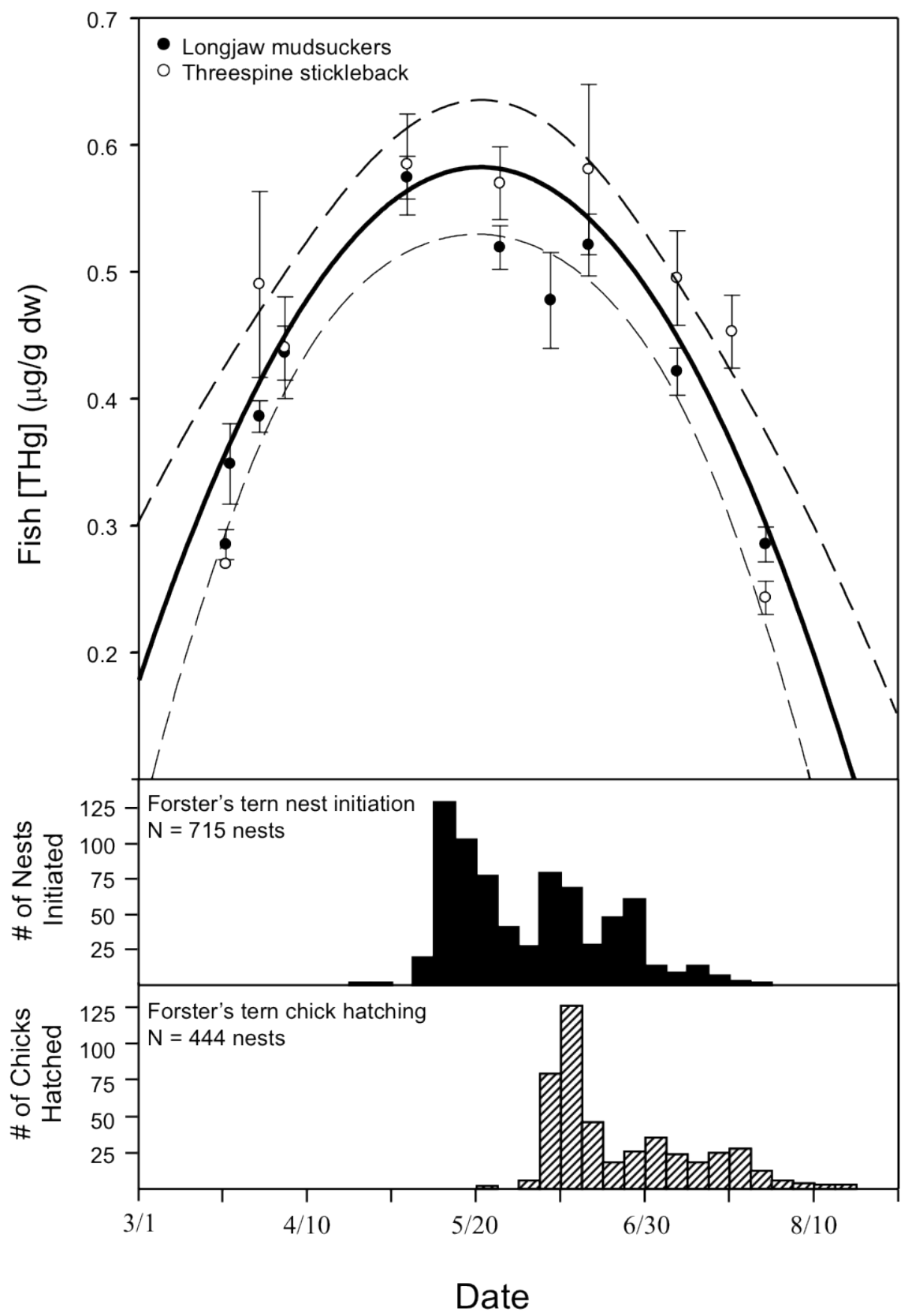

Figure 67. Relation between the temporal trend in whole-body prey fish total mercury $(\mathrm{THg})$ concentrations and the timing of Forster's tern nest initiation and chick hatching. Fish THg concentrations are statistically corrected for wetland effects and are standardized to the average size of fish returned to colonies by Forster's terns (mudsuckers, $68 \mathrm{~mm}$; sticklebacks, $40 \mathrm{~mm}$ ). Figure from Eagles-Smith and Ackerman (2009) and used with permission. 

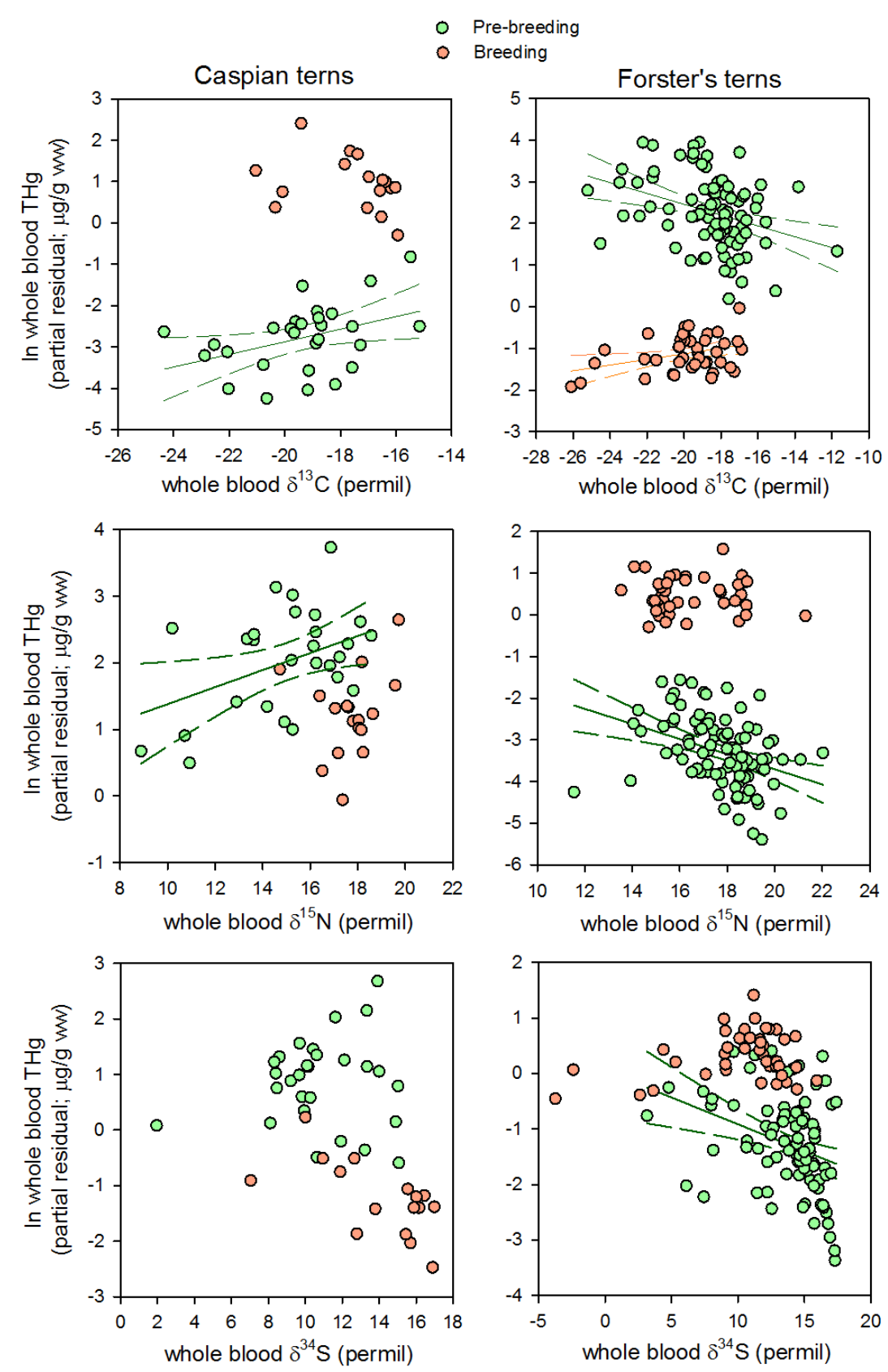

Figure 68. Relations between log whole blood total mercury $(\mathrm{THg})$ concentrations $(\mu \mathrm{g} / \mathrm{g} \mathrm{ww})$ and whole blood table isotope ratios of carbon $\left(\delta^{13} \mathrm{C}\right)$, nitrogen $\left(\delta^{15} \mathrm{~N}\right)$, and sulfur $\left(\delta^{34} \mathrm{~S}\right)$ in pre-breeding (green symbols) and breeding (orange symbols) Caspian terns and Forster's terns. Linear regressions are plotted for relations where $\mathrm{P}<0.05$. Partial residual THg concentrations statistically account for the influence of year, sex, and site effects. 


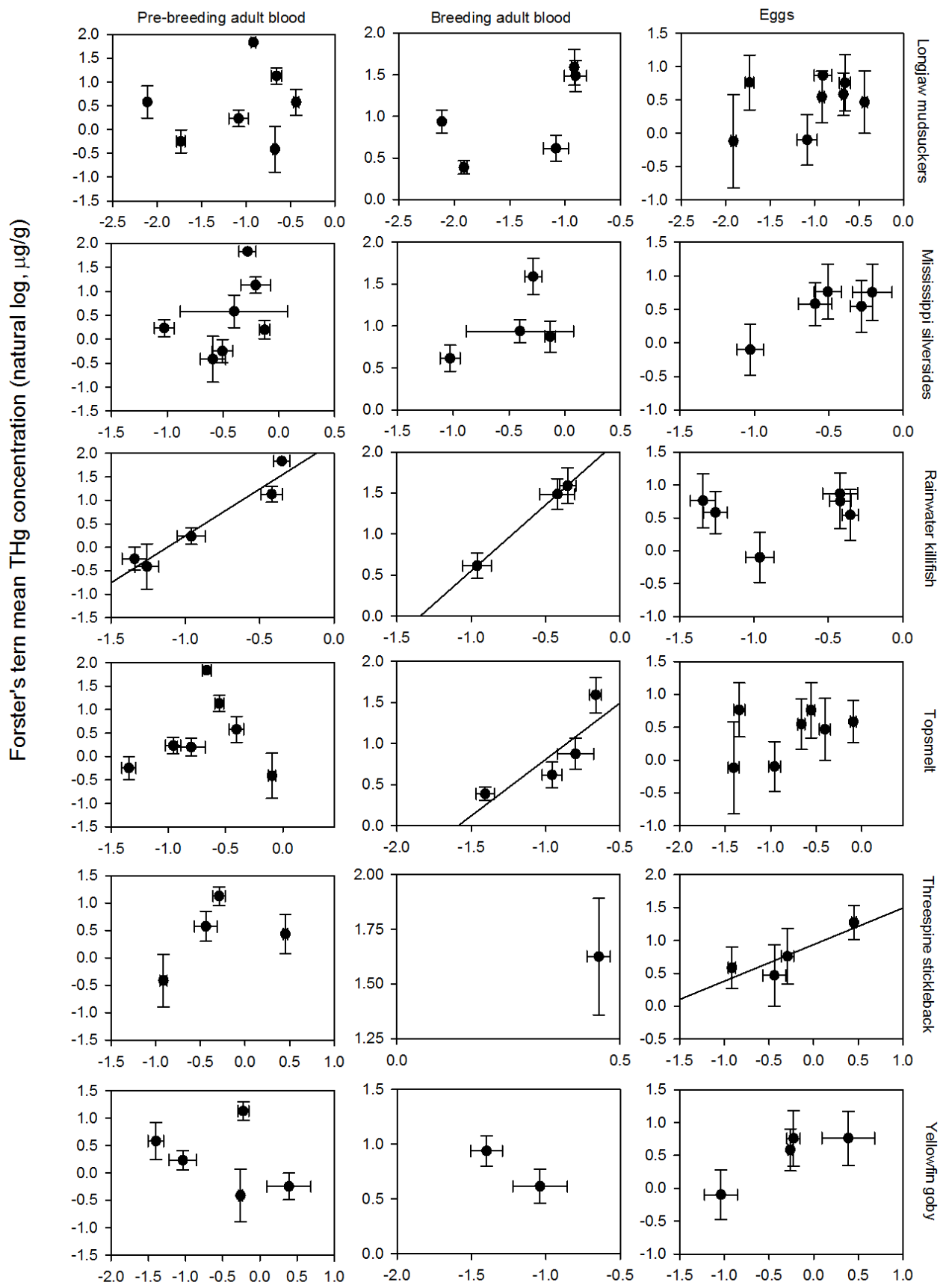

Fish mean $\mathrm{THg}$ concentration (natural $\log , \mu \mathrm{g} / \mathrm{g} \mathrm{dw}$ )

Figure 69. Correlation between single-species in mean fish total mercury $(\mathrm{THg})$ concentrations ( $\mu \mathrm{g} / \mathrm{g} \mathrm{dw} ; \pm \mathrm{SE}$ ), and corresponding Forster's tern THg concentrations in pre-breeding blood ( $\mu \mathrm{g} / \mathrm{g} \mathrm{ww} \pm \pm \mathrm{SE}$ ), breeding blood $(\mu \mathrm{g} / \mathrm{g} \mathrm{ww} ; \pm \mathrm{SE})$, and eggs ( $\mu \mathrm{g} / \mathrm{g}$ fww; $\pm \mathrm{SE}$ ) sampled from the same wetland location where fish were sampled. Regression lines are included for any correlations with $\mathrm{P}<0.05$. 


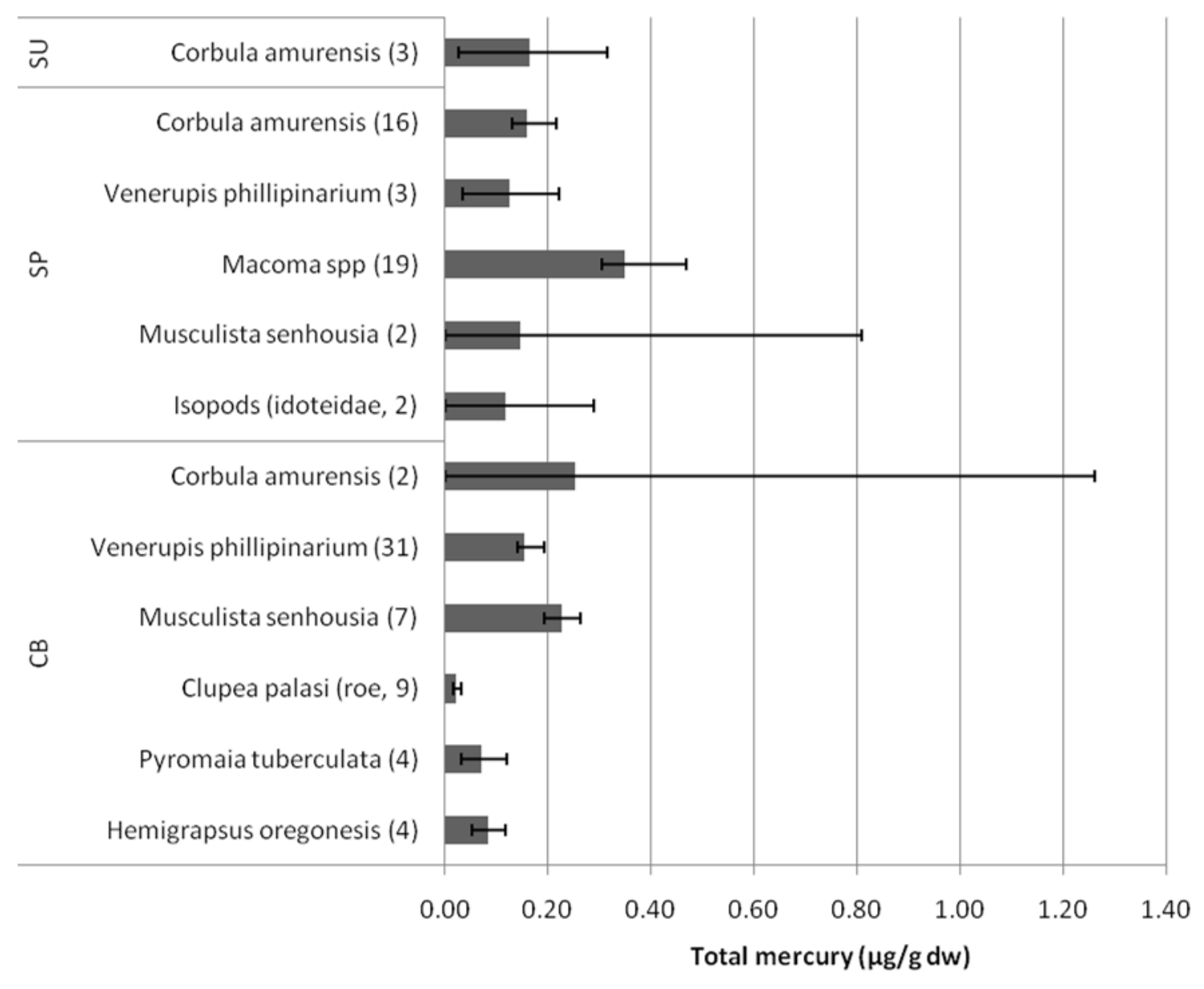

Figure 70. Total mercury (geometric mean and 95 percent confidence intervals) concentrations in predominant surf scoter prey items from three subembayments of the San Francisco Bay Estuary, California. Sub-embayment (SU, Suisun; SP, San Pablo; CB, Central Bay), species, and sample size (n) are indicated on the vertical axis. Bivalve species include Corbula amurensis, Venerupis phillipinarium, Macoma spp., Musculista senhousia. Macoma spp. was not a prey item during our study period, but values are included for comparison purposes. Figure from De La Cruz (2010) and used with permission. 


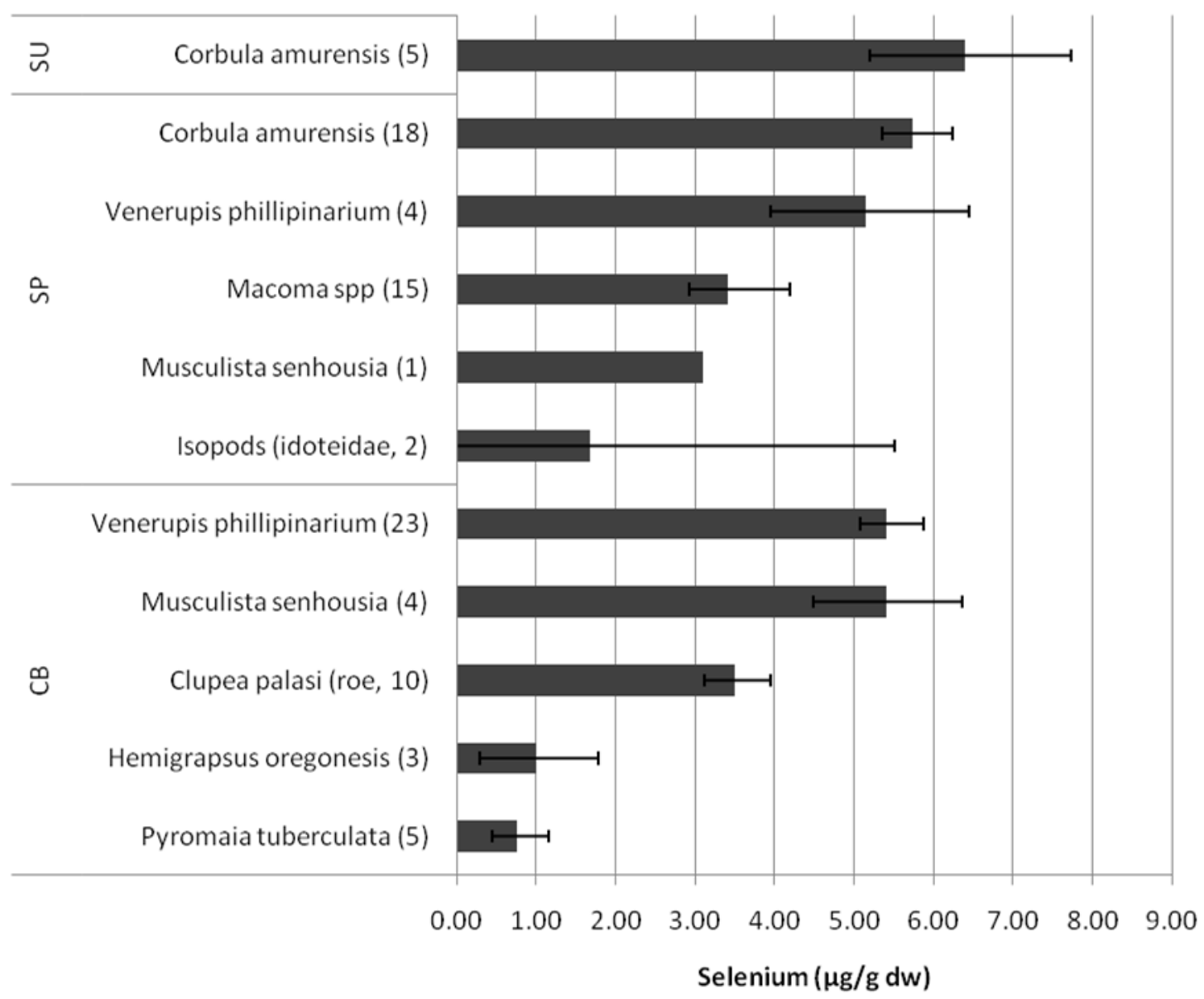

Figure 71. Selenium (geometric mean and 95 percent confidence intervals) concentrations in predominant surf scoter prey items from three sub-embayments of the San Francisco Bay Estuary, California. Sub-embayment (SU, Suisun; SP, San Pablo; CB, Central Bay), species, and sample size (n) are indicated on the vertical axis. Bivalve species include Corbula amurensis, Venerupis phillipinarium, Macoma spp., Musculista senhousia. Macoma spp. was not a prey item during our study period, but values are included for comparison purposes. Figure from De La Cruz (2010) and used with permission. 


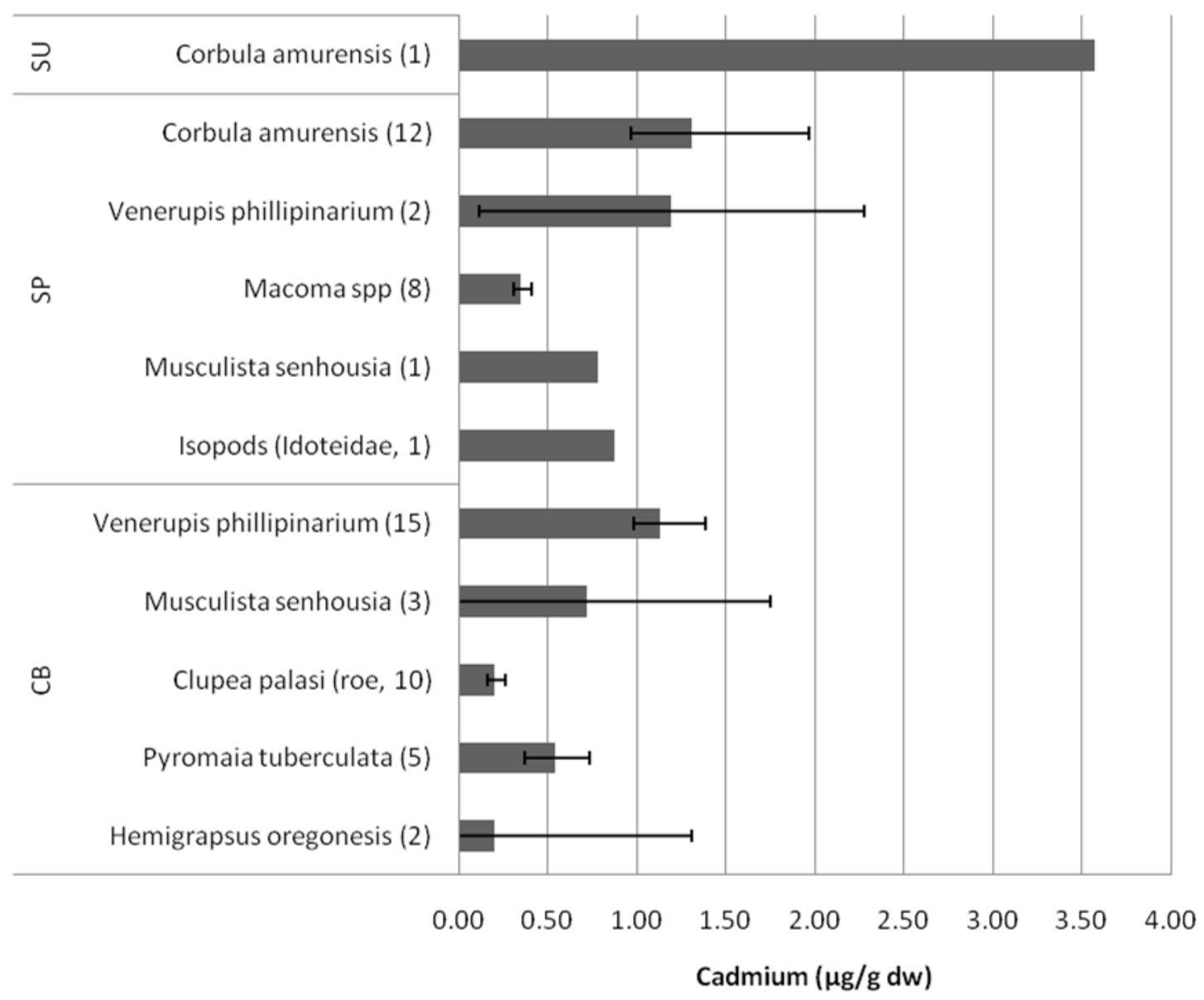

Figure 72. Cadmium (geometric mean and 95 percent confidence intervals) concentrations in predominant surf scoter prey items from three sub-embayments of the San Francisco Bay Estuary, California. Sub-embayment (SU, Suisun; SP, San Pablo; CB, Central Bay), species, and sample size (n) are indicated on the vertical axis. Bivalve species include Corbula amurensis, Venerupis phillipinarium, Macoma spp., Musculista senhousia. Macoma spp. was not a prey item during our study period, but values are included for comparison purposes. Figure from De La Cruz (2010) and used with permission. 


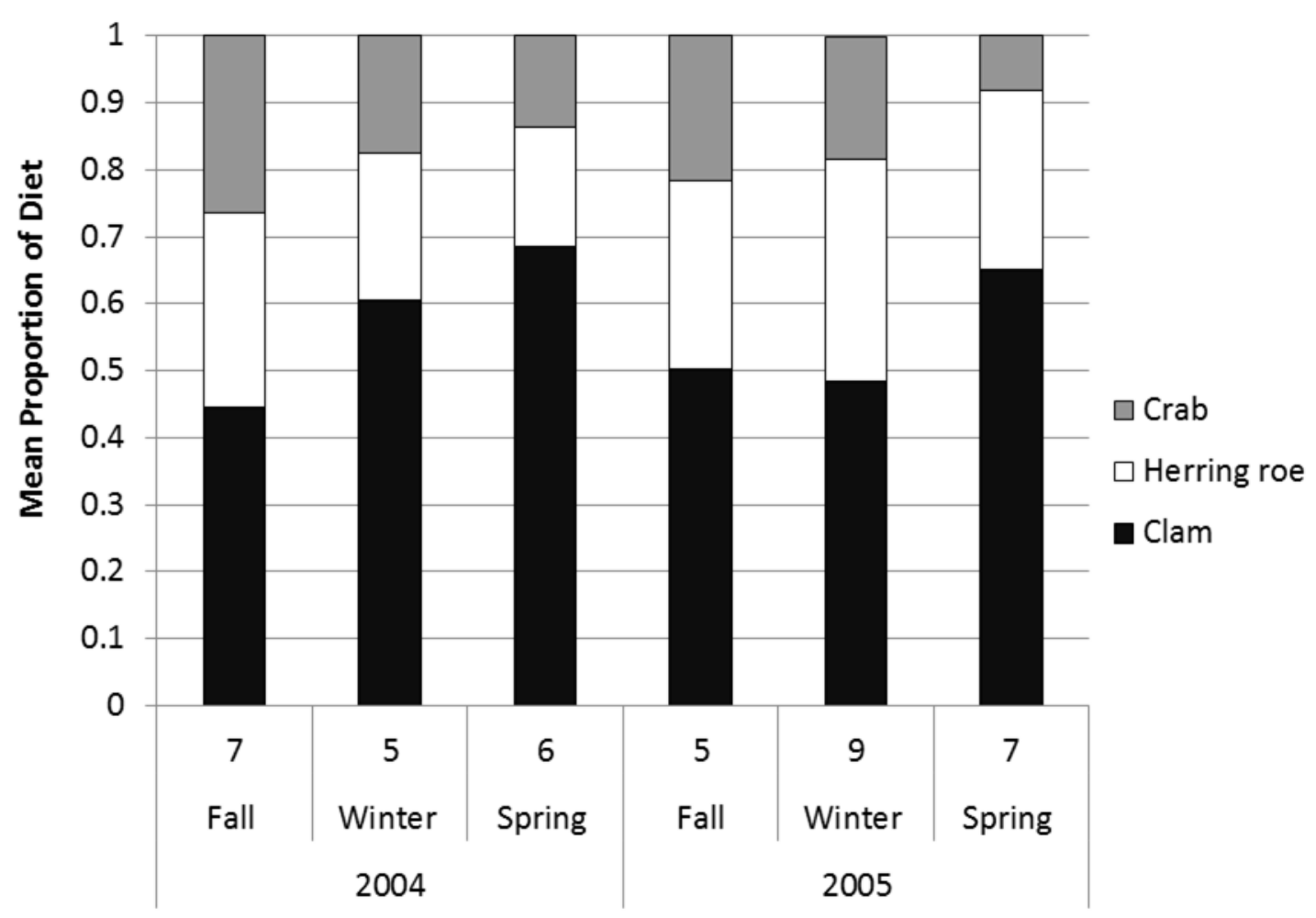

Figure 73. Mean proportion of each prey category in seasonal diets of Central Bay female surf scoters during $2003-04$ and $2004-05$, as determined using stable isotope ratios of nitrogen $\left(\delta^{15} \mathrm{~N}\right)$ and carbon $\left(\delta^{13} \mathrm{C}\right)$ signatures from scoter plasma and prey in isotopic mixing models. Numbers on the $\mathrm{x}$-axis represent sample sizes. Figure from De La Cruz and others (in press). 


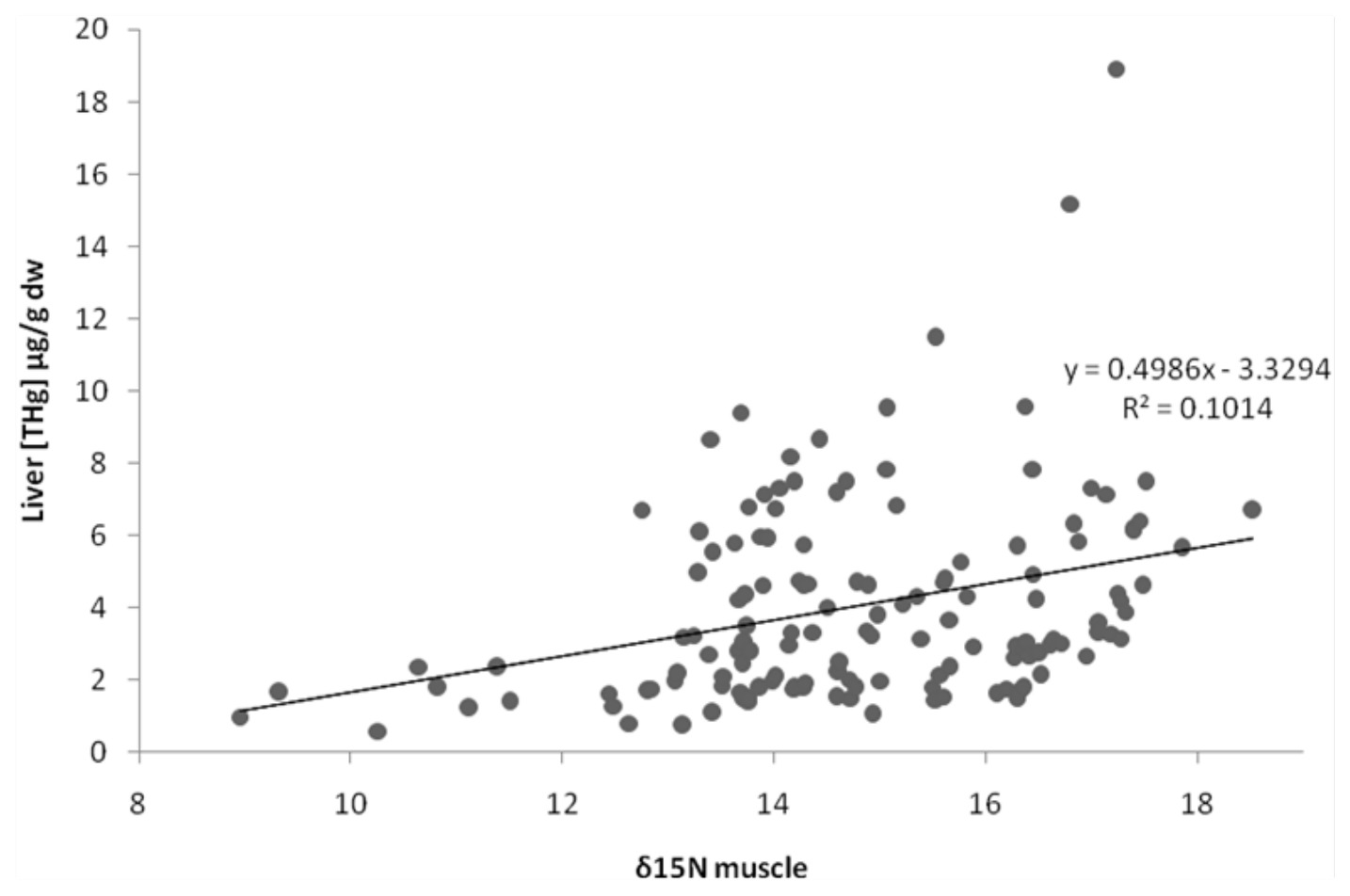

Figure 74. Total mercury concentration in surf scoter livers vs $\delta^{15} \mathrm{~N}_{\text {muscle. }}$. Fall samples are excluded because muscle isotope signatures may have represented the fall migratory period. Figure from De La Cruz (2010) and used with permission. 

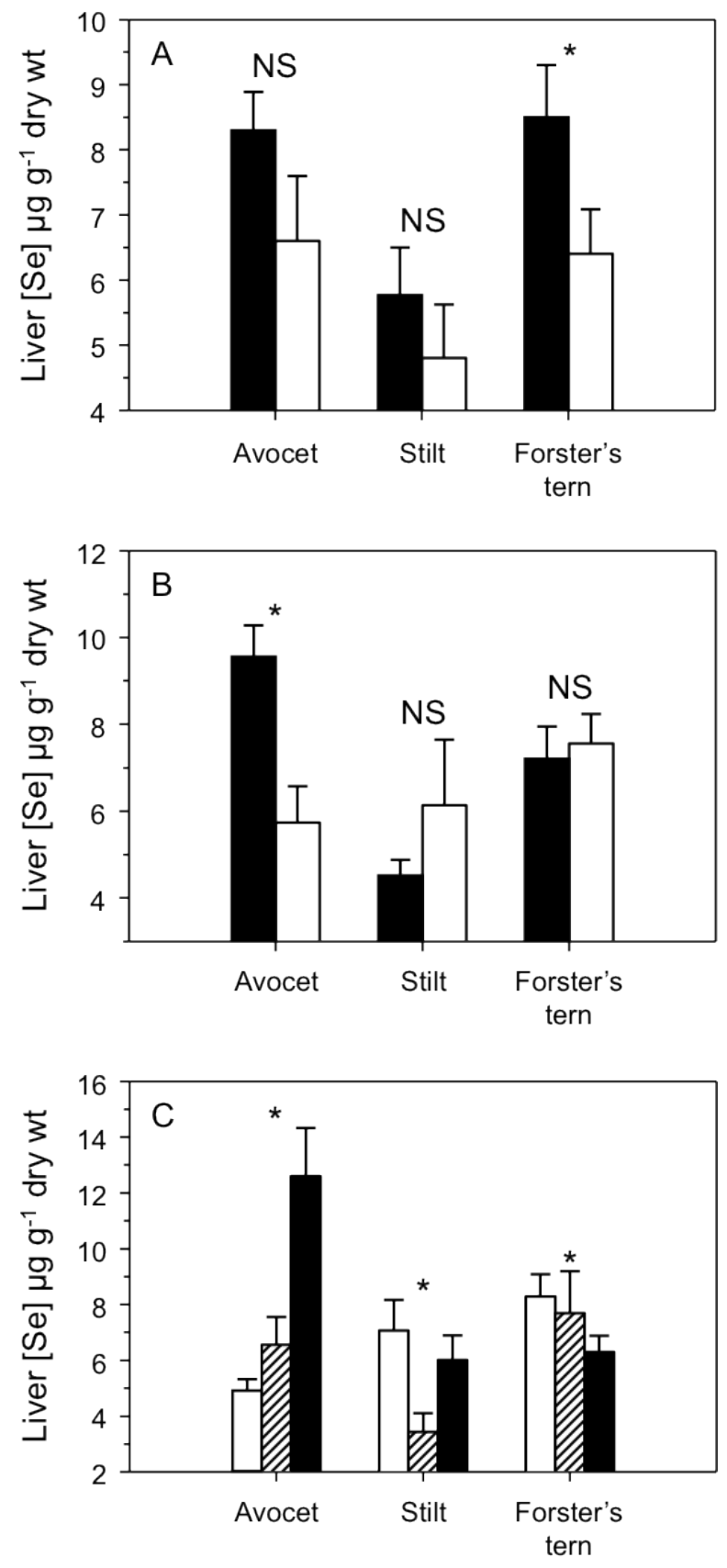

Figure 75. Selenium concentrations (least squares mean $\pm \mathrm{SE}$ ) in adult livers for $(A)$ pre-breeding (solid bars) and breeding (open bars); (B) female (solid bars) and male (open bars); and (C) lower South Bay (open bars), central South Bay (hatched bars), and North Bay (closed bars) waterbirds in San Francisco Bay, California. Asterisk $\left(^{*}\right)$ indicates a statistically significant difference for each species $(P<0.05)$. NS $=$ not significant. Figure from Ackerman and Eagles-Smith (2009b) and used with permission. 


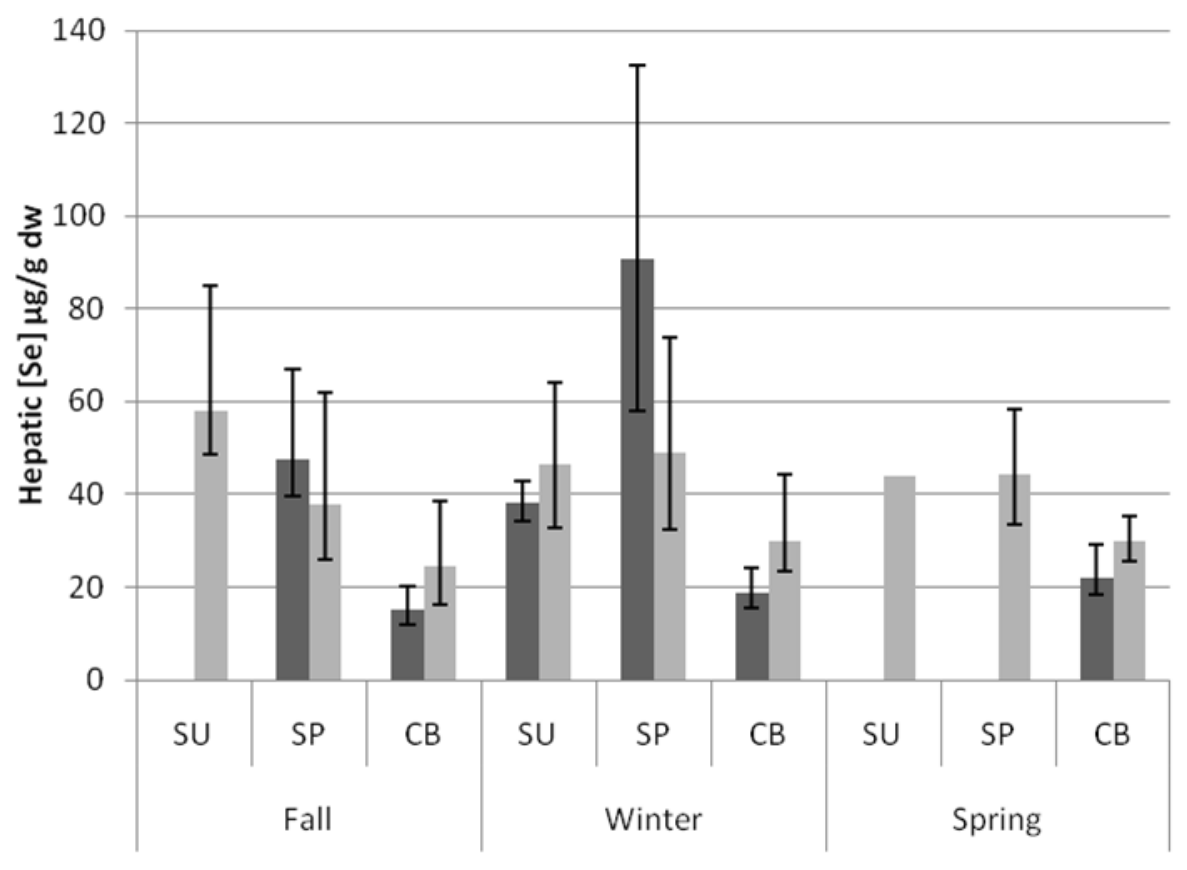

Figure 76. Geometric means and 95 percent confidence intervals for hepatic selenium (Se) in female surf scoters collected in three San Francisco Bay sub-embayments (SU, Suisun; SP, San Pablo; CB, Central Bay) during fall, winter, spring of 2003-04 (dark bars, 2004) and 2004-05 (light grey bars, 2005). Figure from De La Cruz (2010) and used with permission. 

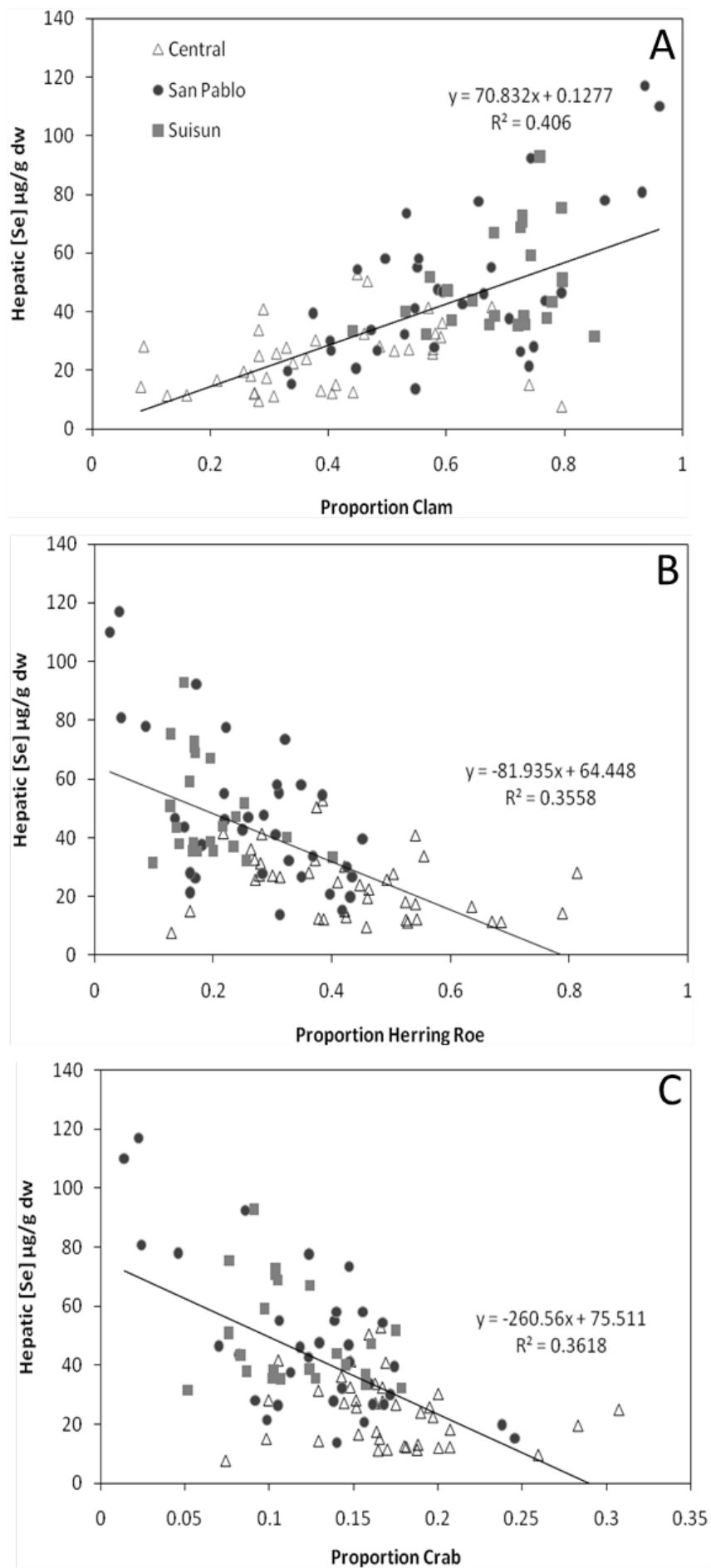

Figure 77. Selenium concentration in liver compared with proportions of (A) clams, $(B)$ herring roe, and $(C)$ crab in surf scoter diets based on mixing models incorporating nitrogen $\left(\delta^{15} \mathrm{~N}\right)$ and carbon $\left(\delta^{13} \mathrm{C}\right)$ in surf scoter plasma and prey. Figure from De La Cruz (2010) and used with permission. 


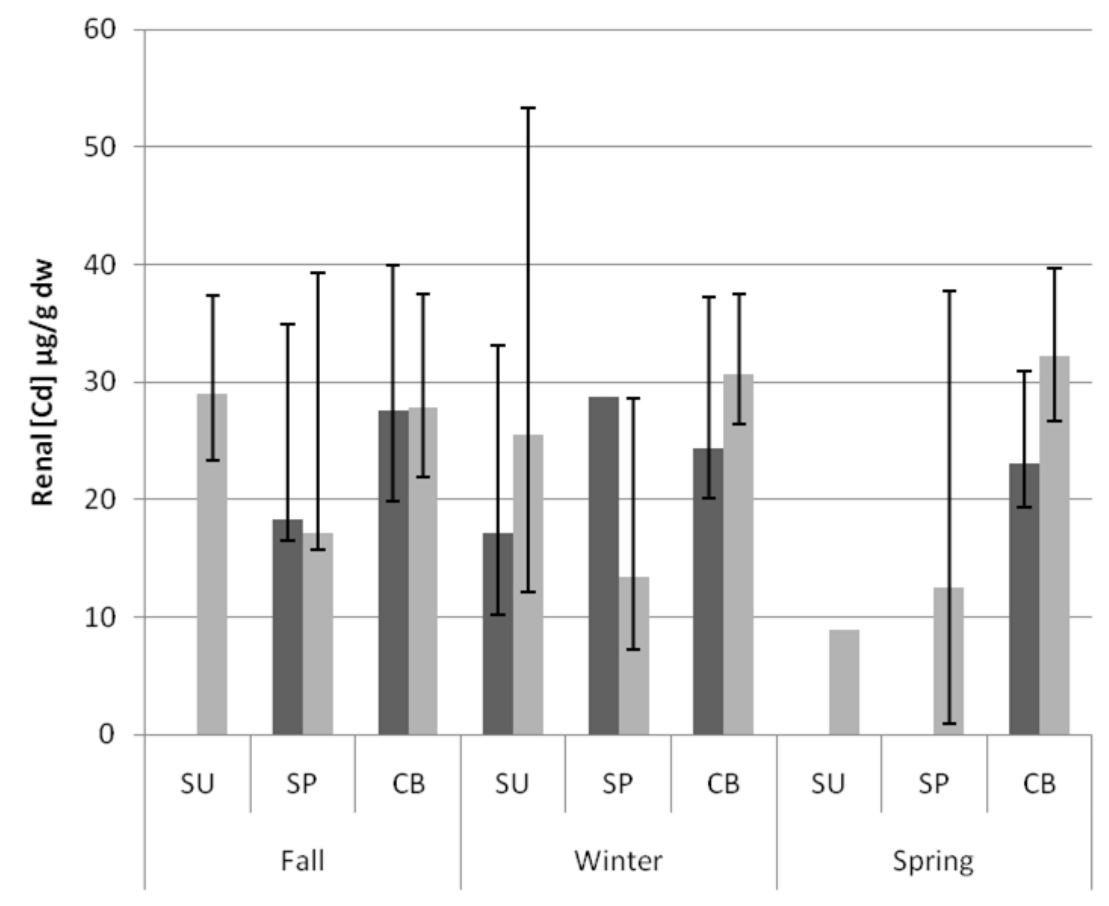

Figure 78. Geometric means and 95 percent confidence intervals renal cadmium (Cd) in female surf scoters collected in three San Francisco Bay sub-embayments (SU, Suisun; SP, San Pablo; CB, Central Bay) during fall, winter, spring of 2003-04 (dark bars, 2004) and 2004-05 (light grey bars, 2005). Figure from De La Cruz (2010) and used with permission. 

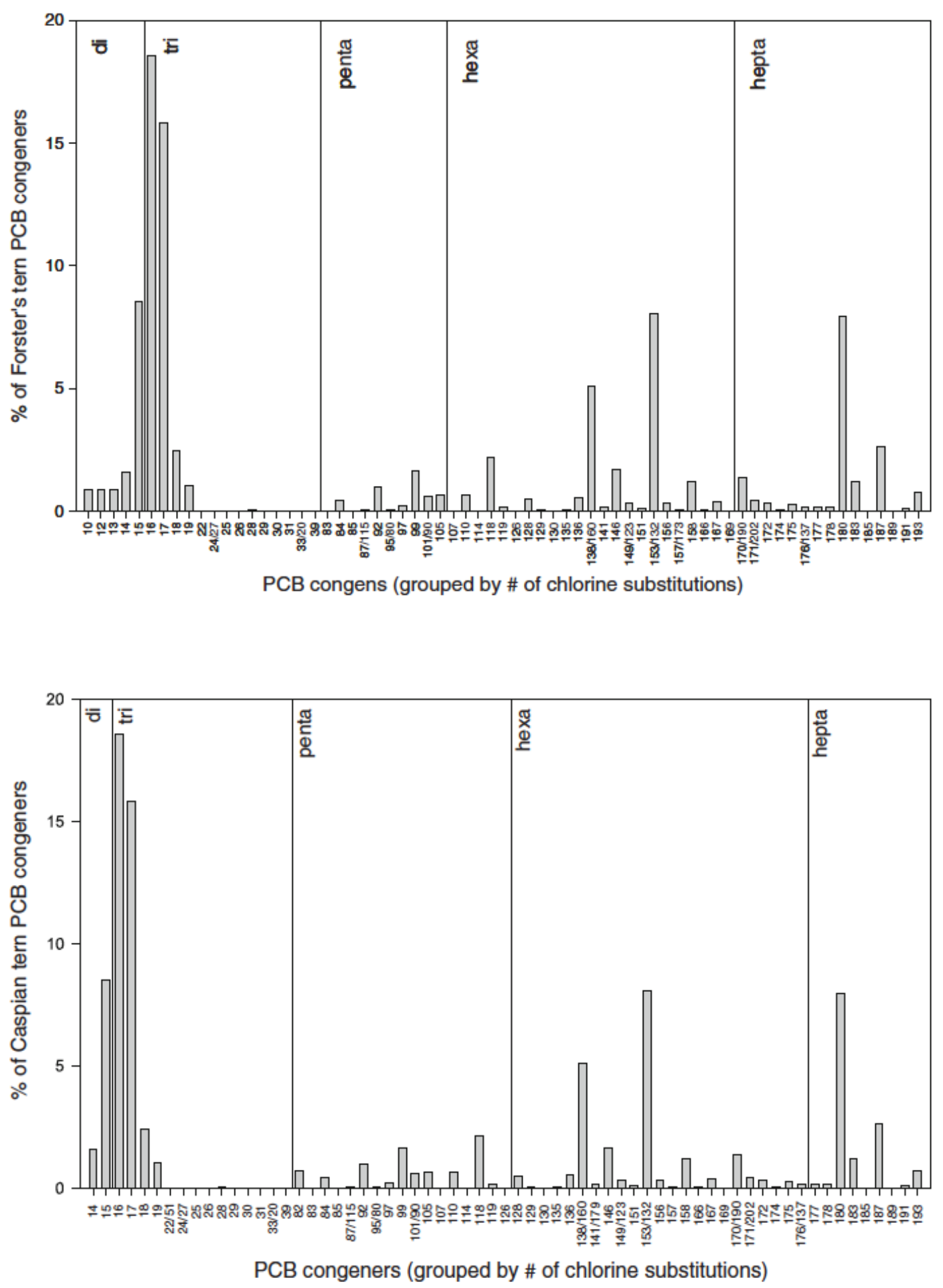

Figure 79. Distribution of PCB congeners in livers of Forster's tern and Caspian tern from San Francisco Bay, California. Figure from Herring and others (2010) and used with permission. 

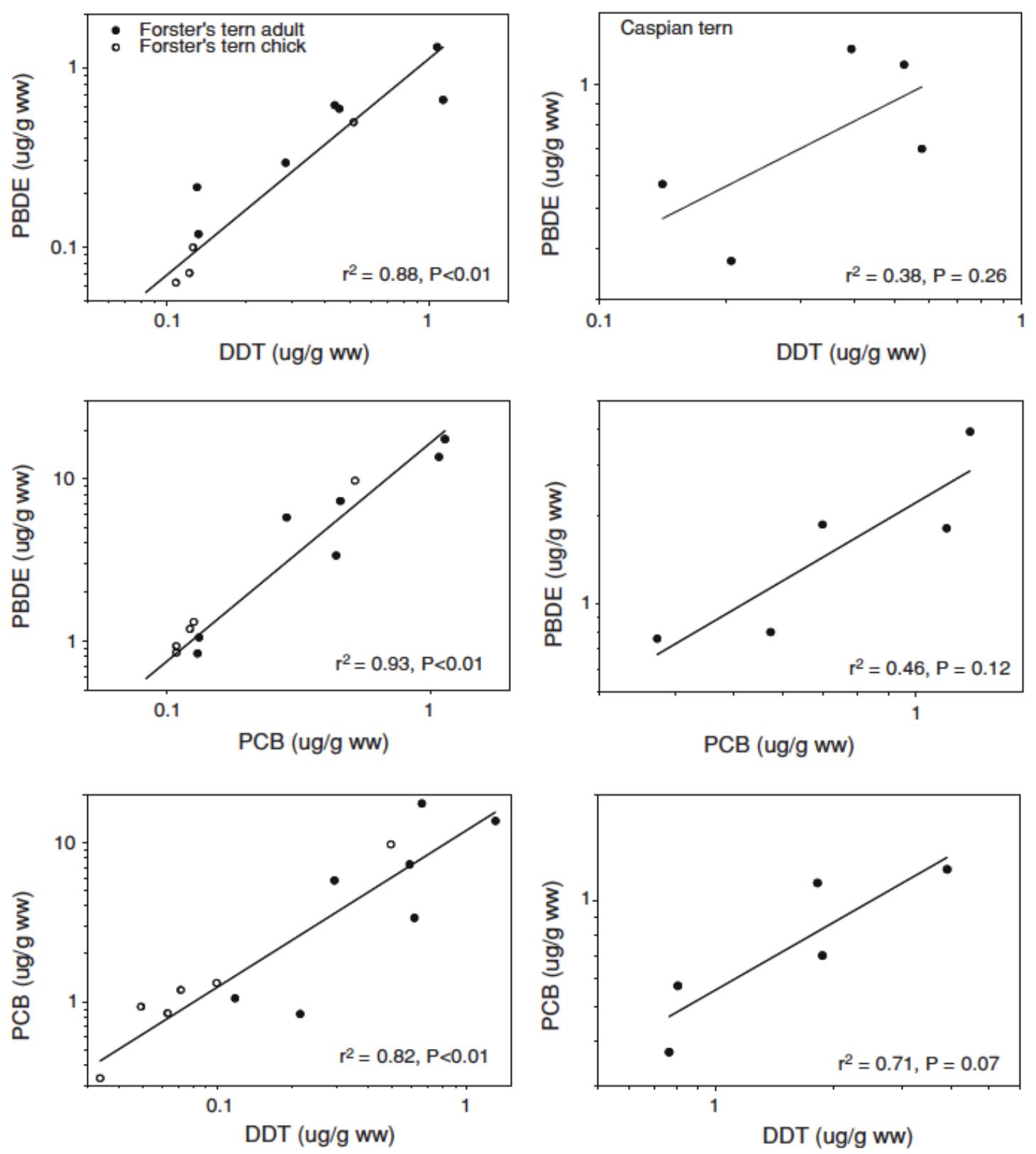

Figure 80. Correlation among PBDEs, PCBs, and DDTs in livers of Caspian tern adults and Forster's tern adults and chicks from San Francisco Bay, California. Figure from Herring and others (2010) and used with permission. 

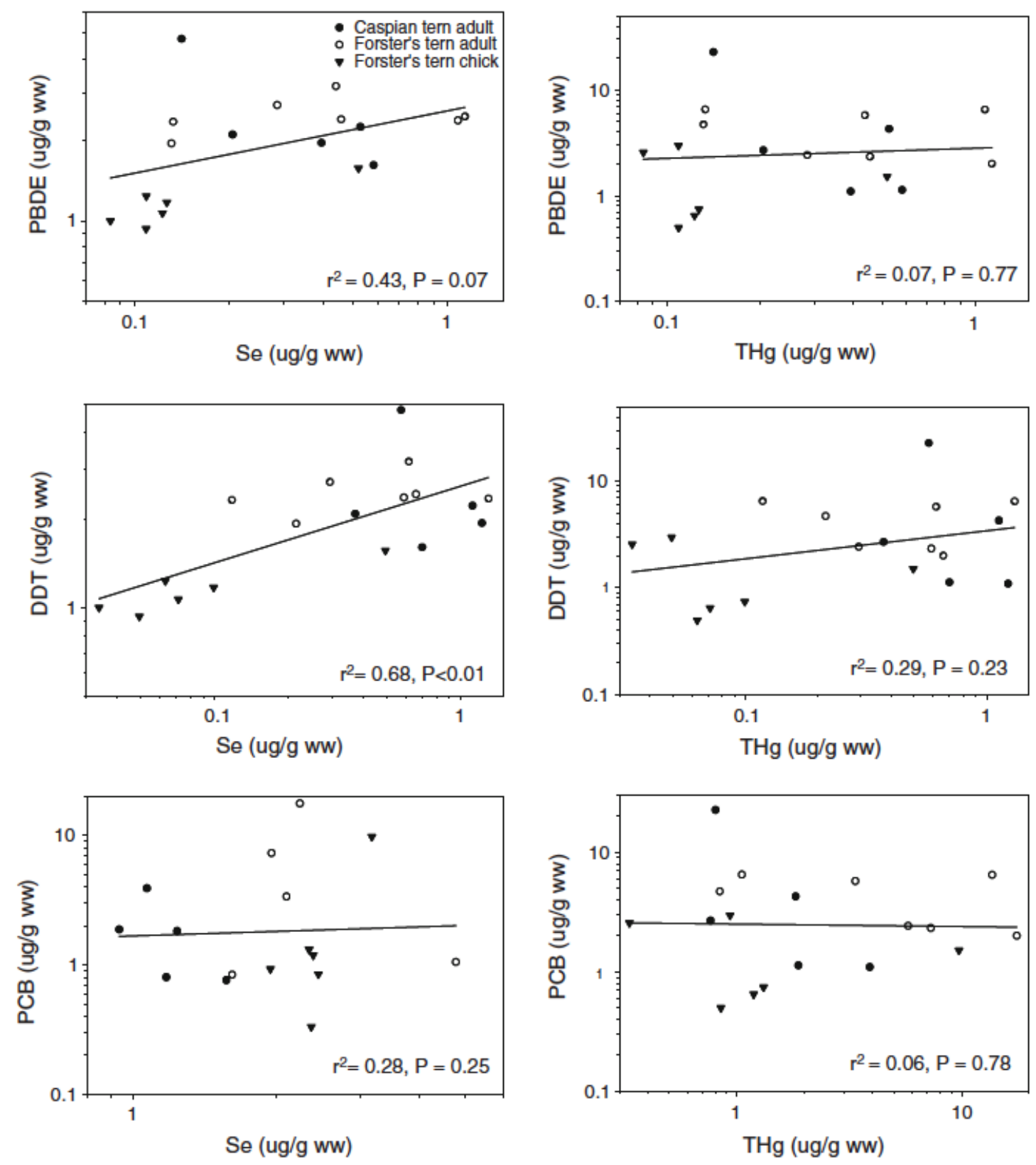

Figure 81. Correlations of PBDEs, PCBs, and DDTs with selenium (Se) and total mercury (THg) in livers of Caspian tern adults and Forster's tern adults and chicks from San Francisco Bay, California. Figure from Herring and others (2010) and used with permission. 


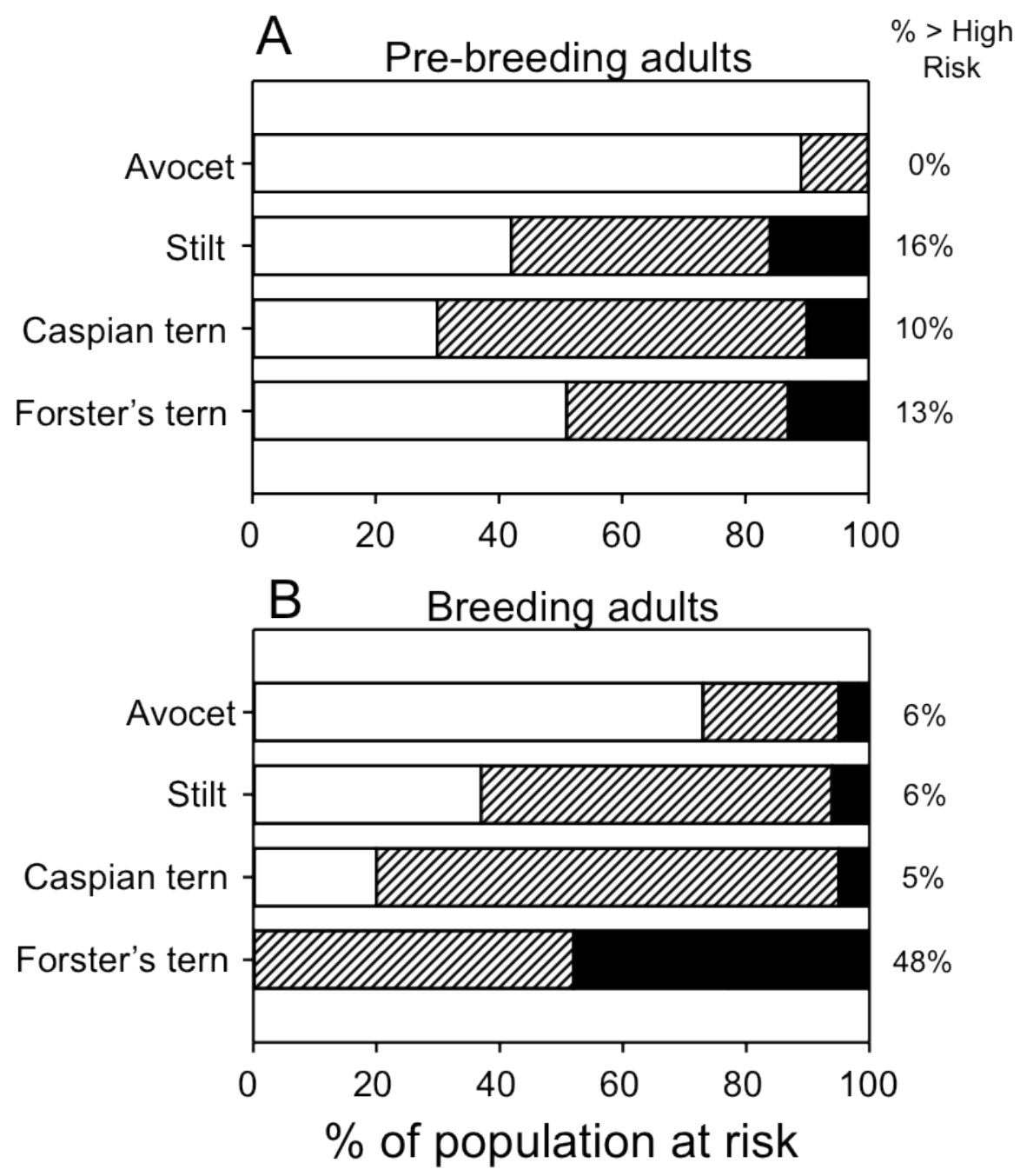

Figure 82. Proportion of $(A)$ pre-breeding and $(B)$ breeding waterbirds at risk to reproductive impairment based on blood mercury (THg) concentrations in San Francisco Bay, California. Low risk, $<1.0 \mu \mathrm{g} / \mathrm{g}$ ww; moderate risk, $1.0-<3.0 \mu \mathrm{g} / \mathrm{g} \mathrm{ww}$; high risk, $\geq 3.0 \mu \mathrm{g} / \mathrm{g}$ ww. Risk factors derived from values developed for common loons (Evers and others, 2008). Figure from Eagles-Smith and others (2009a) and used with permission. 


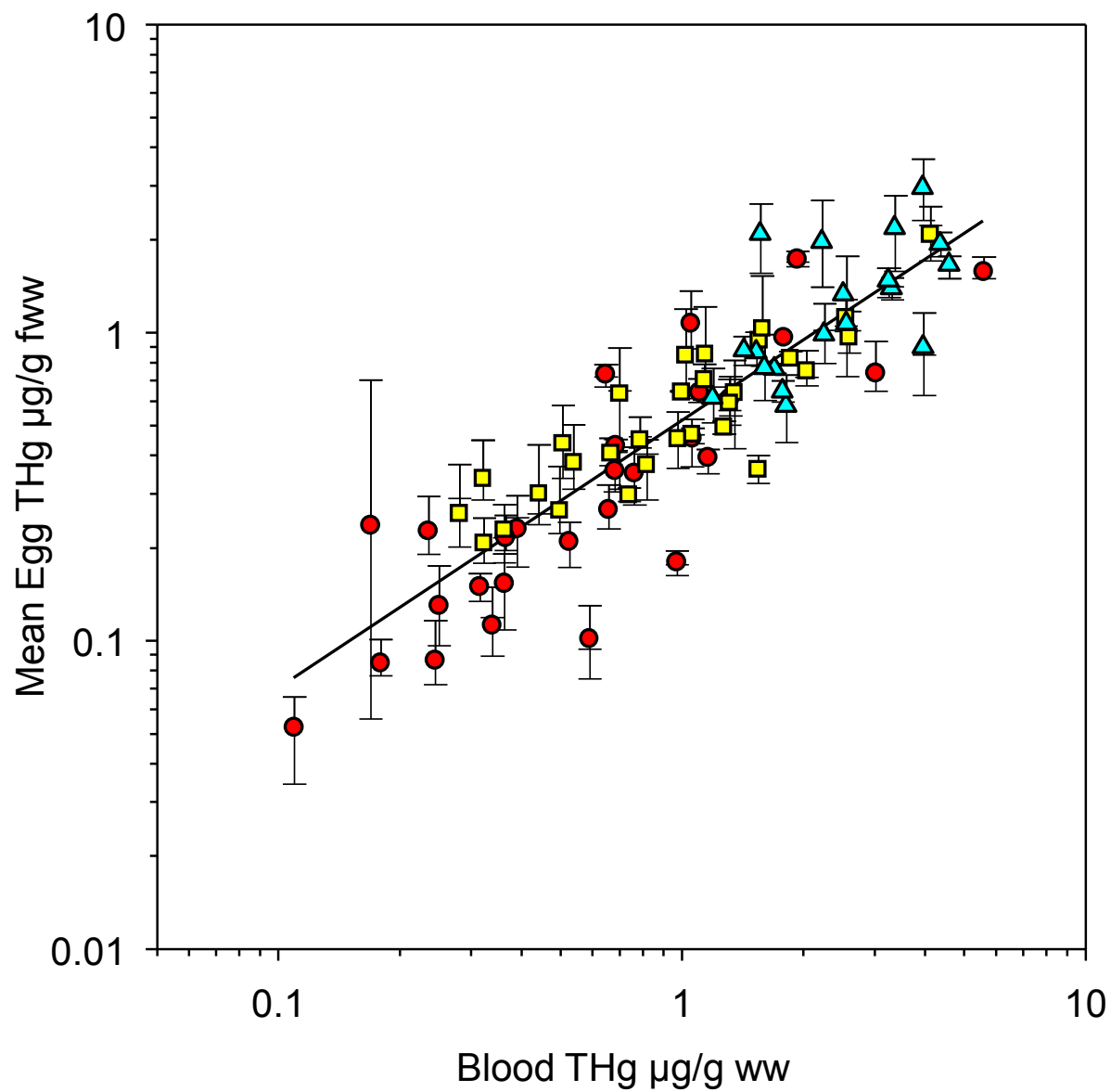

Figure 83. Mean total mercury $(\mathrm{THg})$ concentrations in full clutches of eggs was strongly correlated with blood $\mathrm{THg}$ concentrations of incubating females (American avocets, red; black-necked stilts, yellow; Forster's terns, blue) in San Francisco Bay, California, during 2005-07. Error bars represent the range (minimum and maximum) of the $\mathrm{THg}$ concentrations in eggs within each clutch. 


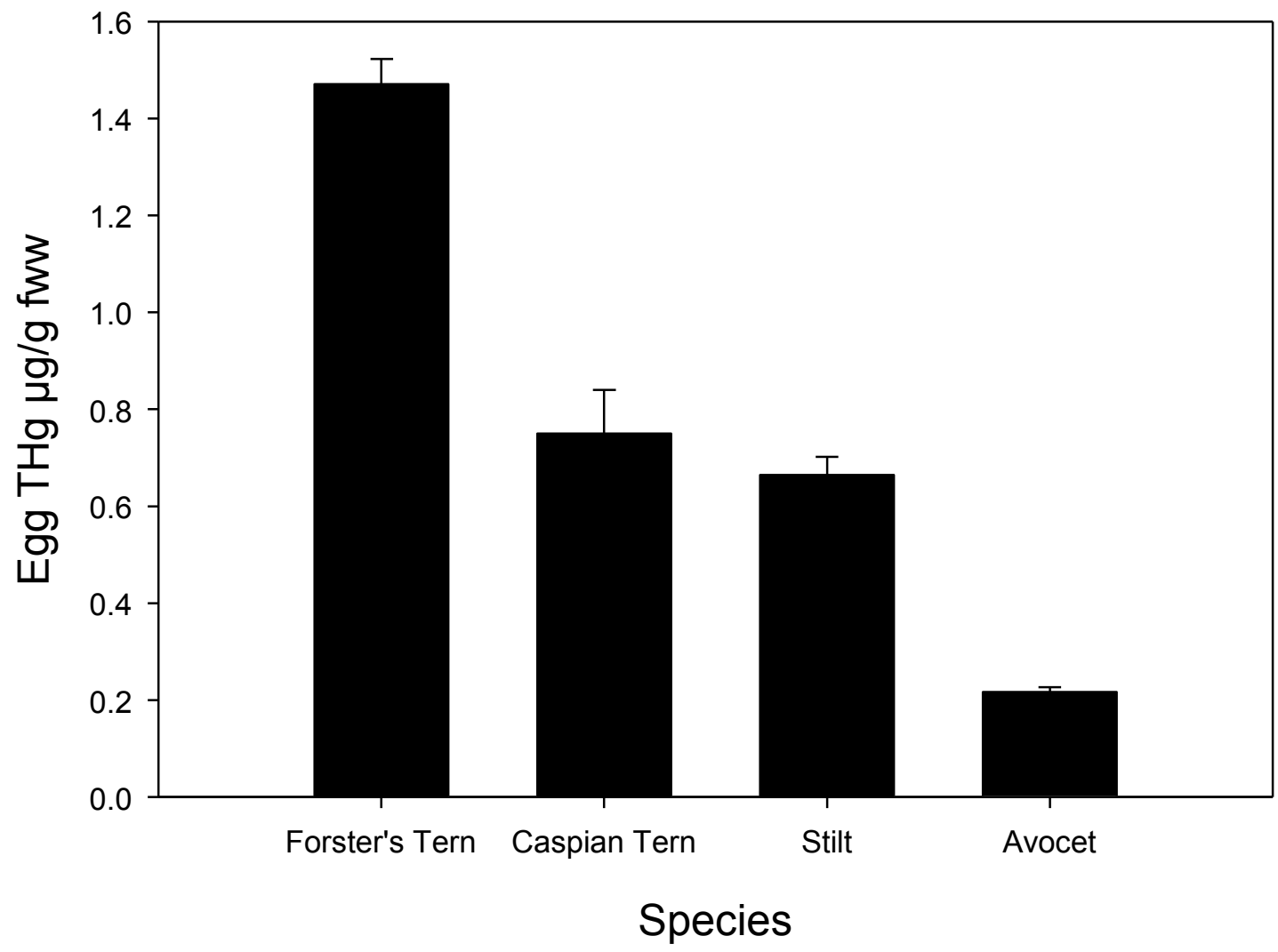

Figure 84. Geometric mean total mercury ( $\mathrm{THg})$ concentrations in eggs of the most common shorebird and tern species that bred in San Francisco Bay, California, during 2005-07.

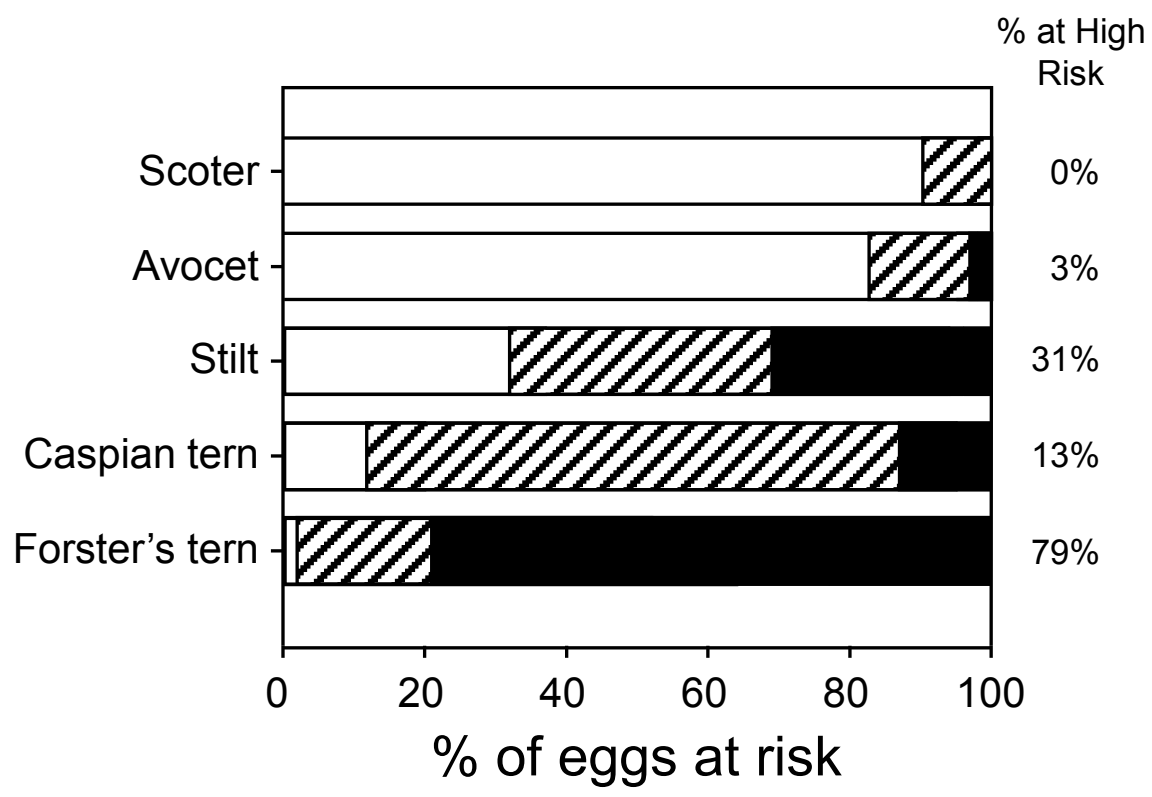

Figure 85. Percentage of eggs with total mercury concentrations $\geq 0.5 \mu \mathrm{g} / \mathrm{g}$ fww (hatched bars, moderate risk) and $\geq 1.0 \mu \mathrm{g} / \mathrm{g}$ fww (solid bars, high risk) in San Francisco Bay, California, during 2005-07. 


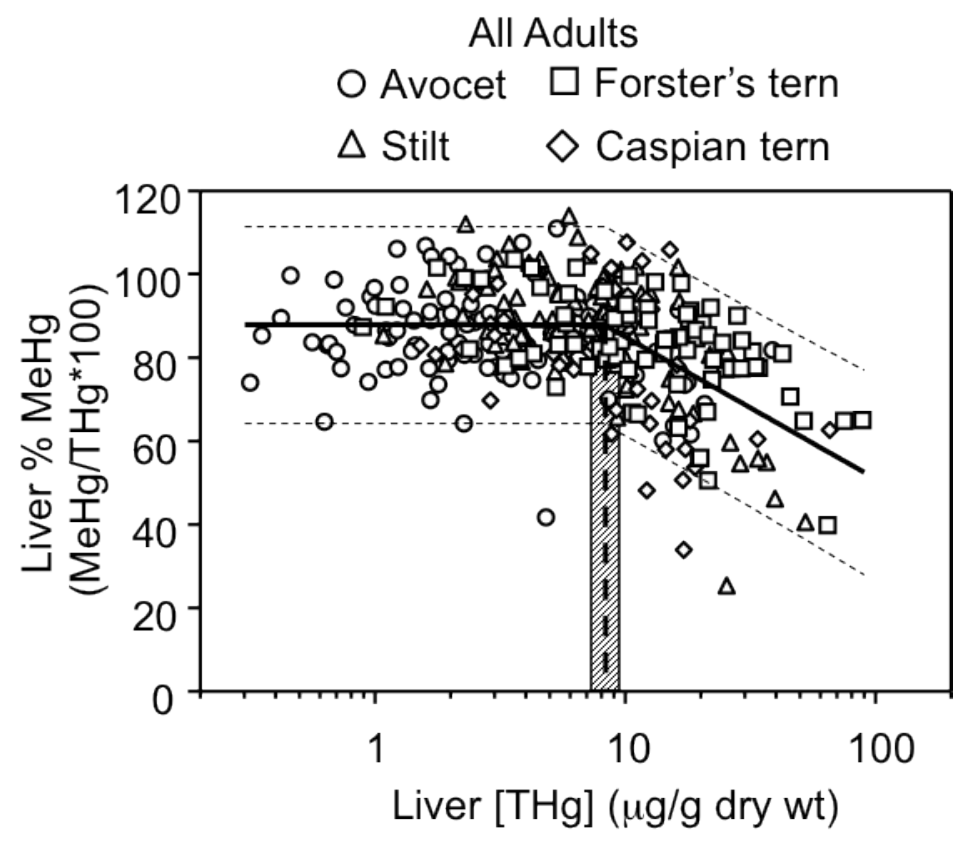

Figure 86. Modeled mercury demethylation response (solid change-point line) \pm 95 percent confidence limits (dashed change-point lines) in livers of adult American avocet, black-necked stilt, Caspian tern, and Forester's terns with all species combined in San Francisco Bay, California. Vertical dashed line and shaded region indicate estimated mean ( \pm standard error) demethylation threshold value. THg, total mercury; MeHg, methylmercury. Figure from Eagles-Smith and others (2009b) and used with permission. 


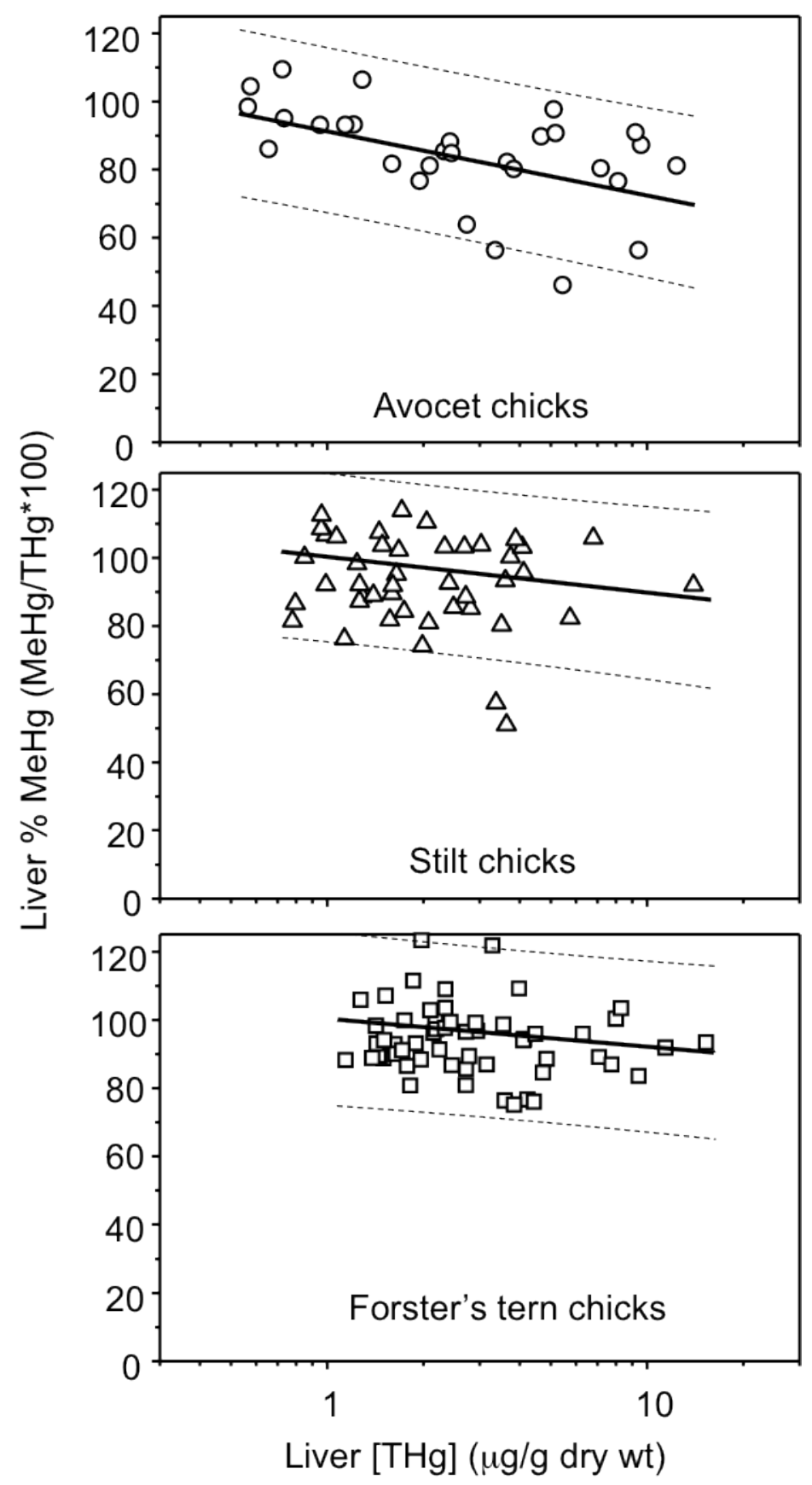

Figure 87. Modeled mercury demethylation responses (solid line) \pm 95 percent confidence limits (dashed lines) in livers of American avocet, black-necked stilt, and Forster's tern chicks in San Francisco Bay, California. THg, total mercury; MeHg, methylmercury. Figure from Eagles-Smith and others (2009b) and used with permission. 


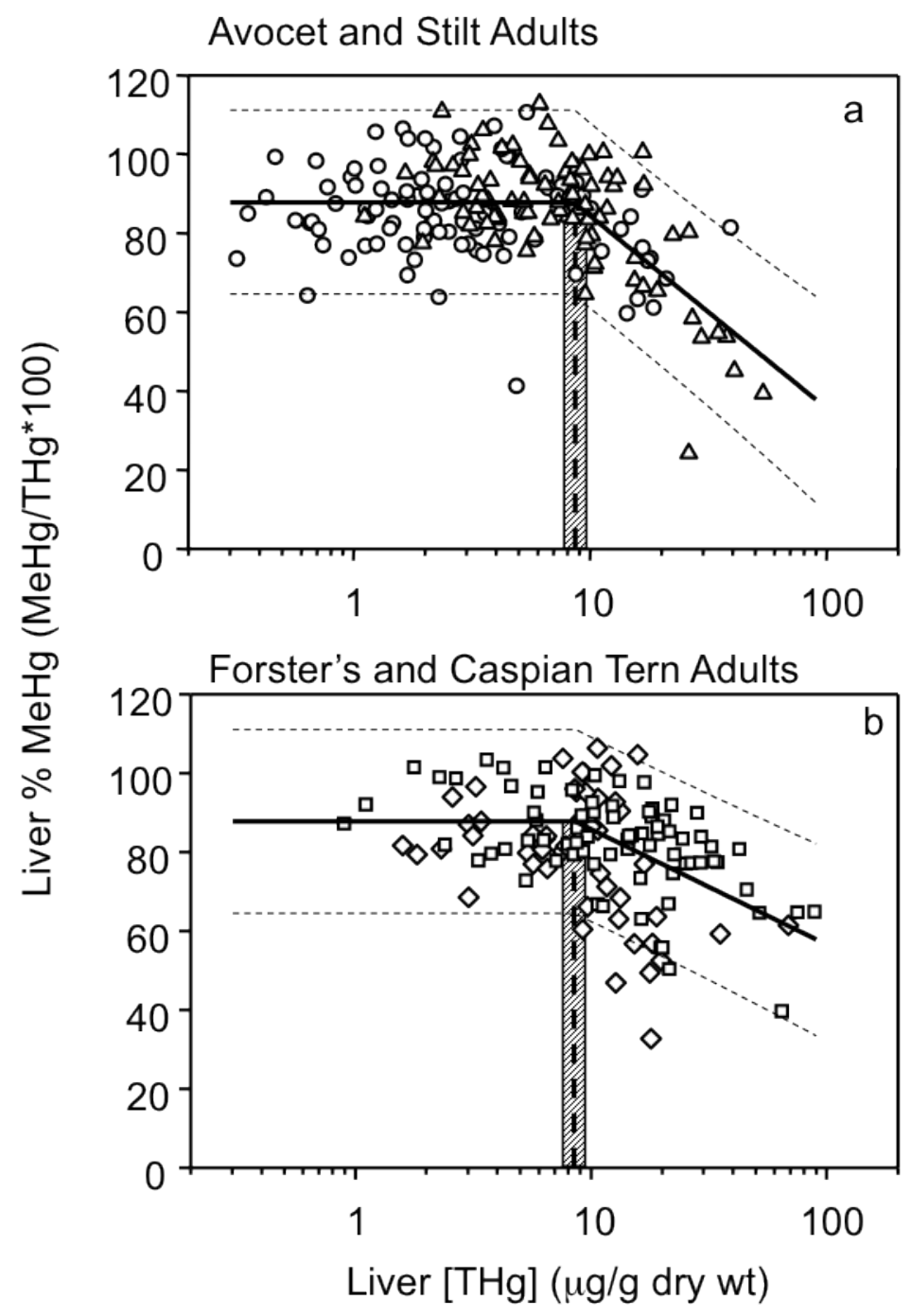

Figure 88. Comparative demethylation responses in (a) American avocet and black-necked stilts and (b) Caspian tern and Forster's tern adults in San Francisco Bay, California. Vertical dashed line and shaded region indicate estimated mean ( \pm standard error) demethylation threshold value. THg, total mercury; MeHg, methylmercury. Avocet=circles, stilts=triangles, Forster's terns=squares, and Caspian terns=diamonds. Figure from EaglesSmith and others (2009b) and used with permission. 

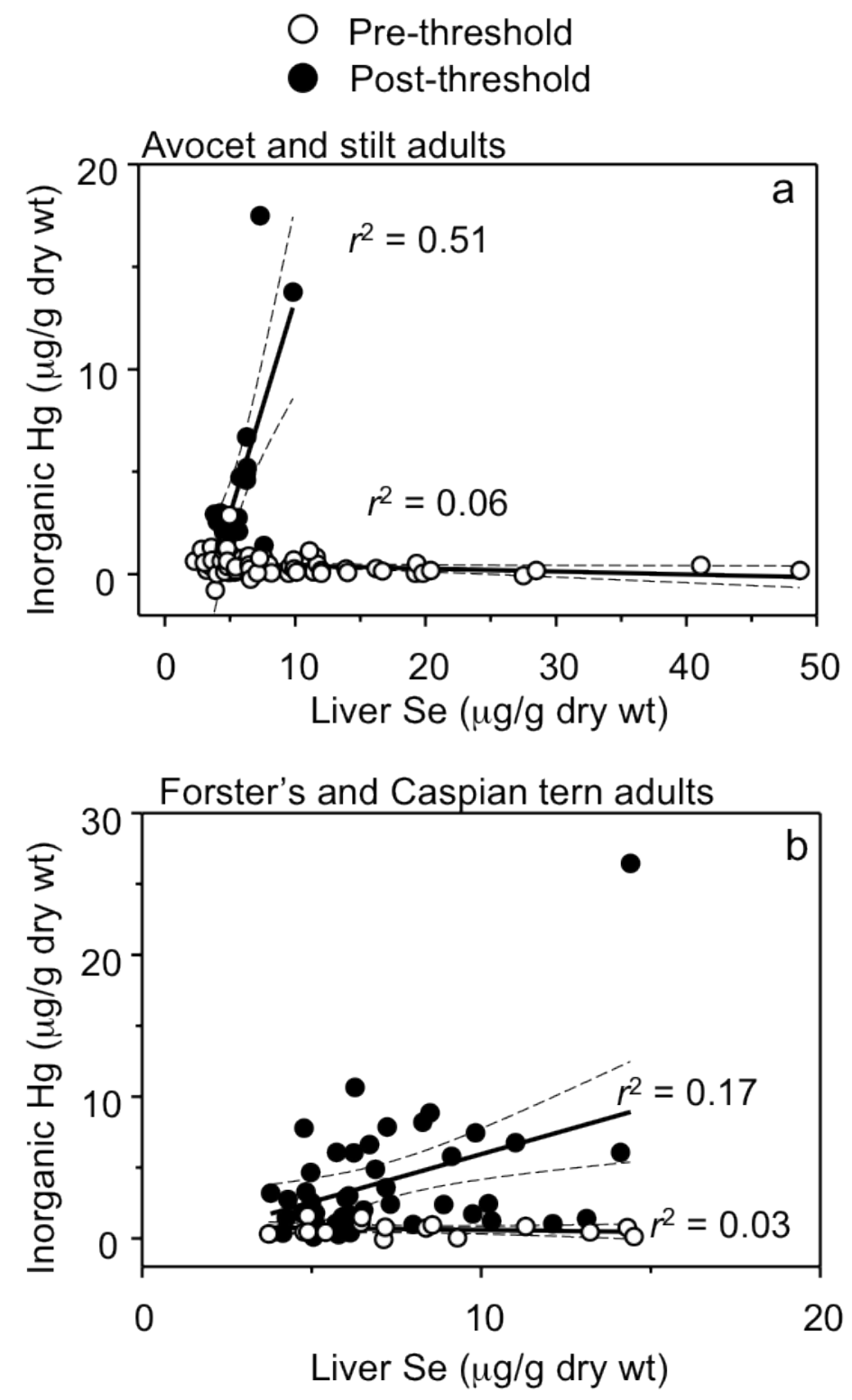

Figure 89. Relationship between inorganic mercury and selenium of adult (a) American avocets and black-necked stilts and (b) Caspian terns and Forster's terns. Figure from Eagles-Smith and others (2009b) and used with permission. 


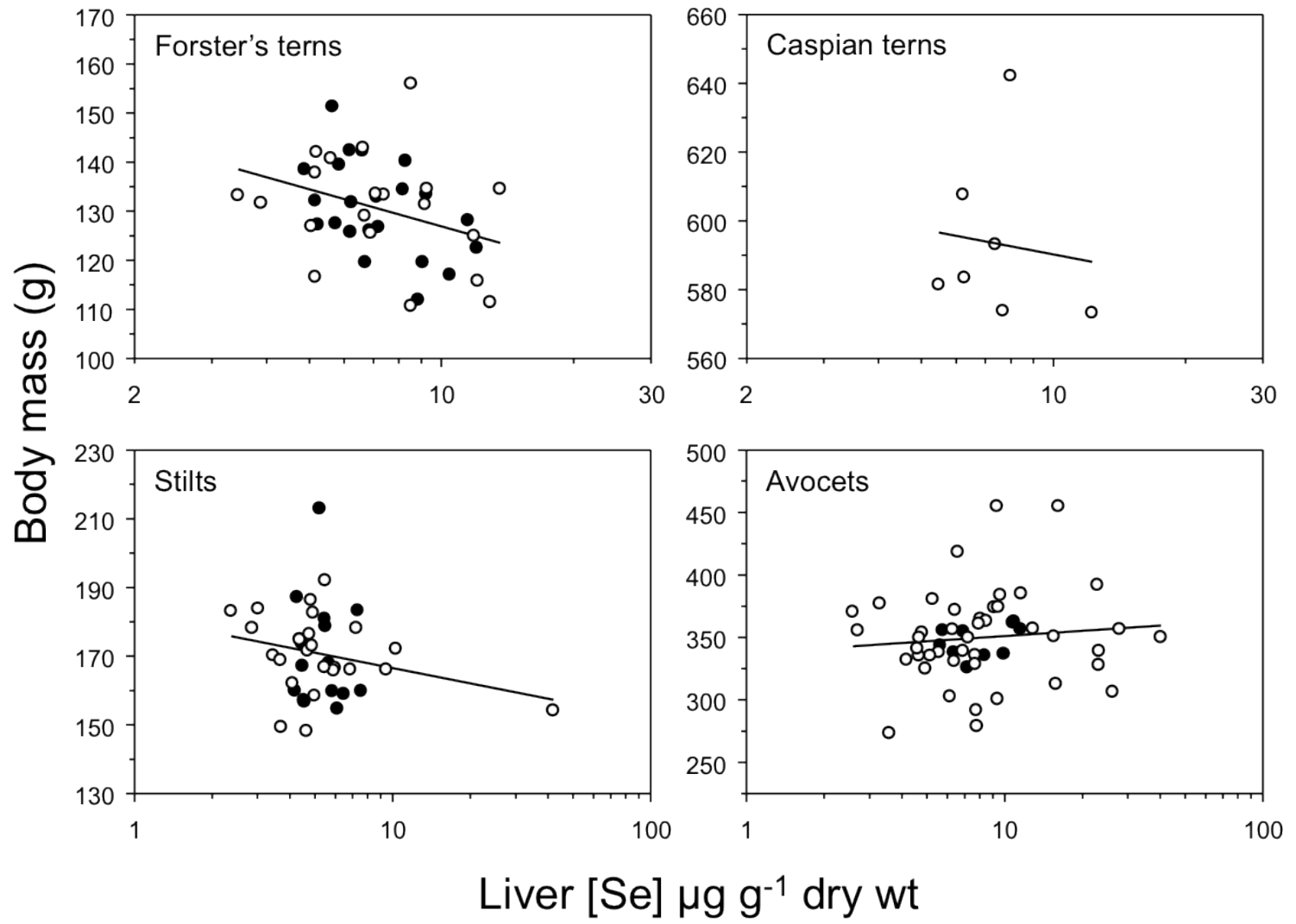

Figure 90. Partial leverage plots depicting the relationship between adult body mass in grams and liver Se concentrations (dry weight) while accounting for the effects of structural body size, reproductive stage, and sex for four waterbird species during pre-breeding (open circles) and breeding (closed circles) seasons in San Francisco Bay, California. Figure from Ackerman and Eagles-Smith (2009b) and used with permission. 

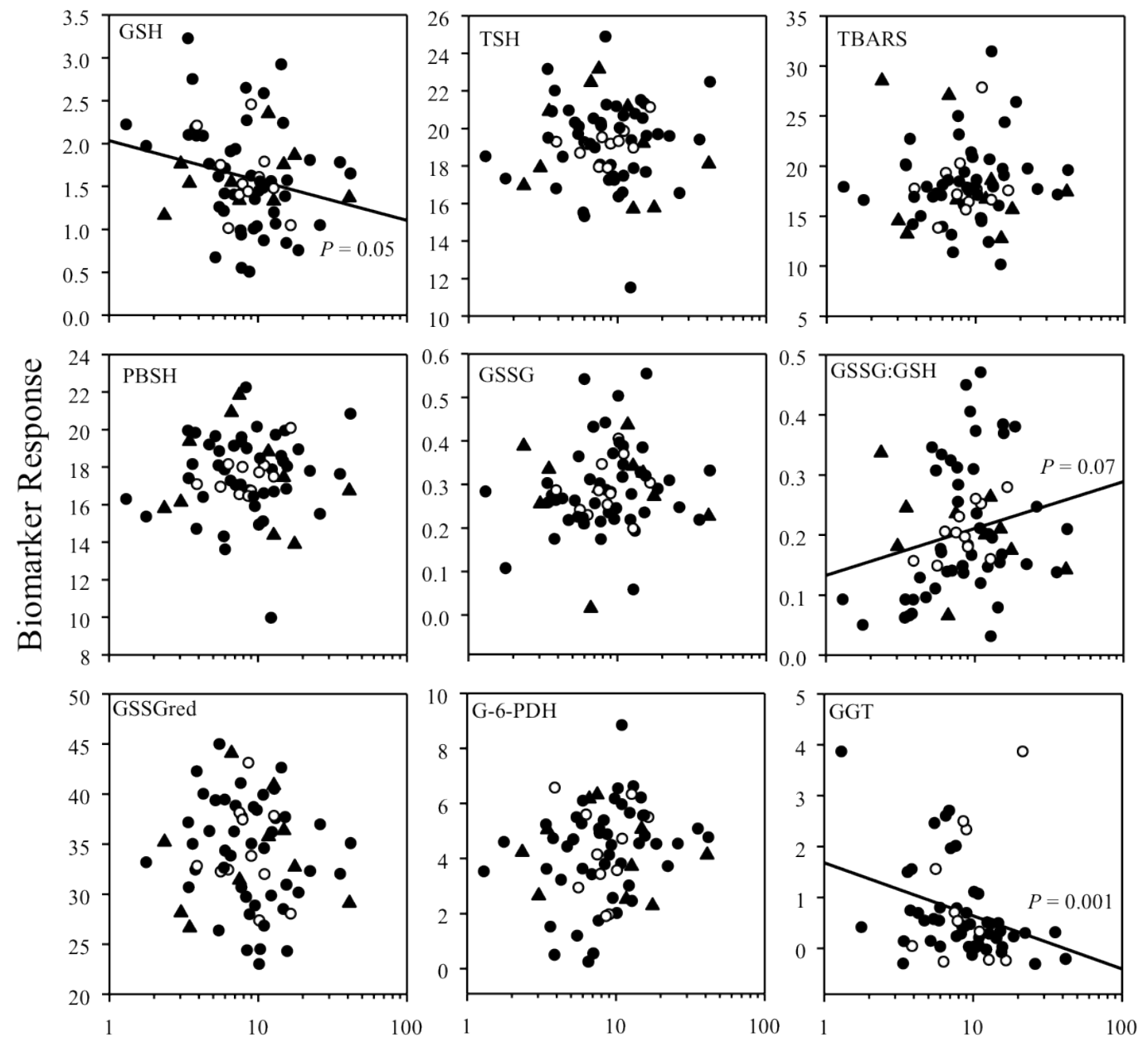

Liver $[\mathrm{THg}](\mu \mathrm{g} / \mathrm{g}$ dry weight)

Figure 91. Leverage plots for the relationship between total mercury ( $\mathrm{THg}$ ) concentrations ( $\mathrm{mg} / \mathrm{g}$ dry weight) and a suite of biomarkers in livers of Forster's tern and Caspian tern adults (closed circles and closed triangles, respectively), and Forster's tern chicks (open circles) from San Francisco Bay, California. Reduced glutathione (GSH), total thiols (TSH), protein bound thiols (PBSH), and oxidized glutathione (GSSG) are expressed as $\mathrm{mmol} / \mathrm{g}$ of tissue; GSSG reductase (GSSGred) as nmoles of reduced nicotinamide adenine dinucleotide phosphate (NADPH) oxidized/min/mg of 10,000 g supernatant protein; and glucose-6-phosphate dehydrogenase (G-6-PDH) and gamma-glutamyl transferase (GGT) as nmoles $/ \mathrm{min} / \mathrm{mg}$ of $10,000 \mathrm{~g}$ supernatant protein. Leverage plots control for the effects of selenium, species, life stage, and sex. Regression lines are included for relationships where $\mathrm{P}<0.10$. Figure from Hoffman and others (2011) and used with permission. 

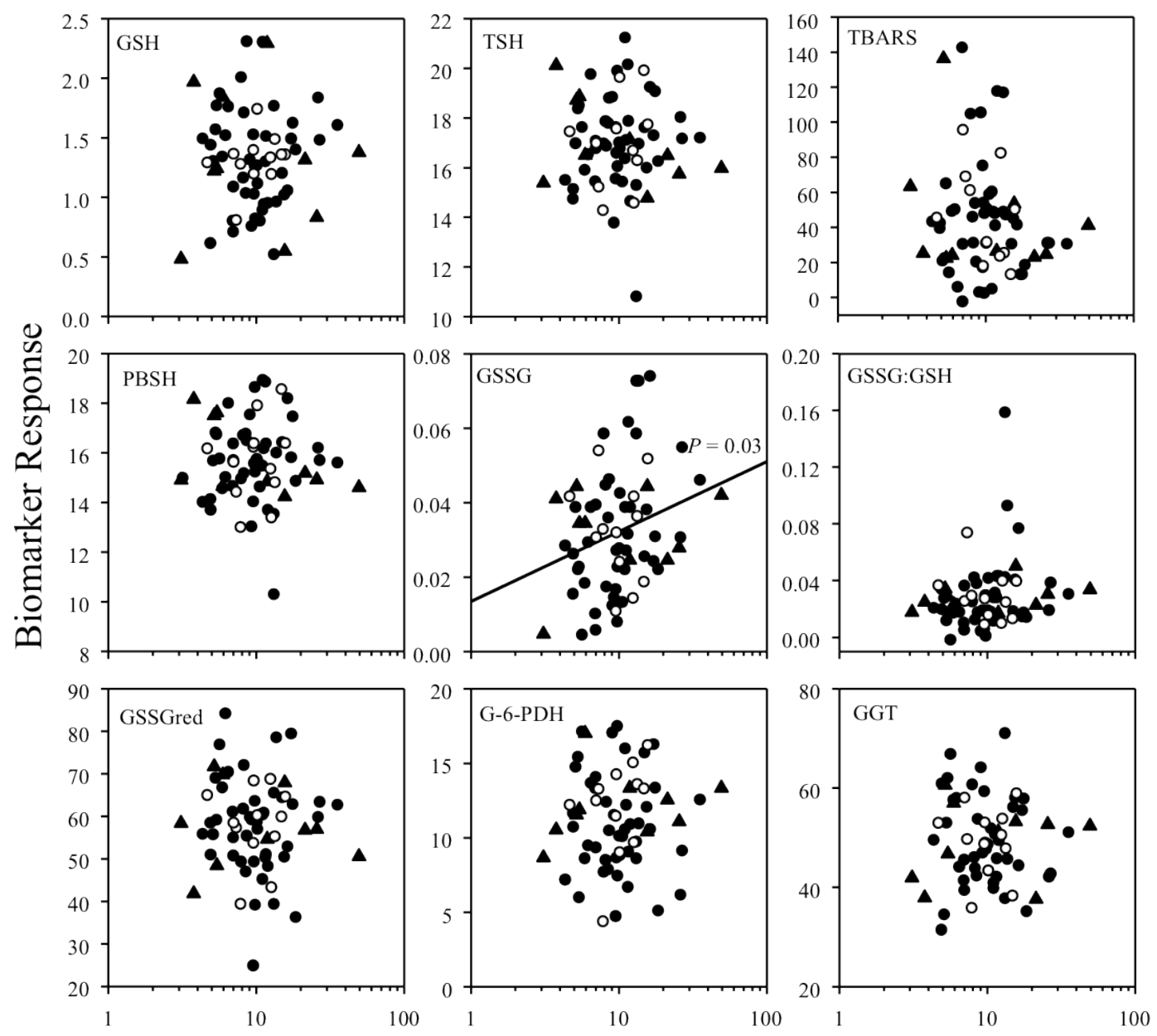

Kidney $[\mathrm{THg}](\mu \mathrm{g} / \mathrm{g}$ dry weight)

Figure 92. Leverage plots for the relationship between total mercury ( $\mathrm{THg}$ ) concentrations ( $\mathrm{mg} / \mathrm{g}$ dry weight) and a suite of biomarkers in kidneys of Forster's tern and Caspian tern adults (closed circles and closed triangles, respectively), and Forster's tern chicks (open circles) from San Francisco Bay, California. Reduced glutathione (GSH), total thiols (TSH), protein bound thiols (PBSH), and oxidized glutathione (GSSG) are expressed as $\mathrm{mmol} / \mathrm{g}$ of tissue; GSSG reductase (GSSGred) as nmoles of reduced nicotinamide adenine dinucleotide phosphate (NADPH) oxidized/min/mg of 10,000 g supernatant protein; and glucose-6-phosphate dehydrogenase (G-6-PDH) and gamma-glutamyl transferase (GGT) as nmoles $/ \mathrm{min} / \mathrm{mg}$ of $10,000 \mathrm{~g}$ supernatant protein. Leverage plots control for the effects of species, life stage, and sex. Regression lines are included for relationships where $P<0.05$. Figure from Hoffman and others (2011) and used with permission. 

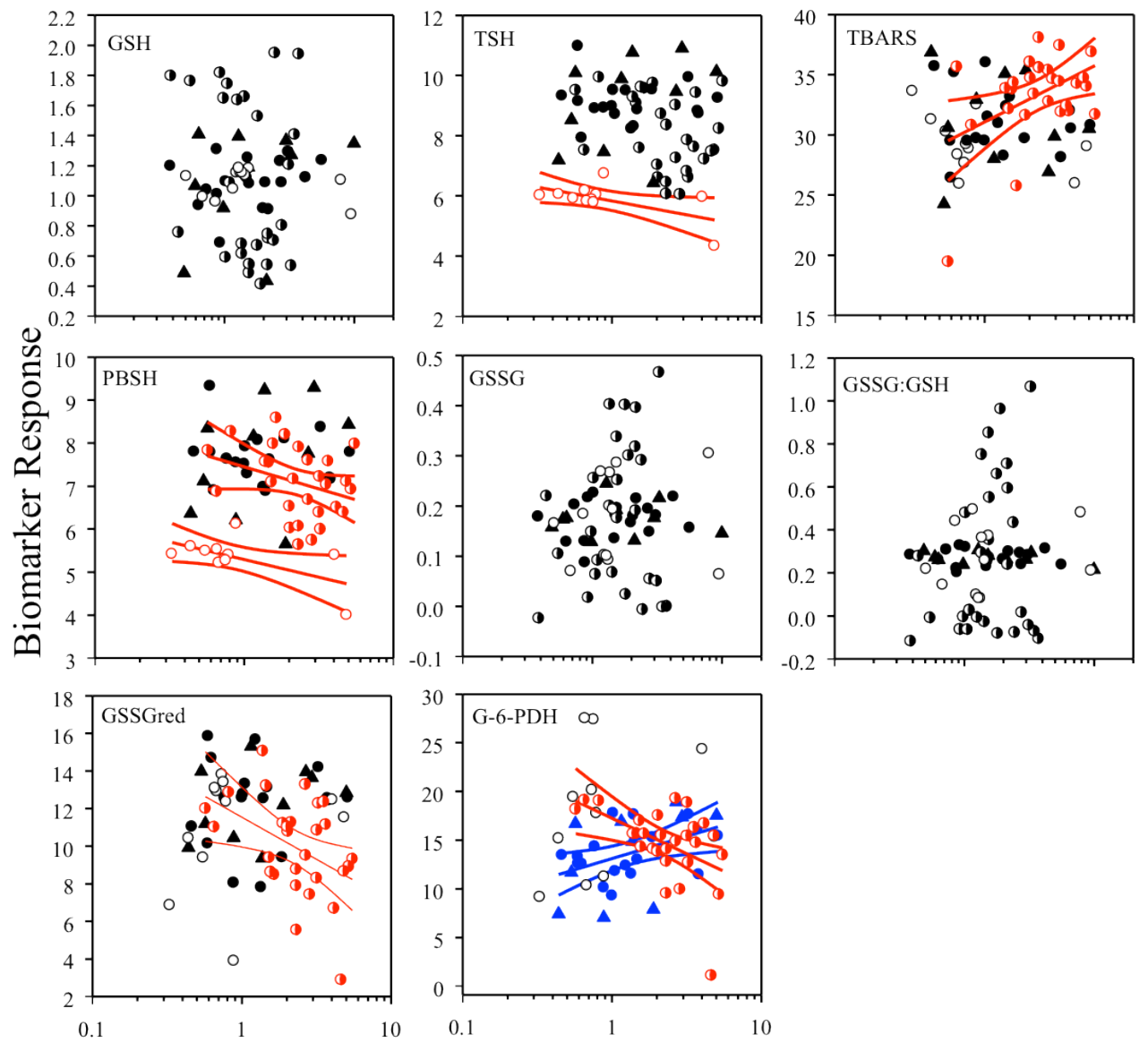

Brain $[\mathrm{THg}](\mu \mathrm{g} / \mathrm{g}$ dry weight)

Figure 93. Leverage plots for the relationship between total mercury ( $\mathrm{THg}$ ) concentrations ( $\mathrm{mg} / \mathrm{g}$ dry weight) and a suite of biomarkers in brains of prebreeding Forster's tern and Caspian tern adults (closed circles and closed triangles, respectively), breeding adult Forster's terns (semi-closed circles), and Forster's tern chicks (open circles) from San Francisco Bay, California. Reduced glutathione (GSH), total thiols (TSH), protein bound thiols (PBSH), and oxidized glutathione (GSSG) are expressed as mmol/g of tissue; GSSG reductase (GSSGred) as nmoles of reduced nicotinamide adenine dinucleotide phosphate (NADPH) oxidized/min/mg of $10,000 \mathrm{~g}$ supernatant protein; and glucose-6-phosphate dehydrogenase (G-6-PDH) and gamma-glutamyl transferase (GGT) as nmoles $/ \mathrm{min} / \mathrm{mg}$ of $10,000 \mathrm{~g}$ supernatant protein. Symbols and lines in color indicate a significant correlation $(P<0.05)$ between biomarkers and brain THg concentrations. Black symbols indicate no relationship between variables. Figure from Hoffman and others (2011) and used with permission. 

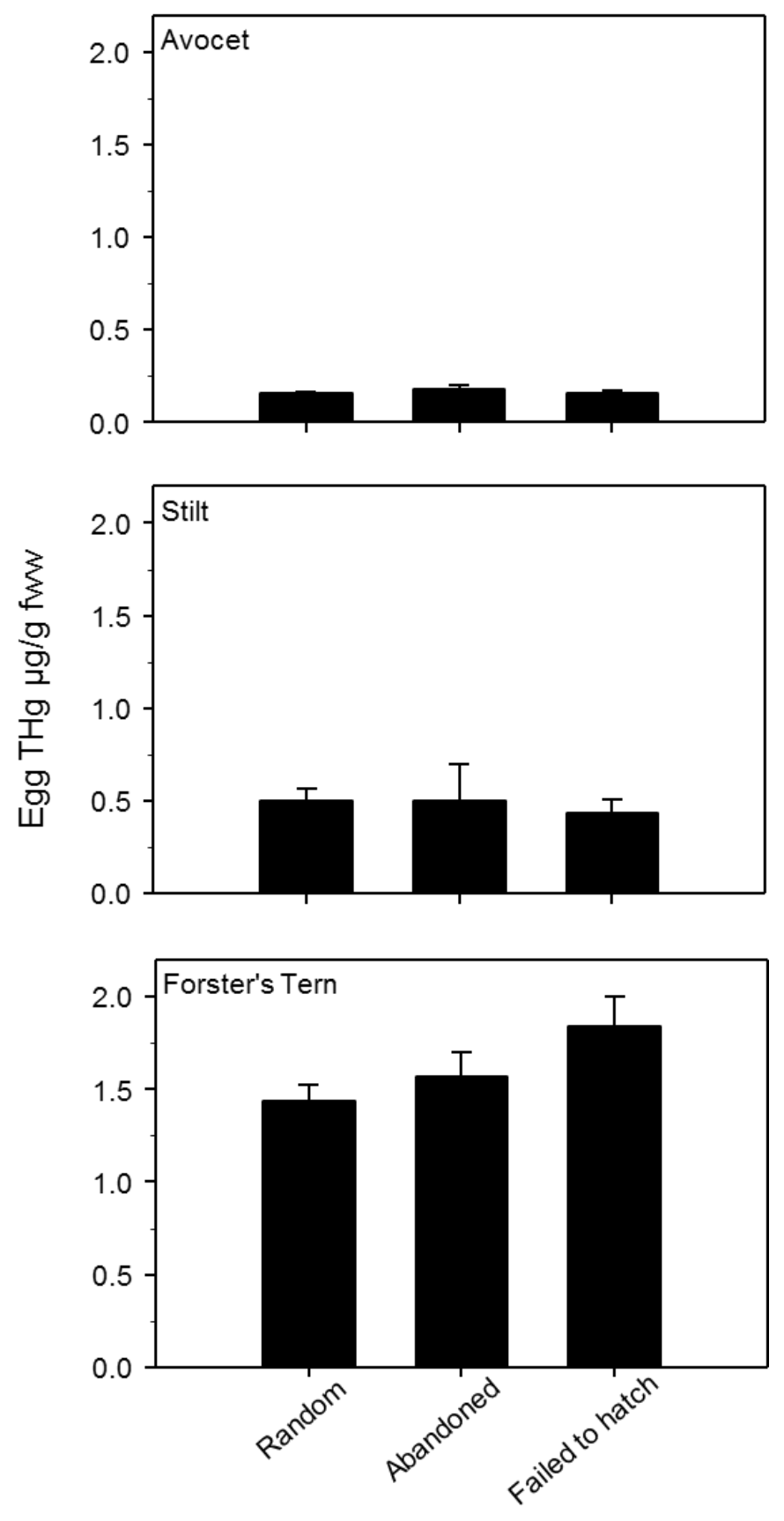

Egg type

Figure 94. Total mercury ( $\mathrm{THg})$ concentrations (least squares means $\pm \mathrm{SE}$ ) in failed to hatch Forster's tern eggs were higher than randomly sampled eggs from successful nests in San Francisco Bay, California, during 200507. There was no difference in THg concentrations among egg type of American avocets or black-necked stilts. Least squares means accounted for the global model effects of egg type, year, and site for each species. 


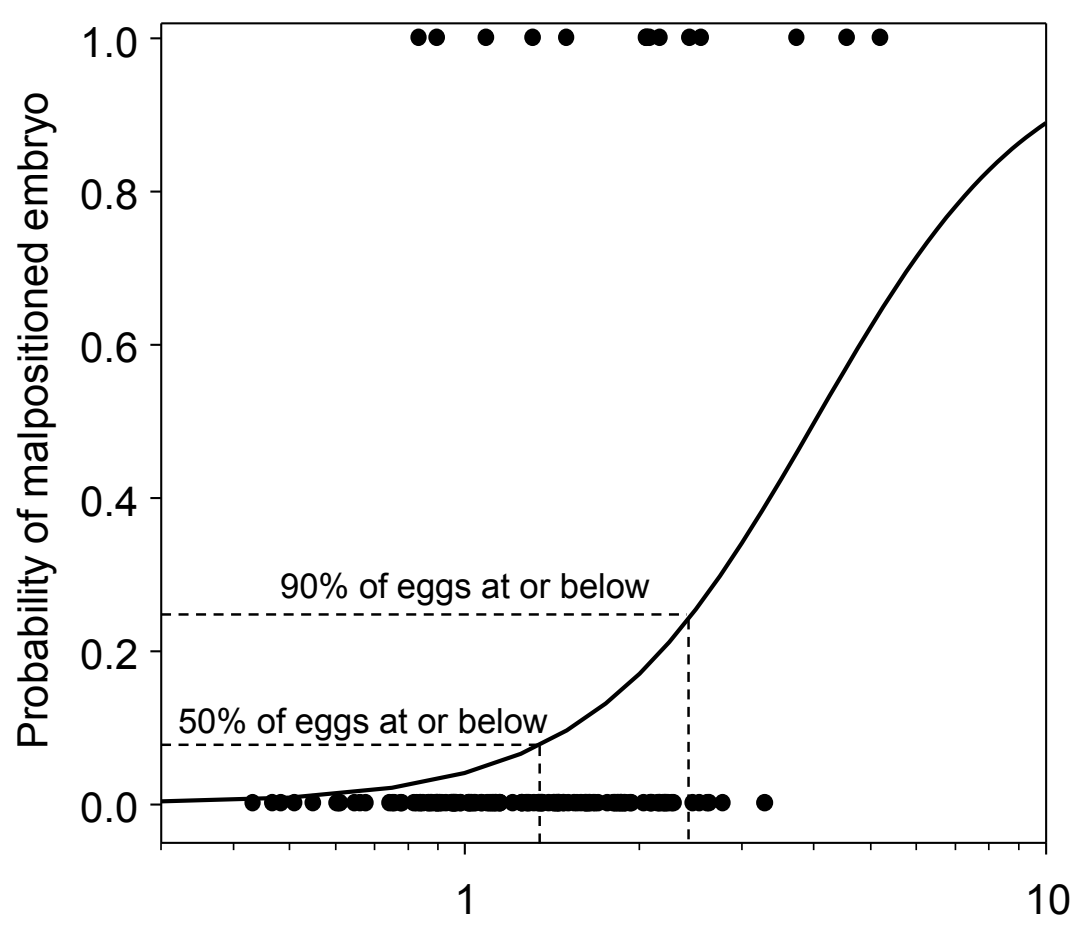

Egg THg $(\mu \mathrm{g} / \mathrm{g}$ fresh wet weight)

Figure 95. The probability that Forster's tern embryos were malpositioned increased with egg total mercury (THg) concentrations in San Francisco Bay, California, during 2005-07. Data points represent eggs with either a malpositioned embryo (value of 1 ) or a normal embryo position required for successful hatching (value of 0 ). The curved line indicates the logistic regression between the probability of an embryo being malpositioned and THg concentrations in eggs. The 8 and 24 percent probabilities of an egg having a malpositioned embryo represent the 50th and 90th percentiles, respectively, of the observed egg mercury concentrations for Forster's terns in San Francisco Bay. Figure from Herring and others (2010) and used with permission. 

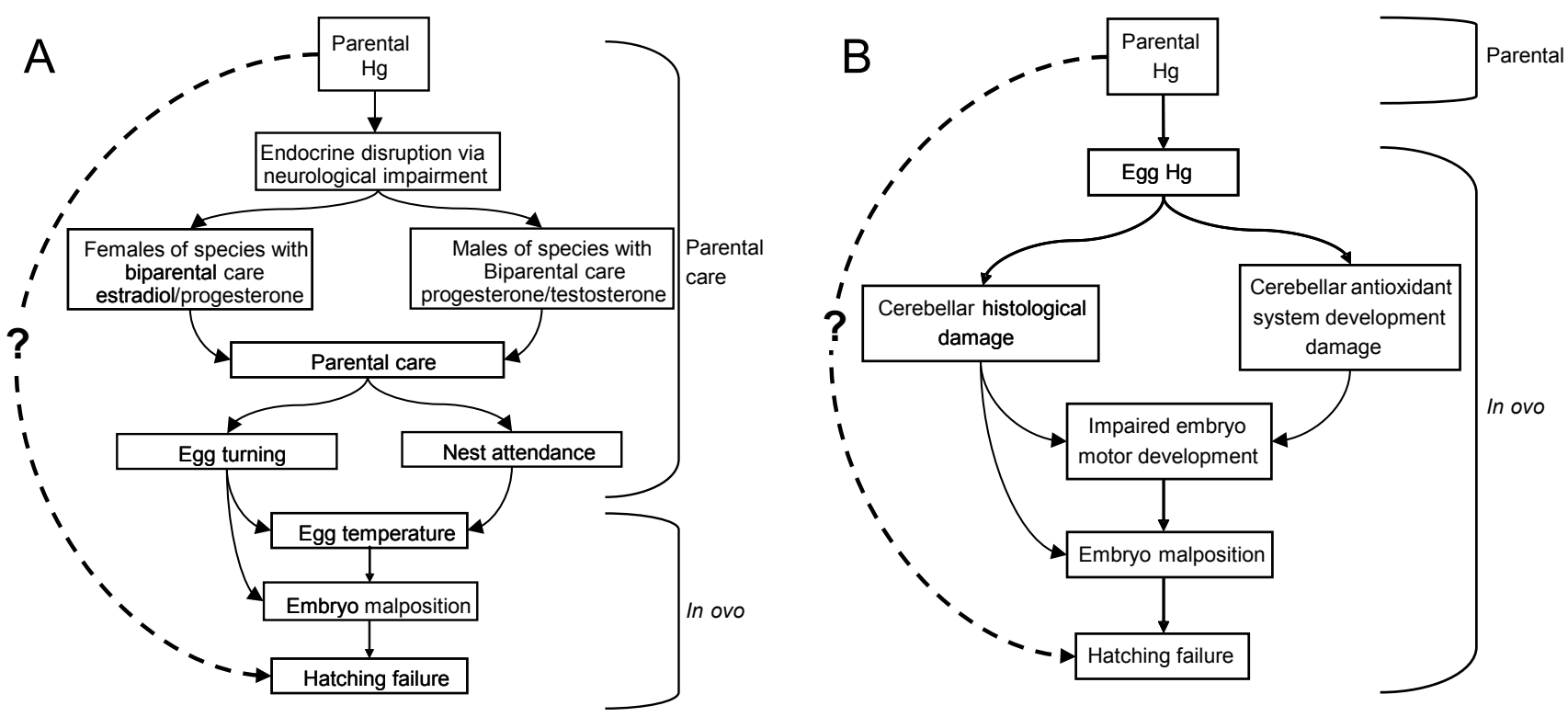

Figure 96. Conceptual diagrams of potential mechanisms for avian egg hatching failure due to (A) parental dietary mercury exposure during reproduction and (B) parental transfer of dietary mercury to the embryo. Solid lines indicate the cascading direct effects of mercury exposure, whereas the dotted line indicates the indirect effect of parental mercury exposure on egg hatching failure. Although mercury within the avian egg in model A might not directly cause an embryo to be malpositioned, adult mercury exposure may reduce parental care of eggs and maintenance of nests and thereby increase the likelihood of embryos within eggs to be malpositioned. Elevated mercury in the embryo in model B may result in cerebellar damage and impaired embryo motor development and thereby increase the likelihood of embryos within eggs to be malpositioned. Malpositioned embryos often have a reduced ability to successfully hatch from an egg. Figure from Herring and others (2010) and used with permission. 


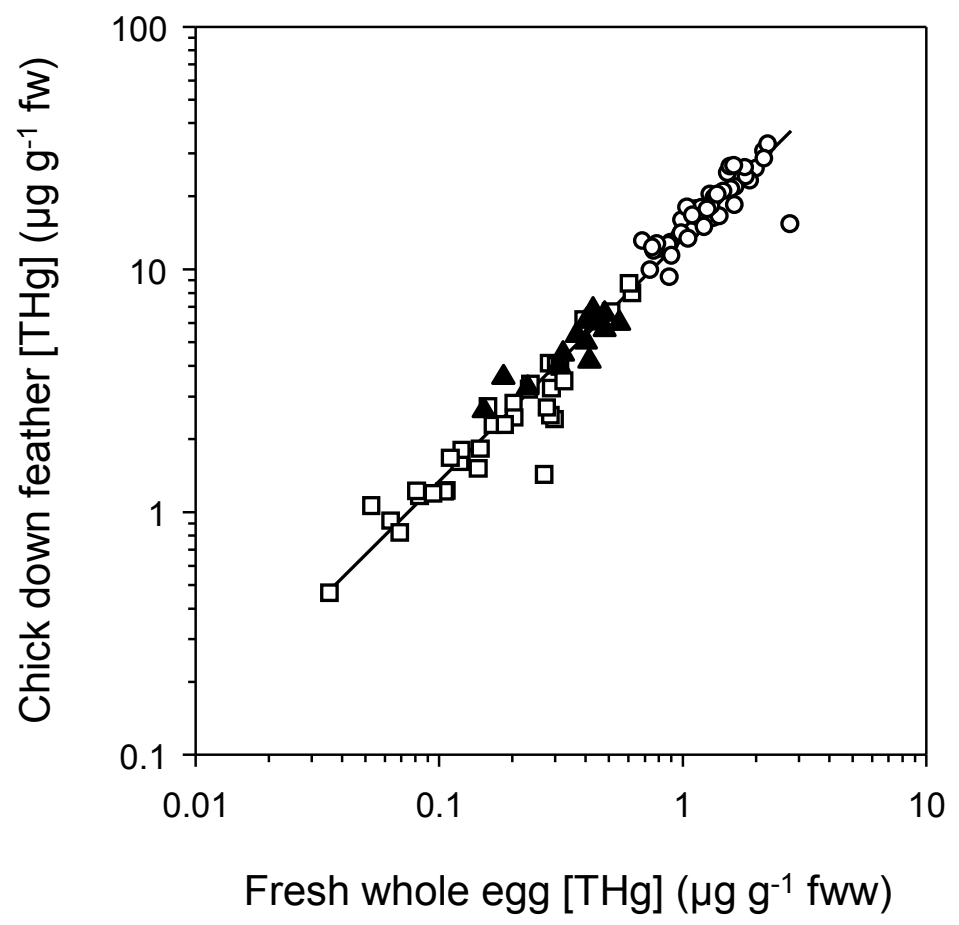

Figure 97. Mercury concentrations in down feathers ( $\mu \mathrm{g} / \mathrm{g}$ fresh weight [fw]) of pipping chicks were highly correlated $\left(R^{2}=0.96\right)$ with mercury concentrations in the reconstructed fresh whole-egg homogenate $(\mu \mathrm{g} / \mathrm{g}$ fresh wet weight [fww]) for Forster's terns (circles), American avocets (squares), and black-necked stilts (triangles) in South San Francisco Bay, California. The linear regression equation describing the data was $\log _{e} Y=2.590+1.000\left(\log _{e} X\right)$. Figure from Ackerman and Eagles-Smith (2009a) and used with permission. 


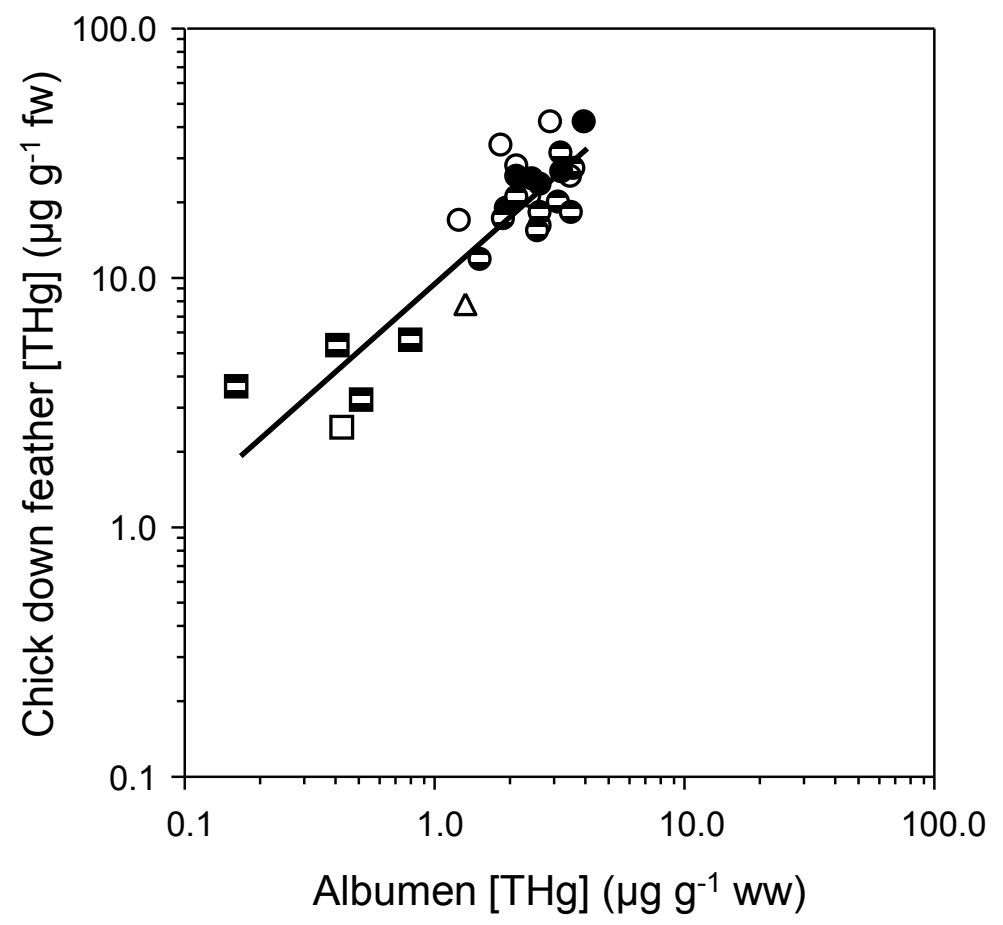

Figure 98. Mercury concentrations in down feathers ( $\mu \mathrm{g} / \mathrm{g}$ fresh weight [fw]) of newly hatched chicks found in the nest were correlated $\left(R^{2}=0.79\right)$ with albumen mercury concentrations $(\mu \mathrm{g} / \mathrm{g}$ wet weight [ww]) micro-sampled from an egg in the same nest when the eggs were $\leq 3$ days incubated in South San Francisco Bay, California. Symbol patterns (Forster's terns [circles], American avocets [squares], and black-necked stilts [triangles]) indicate whether the feathers were sampled from: the same chick that hatched from the albumen microsampled egg (filled), a sibling chick from the same nest that was not micro-sampled during incubation (partially filled), or an unknown chick from the same nest sampled either from the micro-sampled or sibling egg (open). The linear regression equation describing the data was: $\log _{\mathrm{e}} \mathrm{Y}=2.291+0.888\left(\log _{\mathrm{e}} \mathrm{X}\right)$. Figure from Ackerman and Eagles-Smith (2009a) and used with permission. 


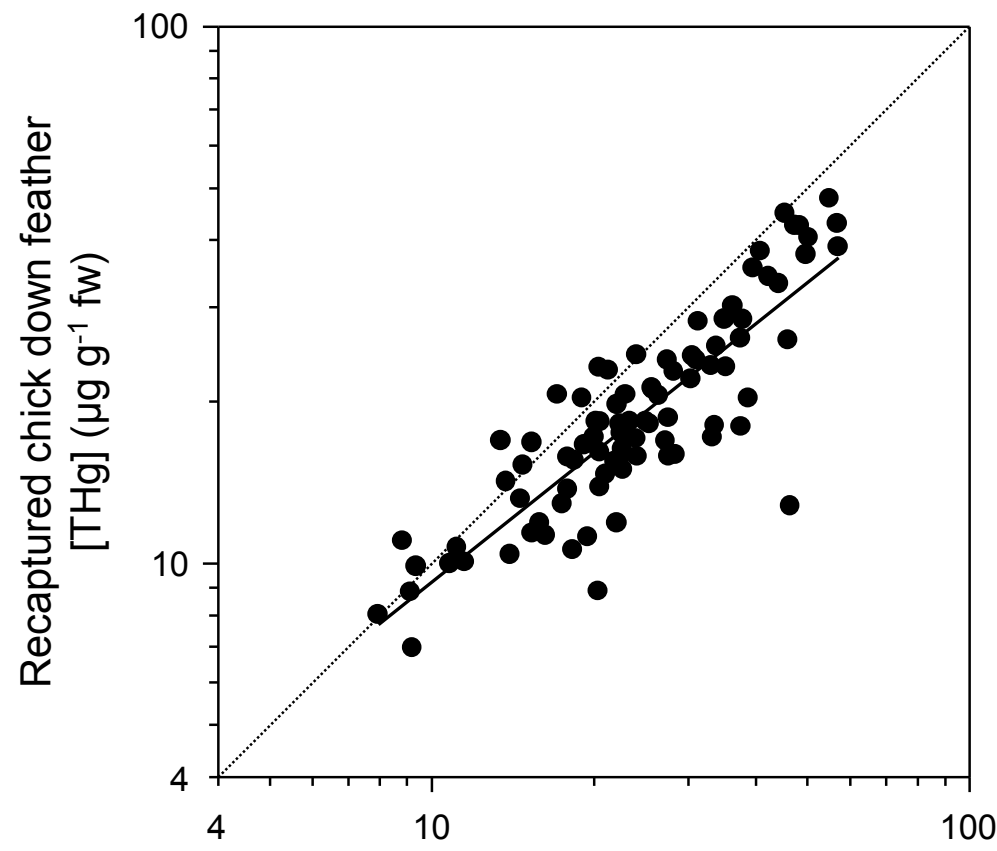

First capture chick down feather

$[\mathrm{THg}]\left(\mu \mathrm{g} \mathrm{g}^{-1} \mathrm{fw}\right)$

Figure 99. Mercury concentrations in down feathers ( $\mu \mathrm{g} / \mathrm{g}$ fresh weight [fw]) of recaptured Forster's tern chicks ( $\leq 10$ days of age) were correlated $\left(r^{2}=0.74\right)$ with mercury concentrations in down feathers of the same chicks sampled just after they hatched ( $\leq 3$ days of age) in South San Francisco Bay, California. The stippled line indicates a one-to-one line. The linear regression equation describing the data was: $\log _{\mathrm{e}} Y=0.384+0.798\left(\log _{\mathrm{e}} X\right)$. Figure from Ackerman and Eagles-Smith (2009a) and used with permission. 


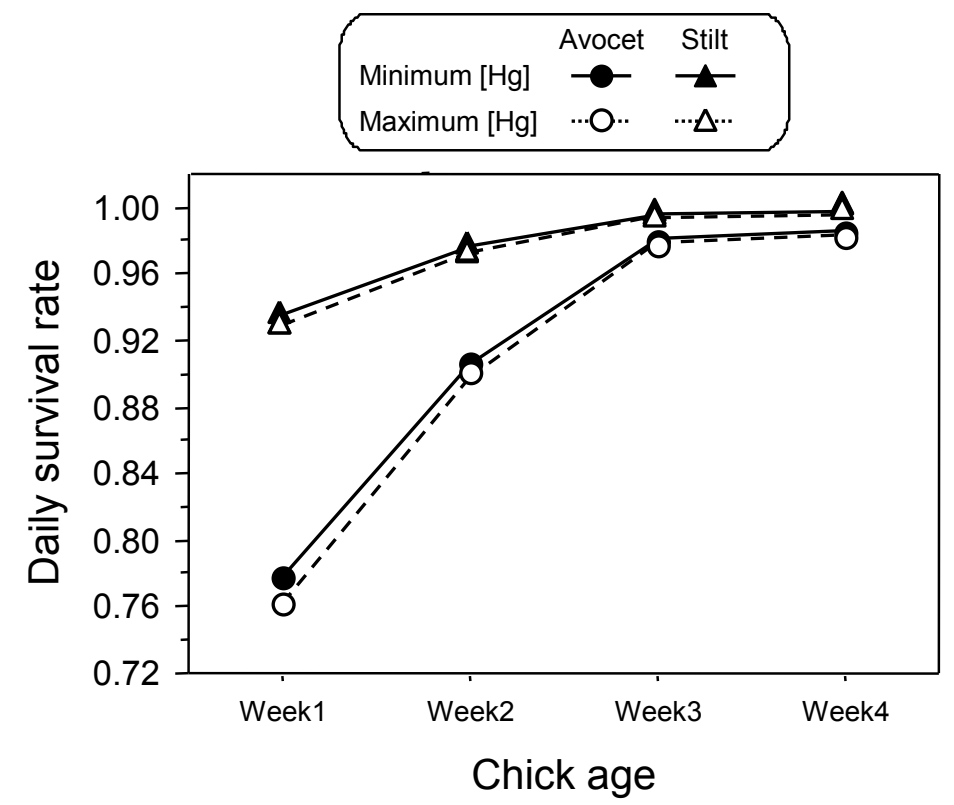

Figure 100. Daily survival rates of American avocet (circles) and black-necked stilt (triangles) chicks increased with chick age, but were relatively unaffected by total mercury concentrations in down feathers at hatching. Shown here are estimated daily survival rates for chicks with down feather mercury concentrations at the range of observed values in South San Francisco Bay, California (minimum was $0.40 \mu \mathrm{g} / \mathrm{g} \mathrm{fw}$ [solid line] and maximum was $44.31 \mu \mathrm{g} / \mathrm{g}$ fw [dashed line]). Daily survival rates were estimated by radio-marking and tracking 158 avocet and 79 stilt chicks. Figure from Ackerman and others (2008d) and used with permission. 


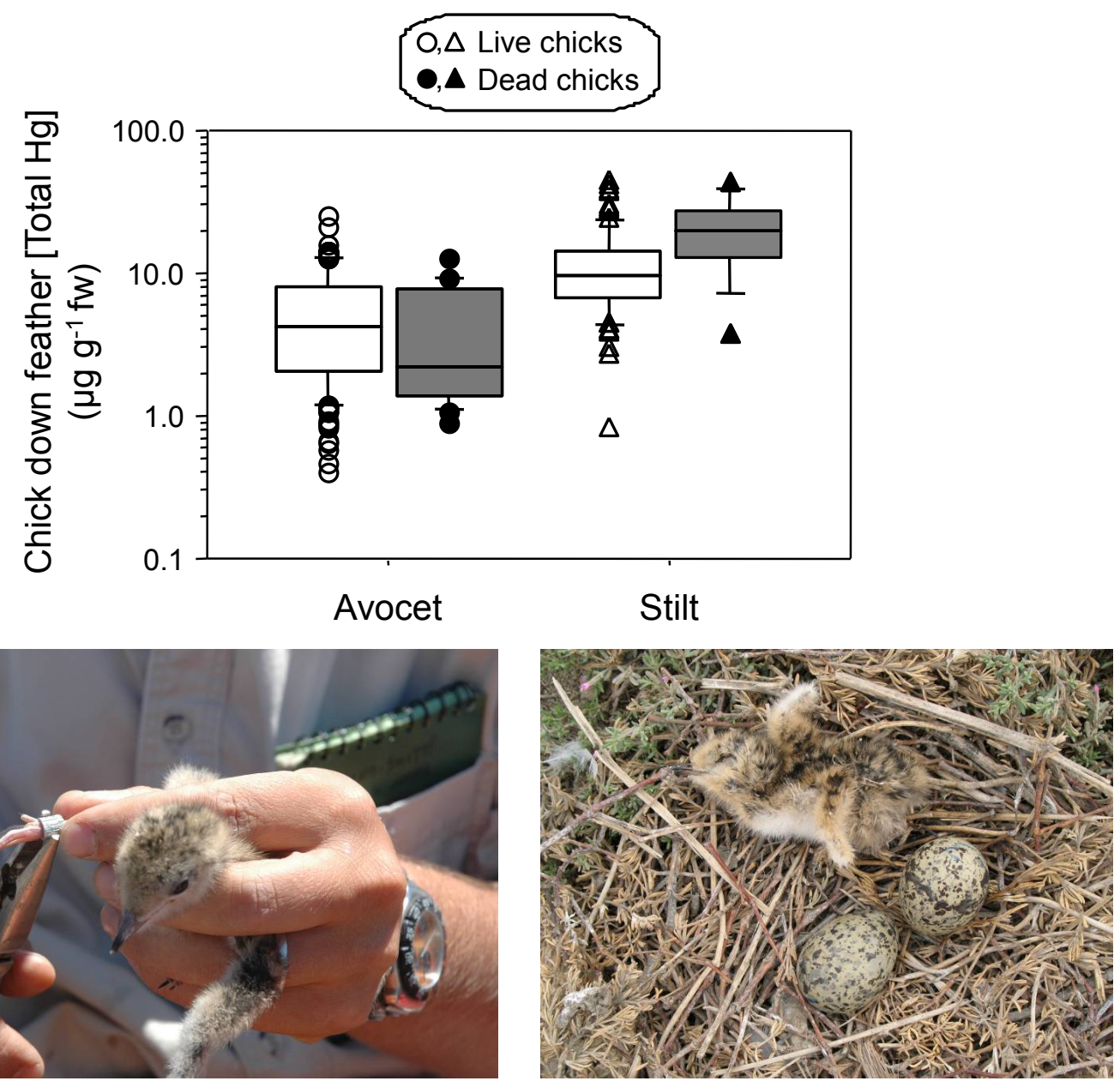

Figure 101. Box plots depicting total mercury concentrations ( $\mu \mathrm{g} / \mathrm{g}$ fresh weight, hereafter $\mathrm{fw}$ ) in down feathers of American avocet and black-necked stilt chicks found dead (filled) were higher than concentrations in chicks that were sampled while live (unfilled) just after hatching in South San Francisco Bay, California. Sample sizes were 158 live and 16 dead avocet chicks and 79 live and 14 dead stilt chicks. Photographs showing (lower left) An example of a live chick (Forster's tern) being banded near the time of hatch. (lower right) An example of a dead chick (Forster's tern) found at the colony during nest monitoring activities. Figure from Ackerman and others (2008d) and used with permission. 


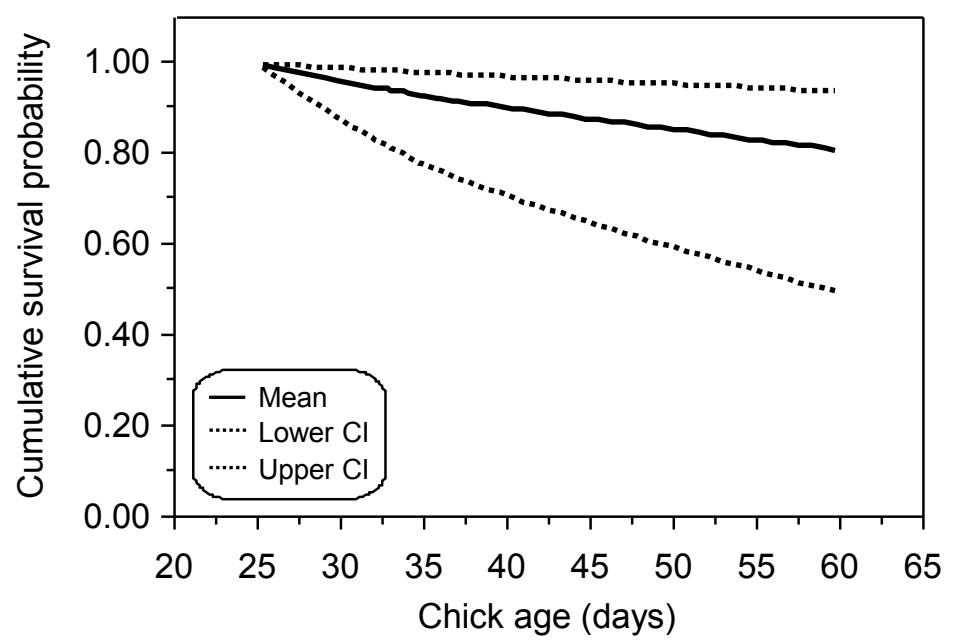

Figure 102. Cumulative survival probability (with confidence intervals [Cl]) for juvenile Forster's terns during the 35day postfledging period at the Pond N7 tern colony in South San Francisco Bay, California, during summer 2006. Survival rates were estimated by radio-marking 30 Forster's terns just before they fledged at $25 \pm 1.4$ (SD) days of age, and tracking them daily for 35 subsequent days. Figure from Ackerman and others (2008b) and used with permission. 

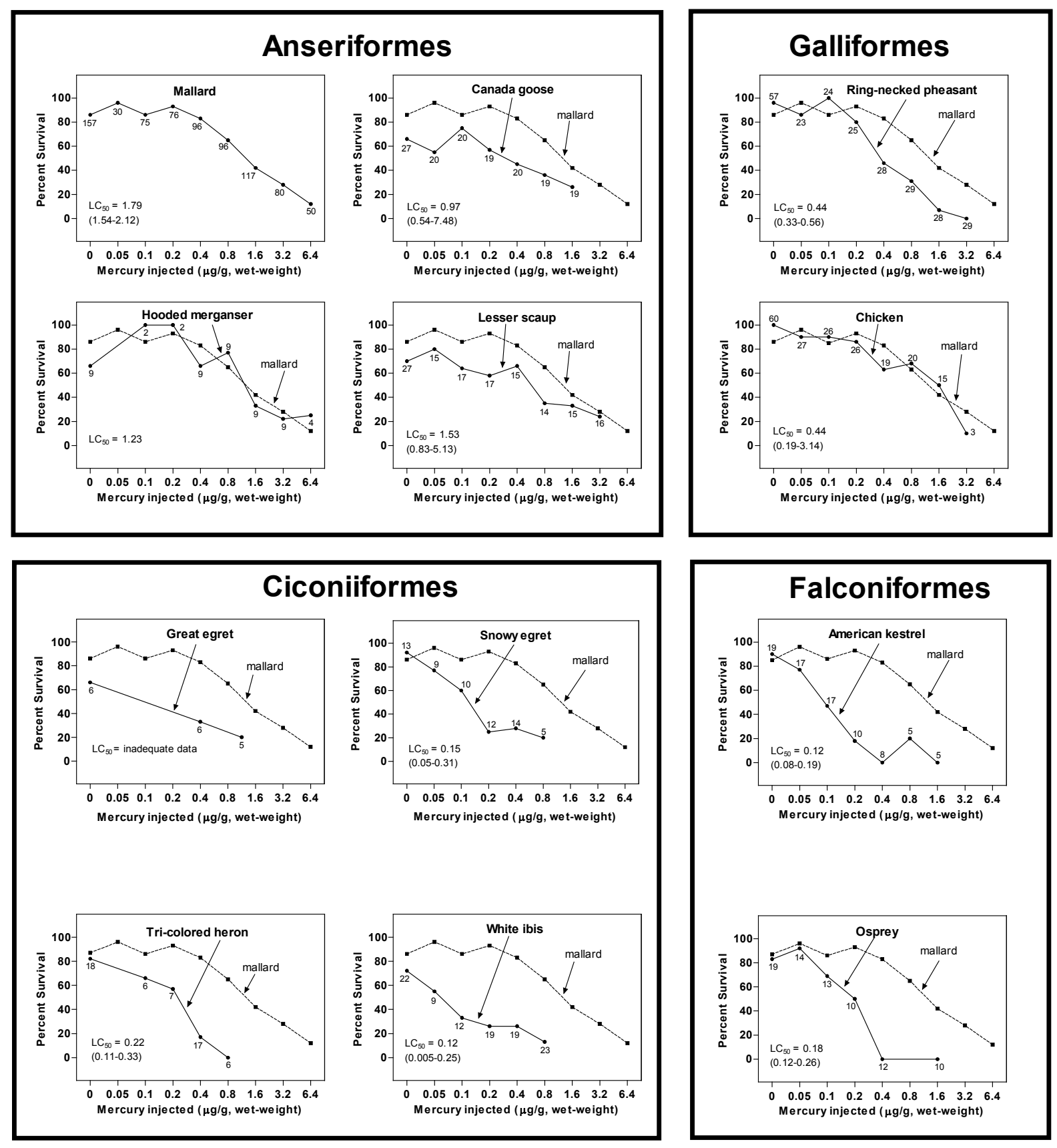

Figure 103. Response of the embryos of 26 species to injected doses of methylmercury. Because toxic mercury thresholds in eggs have been based heavily on findings from mallards, data for mallards are duplicated on each graph to show the difference between mallards and the other species. Figure from Heinz and others (2009b) and used with permission. 

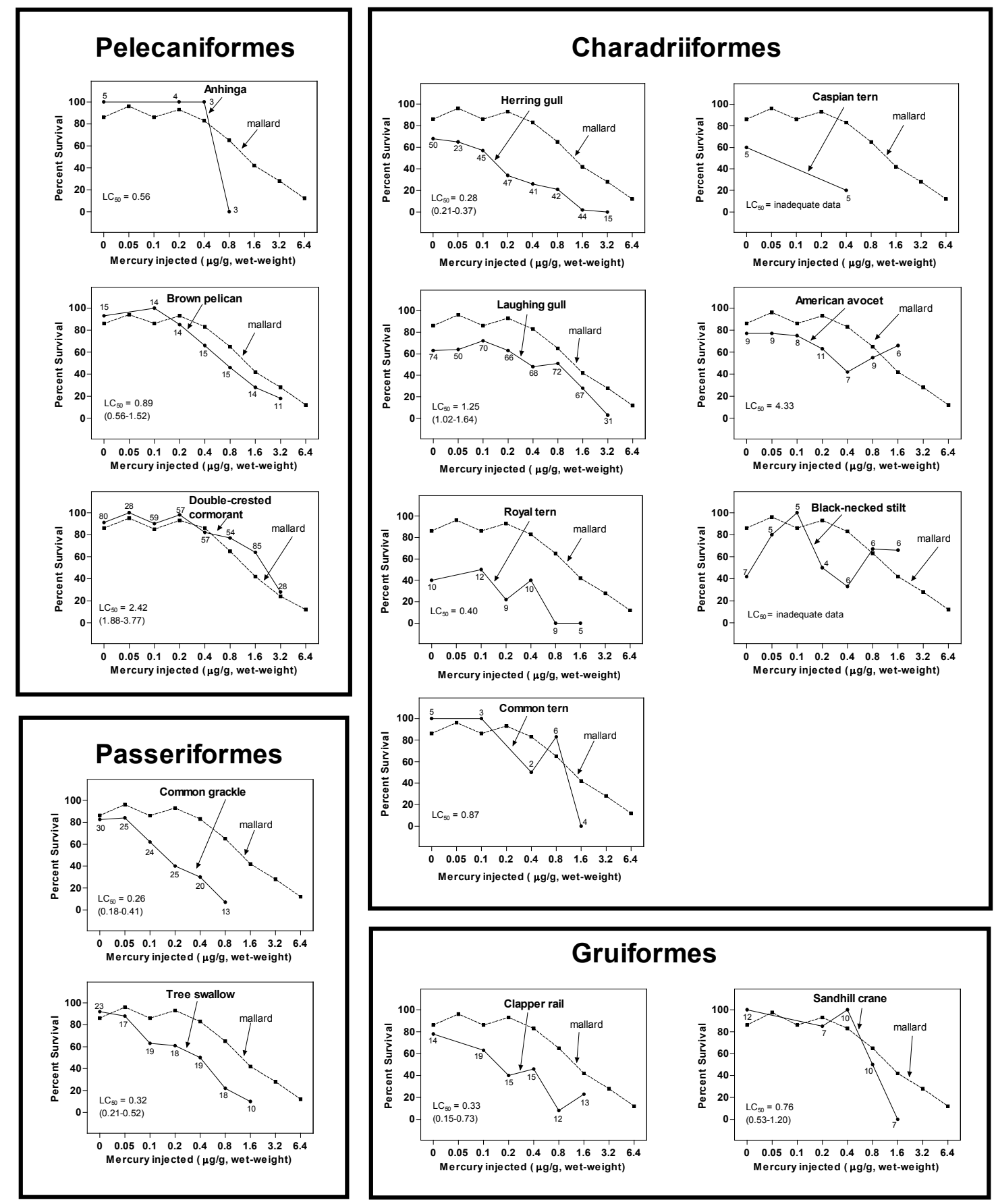

Figure 104. Response of the embryos of 26 species to injected doses of methylmercury. Because toxic mercury thresholds in eggs have been based heavily on findings from mallards, data for mallards are duplicated on each graph to show the difference between mallards and the other species. Figure from Heinz and others (2009b) and used with permission. 

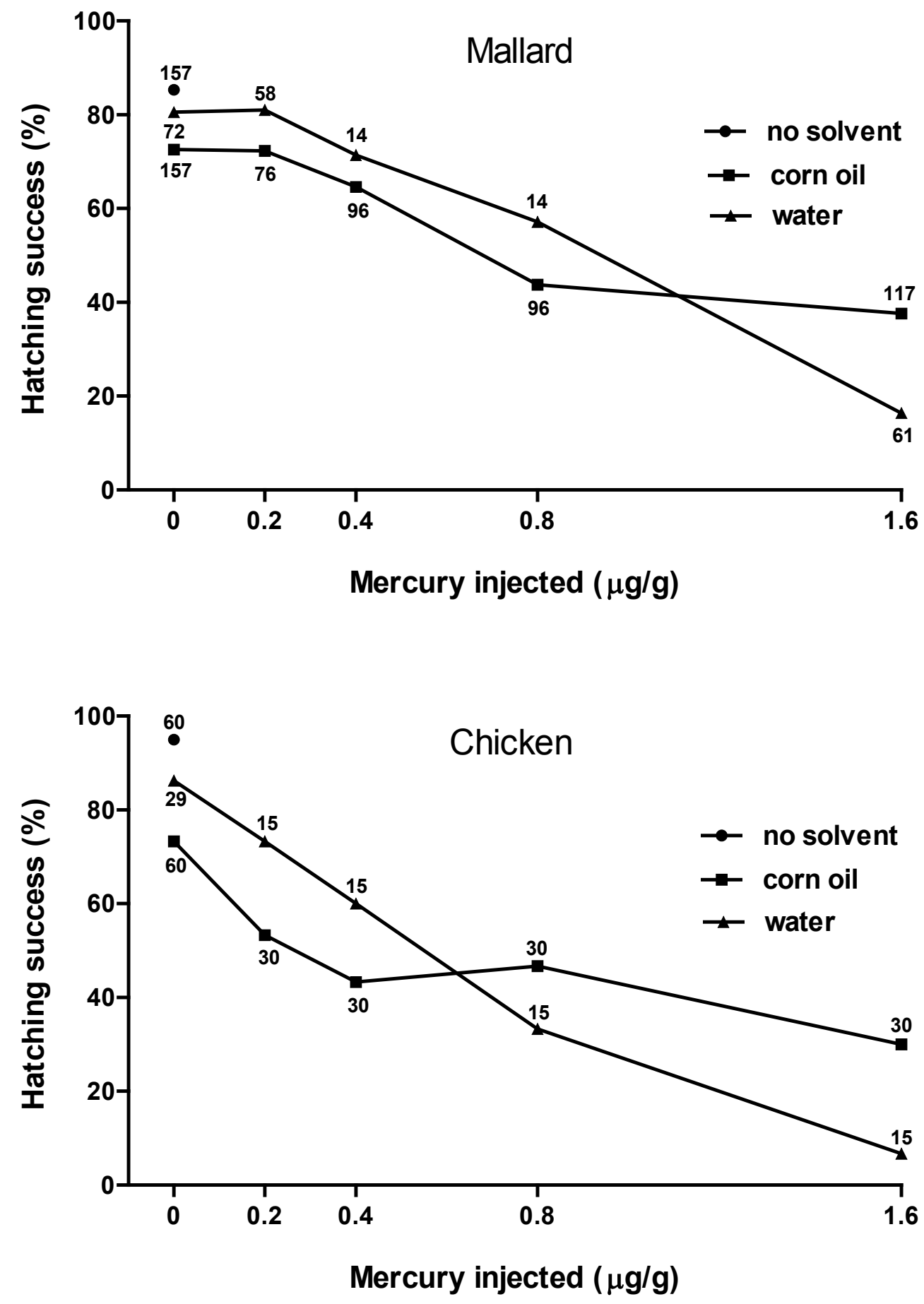

Figure 105. A comparison of the toxicity of methylmercury dissolved in corn oil versus water. Sample sizes are shown above or below each point on the graphs. Figure from Heinz and others (2011a) and used with permission. 


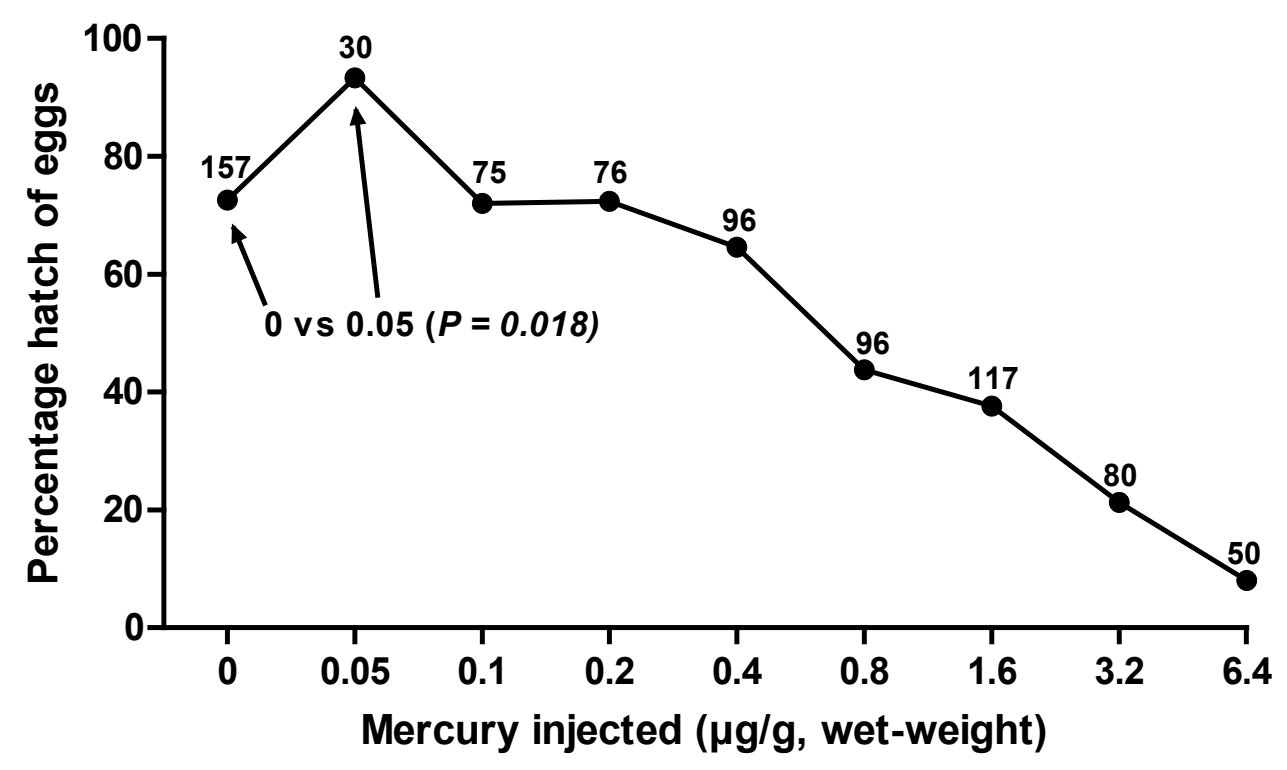

Figure 106. Hatching of mallard eggs dosed with a geometric range of mercury as methylmercury chloride. Sample sizes are shown with a number above each point on the graph. The results of a two-tailed Fisher's exact probability test are shown for the comparison of 0 versus $0.05 \mu \mathrm{g} / \mathrm{g}$ mercury of the toxicity of methylmercury dissolved in corn oil versus water. Sample sizes are shown above each point on the graphs. Figure from Heinz and others (2012b) and used with permission.

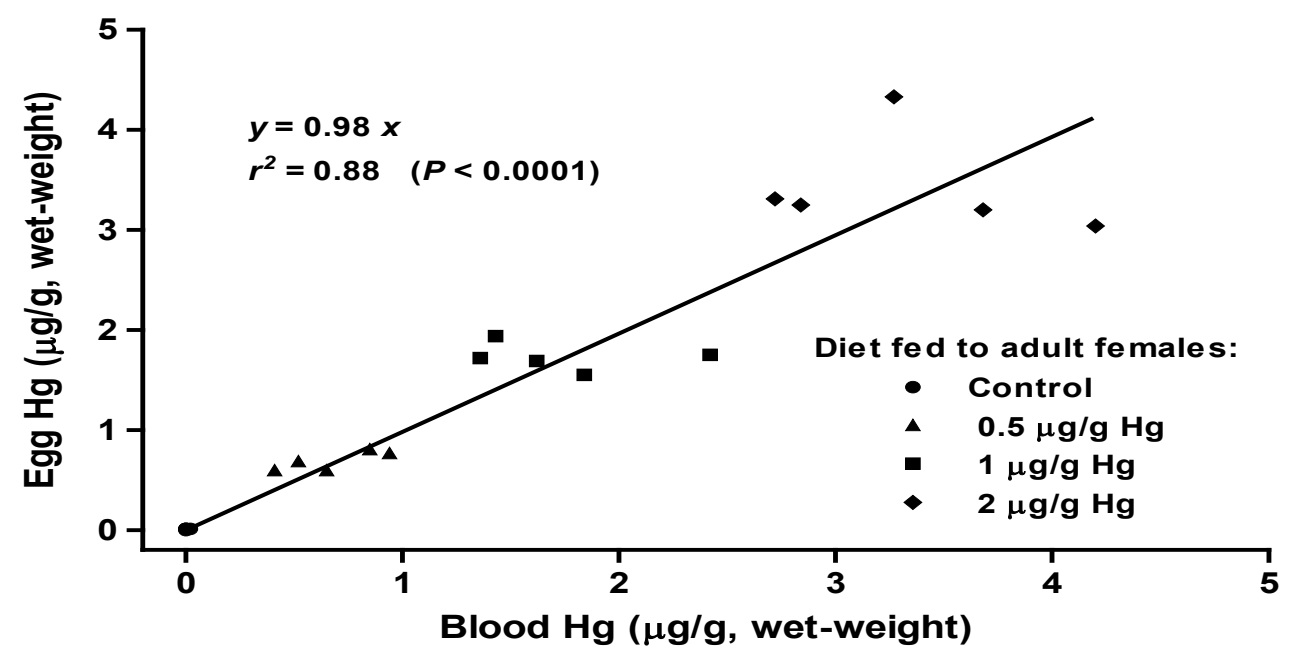

Figure 107. Mercury concentrations in mallard eggs in relation to the concentrations of mercury in the blood of the females that laid the eggs. The eggs were collected on the same day the blood samples were taken. Figure from Heinz and others (2010a) and used with permission. 


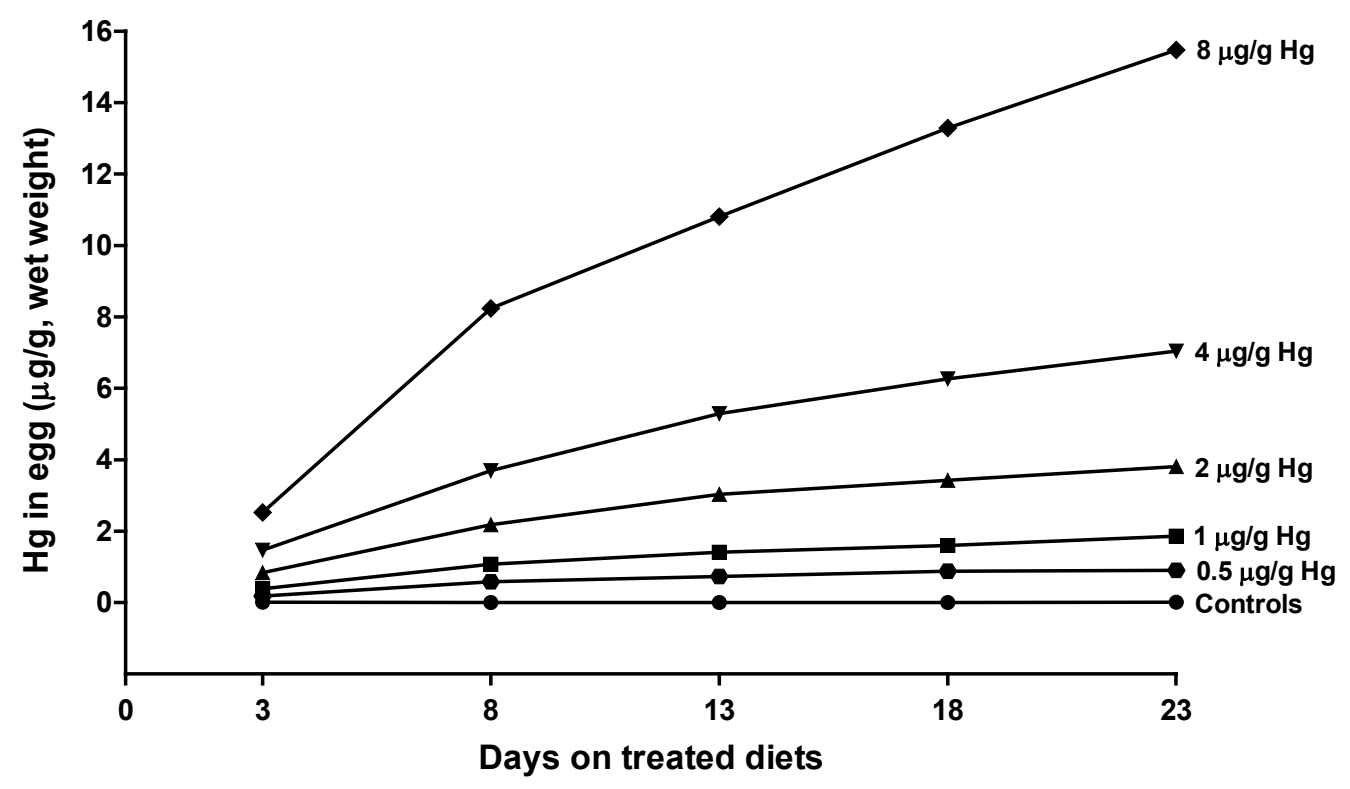

Figure 108. Mercury increases in the eggs of female mallards fed diets containing different concentrations of methylmercury. Figure from Heinz and others (2009a) and used with permission.

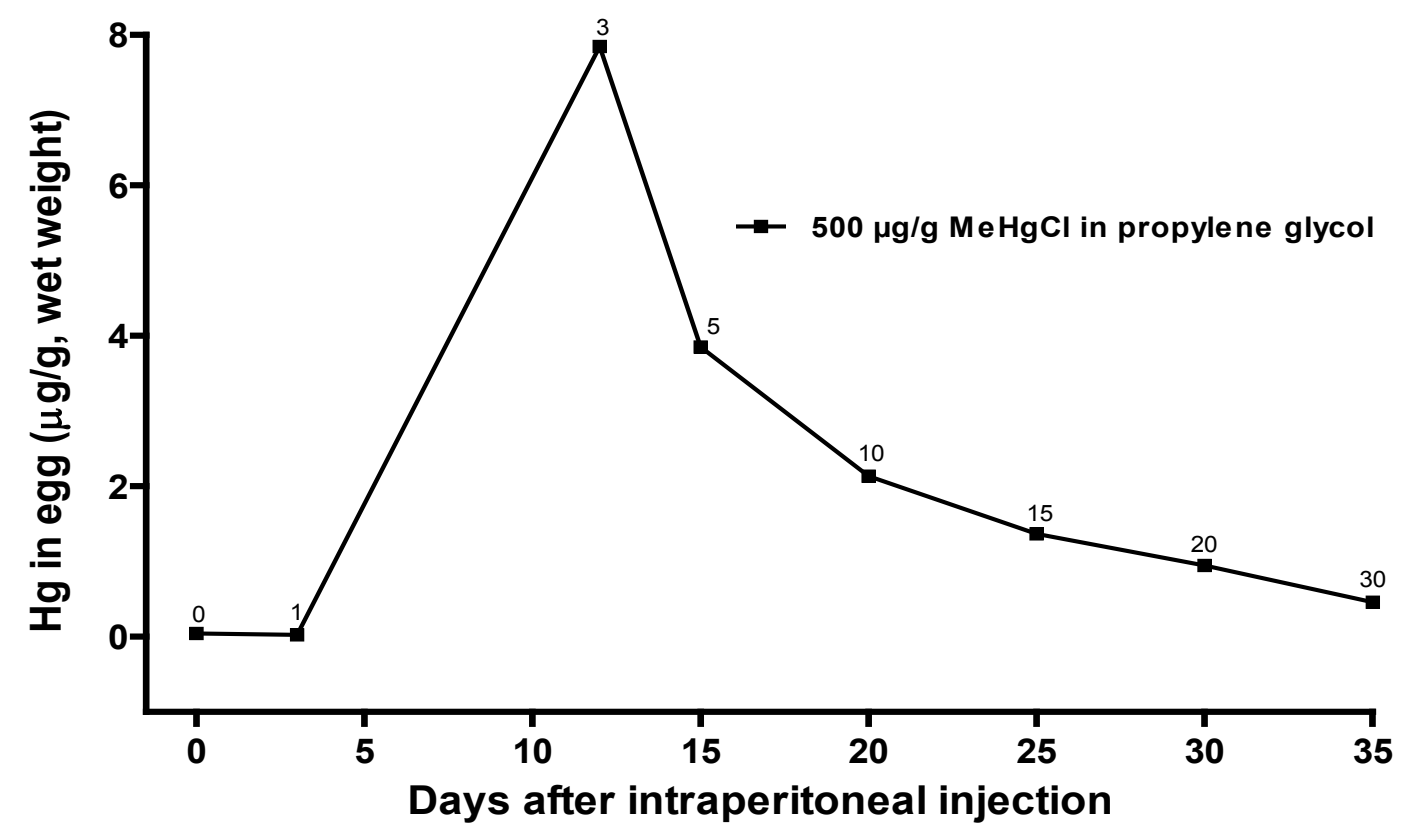

Figure 109. Mercury concentrations in the eggs of a mallard injected with $500 \mu \mathrm{g} / \mathrm{g}$ methylmercury chloride dissolved in propylene glycol. The number directly above each point on the graph is the egg number for that female. Figure from Heinz and others (2010c) and used with permission. 


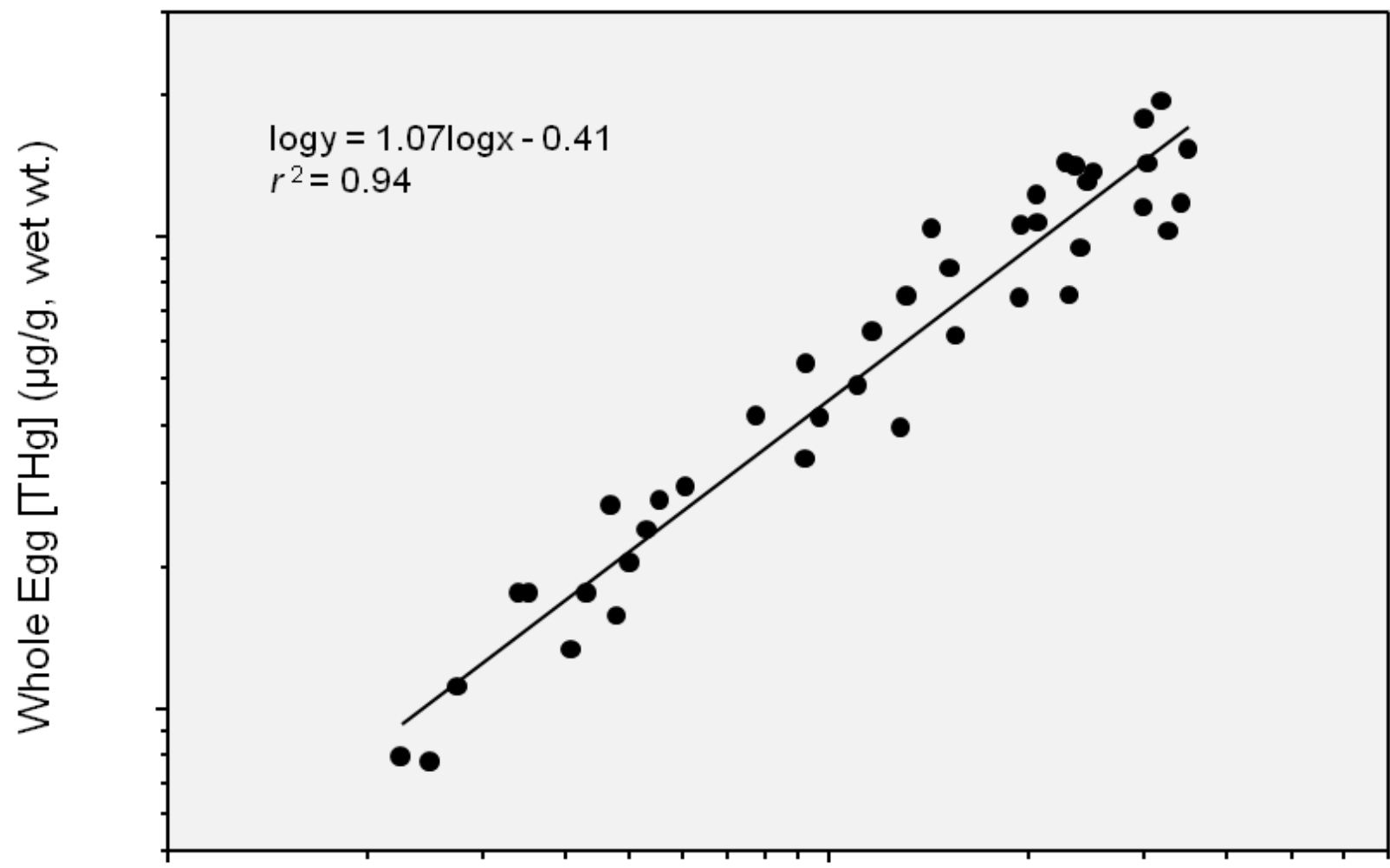

Thin Albumen $[\mathrm{THg}](\mu \mathrm{g} / \mathrm{g}$, wet wt.)

Figure 110. Total mercury $(\mathrm{THg})$ concentrations in the thin albumen of an egg versus total mercury concentrations in the whole egg. Figure from Stebbins and others (2009) and used with permission. 
Table 1. Population range sizes and percentage use of habitat types within 50 and 95 percent utilization distributions (UD) of pre-breeding American avocets and black-necked stilts radio-marked at each site during spring 2005 and 2006 in San Francisco Bay, California.

[Table from Ackerman and others (2007) and used with permission. ha, hectare]

\begin{tabular}{|c|c|c|c|c|c|c|c|c|c|c|c|}
\hline \multirow[b]{2}{*}{ Site $^{b}$} & \multirow{2}{*}{$\begin{array}{l}\text { Number } \\
\text { of radio- } \\
\text { marked } \\
\text { birds }\end{array}$} & \multirow{2}{*}{$\begin{array}{c}\text { Number } \\
\text { of } \\
\text { telemetry } \\
\text { locations }\end{array}$} & \multirow[b]{2}{*}{$\begin{array}{l}\text { Population } \\
\text { range size } \\
\text { (ha) }\end{array}$} & \multirow[b]{2}{*}{$\begin{array}{l}\text { Percentage } \\
\text { of UD within } \\
\text { capture site }\end{array}$} & \multicolumn{7}{|c|}{ Habitat typea } \\
\hline & & & & & $\begin{array}{l}\text { Salt } \\
\text { pond }\end{array}$ & $\begin{array}{c}\text { Managed } \\
\text { marsh }\end{array}$ & $\begin{array}{l}\text { Tidal } \\
\text { marsh }\end{array}$ & $\begin{array}{l}\text { Tidal } \\
\text { flat }\end{array}$ & Slough & Lagoon & Upland \\
\hline \multicolumn{12}{|c|}{ American avocets: $50 \%$ UD } \\
\hline Pond A8 & 45 & 905 & 207.3 & $60 \%$ & $75 \%$ & $1 \%$ & $8 \%$ & $8 \%$ & $1 \%$ & $0 \%$ & $7 \%$ \\
\hline Pond A16 & 6 & 185 & 331.1 & $0 \%$ & $43 \%$ & $21 \%$ & $16 \%$ & $6 \%$ & $0 \%$ & $9 \%$ & $4 \%$ \\
\hline Eden Landing & 18 & 245 & 304.3 & $80 \%$ & $83 \%$ & $3 \%$ & $6 \%$ & $5 \%$ & $0 \%$ & $0 \%$ & $3 \%$ \\
\hline Coyote Creek Marsh & 46 & 1058 & 108.4 & $48 \%$ & $8 \%$ & $11 \%$ & $44 \%$ & $38 \%$ & $0 \%$ & $0 \%$ & $0 \%$ \\
\hline \multicolumn{12}{|c|}{ American avocets: 95\% UD } \\
\hline Pond A8 & 45 & 905 & 2300.3 & $10 \%$ & $52 \%$ & $6 \%$ & $12 \%$ & $16 \%$ & $3 \%$ & $2 \%$ & $10 \%$ \\
\hline Pond A16 & 6 & 185 & 2384.5 & $1 \%$ & $39 \%$ & $13 \%$ & $16 \%$ & $10 \%$ & $2 \%$ & $9 \%$ & $11 \%$ \\
\hline Eden Landing & 18 & 245 & 1770.5 & $71 \%$ & $74 \%$ & $5 \%$ & $7 \%$ & $10 \%$ & $0 \%$ & $0 \%$ & $4 \%$ \\
\hline Coyote Creek Marsh & 46 & 1058 & 873.2 & $12 \%$ & $19 \%$ & $15 \%$ & $36 \%$ & $25 \%$ & $1 \%$ & $2 \%$ & $1 \%$ \\
\hline \multicolumn{12}{|c|}{ Black-necked stilts: $50 \%$ UD } \\
\hline Pond A8 & 5 & 83 & 212.1 & $40 \%$ & $58 \%$ & $28 \%$ & $8 \%$ & $3 \%$ & $0 \%$ & $0 \%$ & $4 \%$ \\
\hline Eden Landing & 15 & 235 & 143.7 & $100 \%$ & $79 \%$ & $14 \%$ & $3 \%$ & $0 \%$ & $2 \%$ & $0 \%$ & $2 \%$ \\
\hline New Chicago Marsh & 66 & 1380 & 211.0 & $75 \%$ & $18 \%$ & $73 \%$ & $3 \%$ & $1 \%$ & $0 \%$ & $0 \%$ & $5 \%$ \\
\hline North Bay & 8 & 230 & 436.5 & $100 \%$ & $35 \%$ & $39 \%$ & $20 \%$ & $0 \%$ & $3 \%$ & $2 \%$ & $1 \%$ \\
\hline
\end{tabular}


Habitat type

\begin{tabular}{|c|c|c|c|c|c|c|c|c|c|c|c|}
\hline \multirow[b]{2}{*}{ Site ${ }^{b}$} & \multirow[b]{2}{*}{$\begin{array}{l}\text { Number } \\
\text { of radio- } \\
\text { marked } \\
\text { birds }\end{array}$} & \multirow[b]{2}{*}{$\begin{array}{c}\text { Number } \\
\text { of } \\
\text { telemetry } \\
\text { locations }\end{array}$} & \multirow[b]{2}{*}{$\begin{array}{l}\text { Population } \\
\text { range size } \\
\text { (ha) }\end{array}$} & \multirow[b]{2}{*}{$\begin{array}{l}\text { Percentage } \\
\text { of UD within } \\
\text { capture site }\end{array}$} & \\
\hline & & & & & $\begin{array}{l}\text { Salt } \\
\text { pond }\end{array}$ & $\begin{array}{c}\text { Managed } \\
\text { marsh }\end{array}$ & $\begin{array}{l}\text { Tidal } \\
\text { marsh }\end{array}$ & $\begin{array}{l}\text { Tidal } \\
\text { flat }\end{array}$ & Slough & Lagoon & Upland \\
\hline \multicolumn{12}{|c|}{ Black-necked stilts: 95\% UD } \\
\hline Pond A8 & 5 & 83 & 957.3 & $16 \%$ & $51 \%$ & $30 \%$ & $5 \%$ & $1 \%$ & $1 \%$ & $1 \%$ & $9 \%$ \\
\hline Eden Landing & 15 & 235 & 955.7 & $82 \%$ & $67 \%$ & $12 \%$ & $3 \%$ & $1 \%$ & $0 \%$ & $2 \%$ & $14 \%$ \\
\hline New Chicago Marsh & 66 & 1380 & 1264.3 & $27 \%$ & $33 \%$ & $35 \%$ & $8 \%$ & $3 \%$ & $1 \%$ & $2 \%$ & $18 \%$ \\
\hline North Bay & 8 & 230 & 2470.1 & $100 \%$ & $16 \%$ & $27 \%$ & $38 \%$ & $9 \%$ & $1 \%$ & $1 \%$ & $8 \%$ \\
\hline
\end{tabular}

a Similar habitat types are grouped into categories as follows: salt ponds (includes active and inactive salt evaporation ponds); managed marshes (includes diked and managed marshes); tidal marshes (includes high-, mid-, and low-elevation tidal marshes and muted tidal marshes); tidal flats (includes shallow water bay, tidal flats, and beaches); sloughs (includes major channels and ditches); lagoons (includes lagoons and storage treatment ponds); and uplands (includes developed and undeveloped fill, farmed and grazed baylands, and other uplands). GIS habitat coverages are from the Bay Area EcoAtlas (version 1.50b).

b Data are pooled for 2005 and 2006, except for sites where we had 1 year of data (only 2006 data for American avocets at Pond A16, only 2006 data for blacknecked stilts at Pond A8, and only 2005 data for black-necked stilts at site North Bay). Thus, the total number of radio-marked birds and the total number of telemetry locations at each site includes 2005 and 2006 data, and the population range size, percentage of UD within capture site, and the percent use of each habitat type are averaged for 2005 and 2006. 
Table 2. Linear movements, home ranges, core areas, and average distance from nest of American avocets in South San Francisco Bay, California during 2005 and 2006.

[Data are presented as means \pm standard error. Table from Demers and others (2008) and used with permission. N, number of samples; m, meter; ha, hectare]

\begin{tabular}{lccccc}
\hline \multicolumn{1}{c}{ Breeding stage } & $\mathbf{N}$ & $\begin{array}{c}\text { Linear } \\
\text { movements } \mathbf{( m )}\end{array}$ & $\begin{array}{c}\text { Home range } \mathbf{9 5} \\
\text { percent kernel; ha) }\end{array}$ & $\begin{array}{c}\text { Core area } \\
\mathbf{5 0} \text { percent Kernel; } \\
\text { ha) }\end{array}$ & $\begin{array}{c}\text { Distance from } \\
\text { nest (m) }\end{array}$ \\
\hline Pre-incubation & 15 & $985 \pm 114$ & $1,310 \pm 310$ & $220 \pm 44$ & $1,756 \pm 240$ \\
Incubation & 14 & $523 \pm 69$ & $383 \pm 125$ & $56 \pm 18$ & $578 \pm 189$ \\
Brood-rearing & 4 & $437 \pm 66$ & $174 \pm 13$ & $38 \pm 26$ & $440 \pm 25$ \\
Post-breeding & 11 & $1,576 \pm 275$ & $3,397 \pm 755$ & $665 \pm 168$ & $4,288 \pm 736$ \\
\hline
\end{tabular}


Table 3. Population range sizes and percentage use of habitat types within 50 and 95 percent utilization distributions (UD) of pre-breeding Forster's terns radio-marked at each site during spring of 2005 and 2006 in the San Francisco Bay, California.

[Table from Ackerman and others (2008a) and used with permission. ha, hectare]

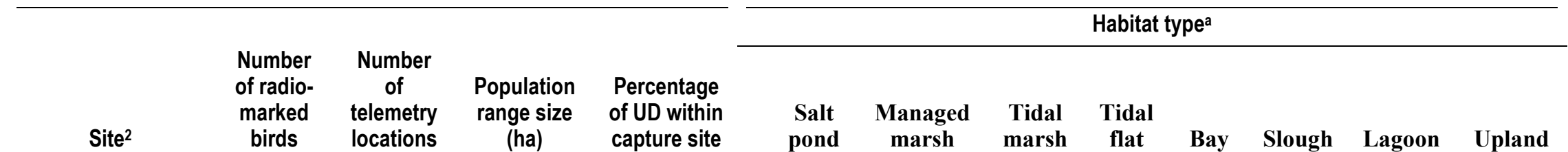

$\underline{2005}$

Forster's Terns: 50\% UD

\begin{tabular}{|c|c|c|c|c|c|c|c|c|c|c|c|c|}
\hline East Alviso & 12 & 141 & 7,373 & $41 \%$ & $61 \%$ & $22 \%$ & $6 \%$ & $2 \%$ & $0 \%$ & $0 \%$ & $0 \%$ & $9 \%$ \\
\hline West Alviso & 13 & 206 & 8,270 & $65 \%$ & $54 \%$ & $17 \%$ & $10 \%$ & $6 \%$ & $0 \%$ & $0 \%$ & $2 \%$ & $11 \%$ \\
\hline Eden Landing & 6 & 62 & 23,300 & $87 \%$ & $70 \%$ & $16 \%$ & $5 \%$ & $0 \%$ & $0 \%$ & $1 \%$ & $0 \%$ & $8 \%$ \\
\hline \multicolumn{13}{|c|}{ orster's Terns: 95\% UD } \\
\hline East Alviso & 12 & 141 & 32,829 & $34 \%$ & $57 \%$ & $6 \%$ & $8 \%$ & $2 \%$ & $0 \%$ & $2 \%$ & $4 \%$ & $21 \%$ \\
\hline West Alviso & 13 & 206 & 63,051 & $13 \%$ & $47 \%$ & $9 \%$ & $9 \%$ & $20 \%$ & $2 \%$ & $1 \%$ & $2 \%$ & $12 \%$ \\
\hline Eden Landing & 6 & 62 & 128,251 & $16 \%$ & $47 \%$ & $8 \%$ & $9 \%$ & $11 \%$ & $6 \%$ & $2 \%$ & $2 \%$ & $21 \%$ \\
\hline
\end{tabular}

\section{$\underline{2006}$}

Forster's Terns: 50\% UD

\begin{tabular}{|c|c|c|c|c|c|c|c|c|c|c|c|c|}
\hline East Alviso & 10 & 111 & 6,294 & $37 \%$ & $73 \%$ & $12 \%$ & $10 \%$ & $2 \%$ & $0 \%$ & $3 \%$ & $0 \%$ & $0 \%$ \\
\hline West Alviso & 22 & 360 & 14,643 & $42 \%$ & $67 \%$ & $8 \%$ & $12 \%$ & $5 \%$ & $0 \%$ & $2 \%$ & $2 \%$ & $4 \%$ \\
\hline \multicolumn{13}{|c|}{ Forster's Terns: 95\% UD } \\
\hline East Alviso & 10 & 111 & 25,820 & $44 \%$ & $72 \%$ & $8 \%$ & $11 \%$ & $2 \%$ & $0 \%$ & $2 \%$ & $5 \%$ & $0 \%$ \\
\hline West Alviso & 22 & 360 & 80,396 & $10 \%$ & $55 \%$ & $8 \%$ & $11 \%$ & $12 \%$ & $2 \%$ & $1 \%$ & $3 \%$ & $10 \%$ \\
\hline
\end{tabular}

${ }^{\text {a }}$ Similar habitat types are grouped into categories as follows: salt ponds (includes active and inactive salt evaporation ponds); managed marshes (includes diked marshes, managed marshes, baylands, and ruderal baylands); tidal marshes (includes high-, mid-, and low-elevation tidal marshes and muted tidal marshes); tidal flats (includes tidal flats and channel flats); bay (includes shallow water bay and deep water bay); sloughs (includes major channels); lagoons (includes lagoons and storage treatment ponds); and uplands (includes developed and undeveloped fill, farmed and grazed baylands, and urban uplands). GIS habitat coverages are from the Bay Area EcoAtlas (version 1.50b). 
Table 4. Factors affecting the mean ( $\pm S E$ ) distance from nest and the mean $( \pm S E)$ foraging range of Forster's terns in South San Francisco Bay, California during 2005 and 2006.

[Results are reported from ANOVA and Tukey-Kramer multiple comparisons tests. Data with same superscript letter are significantly different from each other $(\mathrm{P}<0.05)$. Table from Bluso-Demers and others $(2008)$ and used with permission. $\mathrm{N}$, number of samples; km, kilometer]

\begin{tabular}{|c|c|c|c|c|}
\hline Term & Group & $\mathrm{N}$ & $\begin{array}{c}\text { Distance from nest } \\
(\mathrm{km})\end{array}$ & $\begin{array}{c}\text { Foraging range } \\
(\mathrm{km})\end{array}$ \\
\hline \multirow[t]{2}{*}{ Sex } & Female & 20 & $3.4 \pm 0.97$ & $5.7 \pm 1.29$ \\
\hline & Male & 27 & $4.0 \pm 0.99$ & $7.1 \pm 2.11$ \\
\hline \multirow[t]{4}{*}{ Stage } & Pre-breeding & 10 & $4.0 \pm 0.92^{\mathrm{AB}}$ & $7.2 \pm 1.97^{\mathrm{EF}}$ \\
\hline & Incubation & 13 & $1.0 \pm 0.25^{\mathrm{BCD}}$ & $3.1 \pm 0.92^{\mathrm{FG}}$ \\
\hline & Chick-rearing & 11 & $1.7 \pm 0.56^{\mathrm{AC}}$ & $3.4 \pm 1.23^{\mathrm{EH}}$ \\
\hline & Post-breeding & 13 & $8.1 \pm 1.86^{\mathrm{AD}}$ & $12.0 \pm 3.99^{\mathrm{GH}}$ \\
\hline \multirow[t]{2}{*}{ Site } & East Alviso & 27 & $1.6 \pm 0.30$ & $3.4 \pm 0.80^{\mathrm{I}}$ \\
\hline & N7 & 20 & $6.6 \pm 1.36$ & $10.6 \pm 2.68^{\mathrm{I}}$ \\
\hline \multirow[t]{8}{*}{ Stage $\times$ sex } & Pre-breeding, Female & 4 & $2.7 \pm 0.84$ & $7.2 \pm 4.50$ \\
\hline & Pre-breeding, Male & 6 & $4.8 \pm 1.37$ & $7.2 \pm 1.87$ \\
\hline & Incubation, Female & 5 & $0.9 \pm 0.31$ & $2.8 \pm 0.54$ \\
\hline & Incubation, Male & 8 & $1.0 \pm 0.38$ & $3.3 \pm 1.50$ \\
\hline & Chick-rearing, Female & 5 & $1.4 \pm 0.60$ & $3.4 \pm 2.04$ \\
\hline & Chick-rearing, Male & 6 & $1.8 \pm 0.95$ & $3.4 \pm 1.64$ \\
\hline & Post-breeding, Female & 6 & $7.4 \pm 2.50$ & $8.9 \pm 2.34$ \\
\hline & Post-breeding, Male & 7 & $8.6 \pm 2.89$ & $14.6 \pm 7.25$ \\
\hline \multirow[t]{8}{*}{ Stage $\times$ colony } & Pre-breeding, E. Alviso & 7 & $3.5 \pm 0.69$ & $7.5 \pm 2.48$ \\
\hline & Pre-breeding, N7 & 2 & $6.9 \pm 3.93$ & $8.7 \pm 5.32$ \\
\hline & Incubation, E. Alviso & 8 & $0.7 \pm 0.17$ & $2.2 \pm 0.43$ \\
\hline & Incubation, N7 & 5 & $1.4 \pm 0.58$ & $4.5 \pm 2.29$ \\
\hline & Chick-rearing, E. Alviso & 5 & $0.7 \pm 0.13$ & $1.2 \pm 0.12$ \\
\hline & Chick-rearing, N7 & 6 & $2.4 \pm 0.94$ & $5.2 \pm 2.03$ \\
\hline & Post-breeding, E. Alviso & 6 & $1.3 \pm 0.32^{\mathrm{J}}$ & $2.5 \pm 0.82^{\mathrm{K}}$ \\
\hline & Post-breeding, N7 & 13 & $13.8 \pm 0.91^{\mathrm{J}}$ & $20.1 \pm 5.88^{\mathrm{K}}$ \\
\hline
\end{tabular}


Table 5. Summary of surf scoters marked and total locations in two sub-bays of San Francisco Bay during the winters of 2003-04 and 2004-05.

[Table from De La Cruz and others (2014) and used with permission. AHY (after hatch year) denotes birds captured at least a year after hatching and HY (hatch year) denotes birds captured in the year they were hatched. M, male; F, female]

\begin{tabular}{lccccccccccc}
\hline & \multicolumn{3}{c}{ San Pablo Bay } & \multicolumn{5}{c}{ Central Bay } & Total & Total \\
\cline { 2 - 9 } \multicolumn{1}{c}{ Year } & MHY & HY & AHY & HY & AHY & HY & AHY & HY & Marked & Locations \\
\hline \hline $2003-2004$ & 10 & 13 & 0 & 5 & 11 & 11 & 10 & 5 & 65 & 1,193 \\
$2004-2005$ & 10 & 1 & 2 & 0 & 18 & 5 & 38 & 12 & 86 & 1,533 \\
\hline Totals & 20 & 14 & 2 & 5 & 29 & 16 & 48 & 17 & 151 & 2,726 \\
\hline
\end{tabular}

Table 6. Number and age of foraging females collected in Central, San Pablo, and Suisun Bays during fall (F), winter (W), and spring (S) of 2003-04 and 2004-05.

[Nineteen additional males were collected during the same study are not included here. Table from De La Cruz (2010) and used with permission.]

\begin{tabular}{|c|c|c|c|c|c|c|c|c|c|c|c|c|c|c|c|c|c|c|c|}
\hline \multirow[b]{3}{*}{ Age } & \multicolumn{6}{|c|}{ Central Bay } & \multicolumn{6}{|c|}{ San Pablo Bay } & \multicolumn{6}{|c|}{ Suisun Bay } & \multirow[b]{3}{*}{ Total } \\
\hline & \multicolumn{3}{|c|}{2004} & \multicolumn{3}{|c|}{2005} & \multicolumn{3}{|c|}{2004} & \multicolumn{3}{|c|}{2005} & \multicolumn{3}{|c|}{2004} & \multicolumn{3}{|c|}{2005} & \\
\hline & $F$ & $\mathbf{W}$ & $\mathbf{S}$ & $\mathbf{F}$ & W & S & $F$ & W & S & $\mathbf{F}$ & W & S & $\mathbf{F}$ & W & S & $\mathbf{F}$ & W & S & \\
\hline Adult (AHY) & 10 & 12 & 14 & 9 & 13 & 9 & 12 & 5 & 0 & 9 & 2 & 4 & 0 & 5 & 0 & 9 & 6 & 2 & 121 \\
\hline Juvenile $(\mathrm{HY})$ & 0 & 2 & 1 & 0 & 0 & 0 & 2 & 0 & 0 & 2 & 5 & 2 & 0 & 4 & 0 & 0 & 0 & 0 & 18 \\
\hline Total & 10 & 14 & 15 & 9 & 13 & 9 & 14 & 5 & 0 & 11 & 7 & 6 & 0 & 9 & 0 & 9 & 6 & 2 & 139 \\
\hline
\end{tabular}

Table 7. Tissue samples collected from American avocets (AMAV) and black-necked stilts (BNST) in the North Bay (NB) and South Bay (SB) for isotopic analysis.

\begin{tabular}{llllccc}
\hline Species & Region & Age & Collection stage & Sex & $\begin{array}{c}\text { Muscle } \\
\text { (n) }\end{array}$ & $\begin{array}{c}\text { Whole blood } \\
\text { (n) }\end{array}$ \\
\hline \hline AMAV & NB & Adult & Pre-breeding & F & 2 & 2 \\
AMAV & NB & Adult & Breeding & F & 1 & \\
AMAV & SB & Adult & Pre-breeding & M & 4 & \\
AMAV & SB & Adult & Pre-breeding & F & 14 & 11 \\
AMAV & SB & Adult & Breeding & F & 11 & 8 \\
AMAV & SB & Chick & Chick & All & 17 & 15 \\
BNST & NB & Adult & Pre-breeding & M & 2 & \\
BNST & NB & Adult & Breeding & F & 4 & 4 \\
BNST & SB & Adult & Pre-breeding & M & 1 & \\
BNST & SB & Adult & Pre-breeding & F & 7 & 5 \\
BNST & SB & Adult & Breeding & F & 6 & 5 \\
BNST & SB & Chick & Chick & All & 16 & 15 \\
\hline
\end{tabular}


Table 8. Mean percent number $(\% \mathrm{~N})$ and percent frequency of Occurrence $(\% \mathrm{FO})$ of prey items found in the esophagus and proventriculus of chicks and adult female black-necked stilts collected from the North Bay (NB) and South Bay (SB) in 2005 and 2006. No chicks were collected in the North Bay.

\begin{tabular}{|c|c|c|c|c|c|c|c|}
\hline \multirow[b]{2}{*}{ Prey Item } & & \multicolumn{2}{|c|}{$\begin{array}{l}\text { NB adult female } \\
(\mathrm{N}=10)\end{array}$} & \multicolumn{2}{|c|}{$\begin{array}{l}\text { SB adult female } \\
\qquad(\mathrm{N}=11)\end{array}$} & \multicolumn{2}{|c|}{$\begin{array}{l}\text { SB chicks } \\
(\mathrm{N}=24)\end{array}$} \\
\hline & & $\% \mathrm{~N}$ & $\% \mathrm{FO}$ & $\% \mathrm{~N}$ & $\% \mathrm{FO}$ & $\% \mathrm{~N}$ & $\% \mathrm{FO}$ \\
\hline \multirow[t]{5}{*}{ Coleoptera } & Carabidae & 6.67 & 20.00 & 9.09 & 9.09 & 2.08 & 8.33 \\
\hline & Dytiscidae & 5.00 & 10.00 & & & & \\
\hline & Hydrophilidae & 3.33 & 10.00 & & & 12.50 & 20.83 \\
\hline & Coleoptera Adult & 38.33 & 50.00 & 9.09 & 9.09 & 15.97 & 20.83 \\
\hline & Coleoptera Larva & 13.33 & 20.00 & & & & \\
\hline \multirow[t]{5}{*}{ Diptera } & Ephydridae Adult & & & 4.55 & 9.09 & 2.08 & 4.17 \\
\hline & Ephydridae Larva & & & 27.27 & 27.27 & 6.94 & 12.50 \\
\hline & Syrphidae & 8.75 & 10.00 & & & & \\
\hline & Chironomidae & & & 7.51 & 9.09 & 0.83 & 4.17 \\
\hline & Diptera & & & 3.03 & 9.09 & & \\
\hline \multirow[t]{2}{*}{ Hemiptera } & Corixid & 15.00 & 30.00 & 36.03 & 54.55 & 49.17 & 66.67 \\
\hline & Saldidae & 3.33 & 10.00 & & & 4.86 & 8.33 \\
\hline Hymenoptera & Formicidae & 5.00 & 10.00 & 3.43 & 18.18 & 4.17 & 12.50 \\
\hline Decapoda & Decapod & 1.25 & 10.00 & & & & \\
\hline Crustacea & Crustacean & & & & & 1.39 & 4.17 \\
\hline
\end{tabular}

Table 9. Mean percent number $(\% \mathrm{~N})$ and percent frequency of occurrence $(\% \mathrm{FO})$ of prey items found in the esophagus and proventriculus of chicks and adult female American avocets collected from the North Bay (NB) and South Bay (SB) in 2005 and 2006. No chicks were collected in the North Bay.

\begin{tabular}{|c|c|c|c|c|c|c|c|}
\hline \multirow[b]{2}{*}{ Prey Item } & & \multicolumn{2}{|c|}{$\begin{array}{l}\text { NB adult female } \\
(\mathrm{N}=1)\end{array}$} & \multicolumn{2}{|c|}{$\begin{array}{l}\text { SB adult female } \\
(\mathrm{N}=17)\end{array}$} & \multicolumn{2}{|c|}{$\begin{array}{c}\text { SB chicks } \\
(\mathrm{N}=16)\end{array}$} \\
\hline & & $\% \mathrm{~N}$ & $\% \mathrm{FO}$ & $\% \mathrm{~N}$ & $\% \mathrm{FO}$ & $\% \mathrm{~N}$ & $\% \mathrm{FO}$ \\
\hline \multirow[t]{3}{*}{ Coleoptera } & Anthicidae & & & & & 0.39 & 6.25 \\
\hline & Chrysomelidae & & & & & 0.39 & 6.25 \\
\hline & Hydrophilidae & & & 6.70 & 11.76 & & \\
\hline \multirow[t]{4}{*}{ Diptera } & Ephydridae Adult & & & 10.78 & 11.76 & 0.39 & 6.25 \\
\hline & Ephydridae Larva & & & 34.80 & 47.06 & 19.14 & 25.00 \\
\hline & Chironomidae & & & 11.59 & 11.76 & & \\
\hline & Diptera & & & 5.88 & 5.88 & 3.13 & 6.25 \\
\hline Hemiptera & Corixidae & & & 21.38 & 41.18 & 45.61 & 62.50 \\
\hline Hemiptera & Saldidae & & & 5.88 & 5.88 & 6.25 & 6.25 \\
\hline Pthiraptera & Louse & & & 2.94 & 5.88 & 4.69 & 12.50 \\
\hline Decapoda & Decapod & 100.00 & 100.00 & & & 13.76 & 18.75 \\
\hline Crustacea & Crustacean & & & & & 6.25 & 6.25 \\
\hline
\end{tabular}


Table 10. Mean percent number $(\% \mathrm{~N})$ and percent frequency of occurrence $(\% \mathrm{FO})$ of prey items found in the esophagus and proventriculus of adult female black-necked stilts collected from the North Bay (NB) and South Bay (SB) in 2005 and 2006 during pre-breeding and breeding periods.

\begin{tabular}{|c|c|c|c|c|c|c|c|c|c|}
\hline \multirow[b]{2}{*}{ Prey item } & & \multicolumn{2}{|c|}{$\begin{array}{c}\text { NB pre-breeding } \\
(\mathrm{N}=3)\end{array}$} & \multicolumn{2}{|c|}{$\begin{array}{c}\text { NB breeding } \\
(\mathrm{N}=7)\end{array}$} & \multicolumn{2}{|c|}{$\begin{array}{l}\text { SB pre-breeding } \\
(\mathrm{N}=5)\end{array}$} & \multicolumn{2}{|c|}{$\begin{array}{l}\text { SB breeding } \\
(\mathrm{N}=6)\end{array}$} \\
\hline & & $\% \mathrm{~N}$ & $\% \mathrm{FO}$ & $\% \mathrm{~N}$ & $\% \mathrm{FO}$ & $\% \mathrm{~N}$ & $\% \mathrm{FO}$ & $\% \mathrm{~N}$ & $\% \mathrm{FO}$ \\
\hline \multirow[t]{5}{*}{ Coleoptera } & Carabidae & & & 9.5 & 28.6 & & & 16.67 & 16.67 \\
\hline & Dytiscidae & & & 7.1 & 14.3 & & & & \\
\hline & Hydrophilidae & & & 4.8 & 14.3 & & & & \\
\hline & Coleoptera Adult & 50.0 & 66.7 & 33.3 & 42.9 & & & 16.67 & 16.67 \\
\hline & Coleoptera Larva & & & 19.0 & 28.6 & & & & \\
\hline \multirow[t]{5}{*}{ Diptera } & Ephydridae Adult & & & & & 60.00 & 60.00 & 8.33 & 16.67 \\
\hline & Ephydridae Larva & & & & & & & & \\
\hline & Syrphidae & 29.2 & 33.3 & & & & & & \\
\hline & Chironomidae & & & & & 16.52 & 20.00 & & \\
\hline & Diptera & & & & & & & 5.56 & 16.67 \\
\hline \multirow[t]{2}{*}{ Hemiptera } & Corixidae & & & 21.4 & 42.9 & 22.61 & 40.00 & 47.22 & 66.67 \\
\hline & Saldidae & & & 4.8 & 14.3 & & & & \\
\hline Hymenoptera & Formicidae & 16.7 & 33.3 & & & 0.87 & 20.00 & 5.56 & 16.67 \\
\hline Decapoda & Decapod & 4.2 & 33.3 & & & & & & \\
\hline
\end{tabular}

Table 11. Mean percent number $(\% \mathrm{~N})$ and percent frequency of occurrence $(\% \mathrm{FO})$ of prey items found in the esophagus and proventriculus of adult female American avocets from the North Bay (NB) and South Bay (SB) in 2005 and 2006 during pre-breeding and breeding periods.

[No samples were collected in the North Bay during the Breeding period]

\begin{tabular}{|c|c|c|c|c|c|c|c|}
\hline \multirow[b]{2}{*}{ Prey Item } & & \multicolumn{2}{|c|}{$\begin{array}{c}\text { NB pre- } \\
\text { breeding } \\
(\mathrm{N}=1)\end{array}$} & \multicolumn{2}{|c|}{$\begin{array}{c}\text { SB pre- } \\
\text { breeding } \\
(\mathrm{N}=7)\end{array}$} & \multicolumn{2}{|c|}{$\begin{array}{c}\text { SB breeding } \\
(\mathrm{N}=10)\end{array}$} \\
\hline & & $\% \mathrm{~N}$ & $\% \mathrm{FO}$ & $\% \mathrm{~N}$ & $\% \mathrm{FO}$ & $\% \mathrm{~N}$ & $\% \mathrm{FO}$ \\
\hline \multirow[t]{3}{*}{ Coleoptera } & Hydrophilidae & & & & & 11.39 & 20.00 \\
\hline & Ephydridae Adult & & & 11.90 & 14.29 & 10.00 & 10.00 \\
\hline & Ephydridae Larva & & & 66.67 & 85.71 & 12.50 & 20.00 \\
\hline \multirow[t]{2}{*}{ Diptera } & Chironomidae & & & & & 19.71 & 20.00 \\
\hline & Diptera & & & & & 10.00 & 10.00 \\
\hline Hemiptera & Corixidae & & & 7.14 & 14.29 & 31.40 & 70.00 \\
\hline Hymenoptera & Saldidae & & & 14.29 & 14.29 & & \\
\hline Phthiraptera & Louse & & & & & 5.00 & 10.00 \\
\hline Decapoda & Decapod & 100.00 & 100.00 & & & & \\
\hline
\end{tabular}


Table 12. Mean number of individuals of all identified invertebrates in benthic grab samples located at stilt and avocet foraging areas in the South Bay.

\begin{tabular}{|c|c|c|c|c|c|c|c|c|c|}
\hline \multirow[b]{3}{*}{ Taxa } & & \multicolumn{4}{|c|}{ Avocet } & \multicolumn{4}{|c|}{ Stilt } \\
\hline & & \multicolumn{2}{|c|}{$\begin{array}{l}\text { Pre-breeding } \\
(\mathrm{N}=22)\end{array}$} & \multicolumn{2}{|c|}{$\begin{array}{l}\text { Chick } \\
(\mathrm{N}=33)\end{array}$} & \multicolumn{2}{|c|}{$\begin{array}{l}\text { Pre-breeding } \\
\quad(N=16)\end{array}$} & \multicolumn{2}{|c|}{$\begin{array}{l}\text { Chick } \\
(\mathrm{N}=34)\end{array}$} \\
\hline & & Mean & SE & Mean & SE & Mean & SE & Mean & SE \\
\hline \multirow[t]{3}{*}{ Coleoptera } & Hydrophilidae & 0.09 & 0.06 & 3.76 & 1.31 & 0.19 & 0.14 & 0.82 & 0.43 \\
\hline & Coleoptera & 0 & 0 & 0 & 0 & 0.06 & 0.06 & 0 & 0 \\
\hline & Chrysomelidae & 0 & 0 & 0 & 0 & 0 & 0 & 0.03 & 0.03 \\
\hline \multirow[t]{5}{*}{ Diptera } & Diptera & 0.41 & 0.30 & 0.12 & 0.12 & 0.13 & 0.13 & 0 & 0 \\
\hline & Dolichopodidae & 0.05 & 0.05 & 0.03 & 0.03 & 0 & 0 & 0 & 0 \\
\hline & Muscidae & 0.14 & 0.07 & 0 & 0 & 0.38 & 0.38 & 0 & 0 \\
\hline & Chironomidae & 0.45 & 0.28 & 0.36 & 0.18 & 1.63 & 1.56 & 0.09 & 0.06 \\
\hline & Psychodidae & 0.05 & 0.05 & 0 & 0 & 0 & 0 & 0 & 0 \\
\hline \multirow[t]{2}{*}{ Ephydridae } & Ephydra & 1.32 & 0.69 & 1.06 & 0.81 & 1.25 & 0.88 & 3.53 & 2.29 \\
\hline & Ephydridae & 0.36 & 0.24 & 0.06 & 0.04 & 0.19 & 0.19 & 0.09 & 0.09 \\
\hline Lepidoptera & Lepidoptera & 0 & 0 & 0.03 & 0.03 & 0 & 0 & 0 & 0 \\
\hline Corixidae & Corixidae & 0.64 & 0.31 & 38.24 & 11.67 & 0.63 & 0.50 & 42.76 & 17.70 \\
\hline \multirow[t]{3}{*}{ Polychaete } & Polychaeta & 0 & 0 & 27.39 & 22.74 & 0 & 0 & 0 & 0 \\
\hline & Sabellidae & 0 & 0 & 0.06 & 0.06 & 0 & 0 & 0 & 0 \\
\hline & Eteone sp. & 0 & 0 & 0.03 & 0.03 & 0 & 0 & 0 & 0 \\
\hline \multirow[t]{2}{*}{ Spionidae } & Polydora sp. & 2.14 & 0.86 & 22.70 & 10.06 & 1.44 & 1.24 & 4.47 & 1.75 \\
\hline & Streblospio sp. & 0 & 0 & 0.06 & 0.06 & 0 & 0 & 0 & 0 \\
\hline Capitella & Capitella sp. & 0.68 & 0.42 & 2.67 & 2.64 & 0 & 0 & 0 & 0 \\
\hline \multirow[t]{3}{*}{ Oligochaete } & Oligochaeta & 30.95 & 17.98 & 5.30 & 4.91 & 0 & 0 & 0.03 & 0.03 \\
\hline & Tubificoides sp. & 1.73 & 1.09 & 11.52 & 5.68 & 0 & 0 & 2.32 & 1.64 \\
\hline & Naididae & 0 & 0 & 0 & 0 & 33.31 & 33.31 & 0 & 0 \\
\hline \multirow[t]{2}{*}{ Gastropod } & Gastropod & 0 & 0 & 0.30 & 0.22 & 0 & 0 & 0 & 0 \\
\hline & $\begin{array}{l}\text { Assiminea } \\
\text { californica }\end{array}$ & 0.82 & 0.69 & 5.42 & 4.97 & 0 & 0 & 0.94 & 0.91 \\
\hline \multirow[t]{3}{*}{ Amphipod } & Corophium sp. & 0.00 & 0.00 & 1.85 & 1.52 & 0 & 0 & 10.59 & 10.59 \\
\hline & $\begin{array}{l}\text { Grandidierella } \\
\text { japonica }\end{array}$ & 0.00 & 0.00 & 0.33 & 0.33 & 0 & 0 & 0.03 & 0.03 \\
\hline & Eogammarus sp. & 0.05 & 0.05 & 0.03 & 0.03 & 0 & 0 & 0.79 & 0.79 \\
\hline Ostracoda & Ostracoda & 0.18 & 0.13 & 0.55 & 0.43 & 0 & 0 & 0.53 & 0.33 \\
\hline Mysid & Neomysis sp. & 0 & 0 & 1.70 & 0.90 & 0 & 0 & 1.47 & 1.05 \\
\hline Artemia & Artemia sp. & 0.59 & 0.22 & 0.33 & 0.33 & 0.13 & 0.09 & 0 & 0 \\
\hline Ormosia & Ormosia & 0.05 & 0.05 & 0 & 0 & 0 & 0 & 0 & 0 \\
\hline
\end{tabular}


Table 13. Mean number of individuals of all identified invertebrates in aquatic sweep samples located at stilt and avocet foraging areas in the South Bay.

\begin{tabular}{|c|c|c|c|c|c|c|c|c|c|}
\hline \multirow[b]{3}{*}{ Taxa } & & \multicolumn{4}{|c|}{ Avocet } & \multicolumn{4}{|c|}{ Stilt } \\
\hline & & \multicolumn{2}{|c|}{$\begin{array}{l}\text { Pre-breeding } \\
\quad(\mathrm{N}=10)\end{array}$} & \multicolumn{2}{|c|}{$\begin{array}{l}\text { Chick } \\
(\mathrm{N}=25)\end{array}$} & \multicolumn{2}{|c|}{$\begin{array}{l}\text { Pre-breeding } \\
(\mathrm{N}=12)\end{array}$} & \multicolumn{2}{|c|}{$\begin{array}{l}\text { Chick } \\
(\mathrm{N}=22)\end{array}$} \\
\hline & & Mean & SE & Mean & SE & Mean & SE & Mean & SE \\
\hline \multirow[t]{2}{*}{ Arachnid } & Hydracarina & 0 & 0 & 0.08 & 0.08 & 0 & 0 & 0 & 0 \\
\hline & Arachnid & 0 & 0 & 0 & 0 & 0 & 0 & 0.05 & 0.05 \\
\hline \multirow[t]{3}{*}{ Coleoptera } & Hydrophilidae & 0.90 & 0.46 & 1.64 & 0.50 & 0 & 0 & 0.55 & 0.27 \\
\hline & Coleoptera & 0 & 0 & 0.04 & 0.04 & 0 & 0 & 0 & 0 \\
\hline & Chrysomelidae & 0 & 0 & 0 & 0 & 0 & 0 & 0.05 & 0.05 \\
\hline \multirow[t]{4}{*}{ Diptera } & Diptera & 0 & 0 & 0.36 & 0.15 & 0.33 & 0.33 & 0.27 & 0.13 \\
\hline & Muscidae & 0 & 0 & 0 & 0 & 0.08 & 0.08 & 0 & 0 \\
\hline & Chironomidae & 0 & 0 & 0.40 & 0.22 & 0.08 & 0.08 & 0.14 & 0.10 \\
\hline & Psychodidae & 0 & 0 & 0 & 0 & 0 & 0 & 0 & 0 \\
\hline \multirow[t]{2}{*}{ Ephydridae } & Ephydra & 3.40 & 2.98 & 1.60 & 1.56 & 4.08 & 1.37 & 1.95 & 1.64 \\
\hline & Ephydridae & 0 & 0 & 0 & 0 & 0.58 & 0.58 & 0.05 & 0.05 \\
\hline Corixidae & Corixidae & 33.40 & 4.00 & 1232.48 & 380.27 & 34.33 & 14.57 & 756.95 & 254.55 \\
\hline Polychaete & Polydora sp. & 0 & 0 & 5.00 & 4.63 & 1.75 & 0.91 & 0.27 & 0.23 \\
\hline Capitella & Capitella sp. & 0 & 0 & 0.12 & 0.12 & 0 & 0 & 0 & 0 \\
\hline \multirow[t]{2}{*}{ Oligochaete } & Oligochaeta & 0 & 0 & 3.20 & 1.88 & 0 & 0 & 0.68 & 0.64 \\
\hline & Tubificoides sp. & 0 & 0 & 6.44 & 5.52 & 0.50 & 0.26 & 0.18 & 0.14 \\
\hline \multirow[t]{2}{*}{ Gastropod } & Gastropod & 0 & 0 & 0.52 & 0.52 & 0 & 0 & 0 & 0 \\
\hline & $\begin{array}{l}\text { Assiminea } \\
\text { californica }\end{array}$ & 0 & 0 & 55.20 & 51.53 & 0 & 0 & 0.09 & 0.06 \\
\hline \multirow[t]{5}{*}{ Amphipod } & Corophium sp. & 0 & 0 & 9.16 & 9.16 & 0 & 0 & 0.36 & 0.36 \\
\hline & Grandidierella & & & & & & & & \\
\hline & japonica & 0 & 0 & 0.92 & 0.92 & 0 & 0 & 0 & 0 \\
\hline & Eogammarus sp. & 0 & 0 & 0.40 & 0.28 & 0 & 0 & 0.18 & 0.18 \\
\hline & Ampithoe sp. & 0 & 0 & 1.60 & 1.56 & 0 & 0 & 0 & 0 \\
\hline \multirow{2}{*}{$\begin{array}{l}\text { Cumacea } \\
\text { Ostracoda }\end{array}$} & Nippoleucon sp. & 0 & 0 & 0.08 & 0.08 & 0 & 0 & 0 & 0 \\
\hline & Ostracoda & 0 & 0 & 1.84 & 1.80 & 0 & 0 & 0.09 & 0.06 \\
\hline Isopod & Sphaeromatidae & 0 & 0 & 0.28 & 0.28 & 0 & 0 & 0 & 0 \\
\hline Mysid & Neomysis sp. & 0 & 0 & 218.24 & 127.95 & 1.17 & 1.17 & 144.86 & 85.80 \\
\hline Artemia & Artemia sp. & 1620.90 & 229.62 & 43.92 & 43.80 & 281.83 & 96.12 & 6.18 & 6.18 \\
\hline
\end{tabular}


Table 14. Methylmercury and total mercury dry weight concentrations found in benthic invertebrates located at American avocets foraging areas within San Francisco Bay by season.

[Results are presented as geometric means and back transformed 95 percent confidence intervals. N, number of samples; CI, confidence interval; $\mathrm{MeHg}$, methylmercury; $\mathrm{THg}$, total mercury]

\begin{tabular}{|c|c|c|c|c|c|c|c|c|c|c|c|c|}
\hline \multirow[b]{3}{*}{ Taxa } & \multicolumn{6}{|c|}{ Pre-breeding } & \multicolumn{6}{|c|}{ Chicks } \\
\hline & \multicolumn{3}{|c|}{$\mathrm{MeHg}$} & \multicolumn{3}{|c|}{$\mathrm{THg}$} & \multicolumn{3}{|c|}{$\mathrm{MeHg}$} & \multicolumn{3}{|c|}{$\mathrm{THg}$} \\
\hline & $\mathbf{N}$ & $\mu \mathrm{g} / \mathrm{g}$ & $95 \% \mathrm{Cl}$ & $\mathrm{N}$ & $\mu \mathrm{g} / \mathrm{g}$ & $95 \% \mathrm{Cl}$ & $\mathrm{N}$ & $\mu \mathrm{g} / \mathrm{g}$ & $95 \% \mathrm{Cl}$ & $\mathbf{N}$ & $\mu \mathrm{g} / \mathrm{g}$ & $95 \% \mathrm{Cl}$ \\
\hline Artemia & 11 & 0.36 & $0.26-0.50$ & 11 & 0.57 & $0.44-1.28$ & 1 & 0.25 & - & 1 & 0.47 & - \\
\hline Corixidae & 3 & 1.06 & $0.12-9.47$ & 1 & 2.52 & - & 33 & 0.24 & $0.17-0.33$ & 33 & 0.26 & $0.19-1.36$ \\
\hline Coleoptera & 0 & - & - & - & - & - & 4 & 0.20 & $0.09-0.47$ & 1 & 0.42 & - \\
\hline Ephydridae & 0 & - & - & - & - & - & 1 & 0.11 & - & 1 & 0.21 & - \\
\hline Mysis & 0 & - & - & - & - & - & 2 & 0.91 & $0.44-1.88$ & 2 & 0.72 & $0.61-1.17$ \\
\hline
\end{tabular}

Table 15. Methylmercury and total mercury dry weight concentrations found in benthic invertebrates located at Black-necked stilt foraging areas within San Francisco Bay.

[Results are presented as geometric means and back transformed 95 percent confidence intervals. N, number of samples; CI, confidence interval; $\mathrm{MeHg}$, methylmercury; THg, total mercury]

\begin{tabular}{|c|c|c|c|c|c|c|c|c|c|c|c|c|}
\hline \multirow[b]{3}{*}{ Taxa } & \multicolumn{6}{|c|}{ Pre-Breeding } & \multicolumn{6}{|c|}{ Chicks } \\
\hline & \multicolumn{3}{|c|}{$\mathrm{MeHg}$} & \multicolumn{3}{|c|}{$\mathrm{THg}$} & \multicolumn{3}{|c|}{$\mathrm{MeHg}$} & \multicolumn{3}{|c|}{$\mathrm{THg}$} \\
\hline & $\mathrm{N}$ & $\mu \mathrm{g} / \mathrm{g}$ & $95 \% \mathrm{Cl}$ & $\mathrm{N}$ & $\mu \mathrm{g} / \mathrm{g}$ & $95 \% \mathrm{Cl}$ & $\mathrm{N}$ & $\mu \mathrm{g} / \mathrm{g}$ & $95 \% \mathrm{Cl}$ & $\mathrm{N}$ & $\mu \mathrm{g} / \mathrm{g}$ & $95 \% \mathrm{Cl}$ \\
\hline Amphipod & 1 & 0.10 & - & 1 & 0.09 & - & 0 & - & - & 0 & - & - \\
\hline Artemia & 8 & 0.29 & $0.27-0.32$ & 8 & 0.31 & $0.28-1.11$ & 0 & - & - & 0 & - & - \\
\hline Corixidae & 10 & 0.49 & $0.20-1.56$ & 6 & 0.70 & $0.21-3.40$ & 32 & 0.20 & $0.14-0.27$ & 32 & 0.26 & $0.19-1.35$ \\
\hline Coleoptera & 0 & - & - & 0 & - & - & 0 & - & - & 0 & - & - \\
\hline Crustacea & 1 & 0.10 & - & 0 & - & - & 0 & - & - & 0 & - & - \\
\hline Diptera & 1 & 0.10 & - & 1 & 0.12 & - & 0 & - & - & 0 & - & - \\
\hline Ephydridae & 0 & - & - & 0 & - & - & 1 & 0.04 & - & 1 & 0.06 & - \\
\hline Isopoda & 1 & 0.07 & - & 0 & - & - & 0 & - & - & 0 & - & - \\
\hline Mysis & 1 & 0.06 & - & 1 & 0.07 & - & 0 & - & - & 0 & - & - \\
\hline Ostracoda & 1 & 0.04 & - & 0 & - & - & 0 & - & - & 0 & - & - \\
\hline
\end{tabular}


Table 16. Esophageal contents expressed as aggregate percent dry mass for surf scoters collected during 2003-2004 (2004) and 2004-2005 (2005) in three sub-bays of the San Francisco Bay Estuary.

['Other' category contains species or taxa that comprised less that 2 percent of diet overall: Polychaete (spp.), Ostrea conchaphila, Mytilus (spp.), Crepidula convexa, Gnorimosphaeroma oregonensis, Scleroplax granulate. Note several birds at all sites did not have esophageal food items, and scoters were not collected during 2004 spring in San Pablo, and fall and spring in Suisun. Table from De La Cruz (2010) and used with permission. F, fall; W, winter; S, spring; n, number of samples; -, no data?]

\begin{tabular}{|c|c|c|c|c|c|c|c|c|c|c|c|c|c|c|}
\hline & & \multicolumn{5}{|c|}{ Central Bay } & \multicolumn{5}{|c|}{ San Pablo Bay } & \multicolumn{3}{|c|}{ Suisun Bay } \\
\hline & & \multicolumn{2}{|c|}{2004} & \multicolumn{3}{|c|}{2005} & \multicolumn{2}{|c|}{2004} & \multicolumn{3}{|c|}{2005} & \multirow{2}{*}{$\begin{array}{c}2004 \\
\text { W }\end{array}$} & \multicolumn{2}{|c|}{2005} \\
\hline & & $\mathbf{F}$ & $\mathbf{S}$ & $\mathbf{F}$ & W & $\mathbf{S}$ & $\mathbf{F}$ & W & $\mathbf{F}$ & W & $\mathbf{S}$ & & $\mathbf{F}$ & W \\
\hline \multicolumn{2}{|l|}{ Taxa } & $n=3$ & $n=1$ & $\mathrm{n}=1$ & $n=7$ & $n=5$ & $n=8$ & $n=3$ & $n=5$ & $n=5$ & $n=3$ & $n=3$ & $\mathrm{n}=2$ & $\mathrm{n}=4$ \\
\hline Phylum CNIDARIA & Actinaria spp & -- & -- & -- & 14.3 & -- & -- & -- & -- & -- & -- & -- & -- & -- \\
\hline \multirow[t]{4}{*}{ Phylum MOLLUSCA } & Corbula amurensis & - & - & - & 0.8 & -- & 99.9 & 92.1 & 79.5 & 60 & -- & 100 & 50 & 100 \\
\hline & Venerupis phillipinarium & 100 & 100 & 100 & 23.6 & 78.2 & -- & 7.6 & $<0.1$ & -- & -- & -- & -- & -- \\
\hline & Musculista senhousia & - & - & - & 15 & 20 & - & - & 20.4 & - & - & - & - & - \\
\hline & clam siphons & -- & - & - & 0.2 & - & - & - & -- & - & 66.3 & - & - & - \\
\hline \multirow[t]{3}{*}{ Phylum ARTHROPODA } & Synidotea bicuspida & -- & -- & -- & -- & -- & 0.1 & 0.4 & $<0.1$ & 40.3 & -- & -- & -- & -- \\
\hline & Hemigrapsus oregonensis & - & - & - & - & - & - & - & - & - & 33.3 & - & - & - \\
\hline & Pyromaia tuberculata & - & - & - & 31.3 & 0.3 & - & -- & -- & -- & - & -- & -- & -- \\
\hline Phylum BRYOZOA & encrusting bryozoan & - & - & - & 14.3 & - & - & - & - & - & - & - & - & - \\
\hline Plant Material & Submerged aquatic vegetation & -- & -- & -- & -- & -- & -- & -- & -- & - & $<0.1$ & - & 50 & -- \\
\hline Other & & -- & -- & -- & 0.2 & 1.5 & -- & -- & 1.4 & -- & -- & -- & -- & -- \\
\hline
\end{tabular}


Table 17. Sample size, geometric means $(\mu \mathrm{g} / \mathrm{g} \mathrm{dw}), \pm$ standard error and 95 percent $\mathrm{Cl}$ for hepatic selenium $(\mathrm{Se})$ and total mercury $(\mathrm{THg})$, and renal cadmium (Cd) in female surf scoters only collected during fall (F), winter (W), spring (S) 2003-04 (2004) and 2004-05 (2005) in three sub-bays of San Francisco Bay.

[Numbers of juvenile (hatch year) females are indicated in parentheses next to the number of adult (after hatch year) female in the sample size (N). Total sample size $=139$. NS indicates birds were not present and therefore were not sampled during that period. Table from De La Cruz (2010) and used with permission.]

\begin{tabular}{|c|c|c|c|c|c|c|c|c|c|c|c|c|c|c|c|c|c|c|}
\hline & \multicolumn{6}{|c|}{ Central Bay } & \multicolumn{6}{|c|}{ North Bay } & \multicolumn{6}{|c|}{ Suisun Bay } \\
\hline & \multicolumn{3}{|c|}{2004} & \multicolumn{3}{|c|}{2005} & \multicolumn{3}{|c|}{2004} & \multicolumn{3}{|c|}{2005} & \multicolumn{3}{|c|}{2004} & \multicolumn{3}{|c|}{2005} \\
\hline & $\mathbf{F}$ & W & $\mathrm{S}$ & $\mathbf{F}$ & $\mathbf{W}$ & $\mathrm{S}$ & $\mathbf{F}$ & W & $\mathrm{S}$ & $\mathbf{F}$ & W & $\mathrm{S}$ & $\mathbf{F}$ & W & $\mathrm{S}$ & $\mathbf{F}$ & W & $\mathrm{S}$ \\
\hline $\mathrm{N}$ & $10(0)$ & $12(2)$ & $14(1)$ & $9(0)$ & $13(0)$ & $9(0)$ & $12(2)$ & $5(0)$ & 0 & $9(2)$ & $2(5)$ & $4(2)$ & 0 & $5(4)$ & 0 & $9(0)$ & $6(0)$ & $2(0)$ \\
\hline \multirow[t]{3}{*}{$\mathrm{Se}$} & 15.27 & 18.58 & 21.81 & 24.61 & 30.01 & 29.83 & 47.47 & 90.59 & & 37.70 & 49.05 & 44.40 & & 38.31 & & 57.91 & 46.51 & 43.78 \\
\hline & \pm 1.84 & \pm 1.94 & \pm 2.53 & \pm 4.81 & \pm 4.74 & \pm 2.10 & \pm 6.28 & \pm 13.37 & NS & \pm 8.06 & \pm 8.47 & \pm 4.82 & NS & \pm 1.85 & NS & \pm 7.89 & \pm 6.09 & \pm 7.40 \\
\hline & $\begin{array}{l}11.83- \\
20.29 \\
\end{array}$ & $\begin{array}{l}15.62- \\
24.01 \\
\end{array}$ & $\begin{array}{l}18.40- \\
29.26 \\
\end{array}$ & $\begin{array}{l}16.29- \\
38.46 \\
\end{array}$ & $\begin{array}{r}23.45- \\
44.12 \\
\end{array}$ & $\begin{array}{c}25.54- \\
35.21 \\
\end{array}$ & $\begin{array}{r}39.69- \\
66.82 \\
\end{array}$ & $\begin{array}{l}58.10- \\
132.34 \\
\end{array}$ & & $\begin{array}{c}25.88- \\
61.77 \\
\end{array}$ & $\begin{array}{l}32.38- \\
73.83 \\
\end{array}$ & $\begin{array}{l}33.49- \\
58.25 \\
\end{array}$ & & $\begin{array}{r}34.36- \\
42.88 \\
\end{array}$ & & $\begin{array}{l}48.66- \\
85.07 \\
\end{array}$ & $\begin{array}{r}32.72- \\
64.02 \\
\end{array}$ & $\begin{array}{l}0.00- \\
138.4 \\
\end{array}$ \\
\hline \multirow[t]{3}{*}{$\mathrm{THg}$} & 1.36 & 2.43 & 3.09 & 2.15 & 3.90 & 4.66 & 1.56 & 4.70 & & 1.63 & 6.29 & 4.12 & & 4.26 & & 1.87 & 5.74 & 3.24 \\
\hline & \pm 0.36 & \pm 0.95 & \pm 0.53 & \pm 0.29 & \pm 0.52 & \pm 0.48 & \pm 0.14 & \pm 1.44 & NS & \pm 0.09 & \pm 1.07 & \pm 0.33 & NS & \pm 0.65 & NS & \pm 0.18 & \pm 0.75 & \pm 1.96 \\
\hline & $\begin{array}{c}0.81- \\
2.44 \\
\end{array}$ & $\begin{array}{c}1.11- \\
5.19 \\
\end{array}$ & $\begin{array}{c}2.36- \\
4.63 \\
\end{array}$ & $\begin{array}{l}1.63- \\
3.02 \\
\end{array}$ & $\begin{array}{c}3.19- \\
5.43 \\
\end{array}$ & $\begin{array}{l}3.75- \\
5.94 \\
\end{array}$ & $\begin{array}{c}1.34- \\
1.94 \\
\end{array}$ & $1.41-9.42$ & & $\begin{array}{c}1.46- \\
1.88 \\
\end{array}$ & $\begin{array}{c}4.20- \\
9.46 \\
\end{array}$ & $\begin{array}{c}3.35- \\
5.03 \\
\end{array}$ & & $\begin{array}{c}3.15- \\
6.14 \\
\end{array}$ & & $\begin{array}{l}1.55- \\
2.37 \\
\end{array}$ & $\begin{array}{c}4.08- \\
7.95 \\
\end{array}$ & $\begin{array}{r}0.00- \\
28.72 \\
\end{array}$ \\
\hline \multirow[t]{3}{*}{$\mathrm{Cd}$} & 27.62 & 24.30 & 23.06 & 27.84 & 30.71 & 32.26 & 18.27 & 28.71 & & 17.17 & 13.46 & 12.53 & & 17.18 & & 28.95 & 25.57 & 8.95 \\
\hline & \pm 4.44 & \pm 3.97 & \pm 2.69 & \pm 3.37 & \pm 2.55 & \pm 2.81 & \pm 4.12 & \pm 4.45 & NS & \pm 5.28 & \pm 4.17 & \pm 6.63 & NS & \pm 4.98 & NS & \pm 3.06 & \pm 8.01 & \pm 3.57 \\
\hline & $\begin{array}{l}19.86- \\
39.92\end{array}$ & $\begin{array}{l}20.12- \\
37.25\end{array}$ & $\begin{array}{l}19.32- \\
30.88\end{array}$ & $\begin{array}{l}21.88- \\
37.44\end{array}$ & $\begin{array}{l}26.38- \\
37.50\end{array}$ & $\begin{array}{c}26.72- \\
39.68\end{array}$ & $\begin{array}{l}16.52- \\
34.88\end{array}$ & $\begin{array}{l}0.00- \\
85.59\end{array}$ & & $\begin{array}{l}15.77- \\
39.31\end{array}$ & $\begin{array}{l}7.16- \\
28.61\end{array}$ & $\begin{array}{l}0.93- \\
37.76\end{array}$ & & $\begin{array}{l}10.14- \\
33.11\end{array}$ & & $\begin{array}{l}23.27- \\
37.37\end{array}$ & $\begin{array}{l}12.11- \\
53.30\end{array}$ & $\begin{array}{l}0.00- \\
54.93 \\
\end{array}$ \\
\hline
\end{tabular}


Table 18. Means $\pm \mathrm{SE}$ (sample size) of P450 EROD activity $(\mathrm{pmol} / \mathrm{min} / \mathrm{mg})$ in liver tissue samples from Caspian tern and Forster's tern adults and chicks in San Francisco Bay.

[Table from Herring and others (2010) and used with permission.]

\begin{tabular}{cccccc}
\hline Species and age & North Bay & $\begin{array}{c}\text { Central South } \\
\text { Bay }\end{array}$ & Lower South Bay & Prebreeding & Breeding \\
\hline $\begin{array}{c}\text { Caspian tern } \\
\text { adult }\end{array}$ & $\begin{array}{c}2.5 \pm 0.12 \\
(10)\end{array}$ & - & - & $2.5 \pm 0.12$ & $(10)$ \\
& & & & - \\
Forster's tern & $14.14 \pm 1.90$ & $18.00 \pm 2.41$ & $14.28 \pm 1.80$ & $18.38 \pm 1.74$ & $12.07 \pm 1.46$ \\
adult & $(21)$ & $(4)$ & $(21)$ & $(18)$ & $(28)$ \\
& & & & \\
$\begin{array}{c}\text { Forster's tern } \\
\text { chick }\end{array}$ & - & $12.0 \pm 2.77$ & $0.72 \pm 0.27$ & $(11)$ \\
\hline
\end{tabular}


Table 19. Occurrence of embryo malpositions and deformities in Forster's tern, American avocet, and black-necked stilt eggs in South San Francisco Bay during 2005-07.

[Only eggs $\geq 18$ days old were included in the estimate of embryo malpositions, whereas eggs $\geq 13$ days old were included in the estimate of embryo deformities. Table from Herring and others (2010) and used with permission. N, number of samples]

\begin{tabular}{|c|c|c|c|c|c|c|c|c|c|c|c|c|}
\hline \multirow[b]{3}{*}{ Egg type } & \multicolumn{4}{|c|}{ Forster's tern } & \multicolumn{4}{|c|}{ American avocet } & \multicolumn{4}{|c|}{ Black-necked stilt } \\
\hline & \multicolumn{2}{|c|}{ Malpositioned } & \multicolumn{2}{|c|}{ Deformed } & \multicolumn{2}{|c|}{ Malpositioned } & \multicolumn{2}{|c|}{ Deformed } & \multicolumn{2}{|c|}{ Malpositioned } & \multicolumn{2}{|c|}{ Deformed } \\
\hline & $\begin{array}{l}\text { Total } \\
\text { eggs }\end{array}$ & $\stackrel{\mathrm{N}}{\text { (percent) }}$ & $\begin{array}{l}\text { Total } \\
\text { eggs }\end{array}$ & $\mathbf{N}(\%)$ & $\begin{array}{l}\text { Total } \\
\text { eggs }\end{array}$ & $N(\%)$ & $\begin{array}{l}\text { Total } \\
\text { eggs }\end{array}$ & $N(\%)$ & $\begin{array}{l}\text { Total } \\
\text { eggs }\end{array}$ & $\mathbf{N}(\%)$ & $\begin{array}{l}\text { Total } \\
\text { eggs }\end{array}$ & $\mathbf{N}(\%)$ \\
\hline Random & 53 & $1(2 \%)$ & 98 & $0(0 \%)$ & 69 & $2(3 \%)$ & 132 & $1(1 \%)$ & 21 & $1(5 \%)$ & 42 & $0(0 \%)$ \\
\hline $\begin{array}{l}\text { Failed to } \\
\text { hatch }\end{array}$ & 22 & $6(27 \%)$ & 27 & $1(4 \%)$ & 30 & $6(21 \%)$ & 35 & $5(14 \%)$ & 10 & $3(30 \%)$ & 19 & $0(0 \%)$ \\
\hline Abandoned & 16 & $3(19 \%)$ & 33 & $1(3 \%)$ & 29 & $6(21 \%)$ & 36 & $0(0 \%)$ & 9 & $0(0 \%)$ & 12 & $0(0 \%)$ \\
\hline $\begin{array}{l}\text { Dead: nest } \\
\text { destroyed }\end{array}$ & 12 & $2(17 \%)$ & 15 & $0(0 \%)$ & 10 & $0(0 \%)$ & 16 & $0(0 \%)$ & 1 & $0(0 \%)$ & 5 & $0(0 \%)$ \\
\hline Total & 103 & $12(12 \%)$ & 173 & $2(1 \%)$ & 138 & $14(10 \%)$ & 219 & $6(3 \%)$ & 41 & $4(10 \%)$ & 78 & $0(0 \%)$ \\
\hline
\end{tabular}




\section{Appendix 1. Project's Product List: Citations}

Below is a complete list of all the products produced for this project, including 54 peer-reviewed journal publications and book chapters, 11 magazine articles, 3 reports, and 4 thesis.

\section{$\underline{\text { Peer-Reviewed Publications }}$}

1. Ackerman, J.T., Bluso-Demers, J.D., and Takekawa, J.Y., 2009, Postfledging Forster's tern movements, habitat selection, and colony attendance in San Francisco Bay: Condor, v. 111, no. 1, p. $100-110$.

2. Ackerman, J.T., and Eagles-Smith, C.A., 2010, Accuracy of egg flotation throughout incubation to determine embryo age and incubation day in waterbird nests: Condor, v. 112, no. 3, p. 438-446.

3. Ackerman, J.T., and Eagles-Smith, C.A., 2009a, Integrating toxicity risk in bird eggs and chicks: using chick down feathers to estimate mercury concentrations in eggs: Environmental Science and Technology, v. 43, no. 6, p. 2166-2172.

4. Ackerman, J.T., and Eagles-Smith, C.A., 2009b, Selenium bioaccumulation and body condition in shorebirds and terns breeding in San Francisco Bay, California, USA: Environmental Toxicology and Chemistry, v. 28, no. 10, p. 2134-2141.

5. Ackerman, J.T., Eagles-Smith, C.A., and Herzog, M.P., 2011, Bird mercury concentrations change rapidly as chicks age: toxicological risk is highest at hatching and fledging: Environmental Science and Technology, v. 45, no. 12, p. 5418-5425.

6. Ackerman, J.T., Eagles-Smith, C.A., Takekawa, J.Y., Bluso, J.D., and Adelsbach, T.L., 2008, Mercury concentrations in blood and feathers of prebreeding Forster's terns in relation to space use of San Francisco Bay, California, USA, habitats: Environmental Toxicology and Chemistry, v. 27 , no. 4 , p. $897-908$.

7. Ackerman, J.T., Eagles-Smith, C.A., Takekawa, J.Y., Demers, S.A., Adelsbach, T.L., Bluso, J.D., Miles, A.K., Warnock, N., Suchanek, T.H., and Schwarzbach, S.E., 2007, Mercury concentrations and space use of pre-breeding American avocets and black-necked stilts in San Francisco Bay: Science of the Total Environment, v. 384, no. 1-3, p. 452-466.

8. Ackerman, J.T., Eagles-Smith, C.A., Takekawa, J.Y., and Iverson, S.A., 2008, Survival of postfledging Forster's terns in relation to mercury exposure in San Francisco Bay: Ecotoxicology, v. 17, no. 8, p. 789-801.

9. Ackerman, J.T., Hartman, C.A., Herzog, M.P., Takekawa, J.Y., Robinson, J.A., Oring, L.W., Skorupa, J.P., and Boettcher, R., 2013, American Avocet (Recurvirostra americana), in Poole, A. ed., The Birds of North America Online, Cornell Lab of Ornithology, No. 275, Ithaca, New York.

10. Ackerman, J.T., Herzog, M.P., Hartman, C.A., and Takekawa, J.Y., 2014, Comparative reproductive biology of sympatric species: nest and chick survival of American avocets and black-necked stilts: Journal of Avian Biology, v. 45, p. 609-623.

11. Ackerman, J.T., Takekawa, J.Y., Bluso, J.D., Yee, J.L., and Eagles-Smith, C.A., 2008, Gender identification of Caspian terns using external morphology and discriminant function analysis: Wilson Journal of Ornithology, v. 120, no. 2, p. 378-383. 
12. Ackerman, J.T., Takekawa, J.Y., Eagles-Smith, C.A., and Iverson, S.A., 2008, Mercury contamination and effects on survival of American avocet and black-necked stilt chicks in San Francisco Bay: Ecotoxicology, v. 17, no. 2, p. 103-116.

13. Bluso, J.D., Ackerman, J.T., Takekawa, J.Y., and Yee, J.L., 2006, Sexing Forster's terns using morphometric measurements: Waterbirds, v. 29, no. 4, p. 512-517.

14. Bluso-Demers, J.D., Ackerman, J.T., and Takekawa, J.Y., 2010, Colony attendance patterns by mated Forster's terns Sterna forsteri using an automated data-logging receiver system: Ardea, v. 98, p. 59-65.

15. Bluso-Demers, J.D., Ackerman, J.T., and Takekawa, J.Y., 2014, Habitat selection by Forster's terns at multiple spatial scales in San Francisco Bay: the importance of salt ponds: Condor, submitted.

16. Bluso-Demers, J., Colwell, M.A., Takekawa, J.Y., Ackerman, J.T., and Demers, S.A., 2008, Space use by Forster's terns breeding in South San Francisco Bay: Waterbirds, v. 31, no. 3, p. 357364.

17. Demers, S.A., Colwell, M.A., Takekawa, J.Y., and Ackerman, J.T., 2008, Breeding stage influences space use of female American avocets in San Francisco Bay, California: Waterbirds, v. 31, no. 3, p. 365-371.

18. Demers, S.A., Takekawa, J.Y., Ackerman, J.T., Warnock, N., and Athearn, N.D., 2010, Space use and habitat selection of migrant and resident American avocets in San Francisco Bay: Condor, v. 112 , no. 3, p. 511-520.

19. Eagles-Smith, C.A., and Ackerman, J.T., 2014, Mercury bioaccumulation in estuarine wetland fishes: evaluating habitats and risk to coastal wildlife: Environmental Pollution, v. 193, p. 147155.

20. Eagles-Smith, C.A., and Ackerman, J.T., 2009, Rapid changes in small fish mercury concentrations in estuarine wetlands: implications for wildlife risk and monitoring programs: Environmental Science and Technology, v. 43, no. 22, p. 8658-8664.

21. Eagles-Smith, C.A., Ackerman, J.T., Adelsbach, T.L., Takekawa, J.Y., Miles, A.K., and Keister, R. A, 2008, Mercury correlations among six tissues for four waterbird species breeding in San Francisco Bay, California, USA: Environmental Toxicology and Chemistry, v. 27, no. 10, p. 2136-2153.

22. Eagles-Smith, C.A., Ackerman, J.T., De La Cruz, S.E.W., and Takekawa, J.Y., 2009, Mercury bioaccumulation and risk to three waterbird foraging guilds is influenced by foraging ecology and breeding stage: Environmental Pollution, v. 157, no. 7, p. 1993-2002.

23. Eagles-Smith, C.A., Ackerman, J.T., Yee, J.L., and Adelsbach, T.L., 2009, Mercury demethylation in waterbird livers: dose-response thresholds and differences among species: Environmental Toxicology and Chemistry, v. 28, no. 3, p. 568-577.

24. Heinz, G.H., Hoffman, D.J., Klimstra, J.D., and Stebbins, K.R., 2012, A comparison of the teratogenicity of methylmercury and selenomethionine injected into bird eggs: Archives of Environmental Contamination and Toxicology, v. 62, no. 3, p. 519-528.

25. Heinz, G.H., Hoffman, D.J., Klimstra, J.D., and Stebbins, K.R., 2010a, Enhanced reproduction in mallards fed a low level of methylmercury: an apparent case of hormesis: Environmental Toxicology and Chemistry, v. 29, no. 3, p. 650-653.

26. Heinz, G.H., Hoffman, D.J., Klimstra, J.D., and Stebbins, K.R., 2010b, Intraperitoneal injections as a possible means of generating varied levels of methylmercury in the eggs of birds in field studies: Environmental Toxicology and Chemistry, v. 29, no. 5, p. 1079-1083. 
27. Heinz, G.H., Hoffman, D.J., Klimstra, J.D., and Stebbins, K.R., 2010c, Predicting mercury concentrations in mallard eggs from mercury in the diet or blood of adult females and from duckling down feathers: Environmental Toxicology and Chemistry, v. 29, no. 2, p. 389-392.

28. Heinz, G.H., Hoffman, D.J., Klimstra, J.D., and Stebbins, K.R., 2009, Rapid increases in mercury concentrations in the eggs of mallards fed methylmercury: Environmental Toxicology and Chemistry, v. 28, no. 9, p. 1979-1981.

29. Heinz, G.H., Hoffman, D.J., Klimstra, J.D., and Stebbins, K.R., 2010d, Reproduction in mallards exposed to dietary concentrations of methylmercury: Ecotoxicology, v. 19, no. 5, p. 977-982.

30. Heinz, G.H., Hoffman, D.J., Klimstra, J.D., Stebbins, K.R., and Kondrad, S.L., 2011, Toxicity of methylmercury injected into eggs when dissolved in water versus corn oil: Environmental Toxicology and Chemistry, v. 30, no. 9, p. 2103-2106.

31. Heinz, G.H., Hoffman, D.J., Klimstra, J.D., Stebbins, K.R., Kondrad, S.L., and Erwin, C.A., 2012, Hormesis associated with a low dose of methylmercury injected into mallard eggs: Archives of Environmental Contamination and Toxicology, v. 62, no. 1, p. 141-144.

32. Heinz, G.H., Hoffman, D.J., Klimstra, J.D., Stebbins, K.R., Kondrad, S.L., and Erwin, C.A., 2009, Species differences in the sensitivity of avian embryos to methylmercury: Archives of Environmental Contamination and Toxicology, v. 56, no. 1, p. 129-138.

33. Heinz, G.H., Hoffman, D.J., Klimstra, J.D., Stebbins, K.R., Kondrad, S.L., and Erwin, C.A., 2011, Teratogenic effects of injected methylmercury on avian embryos: Environmental Toxicology and Chemistry, v. 30, no. 7, p. 1593-1598.

34. Heinz, G.H., Hoffman, D.J., Kondrad, S.L., and Erwin, C.A., 2006, Factors affecting the toxicity of methylmercury injected into eggs: Archives of Environmental Contamination and Toxicology, v. 50, no. 2, p. 264-279.

35. Heinz, G., and Stebbins, K.R., 2009, A simplified method for correcting contaminant concentrations in eggs for moisture loss: Environmental Toxicology and Chemistry, v. 28, no. 7, p. 1425-1428.

36. Herring, G., Ackerman, J.T., and Eagles-Smith, C.A., 2010, Embryo malposition as a potential mechanism for mercury-induced hatching failure in bird eggs: Environmental Toxicology and Chemistry, v. 29, no. 8, p. 1788-1794.

37. Herring, G., Ackerman, J.T., Eagles-Smith, C.A., Adelsbach, T.L., Melancon, M.J., Stebbins, K.R., and Hoffman, D.J., 2010, Organochlorine and PBDE concentrations in relation to cytochrome P450 activity in livers of Forster's terns (Sterna forsteri) and caspian terns (Hydroprogne caspia), in San Francisco Bay, California: Archives of Environmental Contamination and Toxicology, v. 58, no. 3, p. 863-873.

38. Herring, G., Ackerman, J.T., Takekawa, J.Y., Eagles-Smith, C.A., and Eadie, J.M., 2011, Identifying Nest Predators of American avocets (Recurvirostra americana) and black-necked stilts (Himantopus mexicanus) in San Francisco Bay, California: Southwestern Naturalist, v. 56, no. 1 , p. 35-43.

39. Hoffman, D.J., Eagles-Smith, C.A., Ackerman, J.T., Adelsbach, T.L., and Stebbins, K.R., 2011, Oxidative stress response of Forster's terns (Sterna forsteri) and Caspian terns (Hydroprogne caspia) to mercury and selenium bioaccumulation in liver, kidney, and brain: Environmental Toxicology and Chemistry, v. 30, no. 4, p. 920-929.

40. Iverson, S.A., Takekawa, J.Y., Schwarzbach, S.E., Cardona, C.J., Warnock, N., Bishop, M.A., Schirato, G.A., Paroulek, S., Ackerman, J.T., Ip, H., and Boyce, W.M., 2008, Low prevalence of avian influenza virus in shorebirds on the Pacific Coast of North America: Waterbirds, v. 31, no. 4, p. 602-610. 
41. Klimstra, J.D., Stebbins, K.R., Heinz, G.H., Hoffman, D.J., and Kondrad, S.R., 2009, Factors related to the artificial incubation of wild bird eggs: Avian Biology Research, v. 2, no. 3, p. 121-131.

42. Klimstra, J.D., Yee, J.L., Heinz, G.H., Hoffman, D.J., and Stebbins, K.R., 2012, Interactions between methylmercury and selenomethionine injected into mallard eggs.: Environmental Toxicology and Chemistry, v. 31, no. 3, p. 579-584.

43. De La Cruz, S.E.W., Eadie, J.M., Miles, A.K., Yee, J., Spragens, K.A., Palm, E.C., and Takekawa, J.Y., 2014, Resource selection and space use by sea ducks during the non-breeding seasonImplications for habitat conservation planning in urbanized estuaries: Biological Conservation, v. 169 , p. $68-78$.

44. De La Cruz, S.E.W., Miles, A.K., Eadie, J.M., and Takekawa, J.Y., 2014, Effects of a bivalve invasion on diet and nutrient reserves of wintering sea ducks: Oecologia, submitted.

45. De La Cruz, S.E.W., Takekawa, J.Y., Wilson, M.T., Nysewander, D.R., Evenson, J.R., Esler, D., Boyd, W.S., and Ward, D.H., 2009, Spring migration routes and chronology of surf scoters (Melanitta perspicillata) - A synthesis of Pacific coast studies: Canadian Journal of Zoology, v. 87, no. 11, p. 1069-1086.

46. Lok, E.K., Esler, D., Takekawa, J.Y., De La Cruz, S.W., Boyd, W.S., Nysewander, D.R., Evenson, J.R., and Ward, D.H., 2012, Spatiotemporal associations between Pacific herring spawn and surf scoter spring migration: evaluating a "silver wave" hypothesis: Marine Ecology Progress Series, v. 457, p. 139-150.

47. Lok, E.K., Esler, D., Takekawa, J.Y., De La Cruz, S.W., Sean Boyd, W., Nysewander, D.R., Evenson, J.R., and Ward, D.H., 2011, Stopover habitats of spring migrating surf scoters in southeast Alaska: The Journal of Wildlife Management, v. 75, no. 1, p. 92-100.

48. Lovvorn, J., De La Cruz, S., Takekawa, J., Shaskey, L., and Richman, S., 2013, Niche overlap, threshold food densities, and limits to prey depletion for a diving duck assemblage in an estuarine bay: Marine Ecology Progress Series, v. 476, p. 251-268.

49. Stebbins, K.R., Klimstra, J.D., Eagles-Smith, C.A., Ackerman, J.T., and Heinz, G.H., 2009, A nonlethal microsampling technique to monitor the effects of mercury on wild bird eggs: Environmental Toxicology and Chemistry, v. 28, no. 3, p. 465-470.

50. Takekawa, J.Y., Ackerman, J.T., Brand, L., Graham, T., Eagles-Smith, C., Herzog, M., Topping, B., Shellenbarger, G., Kuwabara, J., Mruz, E., Piotter, S., and Athearn, N., 2014, Unintended consequences of salt pond restoration on trophic interactions of avian predators: PLoS ONE, in revision.

51. Takekawa, J.Y., Cruz, S.W.D. La, Wilson, M.T., Palm, E.C., Yee, J., Nysewander, D.R., Evenson, J.R., Eadie, J.M., Esler, D., Boyd, W.S., and Ward, D.H., 2011, Breeding distribution and ecology of Pacific coast surf scoters, in Boreal birds of North America: a hemispheric view of their conservation links and significance. Studies in Avian Biology (no. 41), University of California Press, Berkeley, CA., p. 41-64.

52. Takekawa, J.Y., Woo, I., Gardiner, R., Casazza, M., Ackerman, J.T., Nur, N., Liu, L., and Spautz, H., 2011, Avian communities in tidal salt marshes of San Francisco Bay: a review of functional groups by foraging guild and habitat association: San Francisco Estuary and Watershed Science, v. 9 , no. 3, p. 1-24. 
53. Takekawa, J.Y., Woo, I., Gardiner, R., Casazza, M., Ackerman, J.T., Nur, N., Liu, L., and Spautz, H., 2012, Chapter 11: Avian communities in tidal salt marshes of San Francisco Bay: a review of functional groups by foraging guild and habitat association, in Ferner, M.C. ed., A profile of the San Francisco Bay National Estuarine Research Reserve, San Francisco Bay National Estuarine Research Reserve: San Francisco, California, p. 250-281.

54. Takekawa, J.Y., Woo, I., Thorne, K.M., Buffington, K.J., Nur, N., Casazza, M.L., and Ackerman, J.T., 2012, Chapter 12: Bird communities: effects of fragmentation, disturbance, and sea level rise on population viability, in Palaima, A. ed., Ecology, Conservation, and Restoration of Tidal Marshes: The San Francisco Estuary, University of California Press, Berkeley, California, p. 175-194.

\section{$\underline{\text { Popular Publications }}$}

1. Ackerman, J.T., and Eagles-Smith, C.A., 2006, A collaborative project to study mercury levels in San Francisco Bay waterbirds: Bay Bird Review, v. Winter, p. 4-5.

2. Ackerman, J.T., and Eagles-Smith, C.A., 2007, Mercury contamination in waterbirds breeding in San Francisco Bay: Tideline, v. 27, no. 2, p. 1-3.

3. Ackerman, J.T., and Eagles-Smith, C.A., 2007, Mercury contamination in waterbirds breeding in San Francisco Bay: Sound Waves, no. 98, p. 4-5.

4. Ackerman, J.T., Marn, C.M., and Takekawa, J.Y., 2005, Life and death on a salt pond: avocets and stilts survive amidst mercury pollution and invasive gulls: Tideline, v. 25, no. 4, p. 1-3.

5. Eagles-Smith, C.A., and Ackerman, J.T., 2008a, Mercury bioaccumulation and effects on birds in San Francisco Bay, in The Pulse of the Estuary: Monitoring and Managing Water Quality in the San Francisco Estuary, SFEI Contribution 559, San Francisco Estuary Institute, Oakland, CA., p. 5664.

6. Eagles-Smith, C.A., and Ackerman, J.T., 2008b, Mercury bioaccumulation in San Francisco Bay waterbirds: NorCal SETAC News (Newsletter of the Northern California Regional Chapter of the Society of Environmental Toxicology and Chemistry), p. 10.

7. Eagles-Smith, C.A., and Ackerman, J.T., 2010, Mercury in small fish: seasonal variation: The Pulse of the Estuary: Linking the Watershed and the Bay, p. 49.

8. Eagles-smith, C.A., and Ackerman, J.T., 2007a, Mercury may pose substantial risks to breeding birds in San Francisco Bay: The Pulse of the Estuary: Monitoring and Managing Water Quality in the San Francisco Estuary, p. 37.

9. Eagles-smith, C.A., and Ackerman, J.T., 2007b, Mercury poses risks to waterbirds in San Francisco Bay: Regional Monitoring Program Update, p. 1-4.

10. Takekawa, J.Y., 2005, Finding the needle in a big haystack-locating surf scoter nests in the northern boreal forest: Sound Waves, v. FY 2005, no. 75, p. 1-2.

11. Wainwright-De La Cruz, S.E.W., and Takekawa, J.Y., 2005, Scooping for scoters on San Francisco Bay: Tideline, v. 25, no. 1, p. 1-3. 


\section{$\underline{\text { Technical Reports }}$}

1. Ackerman, J.T., Eagles-Smith, C.A., Heinz, G.H., Wainwright-de la Cruz, S.E., Takekawa, J.Y., Adelsbach, T.L., Miles, A.K., Hoffman, D.J., Schwarzbach, S.E., Suchanek, T.H., and Maurer, T.C., 2007, Mercury in birds of the San Francisco Bay-Delta-Trophic pathways, bioaccumulation, and ecotoxicological risk to avian reproduction: U.S. Geological Survey Administrative Report, $44 \mathrm{p}$.

2. Ackerman, J.T., and Herzog, M.P., 2012, Waterbird nest monitoring program in San Francisco Bay (2005-2010): U.S. Geological Survey Open-File Report 2012-1145, 16 p.

3. Schwarzbach, S.E., Suchanek, T.H., Heinz, G.H., Ackerman, J.T., Eagles-Smith, C.A., Adelsbach, T.L., Takekawa, J.Y., Miles, A.K., Hoffman, D., Wainwright-De La Cruz, S.E., Spring, S.E., Ricca, M.A., and Maurer, T.C., 2005, Mercury in birds of the San Francisco Bay-DeltaTrophic pathways, bioaccumulation, and ecotoxicological risk to avian reproduction: U.S. Geological Survey Administrative Report, 17 p.

\section{Thesis}

1. Bluso, J.D., 2007, Sex differences in space use of Forster's terns (Sterna forsteri) breeding in South San Francisco Bay, California: Arcata, Calif., Humboldt State University, M.S. Thesis, 43 p.

2. Demers, S.A., 2007, Space use of American avocets (Recurvirostra americana) in South San Francisco Bay, California: Arcata, Calif., Humboldt State University, M.S. Thesis, 39 p.

3. De La Cruz, S.E.W., 2010, Habitat, diet, and contaminant relationships of surf scoters wintering in San Francisco Bay: implications for conservation in urban estuaries: Davis, University of California, Ph.D. Dissertation, 215 p.

4. Wilson, M.T., 2014, Overwinter survival and breeding propensity of Pacific surf scoters from San Francisco Bay, California: Davis, University of California, M.S. Thesis, 55 p. 
Publishing support provided by the U.S. Geological Survey

Publishing Network, Tacoma Publishing Service Center

For more information concerning the research in this report, contact the Director, Western Ecological Research Center

U.S. Geological Survey

3020 State University Drive East

Sacramento, California 95819

http://werc.usgs.gov/ 
